\title{
Untersuchung von Maßnahmen zur Prävention von Überholunfällen auf einbahnigen Landstraßen
}

Thomas Richter

Stephan Ruhl
Unfallforschung der Versicherer 


\section{Untersuchung von Maßnahmen zur Prävention von Überholunfällen auf einbahnigen Landstraßen}

Univ.-Prof. Dr.-Ing. Thomas Richter

Dipl.-Ing. Stephan Ruhl 


\section{Impressum}

\section{Gesamtverband der Deutschen Versicherungswirtschaft e. V.}

\section{Unfallforschung der Versicherer}

Wilhelmstraße 43/43G, 10117 Berlin

Postfach 0802 64, 10002 Berlin

E-Mail: unfallforschung@gdv.de

Internet: www.udv.de

Facebook: www.facebook.com/unfallforschung

Twitter: @unfallforschung

YouTube: www.youtube.com/unfallforschung

ISBN-Nr.: 978-3-939163-53-4

Redaktion: Dr.-Ing. Jean Emmanuel Bakaba

Bildnachweis: UDV und siehe Quellenangaben

Erschienen: 05/2014 


\section{Untersuchung von Maßnahmen zur Prävention von Überholunfällen auf einbahnigen Landstraßen}

Technische Universiät Berlin Fachgebiet Straßenplanung und Straßenbetrieb Univ.-Prof. Dr.-Ing. Thomas Richter

Dipl.-Ing. Stephan Ruhl

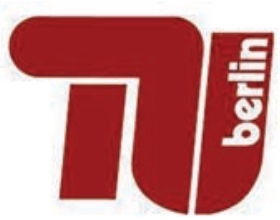

Bei der UDV betreut von: Dr.-Ing. Jean Emmanuel Bakaba

Dipl.-Ing. Jörg Ortlepp

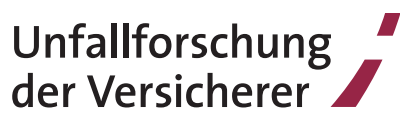


Untersuchung von Maßnahmen zur Prävention von Überholunfällen auf einbahnigen Landstraßen

\section{- Abschlussbericht -}

\section{Auftraggeber:}

Gesamtverband der Deutschen Versicherungswirtschaft e.V.

Wilhelmstraße 43 / 43 G

10117 Berlin

\section{Auftragnehmer:}

Technische Universität Berlin

Fachgebiet Straßenplanung und Straßenbetrieb

Gustav-Meyer-Allee 25

13355 Berlin

Tel.: 03031472421

Fax: 03031472884

\section{Projektleitung:}

Univ.-Prof. Dr.-Ing. Thomas Richter

\section{Bearbeitung:}

Dipl.-Ing. Stephan Ruhl 


\section{INHALTSVERZEICHNIS}

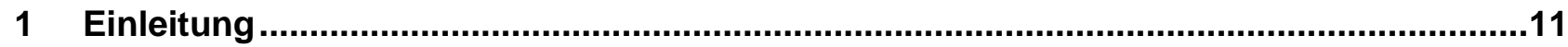

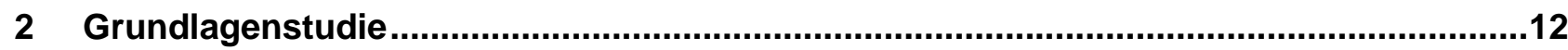

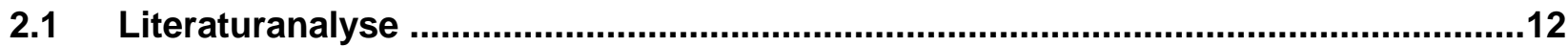

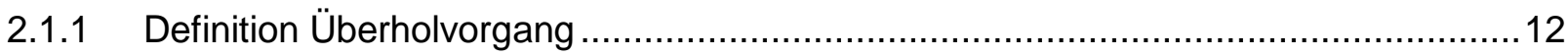

2.1.2 Rechtliche Grundlagen ............................................................................ 13

2.1.3 Fahrverhalten und Straßengestaltung ....................................................... 13

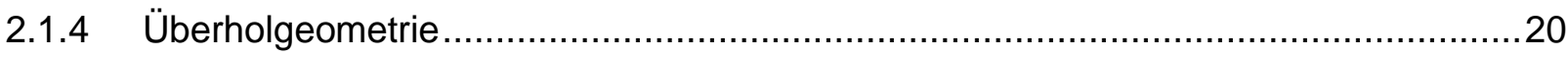

2.1.5 Maßnahmen gegen Überholunfälle.............................................................. 22

2.2 Maßnahmen zur Minimierung von Überholunfällen im Entwurfsregelwerk ..............25

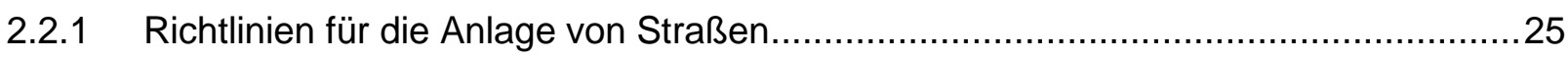

2.2.2 Die neuen Richtlinien für die Anlage von Landstraßen - RAL ................................26

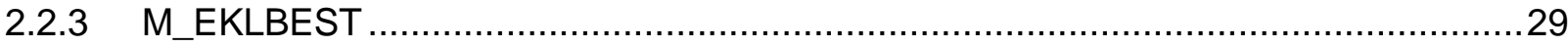

2.2.4 Beurteilung der Maßnahmen gegen Überholunfälle im neuen Entwurfsregelwerk .....30

2.3 Makroskopische Analyse des Unfallgeschehens auf Landstraßen ........................32

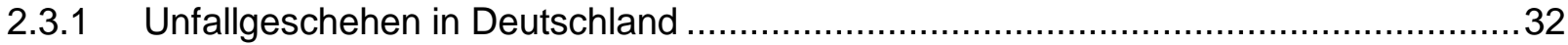

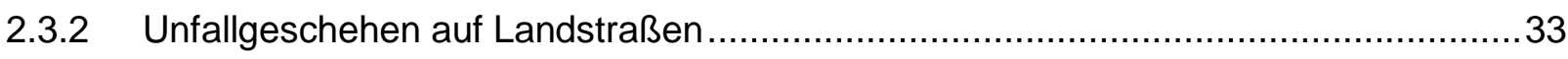

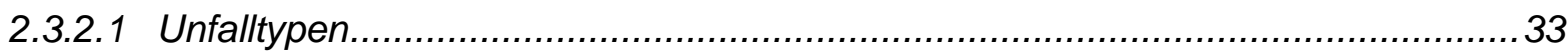

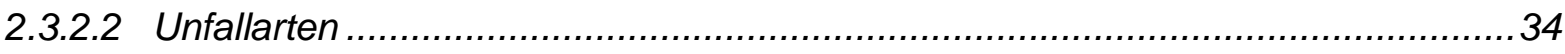

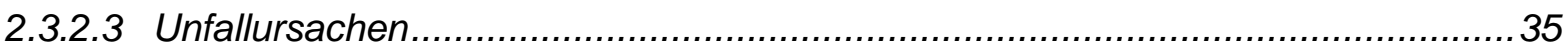

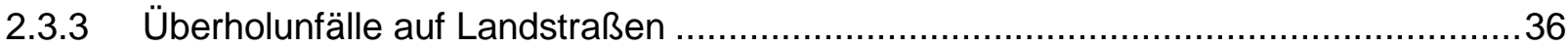

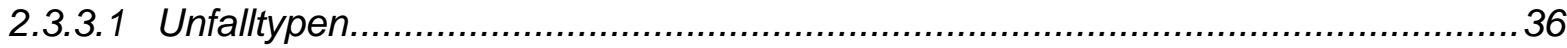

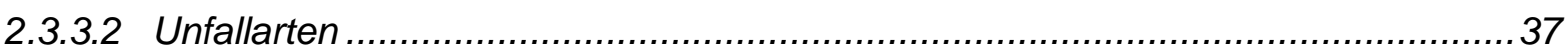

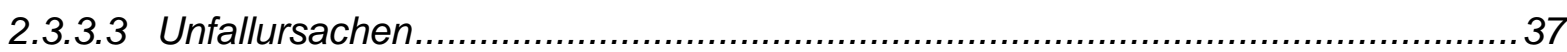

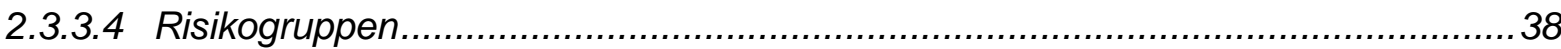

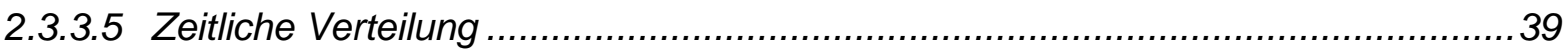

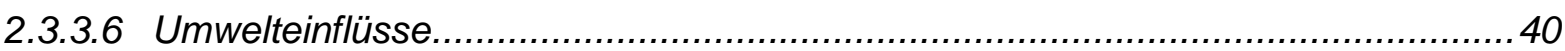

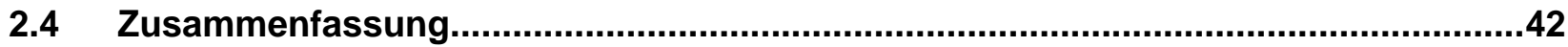

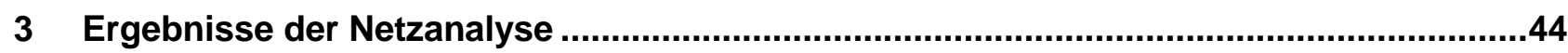

3.1 Festlegung des Untersuchungsgebietes und Datengrundlage ................................44

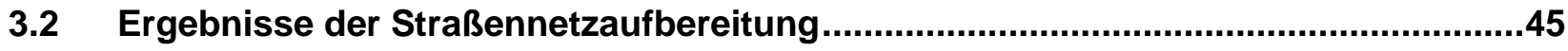

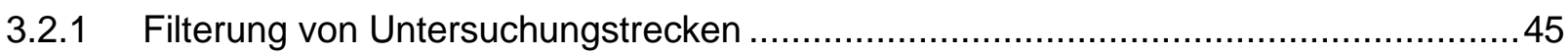

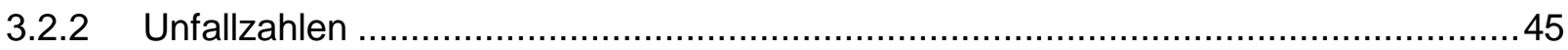

3.3 Makroskopische Unfallanalyse ................................................................. 48

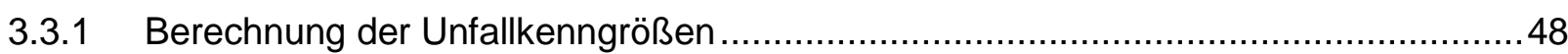


3.3.1.1 Streckenbezogene Unfallkenngrößen ......................................................... 48

3.3.1.2 Anpassung der Unfallkostensätze ............................................................. 48

3.3.1.3 Schlussfolgerungen Rangfolgeerstellung .................................................. 49

3.3.2 Zusammenhänge der Überholunfälle zum Gesamtunfallgeschehen ........................50

3.3.3 Auswahl von 500 unfallauffälligen Untersuchungsstrecken .................................51

3.3.4 Abschließende Betrachtungen zur Rangfolge .................................................52

3.4 Analyse der verkehrsrechtlichen Randbedingungen ..........................................54

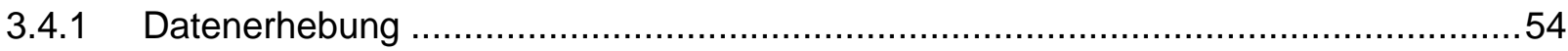

3.4.2 Verkehrsrechtliche Merkmale der Untersuchungsstrecken ..................................56

3.4.3 Unfallgeschehen in Abhängigkeit der verkehrsrechtlichen Anordnungen...................59

3.4.4 Unfallgeschehen bezogen auf Merkmalslängen ..............................................62

3.4.5 Unfallkenngrößen der Merkmalslängen ......................................................64

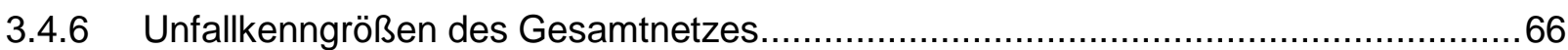

3.4.7 Signifikanz der Ergebnisse bei Betrachtung der verkehrsrechtlichen Anordnungen...68

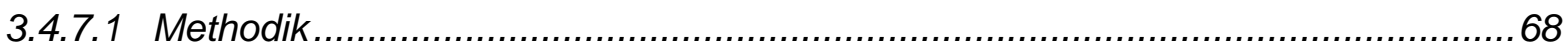

3.4.7.2 Bandbreite der Bezugsgrößen zur Unfallkenngrößenberechnung .........................69

3.4.7.3 Prüfung auf konsistente Bezugsgrößen .................................................. 70

3.4.7.4 Schlussfolgerungen für die Bewertung der Unfallkenngrößen............................. 71

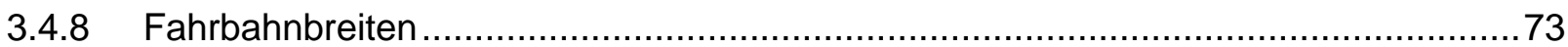

3.4.9 Signifikanz der Ergebnisse bei Betrachtung der Regelquerschnitte .......................78

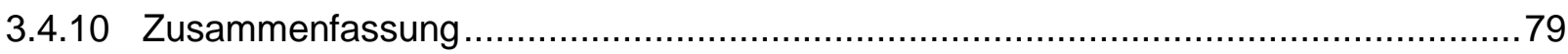

3.5 Analyse der vorhandenen Sichtweiten .............................................................82

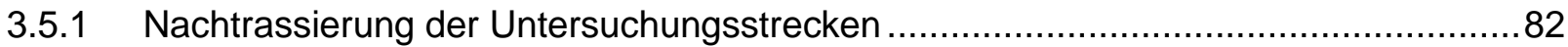

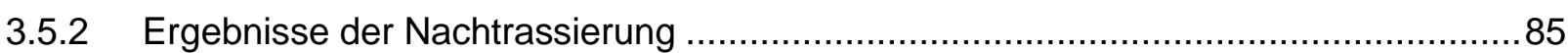

3.5.3 Zusammenhänge zwischen Unfallgeschehen und Landstraßeneigenschaften ..........86

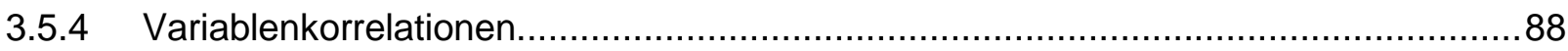

3.5.5 Überholunfälle in Abhängigkeit der Landstraßentrassierung ................................. 89

3.5.5.1 Kriterien der Streckenbandanalyse .......................................................... 89

3.5.5.2 Ergebnisse der Streckenbandanalyse.......................................................91

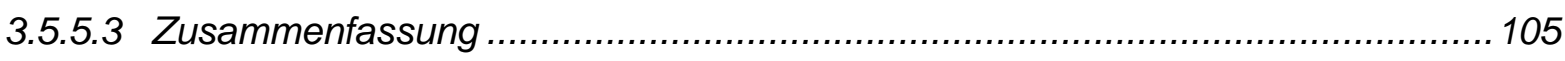

3.5.6 Clusterung der Untersuchungsstrecken für Detailanalyse ..................................106

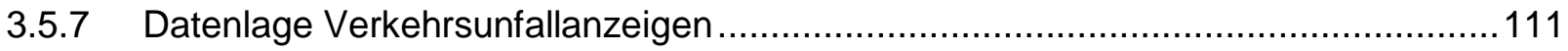

4 Detailanalyse ...................................................................................................112

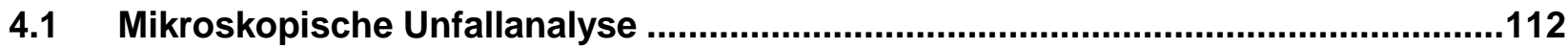

4.1.1 Ergebnisse der mikroskopischen Unfallanalyse ..........................................112

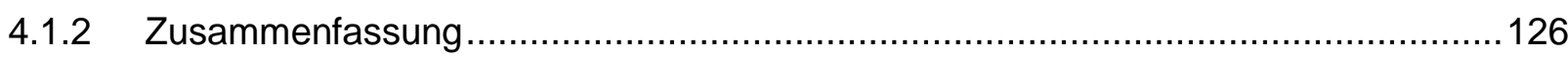




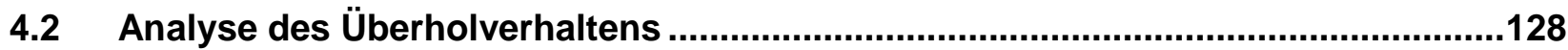

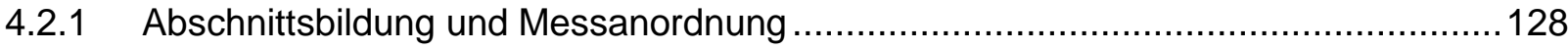

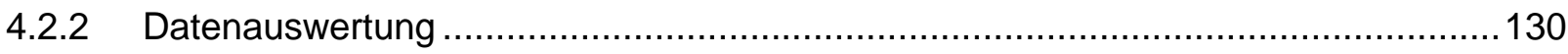

4.2.3 Ergebnisse der Pilotuntersuchung .......................................................... 131

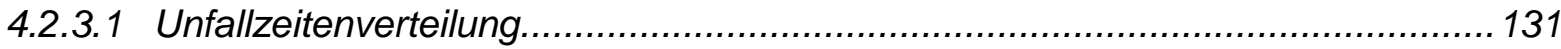

4.2.3.2 Anpassung Untersuchungs- und Erhebungszeitraum .................................. 132

4.2.4 Ergebnisse der Fahrverhaltensanalysen ....................................................133

4.2.4.1 Generelle Zusammenhänge zwischen Überholverhalten und Unfallgeschehen .. 133

4.2.4.2 Überholverhalten in Abhängigkeit äußerer Bedingungen ................................ 136

4.2.4.3 Zusammenfassung .............................................................................. 145

4.3 Besonderheiten und Maßnahmenvorschläge der Untersuchungsstrecken...........147

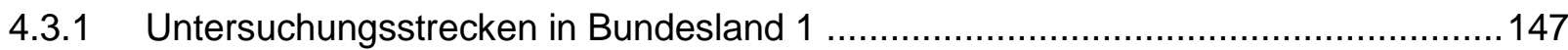

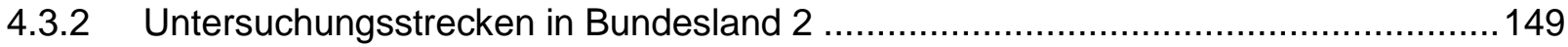

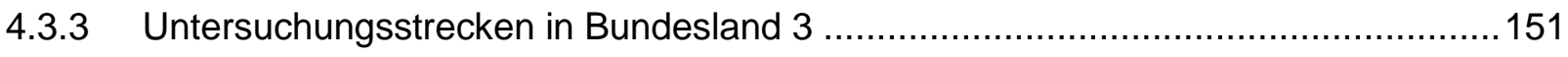

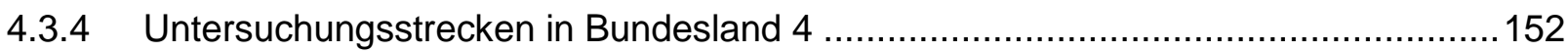

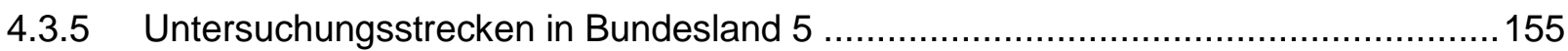

4.3.6 Zusammenfassung wesentlicher Handlungsfelder........................................159

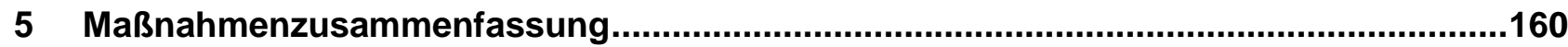

5.1 Maßnahmenansatz Verkehrsinfrastruktur ............................................................160

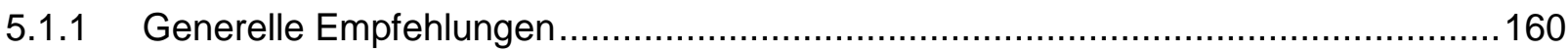

5.1.2 Konkretisierung der infrastrukturellen Maßnahmen ........................................ 163

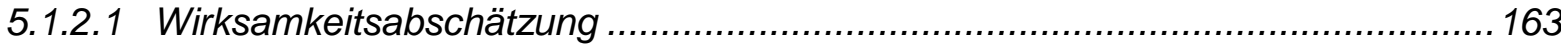

5.1.2.2 Modularer Aufbau von Überholverboten .................................................. 164

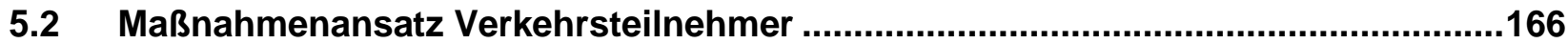

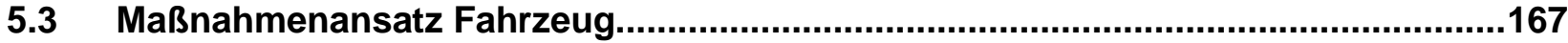

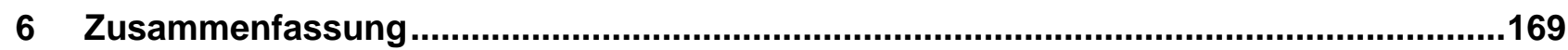

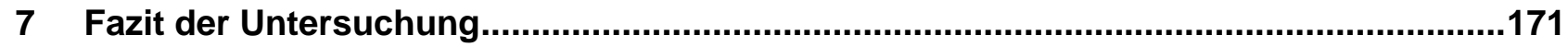

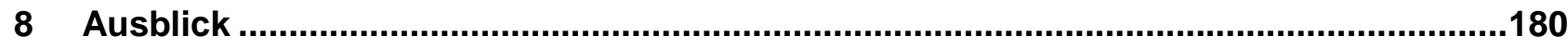

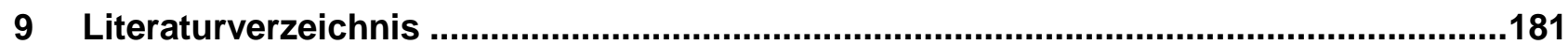




\section{ANHANGVERZEICHNIS}

Anhang A Grundbegriffe der Verkehrssicherheitsarbeit

Anhang B Berechnung von Unfallkenngrößen und angepassten Unfallkostensätzen ...198

Anhang C Zusammenhänge zwischen dem Gesamtunfallgeschehen und dem Kollektiv der Überholunfälle

Anhang D Rangfolge der 500 mit Überholunfällen auffälligsten Untersuchungsstrecken....

Anhang E Ergebnisse der verkehrsrechtlichen Anordnungen ....................................213

Anhang $F \quad$ Ergebnisse der Unfallzuordnung ................................................................216

Anhang G Unfallkategorien der Überholunfälle mit Bezug zu Merkmalslängen ..............219

Anhang H Unfallkenngrößen der Überholunfälle mit Bezug zu unfallauffälligen Merkmalslängen

Anhang I Unfallkenngrößen der Überholunfälle mit Bezug zur Gesamtlänge der Untersuchungsmerkmale im Streckennetz.

Anhang J Signifikanztest der Unfallkenngrößen nach verkehrsrechtlichen Anordnungen .

Anhang K Unfallkenngrößen des Gesamtunfallgeschehens (Unfallkategorie 1-4) differenziert nach Fahrbahnbreiten

Anhang L Unfallkenngrößen der Überholunfälle differenziert nach Fahrbahnbreiten .....234

Anhang M Unfallkenngrößen des Gesamtunfallgeschehens (Unfallkategorie 1-4) differenziert nach Straßenraumbreiten

Anhang N Unfallkenngrößen der Überholunfälle differenziert nach Straßenraumbreiten .....

Anhang 0 Unfallkenngrößen des Gesamtunfallgeschehens (Unfallkategorie 1-4)

differenziert nach Regelquerschnitten

Anhang P Unfallkenngrößen der Überholunfälle differenziert nach Regelquerschnitten 242

Anhang Q Unfallkenngrößen der Überholunfälle differenziert nach verkehrsrechtlichen Anordnungen und Regelquerschnitten

Anhang R Signifikanztest der Unfallkenngrößen nach Fahrbahnbreiten 248

Anhang S Zusammenhänge zwischen Überholunfällen und Landstraßeneigenschaften.....

Anhang $\mathrm{T} \quad$ Analyse korrelierender Variablen

Anhang U Zusätzliche Ergebnisse der Streckenbandanalyse 
7) Überholunfälle auf Landstraßen - Abschlussbericht

Anhang V Streckenzuordnung zu vorhandenen und rechtlichen Überholmöglichkeiten.

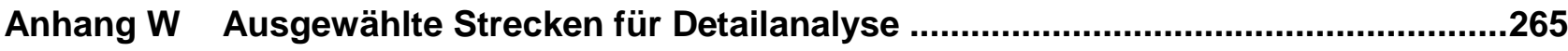

Anhang $X \quad$ Zusätzliche Ergebnisse der mikroskopischen Unfallanalyse .........................267

Anhang Y Überholverhalten und Unfallgeschehen in Abhängigkeit der Verkehrsstärken ...

Anhang Z Überholverhalten und Unfallgeschehen in Abhängigkeit maßgebender Sichtweitenbereiche.

Anhang AA Überholverhalten und Unfallgeschehen in Abhängigkeit verschiedener Überholverbote .276

Anhang BB Gesamtergebnisse der Detailanalyse 279 


\section{ABBILDUNGSVERZEICHNIS}

Abbildung 2.1: Weg-Zeit-Diagramme der Überholtypen..................................................12

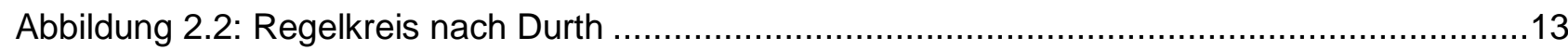

Abbildung 2.3: Zusammenhänge eines Überholvorganges...............................................14

Abbildung 2.4: Phasen der Unfallentstehung nach Durth/Bald.........................................15

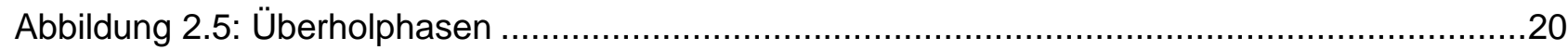

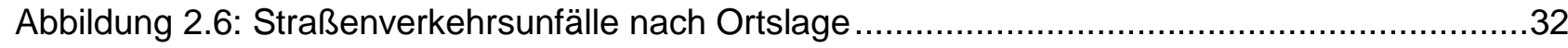

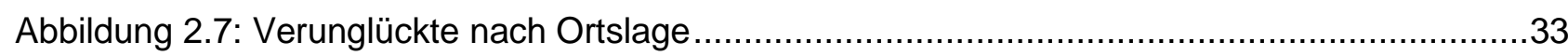

Abbildung 2.8: Unfälle mit Personenschaden auf Landstraßen nach Unfalltypen .......................34

Abbildung 2.9: Unfälle mit Personenschaden auf Landstraßen nach Unfallarten ........................35

Abbildung 2.10: Fehlverhalten bei Unfällen mit Personenschaden auf Landstraßen.....................35

Abbildung 2.11: Überholunfälle mit Personenschaden auf Landstraßen nach Unfalltypen............36

Abbildung 2.12: Überholunfälle mit Personenschaden auf Landstraßen nach Unfallarten .............37

Abbildung 2.13: Fehlverhalten bei Überholunfällen mit Personenschaden auf Landstraßen..........38

Abbildung 2.14: Überholunfälle mit Personenschaden auf Landstraßen nach Altersklassen .........38

Abbildung 2.15: Überholunfälle mit Personenschaden auf Landstraßen nach Wochentagen ........39

Abbildung 2.16: Überholunfälle mit Personenschaden auf Landstraßen nach Monaten................40

Abbildung 2.17: Überholunfälle mit Personenschaden auf Landstraßen nach Lichtverhältnissen ..40

Abbildung 2.18: Straßenzustände bei Überholunfällen mit Personenschaden auf Landstraßen ....41

Abbildung 2.19: Witterungseinflüsse bei Überholunfällen mit Personenschaden auf Landstraßen 41

Abbildung 3.1: Unfalltypenverteilung in Überholunfälle ................................................46

Abbildung 3.2: Unfallartenverteilung in Überholunfällen......................................................47

Abbildung 3.3: Anteil der Bundesländer an den Untersuchungsstrecken ...............................52

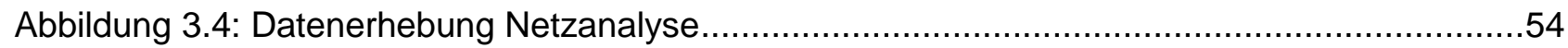

Abbildung 3.5: Rechtliche Überholmöglichkeiten im Untersuchungsgebiet ..............................56

Abbildung 3.6: Angeordnete Geschwindigkeitsbeschränkungen........................................58

Abbildung 3.7: Zusammenfassung der Matrixinhalte - Streckenanteile ..................................59

Abbildung 3.8: Unfallzuordnung zu Streckenmerkmalen..............................................60

Abbildung 3.9: Unfallzuordnung zu Geschwindigkeitsbeschränkungen ..................................60

Abbildung 3.10: Zusammenfassung der Matrixinhalte - Unfallgeschehen ..............................60 
Abbildung 3.11: Bezug Gesamtunfallgeschehen auf Länge der Streckenmerkmale 62

Abbildung 3.12: Einfluss der Abschnittslängen auf die Unfallkenngrößenberechnung .72

Abbildung 3.13: Differenzen zwischen RAS-L und RMS ....................................................... 84

Abbildung 3.14: Überholunfälle in Lageplanelementen ...................................................92

Abbildung 3.15: Verteilung der Unfallpositionen auf Lageplanelemente ...................................93

Abbildung 3.16: Kurven mit Überholunfällen nach Radienbereichen und Richtungssinn...............94

Abbildung 3.17: Unfallzuordnung zu Höhenplanelementen ................................................95

Abbildung 3.18: Rechnerischer Einfluss von Kuppen nach RAS-L an Unfallpositionen .................95

Abbildung 3.19: Eingehaltene Sichtweitenkriterien an den Unfallpositionen ............................97

Abbildung 3.20: Sichtweitenbereiche zwischen RAS-L und RMS an den Unfallpositionen ...........97

Abbildung 3.21: Rechtliche Anordnungen an den Unfallpositionen .........................................99

Abbildung 3.22: Zulässige Geschwindigkeiten an Unfallpositionen.......................................99

Abbildung 3.23: Rechtliche Anordnungen bei Unfällen differenziert nach Sichtweitenbereichen..100 Abbildung 3.24: Unfallkenngrößen nach Sichtweitenbereichen und Überholverboten ................102

Abbildung 3.25: Rechtliche Anordnungen bei Unfällen innerhalb besonderer Elemente .............104

Abbildung 3.26: Ergebnis der Klasseneinteilung von Überholmöglichkeiten ............................108

Abbildung 4.1: Fahrzeugart der Unfallverursacher......................................................113

Abbildung 4.2: Unfallbeteiligtes Hindernisfahrzeug .................................................113

Abbildung 4.3: Konstellation Überholer / Hindernisfahrzeug .............................................114

Abbildung 4.4: Kollisionsgegner des Überholunfalles ..............................................114

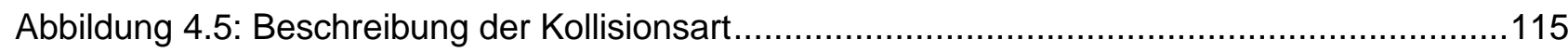

Abbildung 4.6: Differenzierung der Zusammenstöße mit dem Gegenverkehr nach Kollisionsgegnern.......................................................................... 116

Abbildung 4.7: Differenzierung der Zusammenstöße mit Abbiegern nach Kollisionsgegnern.......117

Abbildung 4.8: Differenzierung der Zusammenstöße mit dem Seitenraum nach

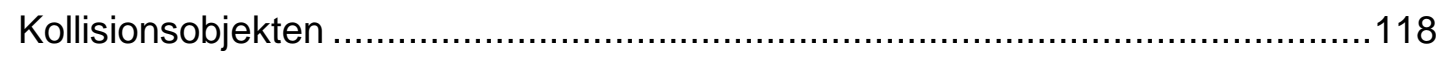

Abbildung 4.9: Kollisionsarten nach Unfallkategorien ....................................................118

Abbildung 4.10: Art der Verkehrsbeteiligung des Unfallverursachers nach Unfallkategorien .......119

Abbildung 4.11: Besonderheit der Unfallörtlichkeit..........................................................120

Abbildung 4.12: Anzahl der Fahrzeuge vor dem Überholer ...........................................120

Abbildung 4.13: Unfallentstehung in Abhängigkeit der Überholphasen nach Durth/Habermehl ...121 
Abbildung 4.14: Kollisionsarten in Abhängigkeit der Überholphasen nach Durth/Habermehl

Abbildung 4.15: Überholphasen gemäß Durth/Habermehl (1985) nach Sichtweitendefinitionen der RMS/RAS-L

Abbildung 4.16: Altersklassen und Geschlecht der Hauptverursacher von Überholunfällen

Abbildung 4.17: Alter der Unfallverursacher und rechtliche Anordnungen an Unfallpositionen ....125

Abbildung 4.18: Eingesetzte Messausrüstung ..... 129

Abbildung 4.19: Zeitpunkte der Überholunfälle im Untersuchungsgebiet

Abbildung 4.20: Zusammenhang zwischen Gesamtüberholungen und repräsentativen Überholungen

Abbildung 4.21: Zusammenhang zwischen Sichtweiten und beiden Überholkollektiven

Abbildung 4.22: Zusammenhang zwischen repräsentativen Überholungen und Sichtweiten 138

Abbildung 4.23: Zusammenhang zwischen repräsentativer Überholrate und Sichtweiten. 139

Abbildung 4.24: Zusammenhang zwischen Überholunfällen und repräsentativen Überholungen 140

Abbildung 4.25: Unfallrisiko bei repräsentativen Überholungen in unterschiedlichen Sichtweitenbereichen 140

Abbildung 4.26: Zusammenhang zwischen Überholunfällen und repräsentativen Überholungen differenziert nach Überholverboten

Abbildung 4.27: Unfallrisiko bei repräsentativen Überholungen nach Sichtweitenbereichen und verkehrsrechtlicher Überholsituation 


\section{TABELLENVERZEICHNIS}

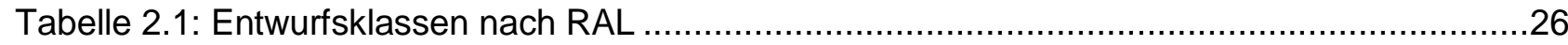

Tabelle 3.1: Übersicht der Straßennetz- und Unfalldaten ...................................................44

Tabelle 3.2: Ergebnis der Straßennetzaufbereitung ........................................................

Tabelle 3.3: Unfallzahlen auf Untersuchungsstrecken ..........................................................45

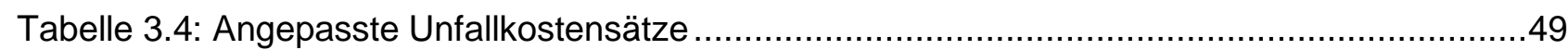

Tabelle 3.5: Unfallkostensätze der Bundesländer nach ESN ..............................................49

Tabelle 3.6: UKD des 100. Rangfolgeplatzes im jeweiligen Bundesland .................................51

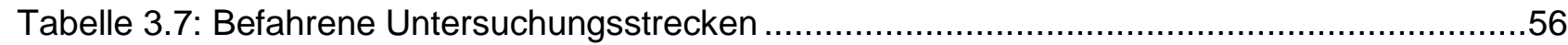

Tabelle 3.8: Anteil der Unfallkategorien differenziert nach Geschwindigkeitsbeschränkungen......61

Tabelle 3.9: Risiko und Folgen von Überholunfällen differenziert nach einzelnen verkehrsrechtlichen Restriktionen

Tabelle 3.10: Allgemeines Risiko und Folgen von Überholunfällen bei Überholverboten und

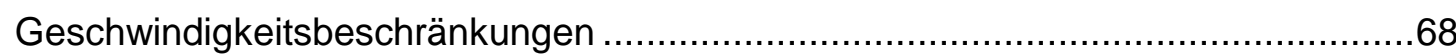

Tabelle 3.11: Spektrum der Bezugsgrößen nach Überholverboten........................................69

Tabelle 3.12: Spektrum der Bezugsgrößen nach Geschwindigkeitsbeschränkungen ..................70

Tabelle 3.13: Untersuchungsstrecken nach Regelquerschnitten der RAS-Q 1996 ....................76

Tabelle 3.14: Untersuchungsstrecken nach Regelquerschnitten der RAS-Q 1996, 1982 inkl.

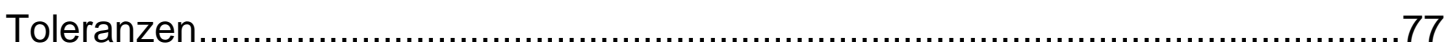

Tabelle 3.15: Richtwerte der Überholsichtweite nach RAS-L und RMS ..................................83

Tabelle 4.1: Erhobene Überholungen im Untersuchungsgebiet ......................................133

Tabelle 4.2: Verknüpfung Überholunfälle mit Überholungen ................................................134 
7) Überholunfälle auf Landstraßen - Abschlussbericht

\section{ABKÜRZUNGSVERZEICHNIS}

$\mathrm{BAB}$

DTV

EKL

ESN

FGSV

$\mathrm{Kfz}$

GLONASS

GPS

M_EKLBEST

nnk

RAL

$\mathrm{RQ}$

SIB

U

UD

UKD

UKR

UR

SIPO

U(GT/SV/LV)

$\mathrm{U}(\mathrm{SP} / \mathrm{LV} / \mathrm{SS})$

V(GT/SV/LV)

vnk
Bundesautobahn

durchschnittliche tägliche Verkehrsstärke

Entwurfsklasse

Empfehlungen für die Sicherheitsanalyse von Straßennetzen

Forschungsgesellschaft für Straßen- und Verkehrswesen

Kraftfahrzeug

Globalnaja Nawigazionnaja Sputnikowaja Sistema

Global Positioning System

Merkblatt für die Übertragung des Prinzips der Entwurfsklassen der RAL auf bestehende Straßen

nach-Netzknotennummer

Richtlinien für die Anlage von Landstraße

Regelquerschnitt

Straßeninformationsbank

Unfallanzahl

Unfalldichte

Unfallkostendichte

Unfallkostenrate

Unfallrate

Sicherheitspotential

Unfälle mit getöteten/schwerverletzten/leichtverletzten Personen

Anzahl der Unfälle mit schwerem Personenschaden/leichtem Personenschaden/schwerem Sachschaden

Anzahl der Getöteten/Schwerverletzten/Leichtverletzten

von-Netzknotennummer 


\section{Einleitung}

Landstraßen weisen über 59 Prozent der Getöteten bei Straßenverkehrsunfällen in Deutschland auf. Unfälle mit entgegenkommenden Fahrzeugen haben an der Gesamtzahl an verunglückten Menschen einen Anteil von 18 Prozent, die dadurch entstehenden Unfallkosten belaufen sich jedoch auf über ein Viertel der gesamten Unfallkosten auf deutschen Landstraßen. Überholunfälle gehören somit insgesamt zu den folgeschwersten Unfällen auf deutschen Straßen.

Das Ziel dieser Untersuchung ist es daher, die infrastrukturellen und verkehrlichen Parameter auf unfallauffälligen Landstraßen zu analysieren, somit die Einflussgrößen auf das Überholverhalten und das entstandene Unfallgeschehen zu bestimmen, um daraus geeignete Maßnahmen zur Reduzierung von Überholunfällen ableiten zu können. Die Empfehlungen können in den „Richtlinien für die Anlage von Landstraßen" (RAL) und dem „Merkblatt für die Übertragung des Prinzips der Entwurfsklassen nach den RAL auf bestehende Straßen" (M_EKLBEST) berücksichtigt werden und dazu beitragen, folgenschwere Überholunfälle zu vermeiden und damit die Verkehrssicherheit auf Landstraßen zu erhöhen.

Die Grundlage der Untersuchung ist die Identifizierung von unfallauffälligen Landstraßenabschnitten in 5 ausgewählten Bundesländern Deutschlands. Hierzu müssen die Straßeninformationsbanken und Unfalldatenbanken aufbereitet und miteinander verknüpft werden. Anschließend soll eine makroskopische Unfallanalyse durch die Berechnung von Unfallkenngrößen dazu dienen, eine Rangfolge mit denen am stärksten mit Überholunfällen belasteten Landstraßen im Untersuchungsgebiet zu erhalten. Die 500 unfallauffälligsten Landstraßenabschnitte sollen in einer Netzanalyse weiter bearbeitet werden, wobei durch Streckenbefahrungen die angeordneten Überholverbote (Markierung und Beschilderung) sowie Geschwindigkeitsbeschränkungen erhoben und Überholunfälle diesen unterschiedlichen Bereichen von verkehrsrechtlichen Anordnungen zugeordnet werden. Darauf aufbauend wird für die ersten 100 Untersuchungsstrecken der Rangfolge eine Nachtrassierung und Sichtweitenermittlung durchgeführt. Abschließend erfolgt auf insgesamt 50 ausgewählten unfallauffälligen Strecken eine mikroskopische Detail- bzw. Fahrverhaltensanalyse zu Überholvorgängen mittels Videobeobachtungen.

Dieser Bericht bildet den Abschluss des Projektes „Untersuchung von Maßnahmen zur Prävention von Überholunfällen auf einbahnigen Landstraßen“ und gibt einen zusammenfassenden Überblick über die Ergebnisse der Literatur-, Netz-, Sichtweiten und Detailanalysen. Im Ergebnis werden die makroskopische Unfallanalyse, die Analysen der verkehrsrechtlichen Randbedingungen und Unfallzuordnung auf den 500 unfallauffälligsten Untersuchungsstrecken, die Nachtrassierung von 100 Untersuchungsstrecken sowie die Sichtweitenanalyse und abschließend die Detailanalysen zum Überholverhalten ausführlich erläutert und Maßnahmenempfehlungen zur Vermeidung von Überholunfällen auf einbahnig zweistreifigen Landstraßen gegeben. 


\section{Grundlagenstudie}

\subsection{Literaturanalyse}

Das Verkehrssystem Straße ist stark vom menschlichen Verhalten geprägt, wodurch es im Vergleich zu anderen Verkehrssystemen eine besondere Störanfälligkeit und Unfallhäufigkeit besitzt. Grund hierfür ist neben dem menschlichen Verhalten der hohe Anteil von menschlichen Fehlern im System, die hohe Anzahl von Interaktionen zwischen den Verkehrsteilnehmern, häufige Störungen von außen (Witterung, Hindernisse auf der Fahrbahn), die Randbedingungen des Verkehrsablaufes (freier gegenüber gebundenem Verkehr) und die der Teilsysteme Auto, Lkw, Fahrrad und Fußgänger (unterschiedliche Geschwindigkeiten) [Topp, 2008]. Besonders letztgenannte Randbedingungen sind für diese Untersuchung von großer Bedeutung, weil sie Grundlage für die Überholvorgänge sind, die es in dieser Untersuchung zu analysieren gilt.

\subsubsection{Definition Überholvorgang}

Eine Überholung auf einbahnig zweistreifigen Landstraßen liegt dann vor, wenn ein Verkehrsteilnehmer an einem vor ihm fahrenden, langsameren Verkehrsteilnehmer unter Nutzung der Fahrstreifen des Gegenverkehrs links vorbeifährt. Auf einbahnig zweistreifigen Landstraßen kann nach Netzer [1966] zwischen Einfachüberholungen (ein Fahrzeug überholt ein anderes Fahrzeug), Mehrfachüberholungen (ein Fahrzeug überholt mehrere Fahrzeuge, mehrere Fahrzeuge überholen ein Fahrzeug oder mehrere Fahrzeuge überholen mehrere Fahrzeuge) und Doppelüberholungen (ein bereits Überholender wird überholt) unterschieden werden (vgl. Abbildung 2.1).

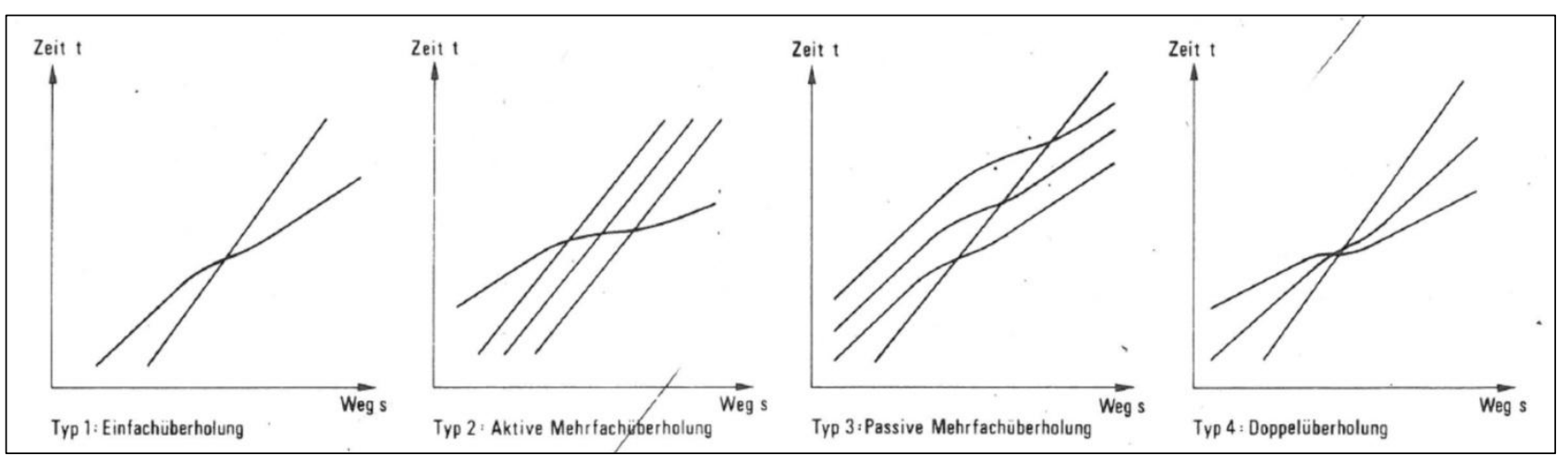

Abbildung 2.1: Weg-Zeit-Diagramme der Überholtypen (Quelle: Durth/Habermehl, 1985)

Einzelüberholungen sollten hierbei den Regelfall darstellen. Mehrfachüberholungen entstehen, wenn entsprechende Sichtverhältnisse vorhanden sind und die zu Überholenden einen geringen Abstand untereinander haben, sodass die Mehrfachüberholung nicht in mehrere Einzelüberholungen zerlegt werden kann. Doppelüberholungen sind nur bei Beteiligung von Fußgängern und Radfahrern denkbar, Doppelüberholungen mit ausschließlicher Beteiligung von Pkws sind selten und bei den meisten Straßenverhältnissen gar nicht möglich. Wegen hohen Differenzgeschwindigkeiten ist das Überholen von Fußgängern und Radfahrern besonders gefährlich, da bei Gegenverkehr vor Unterschreitung des Anhalteweges eine Entscheidung zum starken Abbremsen getroffen werden muss. Diese Fälle sind auf Landstraßen selten, aber nicht auszuschließen [Netzer, 1966]. 


\subsubsection{Rechtliche Grundlagen}

In $\S 5$ der StVO [2010] ist die Verfahrensweise bei einem Überholvorgang gesetzlich geregelt. Demzufolge darf auf den hier zu untersuchenden Landstraßen links überholt werden, wenn abgeschätzt werden kann, dass während des ganzen Überholvorganges jede Behinderung des Gegenverkehrs ausgeschlossen ist und sich die Geschwindigkeiten wesentlich unterscheiden. Bei unklaren Verkehrslagen (z.B. schlechten Sichtverhältnissen) und dem Vorhandensein der Zeichen 276 bzw. 277 oder einer Fahrstreifenbegrenzung nach Zeichen 295 bzw. 296 ist das Überholen verboten. Wie diese Verbote beachtet werden, ist folgenden Kapiteln zu entnehmen. Der Überholvorgang ist nach Prüfung der Hindernisfreiheit des Gegenfahrstreifens und Berücksichtigung des Folgeverkehrs mit dem angekündigtem Ausscheren einzuleiten, in mindestens $1 \mathrm{~m}$ seitlichem Abstand durchzuführen und bei Erreichung des Sicherheitsabstandes vor dem überholten Fahrzeug mit dem Wiedereinordnen zu beenden. Der Überholte hat während des Überholvorgangs seine Geschwindigkeit beizubehalten.

\subsubsection{Fahrverhalten und Straßengestaltung}

Das komplexe Regelsystem zwischen Fahrer, Fahrzeug und Straße beschreibt mit einer Vielzahl von einwirkenden Komponenten der nachstehende Regelkreis von Durth.

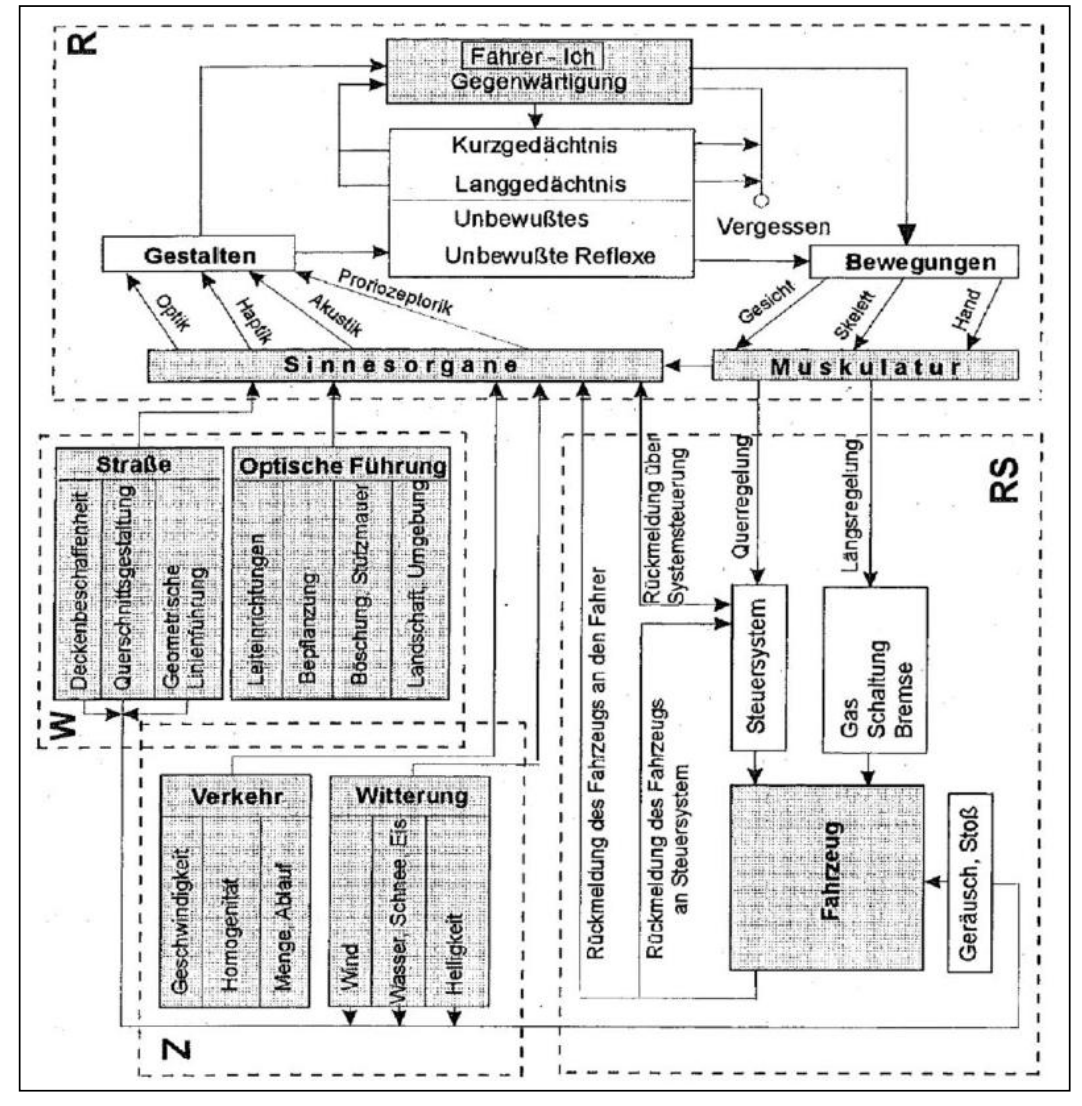

Abbildung 2.2: Regelkreis nach Durth (Quelle: Weise/Durth, 1997)

Der Fahrer als Regler R dieses Systems nimmt kontinuierlich über seine Sinnesorgane die Führungsgrößen W des Straßenraumes und die zufallsverteilten Störgrößen Z wie Witterung und um- 
gebende Verkehrsteilnehmer wahr. Im Zentrum des Regelkreises steht der Fahrer, daher muss auch die Linienführung der Landstraße theoretisch psychologischen Grundlagen genügen.

Mit seinen in weiten Grenzen schwankenden Qualitäts- und Eigenartmerkmalen orientiert sich der Mensch vor allem mit Hilfe des Gesichtssinns am Verkehrsablauf, alle weiteren Sinne besitzen wenn überhaupt nur eine Kontrollfunktion für das über die Sicht gewählte Fahr- und Geschwindigkeitsverhalten. Demzufolge ist die Trassierung als optisches, verkehrspsychologisches Prinzip anzusehen. Überholsichtweiten sind keine reinen geometrischen Größen, die aus der Trasse und der Umgebung bestimmt werden können, sie werden durch eine Vielzahl von Faktoren des Menschen, des Fahrzeugs, der Witterung oder beispielsweise der Tageszeit maßgeblich mitbestimmt [Hiersche, 1968]. Damit werden auch die auf einen Überholvorgang wirkenden Einflussfaktoren deutlich, die im Folgenden näher erläutert werden sollen.

Nach Netzer [1966] ist das Überholen ein sehr komplexer Verkehrsvorgang (vgl. Abbildung 2.3). Bei der Vielzahl der Einflussfaktoren gibt es auch zahlreiche Möglichkeiten, wie es beim Überholen zu Fehlern kommen kann. Besonders schwer sind die menschlichen Einflüsse zu erfassen, die beim Überholen von den individuellen Wünschen und Fähigkeiten von mindestens zwei Fahrzeugführern abhängig sind. Auch ein Überholvorgang unter gleichen Bedingungen ist beim gleichen Fahrer nicht identisch. Der Mensch ist physisch und psychisch gar nicht in der Lage, alle Einflussfaktoren rational zu erfassen und danach eine Entscheidung zu fällen. Die Fahrmanöver sind daher von der Verkehrserfahrung und den Fähigkeiten abhängig, wobei auch Fehlentscheidungen nicht auszuschließen sind.

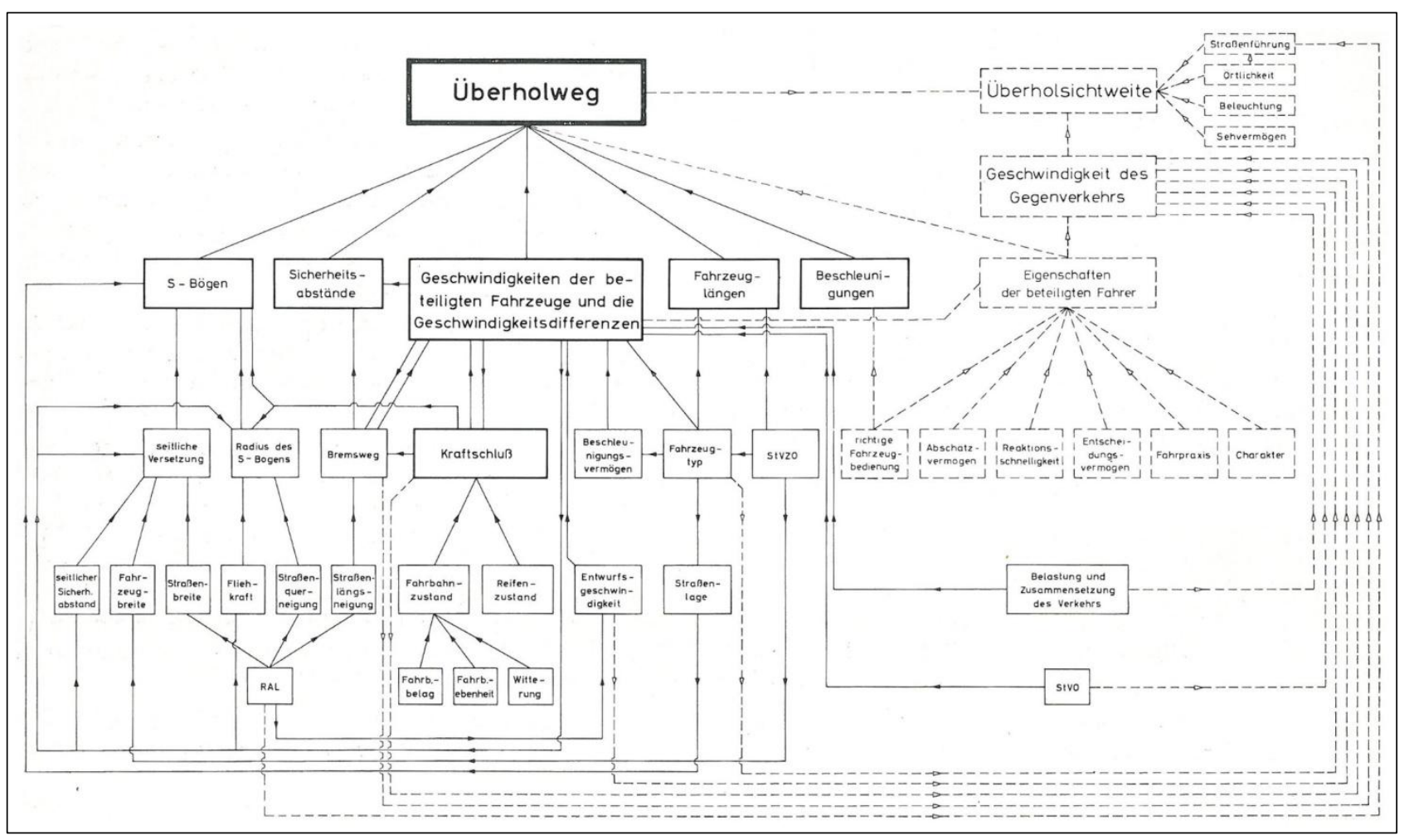

Abbildung 2.3: Zusammenhänge eines Überholvorganges (Quelle: Netzer, 1966) 
Das Verkehrsverhalten ist neben den zahlreichen Einflussfaktoren in Abbildung 2.3 zusätzlich von den Kenntnissen fahrdynamischer Zusammenhänge beim Überholen und der Fahrtüchtigkeit [Runkel, 1970], der Streckenkenntnis [Kayser/Otten/Hahn 1986], der Antizipation [Weise/Durth, 1997] aber auch der Beanspruchung, Wahrnehmungsfähigkeit, Erwartung, Motivation und Adaptationsfähigkeit der Fahrzeugführer [Kämpfe/Schlag/Weller, 2005] abhängig, die wiederum auch von den Führungs- und Störgrößen mitbestimmt werden.

Kommt es im System Fahrer, Fahrzeug, Straße zu Widersprüchen zwischen Erwartungen und den tatsächlichen Gegebenheiten, so treten vermehrt Fehler im Verhalten auf. Nach den in Abbildung 2.4 dargestellten Phasen der Unfallentstehung ist ein Fehler die erste Abweichung aus der Normalsituation und somit der erste Schritt zum Unfall. An dieser Stelle muss dazugesagt werden, dass nicht jeder Fehler zum Unfall führt, jedoch ist dies bei mangelnden Fähigkeiten zur Abwendung einer Gefahrsituation oft unvermeidbar. Bei Betrachtung der komplexen Modelle von Durth und Netzer wird deutlich, dass die Überlagerung von verschiedenen ungünstigen Eigenschaften von Fahrer, Fahrzeug, Fahrbahn und deren Umgebung zu einem Fehler und somit einem Unfall führen kann. Nach Topp [2008] haben Unfälle durchschnittlich 1,4 Ursachen. Daher sollten die human factors im Straßenentwurf berücksichtigt werden, um durch die bauliche Gestaltung Restriktionen vorgeben, die Wahrnehmung von situativen Schwierigkeiten verbessern und die Aufmerksamkeit der Fahrer auf bedeutende Signale und Problembereiche lenken zu können [Kämpfe/Schlag/Weller, 2005].

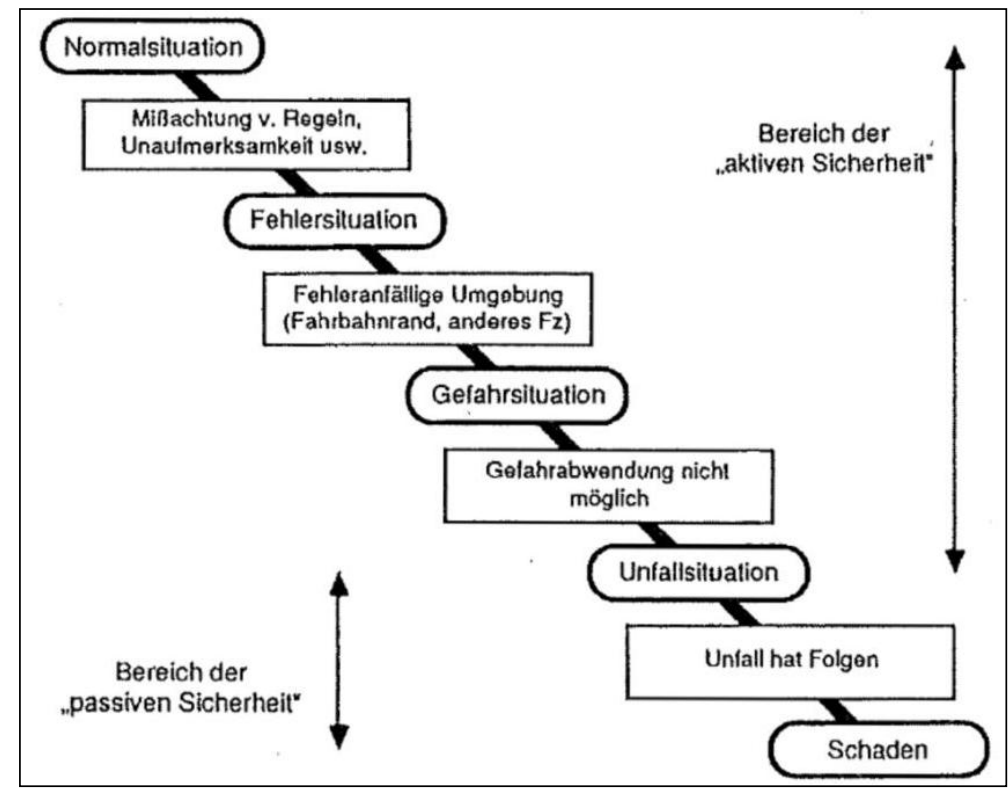

Abbildung 2.4: Phasen der Unfallentstehung nach Durth/Bald (1988)

Zimmer [2001] hat das Fehlermodell von Rasmussen an die Fahrzeugführung angepasst. Dabei werden sieben Fehlerarten in Abhängigkeit vom Auftreten in der Informationskette unterschieden, die nachfolgend, in Anlehnung an Gründl [2006], beispielhaft auf den Überholvorgang übertragen werden sollen.

- Strukturelle Fehler (Gegenverkehr hat keine Möglichkeit, einem riskantem Überholmanöver auszuweichen, wodurch ein Unfall unvermeidbar ist) 
- Informationsfehler (Überholer übersieht ein Überholverbot)

- Diagnosefehler (Geschwindigkeit des Gegenverkehrs wird falsch eingeschätzt)

- Zielsetzungsfehler (trotz erkanntem geringem Gegenverkehrsabstand wird versucht, den Überholvorgang schnell zu beenden, anstatt ihn abzubrechen)

- Fehler bei Vorgehensweise (mehrere Möglichkeiten zur Zielerreichung vorhanden, aber im Straßenverkehr eher selten zu finden)

- Handlungsfehler (Fahrer hat das richtige Ziel und die richtige Strategie gewählt, führt aber die notwendige Handlung falsch aus, z.B. Abbrechen eines Überholvorgangs mit Verreißen des Lenkrades beim Einscheren)

- Bedienungsfehler (Fehler bei Handlung in Mensch-Maschine-Schnittstelle, Fahrer verwechselt Gaspedal mit Bremse)

Zu den Fehlerarten gibt es in Abhängigkeit der Umstände mehrere Gründe bzw. Ursachen. Zu den genannten Beispielen existieren aber auch verschiedene Möglichkeiten, das Fehlverhalten durch die Infrastruktur oder die Fahrzeugtechnik positiv zu beeinflussen (siehe hierzu Kapitel 2.1.5).

Reason [1994] weist darauf hin, dass bei sicherheitsgefährdenden Handlungen zwischen unbeabsichtigten und beabsichtigten Handlungen unterschieden werden muss. In Bezug auf den Überholvorgang ergeben sich unbeabsichtigte Handlungen zum Beispiel durch latente Aufmerksamkeitsfehler die durch fehlende Informationen oder Störungen verstärkt werden können. Trotzdem sind die meisten Handlungen unvorhersehbar und teilweise recht bizarr, daher gilt es, „zuerst ihre Vorläufer so weit wie möglich auszuschalten und dann hinzunehmen, dass einige unsichere Handlungen, welche Maßnahmen auch immer getroffen wurden, weiterhin auftreten werden“. Hierbei können allerdings noch Schutzmaßnahmen zwischen dem Ausführen der fehlerbehafteten Handlung und der negativen Konsequenz vorgesehen werden, um mögliche Unfälle zu vermeiden. Beabsichtigte Handlungen zeigen sich bei Überholvorgängen im Straßenverkehr zum Beispiel durch bewusste Verstöße, wie eine Überholung im Überholverbot. Grundsätzlich haben Verstöße einen bedeutenden Einfluss auf die Unfallentstehung.

Auch wenn gute Sichtbedingungen vorhanden sind, kann es zu Unfällen kommen, weil die Entscheidung für oder gegen einen Überholvorgang von der Schätzung der Entfernungen und Geschwindigkeiten des Gegenverkehrs abhängig ist. Es ist nachgewiesen, dass ein Teil der Kraftfahrer die Zustände des Gegenverkehrs nicht richtig einschätzt. Geschwindigkeiten werden oft zu niedrig und Entfernungen oft zu groß eingeschätzt. Besonders negativ wirkt sich dies auf Überholvorgänge aus, weil sich beide Fehleinschätzungen nicht kompensieren sondern überlagern, was schwere Unfälle zur Folge haben kann [FGSV, 2001a].

Gründe für Fehler innerhalb der komplexen Regelungsprozesse sind beispielsweise situative Überforderungen. Nach Durth [1974] wirkt ein Fahrzeugführer einer Kapazitätsüberlastung des Informationsflusses durch eine Senkung der Geschwindigkeit entgegen. Diese Regelmöglichkeit steht beim Überholvorgang allerdings nicht zur Verfügung, weil für eine erfolgreiche Überholung die Geschwindigkeit erhöht werden muss. Demnach sollte die Straßensituation an Überholstrecken vereinfacht gestaltet werden, um eine Überschreitung der Aufnahmekapazität zu vermeiden. Für 
freie Fahrzeuge ist aber zugleich eine eintönige Gestaltung problematisch, da durch die Minimierung des Zuflusses neuer Informationen die Fahraufgabe mit geringerer Aufnahmekapazität oder geteilter Aufmerksamkeit durchgeführt werden kann. Möglicherweise werden dadurch Geschwindigkeitsüberschreitungen provoziert. Kayser/Struif [1993] vermuten dadurch sogar ein Ansteigen des Überholdrucks bei eintönigen Umgebungen (Gelände einschließlich Bewuchs und Bebauung).

Das Überholbedürfnis nimmt nach Steierwald/Jacobs/Feier [1985] mit wachsender Geschwindigkeitsstreuung zwischen mehreren Fahrzeugen auf einer Strecke und steigender Verkehrsbelastung zu. Allerdings nehmen die Möglichkeiten einen Überholvorgang durchzuführen mit erhöhter Verkehrsstärke im Gegenverkehr ab. Durch die Beschränkung von Überholmöglichkeiten bilden sich hinter dem freifahrenden Hindernisfahrzeug Folgen behinderter Fahrzeuge, die als Fahrzeugschlangen oder Fahrzeugpulks bezeichnet werden. Bei zunehmender Verkehrsstärke muss also auch von einem höheren Zeitverlust durch die fehlenden Überholmöglichkeiten ausgegangen werden. Mit zunehmender Warte- bzw. Verlustzeit im behinderten Fahrzeugpulk muss aber auch davon ausgegangen werden, dass immer kleinere Zeitlücken im Gegenverkehr für die Durchführung eines Überholvorganges akzeptiert werden [vgl. Steierwald/Jacobs/Feier, 1985, in Anlehnung an Retzko, 1961]. Der somit aufgebaute Überholdruck (Differenz von gewünschten und realisierten Überholungen) kann risikobehaftete Überholmanöver hervorrufen. Palm/Schmidt [1999] bestätigen eine Zunahme der Anteile von Überholunfällen an allen Streckenunfällen mit steigender Verkehrsstärke, was die eben getroffenen Vermutungen stützen kann. Andererseits kann man bei höheren Verkehrsstärken seine Fahrgeschwindigkeit nicht mehr frei wählen, wodurch die Anzahl der Fahrunfälle sinkt und somit der Anteil von Überholunfällen an allen Unfällen der freien Strecke automatisch steigt.

Vom Ankunfts- bis zum Überholzeitpunkt handelt es sich um ein instabiles Fahrverhalten und demnach um ein zeitlich nicht konstantes Überholverhalten. Im realen Verkehrsgeschehen kann bei Warteschlangenbildung nicht davon ausgegangen werden, dass die in erster Position hinter dem Hindernisfahrzeug fahrenden Verkehrsteilnehmer auch als erstes einen Überholvorgang durchführen. Fahrzeugführer, welche in erster Position hinter dem Hindernisfahrzeug hinterherfahren und Überholmöglichkeiten nicht nutzen, fühlen sich möglicherweise in ihrer Fahrweise nicht bzw. nur begrenzt behindert, finden keine ausreichenden individuellen Mindestzeitlücken im Gegenverkehrsstrom oder werden nach kurzer Zeit den Streckenabschnitt verlassen und sehen demnach keine Notwendigkeit bzw. Motivation für eine Überholung. Demzufolge kann eine Überholung auch aus höherer Position durchgeführt werden, wenn der Fahrzeugführer die gebotenen Zeitlücke im Gegenverkehr für ausreichend hält. Welchen Einfluss diese Überholung auf die Überholentscheidung des Fahrzeuges in erster Position hat, ist nicht bekannt. Die eben geschilderten Aspekte der Mehrfachüberholung wurden von Steierwald/Jacobs/Feier [1985] erstmals untersucht und in geschwindigkeitsabhängigen Grenz- und Folgezeitlücken ausgedrückt. Aus Sicht der Verkehrssicherheit ist in dem Zusammenhang ein übermäßig angestauter Überholdruck mit einer folgenden risikoreichen aktiven Mehrfachüberholung als kritisch anzusehen. Mit zunehmender Geschwindigkeit des Hindernisfahrzeugs nimmt allerdings auch die Wahrscheinlichkeit eines Überholvorganges aus höherer Position ab. 
In Simulatorversuchen erkannten Kayser/Otten/Hahn [1986], dass sich Häufungen von Überholungen ergeben, die mit den Überholsichtweiten korrelieren und von der momentanen Verkehrssituation mitbestimmt werden. Die Abhängigkeit des Verkehrsverhaltens von Erfahrungen, Motivation und persönlichen Eigenschaften der Fahrzeugführer spiegelte sich in dieser Untersuchung dadurch wieder, dass unterschiedliche Versuchspersonen sich bietende Überholmöglichkeiten verschieden schnell wahrnehmen und einen Überholvorgang einleiten. Bei frühzeitigen Überholentscheidungen können große Sichtweiten und große Gegenverkehrsabstände ausgenutzt werden, eine Verzögerung durch längere menschliche Entscheidungsprozesse kann dagegen zu riskanteren Ausgangsbedingungen führen. Wartezustände hinter Hindernisfahrzeugen ergeben sich häufig bei kleinen Sichtweiten und kleinen Gegenverkehrsabständen, die eine individuelle Entscheidung für einen Überholvorgang nicht zulassen. Bei defensiven Fahrern sind aber auch Wartezustände zu beobachten, wenn sich eine Überholmöglichkeit anbietet. Die Fahrweise im Wartezustand ist abhängig von der Geschwindigkeit des Hindernisfahrzeuges. Demnach ergibt sich eine unstetige Fahrweise bei langsamen Hindernissen und ein entspannteres Hinterherfahren ohne gesteigertes Überholbedürfnis, wenn die gefahrene Geschwindigkeit mehr der eigenen Wunschgeschwindigkeit entspricht. Demzufolge ergibt sich auch ein unterschiedlich forsches Überholen, wenn die individuellen Grundeinstellungen zu Geschwindigkeitswahl und Fahrverhalten von dem Hindernisfahrzeug abweichen. Die Überholhäufigkeit ist also von individuellem Überholverlangen und Situationsbeurteilung abhängig.

Untersuchungen von Laffont/Schmidt [1993] ergaben in Bezug auf den Überholvorgang folgende Ergebnisse. Die drei Haupteinflussgrößen auf die Überholhäufigkeit sind Verkehrsstärke in Fahrtrichtung, Fahrbahnbreite und die Standardabweichung der gefahrenen Geschwindigkeiten. Die größten Überholraten (aktive Überholungen) konnten bei Motorrädern, gefolgt von Kraftfahrzeugen festgestellt werden. Vor allem für die Motorradfahrer, die auf Außerortsstrecken als die schwächsten Verkehrsteilnehmer anzusehen sind, enden Unfälle meist tödlich. Betrachtet man die Überholraten in Stundengruppen und Lagen zu Ballungsgebieten, so ergeben sich hohe Überholraten am Nachmittag in stadtauswärtiger Richtung. Nach der Definition der Kenngröße „relativer Überholdruck" als Anteil der im Pulk fahrenden Fahrzeug zum Gesamtverkehr an den Ein- und Ausfahrquerschnitten der Messstrecken, konnte am Ende der Strecken eine Zunahme des relativen Überholdrucks im Vergleich zum Streckenanfang festgestellt werden. Demzufolge kann nicht davon ausgegangen werden, dass sich auf geraden Landstraßenabschnitten mit nahezu unbegrenzten Sichtweiten der Überholdruck abbaut. Die Empfehlungen zur Umsetzung von breiten Querschnitten stehen aber neueren Erkenntnissen zur Unfallauffälligkeit von breiten Landstraßenquerschnitten entgegen (vgl. Palm/Schmidt [1999], Lamm/Beck/Zumkeller [1999]).

Auf zweistreifigen Landstraßen wird die Verkehrsqualität und das Überholverhalten außerdem durch die vorhandenen Längsneigungen, bei deren Zunahme die Geschwindigkeit des Bemessungsschwerfahrzeugs abnimmt, sowie von den Krümmungsverhältnissen der Straße die sich durch die Kurvigkeit ausdrücken lassen und gleichzeitig die Überholsichtweiten beeinflussen, mitbestimmt [FGSV, 2001b]. 
Nach Pfundt [2001] geht der Anteil der Längsverkehrsunfälle mit abnehmendem Ausbaustandard der Landstraße zurück, der Anteil der Fahrunfälle steigt dagegen an. Veranschaulicht man sich die Unfallcharakteristik in Bezug auf das Alter der Fahrzeugführer, so können hier zunehmende Tendenzen von Unfällen im Längsverkehr mit steigendem Alter festgestellt werden, was somit auch einen Anstieg der Wahrscheinlichkeit von Überholunfällen vermuten lässt. Bei Hegewald/Weber [2008] ergeben sich die gleichen Tendenzen in Bezug auf Fahr- und Längsverkehrsunfälle. Hier wurde jedoch vermutet, dass bei Unfällen im Längsverkehr der Begegnungsunfall mit zunehmender Fahrbahnbreite - im übertragenen Sinne auch zunehmender Ausbaustandard - abnimmt und dagegen die Wahrscheinlichkeit eines Überholunfalles ansteigt.

Diese Vermutungen können durch die Untersuchung von Palm/Schmidt [1999] bekräftigt werden. Breite Querschnitte verleiten den Fahrer zum Überholen von langsamen Fahrzeugen, weil seitlich viel Platz vorhanden ist. Zudem haben breite Querschnitte oftmals eine großzügige Linienführung, wodurch der Fahrer eine längere Strecke einsehen kann. Eine Aufforderung zu riskanten Überholmanövern kann hier nicht ausgeschlossen werden. Demzufolge treten Überholunfälle auf breiten Querschnitten häufiger auf und sind dort in Bezug auf die Unfallfolgen auch schwerer.

In ihrem zweiten Simulatorversuch zur Beeinflussung des Überholverhaltens haben Kayser/Otten/Hahn [1988] die Wirkungen von überbreiten Querschnitten untersucht. Hier wurden Überholungen auch bei geringen Sichtweiten durchgeführt. Es wurden teilweise Überholmanöver eingeleitet, bei denen sich der Gegenverkehr so nah befand, dass die geometrische Lücke zwischen Gegenverkehr und Hindernis als sicher eingeschätzt werden kann. Allerdings sind diese Ansatzpunkte in Bezug zur Verkehrssicherheit als kritisch anzusehen und zu verwerfen.

Nach Otte [2000] können auf einbahnig zweistreifigen Straßen auch Pkw-Alleinunfälle indirekte Folgen eines Überholvorganges sein, ohne dass es zu Kollisionen zwischen verschiedenen Fahrzeugen gekommen ist. Ursache hierfür sind Fehler beim Fahrstreifenwechsel, dies insbesondere bei erhöhter Schleudergefahr bei nassen Fahrbahnen oder gleichzeitigen Brems- und Einschervorgängen bei abgebrochenen Überholvorgängen. Weitere Alleinunfälle können durch Ausweichmanöver von bereits überholenden Fahrzeugen beim Ausscheren eines vorrausfahrenden weiteren Überholers geschehen, aber auch durch Ausweichen vor einem entgegenkommenden Überholer. Alleinunfälle, die bei sachlich richtiger und physisch funktionsfähiger Handlungsweise der Fahrzeugführer entstehen, gibt es in der Regel nicht. Unfälle an vierstreifigen Straßen mit einer verkehrstechnischen Trennung wurden ebenfalls untersucht. Die Ergebnisse können grundsätzlich auch für Querschnitte des RQ 15,5 angenommen werden. Hierbei können durch den Spurwechselvorgang beim Ein- und Ausscheren Auffahrunfälle entstehen, Begegnungsunfälle sind aber auch hier nicht auszuschließen. Durch die jeweils eigenen Fahrstreifen werden die Unfallfolgen aber möglicherweise geringer ausfallen. 


\subsection{4 Überholgeometrie}

Bei der Analyse von Überholvorgängen kann nach Runkel [1970] zwischen einer beschleunigten und einer fliegenden Überholung unterschieden werden. Aus dieser Differenzierung resultieren unterschiedlich lange Überholwege und somit auch unterschiedliche notwendige Abstände zum Gegenverkehr. Die beschleunigte Überholung wird allerdings als der ausschlaggebende Fall angesehen. Zum einen wird bei steigenden Verkehrsmengen die Wahrscheinlichkeit einer fliegenden Überholung immer geringer, zum anderen ist die beschleunigte Überholung wegen längerer Überholwege maßgebend für die Bestimmung von Überholsichtweiten.

Nach Durth/Habermehl [1985] kann ein Überholvorgang in fünf Phasen aufgeteilt werden (siehe Abbildung 2.5). In Phase 1 befindet sich der Überholer noch auf dem gleichen Fahrstreifen wie das Hindernisfahrzeug. Je nachdem ob in Phase 1 die Geschwindigkeit dem Hindernisfahrzeug angepasst wird, handelt es sich bei den weiteren Phasen um eine fliegende oder beschleunigte Überholung. In Phase 2 erfolgt der Ausschervorgang, Phase 3 beinhaltet die Vorbeifahrt bis ein ausreichender Sicherheitsabstand vorhanden ist und der Einschervorgang in Phase 4 einsetzen kann. Danach setzt der Überholer die Fahrt mit der gewünschten Fahrgeschwindigkeit unbehindert fort.

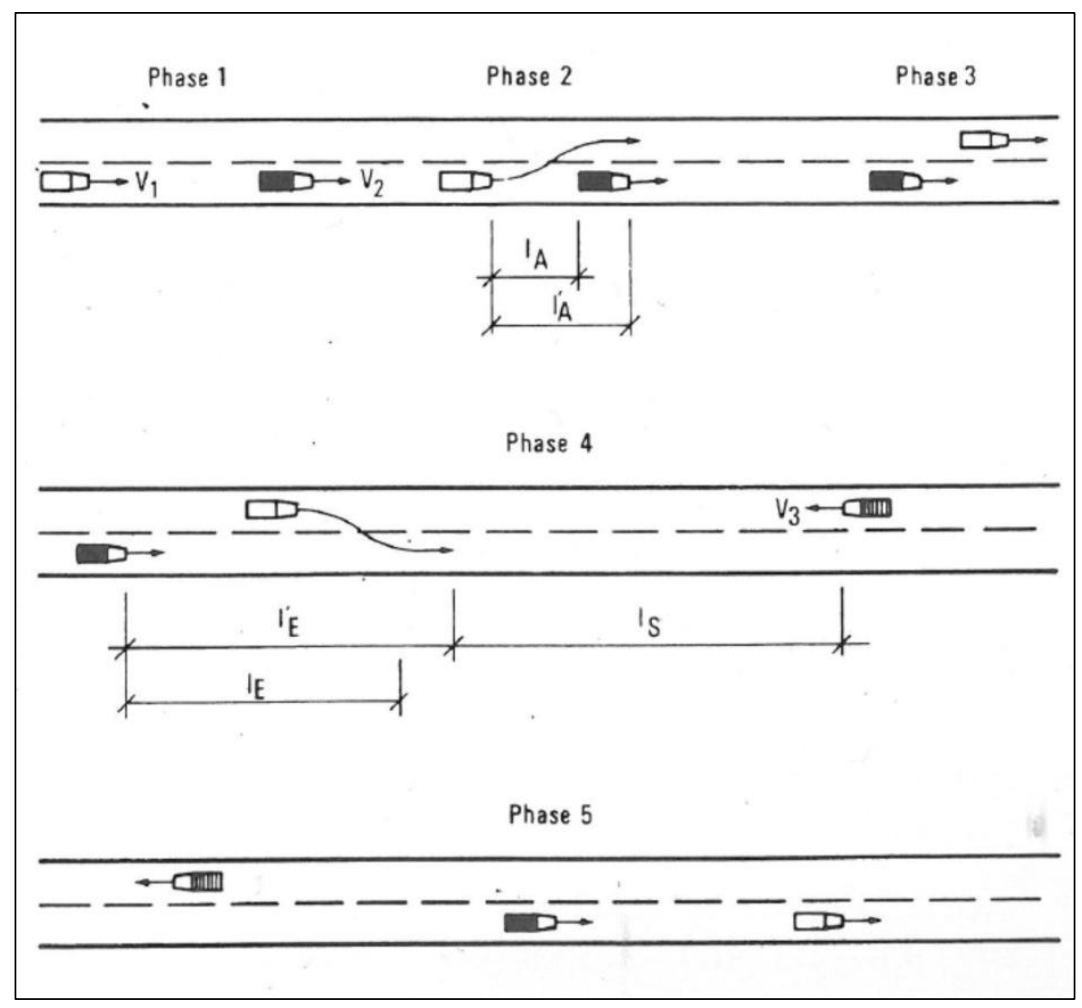

Abbildung 2.5: Überholphasen (Quelle: Durth/Habermehl, 1985)

Auftretender Gegenverkehr während der Phasen 2 oder 3 kann zu einer Entscheidung zum Abbruch eines Überholvorganges führen. Besonders negativ wirkt sich der Abbruch eines Überholvorganges auf eine fliegende Überholung aus, da hier die zu reduzierenden Geschwindigkeiten im Vergleich zur beschleunigten Überholung deutlich höher sind und sich somit die Wege zum Verzögern und somit das Wiedereinscheren verlängern. Bei einer beschleunigten Überholung und noch größeren Abständen zum Hindernis sowie kleineren Differenzgeschwindigkeiten kann möglicher- 
weise sofort wieder eingeschert werden. Bei bereits kleineren Abständen und höheren Differenzgeschwindigkeiten ist eine Verzögerung vor dem Einscheren notwendig, was in kritischen Fällen bei gleichzeitigen Bremsen und Einscheren zum Schleudern führen kann [Runkel, 1970]. Nach Kayser/Otten/Hahn [1988] ergibt sich auf breiten Fahrbahnen kein Anlass einen bereits begonnenen aber als kritisch bemerkten Überholvorgang abzubrechen, weil scheinbar keine Restriktionen mehr vorhanden sind.

Nach Lamm/Psarianos/Mailänder [1999] ist die kritische Position beim Überholvorgang erreicht, wenn sich Überholer und Überholter nebeneinander befinden. An diesem „point of no return“ ist die erforderliche Sichtweite zum Beenden des Überholvorganges gleich der notwendigen Sichtweite zum Abbruch der Überholung. Hier kann vermutet werden, dass nach diesem kritischen Punkt ein Bremsmanöver und anschließend das Wiedereinscheren hinter dem Hindernisfahrzeug zur Vermeidung einer Kollision nicht mehr sinnvoll ist. Im internationalen Vergleich werden von Lamm/Psarianos/Mailänder [1999] erforderliche Überholsichtweiten der verschiedenen Richtlinien gegenübergestellt. Unterschiede in den Zahlenwerten der einzelnen Länder ergeben sich aus unterschiedlichen Annahmen, die hinter der Festlegung der Überholsichtweiten stehen. Hierbei können Entscheidungspunkte für den Überholvorgang und Standorte des Gegenverkehrs variieren.

Der in älteren Fassungen der RAL [FGSV, 2010] enthaltene definierte Entscheidungsprozess zum Weiterführen oder Abbremsen und somit Abbrechen eines Überholvorganges liegt auf dem Gegenfahrstreifen seitlich versetzt hinter einem Hindernisfahrzeug. Dieser Entscheidungspunkt erinnert an die reduzierte Überholsichtweite der RAL-L von 1959. Diese Sichtweite ist nach Netzer [1966] aus Sicht der Verkehrssicherheit abzulehnen. Bei einer Rückkehr in die Position hinter dem Hindernisfahrzeug darf die folgende Autoschlange noch nicht zum Hindernis aufgeschlossen haben, was bei zunehmender Verkehrsstärke immer unwahrscheinlicher wird. Zudem kann bereits ein zweiter Überholender dem ausgescherten Fahrzeug folgen. Des Weiteren sind Missverständnisse durch Bremsungen des Überholten, der die Überholung erleichtern will, als kritisch anzusehen, wenn der Überholende gleichzeitig den Vorgang wegen Gegenverkehr abbrechen will.

Grundsätzlich werden bei Sichtweiten, die den Überholweg deutlich überschreiten, sich bietende Überholmöglichkeiten bereitwillig angenommen. Der Überholweg beinhaltet demzufolge genügend Raum für die Durchführung der Phasen 2 bis 4 eines Überholvorganges zuzüglich eines ausreichenden Sicherheitsabstands zum Gegenverkehr. Kritische Überholentscheidungen können bei zügiger Fahrweise durch sich ergebende kürzere Überholwege kompensiert werden. Allerdings seht dieser Argumentation wegen der hohen Geschwindigkeitsdifferenz eine Vergrößerung der Abstände beim Ein- und Ausscheren entgegen. Bei einer Überholung aus der Warteposition heraus wird vor der Überholung der Abstand zum Hindernisfahrzeug geringfügig vergrößert, um eine fahrdynamische Kraftreserve ausnutzen zu können. Demnach beginnt die fahrdynamische Einleitung einer beschleunigten Überholung meist auf dem eigenen Fahrstreifen vor dem Ausscheren Kayser/Otten/Hahn [1986]. Grundsätzlich konnte durch Messfahrten von Steierwald/Jacobs/Feier [1985] festgestellt werden, dass sich der Sicherheitsabstand hinter dem Hindernisfahrzeug auf bis zu 12 m verringert, wenn sich eine Überholmöglichkeit bietet. 
Durch die angefachte Diskussion über die Einführung von Gigalinern müssen in Bezug auf die Verkehrssicherheit Veränderungen angenommen werden. Durch die Zulassung von 6,5 m längeren Lastkraftwagen als bisher, werden sich auch notwendige Überholwege und Zeitbedarfe erhöhen und möglicherweise neue Risiken beim Überholvorgang generieren. Dabei können häufigere Fehleinschätzungen zu Gefahren und Unfällen führen. Des Weiteren wird sich durch die höhere kinetische Energie die Unfallschwere bei Kollisionen mit Lastkraftwagen deutlich erhöhen [Glaeser et.al., 2006]. Aus Sicht der Verkehrssicherheit ist daher von der Zulassung von Gigalinern abzuraten [bfu, 2010].

\subsubsection{Maßnahmen gegen Überholunfälle}

Maßnahmen zur Erhöhung der Verkehrssicherheit sind Verbesserungen in der Straßenplanung, Fahrzeugtechnik sowie Verkehrserziehung und Aufklärung. Zu den infrastrukturellen Maßnahmen zählen hierbei Sicherheitsanalysen in Straßennetzen, Bekämpfung von Unfallschwerpunkten, Sicherheitsaudits und die Weiterentwicklung der technischen Grundlagen für den Neu- und Ausbau von Straßen [Hartkopf/Weber, 2005]. Nach Wirth [2000] können die bei der Planung in die Straße eingebauten entwurfsbasierten Sicherheitsaspekte zumindest technisch nicht versagen. Maßnahmen zur Vermeidung von Überholunfällen sollen im Folgenden überwiegend für den Bereich der Straßenplanung vorgestellt dennoch aber auch die anderen Bereiche von Einflussmöglichkeiten kurz beleuchtet werden.

Im geltenden Merkblatt der FGSV [2001a] werden folgende Maßnahmen zur Vermeidung von Überholunfällen vorgeschlagen. Bei Unfallhäufungen zwischen Linksabbiegern und Überholenden sind in Knotenpunkten Überholverbote und Geschwindigkeitsbeschränkungen einzurichten oder Aufstellflächen bzw. Linksabbiegestreifen anzuordnen. An Stellen auf der freien Strecke bei denen die Überholsichtweiten nicht gegeben sind, sollte neben einem beschilderten Überholverbot ( $Z$ 276) eine Fahrstreifenbegrenzung ( $Z$ 295) angeordnet werden. Wird diese missachtet, so kann die Fahrstreifenbegrenzung doppelt, gegebenenfalls profiliert und mit Bischofsmützen oder Querschwellen ausgeführt werden. Überholverbote sind zudem mit Warnlinien und Vorankündigungspfeilen anzukündigen. Werden überwiegend Entfernungen und Geschwindigkeiten falsch eingeschätzt und ist der Schwerverkehrsanteil hoch, so können Geschwindigkeitsbeschränkungen oder Überholverbote (ggf. mit Überwachung) angeordnet werden, falls die Anlage eines Überholfahrstreifens nicht möglich ist. Hinweisschilder auf Überholunfälle sind dagegen unwirksam.

Nach Matena et.al. [2006] ist eine einzelne Sperrlinie nur wirksam, wenn das Verkehrsaufkommen sehr hoch ist, demnach Überholungen nicht möglich sind oder eine starke Überwachung des Überholverbotes stattfindet. Dagegen verringert sich die Anzahl der Überholmanöver, je größer bzw. deutlicher die Art der physischen Trennung wird. Bei nicht überfahrbaren Richtungstrennungen entstehen allerdings Probleme bei Ausweichmanövern vor plötzlich auftauchenden Hindernissen [Kayser/Struif, 1993], bei Vorbeifahren an Nothalten sowie durch die Belange des Straßenbetriebsdienstes [Rohloff, 1999]. Nach Kayser/Struif [1993] sind dies Maßnahmen, die einen negativen Einfluss auf das Überholverhalten bzw. die Überholentscheidung haben. Diese sollen Überholungen in ungünstigen Abschnitten verhindern. 
An einbahnigen zweistreifigen Überholstrecken ist der Fahrraum durch Bepflanzung und optische Leiteinrichtungen so einfach wie möglich, aber nicht eintönig zu gestalten. Das Bewusstsein wird dadurch nicht zusätzlich belastet, gleichzeitig wird aber unterbewusst die Aufmerksamkeit erhalten. Knotenpunkte und Beschilderungen sind zu vermeiden (Durth, 1974).

Gemäß Kayser/Struif [1993] ist das Ziel von positiv wirkenden Maßnahmen auf das Überholverhalten, den Fahrzeugführer dahingehend zu beeinflussen, dass er den gewünschten Überholvorgang in einen Bereich mit ausreichenden Sichtweiten oder einen mehrstreifigen Streckenabschnitt verlagert, bei denen zumindest theoretisch Überholmanöver gefahrlos möglich sind. Auf diese ungefährlichen Strecken kann mithilfe von Hinweisschildern aufmerksam gemacht werden. Diese Hinweise können in Abständen von $1000 \mathrm{~m}$ und wiederholt an $500 \mathrm{~m}$ vor dem Überholabschnitt angeordnet werden. Bei zweistreifigen Landstraßen mit ausreichenden Sichtweiten ist am Beginn der Überholstrecken auf ein Hinweisschild für ausreichende Überholsichtweiten zu verzichten, da diese als Aufforderung zu einer sofortigen Überholung fehlinterpretiert werden können.

Kayser/Struif untersuchten 1993 auf einbahnig, zweistreifigen Landstraßen die Wirkungen der Markierung von Warnlinien, die eine Überholentscheidung negativ beeinflussen sollen aber nicht verbieten und die Einflüsse von Hinweisschildern. Dabei wurden diese Maßnahmen auf einem ersten Teilstück eines Streckenabschnittes umgesetzt und die Verhaltensänderungen, auch auf dem angrenzenden günstigen Überholabschnitt, ausgewertet. Insgesamt zeigten sich durch beide Maßnahmen in Bereich 1 nur bei hohen Verkehrsstärken deutliche Verringerungen der Überholmanöver im Vergleich zum Ohnefall. Insgesamt wurden aber in beiden Bereichen Verringerungen der Überholungen und auch der Geschwindigkeiten festgestellt, die erwarteten Verlagerungen zwischen den Bereichen sind allerdings ausgeblieben. Damit wurde festgehalten, dass Fahrzeugführer sich nur wenig von Beschilderungen beeinflussen lassen und die Überholentscheidung anhand der Straßen- und Verkehrsverhältnisse treffen. In Bezug auf die Einführung von Zusatzfahrstreifen in der neuen Richtliniengeneration (vgl. Kapitel 2.2) wird aber vermutet, dass durch Hinweisschilder in ungünstigen Abschnitten die Überholungen ebenfalls zurückgehen ohne zusätzlichen Überholdruck aufzubauen und in den mehrstreifigen Abschnitten gesicherte Überholungen stattfinden. In diesem Zusammenhang ist auch zu klären, welche Verhaltensänderungen sich ergeben, wenn die Warnlinien im Vorfeld von Überholabschnitten durch generelle Überholverbote ersetzt werden.

Durch die Anlage von Überholfahrstreifen können Verbote und Beschränkungen mit Erleichterungen und Vereinfachungen verbunden werden. Demzufolge wird nicht nur verboten sondern auch angeboten [Rohloff, 1999]. Die Untersuchungen zum Forschungsprojekt „AOSI“ (Außerortssicherheit) zu den Überholfahrstreifen sind momentan noch nicht abgeschlossen. Hier wurden einzelne Zusatzfahrstreifen an Landstraßen angebaut und die Wirkungen 3 Jahre vor bzw. 3 Jahre nach der Maßnahme untersucht. Die Zusatzfahrstreifen sind zwischen $500 \mathrm{~m}$ und $1500 \mathrm{~m}$ lang und wurden in Abständen bis zu $3 \mathrm{~km}$ angeordnet. Schilder, welche auf eine bevorstehende Überholmöglichkeit hinweisen, können dazu beitragen, entstehenden Überholdruck in verbleibenden Strecken mit striktem Überholverbot zu mindern [BASt, 2008]. 
Somit werden nur in bestimmten Bereichen der Strecken Überholmöglichkeiten gegeben, was in den USA, Kanada und Australien bereits seit langem angewendet wird (vgl. Kayser/Struif, 1993 bzw. Lamm/Psarianos/Mailänder, 1999). Besonders sinnvoll sind diese Maßnahmen zur Erhöhung der Verkehrsqualität an Steigungsstrecken wegen der sinkenden Geschwindigkeiten des Schwerverkehrs. Umsetzungen dieser Beeinflussungsmöglichkeiten werden für Deutschland in Kapitel 2.2 diskutiert. Durch die Anlage bereits von einzelnen Überholfahrstreifen können nach Elvik/Vaa 18 \% der Unfälle mit Personenschaden auf Landstraßen vermieden werden, weil der Überholdruck auf gesicherten Überholstrecken abgebaut werden kann.

Nachdem Straßen gebaut wurden, auf denen wegen der technischen Voraussetzungen durch die Sichtweiten Überholvorgänge möglich sind, müssen die Verkehrsteilnehmer lernen, wie sie die technisch möglichen Überholungen in der Realität gefahrlos durchführen können. Nach der Bereitstellung entsprechender Straßen mit sicheren Überholmöglichkeiten muss für die Fahrzeugführer ein Lernprozess zur sicheren Durchführung einer Überholung beginnen, der nur über die Verkehrserziehung beeinflusst werden kann [Runkel, 1970]. Die Verkehrserziehung stellt demnach auch bei einer sicher gestalteten Straße einen bedeutenden Einflussfaktor dar.

Die Möglichkeiten der passiven Fahrzeugsicherheit nähern sich allmählich einer Grenze, daher verlagert sich das Interesse der Fahrzeughersteller zunehmend von der passiven zur aktiven Sicherheit, um nicht nur die Unfallfolgen zu mindern, sondern generell die Unfälle zu vermeiden [Gründl, 2006]. Dies ist Ansatzpunkt für verschiedene Fahrerassistenzsysteme. Bei Kollisionen zwischen Linksabbiegern und überholenden Fahrzeugen ergibt sich Potential für Spurwechselassistenten. Bei Informationsfehlern zu Überholverboten können sich Lane Departure WarningSystems an den meist vorhandenen Sperrlinien orientieren und bei Betätigung des Richtungssignalgebers zum Ausscheren ein Warnsignal aussenden [Gründl, 2005]. Möglicherweise könnten auf diese Weise generell Verstöße gegen Überholverbote unterbunden werden.

Kayser/Otten/Hahn [1988] untersuchten ebenfalls die Wirkungen von Überholassistenten. Es handelte sich hierbei um eine Hilfsanzeige, welche angibt, ob eine Überholung bei der gegebenen Verkehrssituation sicher durchführbar ist oder nicht. Die Anzeige überlässt aber die Entscheidung, Häufigkeit und fahrtechnische Bewältigung der Überholung beim Fahrer. Die Anzeige hat bei unterschiedlichen Fahrergruppen verschiedene Wirkungen. Zögernd fahrende Verkehrsteilnehmer vertrauen nicht auf die Anzeige sondern handeln nach ihren eigenen, von Vorsichtsdenken geprägten Entscheidungsmustern. Für mäßig Überholende ist die Anzeige eine Hilfestellung für Überholentscheidungen und häufig oder riskant Überholende werden durch die Anzeige bei unsicheren Situationen gewarnt. Die Anzeige wirkt aktivierend bei sich bietenden Überholmöglichkeiten und führt zum Verzicht bei kritischen Zeitlücken. In Interviews wurde die Verlässlichkeit der Hilfestellung höher eingestuft als die Nützlichkeit, wobei sich ein Akzeptanzgefälle von jungen bzw. männlichen zu alten bzw. weiblichen Befragten ergab. Die Zeitgewinne durch eine einzelne Überholung sind sicherlich vernachlässigbar, einer Erhöhung der Verkehrssicherheit kommt durch die Vermeidung von kritischen Überholsituationen aber eine größere Bedeutung zu. 


\subsection{Maßnahmen zur Minimierung von Überholunfällen im Entwurfsregelwerk}

\subsubsection{Richtlinien für die Anlage von Straßen}

Die Richtlinien für die Anlage von Straßen, Teil Linienführung von 1995 stellen momentan noch den Stand der Technik dar und sind somit "Grundlage für den Entwurf von sicheren und funktionsgerechten Straßen“. Die Anwendung dieser Richtlinien soll sowohl die Einheitlichkeit gleichartiger Straßen fördern als auch durch unterschiedliche Regelungen für ungleichartige Straßen diese unterscheidbar machen. Sie enthält Grenz- und Richtwerte, mit denen im iterativen Planungsprozess ein möglichst guter Kompromiss zwischen Belangen der Sicherheit und Leichtigkeit des Verkehrs, Raumordnung, Wirtschaftlichkeit und Umweltschutz gefunden werden soll. Als Leitgröße für die funktionsbezogene Differenzierung der Straßen gilt die Entwurfsgeschwindigkeit, nach der die grundlegenden Entwurfs- und Betriebsmerkmale der einzelnen Straßenkategorien festgelegt sind. Für die fahrdynamische Bemessung von sicherheitsrelevanten Entwurfselementen muss zudem die Quantilgeschwindigkeit $\mathrm{v}_{85}$ herangezogen werden.

Bei der Trassierung im Lageplan kann mit Geraden eine ausreichende Überholsichtweite geschaffen werden. Im Höhenplan sind die Kuppenhalbmesser mit den Überholsichtweiten abzustimmen, um kritische Überholvorgänge vermeiden zu können. Wirth [2000] zweifelt den Sicherheitsgewinn durch eine solche Regelung allerdings an. Bei der räumlichen Linienführung ist durch die Abstimmung der Lage- und Höhenplanelemente eine optisch vorteilhafte Linienführung mittels Raumelementen anzustreben. Bei Abweichungen von den Raumelementen entstehen Sichtschattenstrecken, die sich negativ auf die Verkehrssicherheit auswirken und somit zu vermeiden sind. Besonders die Fälle „Tauchen“ und „Springen“ können bei Überholvorgängen sehr gefährliche Auswirkungen haben.

Werden dagegen die festgelegten Überholsichtweiten der RAS-L für Straßen der Kategoriengruppe A eingehalten, so kann das Überholen auf den Fahrstreifen des Gegenverkehrs zugelassen werden. Sichtweiten zwischen halber und voller Überholsichtweite fördern gefährliche Überholvorgänge und haben nachteilige Auswirkungen auf die Verkehrssicherheit. In kritischen Bereichen sind daher Überholverbote anzuordnen. Langsame Fahrzeuge können meist sicher überholt werden, was mit einem Zusatzschild verdeutlicht werden kann. Knotenpunkte im Außerortsstraßennetz sollten aus einer Entfernung, die etwa der erforderlichen Überholsichtweite entspricht, erkennbar sei. Somit können möglicherweise Überholverbote im Knotenpunkt rechtzeitig verdeutlicht werden (vgl. FGSV, 1988). Die vorhandenen Sichtweiten ergeben sich aus der räumlichen Linienführung, dem Straßenquerschnitt und dem Straßenumfeld. Demzufolge ist das Sichtfeld von sämtlichen beeinträchtigenden Hindernissen freizuhalten. Beispielsweise ist auf Bepflanzungen am Kurveninnenrand zu verzichten, um den Kurvenverlauf vollständig einsehen zu können. Bei großen Radien können somit Überholsichtweiten gewährleistet und die Geschwindigkeiten entgegenkommender Fahrzeuge besser eingeschätzt werden [MSWV, 2002].

Durch die Ermittlung von Sichtweitenbändern für beide Fahrtrichtungen können die vorhandenen und erforderlichen Sichtweiten miteinander verglichen werden. Die erforderliche Überholsichtweite 
kann mit einem geometrischen Sichtweitenmodell berechnet werden. Allerdings ist die Wahrnehmung von der menschlichen Sehleistung abhängig, die wiederum von den optischen Eigenschaften des Gegenverkehrs und der Fahrbahn sowie von den Licht- und Witterungsverhältnissen mitbestimmt wird. Das Sichtweitenmodell muss daher aus psychologischer bzw. physiologischer Sicht eher als unzureichend angesehen werden. Haltesichtweiten sind auf der gesamten Strecke einzuhalten, für die Überholsichtweite gilt ein Richtwert von 20 bis 25 \% Streckenanteil mit Überholmöglichkeiten, die gleichmäßig über die Strecke zu verteilen sind. Hierbei ist aber zu beachten, dass ein erheblicher Teil der Strecken mit Überholsichtweite durch Überholverbote und zu hohes Verkehrsaufkommen nicht zum Überholen genutzt werden kann. Ist der Mindestanteil von Überholmöglichkeiten nicht vorhanden und auch durch Änderung der Linienführung nicht erreichbar, so können Zusatzfahrstreifen angeordnet werden, auf denen Überholvorgänge durchführbar sind, ohne den Fahrstreifen des Gegenverkehrs benutzen zu müssen.

Die Auswahl von Regelquerschnitten erfolgt bisher nach den RAS-Q in Abhängigkeit von der Straßenkategorie und der Verkehrsstärke. Für mehrere mögliche Regelquerschnitte ist eine Festlegung unter Berücksichtigung der angestrebten Verkehrsqualität, der Verkehrssicherheit und der Wirtschaftlichkeit vorzunehmen. Bei einbahnigen, zweistreifigen Querschnitten nimmt mit abnehmender Fahrbahnbreite ein Sicherheitsrisiko bei Begegnungs- und Überholvorgängen bei gleichbleibenden Geschwindigkeiten zu.

\subsubsection{Die neuen Richtlinien für die Anlage von Landstraßen - RAL}

In den neuen Richtlinien für die Anlage von Landstraßen - RAL (FGSV, 2012b) werden die bisher getrennt behandelten Aspekte der Linienführung, Querschnitts- und Knotenpunktgestaltung in einer Richtlinie vereint. Die wesentliche Veränderung der neuen RAL ist die Abkehr von der Entwurfsgeschwindigkeit und die Definition von 4 Entwurfsklassen für Landstraßen, über die in Zukunft die Parameter der Linienführung, die Querschnitte, die Knotenpunktgrund- und Betriebsformen festgelegt werden. Die Wahl der Entwurfsklasse (vgl. Tabelle 2.1) richtet sich nach der Netzfunktion der betreffenden Straße nach den Richtlinien für die integrierte Netzgestaltung [FGSV, 2008]. Mit Hilfe dieser genauen Entwurfs- und Gestaltungsvorgaben der Entwurfsklassen sollen standardisierte, „selbsterklärende“ Straßen entstehen, auf denen der Fahrzeugführer unterbewusst allein erkennen soll, welches Fahrverhalten auf dem folgenden Streckenabschnitt erforderlich ist [Hartkopf/Weber, 2005].

\begin{tabular}{|c|c|c|}
\hline Straßenkategorie & Verbindungsfunktionsstufe & Entwurfsklasse \\
\hline LS I & großräumig & EKL 1 \\
\hline LS II & überregional & EKL 2 \\
\hline LS III & regional & EKL 3 \\
\hline LS IV & nahräumig & EKL 4 \\
\hline
\end{tabular}

Tabelle 2.1: Entwurfsklassen nach RAL

Ist die Verkehrsbelastung einer Straße mit einer bestimmten Kategorie außergewöhnlich hoch, so kann die Straße auch mit einer dementsprechend höherrangigen Entwurfsklasse geplant werden, als in Tabelle 2.1 vorgegeben. Dies gilt auch analog für Straßen mit geringer Verkehrsbelastung. 
Im neuen Regelwerk sind für die Verkehrssicherheit in Bezug auf die Begegnungs- und Überholvorgänge die nachstehenden Ziele definiert worden. Überholvorgänge sollen auf Abschnitten mit kritischen Sichtweiten verhindert und durch zusätzliche Überholfahrstreifen gesichert werden. Bei hohen Fahrweiten und hohen Geschwindigkeiten sind zudem schnelle und langsame Verkehre generell voneinander zu trennen, was gemäß der Netzfunktion auch eine angemessene Verkehrsqualität sicherstellen soll. Durch diese Maßnahmen können die Straßen entsprechend der Straßenkategorie auch mit angemessenen Geschwindigkeiten befahren werden. Durch die Entwurfsklassen werden in Verbindung mit den Querschnitten auch die damit verbundenen Überholprinzipien der neuen Richtlinien festgelegt, welche nachfolgend erläutert werden.

Der Regelquerschnitt für die Entwurfsklasse 1 sind die dreistreifigen Straßen des RQ 15,5. Hierbei sind die Fahrtrichtungen durchgängig durch einen verkehrstechnischen Mittelstreifen voneinander abzutrennen. Die Mittelstreifen sind einen Meter breit und durch eine auffällige Oberflächengestaltung durch Farbe hervorzuheben. Diese optische Trennung kann aber auch durch weitere verkehrstechnische Einrichtungen (z.B. im Notfall überfahrbare Schwellen) unterstützt werden. Durch die durchgehend wechselseitige Folge von einstreifigen und zweistreifigen Abschnitten entsteht auf ca. 40 \% jeder Fahrtrichtung eine verkehrsrechtlich eindeutige, gesicherte Überholmöglichkeit. Die einzelnen Überholfahrstreifen sind gleichmäßig über die Strecke zu verteilen und dabei so lang auszubilden, dass der Überholbedarf befriedigt werden kann. Dagegen sollten sie allerdings nicht zu lang sein, um eine Missachtung des Überholverbotes und eine große Pulkbildung zu vermeiden.

Bei der Entwurfsklasse 2 soll der Querschnitt RQ 11,5+ Anwendung finden. Hierbei werden zweistreifige Teilstrecken regelmäßig, abschnittsweise aber nicht durchgängig durch zusätzliche Überholfahrstreifen dreistreifig aufgeweitet. Die Fahrstreifen beider Fahrtrichtungen sind auf dreistreifigen Abschnitten grundsätzlich durch eine ununterbrochene Doppellinie voneinander zu trennen. Für die zweistreifigen Abschnitte gilt ein striktes Überholverbot, wenn dem Überholbedürfnis durch eine hinreichende Anzahl von Überholfahrstreifen entsprochen werden kann. In den zweistreifigen Abschnitten kann entstehender Überholdruck durch die Vorankündigung der Überholfahrstreifen abgebaut werden. Durch diese Regelungen sollen auf $20 \%$ jeder Richtung gesicherte Überholmöglichkeiten zur Verfügung stehen. Kann diese Forderung nicht eingehalten werden, so kann auf übersichtlichen zweistreifigen Abschnitten mit mindestens 600 Metern Sichtweite das Überholen auf dem Gegenfahrstreifen durch eine doppelte Leitlinie ermöglicht werden (sichere Überholung eines Lkw). Im Sichtweitenbereich zwischen $300 \mathrm{~m}$ und $600 \mathrm{~m}$ ist aus Sicherheitsgründen zu prüfen, ob Überholverbote anzuordnen sind, da grundsätzlich nicht sicher überholt werden kann. Dieser Sichtweitenbereich kann aber dennoch für Überholungen von landwirtschaftlichen Fahrzeugen (Regelung über Zusatzzeichen) freigegeben werden, da zu deren sicherer Überholung nur mindestens $300 \mathrm{~m}$ erforderlich sind. In älteren Entwurfsfassungen der RAL [FGSV, 2010] wurde ein anderer Entscheidungsprozess zum Überholen (Pkw befindet sich bereits seitlich versetzt hinter dem Hindernisfahrzeug) definiert, welcher auch andere Sichtweitengrenzwerte zur Folge hatte. Diese abweichenden Grenzwerte wurden aber nicht in die aktuellen RAL (FGSV, 2012b) übernommen (vgl. auch Kapitel 2.1.4). 
Bei Strecken der Entwurfsklasse 3 sollen zweistreifige Querschnitte in Form des RQ 11 angewendet werden. Die Fahrbahn soll durch einfache Leitlinien in Fahrstreifen gegliedert werden, wenn das Überholen bei entsprechenden verkehrlichen und geometrischen Voraussetzungen möglich ist. Sind nicht ausreichende Sichtweiten oder andere Gefährdungen vorhanden, ist das Überholen zu untersagen. Für die Freigabe von Abschnitten mit Überholmöglichkeiten gelten die unter Entwurfsklasse 2 genannten Bedingungen. Durch die regionale Verbindung von Grundzentren mit Mittelzentren bzw. zwischen Grundzentren (vgl. FGSV, 2008) sind wegen der nur kurzen bis mittleren Fahrtweiten keine expliziten Anforderungen an einen Streckenanteil mit ausreichend Überholmöglichkeiten vorgesehen. Überholfahrstreifen sind für diese Entwurfsklasse kein planmäßiges Element, können aber vereinzelt zur Verbesserung der Verkehrsqualität (bei hohen Verkehrsstärken oder an Steigungsstrecken) angeordnet werden.

Bei der Entwurfsklasse 4 handelt es sich um Straßen mit nahräumiger Verbindungsfunktion, auf denen der RQ 9 eingesetzt werden soll. Das Fehlen einer mittigen Leitlinie und die durch zwei seitlich angeordnete Leitlinien eingeengte Kernfahrbahn sollen eine langsame Fahrweise bewirken. Das Überholen wird für diese Entwurfsklasse nicht explizit angesprochen. Vermutlich wird ein Überholvorgang aufgrund der geringen Fahrbahnbreite auch nur selten durchgeführt. Außerdem sollte auf diesen untergeordneten kurzen Verbindungsstrecken die Notwendigkeit für einen Überholvorgang entfallen und sich somit kein Überholdruck aufbauen.

Prinzipiell ist pro Entwurfsklasse nur ein einbahniger Querschnitt vorgesehen. Bei hohen Verkehrsbelastungen auf Strecken der Entwurfsklassen 1 bis 3 können auf maximal 15 Kilometern Länge auch zweistreifige Regelquerschnitte in Form des RQ 21 angeordnet werden. Bei diesem zweibahnigen Querschnitt wird der verkehrstechnische Mittelstreifen durch einen 2,50 m breiten baulichen Mittelstreifen ersetzt, der mit Fahrzeug-Rückhaltesystemen und gegebenenfalls Blendschutzeinrichtungen auszustatten ist.

Für die Linienführung werden im Vergleich zur RAS-L sind nicht nur Mindestwerte für Entwurfsparameter wie z.B. den Kurvenradius angegeben, sondern auch zu verwendende Radienbereiche mit entsprechenden Obergrenzen. Hiermit wird das Prinzip der selbsterklärenden Straße unterstützt. Bei den Entwurfsklassen 3 und 4 könnten zu große Radien sonst Überholmöglichkeiten in Bereichen suggerieren, in denen kein sicheres Überholen realisierbar ist. Die gerade Wanne ist als Standardraumelement besonders geeignet für Überholvorgänge, da hier gute Sichtverhältnisse und eine gute optische Führung besser gewährleistet sind, als in der ebenen Geraden. Die Festlegung von geschwindigkeitsabhängigen Überholsichtweiten erfolgt in den RAL nicht mehr, die Grundlagen der Standardraumelemente und zu vermeidenden Sichtschattenbereiche der RAS-L haben nach wie vor ihre Gültigkeit. 


\subsubsection{EKLBEST}

Die neuen Richtlinien für die Anlage von Landstraßen gelten grundsätzlich für den Neubau bzw. Um- und Ausbau von Landstraßen. Die Anpassung an die RAL ist aber kein Grund, eine Landstraße um- oder auszubauen, wenn keine Defizite der Verkehrssicherheit oder des Verkehrsablaufs vorliegen. Deswegen muss erwartet werden, dass sich das Prinzip der Entwurfsklassen und somit der selbsterklärenden Straßen nur langsam in Deutschland durchsetzt. Mit dem M_EKLBEST wird daher ein ergänzendes Merkblatt zur RAL entwickelt, um die zeitnahe Übertragung des neuen Entwurfsprinzips auch auf das Bestandsnetz zu regeln. Dabei müssen auch Ausnahmen und Abweichungen von den Richtwerten der RAL akzeptiert werden, um das Prinzip der Entwurfsklassen durchzusetzen. Hierbei sind allerdings gestalterische Mindestanforderungen zu berücksichtigen, damit die Wiedererkennbarkeit sichergestellt werden kann. Grundsätzlich besteht die Möglichkeit, ein geringes Anpassungsniveau zum neuen Entwurfsprinzip zuzulassen, um viele Straßen den Entwurfsklassen zuweisen zu können oder die Mindestanforderungen zu erhöhen, wodurch weniger Straßen klassifiziert werden können und somit der Prozess der Umsetzung verlängert wird. Im Sinne der Erkennbarkeit der vier Entwurfsklassen sollte allerdings die langsame Umsetzung in Kauf genommen werden. Zur eindeutigen Typisierung der Entwurfsklassen wird vor allem der Querschnittsausbildung mit entsprechender Markierung und dem damit verbundenem Überholprinzip eine erhöhte Bedeutung zukommen, da sie als prägende kontinuierliche Wiedererkennungsmerkmale dienen [Richter/Zierke, 2010].

Die Mindestanforderungen an eine Straße, um einer bestimmten Entwurfsklasse zugeordnet werden zu können, sind nachfolgend auf Grundlage des M_EKLBEST [Richter/Zierke, 2009] beschrieben. Es sollen nur Merkmale in Bezug auf den Überholvorgang erläutert werden. Im Vergleich zur RAL werden Toleranzen und Abweichungen gewährt, um eine Straße mit den Kennzeichen einer bestimmten Entwurfsklasse auszeichnen zu können. Die Kennzeichnung erfolgt über die unverwechselbare längsgerichtete Fahrbahnmarkierung, welche auch das Überholprinzip der Entwurfsklassen verkehrsrechtlich regelt (siehe Kapitel 2.2.2).

Nach den RAL sind Straßen der EKL 1 durchgängig mit einem dreistreifigen Querschnitt auszubilden. Kann dies in einzelnen Teilen nicht umgesetzt werden, so ist in dem verbleibenden zweistreifigen Abschnitte dennoch ein verkehrstechnischer Mittelstreifen anzuordnen, um das Überholen zu unterbinden. Durch den Verzicht auf eine durchgängige Führung eines dreistreifigen Querschnittes darf aber eine Grenze von 30 \% Streckenanteil mit gesicherten Überholmöglichkeiten nicht unterschritten werden. Können die Bedingungen an das zu Grunde gelegte Überholprinzip nicht erfüllt werden, darf keine Kennzeichnung als Straße der Entwurfsklasse 1 erfolgen.

Für die EKL 2 ist in Bezug zum Überholvorgang die Bedingung eines Streckenanteils mit gesicherten Überholmöglichkeiten von mindestens $15 \%$ vorgesehen. In Ausnahmefällen kann der Überholvorgang auf übersichtlichen zweistreifigen Abschnitten durch eine doppelte Leitlinie zugelassen werden. Im Rahmen von Um- und Ausbaumaßnahmen ist aber auf eine Erhöhung der Anzahl der Überholabschnitte zur Erreichung der Mindeststreckenanteile hinzuwirken. Auf Straßen der EKL 3 muss, wie auch bei den anderen Entwurfsklassen, die Bedingung an eine Mindestbreite der Fahr- 
bahn erfüllt sein, um hier dem Überholprinzip gerecht werden zu können. Bei Strecken der EKL 4 wird generell kein Überholbedarf gesehen. Besonders zu beachten sind Übergangsbereiche zwischen um- oder ausgebauten Strecken zum Bestandsnetz, um auch hier ein sicheres Verkehrsverhalten gewährleisten zu können. Beispielsweise ist auf einer maximal 5 Kilometer langen, zweistreifigen Bestandsstrecke zwischen zwei gekennzeichneten Straßen der Entwurfsklassen 1 oder 2 die kennzeichnende Markierung zu übernehmen, um die Beibehaltung des Überholprinzips zu verdeutlichen.

\subsubsection{Beurteilung der Maßnahmen gegen Überholunfälle im neuen Entwurfsregelwerk}

In den Richtlinien für die Anlage von Landstraßen stellt die Abkehr von der Entwurfsgeschwindigkeit und das Entwurfsprinzip nach den Entwurfsklassen in der Geschichte der deutschen Regelwerke eine entscheidende Neuerung dar (vgl. Wirth, 2000).

Für den Neubau von Straßen und auch den Um- und Ausbau bei defizitärer Verkehrssicherheit und -qualität sind mit den vier Entwurfsklassen verschiedene Überholprinzipien verbunden, die zur Vermeidung von Überholunfällen beitragen sollen. Im Regelfall soll ein Überholvorgang auf Strecken der EKL 1 und EKL 2 nur noch auf Überholfahrstreifen ermöglicht werden. Überholvorgänge mit Benutzung der Fahrstreifen des Gegenverkehrs sind grundsätzlich nur bei ausreichenden Sichtweiten auf Straßen der EKL 3 angedacht. Bei den untergeordneten Verbindungen der EKL 4 wird kein Überholbedarf gesehen.

Neben dem Anwendungsbereich der neuen RAL, also dem Neu-, Um- und Ausbau von Straßen, ist auch eine mittelfristige Übertragung des neuen Entwurfsprinzips auch auf das bestehende Landstraßennetz für die Durchsetzung der selbsterklärenden Straße und somit zur Verbesserung der Verkehrssicherheit von großer Bedeutung. Viele Straßen können derzeit den Anspruch an eine sicher zu befahrende, selbsterklärende Landstraße jedoch nicht erfüllen [Richter/Zierke, 2010].

Allerdings muss beachtet werden, dass die ausnahmslose Anpassung des Bestandsnetzes an die Vorgaben einer neuen Richtlinie durch den Um- bzw. Ausbau der Straßen aus finanzieller Sicht gar nicht realisierbar ist. Für die Kennzeichnung von Landstraßen nach den Entwurfsklassenprinzipien der neuen RAL im Bestandsnetz ist somit ein langfristiger Prozess zu erwarten. Hierbei sollten vorrangig besonders unfallauffällige Streckenabschnitte ins Entwurfsklassenprinzip überführt werden, um die größten Effekte in Bezug auf die Verkehrssicherheit im Außerortsstraßennetz zu erreichen. In Anlehnung an das Merkblatt für die Auswertung von Straßenverkehrsunfällen können zur Priorisierung von Strecken erstellte Rangfolgen bzw. berechnete Sicherheitspotentiale genutzt werden.

Diese Priorisierung kann nach Pfundt [2001] bestätigt werden, weil der Ausbau von unzulänglichen untergeordneten Landstraßen mit geringer Verkehrsstärke nur die Vermeidung von speziellen Gefahren führt und somit geringe Sicherheitswirkungen in Bezug auf die betroffenen Fahrzeuge hat. Daher sollten gezielt Straßen verbessert werden, die hohe Unfallraten und Unfalldichten aufweisen und demnach so beschaffen sind, dass durch einen Ausbau bemerkenswerte Sicherheitsgewinne bewirkt werden können. 
Durch die RAL und das ergänzende M_EKLBEST werden gezielte Maßnahmen gegen Überholunfälle vorgeschlagen. Maßnahmen zur Vermeidung von Überholvorgängen auf den Fahrstreifen des Gegenverkehrs betreffen allerdings nur die Strecken der beiden ersten Entwurfsklassen. Auf Strecken der Entwurfsklasse 3 soll im Regelfall bei ausreichenden Sichtweiten ein Überholvorgang auf den entgegen gerichteten Fahrstreifen weiterhin ermöglicht werden. Nach den RAL werden für die EKL 3 wegen der nur regionalen Verbindung von Grundzentren zu Mittelzentren bzw. zwischen Grundzentren und somit nur kurzen bis mittleren Fahrtweiten allerdings keine Mindestanteile von Streckenabschnitten für einen Überholvorgang vorgesehen.

Durch die Möglichkeit der Abstufung von Entwurfsklassen wegen nur geringer Verkehrsstärke werden aber entgegen den RAL trotzdem Strecken mit höherer Verbindungsfunktion und somit größerer Streckenlänge für Überholunfälle anfällig. Bei derartig geringen Verkehrsstärken kann der übermäßige Aufbau von Überholdruck und somit die Notwendigkeit eines Überholvorganges als gering angesehen werden, dennoch ist im Einzelfall ein folgenschwerer Überholunfall nicht unmöglich. Auf langen Abschnitten kann sich Überholdruck anstauen, der dann auch unter Inkaufnahme von kleineren Zeitlücken im Gegenverkehr auf Straßen der EKL 3 versucht wird durch riskante Überholmanöver abzubauen, wenn keine Maßnahmen zur Vermeidung vorgesehen sind. Im Zweifel kann somit ein Überholunfall auch bei richtliniengerechten Ausbau von Streckenabschnitten der Entwurfsklasse 3 nicht verhindert werden. Durch die Erfahrungen, dass der Kraftfahrer unter normalen Bedingungen seine Reisezeit minimieren will, verbunden mit einer teilweisen Unvernunft im Verkehrsverhalten [Wirth, 2000], werden Überholunfälle nicht ausnahmslos aus dem Straßenverkehr wegzudenken sein.

Besonders in Hinblick auf die unteren Entwurfsklassen gilt es daher nach wie vor, das Verhalten beim Überholvorgang sowie die verkehrlichen Zusammenhänge genau zu untersuchen, um Maßnahmen zu entwickeln die besonders auf den Strecken der neuen EKL 3 und auf den Strecken des verbleibenden, noch unmarkierten Bestandsnetzes die folgenschweren Überholunfälle verhindern können.

Die vorliegende Untersuchung wird Aufschluss darüber geben, welche Strecken aufgrund welcher Eigenschaften besonders mit Überholunfällen belastet sind. Daher kann möglicherweise abgeschätzt werden, wie sich das Kollektiv der Überholunfälle bei Einführung der Entwurfsklassen verändern wird bzw. wie die angestrebten Sicherheitswirkungen auch auf das Bestandsnetz übertragen lassen. 


\subsection{Makroskopische Analyse des Unfallgeschehens auf Landstraßen}

Im Rahmen der Grundlagenanalyse wurde eine Untersuchung des Unfallgeschehens auf Landstraßen sowie eine vertiefende Analyse von Überholunfällen auf Landstraßen auf Basis des Jahresberichts zum Unfallgeschehen im Jahr 2009 [Statistisches Bundesamt, 2010a] durchgeführt. Zudem erfolgte eine individuelle Datenabfrage bezüglich des Unfallgeschehens mit der Unfallursache „Überholen“ für das Jahr 2009 beim Statistischen Bundesamt [Statistisches Bundesamt, 2011]. Auf die Betrachtung der Entwicklung der Unfallzahlen der letzten Jahre wurde verzichtet, da hier zwar ein Rückgang der Unfallschwere bei gleichzeitig nahezu stagnierender Anzahl von Unfällen zu verzeichnen ist, dies jedoch in Hinsicht auf die Identifizierung von allgemeinen Zusammenhängen und unfallbegünstigenden Faktoren von Überholunfällen keinen Einfluss hat. Zur Erläuterung der Begrifflichkeiten der Verkehrssicherheitsarbeit wird auf Anhang A und B verwiesen.

\subsubsection{Unfallgeschehen in Deutschland}

Im Jahr 2009 wurden 2.313.453 Unfälle polizeilich erfasst, von denen bei $13 \%$ der Unfälle Personen getötet oder verletzt wurden. Bei Betrachtung der Ortslage zeigt sich dabei, dass im Jahr 2009 $73 \%$ aller Unfälle im Straßenverkehr innerorts sowie $20 \%$ außerorts (ohne BAB) und nur $7 \%$ auf Bundesautobahnen geschehen sind. Abbildung 2.6 verdeutlicht die Verteilung der Unfälle nach Ortslage unter Berücksichtigung der Unfallfolgen. Trotz der Tatsache, dass innerorts $69 \%$ und außerorts $25 \%$ der Unfälle mit Personenschaden geschehen sind, liegt der größte Anteil der 3.867 Unfälle mit Getöteten U(GT) mit 59 \% bei Straßen außerhalb geschlossener Ortschaften und verdeutlicht damit die besondere Unfallschwere auf diesen Teilen des Straßennetzes (Unfälle mit Schwerverletzten $U(S V)$ und Unfälle mit Leichtverletzten $U(L V)$ liegen dagegen nur bei ca. $25 \%$ ).

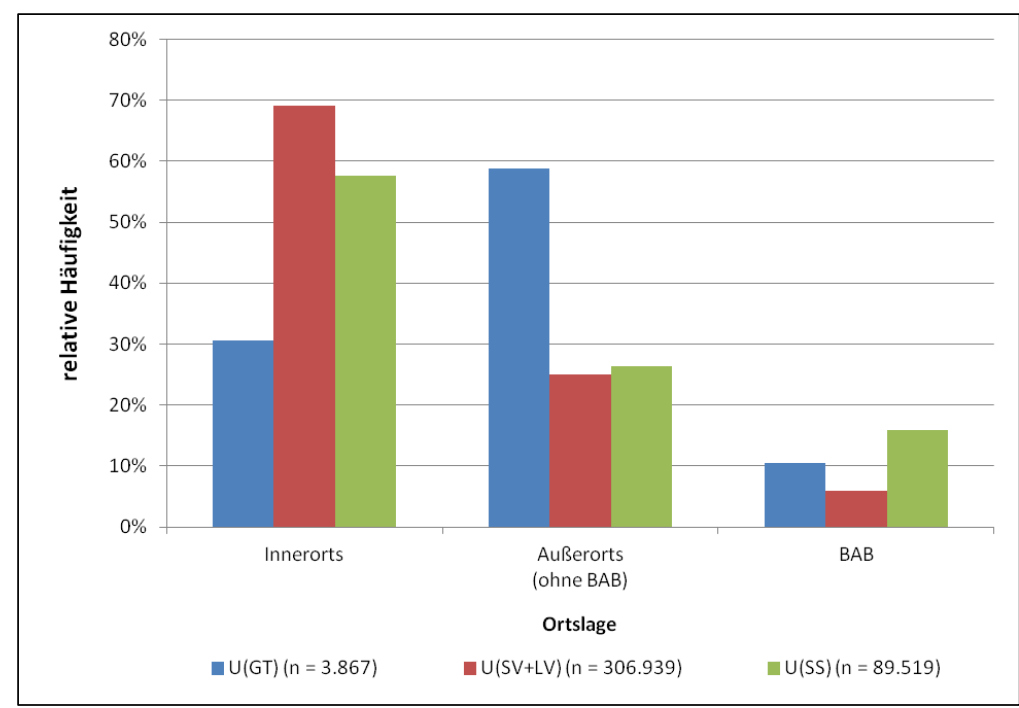

Abbildung 2.6: Straßenverkehrsunfälle nach Ortslage

Auch bei Betrachtung der Verunglücktenstruktur zeigt sich nach Abbildung 2.7, dass entsprechend des hohen Anteils von tödlichen Unfällen außerorts, der Anteil der dort Getöteten mit 59 \% am höchsten ist. Gleichzeitig liegt der Anteil aller Verunglückten außerorts (ohne BAB) bei nur $28 \%$ und liegt somit deutlich unter dem Anteil aller Verunglückten innerorts mit $65 \%$. 


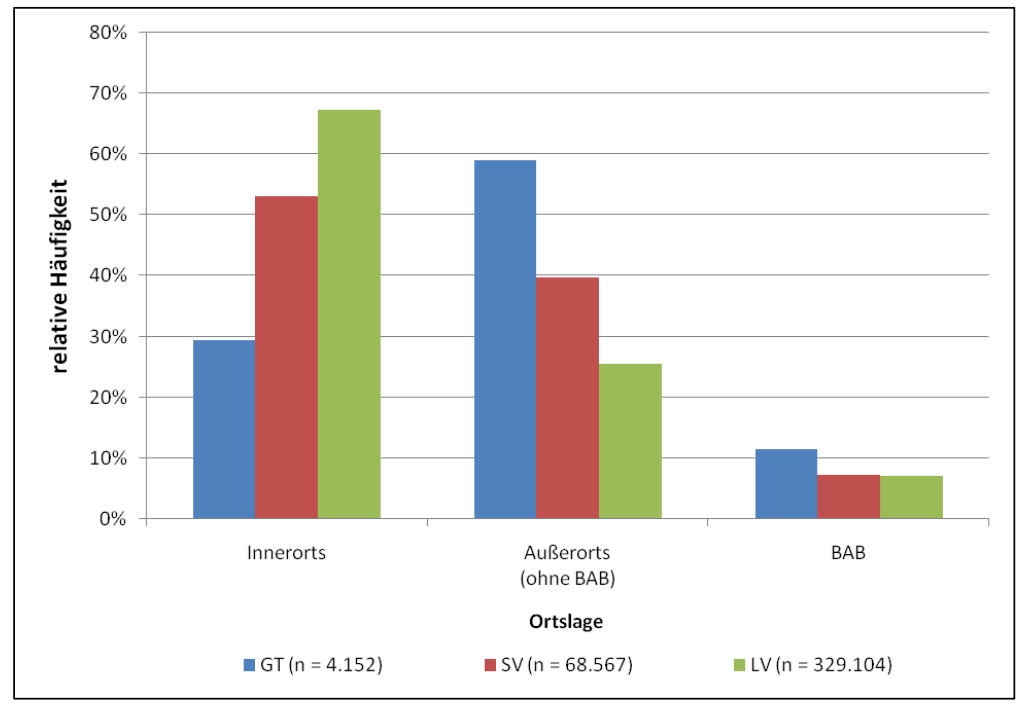

Abbildung 2.7: Verunglückte nach Ortslage

Auf Außerortsstraßen zeigt sich mit 5,2 Getöteten je 1.000 Unfällen [V(GT)/1000*U] die größere Unfallschwere gegenüber Innerortsstraßen $(0,7[\mathrm{~V}(\mathrm{GT}) / 1000 * \mathrm{U}])$ und $\mathrm{BAB}(3,1[\mathrm{~V}(\mathrm{GT}) / 1000 * \mathrm{U}])$. Auch bei der Betrachtung der schwerverletzten Personen liegen Außerortsstraßen mit 57,8 Schwerverletzten je 1000 Unfälle $[\mathrm{V}(\mathrm{SV}) / 1000 * \mathrm{U}]$ über den Werten Innerorts $(21,5[\mathrm{~V}(\mathrm{SV}) / 1000 * \mathrm{U}])$ sowie BAB (32,4 [V(SV)/1000*U]). Hier zeigt sich eine besondere Notwendigkeit von sicherheitsverbessernden Maßnahmen an den Streckenteilen außerhalb geschlossener Ortschaften.

\subsubsection{Unfallgeschehen auf Landstraßen}

Aufbauend auf dem generellen Unfallgeschehen in Deutschland wird im Folgenden der Fokus auf das Unfallgeschehen auf Landstraßen gelegt. Dabei werden im Rahmen der statistischen Analyse Landstraßen als Straßen außerhalb geschlossener Ortschaften bezeichnet, die keine Bundesautobahnen sind.

Generell zeigt sich, dass sich die Verteilungen der untersuchten Merkmale im Hinblick auf Unfälle mit Personenschaden als auch in Hinblick auf die Verunglücktenstruktur nicht wesentlich unterscheiden. Daher wird nachfolgend nur Bezug auf die Unfallkategorien genommen, ohne speziell auf die Verunglücktenzahlen einzugehen.

\subsubsection{Unfalltypen}

Aus Abbildung 2.8 wird deutlich, dass bei $49 \%$ der Unfälle mit Getöteten sowie $47 \%$ der Unfälle mit Schwerverletzten der Fahrunfall $(F)$ vorherrschte. Dieser Unfalltyp ist damit in Hinblick auf alle Unfallkategorien der am häufigsten auftretende Unfalltyp auf Landstraßen. Dabei geschehen bei diesem Unfalltyp auch die meisten Unfälle mit schwerem Personenschaden.

Der zweithäufigste Unfalltyp bezogen auf Unfälle mit schwerem Personenschaden auf Landstraßen ist der Unfall im Längsverkehr (LV). Hier geschehen 23 \% der Unfälle mit Getöteten, sowie 18 $\%$ der Unfälle mit Schwerverletzten. 


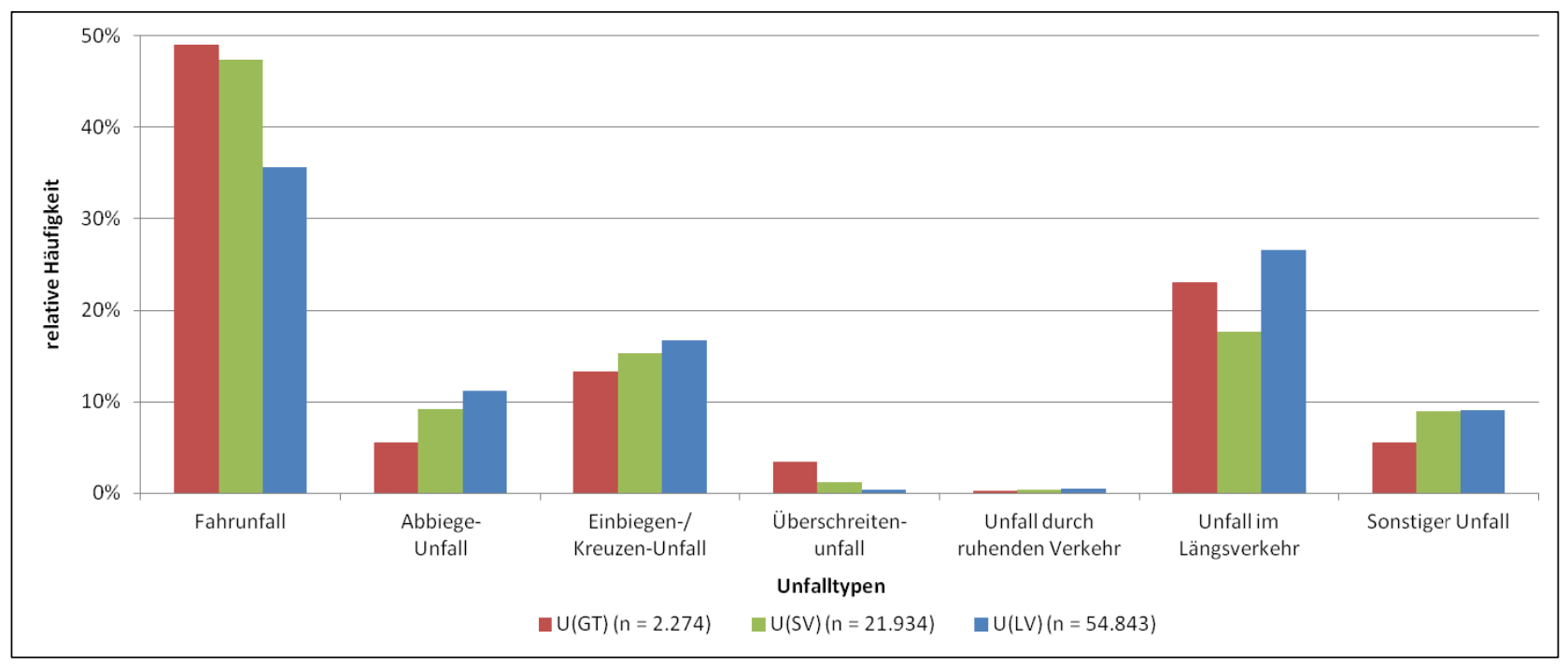

Abbildung 2.8: Unfälle mit Personenschaden auf Landstraßen nach Unfalltypen

Weitere relevante Unfalltypen sind Abbiegeunfälle (AB), Einbiegen/Kreuzen-Unfälle (EK) sowie sonstige Unfälle (SO), wobei der Unfalltyp EK mit 13\% der Unfälle mit Getöteten und 15 \% der Unfälle mit Schwerverletzten der am dritthäufigsten vorkommende Unfalltyp in Bezug auf alle Unfallkategorien ist. Durch die Abbiege- und Einbiegen/Kreuzen- Unfälle werden Knotenpunktunfälle beschrieben, die insgesamt auch einen erheblichen Anteil am Unfallgeschehen haben.

Überschreiten-Unfälle (Ü) sowie Unfälle im ruhenden Verkehr (RV) sind auf Landstraßen nur in geringem Maß vorhanden. Auch wenn Überschreiten-Unfälle mit 13,8 Getöteten je 100 Unfälle mit Personenschaden besonders schwer sind, machen die Unfalltypen ÜS und RV zusammen nur einen Anteil von $3 \%$ der Unfälle mit Getöteten, sowie $1 \%$ der Unfälle mit Schwerverletzten aus. Die schweren Unfallfolgen sind auf das Zusammentreffen der motorisierten Verkehre mit den allgemein schwächsten Verkehrsteilnehmern bei derartigen Unfällen zurückzuführen.

\subsubsection{Unfallarten}

Bei der Betrachtung der Unfallarten (siehe Abbildung 2.9) wird deutlich, dass Unfälle mit Abkommen von der Fahrbahn nach links oder rechts (Unfallart 8 oder 9) und Zusammenstöße mit einem entgegenkommenden Fahrzeug (Unfallart 4), zusammen 69 \% aller tödlichen Unfälle ausmachen. Dabei liegt der Anteil von tödlichen Unfällen mit entgegenkommenden Fahrzeugen bei 30 \%. Diese Unfallarten machen außerdem einen Anteil von 59 \% der Unfälle mit Schwerverletzten aus, wobei hier das Abkommen von der Fahrbahn nach rechts oder links in $40 \%$ aller Unfälle mit Schwerverletzten zutrifft.

Eine weitere Unfallart ist durch einen hohen Anteil an Unfällen mit schwerem Personenschaden gekennzeichnet. Mit 16\% der Unfälle mit Getöteten und $19 \%$ der Unfälle mit Schwerverletzten zeigen Zusammenstöße mit einbiegenden oder kreuzenden Fahrzeugen (Unfallart 5) vor allem Problembereiche an Knotenpunkten auf. 


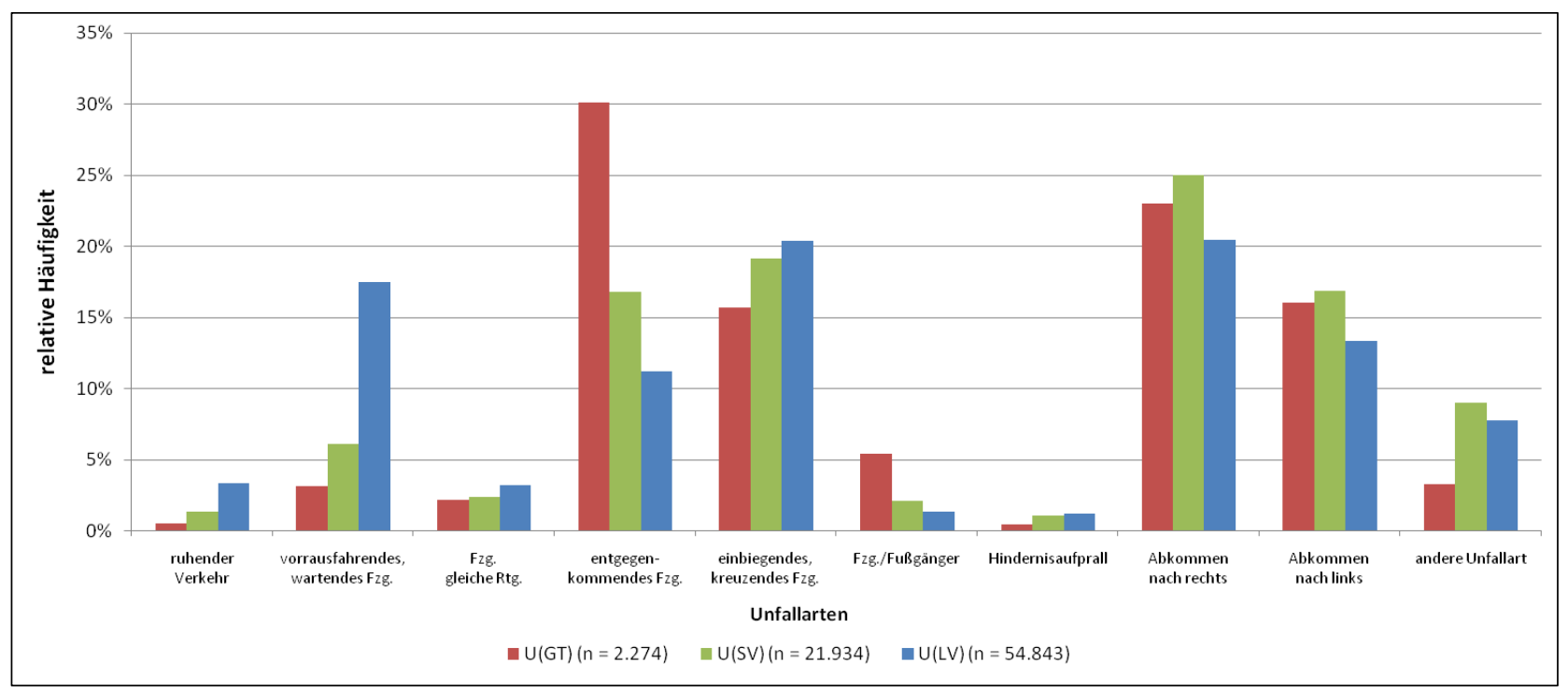

Abbildung 2.9: Unfälle mit Personenschaden auf Landstraßen nach Unfallarten

\subsubsection{Unfallursachen}

Fehler beim Überholen machen bei Unfällen mit Personenschaden auf Außerortsstraßen einen Anteil von $6 \%$ der Fehlverhalten von Fahrzeugführern aus (vgl. Abbildung 2.10). Dagegen liegt der Großteil der Unfallursachen mit $27 \%$ bei nicht angepasster Geschwindigkeit sowie mit 21\% bei anderen Fehlern.

Dabei können jedem Beteiligten mehrere Unfallursachen zugeschrieben werden. Es handelt sich hier demnach nicht um die primäre Unfallursache jedes Unfalls, sondern um die Verteilung aller vorgekommenen Unfallursachen bei allen Unfällen mit Personenschaden auf Landstraßen. Somit sind auch Überlagerungen mehrerer Ursachen an einem Unfall möglich.

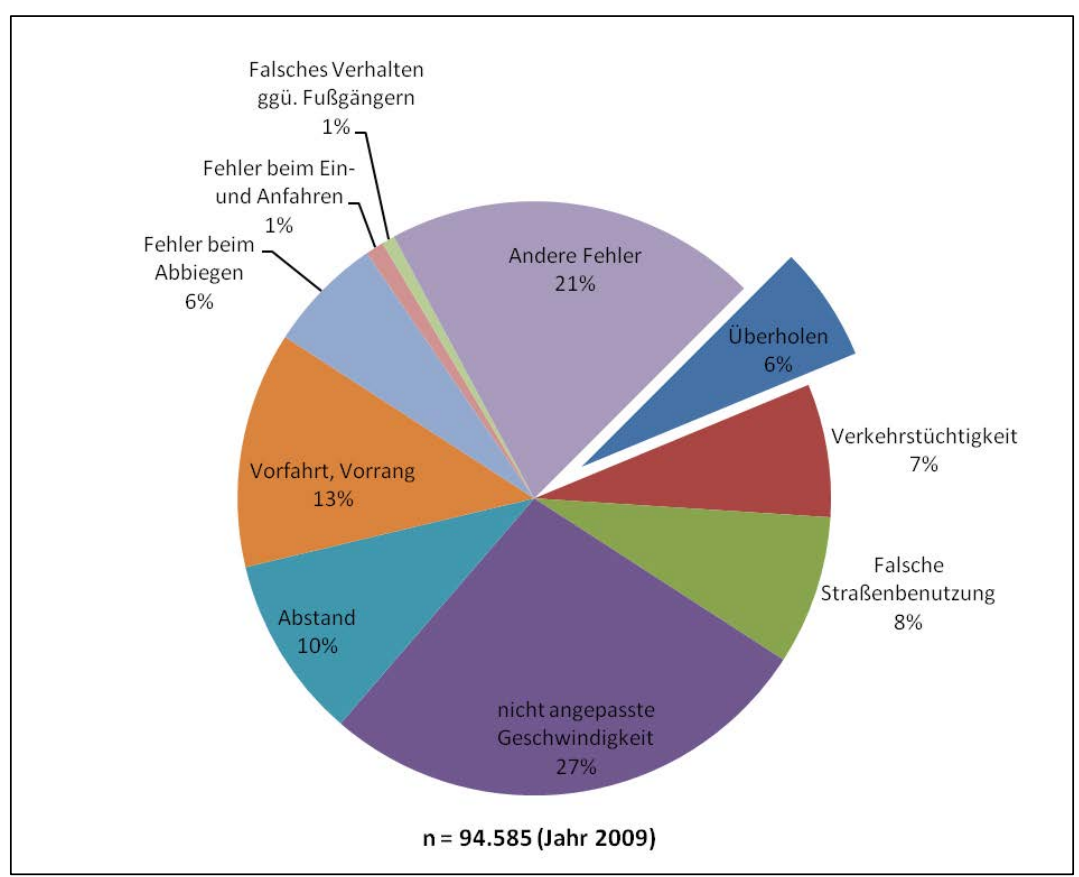

Abbildung 2.10: Fehlverhalten bei Unfällen mit Personenschaden auf Landstraßen 
Bei Unfällen mit der Ursache Überholen starben im Jahr 2009 insgesamt 216 Personen, 2.098 wurden zudem schwer verletzt. Bezogen auf die Gesamtzahl der getöteten und schwerverletzten Personen auf Landstraßen liegt der Anteil der Überholunfälle bei Getöteten bei 8,8 \% und bei Schwerverletzten bei 7,7\%. Dadurch zeigt sich bei einem Anteil von Überholunfällen an allen Unfällen mit Personenschaden von $6 \%$, jedoch einem Anteil von 8,8 \% an den Getöteten, die besondere Schwere von Überholunfällen.

\subsection{3 Überholunfälle auf Landstraßen}

Für die Auswertung der Überholunfälle auf Landstraßen im Jahr 2009 konnte auf 5.091 Unfälle zurückgegriffen werden, bei denen eine der erhobenen Ursachen den Ursachen eines Überholunfalles entsprach. Dabei waren 5.317 Personen beteiligt, denen die Unfallursache Überholen angelastet werden konnte. Somit wurden alle Ursachen von zwei möglichen erhobenen Beteiligter berücksichtigt, um Unfälle mit der Ursache Überholen (Überholunfälle) zu identifizieren. Demzufolge können auch zwei Unfallbeteiligte eine entsprechende Ursache aufgewiesen haben, die zum Unfall geführt hat.

\subsubsection{Unfalltypen}

Abbildung 2.11 verdeutlicht die Verteilung der Unfalltypen von Unfällen mit Personenschaden mit der Unfallursache Überholen (Ursachen 16 - 23). Hierbei zeigt sich deutlich, dass Unfälle im Längsverkehr (LV) sowohl in Bezug auf alle Unfälle mit Personenschaden, als auch in Bezug auf die einzelnen Unfallkategorien mit über $60 \%$ vertreten sind.

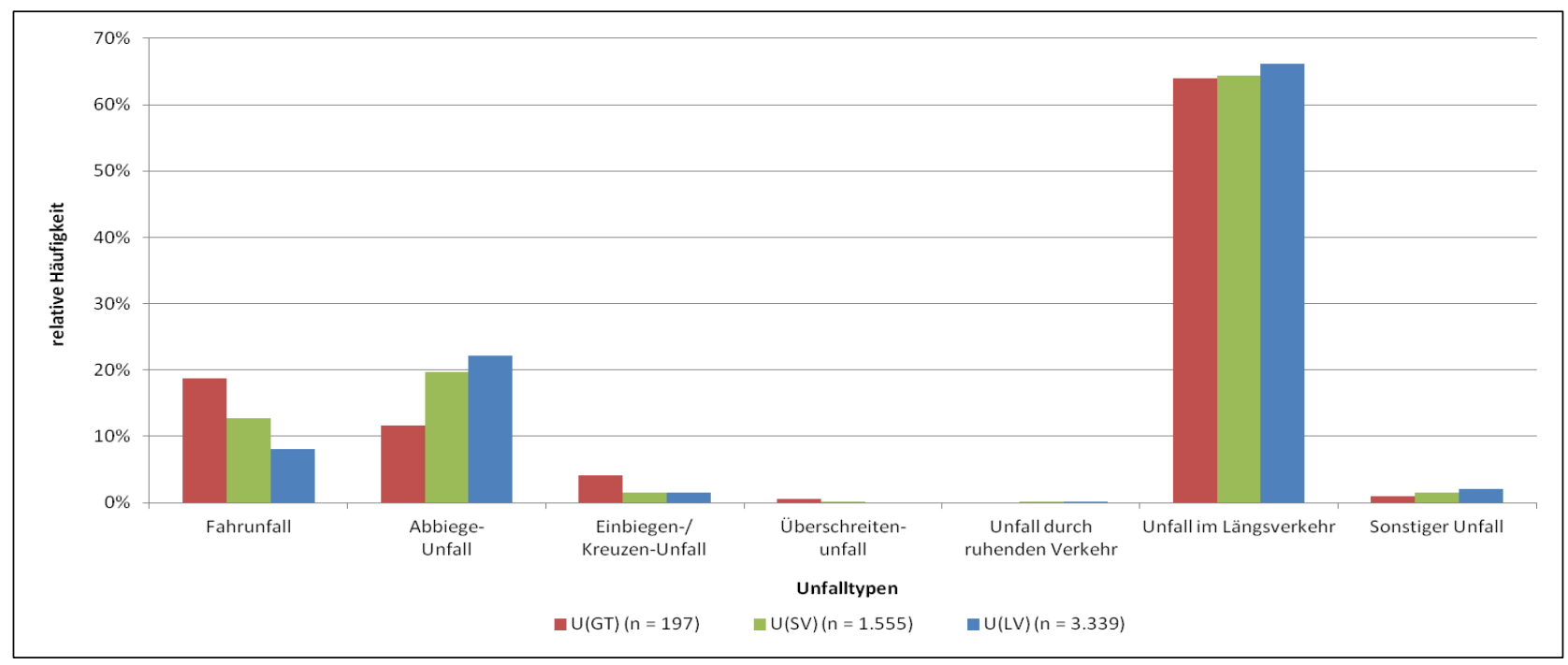

Abbildung 2.11: Überholunfälle mit Personenschaden auf Landstraßen nach Unfalltypen

Fahrunfälle $(F)$ sowie Abbiegeunfälle $(A B)$ sind zu $10 \%$ bzw. $21 \%$ an Unfällen mit Personenschaden beteiligt, wobei Fahrunfälle mit 19 \% im Gegensatz zu Abbiegeunfällen (12\%) der häufigere Unfalltyp bei tödlichen Überholunfällen ist. 


\subsubsection{Unfallarten}

In Abbildung 2.12 wird deutlich, dass Zusammenstöße mit entgegenkommenden Fahrzeugen (Unfallart 4) bei über der Hälfte (51 \%) der Überholunfälle mit Getöteten vorliegen. Gleichzeitig sind bei dieser Unfallart nahezu ein Drittel (32 \%) der Unfälle mit Schwerverletzten zu verzeichnen. Ursache sind hier die entgegen gerichteten Geschwindigkeiten und die somit hohe kinetische Energie, welche diese schweren Unfallfolgen erzeugt.

In Bezug auf alle Überholunfälle mit Personenschaden sind Unfälle mit Zusammenstößen mit entgegenkommenden Fahrzeugen ähnlich oft vertreten wie Unfälle durch Zusammenstöße mit einem Fahrzeug das seitlich in gleicher Richtung fährt (Unfallart 3), wobei hier allerdings die Unfallfolgen deutlich geringer ausfallen.

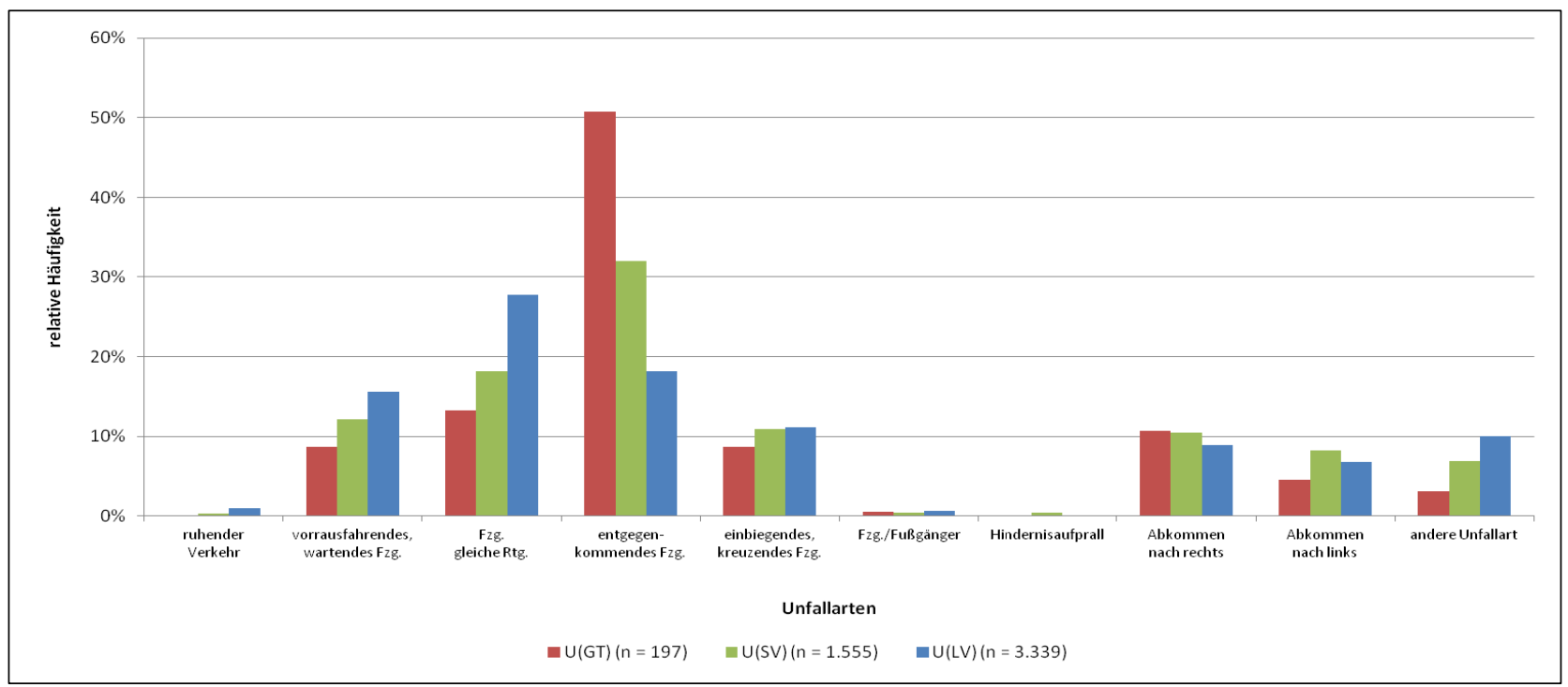

Abbildung 2.12: Überholunfälle mit Personenschaden auf Landstraßen nach Unfallarten

\subsubsection{Unfallursachen}

Im Anschluss an die generelle Untersuchung der Unfallursachen auf Landstraßen wurden die Ursachen von Überholunfällen weiter spezifiziert. Dabei wurde auf bis zu drei Ursachen von zwei erhobenen Unfallbeteiligten zurückgegriffen, wobei bei einem Unfall einzelne Unfallursachen mehrfach auftreten können. Die Ursachenbezeichnungen der Unfallursachennummern nach Abbildung 2.13 sind in Anhang A näher beschrieben.

Die häufigste Unfallursache von Überholunfällen auf Landstraßen ist - sowohl bezogen auf Unfälle mit Getöteten (42\%), als auch bezogen auf Unfälle mit Schwerverletzten (32 \%) - das Überholen trotz Gegenverkehrs (Unfallursache 17). Zusammen mit der am zweithäufigsten auftretenden Unfallursache, dem Überholen trotz unklarer Verkehrslage (Unfallursache 18), sind diese beiden Ursachen mit $61 \%$ der Unfälle mit Getöteten und 59 \% der Unfälle mit Schwerverletzten für mehr als die Hälfte aller Überholunfälle mit schwerem Personenschaden verantwortlich. Sonstige Fehler beim Überholen (Unfallursache 22) und Fehler beim Wiedereinordnen nach rechts (Unfallursache 21) sind für 14 \% bzw. 12 \% der Überholunfälle mit Getöteten und 18 \% bzw. 8 \% der Überholunfälle mit Schwerverletzten ursächlich. 


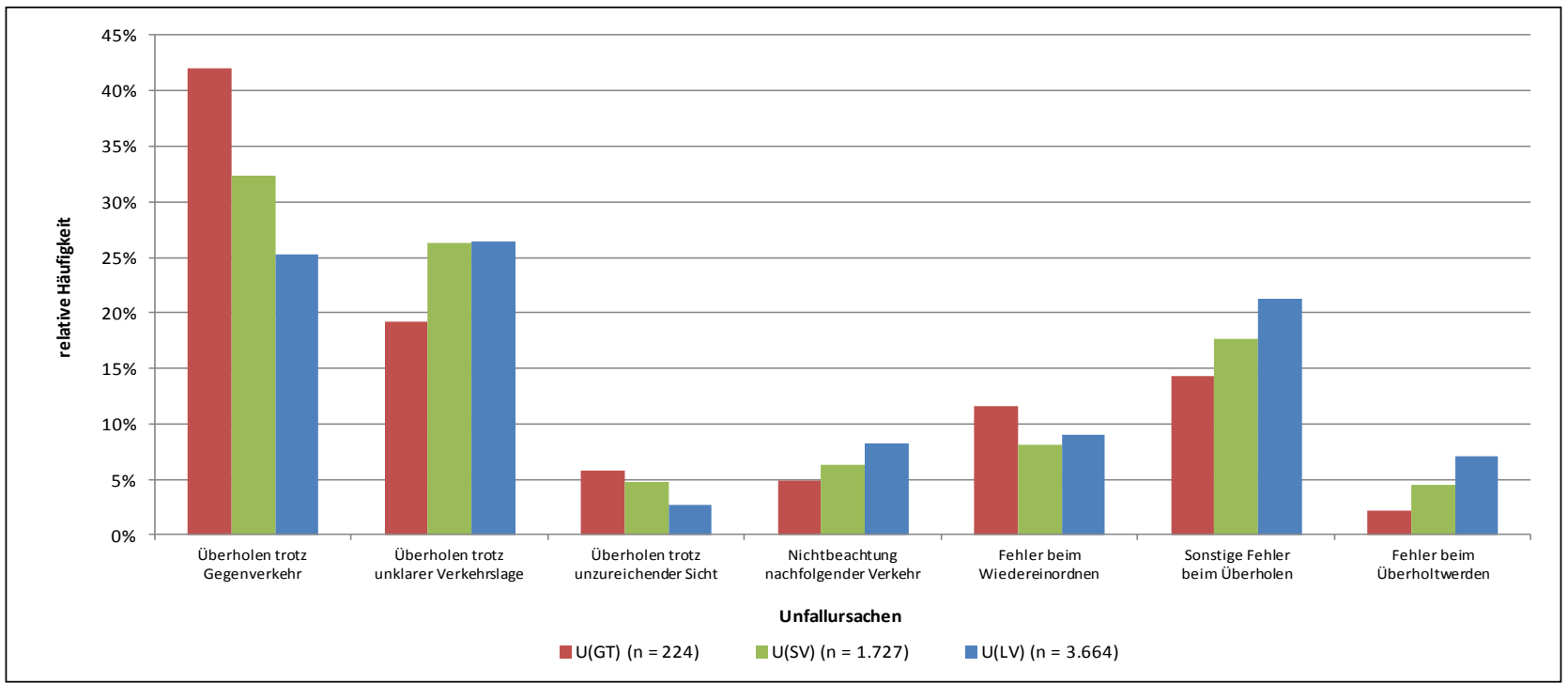

Abbildung 2.13: Fehlverhalten bei Überholunfällen mit Personenschaden auf Landstraßen

\subsubsection{Risikogruppen}

Von den Beteiligten mit Haupt- bzw. Teilunfallschuld bei Überholunfällen mit Personenschaden führten zu $76 \%$ einen Personenkraftwagen, zu $16 \%$ Motorräder sowie zu $8 \%$ Lastkraftwagen (Statistisches Bundesamt, 2010a). Die Verteilungen entsprechen hier den erwartungsgemäßen Anteilen von Überholern im Landstraßennetz. Männliche Fahrzeugführer bilden mit 80 \% der Beteiligten an Unfällen mit der Unfallursache Überholen eine deutliche Risikogruppe bezüglich des Geschlechts. Dabei ist jedoch für $8 \%$ der 5.317 Beteiligten mit einer Haupt- bzw. Teilunfallschuld das Geschlecht nicht verfügbar, was jedoch für die deutliche Tendenz von mindestens $73 \%$ männlicher Beteiligter unerheblich ist. Auch bei den Altersgruppen sind Risikogruppen identifizierbar. Kraftfahrzeugführer im Alter von 18 bis 21 und 21 bis 25 Jahren sind für über $26 \%$ der Unfälle mit Personenschaden verantwortlich und bilden vor 25 bis 30 Jährigen Kraftfahrzeugführern (10,3\%) die größte Risikogruppe.

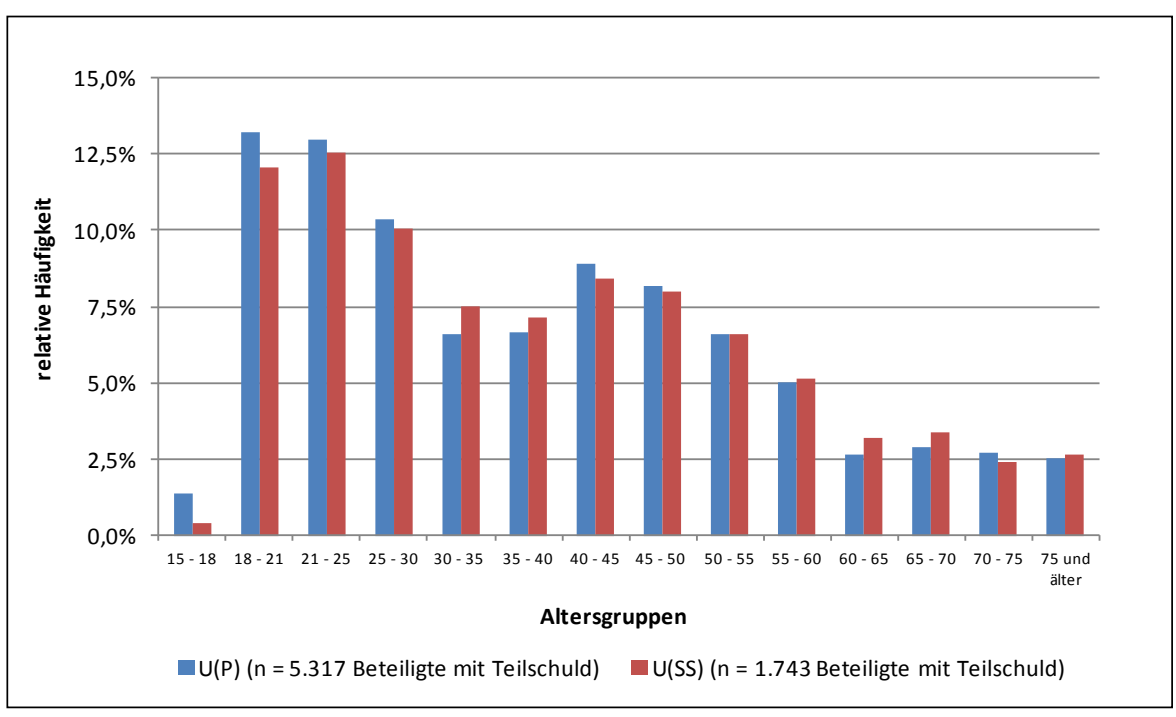

Abbildung 2.14: Überholunfälle mit Personenschaden auf Landstraßen nach Altersklassen 
Weiterhin zeigt sich in Abbildung 2.14 eine generelle Tendenz von sinkender Beteiligung an Überholunfällen bei steigendem Alter. Auffällig ist hierbei jedoch der Anstieg der Überholunfallbeteiligung von 40 bis 50 Jährigen gegenüber der Altersgruppe von 30 bis 40 Jahren bzw. der geringe Anteil von 30 bis 40 -Jährigen an Überholunfällen. Wird dabei die Kohortengröße betrachtet, so erhöht sich das Risiko für die 3 Klassen der jungen Fahrer von 18 bis 30 Jahren (vergleichsweise geringer Bevölkerungsanteil), geht aber für 40-50-Jährige zurück (vgl. Statistisches Bundesamt, 2010b). Möglicherweise sind junge Männer in ihrem grundsätzlichen Fahrverhalten risikobereiter als ältere oder weibliche Fahrzeugführer. Zudem sind bei jungen Fahranfängern die Erfahrungen zum sicheren Durchführen eines Überholvorganges nicht vorhanden, was in Verbindung mit der Risikobereitschaft zu schweren Unfällen führen kann. Die Erfahrungen nehmen mit zunehmendem Alter zu, aber möglicherweise sinken im Gegenzug die Möglichkeiten der Wahrnehmung von situativen Einflussgrößen. Die möglicherweise unterschiedlichen Fahrleistungen und Fahrweisen zwischen den Geschlechtern und den einzelnen Altersgruppen lassen allerdings nur Mutmaßungen in Bezug auf die Schwankungen des Unfallgeschehens zu. Die alleinige Betrachtung der Hauptunfallschuld wurde in diesem Abschnitt nicht berücksichtigt, um einen generellen Überblick über den Überholunfall bekommen zu können. Die Aspekte des Hauptverursachers enthält Kapitel 4.1.1.

\subsubsection{Zeitliche Verteilung}

In Abbildung 2.15 ist die zeitliche Verteilung der Unfälle mit der Unfallursache Überholen bezogen auf die Wochentage dargestellt. Bei Betrachtung aller Unfälle mit Personenschaden bilden sich zwei Gruppen heraus. An den Tagen Dienstag bis Freitag geschehen mit einem Anteil von je $15 \%$ bis $17 \%$ mehr Unfälle als an den Tagen Samstag bis Montag (11\% bis $13 \%)$. Bei Betrachtung der schweren Unfälle zeigt sich, dass generell in der Zeit von Freitag bis Sonntag und speziell an Freitagen der Anteil der Unfälle mit Getöteten höher ist als an den Wochentagen Montag bis Donnerstag. Ursachen sind möglicherweise Pendlerverkehre an Freitagen, die in Erwartung des Wochenendes zu aggressiven Verhaltensweisen führen können oder die Fahrten nach nächtlichen Aktivitäten am Wochenende, die an den Werktagen größtenteils ausfallen. Zudem zeigt sich ein Anstieg der Getöteten am Wochenende durch verunglückte Motorradfahrer (Motorradausfahrten).

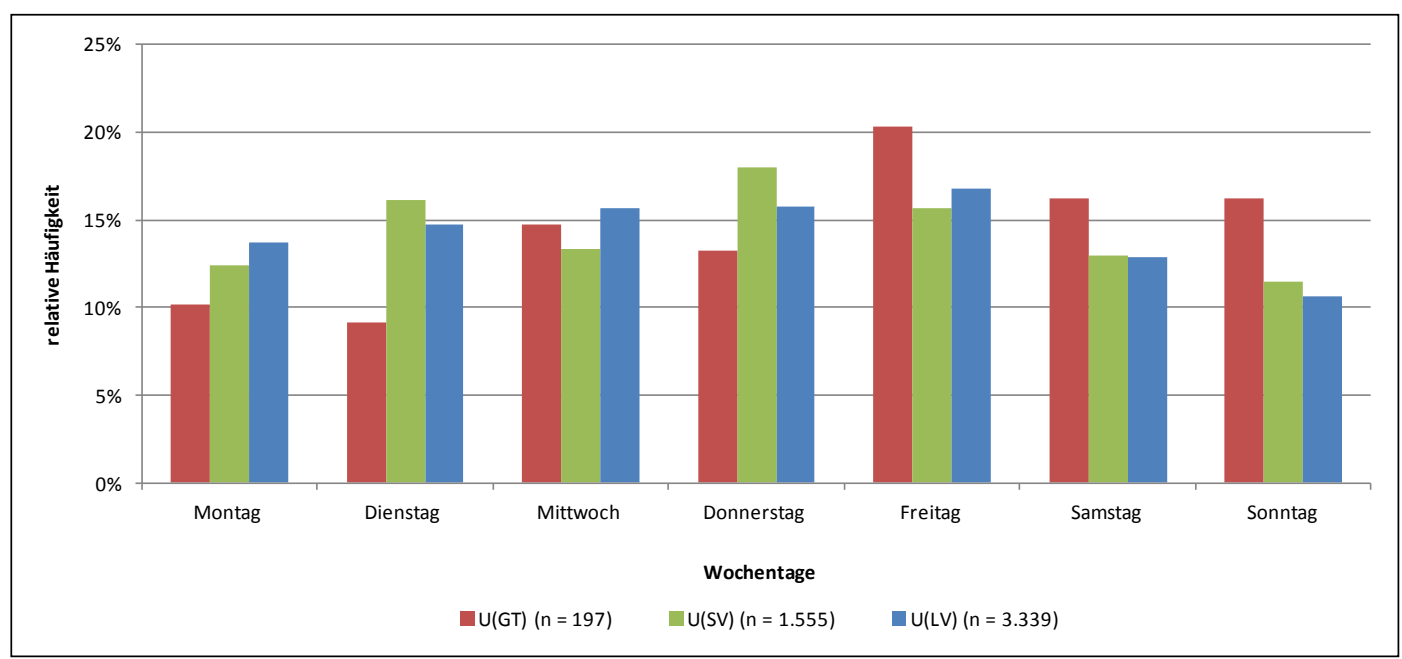

Abbildung 2.15: Überholunfälle mit Personenschaden auf Landstraßen nach Wochentagen 
Die zeitliche Verteilung von Überholunfällen auf Monate zeigt dagegen deutlichere Unterschiede (vgl. Abbildung 2.16). Dabei lassen sich zwei Gruppen von jeweils sechs Monaten identifizieren. In den Monaten April bis September geschieht mit 64 \% gegenüber den Monaten Oktober bis März mit 36 \% ein Großteil der Überholunfälle mit Personenschaden.

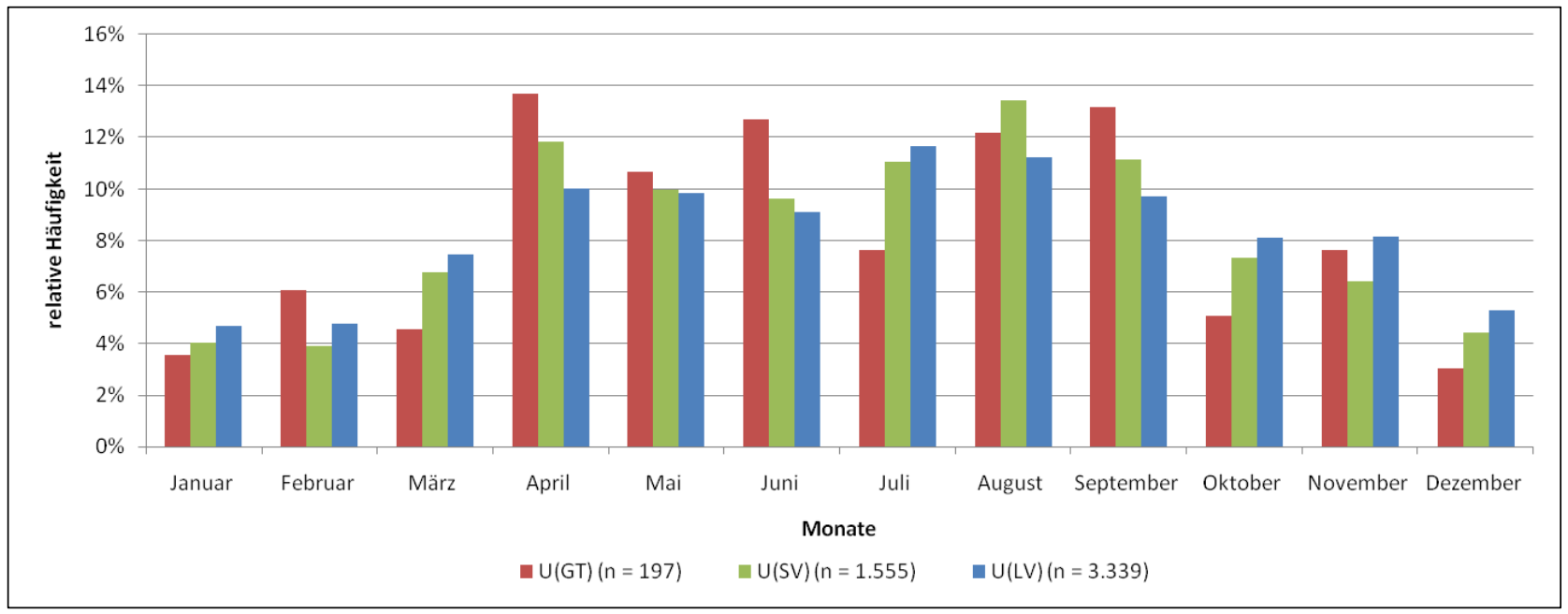

Abbildung 2.16: Überholunfälle mit Personenschaden auf Landstraßen nach Monaten

Im Hinblick auf Unfälle mit schwerem Personenschaden ist diese Tendenz mit $70 \%$ der Unfälle mit Getöteten und 67 \% der Unfälle mit Schwerverletzten in den Monaten April bis September noch deutlicher. Auffällig ist der geringe Anteil von $8 \%$ der tödlichen Unfälle bei konstantem Anteil der Unfälle mit Personenschaden im Juli. Als Ursachen für diese Verteilungen können unterschiedliche Fahrleistungen mit dem Pkw bzw. vorsichtigere Fahrweisen in den Wintermonaten, die Motorradsaison aber auch Einflüsse von Sommerferien auf die Pendleranzahl unterstellt werden.

\subsubsection{Umwelteinflüsse}

Die Verteilung der Überholunfälle bezogen auf die Lichtverhältnisse zeigen hinsichtlich aller Unfallkategorien ein nahezu identisches Ergebnis. Dabei geschehen $81 \%$ aller Überholunfälle mit Personenschaden auf Landstraßen bei Tageslicht, $15 \%$ bei Dunkelheit sowie $5 \%$ bei Dämmerung.

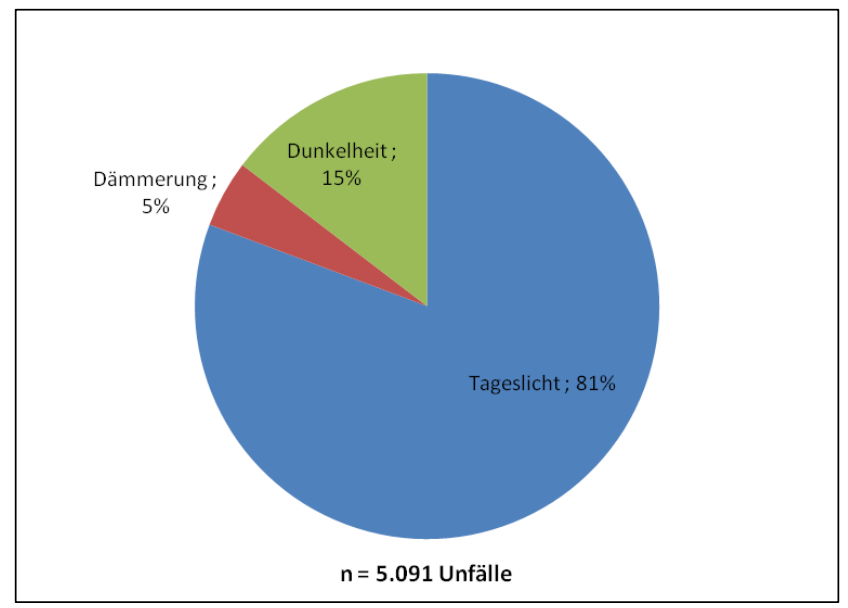

Abbildung 2.17: Überholunfälle mit Personenschaden auf Landstraßen nach Lichtverhältnissen 
Die Verteilung aller Landstraßenunfälle liegt bei Tageslicht $10 \%$ niedriger, dafür bei Dunkelheit mit $8 \%$ und bei Dämmerung mit $1 \%$ jeweils höher. Daher besteht eine Tendenz zu Überholunfällen bei guten Sichtbedingungen am Tage. Auch bei der Verteilung der Überholunfälle bezogen auf den Straßenzustand wurden nur geringfügige Unterschiede bei der Betrachtung der einzelnen Unfallkategorien deutlich. Auf trockener Fahrbahn ereignet sich mit 76,6 \% der Großteilder Überholunfälle mit Personenschaden auf Landstraßen. Auf nasser Fahrbahn sind rund ein Fünftel $(20,4 \%)$ der Unfälle zu verzeichnen. Einen nur geringen Anteil haben Überholunfälle auf glatter $(2,5 \%)$ und schlüpfriger (0,5 \%) Fahrbahn, wobei bei der Beschreibung des Fahrbahnzustandes Mehrfachnennungen möglich waren, so dass bei 5.091 Unfällen insgesamt 5.121 Nennungen zum Straßenzustand ausgewertet wurden. Bei Betrachtung von allen Landstraßenunfällen wird eine Senkung um $15 \%$ bei Tageslicht, dagegen eine Erhöhung bei Nässe um $10 \%$ und bei Glätte um $5 \%$ deutlich, was ebenfalls für Tendenzen von Überholunfällen bei geeigneten Straßenverhältnissen spricht.

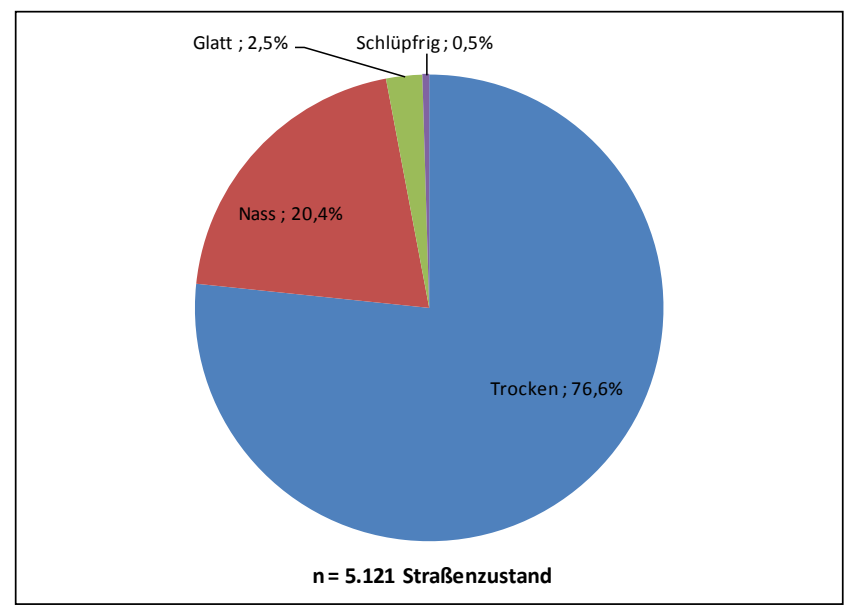

Abbildung 2.18: Straßenzustände bei Überholunfällen mit Personenschaden auf Landstraßen

Für die Auswertung der Witterungseinflüsse standen zu den 5.091 Überholunfällen auf Landstraßen nur 180 Datensätze zu vermerkten Witterungseinflüssen zur Verfügung. Demnach haben Witterungseinflüsse insgesamt eine eher untergeordnete Bedeutung bei Überholunfällen.

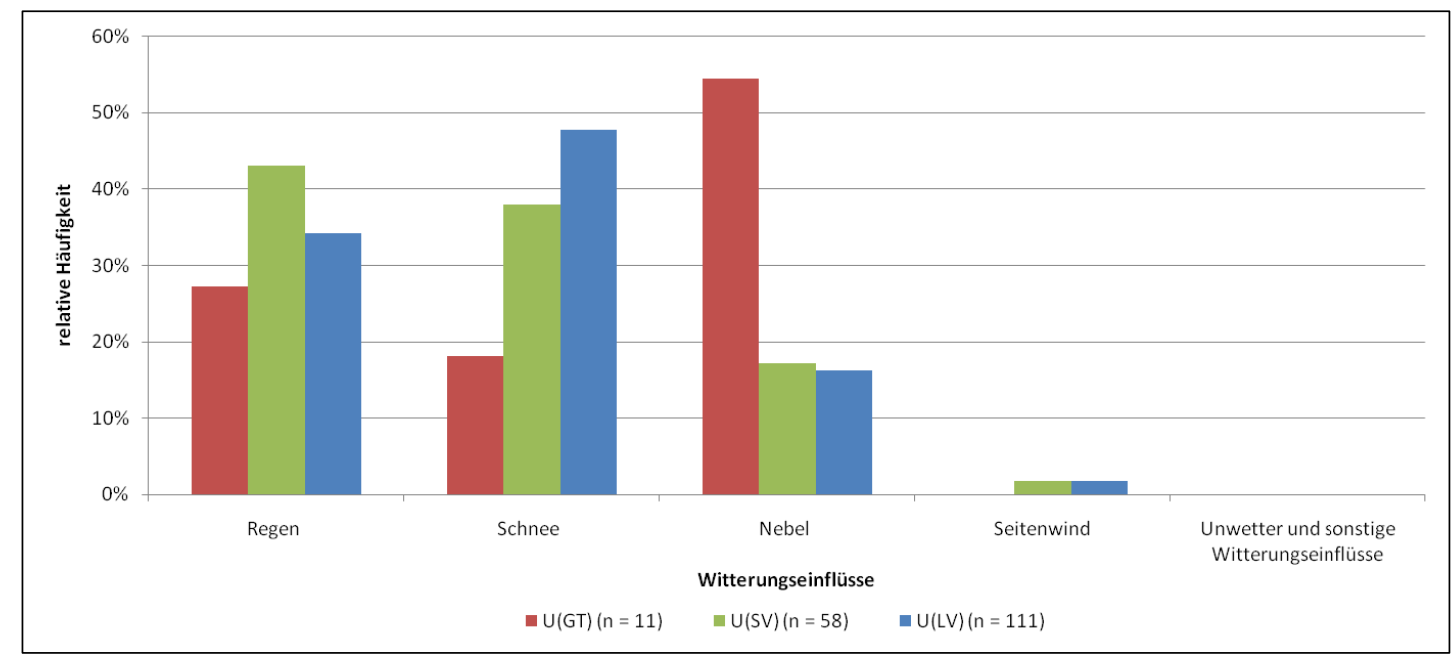

Abbildung 2.19: Witterungseinflüsse bei Überholunfällen mit Personenschaden auf Landstraßen 
Bei Unfällen, bei denen Witterungseinflüsse eine Rolle spielten, waren Schnee (43\%), Regen (37\%) sowie Nebel (19\%) die häufigsten Einflüsse für Unfälle mit Personenschaden. Hierbei ist auffällig, dass Nebel in 55\% der Fälle für Unfälle mit Getöteten relevant war, was jedoch aufgrund der Tatsache, dass insgesamt nur 11 Unfälle mit Getöteten in Verbindung mit Witterungseinflüssen zu verzeichnen sind, nur von untergeordneter Bedeutung ist.

\subsection{Zusammenfassung}

In der Literaturanalyse konnten eine Vielzahl von Einflussfaktoren und Zusammenhänge des Überholvorganges ermittelt werden. Die Komplexität dieses Verkehrsvorganges und mögliche Überlagerungen von ungünstigen Einflussfaktoren von Fahrer, Fahrzeug und Fahrumgebung ergeben zahlreiche Möglichkeiten, wie es bei einer Überholung zu Fehlern und Unfällen kommen kann. Grundlage für einen Überholvorgang ist ein Überholbedürfnis, welches von individuellen Grundeinstellungen zu Geschwindigkeitswahl und Fahrverhalten abhängig ist. Diese Eigenschaften werden wiederum von Erfahrungen, Motivation und persönlichen Eigenschaften der Fahrer mitbestimmt. Ergeben sich durch die gegebene Verkehrssituation (z.B. geringe Zeitlücken im Gegenverkehr) und die Linienführung der Straße (z.B. geringe Überholsichtweiten) keine Überholmöglichkeiten, so kann sich das Überholbedürfnis in Überholdruck steigern. Bei hohem Überholdruck kann unter Inkaufnahme kritischerer Ausgangsbedingungen ein risikobehaftetes Überholmanöver eingeleitet werden, was Unfälle zur Folge haben kann. Das Ziel der Straßenplanung muss es sein, die Ansatzpunkte für Fehler bei der Fahraufgabe und zudem auch beabsichtigte, unsichere Handlungen so weit wie möglich auszuschalten. Aus Sicht der Verkehrsplanung können auf das Überholverhalten bzw. auf die Überholentscheidung negativ und positiv wirkende Maßnahmen angeordnet werden. Negativ beeinflussende Maßnahmen können durch verkehrstechnische Einrichtungen dazu beitragen, in kritischen Bereichen die Überholmanöver zu unterbinden. Neben diesen Restriktionen sollen aber auch positive Maßnahmen umgesetzt werden, welche die Überholungen in Bereiche verlagern, in denen diese Verkehrsvorgänge durch ausreichende Überholsichtweiten oder Überholfahrstreifen theoretisch gefahrlos möglich sind. Durch die gesicherten Vorgaben können eine Vielzahl von Unfällen und kritischen Verkehrssituationen vermieden werden. Durch teilweise unvorhersehbares und nicht den vorherrschenden Verhältnissen angepasstes Verkehrsverhalten sind aber auch hier Missachtungen und Fehlverhalten grundsätzlich nicht auszuschließen. Diesen muss durch die Verkehrserziehung vorgebeugt und spätestens durch Überwachung Einhalt geboten werden.

In der neuen Richtliniengeneration sollen prinzipiell die beschriebenen Verbote und Beschränkungen mit Erleichterungen und Vereinfachungen im Verkehrsablauf bei der Straßenplanung berücksichtigt werden. Für den Neu-, Um- und Ausbau werden in der RAL durch die Einteilung der Straßen in Entwurfsklassen auch die damit verbundenen Überholprinzipien angewendet. Bei den Entwurfsklassen 1 und 2 ist das Überholen im Regelfall nur auf dafür vorgesehenen Überholfahrstreifen angedacht. Bei ausreichenden Sichtbedingungen wird das Überholen auf Straßen der EKL 3 möglich sein, auf Strecken der EKL 4 wird kein Überholbedarf gesehen. Zur Übertragung des neuen Entwurfsprinzips auf das Bestandsnetz werden Toleranzen zugelassen, um Straßen mit einer 
bestimmten Entwurfsklasse kennzeichnen zu können (über unverwechselbare Fahrbahnlängsmarkierung). Bei dieser Anpassung muss zur besseren Akzeptanz des Entwurfsklassenprinzips aber ein längerer Umsetzungszeitraum in Kauf genommen werden, demzufolge dürfen festgelegte Mindestanforderungen zur Kennzeichnung nicht unterschritten werden. Untersuchungen in BadenWürttemberg haben gezeigt, dass ein Großteil des Straßennetzes auf die Entwurfsklasse 3 entfallen, auf der Überholvorgänge weiterhin möglich sein sollen. Auf Grundlage dieser Ergebnisse und auch bei Berücksichtigung von Streckenabschnitten, die bei der langfristigen Einführung des Entwurfsklassenprinzips nicht nach den neuen Entwurfsklassen gekennzeichnet werden, können Überholvorgänge und somit auch Überholunfälle nicht ausnahmslos im Straßenverkehr vermieden werden. Daher gilt es für diese Untersuchung um so mehr, das Verkehrsverhalten sowie die Einflussfaktoren auf den Überholvorgang genau zu untersuchen, um auf den Straßen die sowohl bisher als auch in Zukunft Überholmöglichkeiten aufweisen, die besonders folgenschweren Überholunfälle verhindern zu können.

In einer Datenbankabfrage der Unfalldaten von 2009 des Statistischen Bundesamtes konnten verschiedene Zusammenhänge aufgezeigt werden. Die auffällig hohe Unfallschwere bei Unfällen auf Landstraßen und zudem eine besondere Unfallschwere bei Überholunfällen konnten auf Grundlage der gelieferten Daten nachgewiesen werden. Innerhalb des Unfallkollektivs der Überholunfälle konnten typische Unfalltypen, -arten und -ursachen identifiziert werden. Als Risikogruppe für Überholunfälle können überwiegend junge, männliche Fahrzeugführer (vorrangig Führer von Personenkraftwagen) angesehen werden, wobei sich die Tendenzen bei Berücksichtigung der Kohortengröße noch deutlicher ausprägen. Geringe Fahrerfahrung und erhöhte Risikobereitschaft können hier in kritischen Situationen zu schweren Unfällen führen. Die zeitlichen Verteilungen der Unfälle ergeben steigende Tendenzen zum Wochenende hin und eine geringe Unfallauffälligkeit in den Wintermonaten. Als Gründe können in beiden Fällen unterschiedliche Fahrleistungen und Fahrweisen angenommen werden. Bei Betrachtung der Umwelteinflüsse wurden die größten Anteile von Überholunfällen bei trockenen Fahrbahnen und Tageslicht festgestellt. Ein Vergleich der Verteilungen von Umwelteinflüssen mit allen Landstraßenunfällen bekräftigt dieses Ergebnis, da hier die entsprechenden Anteile bei Tageslicht und trockener Fahrbahn jeweils darunter liegen. Demzufolge können besonders bei Überholvorgängen an die jeweiligen äußeren Einflüsse angepasste Verhaltensweisen unterstellt werden, weshalb äußere Bedingungen an der Entstehung von Überholunfällen nur eine untergeordnete Bedeutung zukommt.

Die in der Literaturanalyse und der Datenbankabfrage gewonnenen Erkenntnisse können bei der weiteren Bearbeitung sowie der späteren Ergebnisinterpretation berücksichtigt werden. Im nachfolgenden Berichtsteil wird die Aufbereitung der Straßennetz- und Unfalldaten, die Unfallkenngrößenberechnung bis hin zur Identifizierung der 500 unfallauffälligsten Untersuchungsstrecken beschrieben. Die gefilterten, unfallauffälligen Strecken werden in den weiteren Arbeitsschritten der Netzanalyse ausführlich untersucht (Streckenbefahrung, Nachtrassierung und Sichtweitenanalyse). Innerhalb einer abschließenden Detailanalyse werden die Ergebnisse durch Analysen zum realen Überholverhalten ergänzt. 


\section{Ergebnisse der Netzanalyse}

\subsection{Festlegung des Untersuchungsgebietes und Datengrundlage}

In der Bundesrepublik Deutschland wurden optional 5 Bundesländer für die Bearbeitung dieses Projektes ausgewählt. Die Festlegung erfolgte hier überwiegend nach der Verfügbarkeit der gewünschten Daten in den Straßeninformationsbanken der Länder. Es wurden folgende Bundesländer zur Unfalluntersuchung herangezogen:

- Baden-Württemberg

- Brandenburg

- Nordrhein-Westfalen

- Rheinland-Pfalz

- Sachsen-Anhalt

Die Analysen der Straßeninformationsbanken und der Unfalldatenbanken wurden bereits in den Zwischenberichten ausführlich dargelegt. Einen Überblick über die verfügbaren Straßennetz- und Unfalldaten in den Bundesländern (BL) gibt Tabelle 3.1.

\begin{tabular}{|c|c|c|c|c|c|}
\hline & BL1 & BL2 & BL3 & BL4 & BL5 \\
\hline \multicolumn{6}{|c|}{ Straßennetzdaten } \\
\hline Bundesstraßen & $x$ & $x$ & $x$ & $x$ & $x$ \\
\hline Landesstraßen & $x$ & $x$ & $x$ & $x$ & $x$ \\
\hline Kreisstraßen & $x$ & $x$ & $x$ & unvollständig & n.v. \\
\hline \multicolumn{6}{|l|}{ Unfalldaten } \\
\hline Bundesstraßen & $x$ & $x$ & $x$ & $x$ & $x$ \\
\hline Landesstraßen & $x$ & $x$ & $x$ & $x$ & $x$ \\
\hline Kreisstraßen & $x$ & n.v. & $x$ & $x$ & n.v. \\
\hline Unfalltypen & 3-stellig & 3-stellig & 1-stellig & 1-stellig & 1-stellig \\
\hline Unfallkategorien & $1-6$ & $1-4$ & $1-4$ und 6 & $1-6$ & $1-4$ \\
\hline Unfallpositionen & ok & ok & ok & ok & ok \\
\hline
\end{tabular}

Tabelle 3.1: Übersicht der Straßennetz- und Unfalldaten

Die Untersuchung soll vorrangig auf Bundes- und Landesstraßen erfolgen. In den Bundesländern, in denen die Strecken- und Unfalldaten auch für Kreisstraßen vorliegen (auch Teilnetze), können diese Strecken als Zusatz zu dem Untersuchungskollektiv der Bundes- und Landesstraßen verwendet werden.

Die Ergebnisse der Netzanalyse werden innerhalb dieses Kapitels ausführlich dargestellt. Die Netzanalyse beinhaltet die anfängliche Straßennetzaufbereitung, die makroskopische Unfallanalyse, die Erhebung der verkehrlichen Randbedingung sowie die Analyse der vorhandenen Überholsichtweiten nach erfolgter Nachtrassierung. 


\subsection{Ergebnisse der Straßennetzaufbereitung}

\subsubsection{Filterung von Untersuchungstrecken}

Nach den Erfordernissen einer Untersuchungsstrecke sind nach deren Filterung in dem verbleibenden Untersuchungsgebiet nur noch Außerortsstrecken mit jeweils einem Fahrstreifen in Hinund Rückrichtung enthalten. Knotenpunkte bleiben in der Datenbank berücksichtigt, auch Knoten mit mehreren Abbiegefahrstreifen. Möglicherweise ergeben sich durch die Erfordernisse von geraden Streckenabschnitten in Knotenpunktbereichen besondere Einflüsse auf das Überholverhalten und das Unfallgeschehen. Diese Aspekte können demnach weiterhin verfolgt werden.

Strecken mit größeren Umbaumaßnahmen während des Untersuchungszeitraumes sollen nicht berücksichtigt werden. Möglicherweise entfallen diese Strecken, weil innen nur für einen Teil des Untersuchungszeitraumes Unfälle zugewiesen werden können. Die spätere Befahrung der 500 unfallauffälligsten Untersuchungsstrecken kann zudem Hinweise auf größere Baumaßnahmen geben (z.B. Trassenverlegung). Gegebenenfalls sind bei der abschließenden Detailanalyse die Untersuchungsstrecken mit Hilfe der entsprechenden Straßenbauverwaltungen der Länder auf Baumaßnahmen zu überprüfen, um später das reale Fahrverhalten erheben und beurteilen zu können. Die Ergebnisse der Filterung von Untersuchungsstrecken sind in nachstehender Tabelle einzusehen.

\begin{tabular}{|c|c|c|c|c|}
\hline & \multicolumn{2}{|c|}{ ursprüngliches Straßennetz } & \multicolumn{2}{c|}{ gefilterte Untersuchungsstrecken } \\
\hline Land & Streckenlänge [km] & n-Abschnitte & Streckenlänge [km] & n-Abschnitte \\
\hline BL1 & 17.590 & 19.436 & 13.319 & 10.293 \\
\hline BL2 & 28.047 & 34.682 & 19.688 & 13.121 \\
\hline BL3 & 11.747 & 9.322 & 8.364 & 4.318 \\
\hline BL4 & 9.037 & 8.283 & 6.416 & 3.629 \\
\hline BL5 & 15.179 & 18.671 & 10.482 & 6.810 \\
\hline \hline Summe & $\mathbf{8 1 . 5 9 9}$ & $\mathbf{9 0 . 3 9 4}$ & $\mathbf{5 8 . 2 6 9}$ & $\mathbf{3 8 . 1 7 1}$ \\
\hline
\end{tabular}

Tabelle 3.2: Ergebnis der Straßennetzaufbereitung

Aus insgesamt 81.599 Kilometer Streckennetz konnten in den fünf Bundesländern 58.269 Kilometer Untersuchungsstrecken auf 38.171 Abschnitten gefiltert werden. In der weiteren Bearbeitung wurde wegen der feingliedrigen Streckenfilterung eine Streckenzusammenfassung von mehreren mit Überholunfällen belasteten Untersuchungsabschnitten durchgeführt, weshalb die hier tatsächlich interessierende, weiter betrachtete Abschnittsanzahl deutlich geringer ausfällt.

\subsubsection{Unfallzahlen}

Unabhängig von der Betrachtung der Abschnittsanzahl konnten den Untersuchungsstrecken in den fünf Bundesländern folgende Unfälle zugeordnet werden.

\begin{tabular}{|c|c|c|c|c|c|}
\hline & BL1 & BL2 & BL3 & BL4 & BL5 $^{\text {a }}$ \\
\hline Unfälle Kategorie 1-6 & 87.948 & - & - & 44.622 & - \\
\hline Unfälle Kategorie 1-4 & 19.357 & 28.654 & 8.515 & 8.332 & 20.487 \\
\hline Überholunfälle & 1.309 & 1.706 & 714 & 848 & 1.632 \\
\hline $\begin{array}{c}\text { Bemerkungen } \\
\text { Überholunfällefilter }\end{array}$ & $\begin{array}{c}\text { Ursachen des 1. und 2. } \\
\text { Beteiligten verwendet }\end{array}$ & \multicolumn{3}{|c|}{ nur Ursachen des Hauptverursachers } \\
vorhanden \\
\hline
\end{tabular}

Tabelle 3.3: Unfallzahlen auf Untersuchungsstrecken 
Für diese Untersuchung können auf dem einbahnig zweistreifigen Landstraßennetz insgesamt 85.345 Unfälle der Kategorien 1 bis 4 ausgewertet werden. Zu den Unfallzahlen von Bundesland 2 sei angemerkt, dass für 1.796 Unfälle keine Lokalisierungsinformationen vorhanden waren und diese Unfälle somit nicht den Untersuchungsstrecken zugeordnet werden konnten. Hiervon waren allerdings nur 18 potentielle Überholunfälle betroffen, diese auch nur mit geringer Unfallschwere. Insgesamt können nach einer Filterung über die Unfallursachen 16 bis 23 im Untersuchungsgebiet insgesamt 6.209 Überholunfälle auf den Untersuchungsstrecken ausgewertet werden. Für Bundesland 1 und Bundesland 2 konnte eine Filterung der Überholunfälle über die Unfallursachen des unmittelbar und mittelbar Beteiligten durchgeführt werden. In den verbleibenden Bundesländern musste die Filterung auf die Unfallursachen des Hauptverursachers beschränkt bleiben. Die Verteilungen der enthaltenen Unfalltypen und Unfallarten in den gefilterten Überholunfällen werden nachfolgend in Abbildung 3.1 und Abbildung 3.2 veranschaulicht, Erläuterungen der verschiedenen Unfallmerkmale finden sich in Anhang A.

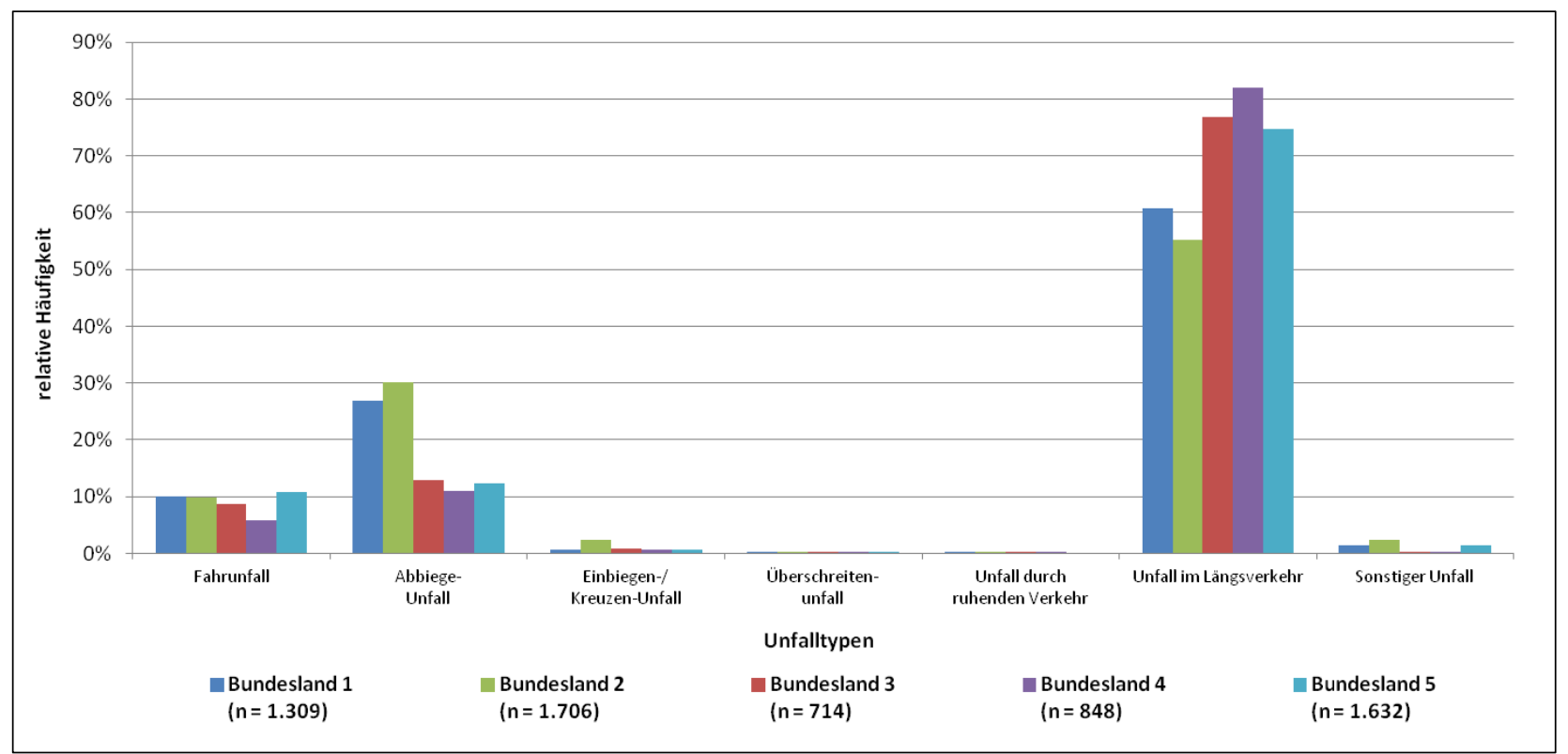

Abbildung 3.1: Unfalltypenverteilung in Überholunfälle

Die Verteilungen der Unfalltypen über die einzelnen Bundesländer sind in ihren Tendenzen durchaus miteinander vergleichbar. Der nahezu dreifach größere Anteil von Abbiegeunfällen (Unfalltyp 2) in Bundesland 1 und Bundesland $2 \mathrm{im}$ Vergleich zu den drei weiteren Bundesländern entspricht augenscheinlich der Differenz bei den Unfällen im Längsverkehr (Unfalltyp 6) im Untersuchungsgebiet. Eine unterschiedliche Auffassung der untersuchten Bundesländer zur Typisierung von Auffahrunfällen in Knotenpunktbereichen stellt hier nur eine Vermutung dar. In den dreistelligen Unfalltypen in Bundesland 1 sind beispielsweise von den gefilterten 352 Überholunfällen mit Unfalltyp 2, insgesamt 318 mit Unfalltyp 202 enthalten. Dies entspricht einem Überholvorgang während des Linksabbiegens. Dieser spezielle Unfall wird möglicherweise in anderen Bundesländern anders bewertet, beispielsweise als Unfall im Längsverkehr wegen des Überholvorgangs, da in diesen verbleibenden 3 Bundesländern keine 3-stellige Unfalltypisierung vorgenommen wird. Hierbei können Differenzen nach Abbildung 3.1 entstehen, weil zufälligerweise genau bei den beiden Bundes- 
ländern mit dreistelligen Unfalltypen der Unfalltyp 2 hervorsticht, da hier Unfälle wegen der genaueren Typisierung des eben beschriebenen Beispiels nicht als Unfälle im Längsverkehr bewertet werden. Das Vorhandensein von eher ungewöhnlichen Unfalltypen im Zusammenhang mit Überholunfällen ist auf wenige Ausnahmen beschränkt und möglicherweise auf eine fehlerbehaftete Unfalltypisierung zurückzuführen.

Die Tendenzen der Unfallartenverteilung sind ebenfalls über alle Bundesländer hinweg vergleichbar, allerdings sind die einzelnen Ausprägungen sehr unterschiedlich. Die Differenzen können dennoch nicht auf die abweichende Identifizierung der Überholunfälle zurückgeführt werden (Berücksichtigung von unmittelbaren und mittelbaren Unfallbeteiligten, vgl. Tabelle 3.3). Dieser Umstand wurde für das Bundesland 1 geprüft, bedeutsame Veränderungen in der Verteilung der Unfallarten haben sich hierbei allerdings nicht ergeben. Die Berücksichtigung der Unfallursachen des mittelbar beteiligten Konfliktpartners am Unfall stellt demnach nur eine Ergänzung der sonst identischen Filterung der Überholunfälle dar, woraus sich ein Mehrwert für diese Untersuchung ergeben kann. Grundsätzlich zeigt Abbildung 3.2, dass über alle betrachteten Bundesländer hinweg die Überholunfälle mit Zusammenstößen mit anderen Fahrzeugen (Unfallarten 1 bis 5) ca. 70 \% der Überholunfälle ausmachen. Dabei kann davon ausgegangen werden, dass die Unfälle mit Zusammenstößen zweier Fahrzeuge meist folgenschwer enden, dies vorrangig bei entgegen gerichteten Fahrten. Die verbleibenden 30 \% der Überholunfälle sind Zusammenstöße mit dem Straßenseitenraum oder Kollisionen mit anderen Hindernissen auf der Fahrbahn.

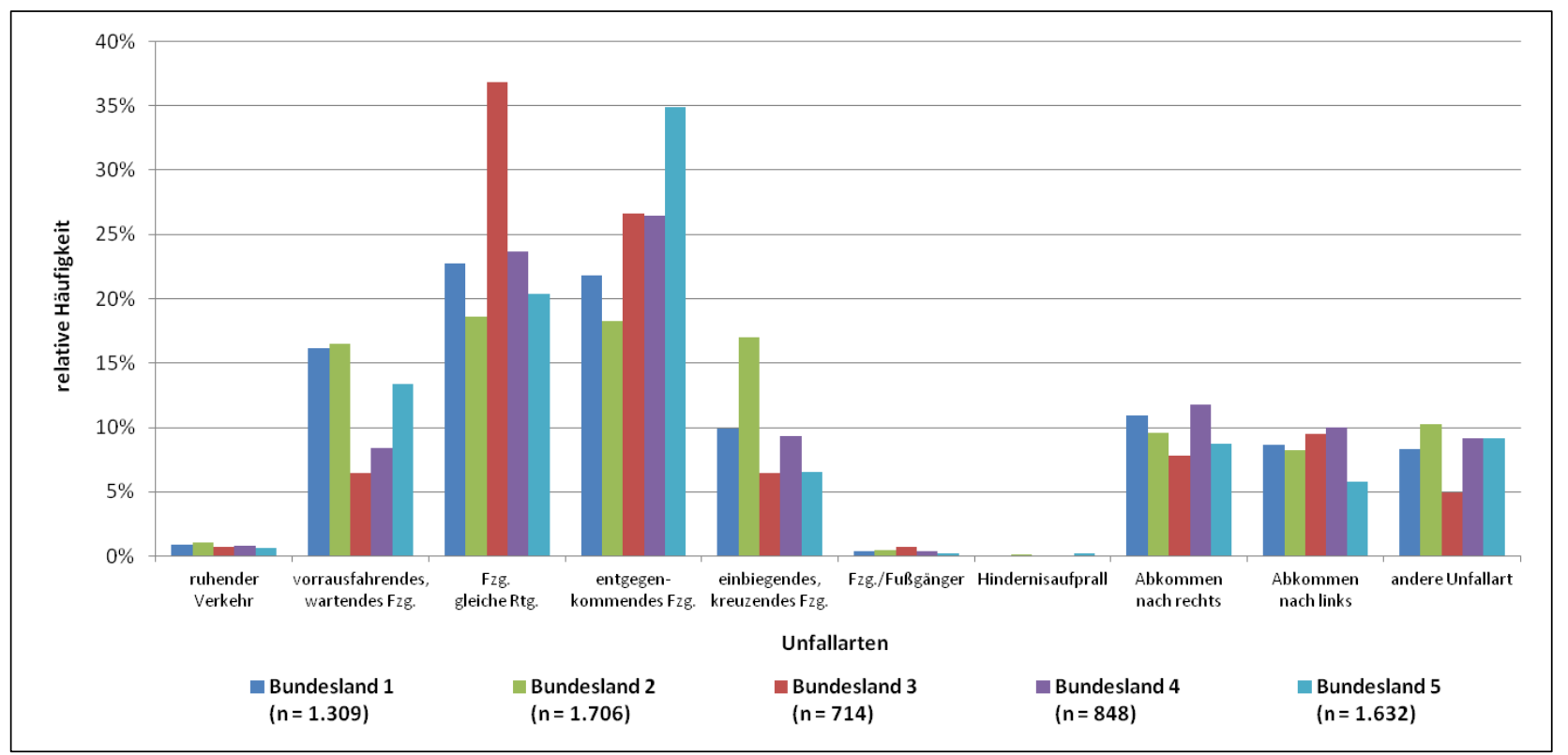

Abbildung 3.2: Unfallartenverteilung in Überholunfällen

Im folgenden Kapitel werden mit der vorstehend beschriebenen Datenbasis der Straßennetz- und Unfalldaten eine makroskopische Unfallanalyse sowie die Berechnung von Unfallkenngrößen durchgeführt. Diese Teiluntersuchung dient der Rangfolgeerstellung innerhalb der Untersuchungsstrecken, somit der Identifizierung von besonders mit Überholunfällen belasteten Landstraßenabschnitten und ist damit die Grundlage für die weiteren Bearbeitungsschritte der Netz- bzw. Detailanalyse. 


\subsection{Makroskopische Unfallanalyse}

\subsubsection{Berechnung der Unfallkenngrößen}

\subsubsection{Streckenbezogene Unfallkenngrößen}

Nach FGSV [2003b] lässt sich eine bewertende Beschreibung des Unfallgeschehens auf Streckenabschnitten nur mit Unfallkenngrößen erreichen, bei denen Bezüge zu streckenspezifischen Größen, wie zum Beispiel der Streckenlänge oder der Fahrleistung hergestellt werden. Mit Hilfe der Unfallkenngrößen soll eine Rangfolge der 500 unfallauffälligsten Untersuchungsstrecken erstellt werden, die für die Detailanalyse vorzubereiten sind. Für die Rangfolgeerstellung können theoretisch Unfallraten oder -dichten verwendet werden. In Verbindung dieser Größen mit den Unfallkosten, welche die Unfallanzahl mit den Unfallfolgen verknüpfen, ergeben sich Unfallkostenraten bzw. -dichten. Das Sicherheitspotential als Kenngröße für die vermeidbare Anzahl und Schwere von Unfällen kann aus der Differenz der tatsächlichen Unfallbelastung und der Grundunfallbelastung berechnet werden. Für die ermittelten Strecken ohne Verkehrsstärke können keine Unfallraten bzw. -kostenraten berechnet werden. Zudem lässt sich durch die nicht berechenbare Grundunfallkostendichte kein Sicherheitspotential ausweisen. Die Berechnungsgrundlagen können Anhang B entnommen werden. Für die Grundunfallkostenrate ist nach der ESN von 2003 nach Straßenkategorien zu unterscheiden. Allerdings existiert nur ein einheitlicher Wert für Außerortsstraßen (ohne Autobahn) unabhängig von deren Verbindungsfunktion. Eine stark unfallbelastete Bundesstraße erhält somit wegen der höheren Verkehrsstärke ein geringeres Sicherheitspotential als eine wenig unfallauffällige Landesstraße mit kleiner Verkehrsstärke [Weinert/Vengels, 2008]. Diese Aspekte sind bei der späteren Rangfolgeerstellung zu berücksichtigen. Es wird darauf hingewiesen, dass der Wert der Grundunfallkostenrate für diese Untersuchung generell nicht korrekt verwendet werden kann. Zum einen ist der Wert für die Unfallkategorien 1 bis 4 und 6 vorgesehen, auf die gemäß Tabelle 3.1 hier nicht in allen Bundesländern zurückgegriffen werden kann. Zum anderen wurde die Grundunfallkostenrate auf Grundlage des Gesamtunfallgeschehens von Außerortsstrecken berechnet und wird in dieser Untersuchung nur auf das Teilkollektiv der Überholunfälle angewendet. Eine Grundunfallkostenrate bezogen auf Überholunfälle wäre geringer. Somit kann eine vergleichende Rangfolge der unfallauffälligsten Untersuchungsstrecken über das Sicherheitspotential durch Verwendung der verfügbaren Grundunfallkostenrate nicht erstellt werden.

\subsubsection{Anpassung der Unfallkostensätze}

Im Merkblatt für die Auswertung von Straßenverkehrsunfällen sind in Abhängigkeit von der Unfallund Straßenkategorie verschiedene pauschale Unfallkostensätze angegeben, die in Unfalluntersuchungen zur Berechnung der volkswirtschaftlichen Verluste herangezogen werden können. Pauschale Unfallkosten haben den Nachteil, dass sie zeitliche Veränderungen im Unfallgeschehen und auch örtliche Abweichungen der Verunglücktenstruktur nicht berücksichtigen. Mittels angepasster Unfallkosten kann dieser Mangel behoben werden. Anpassung bedeutet hierbei, dass die Unfallkostensätze der Unfälle mit Personenschaden an die Verunglücktenstruktur angeglichen werden, wodurch die Anzahl der getöteten, schwerverletzten und leichtverletzten Unfallbeteiligten 
einbezogen wird. Somit werden mögliche Besonderheiten des Untersuchungsgebietes berücksichtigt, was mit pauschalen Unfallkostensätzen nicht möglich ist. In dieser Untersuchung soll die Verkehrssicherheit auf Teilen des Straßennetzes bewertet werden, demnach ist die indirekte Anpassung der Unfallkostensätze anzuwenden [FGSV, 2003b]. Die Berechnung der angepassten Unfallkostensätze kann in Anhang $B$ eingesehen werden. Für die Kostensätze der Verunglückten und Sachschäden bei Unfällen wurde, wie auch für die Grundunfallkostenraten der ESN, einheitlich der Preisstand 2000 verwendet. Die Ergebnisse der angepassten Unfallkostensätze können daher später mit den nach Bundesländern differenzierten Unfallkostensätzen in der ESN verglichen werden. Für den Zweck der Rangfolgeerstellung von auffälligen Untersuchungsstrecken mit Überholunfällen ist der Preisstand 2000 trotzdem angemessen. Die Anpassung der Unfallkostensätze für Unfälle mit Personenschaden wurde für alle identifizierten Unfälle auf den Untersuchungsstrecken sowie nur für das Teilkollektiv der Überholunfälle separat durchgeführt. Die Ergebnisse können in Tabelle 3.4 eingesehen und mit den Werten der ESN in Tabelle 3.5 verglichen werden.

\begin{tabular}{|c|c|c|c|c|c|c|}
\hline & Unfallkategorie & BL1 & BL2 & BL3 & BL4 & BL5 \\
\hline \multirow{2}{*}{$\begin{array}{c}\text { alle Unfälle } \\
\text { (Kategorie 1-4) }\end{array}$} & $\mathbf{U ( S P )}$ & 230.194 & 234.160 & 281.799 & 291.547 & 262.910 \\
\cline { 2 - 7 } & $\mathbf{U ( L V )}$ & 17.964 & 18.062 & 17.730 & 17.929 & 18.221 \\
\cline { 2 - 7 } & $\mathbf{U ( S S )}$ & 13.000 & 13.000 & 13.000 & 13.000 & 13.000 \\
\hline \multirow{2}{*}{$\begin{array}{c}\text { Überholunfälle } \\
\text { (Kategorie 1-4) }\end{array}$} & $\mathbf{U ( S P )}$ & 289.848 & 278.066 & 316.481 & 331.537 & 303.784 \\
\cline { 2 - 7 } & $\mathbf{U ( L V )}$ & 17.982 & 17.828 & 17.788 & 18.229 & 18.029 \\
\cline { 2 - 7 } & $\mathbf{U ( S S )}$ & 13.000 & 13.000 & 13.000 & 13.000 & 13.000 \\
\hline
\end{tabular}

Tabelle 3.4: Angepasste Unfallkostensätze [Euro/Unfall] - Preisstand 2000

\begin{tabular}{|c|c|c|c|c|c|c|}
\hline & Unfallkategorie & BL1 & BL2 & BL3 & BL4 & BL5 \\
\hline $\begin{array}{c}\text { alle Unfälle } \\
\text { (Kategorie 1-3) }\end{array}$ & $\mathbf{U ( S P )}$ & 240.000 & 230.000 & 295.000 & 275.000 & 250.000 \\
\cline { 2 - 7 } & $\mathbf{U ( L V )}$ & 18.000 & 18.000 & 18.000 & 18.000 & 18.000 \\
\hline
\end{tabular}

Tabelle 3.5: Unfallkostensätze der Bundesländer nach ESN [Euro/Unfall] - Preisstand 2000

Die Größenordnungen und auch die Schwankungen der Unfallkostensätze zwischen den einzelnen Bundesländern sind durchaus mit den angegebenen Werten der ESN vergleichbar. Somit scheint sich die Unfallschwere auf den Außerortsstraßen in den Bundesländern nicht wesentlich geändert zu haben. Bei Betrachtung der Unfallkostensätze für das Kollektiv der Überholunfälle wird erkennbar, dass diese in allen Bundesländern deutlich höhere Unfallkostensätze aufweisen. Dies kann als ein offensichtlicher Hinweis auf die besonders hohe Unfallschwere bei Überholunfällen verstanden werden.

\subsubsection{Schlussfolgerungen Rangfolgeerstellung}

Nach erfolgter Streckenzusammenfassung wegen kurzer Abschnittslängen wird für die weitere Bearbeitung auf Grundlage der bisherigen Erkenntnisse (vgl. Zwischenbericht) eine Filterung von 500 unfallauffälligen Untersuchungsstrecken anhand der Unfallkostendichte als Rangfolgekriterium empfohlen. Probleme der Rangfolgeerstellung bereiten Strecken mit geringer Länge und nur einem Überholunfall, was die Unfallkenngrößen verzerren kann. Von einer pauschalen Mindestlänge der Abschnitte ohne Berücksichtigung des Unfallgeschehens ist jedoch abzusehen. 
Stattdessen wird angeraten, alle Streckenabschnitte mit nur einem zufälligen, in einer makroskopischen Unfallanalyse ermittelten Überholunfall zu vernachlässigen. Das Untersuchungspotential an längeren Strecken mit mehr als nur einem Zufallsereignis wird das einer $600 \mathrm{~m}$ langen Strecke mit einem Unfall deutlich übersteigen. Bei Vernachlässigung der einmaligen, zufälligen Unfälle rücken in der Rangfolge bisher nicht betrachtete Untersuchungsstrecken nach vorn. Hierbei enthalten ist beispielsweise eine Strecke mit $4 \mathrm{~km}$ Länge und 5 Unfällen, die vorher unberücksichtigt geblieben wäre. Das Potential für eine spätere empirische Erhebung ist hier deutlich größer. Bei Löschung von Strecken mit nur einem Unfall vor der Streckenzusammenfassung wären viele Strecken unberücksichtigt geblieben. Die Argumentation, dass es sich bei drei hintereinanderliegenden Strecken mit jeweils einem Unfall ebenfalls um drei zufällige Ereignisse handelt und diese wie auch einzelne nicht zusammengefasste Abschnitte nicht berücksichtigt werden sollten, ist unzulässig. Bedingung der Zusammenfassung waren vergleichbare Streckencharakteristiken. Hier werden sich auch auf 3 hintereinanderliegenden Strecken die Überholsituation, der Überholdruck und die Unfallsituation in Bezug zum Überholvorgang nicht wesentlich ändern. Die Zufälligkeit mehrerer Unfälle wird somit ausgeschlossen.

Durch diese Filterung können 353 Unfälle anstelle von 296 Unfällen auf den 100 Strecken (Pilotuntersuchung Bundesland 1) betrachtet werden, was ebenfalls auf ein höheres Untersuchungspotential hindeutet. Zudem wird vermutet, dass sich auf längeren Untersuchungsstrecken ein größerer Überholdruck aufbauen kann, als es auf kurzen Strecken der Fall ist.

\subsubsection{Zusammenhänge der Überholunfälle zum Gesamtunfallgeschehen}

Für diese abschließende Betrachtung der Zusammenhänge des Kollektivs der Überholunfälle zum Gesamtunfallgeschehen werden nochmals alle Überholunfälle der Kategorien 1 bis 4 auf den gefilterten Untersuchungsstrecken berücksichtigt, ohne hierbei eine Mindestunfallanzahl vorzugeben.

Für diese Betrachtung werden die Unfallzahlen und die berechneten Unfallkenngrößen für Überholunfälle mit denen aller Unfälle (Kategorien 1 - 4) auf den gebildeten Streckenabschnitten überlagert. Für die Berechnung der Unfallraten, -kostenraten und des Sicherheitspotentials werden nur die Untersuchungsstrecken betrachtet, auf denen eine Verkehrsstärke als Berechnungsgrundlage vollständig vorliegt. Durch die Streckenzusammenfassung können teilweise Strecken mit DTV mit solchen ohne DTV zusammengefasst worden sein. Diese Untersuchungsabschnitte gilt es bei den drei von der Verkehrsstärke abhängigen Unfallkenngrößen zu vernachlässigen, da sich sonst Verzerrungen innerhalb der Berechnungsergebnisse ergeben können. Hierbei würden sich die Unfallzahlen bzw. die Unfallkosten über beide Teilabschnitte summieren, für die Bezugsgrößen stehen aber nur Werte für einen der Abschnitte zur Verfügung, was die Kennzahlen unberechtigt erhöht. Die Diagramme der Verteilungen der einzelnen Unfallkenngrößen sind in Anhang C dargestellt.

Bei den Diagrammen bzw. Vergleichen auf Basis der Unfallanzahl wie der Unfallrate und -dichte befinden sich erwartungsgemäß keine Punkte oberhalb der Winkelhalbierenden des dargestellten Quadranten, da es sich beim Kollektiv der Überholunfälle lediglich um ein Teilkollektiv aller Unfälle handelt. Hierbei kann jedoch ein Grenzfall auftreten, bei dem alle Unfälle auf einem Untersu- 
chungsabschnitt durch Zusammenhänge zu einem Überholvorgang entstanden sind. Hierbei handelt es sich jedoch um einen Ausnahmefall (3\% aller Untersuchungsstrecken). Des Weiteren ist anzumerken, dass es sich bei diesen Abschnitten zu 90 \% um Strecken mit nur einem zufälligen Unfallereignis handelt.

Bei den Unfallkenngrößen auf Basis der Unfallkosten (UKR, UKD, SIPO) können vereinzelt Punkte oberhalb der Winkelhalbierenden auftreten. Grund hierfür ist der höhere verwendete Unfallkostensatz für Überholunfälle (vgl. Tabelle 3.4). Allerdings handelt es sich auch hier nur um einen Ausnahmefall, bei dem entweder die Unfallanzahl in beiden Kollektiven gleich ist oder bei allen Unfällen lediglich ein Unfall mit geringerer Unfallschwere mehr auf dem Abschnitt geschehen ist. Der Einfluss dieses Aspektes auf die Zusammenhänge zwischen den Überholunfällen und dem Gesamtunfallgeschehen wird dennoch als gering angesehen.

Für die einzelnen Diagramme wurden Regressionsgeraden berechnet. Die angegebenen Bestimmtheitsmaße von maximal 0,31 lassen allerdings keine Schlussfolgerungen auf Zusammenhänge zwischen beiden Unfallkollektiven zu. Demnach kann bei einem bekannten Unfallgeschehen auf einer Landstraße nicht auf die Sicherheit bzw. Unsicherheit von Überholmanövern geschlussfolgert werden. Auch bei der Verwendung von polynomischen Regressionsfunktionen konnten keine wesentlich besseren Bestimmtheitsmaße vorgefunden werden, weshalb offensichtlich zwischen beiden untersuchten Unfallkollektiven keine bzw. nur äußerst geringe Abhängigkeiten vorhanden sind. Die erhöhte Streuung lässt demzufolge keine weiteren Schlussfolgerungen zu.

\subsubsection{Auswahl von 500 unfallauffälligen Untersuchungsstrecken}

Vor der abschließenden Rangfolgeerstellung von insgesamt 500 Untersuchungsstrecken gilt es die Wertebereiche der Unfallkostendichten innerhalb der 100 unfallauffälligsten Strecken pro Bundesland zu überprüfen. Ergeben sich hier starke Abweichungen der Unfallkenngrößen muss gegebenenfalls von einer Gleichverteilung der 500 Untersuchungsstrecken über alle 5 Bundesländer abgesehen werden. Zu bedenken ist zudem, dass die Anteile von Strecken mit bestimmten Unfallkostendichten stark von der Gesamtzahl der auffälligen Untersuchungsstrecken im jeweiligen Bundesland abhängen. Bei der Überprüfung werden sowohl die Werte vor als auch nach der Vernachlässigung von Untersuchungsstrecken mit einem zufälligen Unfall (vgl. Kapitel 3.3.1.3) ausgewiesen. Die Ergebnisse sind in Tabelle 3.6 dargestellt.

\begin{tabular}{|c|c|c|}
\hline & $\begin{array}{c}\text { UKD mit einzelnen, zufälligen } \\
\text { Unfällen }[1.000 € /(\mathrm{km} * \mathrm{a})]\end{array}$ & $\begin{array}{c}\text { UKD ohne einzelne, zufällige } \\
\text { Unfälle }[1.000 € /(\mathrm{km} \text { a })]\end{array}$ \\
\hline BL1 & 28,74 & 23,16 \\
\hline BL2 & 30,13 & 25,67 \\
\hline BL3 & 25,20 & 12,97 \\
\hline BL4 & 26,44 & 21,29 \\
\hline BL5 & 37,95 & 31,25 \\
\hline Differenzen & $\mathbf{1 , 2 4 - 1 2 , 7 6}$ & $\mathbf{8 , 3 2}-\mathbf{1 8 , 2 7}$ \\
\hline
\end{tabular}

Tabelle 3.6: UKD des 100. Rangfolgeplatzes im jeweiligen Bundesland 
Mit Ausnahme von Bundesland 5 sind die Differenzen zwischen den einzelnen Schwellenwerten der Unfallkostendichten vor Vernachlässigung von einzelnen Unfällen gering und lassen eine Abkehr von der Gleichverteilung der Untersuchungsstrecken nicht zwangsläufig erwarten. Durch die Vernachlässigung von Untersuchungsstrecken mit einzelnen Zufallsereignissen ergeben sich allerdings deutliche Verschiebungen innerhalb der Unfallkenngrößen. Werden hierbei die Differenzen der Schwellenwerte betrachtet, so ist eine Gleichverteilung von Untersuchungsstrecken über alle Bundesländer im Untersuchungsgebiet nicht mehr vertretbar. Die Rangfolge der 500 unfallauffälligsten Untersuchungsstrecken ist demzufolge über die Unfallkostendichte ohne Berücksichtigung einer Gleichverteilung zu erstellen.

Als Ergebnis der Unfallkenngrößenberechnung und der Festlegungen zur Rangfolgeerstellung konnten die in Anhang D dargestellten, abschließend identifizierten 500 mit Überholunfällen auffälligsten Untersuchungsstrecken ermittelt werden. Diese bilden die Grundlage für die weiteren Arbeitsschritte der Netzanalyse sowie der folgenden Detailanalyse.

\subsubsection{Abschließende Betrachtungen zur Rangfolge}

In den nachstehenden Abbildungen sind die Verteilungen der 500 (Erhebung der verkehrsrechtlichen Anordnungen), 100 (GPS-Datenerhebung, Nachtrassierung und Sichtweitenanalyse) sowie der 50 (Verkehrsverhaltensanalyse) ersten Untersuchungsstrecken der Rangfolge auf die einzelnen 5 Bundesländer dargestellt.
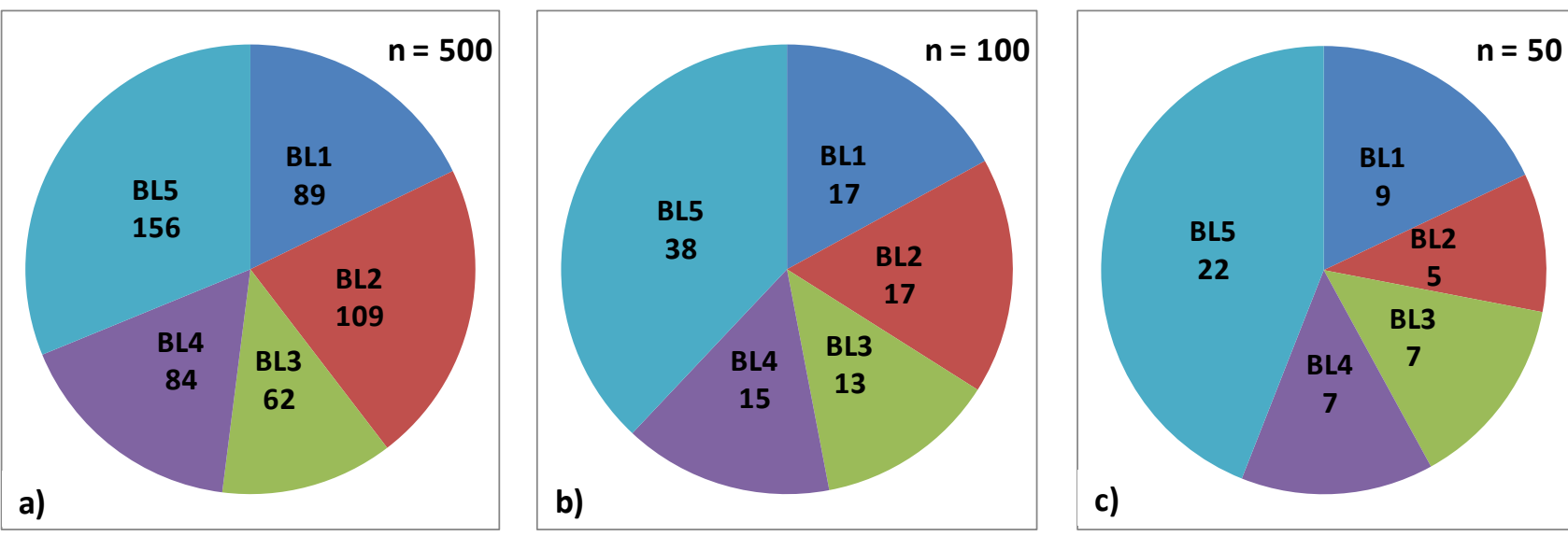

Abbildung 3.3: Anteil der Bundesländer an den Untersuchungsstrecken

Bei der Verknüpfung der Untersuchungsstrecken mit den unterschiedlichen Unfallzahlen und -schweren sind Verteilungen entstanden, die sich nicht ausschließlich mit der Größe der Bundesländer bzw. der Straßennetze begründen lassen, allerdings an diese Merkmale angelehnt sind. Es wird deutlich, dass sich mit zunehmender Detaillierung der geplanten Untersuchung die Verteilungen deutlich verschieben. An der Rangfolgeerstellung (vgl. vorheriges Kapitel) soll aber zumindest für den Teil der Netzanalyse (Abbildung $3.3 \mathrm{a}$ ) und b)) festgehalten werden.

Lediglich bei der anschließenden Detailuntersuchung ist von der Rangfolge der 50 Untersuchungsstrecken abzusehen. Des Weiteren wird darauf hingewiesen, dass sich aufgrund von identifizierten Baumaßnahmen die Verteilung bzw. Rangfolge der ersten 50 Strecken während der De- 
tailanalyse noch verändern kann. Nach den Streckenbefahrungen können Hinweise auf größere Baumaßnahmen identifiziert werden, was somit bei geändertem Verkehrsverhalten im Vergleich zum zugrunde gelegten Untersuchungszeitraum eine nachträgliche Anpassung der Rangfolge zur Folge haben wird. Bei größeren Baumaßnahmen (beispielsweise bei Neubau von Ortsumgehungen oder Trassenverlegung) unterliegt das Verkehrsverhalten auf einem Untersuchungsabschnitt nicht mehr den verkehrlichen Randbedingungen, durch welche die Unfälle im Untersuchungszeitraum entstanden sind. Demzufolge wird eine gegenwärtig durchzuführende Verkehrsverhaltensanalyse auf einigen Strecken nicht mehr sinnvoll sein. Dagegen können aber die Strecken für die makroskopische Unfallanalyse sowie für die Trassierung und Sichtweitenanalyse weiterhin verwendet werden, da sich diese Streckenmerkmale im Vergleich zum Untersuchungszeitraum nicht verändert haben. Außerdem sollte die Entscheidung für oder gegen die Untersuchungsstrecken in der Detailanalyse nicht von Unfallkostendichten abhängig gemacht werden, die sich lediglich im Bereich von Zehnteln oder gar Hundertsteln unterscheiden. Für die Anpassung der Rangfolge bzw. Auswahl der Untersuchungsstrecken für die Detailanalyse wird eine Clusterung innerhalb der ersten 100 unfallauffälligen Abschnitte (Nachtrassierung) über verschiedene Streckencharakteristiken (z.B. Entwurfssituation und Verkehrsaufkommen) sowie die Unfallsituation zu Hilfe genommen.

Aufgabe der weiteren Bearbeitungsschritte ist es, die Zusammenhänge des Unfallgeschehens durch Überholvorgänge mit den betrieblichen und baulichen Merkmalen der Untersuchungsstrecken herzustellen und auszuwerten. Auf den ausgewählten 500 Untersuchungsstrecken werden in der weiteren Netzanalyse die angeordneten Überholverbote bzw. verkehrsrechtlichen Anordnungen (z.B. Geschwindigkeitsbeschränkungen) durch Streckenbefahrungen erhoben. Hierdurch lässt sich das Unfallgeschehen in Abhängigkeit der angeordneten Überholverbote analysieren. Des Weiteren werden für eine Auswahl von 100 Untersuchungsstrecken erhobene Trassierungsdaten in Form von geografischen Punktfolgen mit einer Entwurfssoftware nachtrassiert. Ziel dieses Arbeitsschrittes ist die Ermittlung von Strecken- und Sichtweitenbändern, die mit dem Unfallgeschehen überlagert werden sollen, um weitere Hinweise auf unfallbegünstigende Streckenmerkmale bekommen zu können. Nach Abschluss der Netzanalyse kann mit der Detailanalyse bzw. Verkehrsverhaltensanalyse auf 50 Untersuchungsstrecken begonnen werden, um Hinweise darüber zu bekommen, in welchen Streckenabschnitten Überholungen überhaupt stattfinden. Hierbei soll zwischen Abschnitten mit bzw. ohne Überholmöglichkeiten differenziert und die Zusammenhänge der Überholanzahl zum DTV, Schwerverkehrsanteil und Zeitlückenverteilung im Gegenverkehrsstrom hergestellt werden. 


\subsection{Analyse der verkehrsrechtlichen Randbedingungen}

In diesem Kapitel wird die Erhebung und Analyse der verkehrlichen Anordnungen auf den Untersuchungsstrecken beschrieben. Es gilt hierbei die Zusammenhänge der verkehrsrechtlichen Maßnahmen auf den 500 unfallauffälligsten Untersuchungsstrecken und deren Unfallgeschehen herzustellen, um einen ersten Einblick in die Abhängigkeiten zwischen Überholunfällen und den Streckenmerkmalen (angeordnete Überholverbote und Geschwindigkeitsbeschränkungen) bekommen zu können.

\subsubsection{Datenerhebung}

Bei dieser makroskopischen Streckenanalyse wird mit Hilfe des fachgebietseigenen Messfahrzeuges eine Befahrung aller in Anhang D dargestellten Untersuchungsstrecken durchgeführt. Zur Vorbereitung der Messfahrten werden die Untersuchungsstrecken mit Anfangs- und Endpunkt aus dem GIS-System in einen Plan der Örtlichkeiten übernommen, um eine eindeutige Befahrung sicherstellen zu können. Des Weiteren werden die 100 ersten Untersuchungsstrecken der Rangfolge gekennzeichnet, um parallel die Erhebung der GPS-Punktfolgen für die in Kapitel 3.5 folgende Nachtrassierung zu ermöglichen.

Das Fahrzeug des Fachgebietes verfügt über eine Schnittstelle mit dem fahrzeugeigenen Datenbus (CAN-Bus). Nach Beginn der Messungen werden die fahrzeuginternen Daten (Z.B. Zeitstempel und gefahrene Geschwindigkeit) in einer Datei abgespeichert sowie synchron dazu Frontund Heckvideos der Strecken aufgezeichnet. Des Weiteren wird während der Befahrung eine zweite Protokolldatei der Strecke erstellt. In dieser wird durch die Bedienung von Schaltflächen eines Touchscreens (siehe Abbildung 3.4) im Fahrzeug die Speicherung der entsprechenden vorkommenden verkehrsrechtlichen Merkmale während der Fahrt vorgenommen. Durch die spätere Verknüpfung der Protokolldatei mit den erhobenen Fahrzeugdaten kann die Stationierung und somit die Position der einzelnen Merkmale auf dem befahrenen Streckenabschnitt berechnet werden. Die parallel erhobenen Videos ermöglichen jederzeit eine Prüfung der aufgenommen Daten.

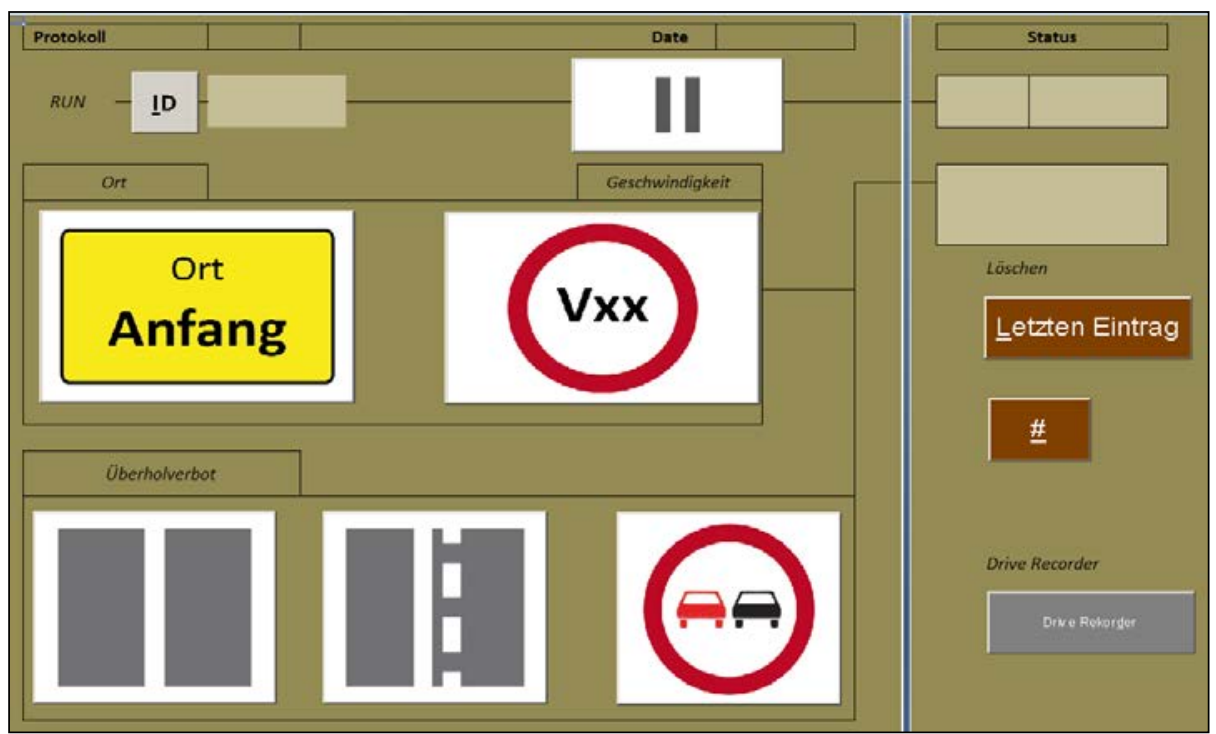

Abbildung 3.4: Datenerhebung Netzanalyse 
Bei der Streckenbefahrung werden folgende verkehrsrechtliche Anordnungen erhoben:

- Lage der Ortstafeln zur Unterscheidung von innerorts/außerorts

- freigegebene Streckenabschnitte

- Überholverbote durch Beschilderung (StVO Zeichen 276)

- Überholverbote durch Markierung

- $\quad$ beidseitiges Überholverbot (StVO Zeichen 295)

- $\quad$ einseitiges Überholverbot (StVO Zeichen 296)

- Geschwindigkeitsbeschränkungen (StVO Zeichen 274).

Zur späteren besseren Orientierung wird die Messung an mindestens einem Netzknoten gestartet oder beendet. Häufig befinden sich die Netzknoten innerhalb geschlossener Ortschaften. Die Erhebung der Ortstafeln dient somit zur genauen Abgrenzung der Untersuchungsstrecken von dem gesamten befahrenen Netzabschnitt. Bei der Erhebung der Überholverbote wird zwischen Beschilderung und Markierung unterschieden. Die angeordneten Überholverbote sind zudem nach vorhandenen Geschwindigkeitsbeschränkungen zu differenzieren. In der makroskopischen Streckenanalyse soll hierbei lediglich zwischen unbeschränkten und beschränkten Abschnitten unterschieden werden. Bei Geschwindigkeitsbeschränkungen außerhalb geschlossener Ortschaften handelt es sich überwiegend um $70 \mathrm{~km} / \mathrm{h}$ an Knotenpunkten sowie $80 \mathrm{~km} / \mathrm{h}$ als Streckengeschwindigkeit. Eine Unterscheidung dieser beiden Geschwindigkeiten für die Beurteilung der Örtlichkeiten scheint hier nicht zielführend. Weitere Geschwindigkeitsbeschränkungen (60 bzw. 90 km/h) treten im Außerortsbereich nur äußerst selten auf, weswegen in diesem ersten Bearbeitungsschritt eine Unterscheidung der Geschwindigkeit nach freigegeben (100 km/h auf Landstraßen) oder beschränkt als ausreichend angesehen wird. Für die auf die Trassierung folgende Sichtweitenanalyse ist die Bestimmung eines Geschwindigkeitsbandes unumgänglich. Zur Bezifferung der Höhe der Geschwindigkeitsbeschränkungen wird hierbei später auf die erhobenen Front- bzw. Heckvideos der Befahrungen zurückgegriffen.

Bei der Auswertung der Protokolldatei sind zudem die Überlagerungen der verschiedenen verkehrsrechtlichen Anordnungen zu berücksichtigen und auszuweisen. Für diese Analyse ist eine Matrix zu erstellen, welche die angeordneten Überholverbote (keine / nur Markierung / nur Beschilderung / Beschilderung + Markierung / halbe Markierung) und die Geschwindigkeitsbeschränkungen (ja / nein) beinhaltet und die Überlagerungen erkenntlich macht. Hierbei können erste Aussagen darüber getroffen werden, welche rechtlichen Überholmöglichkeiten sich auf den Untersuchungsstrecken bzw. den hier gefilterten unfallauffälligen Abschnitten bieten.

Im weiteren Verlauf dieser Analyse werden die einzelnen identifizierten Überholunfälle über die in der Unfalldatenbank enthaltene Stationierung den verschiedenen Bereichen von rechtlichen Anordnungen zugewiesen, um Tendenzen über Unfallauffälligkeiten nicht nur auf Basis der Gesamtstrecke sondern auch kleinteilig nach den erhobenen Bereichen von verkehrsrechtlichen Maßnahmen feststellen zu können. Die Ergebnisse dieser Bearbeitungsschritte werden in den folgenden Kapiteln dargestellt. 


\subsubsection{Verkehrsrechtliche Merkmale der Untersuchungsstrecken}

Im Rahmen der Streckenbefahrungen wurden die in Tabelle 3.7 dargestellten insgesamt $2.235 \mathrm{Ki}-$ lometer auf den 500 unfallauffälligsten Untersuchungsstrecken - außerorts, einbahnig, zweistreifige Landstraße, demzufolge Nettostreckenlänge - analysiert.

\begin{tabular}{|c|c|}
\hline & Nettostreckenlänge [km] \\
\hline Bundesland 1 & 434 \\
\hline Bundesland 2 & 443 \\
\hline Bundesland 3 & 315 \\
\hline Bundesland 4 & 405 \\
\hline Bundesland 5 & 638 \\
\hline \hline Summe & $\mathbf{2 . 2 3 5}$ \\
\hline
\end{tabular}

Tabelle 3.7: Befahrene Untersuchungsstrecken

Die Ergebnisse der Matrixdarstellung der verkehrsrechtlichen Randbedingungen der Untersuchungsstrecken sind differenziert nach den fünf Bundesländern in Anhang $E$ einsehbar. Nachstehende Abbildung enthält eine überschaubare Zusammenfassung der Matrizen in Bezug zu den rechtlichen Überholmöglichkeiten.

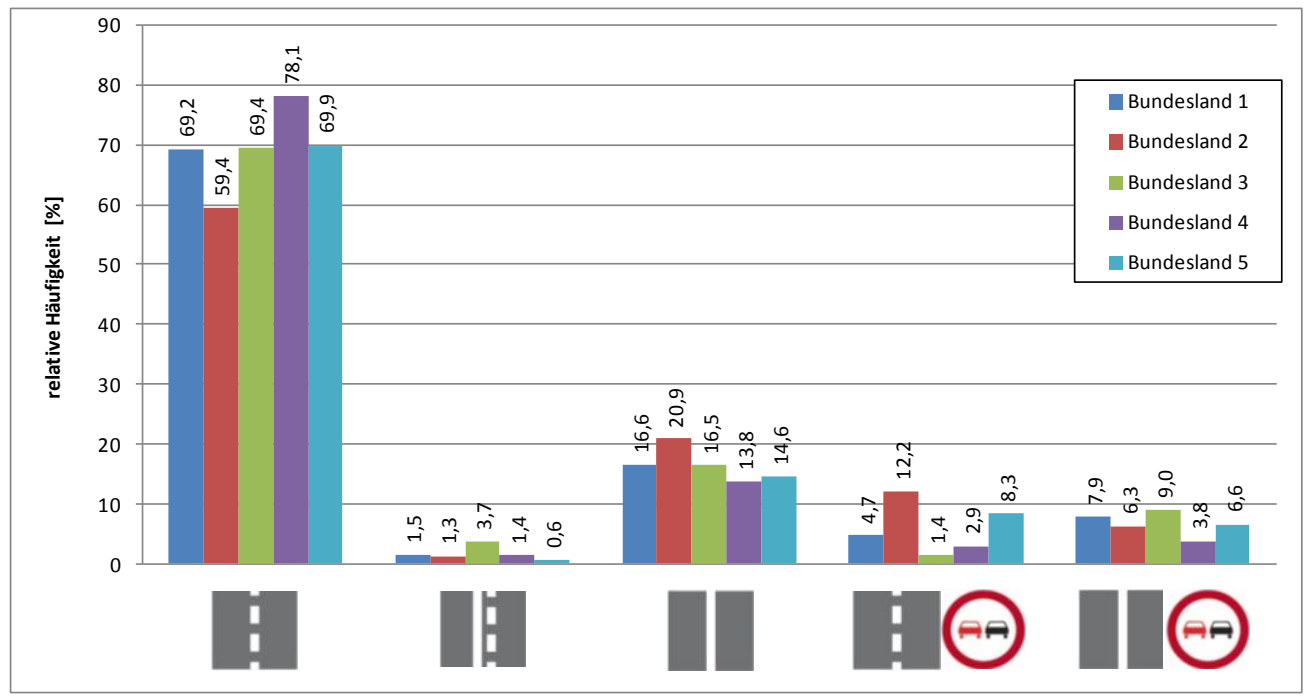

Abbildung 3.5: Rechtliche Überholmöglichkeiten im Untersuchungsgebiet

Es wird deutlich, dass sich die Verteilungen zwischen den einzelnen Bundesländern nicht wesentlich unterscheiden. Einen vergleichsweise hohen Anteil von freigegebenen Streckenabschnitten findet man in Bundesland 4. In Bundesland 2 wird dagegen ein auffallend hoher Anteil von rechtlichen Restriktionen deutlich. Die grundlegenden Tendenzen zwischen freigegebenen Streckenteilen und angeordneten Überholverboten sind allerdings in allen fünf untersuchten Bundesländern sehr ähnlich und die Zusammenhänge offensichtlich.

Insgesamt zeigt sich, dass im Durchschnitt 69,1\% des 2.235 Kilometer langen befahrenen Netzes nicht über ein markiertes oder beschildertes Überholverbot verfügen. Demzufolge sind auf rund $70 \%$ des untersuchten Netzes keine rechtlichen Restriktionen in Bezug zum Überholen vorhanden. Einen äußerst kleinen Anteil von Restriktionen stellen die einseitigen Überholverbote (StVO 
Zeichen 296) dar. Diese werden überwiegend vor bzw. hinter Kurven, Kuppen oder Knotenpunktbereichen vorgesehen, um das Überholen für eine Fahrtrichtung vorzeitig freizugeben. Insgesamt ist dieses Zeichen aber dennoch selten aufgetreten. Ist dagegen ein beidseitiges Überholverbot angeordnet, so handelt es sich zu $56 \%$ um eine reine Markierung, zu $22 \%$ um eine reine Beschilderung und wiederum zu $22 \%$ um eine Kombination aus Markierung und Beschilderung. Demnach ist die offensichtlich bevorzugte verkehrstechnische Maßnahme zur Verhinderung von Überholvorgängen die Markierung. Schilder sind dagegen eher selten und werden häufig nur in Verbindung mit der Markierung der Fahrbahn durch eine durchgehende Fahrstreifenbegrenzungslinie angeordnet.

Letztgenannte Kombination stellt hierbei einen Sonderfall dar. Die Verwaltungsvorschriften zur StVO [2009] geben zu Zeichen 276 folgendes vor: „Wo das Überholen bereits durch Zeichen 295 unterbunden ist, darf das Zeichen nicht angeordnet werden“. An dieser Stelle ist allerdings die Frage zu stellen, warum es sich trotz dieser Festlegungen bei immerhin fast $25 \%$ aller Überholverbote um eine derartige Kombination aus Markierung und Beschilderung handelt bzw. wie diese Regelung entstanden ist. Eine Vielzahl von Knotenpunkten sind mit Zeichen 276 und einer Markierung versehen, dennoch ist diese Kombination auch häufig auf der freien Strecke zu finden. Bei den Messfahrten in Bundesland 1 und Bundesland 5 sind verkehrsrechtliche Anordnungen aufgefallen, bei denen genau am Ende einer Fahrstreifenbegrenzung der Anfang eines Überholverbotes durch Zeichen 276 für den folgenden Abschnitt beschildert war. Dennoch ist auf den dortigen Untersuchungsstrecken zu einem Anteil von nahezu 10 Prozent diese Kombination festzustellen gewesen.

Diese Festlegung dient dem Grundsatz der StVO, dass keine Dopplungen von rechtlichen Anordnungen auftreten dürfen, möglicherweise somit auch zur Minimierung des Schilderwaldes auf deutschen Straßen. Dennoch muss der Sinn des Absatzes in den Verwaltungsvorschriften in Frage gestellt werden, vor allem weil diese Kombination in mehreren Empfehlungen zur Erhöhung der Landstraßensicherheit direkt ausgewiesen wird (vgl. FGSV, 2001a sowie Hecht, 2012).

Die ursprünglich vermuteten Unterschiede einzelner rechtlicher Anordnungen zwischen den einzelnen Bundesländern im Untersuchungsgebiet haben sich bestätigt. Hierbei ist allerdings unklar, ob sich die Verteilungen aufgrund von unterschiedlichen Örtlichkeiten (begründet durch die Streckenauswahl) oder aber wegen verschiedener Anwendungen der StVO in den untersuchten Bundesländern unterscheiden.

Grundlegende Erkenntnis der erhobenen Merkmale ist, dass auf einem Großteil der in der Rangfolge der unfallauffälligsten Untersuchungsstrecken keine Überholverbote (70\% Streckenanteil) angeordnet sind. Dies spricht für eine Häufung von Überholunfällen auf Strecken ohne rechtliche Restriktionen, demnach dort, wo Überholen möglich sein sollte. An dieser Stelle gilt es allerdings zu klären, ob die fehlenden rechtlichen Restriktionen aufgrund der vorhanden entwurfstechnischen Überholsichtweite überhaupt vertretbar sind (Bereich Infrastruktur). Hier gilt es durch eine Analyse der Infrastruktur (Nachtrassierung und Sichtweitenanalyse, vgl. Kapitel 3.5) gegenüberzustellen, welche Überholsichtweiten vorhanden sind und welche dagegen erforderlich wären. Sind diese 
Sichtweiten vorhanden und ist dennoch eine Unfallauffälligkeit entstanden, so haben überwiegend verkehrliche Randbedingungen zur Unfallentstehung beigetragen (Bereich Verkehrsteilnehmer). Möglicherweise kann ein erhöhtes Verkehrsaufkommen auch auf langen Geraden zu kritischen, risikobehafteten Überholungen und im schlimmsten Fall zu Überholunfällen führen, wenn sich über längere Zeit ein gewisser Überholdruck angestaut hat, der durch die danach höhere Risikoakzeptanz bei einer vermeintlich ausreichenden Zeitlücke versucht wird abzubauen. Auf den verbleibenden 30 \% Streckenanteil ist zu klären, wie die Wirksamkeit von bereits vorhandenen Überholverboten erhöht werden kann, da die Unfälle durch die rechtlichen Anordnungen theoretisch vermeidbar sein sollten. Zu berücksichtigen ist an dieser Stelle, dass die Verkehrsbehörde oftmals erst reaktiv auf die vorherrschende Verkehrs- bzw. Unfallsituation Überholverbote anordnet.

Eine Zusammenfassung der angeordneten Geschwindigkeitsbeschränkungen liefert nachstehende Abbildung.

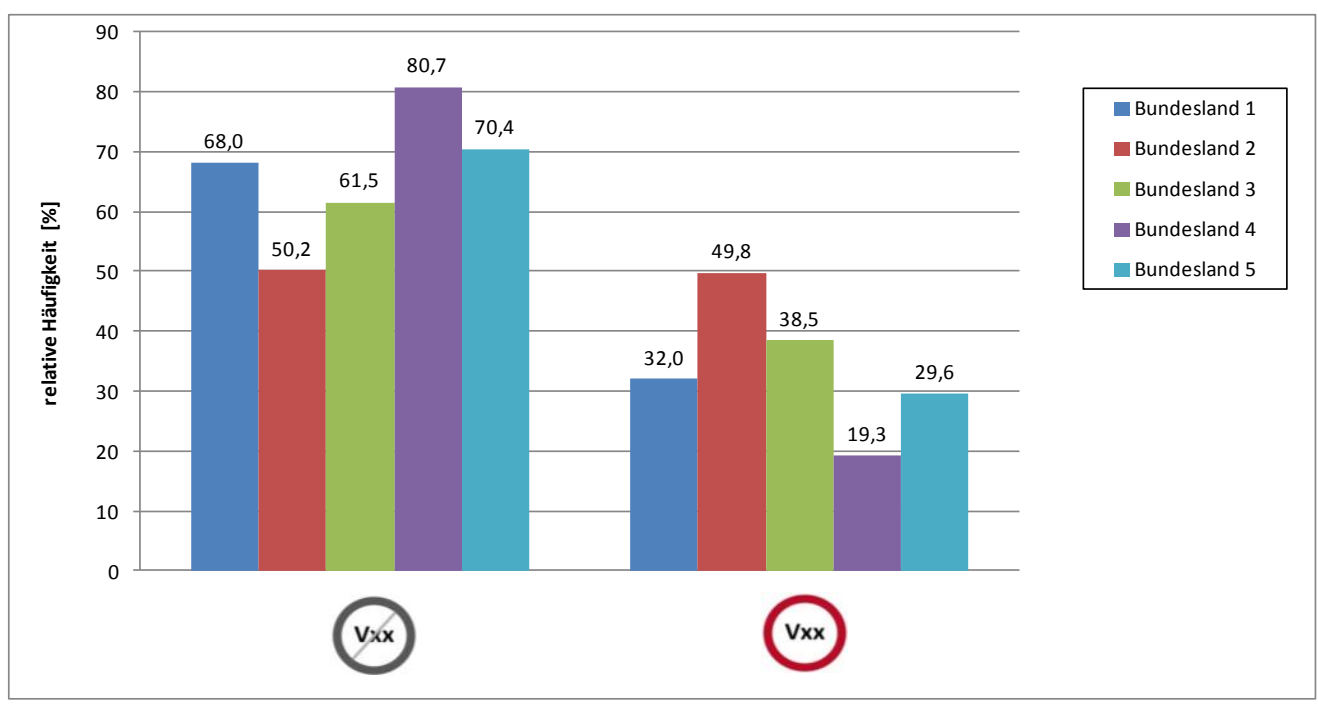

Abbildung 3.6: Angeordnete Geschwindigkeitsbeschränkungen

Bei den Anordnungen von Geschwindigkeitsbeschränkungen konnten mit einem durchschnittlichen Anteil von 66,6 \% freigegebene Streckenabschnitte ermittelt werden. In Bezug auf die zulässige Höchstgeschwindigkeit gibt es zwei unterschiedliche Vermutungen zu den Zusammenhängen zur Entstehung von Überholunfällen. Zum einen nimmt auf freigegebenen Streckenabschnitten die Geschwindigkeitsstreuung zu, was viele Überholungen und ggf. auch Überholunfälle hervorrufen kann, zum anderen werden auf Strecken mit Geschwindigkeitsbeschränkungen (Geschwindigkeitsstreuung geringer) möglicherweise Überholungen bzw. Überholunfälle durch eine unangepasste Geschwindigkeitswahl von zügigen Fahrzeugführern provoziert, da auf beschränkten Streckenabschnitten der Anteil langsam fahrender Fahrzeuge neben den Schwerverkehren (also potentielle Hindernisfahrzeuge) weiter zunimmt. Der Vollständigkeit halber ist eine zusammenfassende, vergleichende Darstellung aller erhobenen rechtlichen Anordnungen und somit Bestandteile der in Anhang $\mathrm{E}$ dargestellten Matrizen in Abbildung 3.7 einzusehen. 


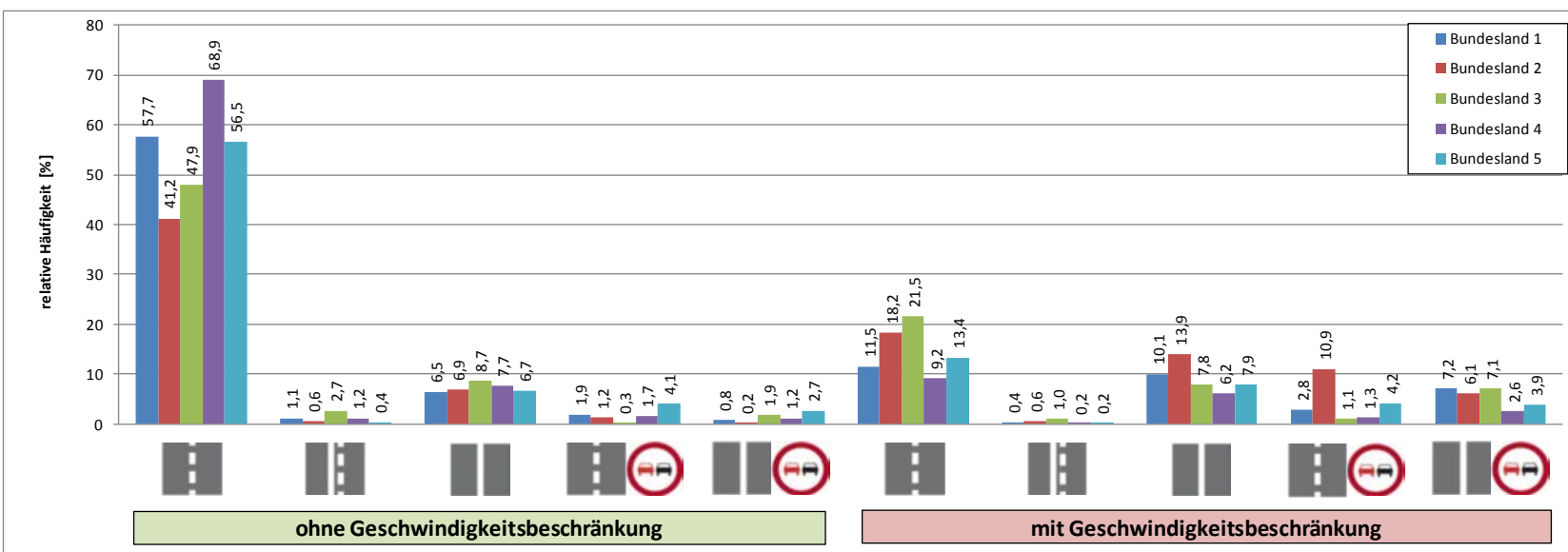

Abbildung 3.7: Zusammenfassung der Matrixinhalte - Streckenanteile

Diese bisherigen Betrachtungen wurden nur auf Basis der Gesamtstrecke durchgeführt und lassen ohne detaillierte Kenntnisse zur genauen Unfallposition keine weiteren Schlüsse zu. Die Zuordnung der Überholunfälle zu den einzelnen Teilabschnitten rechtlicher Anordnungen im nachfolgenden Kapitel wird hier weitere Erkenntnisse liefern.

\subsubsection{Unfallgeschehen in Abhängigkeit der verkehrsrechtlichen Anordnungen}

Für die Unfallzuordnung zu den Streckenteilen mit verschiedenen verkehrsrechtlichen Anordnungen wurden die bei der Streckenbefahrung identifizierten Bereiche mit den georeferenzierten Unfalldaten über die Stationierung miteinander verknüpft. Wegen notwendigen Umrechnungen zwischen der Stationierung des Systems der Netzknoten und den eigenen Streckenbefahrungen war eine manuelle Unfallzuordnung unumgänglich.

Bei der manuellen Zuordnung aller zu den 500 Untersuchungsstrecken gehörenden Überholunfälle ist vorrangig ein Problem aufgetreten und hervorzuheben. Bei Betrachtung der Untersuchungsstrecken gab es zwischen den Nettostreckenlängen der eigenen Befahrungen und denen der Straßeninformationsbank teilweise deutliche Unterschiede. Grund für diese Differenzen sind Verschiebungen von Ortstafeln, welche bei Berechnung der Nettostreckenlänge zu Unterschieden führen. Bei der Bearbeitung sind Ortstafeln aufgefallen, welche tatsächlich bis zu 800 Meter vom Standort entfernt sind, der in der Straßeninformationsbank festgehalten ist. Diese Differenzen mussten bei der Unfallzuordnung geprüft und beseitigt werden. Idealerweise war durch den vorhandenen Bezugspunkt der Messfahrten zu mindestens einem Netzknoten (vgl. Kapitel 3.4.1) ein fester Orientierungspunkt im Straßennetz vorhanden. Die angesprochenen Differenzen verdeutlichen die Notwendigkeit, Straßeninformationsbanken zu pflegen. Durch die Fehler der Straßeninformationsbank mussten in seltenen Fällen Überholunfälle aus dem Untersuchungskollektiv der 500 Strecken entfernt werden, da sie sich nicht mehr auf einer Untersuchungsstrecke sondern tatsächlich im Innerortsbereich ereignet haben.

Die Ergebnisse der insgesamt 1.557 zuordenbaren Überholunfälle sind unterschieden nach den 5 Bundesländern in Anhang $F$ einzusehen. Eine überschaubare Zusammenfassung kann den nachfolgenden 3 Abbildungen entnommen werden. 


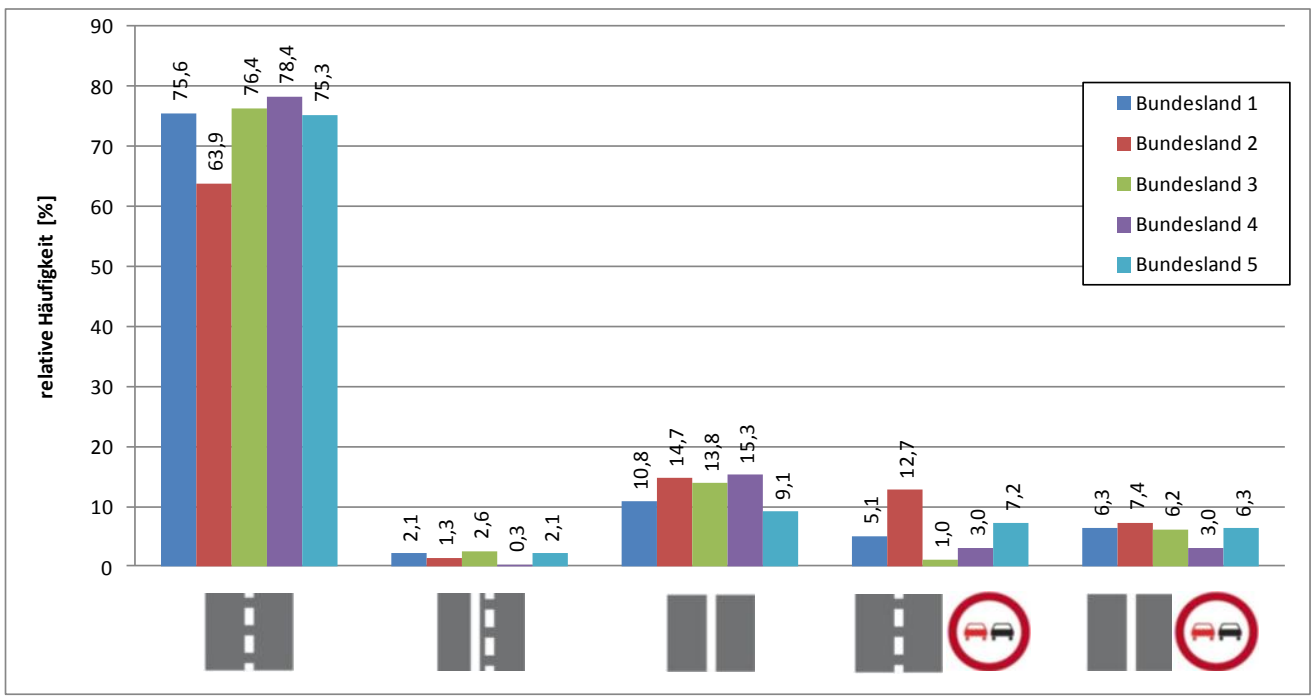

Abbildung 3.8: Unfallzuordnung zu Streckenmerkmalen

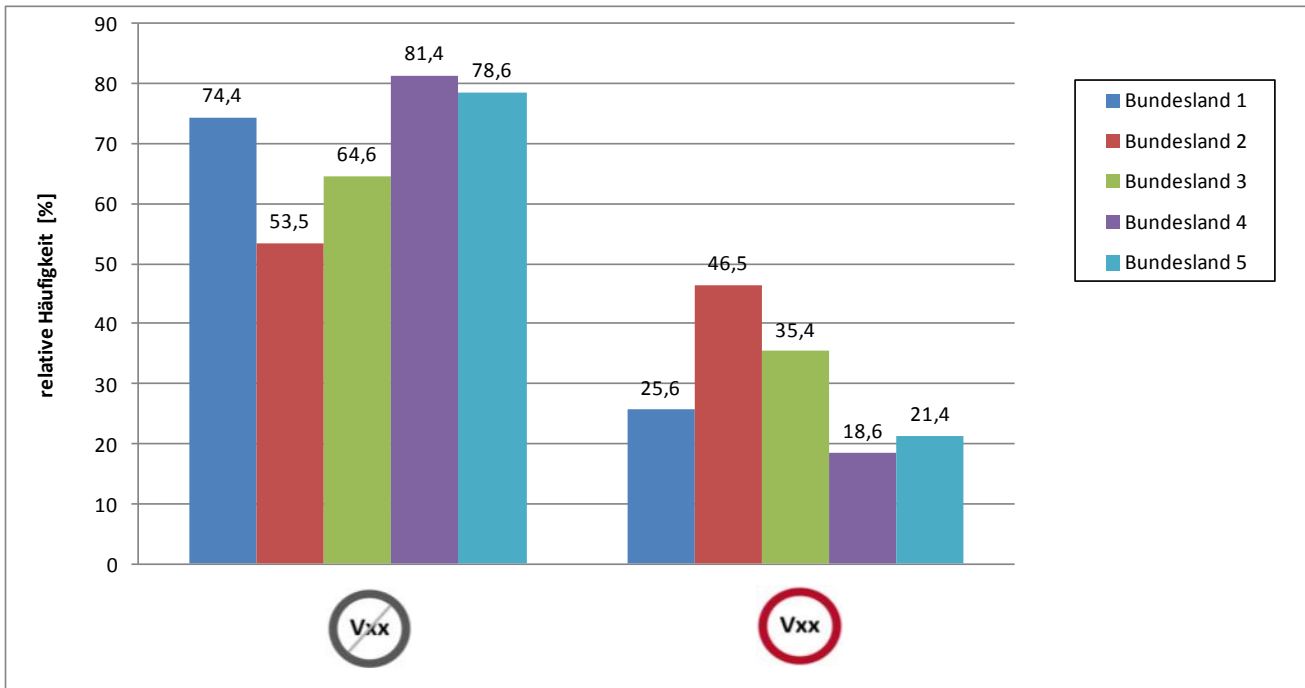

Abbildung 3.9: Unfallzuordnung zu Geschwindigkeitsbeschränkungen

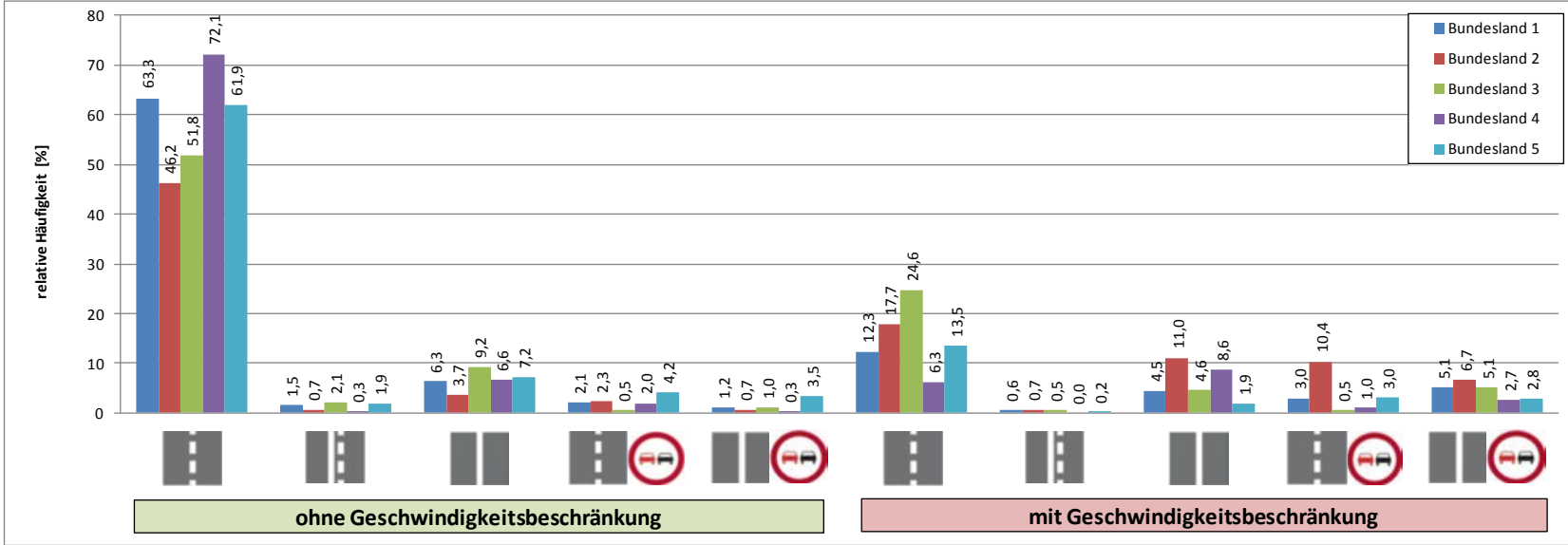

Abbildung 3.10: Zusammenfassung der Matrixinhalte - Unfallgeschehen

In Abstimmung mit den Darstellungen aus Kapitel 3.4.2 ergeben sich sehr ähnliche Verteilungen auch nach der Unfallzuordnung. Beim Vergleich der Darstellungen der Unfallzuordnung mit den 
äquivalenten Abbildungen des vorherigen Kapitels ergeben sich allerdings zwei leichte Tendenzen. Streckenabschnitte ohne Überholverbote haben eine höhere Unfallauffälligkeit als sie anteilsmäßig im Straßennetz vorhanden sind. Demnach entstehen auch dort die meisten Unfälle, wo Überholen eigentlich möglich sein sollte bzw. keine rechtlichen Restriktionen vorhanden sind. Auch bei Betrachtung der Unfälle in Abschnitten mit beidseitigem Überholverbot ergibt sich eine mit Kapitel 3.4.2 vergleichbare Verteilung. Zusammengefasst wurden $73,9 \%$ der Überholunfälle den freigegebenen Abschnitten zugewiesen, dagegen die verbleibenden 26,1 \% den bereits vorhandenen Überholverboten. Des Weiteren besteht eine Tendenz zu Überholunfällen an Streckenabschnitten ohne Geschwindigkeitsbeschränkungen.

Mit den dargestellten Ergebnissen können die Vermutungen und potentiellen Maßnahmenansätze aus Kapitel 3.4.2 auch auf Unfallebene bestätigt und sogar noch weiter bekräftigt werden. Abschließend bleibt aber die Frage zu klären, ob an freigegebenen Abschnitten wo bisher Überholen erlaubt ist, wirklich keine Restriktionen vorgegeben werden sollten, um Überholungen und Überholunfälle zu unterbinden. Hier ist zu prüfen, in welchen Bereichen der Untersuchungsstrecken eine Markierung oder Beschilderung wegen fehlender Sichtweiten eigentlich notwendig wäre. Diese Aspekte können allerdings nur im verkleinerten Rahmen der 100 nachtrassierten Streckenabschnitte eindeutig geklärt werden. Im Umkehrschluss muss für $26 \%$ der Unfälle geprüft werden, ob die Wirksamkeit der vorhandenen Überholverbote nicht ausreichend ist oder ob die Unfälle möglicherweise durch eine frühere Ankündigung der Überholverbote hätten verhindert werden können.

Neben dem Gesamtunfallgeschehen wurden durch die Ermittlung der Unfallkategorie auch die Beziehungen zwischen schweren Unfällen (Unfallkategorie 1 und 2) und eher leichten Unfällen (Unfallkategorie 3 und 4) und den Streckenmerkmalen ermittelt. Der Anteil von Unfällen in Bereichen mit verschiedenen rechtlichen Anordnungen in Bezug zum Überholvorgang ist bei beiden Unfallkollektiven nahezu identisch. Die im Zwischenbericht angedeuteten Tendenzen für Bundesland 3, dass die oben definierten schweren Unfälle häufiger auf Strecken ohne Geschwindigkeitsbeschränkungen geschehen (Verteilung Bundesland 3 - 69 \% zu $31 \%$ ) und leichte Unfälle dagegen um $10 \%$ häufiger in Bereichen mit einer zulässigen Geschwindigkeit unter $100 \mathrm{~km} / \mathrm{h}$, lassen sich für das verbleibende Untersuchungsgebiet nur vermuten (vgl. Tabelle 3.8). In Bundesland 4 sind die Verteilungen andersherum zu betrachten. Grundsätzlich sind aber die angedeuteten Tendenzen erwartungsgemäß und auf die schwereren Unfallfolgen bei höheren Geschwindigkeiten (höhere kinetische Energie) zurückzuführen.

\begin{tabular}{|c|c|c|c|c|}
\hline & \multicolumn{2}{|c|}{ Unfallkategorie 1 und 2 } & \multicolumn{2}{c|}{ Unfallkategorie 3 und 4 } \\
\cline { 2 - 5 } & $\mathbf{v}_{\mathbf{z u l}} \mathbf{1 0 0} \mathbf{~ k m} / \mathbf{h}$ & $\mathbf{v}_{\mathbf{z u l}}<\mathbf{1 0 0} \mathbf{~ k m} / \mathbf{h}$ & $\mathbf{v}_{\mathbf{z u l}}=\mathbf{1 0 0} \mathbf{~ k m} / \mathbf{h}$ & $\mathbf{v}_{\mathbf{z u l}}<\mathbf{1 0 0} \mathbf{~ k m} / \mathbf{h}$ \\
\hline Bundesland 1 & $75,4 \%$ & $24,6 \%$ & $73,3 \%$ & $26,7 \%$ \\
\hline Bundesland 2 & $55,6 \%$ & $44,4 \%$ & $51,1 \%$ & $48,9 \%$ \\
\hline Bundesland 3 & $68,5 \%$ & $31,5 \%$ & $59,5 \%$ & $40,5 \%$ \\
\hline Bundesland 4 & $80,5 \%$ & $19,5 \%$ & $82,1 \%$ & $17,9 \%$ \\
\hline Bundesland 5 & $79,8 \%$ & $20,2 \%$ & $77,1 \%$ & $22,9 \%$ \\
\hline \hline Gesamt & $72,6 \%$ & $27,4 \%$ & $70,7 \%$ & $29,3 \%$ \\
\hline
\end{tabular}

Tabelle 3.8: Anteil der Unfallkategorien differenziert nach Geschwindigkeitsbeschränkungen 


\subsubsection{Unfallgeschehen bezogen auf Merkmalslängen}

Ein zusammenfassender Überblick über das Unfallrisiko in Bezug auf die Merkmalslängen der verkehrsrechtlichen Anordnungen im befahrenen Straßennetz soll in diesem Kapitel hergestellt werden. Hierzu werden die Ergebnisse von Kapitel 3.4.2 und Kapitel 3.4.3 miteinander in Verbindung gebracht. Die Zusammenfassung des Gesamtunfallgeschehens und des gesamten Streckennetzes der 500 befahrenen Strecken ist in nachstehender Matrix dargestellt.

\begin{tabular}{|c|c|c|}
\hline & 0,76 & 0,68 \\
\hline & 0,84 & 0,62 \\
\hline & 0,63 & 0,44 \\
\hline I & 0,82 & 0,60 \\
\hline & 0,75 & 0,58 \\
\hline
\end{tabular}

Abbildung 3.11: Bezug Gesamtunfallgeschehen auf Länge der Streckenmerkmale [U/km³a]

Hierbei wird ausnahmslos deutlich, dass die am meisten mit Unfällen belasteten Streckenmerkmale grundsätzlich in Bereichen ohne Geschwindigkeitsbeschränkung zu finden sind. Die berechnete Bezugsgröße der rechtlichen Anordnungen zum Überholvorgang in den für die Geschwindigkeit freigegebenen Abschnitten übersteigt die äquivalente Größe mit vorhandener Geschwindigkeitsbeschränkung teilweise sehr deutlich. Hier kann vermutet werden, dass mit der Geschwindigkeitsbeschränkung eine Senkung der Geschwindigkeitsstreuung und somit eine Reduzierung des Überholbedarfs einhergeht. Die Tendenzen zwischen den rechtlichen Anordnungen im Vergleich beider Geschwindigkeitsvorgaben sind dagegen relativ ähnlich. Generell geschieht alle 1,4 Kilometer im analysierten, unfallauffälligen Straßennetz ein Überholunfall.

An dieser Stelle sei ausdrücklich darauf hingewiesen, dass es sich bei den berechneten Bezugsgrößen nicht um die klassische Unfalldichte handelt. Abbildung 3.11 enthält lediglich den Bezug der Überholunfälle im 3-jährigen Untersuchungszeitraum zum gesamten befahrenen Landstraßennetz. Daher wird auch ein Vergleich mit der tatsächlichen Unfalldichte gemäß Kapitel 3.4.5 wegen der verringerten Grundgesamtheit (geringere Streckenanzahl durch fehlende Verkehrsstärkedaten zur Erhaltung der Vergleichbarkeit der Unfallkenngrößen untereinander) nicht möglich sein.

Die drei unfallauffälligsten Streckenmerkmale nach Abbildung 3.11 sind die halben Überholverbote, das Zeichen 276 sowie die zum Überholen freigegebenen Abschnitte jeweils ohne Geschwin- 
digkeitsbeschränkung. Hierzu sei angemerkt, dass es sich bei den halben Überholverboten überwiegend nur um sehr kurze Streckenabschnitte handelt, was sich auch in der Summe des Vorhandenseins dieses Merkmals (vgl. Abbildung 3.5) wiederspiegelt. Demzufolge sorgen die 20 Überholunfälle auf den insgesamt wenigen 24 Kilometern mit halben Überholverboten für eine derart hohe Bezugsgröße. Außerdem bleibt bei dieser Betrachtung noch offen, auf welcher fahrtrichtungsabhängigen Seite der halben Markierung die Überholunfälle geschehen sind. Diese Frage kann nach mikroskopischer Analyse der 100 unfallauffälligsten Landstraßenabschnitte geklärt werden. In Abhängigkeit der Fahrtrichtung handelt es sich bei halben Markierungen um einen Verstoß gegen eine Fahrstreifenbegrenzung oder um einen rechtlich möglichen Überholvorgang. Bei beiden Varianten können auch unterschiedliche Motive unterstellt werden. Auf der freigegebenen Seite der halben Markierung sollten eigentlich Sichtweiten nach einem möglicherweise längeren Überholverbot vorhanden sein, da die Richtung vorzeitig freigegeben wird. In der Gegenrichtung beginnt im Gegenzug dazu ein Überholverbot nach einem Abschnitt mit Leitlinie, was unter anderem zu Unfällen wegen fehlender Vorankündigung des Überholverbotes führen kann. Relativ auffällig sind nach der o.g. Rangfolge die Überholverbote nach Zeichen 276, welche allerdings diese kurzen Merkmalslängen nicht zwangsläufig aufweisen. Hier besteht die Möglichkeit, dass ein angeordnetes Überholverbot nach Zeichen 276 übersehen werden kann und bei gleichzeitig markierter Leitlinie somit eine Überholung ohne Kenntnis des Überholverbotes durchgeführt wird. Möglicherweise führt die unterschiedliche Markierung und Beschilderung aber auch zu Missverständnissen bei den Fahrzeugführern. Eine Fahrstreifenbegrenzung nach Zeichen 295 ist dagegen immer sichtbar und zeigt nach Abbildung 3.11 auch die geringste Unfallbelastung. Der hier erst an dritter Stelle genannte Bereich ohne Überholverbote sollte aber wegen seines hohen Anteils am Gesamtunfallgeschehen dennoch den Fokus für potentielle Maßnahmen gegen Überholunfälle darstellen. Prinzipiell ist hier noch die Frage zu klären, welcher Anteil der insgesamt 1.151 Überholunfälle in den $1.545 \mathrm{~km}$ Streckenabschnitten des $2.235 \mathrm{~km}$ langen untersuchten Landstraßennetzes mit markierter Leitlinie aber von den Trassierungsmerkmalen eher unzureichenden Überholsichtweiten durch die Anordnung eines Überholverbotes hätten verhindert werden können. Diesem Aspekt soll nach erfolgter Nachtrassierung nachgegangen werden.

Die Ergebnisse einer Differenzierung der oben dargestellten Matrix nach den vier betrachteten Unfallkategorien ist in Anhang $G$ einsehbar. Schon bei Betrachtung der reinen Unfallzahlen in Anhang G wird eine Tendenz zu Unfällen mir schweren Personenschäden deutlich, was die ursprüngliche Annahme der besonderen Unfallschwere bei Überholunfällen durch entgegengesetzte Fahrtrichtungen erneut bestätigt. Unfälle der Kategorie 4 können beispielsweise durch überholende Fahrzeuge entstanden sein, die gerade noch eine kritische Überholung beenden konnten bzw. hinter dem Hindernisfahrzeug nach abgebrochenem Überholansatz wieder eingeschert sind, was im weiteren Verlauf allerdings einen Sachschaden zur Folge hatte. Die oben angesprochenen Tendenzen zwischen Streckenabschnitten mit bzw. ohne Geschwindigkeitsbeschränkung lassen sich unabhängig von den rechtlichen Anordnungen zum Überholungen sowie der Unfallkategorie bestätigen. Die teilweise herausstechenden Kennwerte der halben Überholverbote sollten wegen der oben bereits angesprochenen Zusammenhänge sowie der eher geringen Fallzahl nicht besonders 
gewichtet werden. In allen vier Unfallkategorien sind allerdings die fehlenden rechtlichen Restriktionen an vorderer Stelle zu finden.

Die tatsächlichen Zusammenhänge der angesprochenen Tendenzen bei Streckenabschnitten mit fehlenden rechtlichen Anordnungen können allerdings erst durch die mikroskopische Untersuchung der Strecken sowie der dazugehörigen Sichtweitenbänder analysiert werden. Hierbei kann gegebenenfalls ein Mangel an rechtlichen Vorgaben aufgedeckt werden.

\subsubsection{Unfallkenngrößen der Merkmalslängen}

Ergänzend zu den bereits dargestellten Matrizen wurden im Rahmen der Netzanalyse die Unfallkenngrößen für die einzelnen erhobenen Merkmale im gesamten Untersuchungsgebiet berechnet. Die Ergebnisse sind in Anhang $\mathrm{H}$ dargestellt. Die einführende Darstellung der gesamten entstandenen Unfallkosten (siehe Anhang H/a) innerhalb der 500 Untersuchungsstrecken spiegelt die bisherigen Erkenntnisse der ausgewerteten Matrizen wieder.

Bei der Berechnung der Unfallkenngrößen wurden Strecken ohne vorhandene Verkehrsstärkedaten generell vernachlässigt. Dies bedeutet, dass trotz theoretisch berechenbarer Unfall(kosten)dichten Strecken ohne DTV-Angaben nicht zur Berechnung herangezogen wurden, da sonst für die Berechnung von Unfallraten und -dichten zwei unterschiedliche Datenbasen bzw. Streckenkollektive herangezogen werden, was die Vergleichbarkeit der Unfallkenngrößen untereinander einschränkt. Die Berechnungen erfolgten hier auf Ebene der einzelnen Untersuchungsstrecken, wobei innerhalb dieser Strecken die zugeordneten Überholunfälle auch mit der entsprechenden Bezugslänge des vorliegenden Merkmals in Verbindung gebracht und über die Berechnungsgrundlagen für Straßenzüge nach Anhang B zusammengefasst wurden. Die Bezugswerte der Unfallkenngrößen sind in Anhang $\mathrm{H} / \mathrm{b}$ einsehbar. Durch Vernachlässigung der Strecken ohne Verkehrsstärken verbleiben 1.148 Überholunfälle auf 1.228 Kilometern im Untersuchungskollektiv. Es wird darauf verwiesen, dass hier die Länge des Netzes im Vergleich zur Unfallanzahl sehr deutlich abgenommen hat. Dies ist damit zu erklären, dass hier nur noch die Abschnittslängen von Bedeutung sind, auf denen der Überholunfall innerhalb einer einzelnen Untersuchungsstrecke geschehen ist. Alle weiteren Längen von unfallfreien Streckenabschnitten einer Untersuchungsstrecke zählen hier nicht (gegensätzliche Betrachtungsweise zu Kapitel 3.4.6).

Bei den Unfallraten und -kostenraten sind die Streckenmerkmale mit Geschwindigkeitsbeschränkung und Beschilderung von Überholverboten (sowohl mit als auch ohne Markierung) die sichersten Elemente. Darauffolgend sind die rechtlichen Anordnungen mit der nahezu geringsten Unfallkenngröße, die im letzten Kapitel als besonders auffällig benannten freigegebenen Abschnitte. Bei den Unfalldichten und -kostendichten sind es zudem genau diese Bereiche im Straßennetz, die nach diesen Kenngrößen die sicherste rechtliche Anordnung darstellen. Kurzum, die in den vorangegangenen Auswertungen ausgewiesenen Zusammenhänge der verkehrsrechtlichen Anordnungen zum Unfallgeschehen innerhalb der Matrix sind komplett gekippt.

Unter Berücksichtigung von Anhang $\mathrm{H} / \mathrm{b}$ müssen diese Ergebnisse allerdings auch kritisch hinterfragt werden. Die insgesamt höchsten, teilweise schon unkonventionellen Wertebereiche von Un- 
fallkenngrößen ergeben sich bei den halben Markierungen. Werden allerdings als Grundlage der Berechnung 5 Unfälle auf eine Merkmalslänge von 1,8 km bezogen, so kann dies durchaus die dargestellten Dimensionen annehmen. Hinzu kommt, dass sich die 5 Unfälle nicht auf die 1,8 Kilometer gleichverteilen, sondern im Beispiel von Bundesland 3 ein Unfall auf eine Merkmalslänge von lediglich 80 Meter bezogen wurde, was die ohnehin verzerrten Kenngrößen weiter negativ beeinflusst.

In den Bezugswerten nach Anhang $\mathrm{H} / \mathrm{b}$ wird grundsätzlich eine höhere Unfallanzahl deutlich, als Kilometer im Straßennetz vorhanden sind. Eine Ausnahme bilden hier die freigegebenen Abschnitte. Demzufolge sind Bereiche mit Überholverboten die aus Sicht der Unfallkenngrößen eher kritischen Bereiche. Die Argumentation, dass Überholverbote negative Auswirkungen auf das Überholunfallgeschehen haben, verbietet sich allerdings. Das erhöhte Unfallgeschehen in freigegebenen Abschnitten kann nicht auf Grundlage von vereinzelten eher seltenen Unfällen in anderen Streckenmerkmalen abgewertet werden. Die einzelnen Merkmalslängen, welche bei den Überholverboten überwiegend kurz ausfallen, haben einen stark verzerrenden Einfluss auf die berechneten Unfallkenngrößen. Die Ergebnisse der Berechnungen dürfen nicht ohne Rückblick auf die zugrunde liegende Unfallzahlen und Streckenlängen bewertet werden.

Nach den Erfahrungen der bisherigen Streckenanalyse wird vermutet, dass nicht alle Abschnitte ohne vorhandene Überholsichtweiten tatsächlich ein Überholverbot aufweisen. Demzufolge wäre eine Betrachtung der Ergebnisse der Unfallkenngrößen interessant, wenn alle Landstraßen so markiert bzw. beschildert wären, wie es die vorhandenen Sichtweiten vorgeben. Hier kann davon ausgegangen werden, dass sich die Längenverhältnisse im Straßennetz zwischen fehlenden und angeordneten Überholverboten deutlich verschieben würden. Die offene Frage an dieser Stelle ist allerdings auch, in welchem Maße das Unfallgeschehen einer solchen Verschiebung folgen würde. Es wird vermutet, dass die freigegebenen Streckenlängen zugunsten der mit Überholverboten versehenen Abschnitte abnehmen würden. Bei den Unfällen sollte aber eine ebenso starke Verschiebung nicht erwartet werden, da nur ein bestimmter Anteil der Unfälle durch regelkonformes Fahrverhalten vermieden werden kann. Eine gleichwertige Verschiebung zwischen Streckenlänge und Unfällen wird nicht erwartet. Unterstellt man nach gewisser Verlagerung dennoch die hier angedeutete Häufung von Überholunfällen in freigegebenen Abschnitten, so werden sich die Unfallkenngrößen aneinander angleichen und sich die gekippten Tendenzen relativieren.

Eine weitere Argumentation wäre, dass in Bereichen, wo bereits bekannt ist das Überholungen wegen fehlender Sichtweiten nicht möglich sind und demzufolge ein Überholverbot angeordnet wurde, das Überholen besonders gefährlich ist und schwerwiegende Folgen haben kann. An dieser Stelle bleibt allerdings die offene Frage, ob das Überholverbot präventiv oder reaktiv angeordnet wurde. Bei reaktiven Anordnungen der Verkehrsbehörden auf das entstandene Unfallgeschehen zählte der Unfall vor der Maßnahme womöglich zu einem längeren Abschnitt mit Leitlinie. Durch die folgende Maßnahmenumsetzung wurden kurze und kleinteilige Abschnittslängen erst nachträglich im Straßennetz erzeugt. 
Auf eine ergänzende Darstellung von Unfallkenngrößen differenziert nach den einzelnen Bundesländern zusätzlich zu den Matrizen des gesamten Untersuchungsgebietes wird an dieser Stelle verzichtet. Der weiter oben angeprangerte verzerrende Einfluss von kurzen Merkmalslängen mit nur einem Überholunfall nimmt durch die weitere Differenzierung nach Bundesländern noch wesentlich stärkere Ausmaße an, da dadurch die Mittelung über das gesamte Untersuchungsgebiet verloren geht.

Von der Herangehensweise der Berechnungen her ist der Bezug auf die Länge der einzelnen unfallauffälligen Merkmale wegen der aufrechterhaltenen Gewichtung der unterschiedlichen Streckenlängen im Sinne des Merkblattes für die Auswertung von Straßenverkehrsunfällen [FGSV, 2001] als korrekt anzusehen. Lediglich die Ergebnisse sind ohne Betrachtung der zugrunde liegenden Unfall- und Streckengrundlage eher unbrauchbar. Die Aussagekraft der berechneten Unfallkenngrößen wird wegen des starken vorhandenen, verzerrenden Einflusses von teilweisen Einzelunfällen auf kurzen Merkmalslängen eher als gering angesehen.

\subsubsection{Unfallkenngrößen des Gesamtnetzes}

Zur Relativierung des verzerrenden Einflusses von einzelnen Unfällen auf kurzen Merkmalslängen werden in nachfolgendem Kapitel auch die unfallfreien Teilabschnitte der einbezogenen Untersuchungsstrecken mit berücksichtigt. Durch diese Erweiterung ist nicht nur eine Beurteilung der Unfallkenngrößen sowie der Verkehrssicherheit von unfallauffälligen Merkmalen bzw. Teilabschnitten von Untersuchungsstrecken möglich, stattdessen kann das gesamte zugrundegelegte Netz (mit verfügbaren Verkehrsstärkedaten) und dessen Merkmale bewertet werden. Die vollständigen Ergebnisse sind Anhang I zu entnehmen, einen zusammenfassenden Überblick der berechneten Unfallkenngrößen gibt Tabelle 3.9 .

Beim Vergleich der Bezugswerte von Anhang $\mathrm{H}$ und Anhang I wird ersichtlich, dass sich bei gleichbleibender Unfallanzahl die Längenbezüge der einzelnen Merkmale teilweise deutlich erhöht haben, da zur Bewertung des Gesamtnetzes auch die unfallfreien Abschnitte berücksichtigt werden müssen. Diese Erhöhung der Bezugsgrößen tritt bei den zum Überholen freigegebenen Abschnitten nicht so deutlich hervor wie bei den Überholverboten. Grund hierfür ist die ohnehin hohe Unfallbelastung von freigegebenen Abschnitten und auch das häufige Vorhandensein dieser Merkmale im Straßennetz. Es sind daher nur wenige freigegebene Abschnitte vorhanden, die nicht unfallauffällig waren und somit auch noch nicht in vorherigem Kapitel berücksichtigt wurden. Bei den vorhandenen Überholverboten stellt sich die Situation anders dar. Hier werden zum einen durch das geringe längenmäßige Vorhandensein dieser Merkmale als auch durch deren eher geringe Unfallbelastung nun bei der Betrachtung des Gesamtnetzes geringere Unfallkenngrößen erzeugt als es in vorherigem Kapitel der Fall war, da sich durch viele hinzugekommene unfallfreie Streckenabschnitte die Bezugslängen nun vergleichsweise deutlich erhöht haben. Die Ergebnisse der Unfallkenngrößen innerhalb der Matrizen werden nun demnach nicht mehr durch geringe Einzellängen verzerrt, was sich auch in den Resultaten widerspiegelt. 


\begin{tabular}{|c|c|c|c|c|c|c|c|c|}
\hline \multirow{2}{*}{$\begin{array}{c}\text { Regelungen } \\
\text { von } \\
\text { Überholmög } \\
\text { lichkeiten }\end{array}$} & \multicolumn{8}{|c|}{ Risiko und Folgen von Überholunfällen auf Landstraßen nach $\mathbf{V}^{1{ }^{1}}{ }_{\text {zul. }}$} \\
\hline & $\begin{array}{c}\begin{array}{c}\text { Unfall- } \\
\text { rate } \\
{\left[\mathrm{U} /\left(10^{6} \cdot \mathrm{kfz} \cdot \mathrm{km}\right)\right]}\end{array} \\
\end{array}$ & $\begin{array}{c}\text { Unfall- } \\
\text { dichte } \\
{[\mathrm{U} /(\mathrm{km} \cdot \mathrm{a})]}\end{array}$ & $\begin{array}{c}\text { Unfall- } \\
\text { kostenrate } \\
{[\epsilon /(1000 \cdot \mathrm{kfz} \cdot \mathrm{km})]}\end{array}$ & $\begin{array}{c}\text { Unfall- } \\
\text { kostendichte } \\
{[1000 € /(\mathrm{km} \cdot \mathrm{a})]} \\
\end{array}$ & $\begin{array}{c}\begin{array}{c}\text { Unfall- } \\
\text { rate } \\
{\left[\mathrm{U} /\left(10^{6} \cdot \mathrm{kfz} \cdot \mathrm{km}\right)\right]}\end{array} \\
\end{array}$ & $\begin{array}{c}\text { Unfall- } \\
\text { dichte } \\
{[\mathrm{U} /(\mathrm{km} \cdot \mathrm{a})]}\end{array}$ & $\begin{array}{c}\text { Unfall- } \\
\text { kostenrate } \\
{[\epsilon /(1000 \cdot \mathrm{kfz} \cdot \mathrm{km})]}\end{array}$ & $\begin{array}{c}\text { Unfall- } \\
\text { kostendichte } \\
{[1000 \epsilon /(\mathrm{km} \cdot \mathrm{a})]} \\
\end{array}$ \\
\hline ! & 0,12 & 0,26 & 19,0 & 41,2 & 0,09 & 0,23 & 14,5 & 35,8 \\
\hline & 0,09 & 0,21 & 15,8 & 37,9 & 0,06 & 0,17 & 8,9 & 25,3 \\
\hline (A) & 0,10 & 0,27 & 12,0 & 32,2 & 0,07 & 0,21 & 9,4 & 29,5 \\
\hline (A) & 0,07 & 0,20 & 13,9 & 41,1 & 0,07 & 0,20 & 9,7 & 27,9 \\
\hline 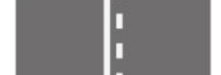 & 0,08 & 0,21 & 17,8 & 44,5 & 0,08 & 0,21 & 5,6 & 14,6 \\
\hline
\end{tabular}

1) $\mathrm{V}_{\text {zul }}:$ zulässige Höchstgeschwindigkeit auf zweistreifigen Landstraßen

Tabelle 3.9: Risiko und Folgen von Überholunfällen differenziert nach einzelnen verkehrsrechtlichen Restriktionen

Die Ergebnisse mit Netzlängenbezug (vgl. Tabelle 3.9) entsprechen den ermittelten Zusammenhängen der Kapitel 3.4.2 bis 3.4.4. Somit befinden sich die zum Überholen freigegeben Abschnitte (mit Ausnahme bei den Unfalldichten) an erster Position der Gefahrenrangfolge unabhängig der zulässigen Geschwindigkeiten. Werden die sichersten Regelungen betrachtet, so sind diese grundsätzlich in Abschnitten mit vorhandener Geschwindigkeitsbeschränkung zu suchen, da hier die Unfallkenngrößen in allen Merkmalsbereichen der vorhandenen Überholsituation unterhalb der Abschnitte mit freigegebenen Geschwindigkeiten liegen. Die sichersten Elemente von beidseitigen Überholverboten auf Landstraßen sind ausnahmslos die Markierungen. Das auf Strecken mit geringen Verkehrsstärken wegen geringerer Verbindungsfunktion auch mehr Knotenpunkte vorhanden sein können und somit die Kombination aus Markierung und Beschilderung häufiger auftritt und dadurch die Differenzen der unsichersten beidseitigen Überholverbote (reine Beschilderung vs. Kombination aus Markierung und Beschilderung) zwischen Unfallraten und -dichten auftreten, ist nur eine vage Vermutung. Bei den Betrachtungen der halben Markierungen muss nochmals auf die fehlende Fahrtrichtungszuordnung hingewiesen werden, weshalb hier die Wertung vernachlässigt wird. Zudem sind diese Markierungen nur sehr selten im Landstraßennetz aufzufinden, weshalb auch die zugrundeliegende Datenbasis keine tiefere Interpretation zulässt. Durch die Betrachtung aller untersuchten Einzelabschnitte der Landstraßen ohne Beschränkung auf deren unfallauffällige Teilmenge und die daraus folgende Eliminierung von verzerrenden Einflüssen durch kurze Einzellängen können die hier ermittelten Kenngrößen auch als maßgebend für die Beschreibung des Gefahrenpotentials von Überholunfällen in Landstraßennetzen angesehen werden.

Aufgrund der schwankenden Ergebnisse zwischen den einzelnen Unfallkenngrößen differenziert nach den 3 Arten von beidseitigen Überholverboten werden die Ergebnisse abschließend aggre- 
giert, um Aussagen zur allgemeinen Sicherheitswirkung von Überholverboten und Geschwindigkeitsbeschränkungen treffen zu können. Die nur vereinzelt auftretenden halben Markierungen nach Z 296 StVO werden an dieser Stelle nicht weiter betrachtet. Die Ergebnisse sind nachfolgender Tabelle 3.10 zu entnehmen.

\begin{tabular}{|c|c|c|c|c|c|c|c|c|}
\hline \multirow{2}{*}{$\begin{array}{l}\text { Regelungen } \\
\text { von } \\
\text { Überholmög- } \\
\text { lichkeiten }\end{array}$} & \multicolumn{8}{|c|}{ Risiko und Folgen von Überholunfällen auf Landstraßen nach $\mathbf{V}^{11}{ }_{\text {zul. }}$} \\
\hline & $\begin{array}{c}\text { Unfall- } \\
\text { rate } \\
{\left[\mathrm{U} /\left(10^{6} \cdot \mathrm{kfz} \cdot \mathrm{km}\right)\right]}\end{array}$ & $\begin{array}{c}\text { Unfall- } \\
\text { dichte } \\
{[\mathrm{U} /(\mathrm{km} \cdot \mathrm{a})]}\end{array}$ & $\begin{array}{c}\text { Unfall- } \\
\text { kostenrate } \\
{[\epsilon /(1000 \cdot \mathrm{kfz} \cdot \mathrm{km})]}\end{array}$ & $\begin{array}{c}\text { Unfall- } \\
\text { kostendichte } \\
{[1000 \epsilon /(\mathrm{km} \cdot \mathrm{a})]}\end{array}$ & $\begin{array}{l}\text { Unfall- } \\
\text { rate } \\
{\left[\mathrm{U} /\left(10^{6} \cdot \mathrm{kfz} \cdot \mathrm{km}\right)\right]}\end{array}$ & $\begin{array}{l}\text { Unfall- } \\
\text { dichte } \\
{[\mathrm{U} /(\mathrm{km} \cdot \mathrm{a})]}\end{array}$ & $\begin{array}{c}\text { Unfall- } \\
\text { kostenrate } \\
{[\in /(1000 \cdot \mathrm{kfz} \cdot \mathrm{km})]}\end{array}$ & $\begin{array}{c}\text { Unfall- } \\
\text { kostendichte } \\
{[1000 € /(\mathrm{km} \cdot \mathrm{a})]}\end{array}$ \\
\hline : & & & \multicolumn{4}{|c|}{ Überholen erlaubt / möglich } & & \\
\hline i & 0,12 & 0,26 & 19,0 & 41,2 & 0,09 & 0,23 & 14,5 & 35,8 \\
\hline & \multirow{3}{*}{0,09} & \multirow{3}{*}{0,21} & \multicolumn{4}{|c|}{ Überholen verboten / nicht möglich } & & \\
\hline : & & & 14,9 & 37,4 & 0,06 & 0,18 & 9,2 & 27,0 \\
\hline$\Theta$ & & & & & & & & \\
\hline
\end{tabular}

Tabelle 3.10: Allgemeines Risiko und Folgen von Überholunfällen bei Überholverboten und Geschwindigkeitsbeschränkungen

Es zeigt sich ausnahmslos eine Verringerung der Unfallkenngrößen (Verringerung des Unfallrisikos und der Unfallschwere) und somit eine Erhöhung der Verkehrssicherheit, wenn Überholverbote oder Geschwindigkeitsbeschränkungen angeordnet werden. Die größte Sicherheitswirkung ergibt sich, wenn Überholverbote und Geschwindigkeitsbeschränkungen überlagert werden, da hier insgesamt alle vier berechneten Unfallkenngrößen am geringsten sind.

\subsubsection{Signifikanz der Ergebnisse bei Betrachtung der verkehrsrechtlichen Anordnungen}

Die im vorherigen Kapitel berechneten Ergebnisse von Unfallkenngrößen für die Überholunfälle des betrachteten Streckennetzes gilt es mit Hilfe von Signifikanztests zu überprüfen. Hierbei soll festgestellt werden, ob die Abweichungen der vorliegenden Kennwerte zufallsbedingt sind oder sich die Unfallkenngrößen signifikant unterscheiden (vgl. Herz/Schlichter/Siegener, 1993).

\subsubsection{Methodik}

Vor der näheren Signifikanzanalyse muss auf die grundlegende Berechnung der Unfallkenngrößen eingegangen werden. Um die Streuungen der zugrunde liegenden Datenbasis analysieren zu können, müssen die Unfallkenngrößen jedes einzelnen aufgetretenen Merkmals herangezogen werden, die Berechnungsgrundlage wären hier die Formeln für einzelne Streckenabschnitte gemäß Anhang B (vgl. FGSV, 2003b). 
Um aus den streckenbezogenen Einzelwerten eine aggregierte Kennziffer für unterschiedliche verkehrsrechtliche Anordnungen im Straßennetz zu berechnen, ist hier eine anschließende arithmetische Mittelwertbildung wenig geeignet. Die Unfallkenngrößen der in Anhang I dargestellten Matrizen berechnen sich nach den Formeln für Straßenzüge (vgl. ebenfalls Anhang B). Hierbei handelt es sich um eine über die Länge und Verkehrsstärke gewichtete Unfallkenngröße. Diese Gewichtung ginge mit einer arithmetischen Mittelwertbildung verloren. Aufgrund dieser grundlegenden Differenzen beider Berechnungsverfahren, welche die Berechnung der statistischen Signifikanz der Unterschiede zweier Kenngrößen nicht ermöglichen, wird eine Prüfung der inneren Signifikanz der Datengrundlagen (Bezugsgrößen wie Verkehrsstärke und Abschnittslänge) durchgeführt und nicht der Unfallkenngrößen selbst. Durch die innere Signifikanz der Bezugswerte kann aber auf die statistische Bedeutsamkeit der berechneten Unfallkenngrößen geschlussfolgert werden. Durch die Analyse der Bezugsgrößen für die Unfallkenngrößenberechnung einzelner verkehrsrechtlicher Anordnungen werden die Definitionsbereiche von Streckenlänge und Verkehrsstärke gegenübergestellt und die Auswirkungen auf die Unfallkenngrößen bewertet. Zeigen sich in den Spektren der Datenbasen strukturelle Unterschiede für zwei Merkmale, so können die sich daraus ergebenden Abweichungen in den berechneten Unfallkenngrößen gegebenenfalls nicht auf die Merkmale selbst zurückgeführt werden, sondern liegen in den Bezugsgrößen begründet. Für den statistischen Nachweis der Abhängigkeiten bzw. Unabhängigkeiten innerhalb der Datengrundlage werden Verteilungstests für zwei unabhängige Stichproben durchgeführt. Hierbei wird auf den $\mathrm{Chi}^{2}{ }^{2}$ Test, den Kolmogorov-Smirnov-Test sowie den Mann-Whitney-U-Test zurückgegriffen (vgl. Herz/Schlichter/Siegener, 1993).

Wenn die Datenbasen für zwei Merkmale konsistent sind, dann können auch die Ergebnisse bzw. die Unterschiede der Unfallkenngrößen als signifikant angesehen werden.

\subsubsection{Bandbreite der Bezugsgrößen zur Unfallkenngrößenberechnung}

Beginnend mit der Betrachtung der Spektren der Bezugsgrößen der Unfallkenngrößenberechnung ergeben sich die Definitionsbereiche wie folgt. Als Erstes werden hier die aggregierten Spektren gegenübergestellt, wenn jeweils Überholverbote bzw. Geschwindigkeitsbeschränkungen vorhanden sind oder nicht.

\begin{tabular}{|c|c|c|c|c|}
\hline & Abschnittlänge & DTV & Abschnittlänge & DTV \\
\hline \begin{tabular}{|l|} 
Abschnittsanzahl \\
\end{tabular} & \multicolumn{2}{|c|}{584} & \multicolumn{2}{|c|}{852} \\
\hline Summe & $1.154,9$ & - & 488,7 & - \\
\hline Minimum & 0,0 & 1.088 & 0,0 & 1.253 \\
\hline \begin{tabular}{|l|} 
Maximum \\
\end{tabular} & 12,7 & 21.763 & 9,0 & 21.763 \\
\hline Mittelwert & 2,0 & 6.584 & 0,6 & 7.229 \\
\hline Standardabweichung & 1,7 & 3.607 & 0,7 & 3.580 \\
\hline
\end{tabular}

Tabelle 3.11: Spektrum der Bezugsgrößen nach Überholverboten 


\begin{tabular}{|c|c|c|c|c|}
\hline & Abschnittlänge & DTV & Abschnittlänge & DTV \\
\hline Abschnittsanzahl & \multicolumn{2}{|c|}{694} & \multicolumn{2}{|c|}{742} \\
\hline Summe & $1.090,5$ & - & 553,0 & - \\
\hline Minimum & 0,0 & 1.088 & 0,0 & 1.253 \\
\hline Maximum & 12,7 & 19.118 & 9,0 & 21.763 \\
\hline Mittelwert & 1,6 & 6.677 & 0,7 & 7.238 \\
\hline Standardabweichung & 1,7 & 3.469 & 0,8 & 3.707 \\
\hline
\end{tabular}

Tabelle 3.12: Spektrum der Bezugsgrößen nach Geschwindigkeitsbeschränkungen

In Bezug zur Verkehrsstärke wird deutlich, dass sich die Mittelwerte und Standardabweichungen nur unwesentlich unterscheiden. Dagegen treten bei den Mittelwerten der Längen der unterschiedlichen Merkmale deutlich größere Differenzen auf. Grund hierfür ist das generelle Auftreten der Merkmale im Landstraßennetz, was bereits in Kapitel 3.4.2 als Ergebnis der Befahrungen dargestellt wurde. Grundsätzlich können hier häufig Strecken mit großer Länge ohne ein Überholverbot bzw. auch ohne Geschwindigkeitsbeschränkung vorgefunden werden. Dem entgegen stehen eher kurze Strecken bzw. Teilabschnitte mit tatsächlich vorhandenen verkehrsrechtlichen Anordnungen. Die Unterschiede sind bei den Geschwindigkeitsbeschränkungen nicht so deutlich ausgeprägt wie bei den Überholverboten, da durchaus auch mal längere Abschnitte im Landstraßennetz eine Geschwindigkeitsbeschränkung aufweisen können (z.B. Alleen).

Betrachtet man die Spektren der nicht aggregierten Merkmale, wie sie auch in der ursprünglichen Matrixdarstellung (vgl. Anhang l/b) vorgefunden werden können, so ergeben sich die Bezugsgrößen gemäß Anhang J/a. Auch hier sind zwischen den einzelnen Merkmalen die Unterschiede der Verkehrsstärken nicht so stark ausgeprägt, wie die Differenzen zwischen den Abschnittslängen. Erwartungsgemäß haben hier die halben Markierungen den kleinsten Mittelwert an Längenausdehnung, da sie im Landstraßennetz oftmals nur zur Ankündigung bzw. vorzeitigen Freigabe von Überholverboten in einer bestimmten Fahrtrichtung angeordnet werden. Grundsätzlich werden die halben Markierungen in den nachfolgenden Untersuchungen den beidseitigen Überholverboten untergeordnet bzw. vernachlässigt. Zusammenfassend kann festgehalten werden, dass die Verkehrsstärke anscheinend als Bezugsgröße als sehr stabil angenommen werden kann. Deutliche Unterschiede der Datengrundlagen können erwartungsgemäß nur bei den Streckenlängen vorgefunden werden.

\subsubsection{Prüfung auf konsistente Bezugsgrößen}

In Anhang $\mathrm{J} / \mathrm{b}$ sind die Ergebnisse der Prüfung der inneren Signifikanz in den Datengrundlagen dargestellt. Im Rahmen der Analysen wurden die 4 aggregierten Fälle (Überholverbot ja/nein bzw. Geschwindigkeitsbeschränkung ja/nein) gegenübergestellt sowie die Auswirkungen der 3 potentiellen beidseitigen Überholverbote. Dargestellt sind jeweils die Irrtumswahrscheinlichkeiten, wenn die Nullhypothese abgelehnt wird bzw. die Wahrscheinlichkeiten/Signifikanzniveaus, wenn die Alterna- 
tivhypothese angenommen wird (vgl. Brosius, 1998). Bei den aggregierten Merkmalen kommen die 3 vorgeschlagenen Tests teilweise zu anderen Ergebnissen. Es wird davon ausgegangen, dass der $\mathrm{Chi}^{2}$-Test aufgrund der teilweise schwach besetzten Klassen nicht die sichersten Testergebnisse liefert, bei den beiden anderen vorgeschlagenen Tests existieren dagegen keine Mindestanforderungen an die Datengrundlage (vgl. Brosius, 1998). Bei den Streckenlängen werden die Nullhypothesen auf sehr hohem Niveau abgelehnt, demzufolge liegen unterschiedliche Verteilungen der Bezugsgrößen vor (Kolmogorov-Smirnov-Test und Mann-Whitney-U-Test). Betrachtet man die feiner gegliederten Merkmalsausprägungen (bspw. Vergleich Markierung vs. Schild), so kann hier eine steigende Irrtumswahrscheinlichkeit festgestellt werden. Demzufolge erhöhen sich die Unterschiede in der Datengrundlage, wenn die nicht aggregierten Merkmale miteinander verglichen werden (geringe Merkmalsausprägung entsprechend des Auftretens im Landstraßennetz).

An dieser Stelle muss aber auch generell die Abschnittsanzahl berücksichtigt werden. Betrachtet man die Anzahl der Abschnitte mit/ohne Überholverbot (vgl. Tabelle 3.11) bzw. Geschwindigkeitsbeschränkung (vgl. Tabelle 3.12), dann wird deutlich, dass mit rechtlichen Restriktionen zahlenmäßig mehr Abschnitte verfügbar sind als ohne rechtliche Anordnungen. Grund hierfür ist ebenfalls das Auftreten der Merkmale im Landstraßennetz, da auf einer Strecke mehrere verschiedene, kurze Überholverbote aber nur ein freigegebener Abschnitt vorhanden sein können. Diese Abschnittsanzahl beeinflusst den Mittelwert der Längen aber vor allem auch den Mittelwert der Verkehrsstärke. Neben der Anzahl der Strecken mit bestimmten Merkmalen können weitere Einflüsse durch den steigenden Anteil von unfallfreien Abschnitten mit rechtlichen Restriktionen entstehen. Nach den Auswertungen stammen die untersuchten Verteilungen der Bezugsgrößen Länge und Verkehrsstärke offensichtlich nicht mit statistisch ausreichender Sicherheit aus einer Grundgesamtheit. Nach den oben geschilderten Beispielen werden aber konsistente Verteilungen zwischen zwei Merkmalen auch nur schwer erreichbar sein. Das längenmäßige Vorhandensein der unterschiedlichen Merkmale im Landstraßennetz ermöglicht hier grundsätzlich keine anderen Schlussfolgerungen.

\subsubsection{Schlussfolgerungen für die Bewertung der Unfallkenngrößen}

Insgesamt können durch die Prüfung der inneren Signifikanz der Bezugsgrößen folgende Schlussfolgerungen für die berechneten Unfallkenngrößen festgehalten werden. Grundsätzlich zeigen die Unfallkenngrößen der aggregierten Merkmale die statistisch sichersten Ergebnisse in Bezug auf die Datengrundlage, da hier auf eine breitere Datenbasis zurückgegriffen werden kann. Wird bei der Bewertung der Unfallkenngrößen der Bezug zu den analysierten eher inkonsistenten Datenbasen hergestellt, so dürfte die statistische Bedeutung der Unterschiede der Unfallkenngrößen abnehmen, da vornehmlich die Streckenlängen der Merkmale verschiedene Spektren und Mittelwerte aufweisen. Berücksichtigt man allerdings die tatsächlichen Effekte dieser Bezugsgrößen bei der Unfallkenngrößenberechnung, so ergibt sich ein anderes Bild. Wie in Kapitel 3.4.7.3 angegeben, liegen die durchschnittlichen Längen von rechtlich beschränkenden Untersuchungsmerkmalen unter denen der freigegebenen Abschnitte. Grundproblem von geringen Merkmalslängen bei der Unfallkenngrößenberechnung ist aber die unverhältnismäßige Vergrößerung der sich ergebenden 
Kenngrößen mit geringer werdender Streckenlänge. Demnach sorgen besonders die kurzen Strecken für erhöhte Unfallkenngrößen, da sie bei der Berechnung der Unfallkenngrößen in den Gleichungen nach Anhang B mit ihrem Kehrwert eingehen. Die Zusammenhänge verdeutlicht folgende Abbildung.

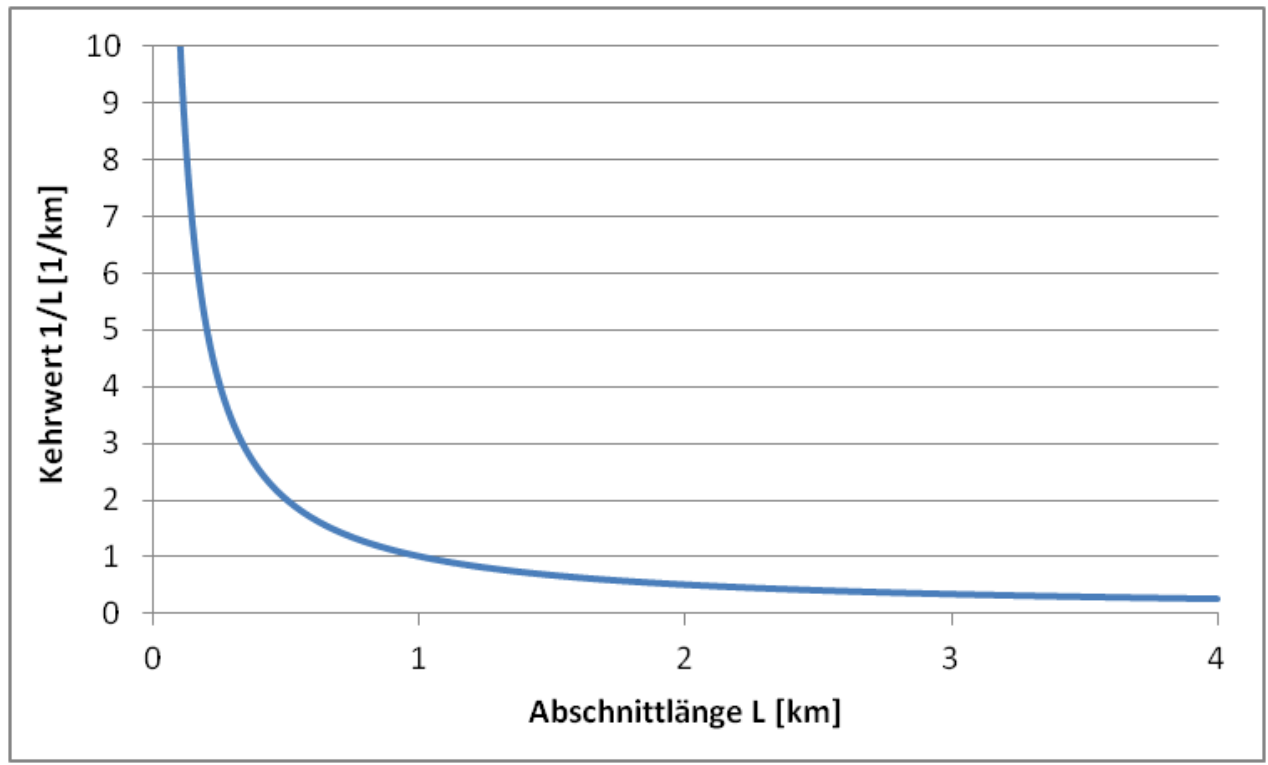

Abbildung 3.12: Einfluss der Abschnittslängen auf die Unfallkenngrößenberechnung

Trotz dieser trivialen Zusammenhänge sind es aber genau die kurzen Abschnitte mit rechtlichen Restriktionen - sowohl in Bezug zum Überholverbot als auch zur Geschwindigkeitsbeschränkung die bei den aggregierten Merkmalen die kleinsten berechneten Unfallkenngrößen aufweisen. Demnach kann die Tatsache der verschiedenen Bezugsgrößen (Merkmalslänge) in der Datenbasis nicht als ursächlich für die Differenzen angesehen werden. Würden die kurzen Merkmale die Unfallkenngrößen beeinflussen, so wären die Unfallkenngrößen der Abschnitte mit rechtlichen Restriktionen nicht unterhalb der freigegebenen Abschnitte angesiedelt, sondern darüber. Dies bedeutet, dass sich die ergebenden Zusammenhänge zur Verkehrssicherheit bzw. die Unterschiede zwischen den Unfallkenngrößen bei einer angenommenen grundsätzlich ähnlichen Datenbasis (ähnliche Abschnittslängen entgegen der Realität des Auftretens im Landstraßennetz) sogar noch verstärken würden.

Daher wird davon ausgegangen, dass die aufgetretenen Unterschiede nicht auf die Merkmalslängen zurückzuführen sind und sich hinter den Unterschieden der Unfallkenngrößen zwischen freigegebenen Abschnitten und Abschnitten mit vorhandenen verkehrsbehördlichen Restriktionen deutliche Sicherheitsgewinne verbergen. Neben der Längenausdehnung der Merkmale als erster Einfluss existieren als zweiter anzumerkender Aspekt sehr viele unfallfreie Abschnitte mit rechtlichen Restriktionen, was die Unfallkenngrößen in Summe verbessert. Demnach müssen auch trotz ungleicher Bezugsgrößen bzw. inkonsistenter Datenbasen (die Merkmale im Landstraßennetz lassen aber grundsätzlich keine andere Betrachtungsweise zu) die Überholverbote bzw. Geschwindigkeitsbeschränkungen als sicherer angesehen werden als die freigegebenen Abschnitte. Daher 
werden die Ergebnisse der aggregierten Merkmale bzw. die sich ergebenden Sicherheitseffekte auch als maßgebend angesehen.

Für die Unterschiede der Unfallkenngrößen bei Betrachtung der nicht aggregierten rechtlichen Anordnungen ergeben sich aufgrund der zunehmenden Detaillierung auch deutlich geringere Signifikanzniveaus. Dies bedeutet, dass die Differenzen der Unfallkenngrößen verschiedener verkehrsrechtlicher Kombinationen (unterschiedliche Überholverbote mit bzw. ohne Geschwindigkeitsbeschränkung) nicht als signifikant angesehen werden können. Mit statistisch ausreichender Sicherheit kann keine Aussage über bessere oder schlechtere Überholverbote getroffen werden.

\subsubsection{Fahrbahnbreiten}

Im Zuge der Streckenbefahrungen wurden an für die jeweilige Untersuchungsstrecke maßgebenden Referenzquerschnitten die Breiten der folgenden Elemente differenziert nach Fahrtrichtungen erhoben:

- Fahrstreifen- bzw. Fahrbahnbreite

- Randstreifenbreite

- Seitenraumbreite (inkl. Bankett).

Ziel dieses Arbeitsschrittes ist neben grundsätzlichen Auswertungen zu den erhobenen Breiten die Zuordnung der Querschnittsabmessungen der repräsentativen Standorte zu den Regelquerschnitten der RAS-Q [FGSV, 1996]. Damit wird eine Auswertung der Überholunfälle bezogen auf die verschiedenen Regelquerschnitte ermöglicht. Es wird darauf hingewiesen, dass die eindeutige Abgrenzung der Bankettbreite von der Böschung bzw. der Entwässerungsmulde bei älteren Bestandsstrecken schwierig ist, da hier durch Begrünung beide Querschnittselemente ineinander übergehen und somit keine eindeutige Abgrenzung möglich ist. Dies ist jedoch für diese Untersuchung nicht erheblich, da im Wesentlichen der Abstand des Fahrbahnrandes von den Seitenraumelementen (Büsche, Bäume etc.) bzw. der zur Verfügung stehende Verkehrsraum für eine zu treffende Überholentscheidung relevant ist.

Des Weiteren ist zu beachten, dass sich die Querschnittsaufteilung auf den Untersuchungsstrecken ändern kann. Besonders die Randstreifenbreiten können sich auf den Strecken im ungünstigsten Fall alle $50 \mathrm{~m}$ ändern (ältere Bestandstrecken mit weggebrochenen Randstreifen). Die Festlegung eines maßgebenden Querschnittes erfolgt nach der Streckenbefahrung im Rahmen der Erhebung der verkehrsrechtlichen Anordnungen. Hierbei kann vom Verlauf der gesamten Untersuchungsstrecke ein Eindruck gewonnen, die Entscheidung für einen repräsentativen Straßenquerschnitt gefällt und an diesem die Referenzbreiten der Strecke gemessen werden. Demnach wird als repräsentativer Querschnitt ein Streckenteil ausgewählt, der die Streckencharakteristik der gesamten Untersuchungsstrecke wiederspiegelt. Eine Änderung der Seitenraumbepflanzung für $200 \mathrm{~m}$ kann demzufolge für diese makroskopische Analyse nicht berücksichtigt werden, wird aber später für die Nachtrassierung der 100 unfallauffälligsten Untersuchungsstrecken detailliert aufbereitet. Ist an einer Untersuchungsstrecke die Abgrenzung eines repräsentativen Quer- 
schnitts nicht zweifelsfrei möglich, werden theoretisch mehrere maßgebende Querschnitte erforderlich. Für diese makroskopischen Auswertungen können jedoch nur die Breiten eines maßgebenden Querschnittes herangezogen werden. Demzufolge werden Untersuchungsstrecken mit Querschnittsänderungen hier nicht berücksichtigt. Über die gemessenen Breiten der einzelnen Querschnittselemente (siehe oben) können die Abhängigkeiten zum Unfallgeschehen der Überholunfälle ermittelt werden. In der Literatur wird von einem Aufforderungsgehalt zu Überholungen bei breiten Straßen bzw. Querschnitten berichtet [vgl. Palm/Schmidt, 1999].

Die Verknüpfung der ermittelten Fahrbahnbreiten mit den berechneten Unfallkenngrößen auf den einzelnen Untersuchungsstrecken ist für das Gesamtunfallgeschehen (Unfallkategorie 1-4) und für das Teilkollektiv der Überholunfälle in Anhang $K$ und Anhang $L$ dargestellt. Es wird darauf verwiesen, dass von den 500 ersten Untersuchungsstrecken der Rangfolge für diese Betrachtungen nur 341 Strecken herangezogen werden können. Grund für die fehlenden Strecken ist, dass diesen kein eindeutiger Querschnitt zugewiesen werden kann (s.o.) oder sie die für die Unfallkenngrößenberechnung erforderlichen Verkehrsstärkedaten nicht aufweisen. Bei den befahrenen Strecken handelt es sich überwiegend um Landstraßen mit schmalen Fahrbahnbreiten. Hierbei ist zu beachten, dass es sich bei einer Fahrbahnbreite von 7,5 m bereits um einen RQ 10,5 handelt. Größere Fahrbahnbreiten sind eher selten aufgetreten. In Ausnahmefällen können hier aber Mehrzweckstreifen zu einer erhöhten Fahrbahnbreite geführt haben. Demnach wurde im Untersuchungsgebiet die breiteste Fahrbahn mit insgesamt 15,1 m gemessen. Die schmalste festgestellte hier enthaltene Querschnittsbreite beträgt 4,5 m.

Bei Betrachtung der Unfallkenngrößen für das Gesamtunfallgeschehen (Unfallkategorie 1-4) und für das Teilkollektiv der Überholunfälle ergibt sich in den Darstellungen der Unfallraten und -kostenraten eine leichte Tendenz zu mehreren und auch schwereren Unfällen bei eher schmalen Landstraßen. Bei breiten Landstraßen sind die Unfallzahlen als auch die Unfallfolgen vergleichsweise als gering anzusehen. In Bezug zum Gesamtunfallgeschehen kann vermutet werden, dass durch die höheren Bewegungsspielräume auch die Unfallauffälligkeit der breiten Landstraßen abnimmt, wohingegen die schmalen Landstraßen einen negativen Einfluss auf die Verkehrssicherheit haben. Die durch die Literatur bekannten Tendenzen können somit grundsätzlich bestätigt werden, U-förmige Verläufe von Unfallkenngrößen konnten aber auch mittels exponentieller Regressionen nicht festgestellt werden (vgl. Brannolte et.al. [1993], Palm/Schmidt [1999], Lamm/Beck/Zumkeller [1999]). Allerdings müssen hier auch die verschiedenen verwendeten Datenbasen berücksichtigt werden. Betrachtet man das Kollektiv der Überholunfälle und die bisherigen Erkenntnisse der Literatur, so besteht zwar ein Aufforderungsgehalt zu Überholungen auf breiten Landstraßenquerschnitten, allerdings sind diese dann wegen größerer Bewegungsspielräume und ggf. größeren Sichtweiten auch sicherer. Im Umkehrschluss lässt sich vermuten, dass bei schmalen Fahrbahnbreiten möglicherweise aus Vorsicht von einer Vielzahl der Verkehrsteilnehmer nicht überholt wird, doch wenn Überholmanöver durchgeführt werden, dann bestehen hier besonders negative Folgen für die Verkehrssicherheit. Die gerechneten Regression sowie die Bestimmtheitsmaße der Punktwolken lassen allerdings diese Zusammenhänge aber nur vermuten. 
Bei Betrachtung der Ergebnisse für die Unfalldichten und -kostendichten ergeben sich dagegen steigende Tendenzen beim Gesamtunfallgeschehen in einer jedoch sehr stark streuenden Punktwolke. Bei den Überholunfällen ist nahezu keine Tendenz festzustellen. Die Ergebnisse der Unfalldichten sind aber durch noch wesentlich geringere Bestimmtheitsmaße als die Unfallraten gekennzeichnet, weswegen hier - wie auch schon bei den Unfall(kosten)raten - von Zusammenhängen zur Fahrbahnbreite eigentlich nicht mehr gesprochen werden kann. Auffällig ist bei den Unfallkostendichten der Schnitt von enthaltenen Strecken mit einer Unfallkostendichte von weniger als $20.000 € /\left(\mathrm{km}^{*} \mathrm{a}\right)$. Dieser Aspekt ist auf die Rangfolgeerstellung durch die Unfallkostendichten zurückzuführen, da nur die unfallauffälligsten Untersuchungsstrecken zur Analyse herangezogen wurden. Hierbei wird außerdem vermutet, dass durch das gewählte Rangfolgekriterium auch von einem gewissen verzerrenden Effekt in den Ergebnissen der Zusammenhänge zwischen Fahrbahnbreite und Unfall(kosten)dichten ausgegangen werden muss.

In Anhang $\mathrm{M}$ und Anhang $\mathrm{N}$ sind die Zusammenhänge der Unfallkenngrößen der beiden Unfallkollektive zu den Straßenraumbreiten dargestellt. Es wird darauf hingewiesen, dass bei 23 Strecken die Festlegung eines maßgebenden Seitenraumes wegen starker Änderungen der Seitenraumgestaltung nicht möglich war und diese Strecken somit hier nicht weiter betrachtet werden. Sind bei den Straßenräumen freie Flächen bzw. Seitenräume ohne Sichthindernisse vorhanden, so wurde hier der Wert des Straßenraumes auf 100 als Maximum gesetzt. Die dargestellten Diagramme zeigen allesamt keine klaren Tendenzen bzw. Zusammenhänge der Unfallkenngrößen zu den Straßenraumbreiten. Die verbesserten Sichtverhältnisse durch Freiflächen im Seitenraum, welche beispielsweise auch Überholungen in langgestreckten Kurven ermöglichen, bleiben demnach nur Vermutungen. Die Bestimmtheitsmaße der untersuchten Zusammenhänge lassen an dieser Stelle allerdings keine weiteren Schlussfolgerungen zu, da offensichtlich keine Abhängigkeiten existieren. Auch der möglicherweise vorhandene negative Einfluss des maximalen Wertes für Seitenräume von 100 m wurde untersucht. Verbesserungen der Bestimmtheitsmaße bzw. deutlichere Abhängigkeiten zwischen Seitenraum und Unfallgeschehen konnten aber auch hier nicht festgestellt werden, klare Abhängigkeiten sind somit nicht vorhanden.

Nach Darstellung der Zusammenhänge der Fahrbahn- und Straßenraumbreiten zu den berechneten Unfallkenngrößen kann daher vermutet werden, dass die erhobenen Fahrbahnbahn- bzw. Seitenraumbreiten als alleinige Kriterien für die Beurteilung des betrachteten Unfallgeschehens (betrifft sowohl das Gesamtunfallgeschehen als auch das Teilkollektiv der Überholunfälle) nicht ausreichend sind.

Folgendes Beispiel in Bezug zum Überholvorgang kann diese These untermauern. Betrachtet man 2 gleichlange Landstraßenabschnitte mit jeweils links und rechts $4 \mathrm{~m}$ freien Seitenraum und handelt es sich zudem bei einer Strecke um einen komplett geraden Abschnitt und bei dem anderen um eine Strecke mit hoher Kurvigkeit, so kann hier beim Vergleich sowohl das Überholverhalten und auch das Überholunfallgeschehen grundsätzlich verschieden sein. Möglicherweise kann hiermit auch die erhöhte Streuung der Ergebnisse erklärt werden. Ohne Kenntnis weiterer Randbedingungen ist die Beschreibung von Überholunfällen auf Basis von Fahrbahn- und Seitenraumbreiten 
nicht zielführend. Erst das Zusammenspiel von Querschnittsbreiten, Lageplan- und Höhenplaninformationen, welche in der vorhandenen Sichtweite aggregiert werden, kann die Zusammenhänge zum Überholunfallgeschehen erkenntlich machen.

Neben den Auswertungen zu den Querschnittsbreiten wurden die vorgefundenen Fahrbahnbreiten den Regelquerschnitten der RAS-Q [FGSV, 1996] zugeordnet. Für die Zuordnung wurde für die Fahrstreifenbreiten eine Toleranz von $20 \mathrm{~cm}$ gewährt. Das Ergebnis dieser Zuordnung ist in nachstehender Tabelle einzusehen.

\begin{tabular}{|c|c|}
\hline Regelquerschnitt & Streckenanzahl \\
\hline RQ 7,5 & 45 \\
\hline RQ 9,5 & 44 \\
\hline RQ 10,5 & 53 \\
\hline kein RQ & 339 \\
\hline
\end{tabular}

Tabelle 3.13: Untersuchungsstrecken nach Regelquerschnitten der RAS-Q 1996

Von den verbleibenden 481 Strecken, auf denen keine nennenswerte Querschnittsänderung festgestellt wurde, konnten trotz der gewährten Toleranz insgesamt 339 Strecken keinem Querschnitt der geltenden RAS-Q von 1996 zugewiesen werden.

Bei einer derartigen Zuordnung muss allerdings auch die geschichtliche Entwicklung des Straßennetzes bzw. der befahrenen Bestandsstrecken berücksichtigt werden. Die Einführung einer neuen Richtlinie kann nicht die ausnahmslose Anpassung des Bestandsnetzes an die neuen Vorgaben zur Folge haben. Daher wurden die 339 Strecken mit den Regelquerschnitten der älteren RAS-Q von 1982 verglichen. Allerdings konnten auch durch diese Ergänzung nur ca. $40 \%$ der 339 Abschnitte einem älteren Richtlinienquerschnitt zugewiesen werden. Hauptsächlicher Grund für die unzureichende Zuordnung sind teilweise Randstreifenbreiten von unter $15 \mathrm{~cm}$. In den vergangenen 60 Jahren über mehrere Richtliniengenerationen hinweg hat es aber grundsätzlich nur Randstreifenbreiten von $25 \mathrm{~cm}$ gegeben, aber nicht kleiner. Demzufolge können auf hier enthaltenen älteren Bestandsstrecken möglicherweise Ummarkierungen für die Differenzen verantwortlich sein oder aber auch ein schlechter Zustand der Fahrbahnoberfläche (ausgefahrene, weggebrochene Randstreifen).

Für die Querschnittszuordnung wurde somit ein weiterer Zwischenschritt vereinbart. Hierbei soll in Fällen einer ausbleibenden Querschnittszuordnung ein Regelquerschnitt lediglich über die vorhandene Fahrbahnbreite (Summe aus Fahrstreifen- und Randstreifenbreite) zugeordnet werden. Die Ergebnisse dieser mehrstufigen Querschnittszuordnung enthält Tabelle 3.14. Bei 145 der nach RAS-Q 1996 nicht zuordenbaren Strecken handelt es sich offensichtlich um 20 bis 30 Jahre alte Bestandsstrecken, welche einem Querschnitt nach den RAS-Q von 1982 entsprechen. Daher müssen die veralteten Regelquerschnitte bei einer solchen Querschnittszuordnung nach wie vor berücksichtigt werden. 


\begin{tabular}{|c|c|c|}
\hline Regelquerschnitt & RAS-Q & Streckenanzahl \\
\hline RQ 7,5 & 1996 & 45 \\
\hline RQ 9, e2 & 1982 & 97 \\
\hline RQ 9,5 & 1996 & 130 \\
\hline RQ 10, d2 & 1982 & 48 \\
\hline RQ 10,5 & 1996 & 98 \\
\hline kein RQ & - & 63 \\
\hline
\end{tabular}

Tabelle 3.14: Untersuchungsstrecken nach Regelquerschnitten der RAS-Q 1996, 1982 inkl. Toleranzen

Nach Einbeziehung der RAS-Q von 1982 sowie der Toleranzen verbleiben lediglich 63 Strecken, die keinem Regelquerschnitt eindeutig entsprechen. Diese Untersuchungsstrecken können zusätzlich bei der Aggregation nach Regelquerschnitten und der folgenden Unfallkenngrößenberechnung nicht berücksichtigt werden. Nach Vernachlässigung von Strecken mit Querschnittsänderungen, Strecken ohne Verkehrsstärken sowie Strecken ohne zuordenbaren Querschnitt verbleiben 297 Strecken für die folgenden Betrachtungen.

In Anhang $\mathrm{O}$ sowie Anhang $\mathrm{P}$ sind die Ergebnisse der Neuberechnung der Unfallkenngrößen beider betrachteter Unfallkollektive aggregiert nach den zugeordneten Regelquerschnitten dargestellt. Die Ergebnisse in Anhang $\mathrm{K}$ und Anhang $\mathrm{L}$ lassen sich hier durch fallende Unfallauffälligkeiten mit zunehmender Querschnittsbreite zumindest bei den Unfall(kosten)raten grundsätzlich bestätigen. Lediglich die Werte der Unfall(kosten)dichten ermöglichen diese Schlussfolgerungen nicht. Nach der hier durchgeführten Querschnittsauswertung und somit der Bezug auf eine breite Datenbasis (ca. 300 Untersuchungsstecken) wird für die Unfall(kosten)dichten ein verzerrender Einfluss durch das verwendete Rangfolgekriterium der Unfallkostendichte bei der Auswahl der 500 unfallauffälligsten Untersuchungsstrecken aus dem Gesamtkollektiv an Landstraßenabschnitten in den 5 Bundesländern unterstellt.

In Anhang Q wird das Kollektiv der Überholunfälle auf den ermittelten Regelquerschnitten mit den entsprechenden verkehrsrechtlichen Anordnungen verknüpft (Unfallzuordnung vgl. Kapitel 3.4.3). Die ermittelten Bezugswerte (Unfallanzahl und entsprechende Streckenlänge der Merkmale) sind in Anhang Q/a einsehbar. Es wird erkennbar, dass sich auch bei der großen hier zugrunde gelegten Fallzahl von 297 Strecken, welche einem Regelquerschnitt zugewiesen werden konnten und auch Verkehrsstärkedaten enthalten, mit den insgesamt 972 Überholunfällen bei einer Differenzierung in 25 verschiedene Klassen deutliche Unterschiede in den Grundgesamtheiten ergeben. Durch das Übergewicht der freigegebenen Abschnitte an der Unfallanzahl (vgl. Kapitel 3.4.3) verbleiben in einigen anderen Klassen nur äußerst wenige Unfälle für die angestrebte Unfallkenngrößenberechnung. Beim Längenbezug wurde hier der Bezug zum Gesamtnetz der einzelnen Merkmale hergestellt (entsprechend der Berechnungsweise nach Kapitel 3.4.6), um nicht noch zusätzlich Verzerrungen durch kurze Einzellängen der Merkmale in den folgenden Auswertungen berücksichtigen zu müssen. 
Betrachtet man die Ergebnisse in Anhang Q/b bis Anhang Q/e, so spiegeln sich in den Ergebnissen der Unfall(kosten)raten die bisherigen Teilergebnisse von Unfallkenngrößen der Unfallzuordnung sowie der Querschnittsauswertung wider. Es zeigen sich erhöhte Unfallkenngrößen bei den freigegebenen Abschnitten sowie insgesamt eine leichte Tendenz für fallende Unfallkenngrößen bei steigenden Querschnittsbreiten. Bei den Unfall(kosten)dichten sind die Ergebnisse nicht so stark ausgeprägt, daher wird hier erneut der Einfluss der Rangfolgeerstellung als negativer Effekt angesehen. Bei der Betrachtung sind stets die Fallzahlen der einzelnen Klassen zu berücksichtigen und die Ergebnisse zu hinterfragen. Die hier enthaltenen Einzelunfälle bzw. Unfälle mit geringer Fallzahl können nicht als repräsentativ für die jeweiligen Klassen angesehen werden.

Bei allen Auswertungen wird darauf hingewiesen, dass die hier betrachteten Strecken durch eine Rangfolge der am stärksten mit Überholunfällen belasteten Strecken im Untersuchungsgebiet ausgewählt wurden. Des Weiteren wurden während der Datenaufbereitung die Abschnitte mit nur einem Unfall vernachlässigt und für die Berechnung der Unfallkenngrößen angepasste Unfallkostensätze verwendet. Vergleiche der Unfallkenngrößen mit anderen Untersuchungen bzw. Angaben von Kenngrößen zu einzelnen Regelquerschnitten (vgl. bspw. RAS-Q 1996) sind nur unter Beachtung dieser Randbedingungen zulässig.

Die Erweiterung der makroskopischen Analyse der Querschnittsbreiten um eine detaillierte Aufarbeitung der Seitenräume erfolgt bei der Trassierung der 100 Untersuchungsstrecken, weil für die Sichtweitenberechnung genaue Informationen zum Straßenraum zwingend erforderlich werden. Hierbei ist ein repräsentativer Querschnitt im Regelfall nicht ausreichend, da sich die Bepflanzungen (Vorhandensein oder nicht sowie die seitlichen Abstände) ständig ändern können. Für die Nachtrassierung sind demzufolge umfassende Informationen zu den Sichthindernissen im Straßenseitenraum erforderlich (vgl. Kapitel 3.5.1). Diese Streckeneigenschaften können über mehrere gemessene Referenzquerschnitte und ergänzend über die CAN-Daten sowie die Videoaufnahmen der Strecken bestimmt werden.

\subsubsection{Signifikanz der Ergebnisse bei Betrachtung der Regelquerschnitte}

Abschließend wird auch für die Unfallkenngrößenberechnung nach Regelquerschnitten eine Signifikanzanalyse vorgenommen. Die Ausführungen orientieren sich dabei an den Ausarbeitungen in Kapitel 3.4.7. Die zugehörigen Tabellen sind Anhang $\mathrm{R}$ zu entnehmen.

Bei Betrachtung der Verkehrsstärke als Bezugsgröße in den 5 gebildeten Querschnittsklassen (vgl. hierzu Anhang R/a) werden steigende Mittelwerte und Standardabweichungen mit höherer zugrundeliegender Fahrbahnbreite erkennbar. Ursache hierfür ist die im Straßennetz verankerte Querschnittsauswahl gemäß der Verbindungsfunktion der Straße. Demzufolge nehmen mit breiter werdendem Querschnitt auch die Verbindungsfunktion sowie die Verkehrsbedeutung und die Verkehrsstärken zu. Da somit die Regelquerschnitte abhängig von der Verkehrsstärke sind, können auch hier keine konsistenten Datenbasen angenommen werden. Im Gegenzug sind bei Betrachtung der Regelquerschnitte die Mittelwerte und Standardabweichungen der Abschnittslängen verhältnismäßig stabil. 
Entsprechend dieser Vermutungen ergeben sich auch bei den Verteilungstests der Datengrundlagen (vgl. Anhang R/b) erwartungsgemäße Ergebnisse. Bei den Verkehrsstärken werden die Nullhypothesen mit sehr hohem Signifikanzniveau abgelehnt, wonach hier unterschiedliche Verteilungen der Datengrundlagen auch aus statistischer Sicht bestätigt werden können. Betrachtet man die Abschnittslängen über die 5 Querschnittsklassen, so können hier überwiegend gleiche zugrunde liegende Verteilungen angenommen werden. Ein verzerrender Einfluss der Abschnittslängen auf die berechneten Unfallkenngrößen ist somit nicht vorhanden.

Wie auch schon bei der Signifikanzanalyse der verkehrsrechtlichen Anordnungen in Kapitel 3.4.7 können auch bei Betrachtung der Regelquerschnitte konsistente Datengrundlagen nicht ausnahmslos angenommen werden. Die Ursachen liegen grundsätzlich in der Landstraßentrassierung nach bestimmten Netzfunktionen begründet.

In Bezug auf die Querschnittsbreiten kann festgehalten werden, dass statistisch abgesicherte bzw. eindeutige Aussagen über die Verkehrssicherheitswirkung verschiedener Regelquerschnitte in Bezug zum Überholunfallgeschehen nicht möglich sind. Möglicherweise wird hierdurch der verzerrende Einfluss der als verschieden anzusehenden Verkehrsstärken in den jeweiligen Kollektiven sichtbar. Die potentiellen Thesen, dass schmale Landstraßenquerschnitte negativ auf das Überholunfallgeschehen wirken und das breite Querschnitte zwar einen gewissen Aufforderungsgehalt zu Überholmanövern besitzen, hier aber dagegen weniger Unfälle geschehen, lassen sich somit nicht zweifelsfrei bestätigen.

\subsubsection{Zusammenfassung}

Im Rahmen der hier vorgestellten Netzanalyse wurden die 500 unfallauffälligsten Untersuchungsstrecken mit insgesamt 2.235 Kilometern Streckenlänge befahren. Die Auswertungen der rechtlichen Anordnungen zeigten, dass auf ca. $70 \%$ des Netzes keine rechtlichen Restriktionen in Bezug zum Überholvorgang vorhanden sind. Auf den verbleibenden $30 \%$ muss gegebenenfalls die Wirksamkeit der bereits vorhandenen Maßnahmen überprüft werden. Wird ein Überholverbot angeordnet, so handelt es sich zu 56 \% um eine Markierung, zu $22 \%$ um eine Beschilderung und zu weiteren $22 \%$ um eine Kombination aus Markierung und Beschilderung, die nach den rechtlichen Vorgaben eigentlich nicht auftreten sollte. Zwischen den 5 untersuchten Bundesländern sind vereinzelt unterschiedliche rechtliche Anordnungen aufgetreten, die grundlegenden Tendenzen zwischen freigegebenen Abschnitten und angeordneten Überholverboten sind allerdings im gesamten Untersuchungsgebiet offensichtlich.

Die Ergebnisse der Streckenbefahrung lassen sowohl auf Streckenebene als auch auf Unfallebene eine Auffälligkeit von Abschnitten ohne rechtliche Einschränkungen zu den Überholvorgängen vermuten. Die genaue Zuordnung der Überholunfälle zu den ermittelten Bereichen der Streckenbefahrung ergab eine geringfügig höhere Unfallauffälligkeit von freigegebenen Abschnitten als diese anteilsmäßig im Straßennetz vorhanden sind. In der anschließenden Sichtweitenanalyse gilt es daher die Frage zu beantworten, ob in den Bereichen ohne rechtliche Restriktionen wegen fehlender Sichtweiten der Fahrzeugführer nicht tatsächlich durch regelnde Vorgaben der Straßenver- 
kehrsbehörde in seinem Fahrverhalten unterstützt werden sollte, um schwerwiegende Überholunfälle in ungeeigneten Bereichen zu vermeiden.

In Bezug zur zulässigen Höchstgeschwindigkeit kann eine hohe Geschwindigkeitsstreuung auf freigegebenen Abschnitten Überholungen und auch Überholunfälle provozieren. Bei vorhandenen Geschwindigkeitsbeschränkungen sinkt die Geschwindigkeitsstreuung, allerdings sind die Überholunfälle womöglich auch nur in Verbindung mit einer überhöhten Geschwindigkeit entstanden. Eine geringe Geschwindigkeitsstreuung lässt grundsätzlich auch weniger Überholvorgänge und -unfälle erwarten, was sich auch in den Auswertungen wiederspiegelt. Die Geschwindigkeitsbeschränkung steht somit im engen Zusammenhang zum Überholdruck. Erwartungsgemäß sind die Unfallfolgen bei hohen Geschwindigkeiten ebenfalls schwerer. Durch den hergestellten Bezug von Unfallgeschehen zu Streckenlängen konnten die angesprochenen Tendenzen bestätigt werden.

In den Ergebnissen der Unfallkenngrößenberechnung mit Bezug auf die Längen von unfallauffälligen Einzelabschnitten wurde allerdings eine komplette Umkehr der bisherigen Tendenzen festgestellt. Allerdings darf das erhöhte Unfallgeschehen in freigegebenen Abschnitten nicht auf Grundlage von einzelnen Unfällen auf kurzen Merkmalslängen, was einen stark verzerrenden Einfluss auf die Unfallkenngrößen hat, abgewertet werden. Demzufolge wurde der Längenbezug geändert und sowohl die unfallauffälligen als auch die unfallfreien Landstraßenabschnitte in die Bewertung mit einbezogen. Die verzerrenden Einflüsse kurzer Einzellängen konnten dadurch eliminiert und Unfallkenngrößen zur Bewertung des Gesamtnetzes berechnet werden, wobei sich auch die erwartungsgemäßen Tendenzen ergaben.

Grundlegend zeigte sich eine Erhöhung der Verkehrssicherheit, wenn Überholverbote oder Geschwindigkeitsbeschränkungen angeordnet werden. Die Effekte erreichen ihr Maximum, wenn sowohl Überholverbote als auch Geschwindigkeitsbeschränkungen angeordnet sind.

Um die Güte der berechneten Unfallkenngrößen bestimmen zu können, wurden Tests zur Prüfung der inneren Signifikanz der zugrundeliegenden Bezugsgrößen durchgeführt und deren Einfluss auf die berechneten Unfallkenngrößen bewertet. Abnahmen der Unfallkenngrößen sowie statistisch signifikante Bezugsgrößen können nur für aggregierte Merkmale (Überholverbote und Geschwindigkeitsbeschränkungen als dichotome Variablen mit dem Ausprägungen ja/nein) der verkehrsrechtlichen Anordnungen eindeutig nachgewiesen werden. Im Ergebnis verringert sich demnach das Überholunfallgeschehen mit der Anordnung von verkehrsrechtlichen Restriktionen. Mit zunehmendem Detaillierungsgrad der Betrachtungen (Einbeziehung der Unfallschwere sowie Differenzierung verschiedener Überholverbote) nehmen Unterschiede der Ergebnisse sowie die Sicherheit einer konsistenten Datengrundlage ab. Sicherheitstechnisch als gut anzusehende Überholverbote können demnach nicht angegeben werden.

Für die ermittelten Fahrbahnbreiten ergaben sich bei den Unfall(kosten)raten fallende Tendenzen mit steigenden Elementbreiten, dagegen stiegen die Unfall(kosten)dichten leicht an. Für die Seitenraumbreiten konnten keine Aussagen über Zusammenhänge zum Unfallgeschehen getroffen werden. Insgesamt waren beide Teilauswertungen durch äußerst geringe Bestimmtheitsmaße gekennzeichnet, weswegen mit den vorliegenden Ergebnissen nicht mehr als Mutmaßungen über 
gewisse Abhängigkeiten und Zusammenhänge zulässig sind. Jedoch kann vermutet werden, dass diese betrachteten Breiten als alleiniges Kriterium zur Beschreibung des Unfallgeschehens nicht ausreichend sind, da wesentlich mehr Faktoren eine Überholentscheidung beeinflussen können.

Die analysierten teilweise alten Bestandsstrecken wurden den Regelquerschnitten verschiedener Richtliniengenerationen zugewiesen. Auch bei diesen Auswertungen können fallende Tendenzen mit breiterem Regelquerschnitt grundsätzlich bestätigt werden. Insgesamt lassen die Ergebnisse der durchgeführten Auswertungen verschiedener Querschnitte aber keine belastbaren Schlussfolgerungen zu. Die abschließende Signifikanzanalyse bestätigt diese Vermutung. Statistisch ausreichend abgesicherte Aussagen über die Unfallauffälligkeit verschiedener Querschnittsbreiten sind nicht möglich. Es wird angenommen, dass die Querschnittsbreiten somit nicht als alleiniges Merkmal zur Beschreibung des Überholunfallgeschehens genügen. Das Überholverhalten wird im Wesentlichen durch eine Überlagerung der Lagepläne, Höhenpläne sowie Querschnitte und der daraus resultierenden vorhandenen Sichtweiten beeinflusst

In der weiteren Projektbearbeitung lässt sich in verkleinertem Rahmen mittels Nachtrassierung der 100 unfallauffälligsten Untersuchungsstrecken überprüfen, ob die vorhandenen Sichtweiten den verkehrsrechtlichen Anordnungen auf den Landstraßenabschnitten entsprechen. Die Vorgaben der Regelwerke (RAS-L bzw. RAL und RMS) und deren Umsetzung können durch die Nachtrassierung zur Diskussion gestellt werden. Inwieweit die Einheit von Bau (vorhandene Sichtweiten) und Betrieb (rechtliche Restriktionen) hier sichergestellt ist, bleibt abzuwarten. Zudem muss auch die Wirksamkeit der verschiedenen Überholverbote in Frage gestellt werden. Bei der Klassifizierung der Straßen nach den Vorgaben der RAL sind diese Aspekte unbedingt zu beachten, da mit der Festlegung bzw. Übertragung der Entwurfsklassen auf das Bestandsnetz auch ein entsprechendes Überholprinzip sichergestellt werden soll. 


\subsection{Analyse der vorhandenen Sichtweiten}

Ziel dieses Arbeitspaketes ist die Ergänzung der im vorhergehenden Kapitel beschriebenen Zusammenhänge zwischen dem Unfallgeschehen und den rechtlichen Überholmöglichkeiten um die vorhandenen Sichtweiten. Diese werden stellvertretend für die tatsächlich vorhandenen Überholmöglichkeiten auf den Untersuchungsstrecken betrachtet.

Die Datengrundlage für die Nachtrassierung der Untersuchungsstrecken kann über vorhandene Trassierungsdaten der Straßenbauverwaltungen (lediglich in Bundesland 3 liegen hinreichend genaue Daten vor) sowie ergänzend durch eigene Erhebungen mit GPS-Empfängern bereitgestellt werden. Die Methodik der GPS-Erhebung sowie Trassierung und Sichtweitenanalyse wird in diesem Teil des Berichtes ausführlich beschrieben.

\subsubsection{Nachtrassierung der Untersuchungsstrecken}

Die Nachtrassierung der erhobenen dreidimensionalen Raumpunkte wird mit Hilfe des Programmsystems Card/1 durchgeführt. Nach der Umrechnung der erhobenen geographischen Koordinaten in Gauß-Krüger-Koordinaten werden die Punktfolgen in Card/1 eingelesen. Auf Basis dieser Punktfolgen wird mit der Entwurfssoftware eine Generierung der Achse im Lageplan und der entsprechenden Gradiente im Höhenplan durchgeführt. Diesem nachtrassierten dreidimensionalen Streckenband werden von Anfangs- bis Endstation, auf Basis der während der Streckenbefahrungen erhobenen Daten die entsprechenden Fahrbahnbreiten und Querprofile zugeordnet.

Durch die Überlagerung von Achse, Gradiente und Straßenquerschnitt entsteht die räumliche Linienführung der Untersuchungsstrecke. Zur Berechnung von Sichtweitenbändern werden außerdem noch Sichthindernisse im Straßenseitenraum benötigt, da besonders in Kurven die Seitenraumgestaltung für das Vorhandensein einer Überholsichtweite entscheidend ist. Befinden sich beispielsweise in einer gestreckten Linkskurve keine Hindernisse, so kann hier die erforderliche Überholsichtweite durchaus vorhanden sein und ein Überholvorgang bei entsprechender Verkehrssituation auch sicher durchgeführt werden. Befindet sich dagegen an der Kurveninnenseite ein Wald oder im Einschnitt eine Böschung, so ist der Überholvorgang nicht durchführbar.

Nach Lippold et.al. [2009] kann bei der Seitenraumgestaltung nach punktuellen, linienhaften und flächigen Bepflanzungen differenziert werden. Für die Hindernisdarstellung dieser Untersuchung sollen beispielsweise Einzelbäume nicht berücksichtigt werden, einzelne punktuelle Baumgruppen können dagegen in bestimmten Situationen für eine Behinderung sorgen und sind mit ihrer entsprechenden Länge als Querprofil anzulegen. Linienhafte Bepflanzungen wie Alleen können zwar in bestimmten Betrachtungswinkeln einen durchgehenden Sichtstrahl ermöglichen, dennoch aber bei einer gewissen Staffelung der Baumreihe ein unüberwindbares Sichthindernis darstellen. Als Sichthindernis im Sinne dieser Untersuchung gelten demzufolge alle Seitenraumelemente, die einen Einfluss auf die Sichtbeziehungen zwischen zwei entgegenkommenden Fahrzeugen haben.

Zur Beurteilung der Straßenraumgestaltung werden zur Nachtrassierung die Aufnahmen der Videobefahrung herangezogen. Die Stationierung von Beginn und Ende eines Sichthindernisses lässt sich über eine Verknüpfung der CAN-Daten und des entsprechenden Zeitstempels berech- 
nen und kann somit in Card/1 übernommen werden. Der seitliche Abstand der Sichthindernisse von der Fahrbahn wird über mehrere gemessene Referenzquerschnitte während der Streckenbefahrung ermittelt. Die Hindernisse im Straßenseitenraum werden an den entsprechenden Stationierungen im Straßenmodell als unendlich hohe Wand dargestellt, an der kein Sichtstrahl vorbeigehen kann. Böschungen sowie passive Schutzeinrichtungen mit geringer Höhe, über die teilweise der Sichtstrahl hinweggehen kann, wurden dagegen mit einer entsprechenden realistischen Höhe nachgebildet. Durch diese Anpassung der Querprofile der Untersuchungsstrecken ist ein Abbild des gesamten Straßenraumes entstanden, welches alle für die Sichtweitenermittlung erforderlichen Elemente beinhaltet.

Bei der Bestimmung der erforderlichen Überholsichtweiten werden die definierten fahrdynamischen und geometrischen Modellvorstellungen der RAS-L [FGSV, 1995] verwendet. Demzufolge wird mit Aug- und Zielpunkthöhen von jeweils 1 Meter eine dreidimensionale Sichtweitenberechnung durchgeführt. Grundlage des Berechnungsalgorithmus ist das sogenannte Sichtkegelverfahren, bei dem die Sichtstrahlen des Augpunktes vom Fahrzeugführer zu allen Zielpunkten bis zum Endquerschnitt zu einem Sichtkegel zusammengefasst werden. Durch die Rückprojektion des maßgebenden Querschnittes kann somit eine hohe Berechnungsgenauigkeit erreicht werden [Kuczora, 2004]. Grundlage für die folgende Sichtweitenbewertung ist ein Vergleich der berechneten, tatsächlich vorhandenen Sichtweiten im Straßenraum mit den erforderlichen Sichtweitendefinitionen der aktuell gültigen Regelwerke des Straßenentwurfs. Die erforderliche Überholsichtweite wird unterschieden nach den RAS-L [FGSV, 1995] und der RMS [FGSV, 1980] und ist darin wie folgt angegeben:

\begin{tabular}{|c|c|c|}
\hline $\mathrm{V}_{85}[\mathrm{~km} / \mathrm{h}]$ & $\mathrm{s}_{\mathrm{u}}[\mathrm{m}]$ nach RAS-L & $\mathrm{s}_{\mathrm{u}}[\mathrm{m}]$ nach RMS \\
\hline 60 & 475 & 90 \\
\hline 70 & 500 & 125 \\
\hline 80 & 525 & 170 \\
\hline 90 & 575 & 225 \\
\hline 100 & 625 & 280 \\
\hline
\end{tabular}

Tabelle 3.15: Richtwerte der Überholsichtweite nach RAS-L und RMS

Eine Markierung von Fahrstreifenbegrenzungen zur Verhinderung des Befahrens von Fahrstreifen durch den Gegenverkehr ist bei deutlich geringeren Überholsichtweiten erforderlich als es die Sichtweitendefinition der RAS-L vorgibt. Zudem ist nach RAS-L ein Sichtweitenbereich zwischen voller und halber Überholsichtweite zu vermeiden. Im Gegenzug muss aber vermutet werden, dass die Überholsichtweiten der RAS-L für zügige Fahrer zu hoch sind, da diese für eine Überholung oftmals eine geringere Strecke benötigen. Allerdings können für ein Modell für Überholsichtweiten nicht diese Fahrer bzw. Fahrzeuge als maßgebend angesehen werden. In den RAS-L-1 von 1984 waren die Richtwerte der Überholsichtweiten vermutlich wegen anderer Fahrzeugeigenschaften sogar noch größer. Das Überholmodell der RAS-L geht allerdings davon aus, dass ein begonnener Überholvorgang auch sicher abgeschlossen werden kann. Die Richtwerte der RMS stellen ein absolutes Minimum an Sichtweiten dar, bei denen ein begonnener Überholvorgang sicher wieder abgebrochen werden kann. Bei den angegebenen Mindestwerten einer Überholsichtweite nach RMS 
handelt es sich demzufolge um eine Mindestsichtweite, um eine Leit- bzw. Warnlinie anordnen zu können. Folgende Abbildung verdeutlicht die Unterschiede zwischen beiden Regelwerken.

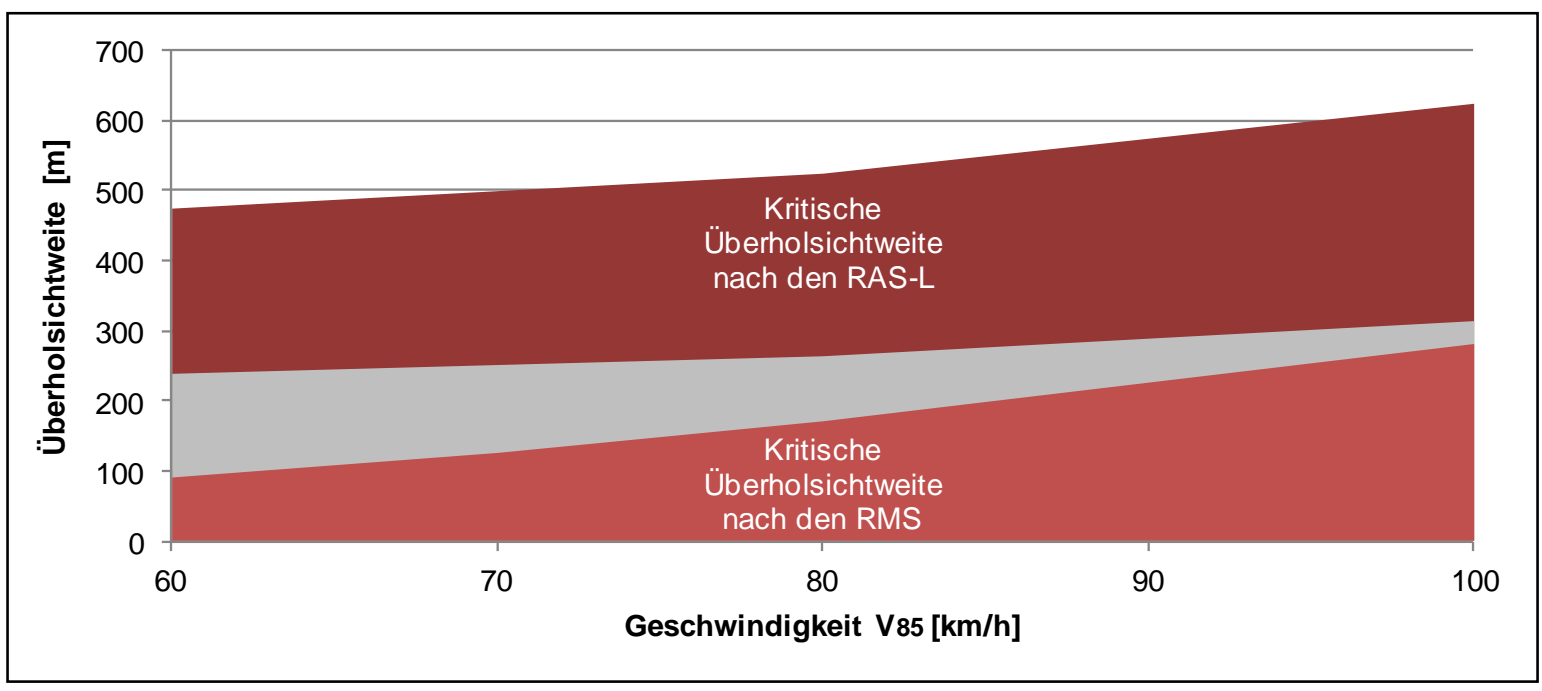

Abbildung 3.13: Differenzen zwischen RAS-L und RMS [Künzelmann, 2012]

Die Verschneidung der kritischen Sichtweiten nach den RMS und den RAS-L zeigt, dass eine Grauzone zwischen den kritischen Sichtweitenbereichen vorhanden ist. Hier liegen die Sichtweiten nach den RAS-L in einem Bereich unterhalb der halben Überholsichtweite und sind daher unkritisch, da für die Verkehrsteilnehmer klar erkennbar ist, dass ein Überholvorgang nicht durchgeführt werden kann. Gleichzeitig sehen die RMS kein Überholverbot vor, da die kritischen Sichtweiten nach den RMS nicht unterschritten sind. Bei Sichtweiten innerhalb der Grauzone bleibt jedoch offen, ob die Situation durch die Verkehrsteilnehmer immer entsprechend eingeschätzt werden kann. Überholungen sind hier in jedem Fall kritisch. Die Forderung nach einer einheitlichen erforderlichen Sichtweite, bei deren Unterschreitung das Überholen zu untersagen ist, erscheint demnach als notwendige Konsequenz [Künzelmann, 2012]. Mit Blick auf diese vorhandenen Differenzen und die grundsätzlich angestrebte Einheit von Bau und Betrieb zur Verbesserung der Verkehrssicherheit ist daher für die Darstellung der Sichtweitenbänder (Höhe bzw. Änderung der Sichtweiten im Streckenverlauf) ein Vergleich der berechneten Überholsichtweiten mit den erforderlichen Sichtweiten beider Regelwerke vorgesehen.

Wie bereits Tabelle 3.15 verdeutlicht, ist die Zuordnung von erforderlichen Sichtweiten zu entsprechenden Teilen der Untersuchungstrecken abhängig von der darauf gefahrenen Quantilgeschwindigkeit $\mathrm{v}_{85}$. Stellvertretend für diese Geschwindigkeit wird in dieser Untersuchung die gesetzlich zulässige Höchstgeschwindigkeit auf den Untersuchungsstrecken verwendet. Unter der $\mathrm{V}_{85}$ wird die Geschwindigkeit verstanden, die von $85 \%$ der freifahrenden Verkehrsteilnehmer nicht überschritten wird und dient nach RAS-L (1995) zur Beschreibung des tatsächlichen Fahrverhaltens. Die zulässige Höchstgeschwindigkeit wird hier als Orientierungsgröße und somit als gute Näherung für die Erzeugung eines stationierungsabhängigen Geschwindigkeitsbandes auf den Untersuchungsstrecken angesehen. Im Gegensatz zur makroskopischen Streckenanalyse (vgl. Kapitel 3.4.1) ist somit eine Bezifferung der Geschwindigkeitsbeschränkung notwendig, die ebenfalls im Rahmen der Videoanalyse stattfindet. 


\subsubsection{Ergebnisse der Nachtrassierung}

Als Ergebnis der Nachtrassierung bzw. Grundlage für die Analyse der Zusammenhänge von Überholunfällen zu den baulichen Streckencharakteristiken werden Streckenbänder erstellt, welche die folgenden Bestandteile aufweisen:

- Krümmungsband

- Höhenplan

- vorhandene Überholsichtweiten in Richtung und Gegenrichtung

- $\quad$ erforderliche Überholsichtweiten nach Definition der RAS-L und RMS

- verkehrsrechtliche Anordnungen (vgl. Kapitel 3.4.1)

- Knotenpunkte inkl. Einflussbereiche

- Unfallpositionen

Die Darstellung der Unfälle erfolgt im Streckenband der verkehrsrechtlichen Anordnungen, wobei die Unfallposition über alle anderen Bänder hinweg markiert wird. Hierbei sind auch besonders die Fahrtrichtungen der Hauptverursacher der Überholunfälle von Bedeutung, welche den Unfalldaten der Polizeibehörden entnommen werden. Zur Festlegung der Einflussbereiche von Knotenpunkten werden die Verziehungen der Knotenpunktgeometrie bzw. die Positionen der angeordneten Knotenpunktgeschwindigkeiten als Orientierung herangezogen. Es werden hier Längen von ca. $150 \mathrm{~m}$ bis $200 \mathrm{~m}$ vor und nach dem Kreuzungsbereich angestrebt und farblich hervorgehoben. Sind keine Verziehungen durch zusätzliche Abbiegefahrstreifen oder abweichende Knotenpunktgeschwindigkeiten vorhanden, so verringert sich der Knotenpunktbereich pauschal auf insgesamt $100 \mathrm{~m}$ und dient hier lediglich der Kenntlichmachung einer besonderen Situation im Streckenband.

Als Übersicht und Einleitung der Streckenbänder sind Datenblätter mit den grundlegenden Merkmalen zur Untersuchungsstrecke zu erstellen. Diese beinhalten beispielsweise die Streckenlänge, Unfallanzahl, Seitenraumgestaltung, die Anteile verschiedener rechtlicher Anordnungen sowie einen Luftbildausschnitt zur groben Darstellung der Örtlichkeit. Die Ergebnisse der Datenblätter und Streckenbänder sind in den Anlagen 1 bis 3 zum Bericht einzusehen.

Es wird darauf hingewiesen, dass sich die Längenangaben der Untersuchungsstrecken zwischen Anhang D und den Streckenbändern in Anlage 1 unterscheiden können. Dieser Umstand wurde nach den Streckenbefahrungen geprüft und ist auf Ungenauigkeiten bei der Verortung der Ortstafeln in der Straßeninformationsbank zurückzuführen. Die Positionen der Ortstafeln in den Datenbanken der Straßenbauverwaltung können sich in schlechten Fällen um mehrere hundert Meter von den tatsächlichen Begrenzungen der Ortsdurchfahrten unterscheiden (vgl. Kapitel 3.4.3). Die erhobenen Längenangaben der Streckenbefahrung sind daher als maßgebend anzusehen.

Die Plausibilität der Ergebnisse der Nachtrassierung in den Streckenbändern wurde parallel mit den Videos der Streckenbefahrung überprüft. Hierbei konnte eine insgesamt sehr gute Qualität der Ergebnisse der Trassierung in Lage- und Höhenplan sowie der sich daraus ergebenden vorhan- 
denen Sichtweiten festgestellt werden. Die in den Datenblättern enthaltenen Eigenschaften einer Gesamtstrecke wurden außerdem für das gesamte Untersuchungsgebiet in einer großen Datenbank zusammengefasst. Mittels dieser Datenbank soll im folgenden Kapiteln versucht werden, die Zusammenhänge zwischen dem Überholunfallgeschehen und den allgemeinen Merkmalen auf Ebene der einzelnen Landstraßen auszuweisen. Hierbei soll die Grundlage für die Auswahl von geeigneten Kenngrößen gebildet werden, welche im Rahmen der späteren Clusterung (vgl. Kapitel 3.3.4 sowie Kapitel 3.5.6) innerhalb der ersten 100 unfallauffälligsten Untersuchungsstrecken zur Auswahl von 50 für die Detailanalyse vorzubereitende Strecken herangezogen werden sollen. Bereits gesichtete Untersuchungen im Rahmen der Literaturanalyse lassen derartige Zusammenhänge nicht zwangsläufig erwarten, allerdings gilt es dies auf Basis der vorliegenden Untersuchung zu bestätigen oder zu widerlegen.

\subsubsection{Zusammenhänge zwischen Unfallgeschehen und Landstraßeneigenschaften}

In diesem Kapitel werden die Ergebnisse der Wechselwirkungen von Eigenschaften der einzelnen Landstraßen sowie der verkehrlichen Randbedingungen auf das Unfallgeschehen mit Bezug zum Überholvorgang vorgestellt. Die dazugehörigen Darstellungen sind Anhang S zu entnehmen.

Anhang S/a beinhaltet die noch relativ deutlichen Zusammenhänge zwischen der betrachteten Nettostreckenlänge und der Anzahl der Überholunfälle. Erwartungsgemäß nimmt mit steigender Länge einer Untersuchungsstrecke auch die Wahrscheinlichkeit von Überholunfällen zu. Die dennoch enthaltene Streuung erzeugt ein Bestimmtheitsmaß von 0,32, was in Anlehnung an die Interpretationen von Stolz [1967] trotzdem auf einen deutlichen Zusammenhang schließen lässt.

In den folgenden 8 Darstellungen sind sowohl die Streckenanteile als auch die Streckenlängen der rechtlichen Überholmöglichkeiten, der Überholmöglichkeiten wie sie nach RAS-L und RMS tatsächlich vorhanden sind und den Geschwindigkeitsbeschränkungen einsehbar. Hierbei wird beim grundsätzlichen Vergleich von Streckenanteilen und absoluten Streckenlängen deutlich, dass die Zusammenhänge zwischen allen dargestellten Streckenanteilen und dem Unfallgeschehen vernachlässigbar gering sind. Daher wird an dieser Stelle nur auf die Wechselwirkungen der absoluten Streckenlängen zum Unfallgeschehen eingegangen, zumal sich auch die generellen Tendenzen nicht anders darstellen. Die Kenntnis über die nicht vorhandenen Zusammenhänge wird später dennoch bei der Clusterung von 50 Untersuchungsstrecken von Bedeutung sein.

Betrachtet man die rechtlichen Restriktionen in Bezug zum Überholen auf den Untersuchungsstrecken, so ergibt sich eine erhöhte Unfallauffälligkeit mit steigender Länge von freigegebenen Abschnitten. Die Matrixdarstellungen aus Kapitel 3.4 beinhalteten den Hinweis einer Unfallhäufung auf den freigegeben Abschnitten im gesamten Untersuchungsgebiet, welcher nun durch die Zusammenhänge auf Streckenebene bestätigt werden kann. Es wird darauf verwiesen, dass an dieser Stelle nicht berücksichtigt wurde, ob die Überholunfälle in dem freigegebenen oder restriktiven Abschnitt einer Strecke geschehen sind. Die Zuordnungen auf Unfallebene (vgl. Kapitel 3.4.3) lassen hier aber keine grundsätzlich anderen Tendenzen erwarten, daher sind die getroffenen 
Schlussfolgerungen als korrekt anzusehen. Ob die rechtlichen Überholmöglichkeiten auf den Strecken gerechtfertigt sind, soll an anderer Stelle geklärt werden.

Berücksichtigt man die tatsächlichen Überholsichtweiten einer Strecke, welche nach den RAS-L vorhanden sind, so ergibt sich ebenfalls ein steigender Zusammenhang. Die Überholmöglichkeit nach RAS-L ist dann gegeben, wenn die vorhandenen Sichtweiten der Landstraßentrassierung die erforderlichen Sichtweiten - die durch die Geschwindigkeitsangaben vorgegeben werden - überschreiten. Gleiches gilt auch analog für die Sichtweiten nach RMS. Die steigenden Zusammenhänge verweisen darauf, dass durchaus auch Überholunfälle entstehen können, wenn die Sichtweitenverhältnisse ausreichend sind. Die vorhandene Streuung verdeutlicht aber auch, dass hier durchaus Unregelmäßigkeiten auftreten können. Ähnliche Zusammenhänge ergeben sich auch nach den vorhandenen Sichtweiten nach RMS, allerdings sind die Ausprägungen der Wechselwirkungen hier noch deutlicher.

Zwischen den RAS-L und den RMS sorgt die unterschiedliche Sichtweitendefinition nach Tabelle 3.15 für Unterschiede. Die weiteren Unterschiede der Zusammenhänge zwischen den rechtlichen sowie tatsächlichen vorhandenen Überholmöglichkeiten und dem Unfallgeschehen lassen teilweise fehlende rechtliche Restriktionen im Straßennetz vermuten. Wenn auf den Untersuchungstrecken so markiert bzw. beschildert worden wäre wie es die RMS vorgeben, dann wären die Verteilungen der rechtlichen Anordnungen auch miteinander vergleichbar. Stattdessen nimmt das Bestimmtheitsmaß von den rechtlichen Anordnungen über die Sichtweiten nach RAS-L bis hin zu den Sichtweiten nach RMS zu.

Bei Betrachtung der vorhandenen Geschwindigkeitsbeschränkungen auf Streckenebene ergeben sich ebenfalls steigende Tendenzen. Demzufolge nimmt die Unfallanzahl zu, wenn die Streckenlänge mit freigegebenen Abschnitten ebenfalls ansteigt. Hier können erneut die in Kapitel 3.4.2 angegebenen Vermutungen aufgegriffen werden. Nimmt demnach die Geschwindigkeit von beschränkten zu freigegebenen Streckenteilen zu, so steigt die Geschwindigkeitsstreuung und das Überholbedürfnis bei den Interaktionen zwischen den Verkehrsteilnehmern nimmt ebenfalls zu. Zu berücksichtigen ist hier allerdings auch, die einzelnen hier betrachteten Variablen untereinander korrelieren können, da die Erhöhung der Streckenlänge ohne Geschwindigkeitsbeschränkungen auch generell mit einer Erhöhung der Nettostreckenlänge einhergeht. In Bezug zur Überholsituation werden ergänzend in Kapitel 3.5.4 nochmals die inneren Abhängigkeiten dieser Variablen analysiert.

Die Zusammenhänge zwischen der Unfallanzahl und der Verkehrsstärke sowie dem Schwerverkehrsanteil sind in Anhang S/j bzw. Anhang S/k einsehbar. Es ergibt sich mit erhöhter Verkehrsstärke auch eine leicht ansteigende Regressionsgerade. Allerdings kann bei Betrachtung des Bestimmtheitsmaßes nicht mehr von Zusammenhängen gesprochen werden. Eine Häufung von Überholunfällen ergibt sich in Verkehrsstärkebereichen zwischen 5.000 und 10.000 Fzg./24h. Hier wird angenommen, dass dieser Bereich die durchaus überwiegenden Verkehrsstärkewerte für einbahnig, zweistreifige Landstraßen darstellt, woraus automatisch ein gewisses Übergewicht entsteht. Unter 5.000 Fzg./24h nimmt wahrscheinlich auch die Notwendigkeit von Überholmanövern 
ab und kann im Umkehrschluss auch seltener zu Überholunfällen führen. Steigt die Verkehrsstärke dagegen über $10.000 \mathrm{Fzg} . / 24 \mathrm{~h}$, so können wegen des hohen Verkehrsaufkommens ebenfalls nicht mehr viele Überholungen durchgeführt werden. Treten sie aber dennoch auf, dann kann dies schwerwiegende Überholunfälle zur Folge haben. Mit steigenden Schwerverkehrsanteilen ist ebenfalls ein geringer Anstieg der Überholunfälle zu verzeichnen, aber auch hier sind die Interpretationen wegen des geringen Bestimmtheitsmaßes eher vage. Mit zunehmender Schwerverkehrsbelastung nimmt die Anzahl von potentiellen Hindernisfahrzeugen zu, was den Überholdruck steigern und Überholunfälle zur Folge haben kann. Allerdings bleiben auch bei diesen Betrachtungen weitere unfallbegünstigende Einflussfaktoren unberücksichtigt. Eine Ursache für die eher schwach ausgeprägten Zusammenhänge ist möglicherweise in der Multikausalität von Unfallereignissen zu suchen. Die Aussagekraft der Abhängigkeiten von Einzelmerkmalen zum Überholunfallgeschehen wurde bereits in Kapitel 3.4.8 angezweifelt. Dieser Aspekt kann auf Grundlage der hier erzielten Ergebnisse bestätigt werden.

\subsubsection{Variablenkorrelationen}

Die inneren Zusammenhänge bzw. bereits vorhandene Korrelationen einzelner Variablen untereinander können Anhang T entnommen werden. In den Abbildungen a und b werden die rechtlichen Überholmöglichkeiten (angeordnete Restriktionen) mit den tatsächlich vorhandenen Überholsichtweiten nach RAS-L und RMS überlagert. In beiden Fällen ergeben sich steigende Tendenzen, demnach nehmen mit steigenden tatsächlich vorhandenen Überholmöglichkeiten der Trassierung nach RAS-L auch die rechtlichen Überholmöglichkeiten zu bzw. angeordnete Überholverbote ab. Die Zusammenhänge sind bei den Sichtweiten nach RMS stärker ausgeprägt als bei den RAS-L, da hier erneut die unterschiedlichen Sichtweitendefinitionen zum Tragen kommen. Die RAS-L sind Grundlage der Trassierung, die RMS bilden die Basis für die Anordnung von Überholverboten und zwischen beiden existiert die in Abbildung 3.13 dargestellte Lücke. Die Zusammenhänge der rechtlichen Anordnungen zu den Sichtweiten nach RMS sind aber mit einer gewissen Streuung deutlich erkennbar. Wegen der geringeren erforderlichen Überholsichtweite nach RMS werden diese Forderungen im Straßenbetrieb (Markierung und Beschilderung) auch vergleichsweise häufiger durchgesetzt.

Befinden sich Punkte oberhalb der Winkelhalbierenden, so sind mehr Überholmöglichkeiten vorhanden als die rechtlichen Vorgaben auf den Landstraßen tatsächlich zulassen. Kurzum sind hier mehr Streckenabschnitte mit einem Überholverbot belegt, als eigentlich nach der Sichtweitendefinition notwendig wäre. Hauptmerkmal derartiger Strecken ist eine Vielzahl von Knotenpunkten. In Knotenpunktbereichen sind mit den erforderlichen freizuhaltenden Sichtfeldern der untergeordneten Verkehrsströme auch bestimmte Sichtweiten im bevorrechtigten Verkehrsstrom verbunden. Jedoch sind in Knotenpunktbereichen häufig Überholverbote angeordnet, obwohl die Sichtweiten vorhanden sind. Bei Untersuchungsstrecken unterhalb der Winkelhalbierenden übersteigen die rechtlichen Überholmöglichkeiten die Möglichkeiten, die durch die Sichtweitendefinition eigentlich vorhanden sein dürften. Dies kann als Hinweis auf fehlende rechtliche Anordnungen verstanden werden. Bei den Zusammenhängen der RMS liegt Homoskedastizität vor, dagegen ist 
bei den Vergleichen mit der RAS-L eine veränderte Streuung festzustellen. Demzufolge sind auch die Zusammenhänge der Überholmöglichkeiten nach RMS zu den rechtlichen Anordnungen relativ deutlicher ausgeprägt.

Auch bei der Gegenüberstellung der vorhandenen Überholmöglichkeiten nach beiden Regelwerken und der Nettostreckenlänge ergibt sich erwartungsgemäß ein steigender Zusammenhang. Insgesamt zeigt sich in Anhang T/c aber auch eine Tendenz der Regressionsgeraden in Richtung der x-Achse, da die harten Sichtweitenkriterien (vgl. Tabelle 3.15) auf den Landstraßen durchaus selten auffindbar sind. Die Sichtweiten nach RMS sind dagegen häufiger anzutreffen, was sich durch die Tendenz der Regressionsgeraden hin zur Winkelhalbierenden widerspiegelt. Betrachtet man dagegen die Zusammenhänge der Nettostreckenlänge zu den rechtlichen Überholmöglichkeiten besteht ebenfalls eine Tendenz in Richtung der Winkelhalbierenden, allerdings liegt die Regressionsgerade unterhalb der Gerade in Anhang T/d. Dies kann erneut auf die Knotenpunktbereiche zurückgeführt werden, in denen trotz vorhandener Sichtweiten auch Überholverbote angeordnet sind. In allen drei beschriebenen Fällen kann die Winkelhalbierende nicht überschritten werden, da nicht mehr Überholmöglichkeiten vorhanden sein können, als die Untersuchungsstrecken lang sind.

Grundsätzlich wird aber erkennbar, dass womöglich auch die Zusammenhänge von Anhang S/c,e,g,i auf die Zusammenhänge des Unfallgeschehens zur Nettostreckenlänge zurückzuführen sind. Die sich ergebenden Sichtweiten in der Landstraßenführung korrelieren stark mit der Länge der Streckenabschnitte, daher sind diese Umstände auch bei der Betrachtung weiterer Einflussfaktoren zu berücksichtigen. Welche Wechselwirkungen zwischen den einzelnen hier beschriebenen Variablen bestehen bzw. welche Zusammenhänge in welchen Größenordnungen noch vorhanden sind, kann mit der hier dargelegten linearen Regression nicht genauer beziffert werden. Die hier ermittelten Ergebnisse können zur Plausibilitätsprüfung der Erkenntnisse in Kapitel 3.5.3 herangezogen werden.

\subsection{5 Überholunfälle in Abhängigkeit der Landstraßentrassierung}

Im Rahmen dieses Kapitels werden die einzelnen, in den Streckenbändern verankerten Überholunfälle mit den Ergebnissen der Nachtrassierung verschnitten. Diese Analyse ist eine Erweiterung der Untersuchungen des Unfallgeschehens auf Streckenebene (vgl. Kapitel 3.5.3) durch eine Betrachtung der Zusammenhänge auf Unfallebene. Demzufolge können die Abhängigkeiten der Überholunfälle zu den Merkmalen des Lage- und Höhenplanentwurfs sowie in Abhängigkeit der entsprechenden Querprofile die Sichtweiten am Unfallort bewertet und mit den vorhandenen rechtlichen Anordnungen verglichen werden. Die Analysen werden Defizite in der Landstraßentrassierung sowie im Betrieb der Straßenverkehrsanlagen erkenntlich machen.

\subsubsection{Kriterien der Streckenbandanalyse}

Für die Analyse der Streckenbänder wird das Unfallgeschehen fahrtrichtungsfein mit den folgenden Landstraßenmerkmalen verschnitten: 
- Krümmungsband (Gerade, Kurve)

- Höhenplan (Gerade, Kuppe, Wanne, Steigung, Gefälle)

- $\quad$ vorhandene sowie erforderliche Sichtweiten nach RAS-L und RMS

- verkehrsrechtliche Anordnungen (Überholverbote, Geschwindigkeitsbeschränkungen, Einflussbereiche von Knotenpunkten)

Zusätzlich zu den beschriebenen Streckeneigenschaften gelten die folgenden Annahmen. Befindet sich ein Unfall unmittelbar innerhalb eines Kreisbogens bzw. innerhalb einer Verbundkurve im Lageplan sowie einer Kuppe oder Wanne im Höhenplan, so wird dieses Merkmal dem Unfall zugewiesen. Zusätzlich zu diesem strikten Kriterium wurde ein Toleranzbereich von 100 m vor bzw. nach dem Element gewährt, dieser gesondert ausgewiesen und später bewertet. Hierbei zählt immer das nächstgelegene Element. Darüberhinaus werden die Radien und Krümmungsrichtungen der Kurven vermerkt. Grund für die gewährte Toleranz um die Elemente herum ist die Annahme, dass beispielsweise bei zwei längeren Geraden, welche durch einen Kreisbogen voneinander getrennt sind und einem Unfall im direkten Umfeld der Kurve auch von einem Einfluss dieses Elementes auf das Unfallgeschehen ausgegangen werden kann. Befindet sich ein Unfall unmittelbar vor der Kurve, so liegt die Vermutung nahe, dass die Überholung in der Geraden begonnen wurde, die Sichtweiten wegen der Kurve aber für einen sicheren Abschluss der Überholung nicht ausreichend waren. In diesem Fall besteht die Möglichkeit, dass während der Überholung aus der Kurve plötzlich Gegenverkehr auftaucht, was in der weiteren Folge zu einem Überholunfall geführt hat. Befindet sich ein Unfall nach einer Kurve, so kann unterstellt werden, dass nach der Kurve mit der Überholung begonnen wurde und es dennoch zu einem Unfall bei besseren Sichtweiten als vor der Kurve gekommen ist. Hier können Probleme durch den schlagartigen Sichtweitensprung nach oben entstehen, da nach der Kurve bessere Sichtweiten als direkt in bzw. vor der Kurve vorhanden sind. Dies kann dazu führen, dass beispielsweise bei dennoch unzureichenden Sichtweiten in der folgenden Geraden eine gewisse Verbesserung der Sichtweiten erkannt wird und diese dem Fahrzeugführer eine potentielle Überholmöglichkeit suggeriert. Darüberhinaus kann bei sich plötzlich bietenden potentiellen Möglichkeiten auch ein Drang zum raschen Abbau des Überholdrucks angenommen werden, was bei unzureichender Abwägung der entsprechenden Verkehrssituation (Beobachtung der rückwärtigen und entgegenkommenden Fahrzeuge) zu Konflikten führen kann. Grundsätzlich können auch Unfälle beim Ein- bzw. Ausschervorgang in den entsprechenden Bereichen aufgetreten sein.

Grundlage dieser Thesen ist die Tatsache, dass die Unfälle der Unfalldatenbanken an den Positionen auf der Landstraße verortet werden, an denen der konfliktauslösende Umstand eingetreten ist. Demzufolge ermittelt sich die Endposition eines Unfalls lediglich aus dem weiteren Unfallverlauf (z.B. Schleudervorgang) [FGSV, 2012a]. Nach Leutzbach/Zoellmer [1989] wurde damals als Station des Unfalles die Endstellung bzw. der Kollisionsort des Fahrzeuges durch den unfallaufnehmenden Polizeibeamten angegeben. Möglicherweise hat sich diese Ansicht in den vergangenen Jahren durch die Einführung von Unfalldatenbanken zu Gunsten der Sicherheitsanalysen verbessert. 
Die gleiche Argumentation wie bei den Kurven kann auch auf den Einflussbereich von Kuppen im Höhenplan übernommen werden. Die Differenzierung der Lage des Unfalls zum entsprechenden Element (davor/mittig/danach) ermöglicht später eine genauere Betrachtung. Bei Kuppen wurden zusätzlich anhand der vorliegenden Halbmesser der Einfluss auf die Sichtweiten abgeschätzt. Ist für einen Unfall keine Angabe der Stationierungsrichtung bzw. Fahrtrichtung des Hauptverursachers aus den Unfalldaten ableitbar, so wurden nur die Merkmale zugewiesen, die eindeutig ermittelt werden konnten.

Innerhalb der Sichtweitenbänder wurde der Wert der tatsächlich vorhandenen Sichtweite aufgenommen und in Verbindung mit den zulässigen Geschwindigkeiten mit den sich ergebenden erforderlichen Sichtweite an dieser Stelle verglichen. Im Ergebnis ergibt sich eine Zuordnung der Unfälle zu 3 Klassen von eingehaltenen Sichtweiten. Hier wird differenziert, ob die Sichtweitenkriterien nach RAS-L bzw. RMS (vgl. Tabelle 3.15) eingehalten sind oder nach beiden Regelwerken keine Sichtweiten vorhanden sind. Außerdem wurde festgehalten, ob sich ein Unfall in einem Sichtweitengefälle befindet oder ob $100 \mathrm{~m}$ vor bzw. unmittelbar nach der Unfallposition ein Sichtweitensprung vorhanden ist. Hiermit kann bestimmt werden, ob durch die sprunghaft ansteigende Sichtweite eine potentielle Überholmöglichkeit suggeriert wird. Befindet sich die vorhandene Sichtweite knapp unter der vorgegebenen Grenze einer der beiden relevanten Regelwerke, so zählt hier der für die Sichtweiten schlechtere Fall. Bewegt sich die vorhandene Sichtweite knapp oberhalb eines Grenzwertes, so wird mithilfe der Sichtweiten der vorherigen 100 m langen Landstraßenabschnittes abgewogen, welcher der zwei möglichen Bereiche um den Grenzwert herum zur Kennzeichnung der vorhandenen Situation am geeignetsten ist. Überschreitet die Überholsichtweite einen Grenzwert beispielsweise um $50 \mathrm{~m}$ und befindet sich der Unfall in einem Sichtweitengefälle und vor der Unfallposition ist ein Sichtweitensprung erkennbar, so muss hier eine eher geringe vorhandene Sichtweite unterstellt werden, da diese im Vorfeld der Unfallsituation nicht vorhanden ist.

Abschließend werden sämtliche Merkmale der erhobenen rechtlichen Anordnungen festgehalten (Überholverbote, Geschwindigkeitsbeschränkung, Knotenpunktbereiche). Die Ergebnisse dieser umfangreichen Erhebungen sind in nachfolgendem Kapitel dargestellt.

\subsubsection{Ergebnisse der Streckenbandanalyse}

Bei der beschriebenen Analyse der Streckenbänder ist eine Datenbank entstanden, welche auf Unfallebene alle Merkmale der Landstraßengestaltung enthält. Die Ergebnisse der zugeordneten 333 Überholunfälle werden nachfolgend beginnend mit den Lageplanelementen dargestellt. Es wird darauf hingewiesen, dass hier lediglich die Ergebnisse der Unfallzuordnung mit der Nachtrassierung verknüpft werden. Eine genaue Kenntnis der Überholsituation, welche zum Unfall geführt hat, liegt an dieser Stelle nicht vor. Dieser Aspekt wird durch die Auswertung der Unfallhergangsbeschreibungen (mikroskopische Unfallanalyse) für die 50 Strecken im Rahmen der Detailanalyse genauer betrachtet. Hier wird die erstellte Datenbank mit den unterschiedlichen Phasen des Überholvorganges - im Umkehrschluss lässt sich der Beginn des Überholvorganges ableiten sowie weiteren unfallbegünstigenden Faktoren erweitert. 


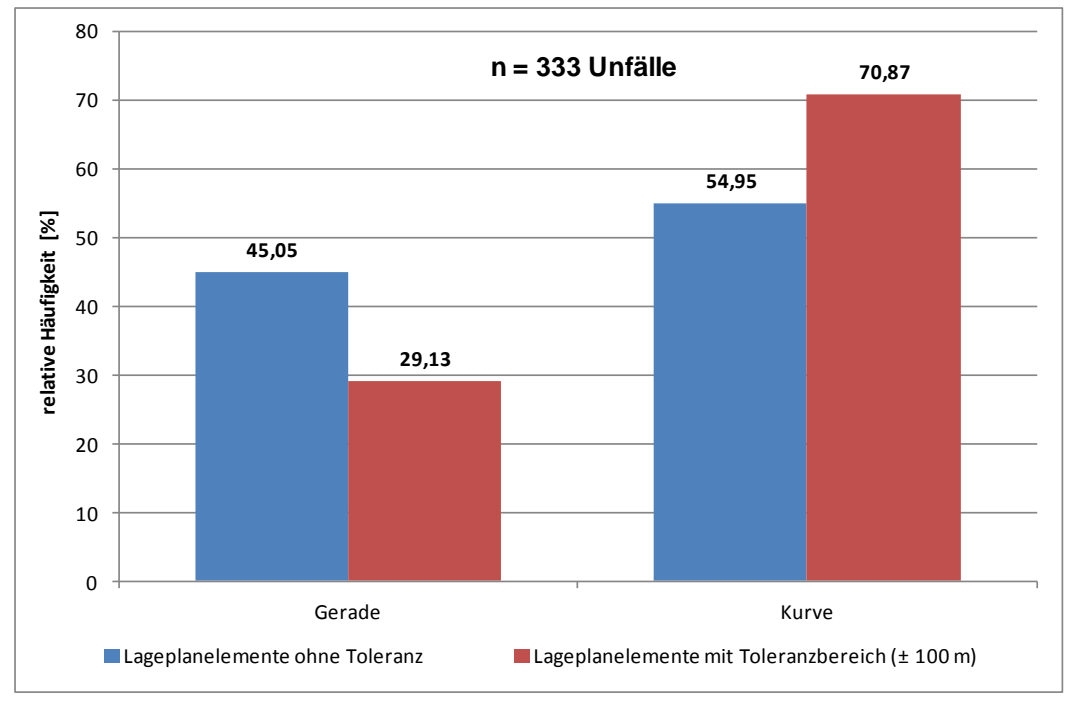

\section{Abbildung 3.14: Überholunfälle in Lageplanelementen}

Aus Abbildung 3.14 wird erkennbar, dass bereits ohne Berücksichtigung eines Toleranzbereiches um Lageplankurven herum eine Tendenz zu diesen Elementen erkennbar wird. Demzufolge geschehen 55 \% der Überholunfälle in Kurven bzw. werden durch diese hervorgerufen. Wird zusätzlich ein Toleranzbereich vor und nach der Kurve zur Auswertung herangezogen - da auch hier ein Einfluss dieses Elementes auf das Fahr- bzw. Überholverhalten vorhanden ist - so steigt der Anteil von Überholunfällen in Kurven auf 71 \%. Hier kann vermutet werden, dass in Geraden - also dort wo möglicherweise ausreichende Sichtweiten vorhanden sind und man tatsächlich überholen kann - auch vergleichsweise wenige Überholunfälle geschehen. Dagegen wird bei dem Einfluss von Kurvenbereichen auf die Überholsichtweiten ein erhöhtes Überholunfallgeschehen erzeugt. Die Differenzierung der Elemente nach der Unfallkategorie ergab keine weiteren nennenswerten Erkenntnisse. Setzt man bei der Auswertung noch die Lage des Überholunfalles in Bezug zur Lageplankurve, so geschahen $10 \%$ im Toleranzbereich vor der Kurve, $12 \%$ im Toleranzbereich hinter der Kurve sowie die verbleibenden 78 \% direkt innerhalb des Kreisbogens bzw. der Verbundkurve.

An dieser Stelle muss aber auch die Topographie der einzelnen Bundesländer des Untersuchungsgebietes berücksichtigt werden. Es ist grundsätzlich davon auszugehen, dass mit zunehmendem bewegten Gelände und dementsprechender Trassierung auch die Anzahl der ausgewerteten Lageplankurven ansteigt. In Bundesland 3 und Bundesland 4 war der Anteil von Unfällen in geraden Lageplanelementen vergleichsweise hoch, wohingegen die Anteile in den verbleibenden Bundesländern abgenommen haben. Diese Differenzierung kann Anhang U/a entnommen werden, die hier angegebenen Zahlen beziehen sich jedoch auf das gesamte Untersuchungsgebiet.

Bei der Zuordnung der Überholunfälle zu den Elementen des Lage- bzw. später auch des Höhenplans ist zu beachten, dass bei der Auswertung dieser Merkmale tatsächlich nur eine Aussage über die entsprechenden Elemente und deren Einzeleinfluss getroffen werden kann. Wird ein Überholunfall beispielsweise einer langgestreckten Linkskurve ohne Sichthindernisse im Seitenraum zugeordnet, so bleibt unbeantwortet, ob der Unfall nicht durch eine folgende Kuppe im Höhenplan begünstigt wurde, da im Lageplan offensichtlich keine Hindernisse vorhanden sind. Die 
Wechselwirkungen zwischen dem Lage- und Höhenplan sowie den Querschnittselementen resultieren aber in den vorhandenen Überholsichtweiten und können später bei deren Betrachtung weitere Erkenntnisse liefern. Die hier ermittelten Zusammenhänge bleiben dadurch unbeeinflusst, da den Kurven durchaus ein gewisser Einzeleinfluss auf die Sichtweiten und das Unfallgeschehen zugesprochen werden kann. Abbildung 3.15 enthält eine genauere Aufschlüsselung der Lageplanelemente. Hierbei werden wegen des vorhandenen Einzeleinflusses von Kurven auch deren Einflussbereiche (festgelegte Toleranz) zugrundegelegt.

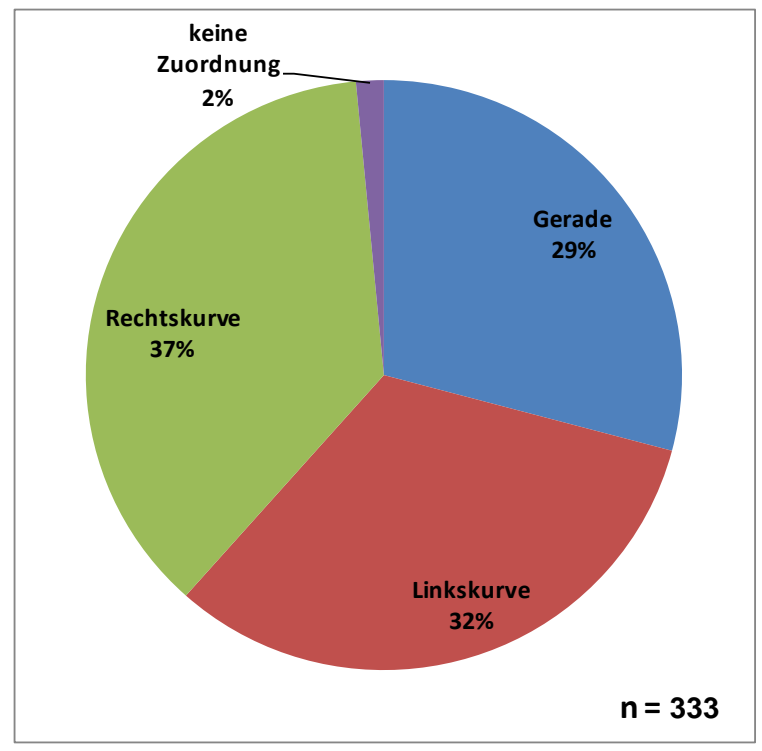

\section{Abbildung 3.15: Verteilung der Unfallpositionen auf Lageplanelemente}

Die Erweiterung von Abbildung 3.14 zeigt eine geringfügig höhere Auffälligkeit von Überholunfällen im Umfeld von Rechtskurven als in Linkskurven. Ursache hierfür sind die grundsätzlich besseren Sichtverhältnisse in Linkskurven. An einem potentiellen Hindernisfahrzeug kann in Linkskurven besser vorbeigeschaut werden, als dies in Rechtskurven der Fall ist. Hier stellen die Hindernisfahrzeuge nicht nur im Sinne des Fahrverhaltens eine Behinderung dar, sondern auch bei Betrachtung der Sichtverhältnisse. Gleiche Argumentation findet sich beispielsweise auch bei Netzer [1966]. Zusätzlich berichtet Netzer in Geraden von Problemen der Abschätzung von Entfernungen und Geschwindigkeiten des Gegenverkehrs, was in diesen Elementen auch trotz vorhandener Sichtweiten zu Unfällen führen kann. Fünf Überholunfälle konnten wegen fehlender Fahrtrichtungsangaben keiner Krümmungsrichtung zugewiesen werden.

Nachstehende Abbildung enthält eine Differenzierung der Kurven nach verschiedenen Radienbereichen. Es wird deutlich, dass eine Häufung von Überholunfällen in Kurven mit geringen Radien vorhanden ist. Kurven mit Radien unter 200 m treten möglicherweise im Landstraßennetz verhältnismäßig selten auf bzw. sind durch eine entsprechende hohe Kurvigkeit der Landstraßenabschnitte vor sowie nach der Unfallposition durch ein sich ergebendes gering ausgeprägtes Überholverhalten gekennzeichnet, wodurch auch relativ wenige Unfälle ermittelt werden konnten. Grundsätzlich ist aber auch davon auszugehen, dass sich mit sinkendem Kurvenradius und somit steigendem Richtungsänderungswinkel auch die Einflüsse auf die vorhandenen Sichtweiten erhöhen, was die hier ergebenden Tendenzen erzeugt. Die Radienbereiche über $1.800 \mathrm{~m}$ haben nach 
Lippold [1997] nur noch einen geringen Einfluss auf das Fahrverhalten, allerdings kann ein Einfluss auf die Sichtweiten weiterhin vorhanden sein. Durch die Aggregation von mehreren Radienbereichen in dieser letzten Radienklasse ist hier aber auch nochmals ein Anstieg der Unfallzahlen zu verzeichnen, hierbei muss aber eine Verteilung auf mehrere Klassen beachtet werden, was die Unfallzahlen innerhalb der einzelnen Klassen deutlich verringert. Für die empfohlenen Radienbereiche nach RAL der EKL mit weiterhin möglichen Überholen im Fahrstreifen des Gegenverkehrs (EKL 2: 400 - 900 m, EKL 3: 300 - 600 m) sollten in Anlehnung an die Unfallauffälligkeit nach Abbildung 3.16 vorrangig die größeren Radien zur Trassierung gewählt oder aufgrund topographischer Zwangspunkte entsprechend Überholverbote vorgesehen werden. Die geringste Unfallbelastung ist ab Radien von $800 \mathrm{~m}$ feststellbar. Mit steigenden Radien nehmen erwartungsgemäß die Anteile guter Sichtweitenbereiche ebenfalls zu (vgl. vgl. Anhang U/f).

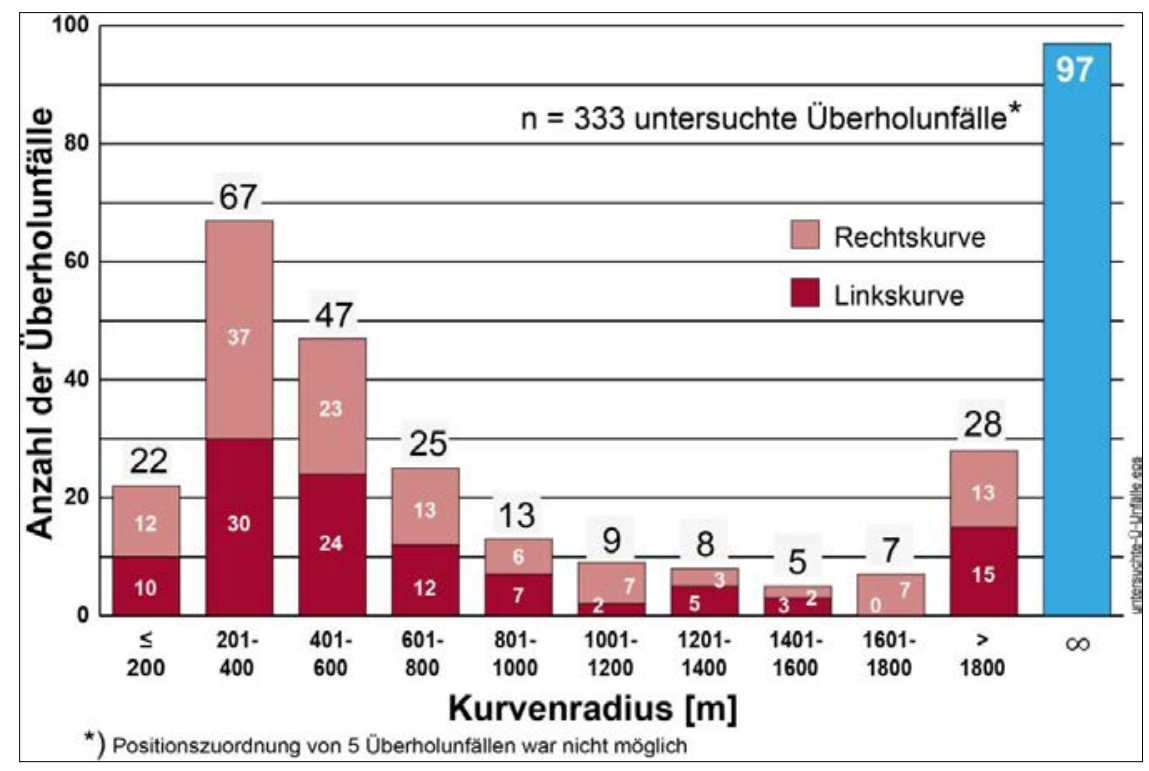

Abbildung 3.16: Kurven mit Überholunfällen nach Radienbereichen und Richtungssinn

Abbildung 3.17 enthält die Ergebnisse der Unfallzuordnung zu den Höhenplanelementen. Auch an dieser Stelle erfolgt der Verweis darauf, dass hier nur die reinen Elemente zugewiesen werden und keine Bewertung der Gesamtsituation erfolgen kann. Demzufolge kann ein Unfall in einer Wanne durch eine Sichtweitenbehinderung einer nachfolgenden Kuppe verursacht worden sein. Auch diese Zusammenhänge lassen sich erst bei Untersuchung der tatsächlichen Sichtweiten analysieren. Insgesamt besteht eine leichte Tendenz von Unfällen im Bereichen von Kuppen, diese aber unmittelbar gefolgt von Wannen. Den Wannen kann aber nur ein geringer Einfluss auf die vorhandenen Sichtweiten unterstellt werden. Demnach ist anzunehmen, dass bei Betrachtung der Umgebung von Wannen hier die tatsächlich die Sichtweiten beeinflussenden Elemente zusätzlich an Bedeutung gewinnen werden. Überholunfälle in konstanten Längsneigungen (Höhenplangeraden, Gefälle- oder Steigungsstrecken) sind dagegen eher selten. Allerdings wird vermutet, dass der Einfluss von Kuppen sich auch über den gewährten Toleranzbereich hinweg über die anderen Höhenplanelemente erstreckt und den Kuppen demzufolge eine noch größere ursächliche Unfallauffälligkeit zugeschrieben werden muss. Prinzipiell können aber die Ergebnisse der Höhenplanelemente auf die der Lageplanelemente übertragen werden. Demnach ergibt sich eine Häufung von Überholun- 
fällen, wenn sich aufgrund einer Änderung der vorhandenen Sichtweiten - sowohl durch Kurven als auch durch Kuppen - ein Sichtweitengefälle ergibt. An dieser Stelle kann unter Berücksichtigung der Ergebnisse aus Kapitel 3.4.3 bereits vermutet werden, dass eine deutlichere Kennzeichnung von Bereichen ohne Überholmöglichkeiten hier den Fahrer in seinem Überholempfinden bereits bremsen und somit Unfälle vermeiden kann.

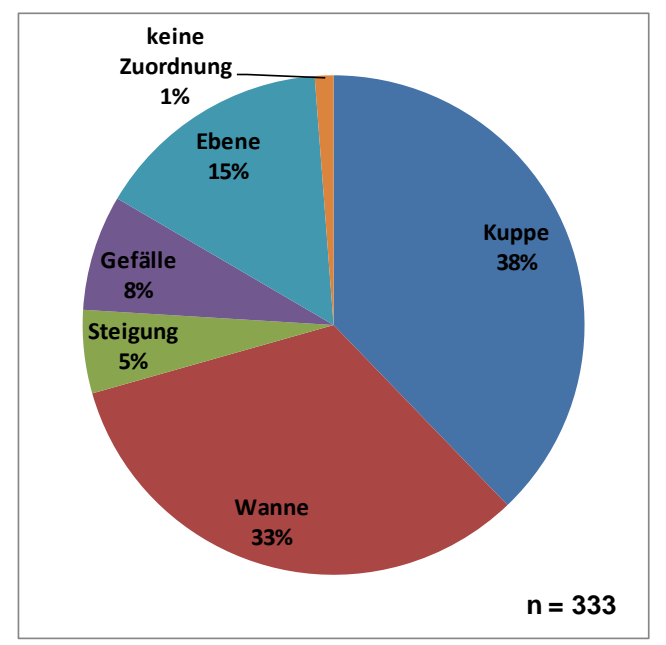

Abbildung 3.17: Unfallzuordnung zu Höhenplanelementen

Insgesamt können auch bei den Analysen im Höhenplan - wie auch schon für die Lageplanelemente - zwischen den einzelnen Bundesländern im Untersuchungsgebiet strukturelle Unterschiede der Landstraßentrassierung festgestellt werden. Grundsätzlich muss auch hier der Einfluss einer unterschiedlichen Trassierung wegen verschiedener Örtlichkeiten (bewegtes Gelände vs. Flachland) berücksichtigt werden (vgl. Anhang U/b). In nachstehender Abbildung 3.18 wird der Einfluss von Kuppen auf die vorhandenen Sichtweiten dargestellt. Der Einfluss von Kuppen wurde rechnerisch nach den Modellen der RAS-L bestimmt, da diese Annahmen auch Grundlage für die zweidimensionale Sichtweitenbestimmung im Höhenplan sind. Der Sichtweiteneinfluss wurde hier berechnet durch die abgelesenen Halbmesser innerhalb der erzeugten Streckenbänder. Die damit ermittelbaren vorhandenen Sichtweiten wurden mit den durch die vorgegebene Höchstgeschwindigkeit ergebenden erforderlichen Sichtweiten verknüpft und verglichen.

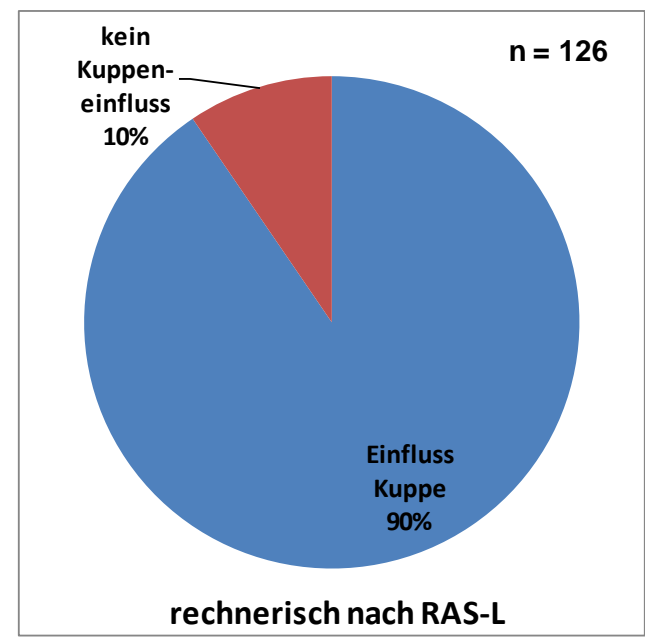

Abbildung 3.18: Rechnerischer Einfluss von Kuppen nach RAS-L an Unfallpositionen 
Insgesamt wird deutlich, dass die Überholunfälle innerhalb der Kuppen überwiegend mit einem Sichtweiteneinfluss in Verbindung gebracht werden können. Ist kein Einfluss von Kuppen vorhanden, so handelt es sich hier um große Halbmesser. Bei Betrachtung der Streckenbänder kann bei einigen Kuppen allerdings kein Sichtweiteneinfluss festgestellt werden. Durch die Vorgaben der Nachtrassierung in CARD/1 und die Genauigkeit der GPS-Datenerhebung können teilweise große Halbmesser entstanden sein, die zwar zwischen der halben und vollen Überholsichtweite liegen und somit rechnerisch ein Sichtweitenhindernis darstellen, aber in der tatsächlichen Anordnung der Elemente keine Einflüsse aufweisen. An dieser Stelle wird angemerkt, dass das Modell der Sichtweitenbestimmung in Kuppen in den RAS-L nur ein Einzelelement - dieses losgelöst von anderen umgebenden Elementen - berücksichtigt. Demnach kann rechnerisch ein Einfluss entstehen, der bei bestimmten Konstellationen in Wirklichkeit nicht vorhanden ist. Folgt auf eine Kuppe mit großem Halbmesser eine Wanne mit ebenfalls großem Halbmesser und haben beide kurze Tangentenlängen, so kann unter Umständen ein tatsächlicher Sichtweiteneinfluss verneint werden, wenn den Aug- und Zielpunkthöhen von einem Meter in den Modellvorstellungen nur ein geringer Höhenunterschied zwischen den entsprechenden Hoch- und Tiefpunkten gegenübersteht. In keinem dieser Sonderfälle ist ein Einfluss im Sichtweitenband festgestellt worden. Ein weiterer Grund für den fehlenden offensichtlichen Einfluss ist die Tatsache, dass bei fallenden Sichtweiten - wegen beispielsweise einer 300 m entfernten Kurve - der Einfluss einer davorliegenden Kuppe, die zwar rechnerisch einen Einfluss auf den Bereich zwischen der halben und der vollen Überholsichtweite ergibt, geringer ist als die Hinderniswirkung der Kurve. Bei der Prüfung aller Sichtweitenbänder im Rahmen der Nachtrassierung und die Gegenüberstellung mit den tatsächlichen Gegebenheiten der Befahrungen wurden keine Unstimmigkeiten innerhalb der Sichtweitenbänder festgestellt, ein negativer Einfluss der oben beschriebenen Zusammenhänge existiert nicht.

Werden als Ergebnis einer Überlagerung von Lage- und Höhenplanelementen und Querprofilen die sich ergebenden Sichtweitenbänder analysiert, ergibt sich Abbildung 3.19. Es wird deutlich, dass an $24 \%$ der Unfallpositionen weder die Sichtweitenkriterien der RAS-L noch der RMS erfüllt sind. Hier können Unfälle entstanden sein, die auf Überholungen, welche bis in einen Bereich mit geringen Sichtweiten hineinreichten (plötzliches Auftauchen von Gegenverkehr), zurückzuführen sind. Dagegen ist es aber auch denkbar, dass bei generell geringen Sichtweiten und dem Suggerieren einer Überholmöglichkeit durch einen kleinen Sichtweitensprung hier Überholunfälle in diesen Bereichen geschehen sind. Insgesamt befinden sich $70 \%$ aller Überholunfälle unabhängig von der Größenordnung in einem Sichtweitengefälle und nur $28 \%$ der Überholunfälle in unmittelbarer Umgebung zu einem Sichtweitensprung. Es kann angenommen werden, dass die Sichtweitengefälle hier die Problembereiche darstellen. Diesem Umstand kann durch eine frühzeitige Ankündigung von Bereichen mit geringen Sichtweiten entgegengewirkt werden. Sichtweitensprünge, welche kurzfristige Überholmöglichkeiten suggerieren können, sind dagegen vergleichsweise unauffällig. Es wird darauf hingewiesen, dass die Sichtweitenbänder in CARD/1 bei maximalen Sichtweiten von 700 m enden. Oberhalb dieser Grenze können durchaus auch Sichtweitengefälle vorhanden sein, allerdings haben diese keine negativen Auswirkungen auf die vorhandene Überholsichtweite, weil sie weit über den erforderlichen Sichtweiten nach RAS-L angesiedelt sind. 


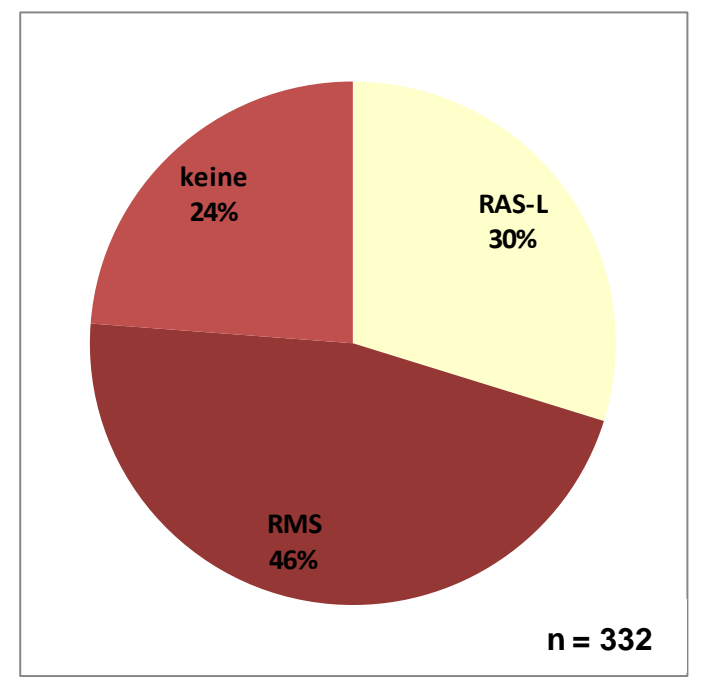

Abbildung 3.19: Eingehaltene Sichtweitenkriterien an den Unfallpositionen

Die Vermutung liegt nahe, dass in Verbindung mit den Matrizen in Kapitel 3.4.3 eine Unterstützung der Fahrer bei der Überholentscheidung durch Restriktionen zu einem verminderten Unfallgeschehen führt, auch wenn die Prozentzahlen der Unfälle in freigegebenen Abschnitten mit denen der eigentlich nicht zu markierenden Bereiche (Sichtweiten über Grenzwert der RMS) übereinstimmen (genaue Überlagerung vgl. Abbildung 3.23). Hier muss aber erneut auf die Differenzen beider Regelwerke eingegangen werden. Die Analyse der tatsächlichen Sichtweiten an den Unfallpositionen in Verbindung mit den eigentlich erforderlichen Sichtweiten durch die vorgegebenen Geschwindigkeiten ermöglicht hier die Aufteilung des Sichtweitenbereiches in dem die Grenzwerte der RMS eingehalten sind - demzufolge nicht grundsätzlich markiert werden sollte - jedoch die Grenzwerte der RAS-L unterschritten werden (vgl. Abbildung 3.13). Hierbei entsteht Abbildung 3.20. $34 \%$ der Überholunfälle befinden sich im Bereich zwischen halber und voller Überholsichtweite, der gemäß den RAS-L vermieden werden soll. Jedoch heißt es hier nur, dass sich diese Sichtweitenbereiche negativ auf die Verkehrssicherheit auswirken, Maßnahmenempfehlungen existieren nicht. Zudem sieht auch die RMS für diesen Sichtweitenbereich keine Überholverbote vor. $12 \%$ aller Überholunfälle entfallen auf den Bereich, in dem weder die Kriterien der RMS noch der RAS-L erfüllt werden.

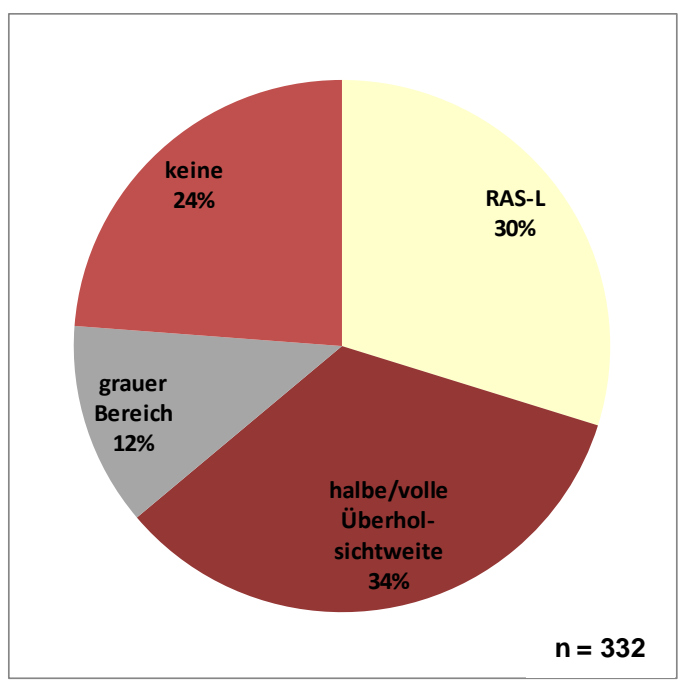

Abbildung 3.20: Sichtweitenbereiche zwischen RAS-L und RMS an den Unfallpositionen 
Bei Betrachtung der Darstellungen kann die möglicherweise etwas gewagte These aufgestellt werden, dass durch die tatsächliche Anordnung von Überholverboten in Bereichen ohne Überholmöglichkeiten (Richtwerte der RMS und der RAS-L unterschritten) $70 \%$ der Überholunfälle vermieden werden können. Allerdings muss auch davon ausgegangen werden, dass bei Anordnung von Überholverboten in Abschnitten mit vergleichsweise hohen Sichtweiten (zwischen der halben und vollen Überholsichtweite) die Regelakzeptanz der Fahrzeugführer abnimmt bzw. die Anordnungen schwierig vermittelbar sind. Dennoch ist ein einheitlicher akzeptabler Grenzwert für die Anordnung von Überholverboten erforderlich, um in Zukunft diese schweren Unfälle vermeiden zu können. Die Ergebnisse von eingehaltenen Sichtweiten an den Unfallpositionen differenziert nach den 5 Bundesländern ist in Anhang U/c dargestellt. Diese Überlagerung aus Lage- und Höhenplanelementen (vgl. Anhang U/a und Anhang U/b) ergibt erwartungsgemäß ebenfalls eine Abnahme von ausreichenden Sichtweitenbereichen mit zunehmender Schwierigkeit des Geländes.

Anhang U/d enthält abschließend eine Darstellung, welche Kombinationen von Einzelelementen des Lage- und Höhenplans zu welchen Sichtweitenbereichen führen. Erwartungsgemäß nimmt mit zunehmender Schwierigkeit von Elementfolgen auch der Anteil von ausreichenden Sichtweitenverhältnissen ab. Jedoch wird an dieser Stelle erneut darauf hingewiesen, dass bei diesen Auswertungen nur die Elemente der Unfallpositionen betrachtet werden, nicht aber die evtl. ebenfalls beeinflussenden Folgeelemente und ihre Hinderniswirkung. Daher wird für die reinen Elementkombinationen angenommen, dass die ausgewerteten Sichtweiten ein deutlich besseres Kriterium zur Beschreibung der örtlichen Situation darstellen.

Abschließend soll die Frage geklärt werden, wie sich die Ergebnisse verändern, wenn die rechtlichen Anordnungen in Verbindung mit dem Unfallgeschehen und den Trassierungsmerkmalen bzw. der sich daraus ergebenden Sichtweiten dargestellt werden.

Abbildung 3.21 gibt einen allgemeinen Überblick über die rechtlichen Anordnungen an den Unfallpositionen der 100 unfallauffälligsten Untersuchungsstrecken. Die sich hier ergebende Verteilung spiegelt auch für dieses verkleinerte Unfallkollektiv die Ergebnisse der größeren Grundgesamtheit bei Betrachtung der ersten 500 Strecken der Rangfolge (vgl. Ergebnisse in Kapitel 3.4.3) wider. Demnach geschehen 77 \% der Überholunfälle in Bereichen, in denen keine rechtlichen Restriktionen vorhanden sind, aber gegebenenfalls notwendig wären. Der Unterschied zur Matrixdarstellung besteht in der Differenzierung von freigegebenen Abschnitten in Bereiche mit Leitlinie und Bereiche mit Warnlinie. Beide Varianten des Zeichens 340 nach StVO stellen jedoch kein verkehrsrechtliches Verbot von Überholungen dar. Verbote werden dagegen oft nur reaktiv angeordnet, wenn eine Beeinträchtigung der Verkehrssicherheit entstanden ist. Dennoch geschehen $23 \%$ der Überholunfälle in Bereichen mit bereits vorhandenen Überholverboten. Unterschied zur Matrixdarstellung ist die fahrtrichtungsfeine Unfallzuordnung zu halben Überholverboten. Diese Unfälle befinden sich nun entweder in freigegebenen Abschnitten oder Bereichen mit Markierungen. Bei den Unfällen im Überholverbot bleibt jedoch auch ungeklärt, ob das Verbot nicht schon reaktiv auf die vorherige vorherrschende Unfallsituation im Nachhinein angeordnet wurde. Diese Vermutung würde die sich hier ergebenden Tendenzen weiter bekräftigen, da somit vorher noch mehr Streckenteile freigegeben waren. 


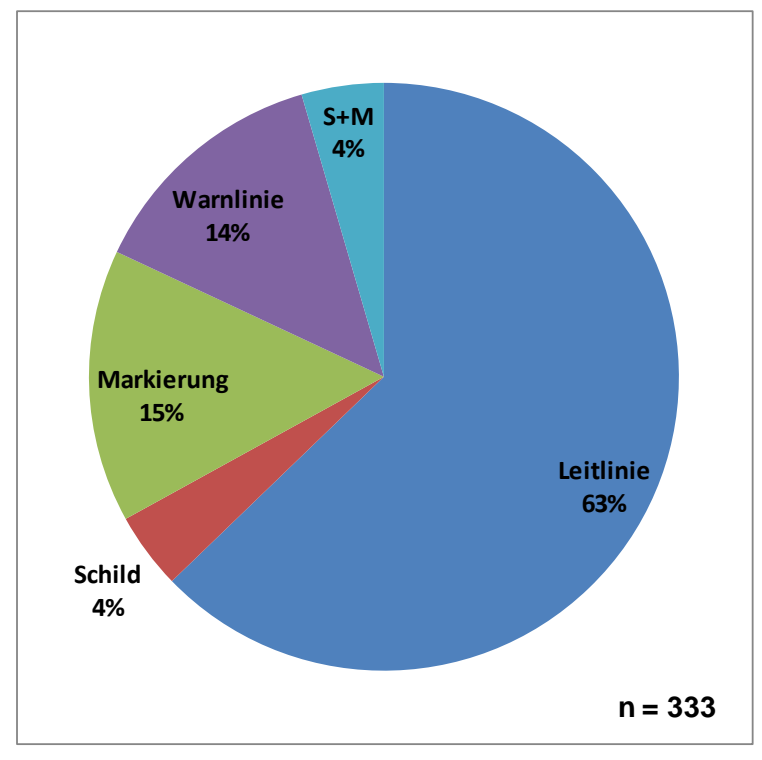

Abbildung 3.21: Rechtliche Anordnungen an den Unfallpositionen

Die Anordnungen von Geschwindigkeitsbeschränkungen an den Unfallpositionen können differenziert nach den verschiedenen Größenordnungen in Abbildung 3.22 eingesehen werden. Grundsätzlich lassen sich auch hier die generellen Tendenzen der ursprünglichen Matrixdarstellungen bestätigen. Demnach geschehen ca. 70 \% der Überholunfälle in freigegebenen Abschnitten, was die Vermutungen der hohen Geschwindigkeitsstreuung erneut aufkommen lässt. Andererseits kann hier auch ein Einfluss der generellen Auffindbarkeit verschiedener Geschwindigkeiten im Landstraßennetz nicht vernachlässigt werden (vgl. Abbildung 3.6). Landstraßen dienen der großräumigen Verbindung von Orten, demnach sind die angestrebten Geschwindigkeiten möglichst hoch und Geschwindigkeitsbeschränkungen eher selten. Sind dagegen Geschwindigkeitsbeschränkungen vorhanden, so handelt es sich überwiegend um eine Beschränkung auf 70 bzw. 80 $\mathrm{km} / \mathrm{h}$. Alle weiteren Geschwindigkeitswerte treten nur selten bzw. gar nicht auf.

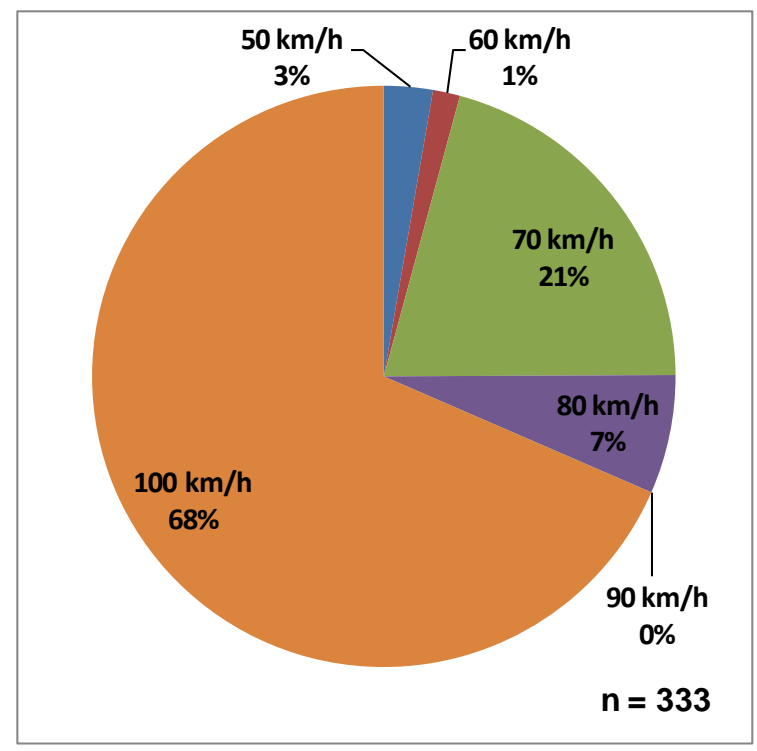

Abbildung 3.22: Zulässige Geschwindigkeiten an Unfallpositionen 
Neben den rechtlichen Anordnungen kann der Auswertung der Streckenbänder entnommen werden, dass lediglich $12 \%$ der Überholunfälle den definierten Knotenpunktbereichen zugewiesen wurden. Die Auffälligkeit von Überholunfällen liegt somit überwiegend auf der freien Strecke. An Knotenpunkten sind oftmals durch zusätzliche Abbiegefahrstreifen auch schon Überholverbote vorhanden, dennoch muss hier teilweise die Frage nach deren Wirksamkeit gestellt werden.

In folgender Abbildung sind die rechtlichen Überholmöglichkeiten in Abhängigkeit der tatsächlichen vorhandenen Überholsichtweiten dargestellt. Hierbei wird nach drei Bereichen von erforderlichen Sichtweiten differenziert (vgl. Abbildung 3.19). Insgesamt ergibt sich ein sehr deutliches Ergebnis.

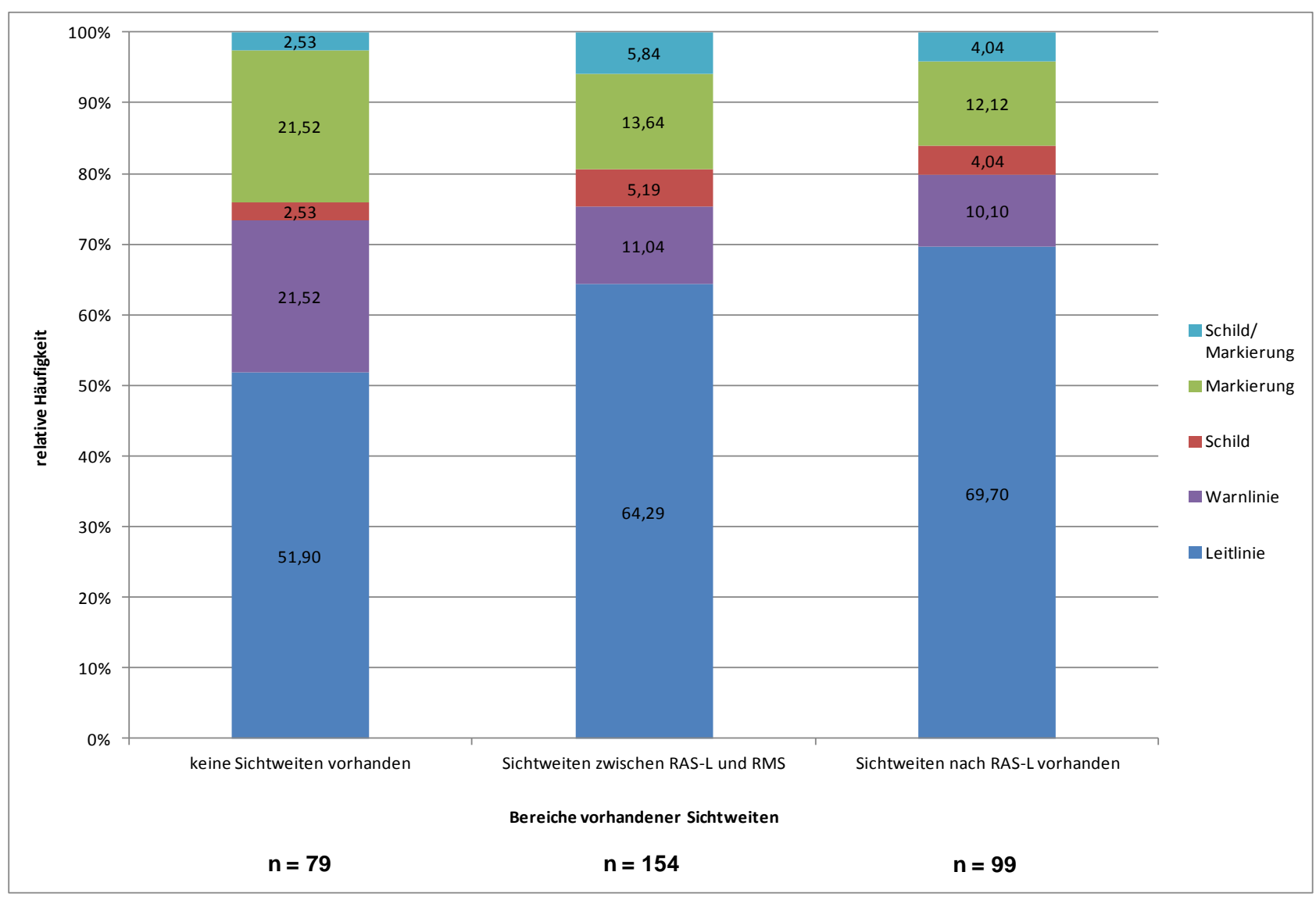

Abbildung 3.23: Rechtliche Anordnungen bei Unfällen differenziert nach Sichtweitenbereichen

In Abschnitten in denen die Sichtweiten nach RAS-L eingehalten sind, findet sich der geringste Anteil von rechtlichen Restriktionen in Bezug zum Überholvorgang. Grundsätzlich sind in diesen Abschnitten sämtliche Sichtweitenbedingungen erfüllt und ein Überholen sollte möglich sein. Sind Überholverbote vorhanden, so können beispielsweise Knotenpunkte für die Restriktionen verantwortlich sein. Trotzdem kann es aber unter Berücksichtigung der verkehrlichen Randbedingungen und des komplexen Überholvorganges bzw. des schwierigen Entscheidungsprozesses zur Überholentscheidung, dem auch die fehlerbehaftete Abschätzung von Entfernungen und Geschwindigkeiten des Gegenverkehrs zugrunde liegt, auch in freien Landstraßenabschnitten außerhalb der Knotenpunkte zu Überholunfällen kommen. Auf Basis der Trassierung ist in diesen Abschnitten keine Grundlage für ein Überholverbot gegeben, jedoch ist hier bei einer gewissen entstandenen Unfallhäufung nachträglich ein Überholverbot vorzusehen. Erzeugen hohe Verkehrsstärken im 
Gegenverkehr einen zu hohen Überholdruck und sinkt dadurch die Risikoakzeptanz auf einen Schwellenwert der nicht mehr vertretbar ist, so sind Überholverbote anzuordnen, welche die Grundlagenentscheidung für und wider dem Überholen, dem Fahrzeugführer bereits abnehmen. Hier muss aber auch die Regelakzeptanz berücksichtigt werden, wenn die hohen Verkehrsstärken nicht mehr vorherrschen (Schwachverkehrszeiten). Auf Autobahnen findet man häufig dynamische Beschilderungen, welche bei bestimmten Verkehrsstärken eine Geschwindigkeitsbeschränkung vorgeben, um die Verkehrsqualität bzw. den Verkehrsfluss aufrechtzuerhalten. Gleiches Prinzip kann auch zur die Erhöhung der Verkehrssicherheit der Überholvorgänge auf Landstraßen übertragen werden. Dadurch könnten riskante Überholungen in hochbelasteten Stundengruppen vermieden werden und das Überholen in schwachbelasteten Stundengruppen weiterhin möglich sein (vgl. Brilon, 1976 sowie Künzelmann, 2012).

Im Zwischenbereich der Regelwerke, also oberhalb der Sichtweiten für die nach RMS ein Überholverbot notwendig ist und unterhalb der erforderlichen Sichtweiten des Überholmodells nach den RAS-L, findet sich die höchste Unfallanzahl. Hier ist davon auszugehen, dass Bereiche zwischen den Schwellenwerten beider Regelwerke auch am häufigsten im Landstraßennetz zu finden sind. Abschnitte in denen nach dem Überholmodell der RAS-L tatsächlich Sichtweiten ergeben, sind vor allem in bewegtem Gelände äußerst selten. Zudem dürften aber auch bei bestimmten Verkehrsbedeutungen Sichtweiten unterhalb der RMS vergleichsweise selten auftreten. Die Verteilungen der rechtlichen Anordnungen an den Unfallpositionen innerhalb dieses Sichtweitenbereiches unterscheiden sich aber nicht wesentlich von dem Bereich in dem die Sichtweiten nach RAS-L vorhanden sind. Hier sind in Summe lediglich mehr $5 \%$ mehr Unfälle innerhalb von rechtlichen Restriktionen feststellbar gewesen. Bei der Trassierung sollen Sichtweitenbereiche zwischen der halben und der vollen Überholsichtweite nach RAS-L vermieden werden, Maßnahmen sind allerdings nicht vorgesehen. Die Maßnahmen nach RMS entfallen auf den nächstkleineren Sichtweitenbereich. Demnach findet sich in keinem der beiden Regelwerke die klare Notwendigkeit für ein grundlegend anzuordnendes Überholverbot. Problematisch an dieser Stelle ist, dass diese Sichtweitenbereiche innerhalb der Trassierung gar nicht vermeidbar sind, da es zwischen Bereichen mit vorhandenen Sichtweiten und Bereichen mit Überholverboten gemäß RMS bzw. Sichtweiteneinschränkungen durch Kurven/Kuppen immer ein allmähliches Sichtweitengefälle geben wird. Sind aber im Kontext der Einheit von Bau und Betrieb keine trassierungstechnischen Möglichkeiten vorhanden, so müssen betriebliche Maßnahmen an deren Stelle treten. Markierungen, Beschilderung und vor allem die rechtzeitige Ankündigung von Sichtweiteneinschränkungen sind hier essentiell.

Im Sichtweitenbereich unterhalb der Grenzwerte der RMS sind beachtliche $73 \%$ der Unfälle in Abschnitten ohne rechtliche Vorgaben entstanden. Der Anteil von Warnlinien ist hier zwar gestiegen, allerdings ist eine strikte rechtliche Regelung durch ein geändertes Strich-Lücken-Verhältnis nicht gegeben. In Bereichen, in denen keine Sichtweitenbedingung mehr erfüllt ist und sogar schon Unfälle in Bezug zum Überholen geschehen sind, sollte über ein gewisses Strich-Lücken-Verhältnis nicht mehr diskutiert werden. In den Verwaltungsvorschriften zur StVO heißt es zu Zeichen 276: „Das Zeichen sollte nur dort aufgestellt werden, wo die Gefährlichkeit des Überholens dem Fahrzeugführer nicht so erkennbar ist, dass er von sich aus nicht überholt“. Demnach bleibt die Frage 
zu klären, ob die Entscheidung zum Überholen weiterhin dem Fahrzeugführer überlassen werden sollte. Oftmals ist es nicht wie ursprünglich vorgesehen der Fall, dass der Fahrzeugführer Bereiche ohne Überholmöglichkeiten eigenständig erkennt und demnach keine Überholgelegenheiten sucht. Vielmehr kann im Umkehrschluss vermutet werden, dass die Fahrzeugführer annehmen, was nicht verboten ist, bleibt möglich. Demzufolge werden möglicherweise in freigegebenen Abschnitten die Überholmöglichkeiten angenommen, weil es nicht verboten ist. Ferner heißt es in den StVO-VwV: „Überholverbote kommen vor allem in Frage, wenn [..] die Sichtweite geringer ist, als sie zu sein scheint". Abgesehen davon, dass laut menschlich möglicher Sichtweitenschätzung überwiegend eine Überschätzung von Entfernungen vorherrscht (vgl. FGSV, 2001a), verweist dieser Absatz indirekt auf den Zwischenbereich zwischen RAS-L und RMS. Rechtliche Restriktionen finden sich dennoch nicht. Mit den Darstellungen lassen sich die bereits vermuteten Defizite der Anordnung von rechtlichen Restriktionen bestätigen. Unabhängig vom zugeordneten Sichtweitenbereich sind zu über $70 \%$ keine Überholverbote angeordnet. Insgesamt nimmt der Anteil von Restriktionen ganz leicht zu, je weniger Sichtweiten vorhanden sind. Die Situation, dass aber selbst in Bereichen ohne vorhandene Überholsichtweiten auch trotz des vorhandenen Unfallgeschehens keine rechtlichen Restriktionen vorhanden sind, ist nicht hinnehmbar.

Neben den Unfallzahlen in den Bereichen verschiedener Sichtweiten und verkehrsrechtlichen Regelungen wurden auch die Unfallkenngrößen für diese Streckenabschnitte berechnet. Berechnungsgrundlage ist hier wie bereits in Kapitel 3.4.6 angewendet der Bezug zu den Merkmalslängen des Gesamtnetzes. Demzufolge wurden die Längen der Sichtweitenbereiche mit den entsprechenden verkehrsrechtlichen Vorgaben mit Bezug zum Überholverhalten verschnitten und abschließend alle unfallfreien und unfallbelasteten Netzteile in die Berechnung einbezogen (Hintergründe siehe Kapitel 3.4.6). Die Ergebnisse der Unfallkenngrößen sind nachfolgend dargestellt.
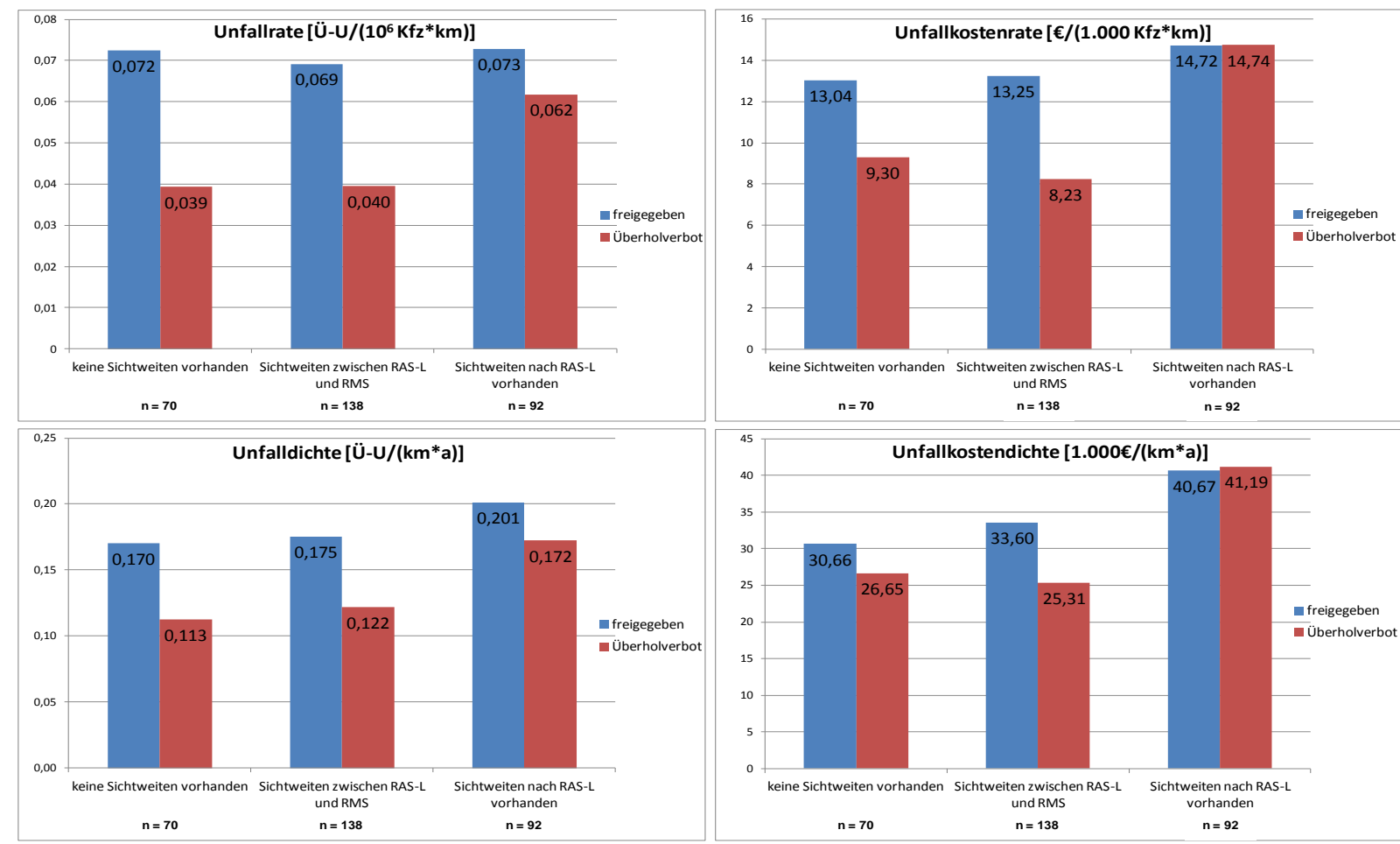

Abbildung 3.24: Unfallkenngrößen nach Sichtweitenbereichen und Überholverboten 
Zur Berechnung der vier Unfallkenngrößen ist anzumerken, dass die Berechnungen nur für Strecken mit vorhandenen Verkehrsstärkedaten durchgeführt wurden, um die Vergleichbarkeit zwischen Unfallraten und -dichten nicht zu beeinträchtigen. Demzufolge wurden die Berechnungen für 89 der insgesamt 100 nachtrassierten Untersuchungsstrecken durchgeführt. Damit verbunden war eine Verringerung der auswertbaren Unfallzahlen von 332 auf 300 Überholunfälle. In Hinblick auf Abbildung 3.23 ergaben sich allerdings nur vernachlässigbar kleine Änderungen der dort ermittelten Anteile/Tendenzen, weswegen die Verringerung auf die Abschnitte mit vorhandenen Verkehrsstärken als sehr gute Stichprobe der gesamten nachtrassierten Strecken anzusehen ist.

Die Ergebnisse werden nur für die aggregierten verkehrsrechtlichen Anordnungen (Überholverbot vorhanden oder nicht, unabhängig der Art der jeweiligen Regelung) ausgewiesen, da die Differenzierung nach den 5 Einzelmerkmalen (vgl. Abbildung 3.23) starke Schwankungen der Unfallkenngrößen ergibt. Grundsätzlich sollen die Unfallkenngrößen nur der Bekräftigung der Erkenntnisse dienen, in welchen Bereichen Überholverbote zweckmäßig sind oder nicht.

Im Wesentlichen zeigen sich zwei Tendenzen. Zum einen nehmen mit schlechteren Sichtweiten die Unfallkenngrößen und damit auch die Unfallbelastung ab - dies unabhängig von der rechtlichen Überholsituation - und zum anderen sind Überholverbote insgesamt unauffälliger als freie Streckenabschnitte mit Leit- oder Warnlinien. Bei den generellen Zusammenhängen ergeben sich allerdings 2 Ausnahmen. Das Unfallrisiko in Form der Unfallrate ist für die freigegebenen Streckenabschnitte über alle 3 Sichtweitenbereiche nahezu unverändert auf einem ähnlichen Niveau. Bei den Überholverboten nimmt das Unfallrisiko dagegen entsprechend der allgemeinen Tendenz mit schlechteren Sichtweiten ab. Bei Berücksichtigung der Unfallschwere bei den Unfallkostenraten und -kostendichten existieren in Bereichen mit ausreichenden Sichtweiten keine Unterschiede zwischen freigegebenen Abschnitten und Überholverboten. Das Unfallrisiko ist hier zwar geringer, wenn aber ein Unfall geschieht, dann ist er auch ähnlich schwer wie Unfälle in freigegebenen Abschnitten.

Neben den beschriebenen Tendenzen ergibt sich aber auch eine deutliche Grenze. Vergleicht man die Unfallkenngrößen oberhalb von $600 \mathrm{~m}$ Sichtweiten mit denen unterhalb von $600 \mathrm{~m}$, so zeigt sich eine deutliche Abnahme der Unfallkenngrößen bei den vorhandenen Überholverboten, die allerdings zwischen $300 \mathrm{~m}$ und $600 \mathrm{~m}$ und unterhalb der $300 \mathrm{~m}$ Grenze immer auf einem ähnlichen Niveau liegen. Dies verdeutlicht, dass bei Sichtweiten unterhalb von $600 \mathrm{~m}$ ein Überholverbot grundsätzlich zur Verringerung des Unfallrisikos und der Unfallschwere im Vergleich zu freigegebenen Abschnitten führt. Demzufolge ergibt sich die Forderung, bei unzureichenden Sichtweiten (unter $600 \mathrm{~m}$ ) immer ein Überholverbot anzuordnen, da hier Sicherheitsverbesserungen zu erwarten sind. Dagegen steigt das Unfallrisiko und die Unfallschwere, wenn bei Sichtweiten unter $600 \mathrm{~m}$ auf ein Überholverbot verzichtet wird.

Grundlegend kann also festgehalten werden, dass die in Abbildung 3.23 angedeutete 70 \% / 30 \% Verteilung zwischen freien Abschnitten und Überholverboten unabhängig von der vorhandenen Sichtweitensituation nicht ausnahmslos bestätigt werden kann. Stattdessen sinkt das Unfallrisiko und die Unfallschwere mit schlechter werdenden Sichtweiten. Die Unfallkenngrößen der Überhol- 
verbote unterscheiden sich hierbei deutlich von den der freigegebenen Abschnitte und sind als verkehrssicherer anzusehen. Diese Sicherheitswirkung steigt bei schlechten Sichtweiten an. Hier lässt sich vermuten, dass mit schlechten Sichtweiten auch die Akzeptanz von Überholverboten zunimmt, da bei schlechteren Sichtweiten die Differenzen der Unfallkenngrößen zwischen freigegebenen Abschnitten und Überholverboten zunehmen. Liegen dagegen gute Sichtweiten vor, so führt dies häufiger zur Missachtung von Überholverboten und ansteigender Unfallschwere.

Die rechtlichen Anordnungen an besonderen Elementen im Landstraßenbereich sind in nachstehender Abbildung einsehbar. Über die verschiedenen betrachteten Elemente hinweg nimmt der Anteil der Überholverbote zu. In Kurven sind am wenigsten Überholverbote zu finden, in Knotenpunktbereichen konnten immerhin schon zu $55 \%$ rechtliche Anordnungen ermittelt werden.

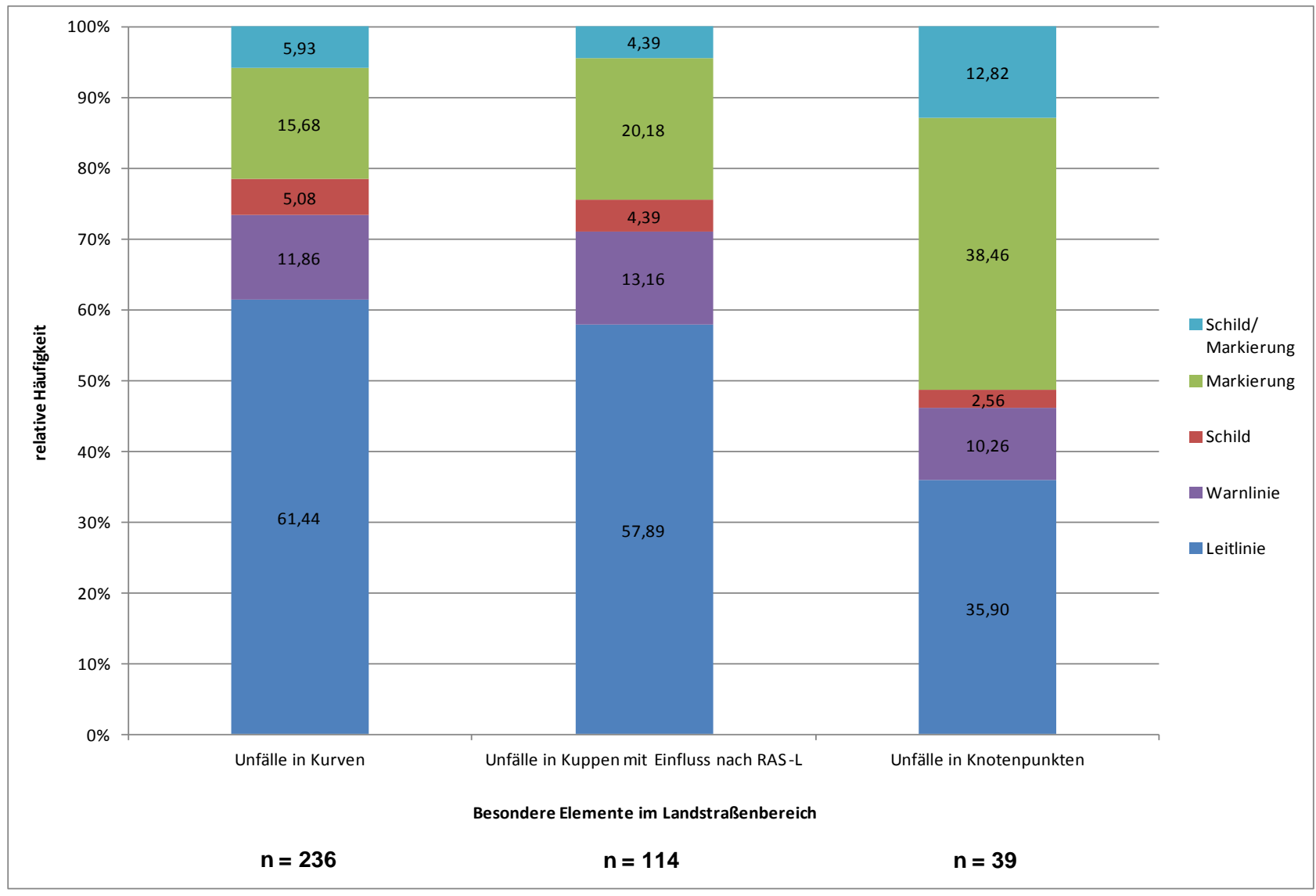

Abbildung 3.25: Rechtliche Anordnungen bei Unfällen innerhalb besonderer Elemente

Geht man davon aus, dass an einer Vielzahl von Kurven durch deren Richtungsänderungswinkel sowie durch den Neigungswechsel an Kuppen auch gewisse Sichtbehinderungen erzeugt werden, so ist nicht nachvollziehbar, warum an diesen Elementen zu über $70 \%$ keine Überholverbote vorhanden sind. Auch in Knotenpunktbereichen ist der Anteil von Überholverboten trotzdem zu gering. Dieser sollte vor allem in unfallauffälligen Knotenpunkten gegen null gehen. Zwischen den genannten Elementen gibt es allerdings keine nennenswerten Unterschiede zwischen den 3 Sichtweitenbereichen. Hier ergaben sich zu $26 \%$ Sichtweiten nach RAS-L, zu $46 \%$ nach RMS und zu 28 \% keine erfüllten Sichtweitenbedingungen. StVO-VwV geben zu Zeichen 295 an: „[Die Fahrstreifenbegrenzung] soll [...] vor und im Bereich gefährlicher Kuppen und Kurven und vor ge- 
fährlichen Kreuzungen und Einmündungen angebracht werden“. Bei den ermittelten Ergebnissen sollte man annehmen können, dass durch das dargestellte Unfallgeschehen bereits eine gewisse Gefährlichkeit sichtbar geworden ist, Verbote aber dennoch fehlen.

In Bezug auf die vorstehenden Auswertungen wurde versucht, verschiedene weitere vorhandene Zusammenhänge zwischen Trassierungselementen, Sichtweiten und verkehrsrechtlichen Anordnungen ausfindig zu machen. Die zusätzlichen Ergebnisse sind in Anhang U/e bis Anhang U/j dargestellt. In Bezug zu Anhang U/e sind zwei Tendenzen feststellbar. Zum einen nimmt, wie schon in Abbildung 3.16 dargestellt, die Unfallauffälligkeit mit zunehmendem Kurvenradius ab. Dies ist unter anderem darauf zurückzuführen, dass die Sichtweiteneinschränkungen bei großen Kurvenradien eher gering sind, was auch zu weniger Überholunfällen führt (vgl. Anhang U/f). Zum anderen nimmt der Anteil der freigegeben Abschnitte (keine Überholverbote angeordnet) mit zunehmendem Kurvenradius ebenfalls leicht zu, da wegen besserer Sichtweiten auch weniger Überholverbote notwendig sind. Betrachtet man zusätzlich den Sichtweitenaspekt, so können diese beiden letztgenannten Thesen bestätigt werden (vgl. Anhang U/g bis Anhang U/i). Zu beachten sind hier allerdings die teilweise geringen Unfallzahlen in den theoretisch vorhanden 50 gebildeten Klassen. Anhang $U / j$ vervollständigt die Auswertungen der Radienbereiche. Es zeigt sich eine leicht fallende Tendenz der Anteile von Kurven mit vorhandenen Geschwindigkeitsbeschränkungen bei zunehmenden Radienbereichen. Grundsätzlich liegt das Niveau der Kurven mit Geschwindigkeitsbeschränkungen bei Radien über $200 \mathrm{~m}$ bei ca. $30 \%$, wohingegen es sich bei Radien unter $200 \mathrm{~m}$ auf $60 \%$ erhöht.

\subsubsection{Zusammenfassung}

Grundlegende Erkenntnis der Streckenbandanalyse ist die Tatsache, dass an einer Vielzahl von Landstraßenelementen, welche einen negativen Einzeleinfluss auf die Sichtweiten haben, oftmals keine Überholverbote ausgewiesen sind. $71 \%$ der Überholunfälle geschehen innerhalb von Kurvenbereichen bzw. in deren direktem Umfeld. Wegen schlechterer Sichtbeziehungen sind hier die Rechtskurven auffälliger als Linkskurven. Mit sinkendem Kurvenradius und somit erhöhten Einfluss auf die vorhandenen Sichtweiten nimmt die Unfallauffälligkeit zu. Im Höhenplan stellen die Kuppen überwiegend die Problembereiche dar. Grundsätzlich sind aber in Lage- und Höhenplan die Elemente auffällig, welche einen Sichtweiteneinfluss hervorrufen. Es wird darauf hingewiesen, dass sich die Trassierung topographiebedingt in den betrachteten Bundesländern grundsätzlich unterscheidet. Wird der Sichtweiteneinfluss beziffert, so sind bei $24 \%$ der Unfälle weder Sichtweiten nach RAS-L noch nach RMS eingehalten. Zusätzlich sorgen die Differenzen zwischen den Sichtweitenvorgaben beider Regelwerke womöglich bei der Anordnung von Überholverboten für Missverständnisse. 34 \% der Unfälle liegen im Bereich der halben und vollen Überholsichtweite, für den keine Maßnahmenempfehlungen vorliegen. Weitere $12 \%$ der Unfälle geschehen bei Sichtweiten, für die weder RAS-L noch RMS in irgendeiner Form Stellung nehmen bzw. klare Regelungen enthalten. Grundproblem der Überholunfälle ist aber, dass der Anteil von Unfällen in freigegebenen Streckenabschnitten unabhängig von dem jeweiligen Sichtweitenbereich bei über $70 \%$ liegt. Die ermittelten Unfallkenngrößen nach Sichtweitenbereichen und der rechtlichen Überholsi- 
tuation heben die Sicherheitswirkung von Überholverboten deutlich hervor. Oftmals werden im Straßennetz Überholverbote nicht angeordnet, wenn der Fahrzeugführer vermeintlich eigenständig erkennen kann, dass ein Überholen nicht möglich ist. Zur Erhöhung der Landstraßensicherheit muss diese Philosophie allerdings aufgegeben und ein strikt einzuhaltender Grenzwert für Überholverbote definiert und angewendet werden, um dem Verkehrsteilnehmer die Entscheidung für ein durchzuführendes Überholmanöver grundlegend abzunehmen. Hierbei muss auch die bisher vorhandene Lücke zwischen RAS-L und RMS geschlossen werden. Wichtiger Bestandteil von rechtlichen Regelungen muss auch die rechtzeitige Ankündigung von vorhandenen Überholverboten sein. Für die künftigen RAL sowie für die in Überarbeitung befindlichen RMS ist ein einheitlicher Grenzwert zur Anordnung von Überholverboten festzulegen, da bei dessen Unterschreitung ein Überholvorgang nicht mehr sicher durchführbar ist. Dieser Grenzwert ist als Maßgabe für die Anordnung von Überholverboten strikt einzuhalten, die Überlassung der Überholentscheidung beim Fahrzeugführer ist in Bereichen ohne Sichtweiten nicht hinnehmbar, wenn riskante Überholungen vermieden und die Verkehrssicherheit auf Landstraßen erhöht werden soll.

\subsubsection{Clusterung der Untersuchungsstrecken für Detailanalyse}

Zur Identifizierung von 50 interessierenden Untersuchungsstrecken aus dem Datenkollektiv der Ergebnisse der 100 nachtrassierten Strecken wurde eine Clusterung vorgenommen. Grundlage dieser Clusterung ist die Erstellung einer Datenbank, in der auf Streckenebene sämtliche Merkmale der Landstraßengestaltung enthalten sind. Bestandteil dieser Datenbank sind die zusammengetragenen Informationen der Einzelstrecken, welche auch in den Datenblättern enthalten sind.

Darüber hinaus wurde in der Datenbank eine Neuberechnung der Unfallkenngrößen vorgenommen. Es wird darauf hingewiesen, dass sich für einige Strecken die Werte der Unfallkenngrößen verändert haben. Grund für größere Wertänderungen im Vergleich zu Anhang D ist der Umstand, dass bei der Unfallzuordnung (vgl. Kapitel 3.4.3) einige wenige Unfälle wegen Verschiebungen von Ortstafeln nicht mehr berücksichtigt werden können.

Des Weiteren ist der Grund für kleinere Differenzen der Unfallkenngrößen auch auf diese Verschiebungen der Innerortsbereiche zurückzuführen. Hierbei wurde demzufolge eine andere Länge der Untersuchungsabschnitte ermittelt als in den Straßeninformationsbanken ursprünglich enthalten war.

Für die Clusterung können die folgenden bedeutsamen Kriterien zur Beschreibung der Streckenund Überholsituation herangezogen werden:

- Verkehrsstärke

- rechtliche Überholsituation

- vorhandene Überholmöglichkeiten nach RAS-L stellvertretend für Entwurfssituation

- Anzahl der Überholunfälle

Für die aufgezählten Kriterien werden jeweils 3 Klassen gebildet. Bei den Verkehrsstärken wird differenziert in Strecken mit weniger als $5.000 \mathrm{Kfz} / 24 \mathrm{~h}$, zwischen 5.000 und $10.000 \mathrm{Kfz} / 24 \mathrm{~h}$ und mehr 
als $10.000 \mathrm{Kfz} / 24 \mathrm{~h}$. Bei der Anzahl der Überholunfälle wird unterschieden zwischen wenig (1-2 Unfälle), mittel (3-4 Unfälle) und viel (>4 Unfälle).

Für die vorhandenen Überholmöglichkeiten nach RAS-L und die tatsächliche Überholsituation nach den rechtlichen Anordnungen kann zwischen einer relativen und absoluten Betrachtungsweise der Kennzahlen unterschieden werden. Die Clusterung soll vorrangig über diese beiden Kriterien vorgenommen werden. Hierbei ist eine $3 \times 3$ Matrix mit den entsprechenden gebildeten Klassen zu erstellen. Die Frage, ob relative oder absolute Betrachtungen sinnvoll sind, soll vorab geklärt werden.

Bei den vorhandenen Überholmöglichkeiten nach RAS-L muss von einer relativen Betrachtung abgesehen werden, weil entweder Sichtweiten vorhanden sind oder nicht. Diese Überholmöglichkeiten sind dann vorhanden, wenn die tatsächlich vorhandenen Sichtweiten die Grenzwerte der RAS$\mathrm{L}$ überschreiten. Eine relative Betrachtung ist hier allerdings nicht sinnvoll. Nachfolgende Beispiele verdeutlichen diese Argumentation. Die Untersuchungsstrecke BL3-1184 besitzt einen Anteil von vorhandenen Überholmöglichkeiten nach RAS-L von 57 \%, was bezogen auf die Streckenlänge insgesamt 751 m ergibt. Die Strecke BL4-236 hat dagegen nur ein Prozent mehr vorhandene Sichtweiten (58\%), was aber in Bezug zur vorhandenen Nettostreckenlänge eine Überholmöglichkeit auf insgesamt 2.613 m ergibt. Auch wenn der relative Anteil von potentiellen Überholmöglichkeiten beider Strecken bis auf ein Prozent nahezu gleich ist, kann man diese Strecken nicht in einer Klasse zusammenfassen, weil die tatsächliche Überholsituation grundverschieden ist. Ein weiteres Beispiel zeigt der Vergleich der Strecken BL3-73 mit BL4-387. Auf BL3-73 sind lediglich auf $16 \%$ der Streckenlänge Überholsichtweiten nach RAS-L vorhanden, was einer Absolutzahl von 1.071 m entspricht. Strecke BL4-387 hat dagegen einen Anteil von $24 \%$, was allerdings unter Berücksichtigung der Streckenlänge nur $252 \mathrm{~m}$ ergibt. Hier hat sich der Anteil der Streckenlänge mit Überholmöglichkeiten nahezu verdoppelt, die tatsächliche Länge beträgt aber nur ein Viertel. Die Zusammenhänge dieser erläuterten Strecken sind mehr als widersprüchlich. Demzufolge muss die absolute Länge betrachtet werden, um die tatsächlichen Überholmöglichkeiten beschreiben zu können.

Bei der ebenfalls zugrundgelegten absoluten Betrachtungsweise von rechtlichen Überholmöglichkeiten kommt es dagegen erneut zu Widersprüchen. Bei absoluter Betrachtung kann es vorkommen, dass Strecken aufgrund ihrer geringen Länge - und somit einer geringen Wahrscheinlichkeit, bestimmte Längen mit rechtlichen Überholmöglichkeiten zu erreichen - in eine Klasse mit wenigen rechtlichen Überholmöglichkeiten gelangen. Betrachtet man das Streckenband der Strecke BL4387 so fällt auf, dass diese Strecke bei einer absoluten Klasseneinteilung in eine Klasse mit wenig rechtlichen Möglichkeiten fallen kann, weil im Vergleich zu anderen Untersuchungsstrecken nur wenig absolute Möglichkeiten vorhanden sind (nur ca. $1.000 \mathrm{~m}$ ). Allerdings ist dies auf Grundlage der tatsächlichen Situation mehr als bedenklich, da $100 \%$ der Strecke freigegeben sind. Wird hier der relative Ansatz verwendet, rutscht diese Strecke dagegen in eine Klasse mit vielen rechtlichen Möglichkeiten. Derartige Beispiele lassen sich in der Clustertabelle mehrfach finden. Daher wird eine relative Betrachtung der rechtlichen Überholmöglichkeiten bevorzugt. 
Auf Basis der Clustertabelle der 100 Strecken werden für das weitere Vorgehen die folgenden Klasseneinteilungen gewählt. Die absoluten Klassen der vorhandenen Überholmöglichkeiten nach RAS-L werden unterschieden zwischen wenig $(0-300 \mathrm{~m})$, mittel $(301-800 \mathrm{~m})$ und viel (> $800 \mathrm{~m})$. Hintergrund dieser Klasseneinteilung ist die Annahme, dass bei einer beschleunigten Überholung - also dem kritischen Fall eines Überholvorganges - mit einem Hindernisfahrzeug von 80 km/h dem Fahrzeugführer bei wenig gegebenen Überholmöglichkeiten für maximal $15 \mathrm{~s}$ die Chance gegeben wird, eine Überholentscheidung zu treffen. Für den mittleren Fall sind zwischen 16 und $40 \mathrm{~s}$ vorhanden. Sind auf einer Strecke über $40 \mathrm{~s}$ vorhanden, um bei ausreichenden Sichtweiten eine Überholentscheidung zu treffen, so kann dies als viel angesehen werden. Mit der gewählten Klasseneinteilung ergibt sich ungefähr eine Gleichverteilung der Untersuchungsstrecken über die 3 Klassen. Bei einer relativen Clusterung der rechtlichen Überholmöglichkeiten werden die Klassen zu 0 - $33 \%, 33$ - $66 \%$ und > $66 \%$ gebildet.

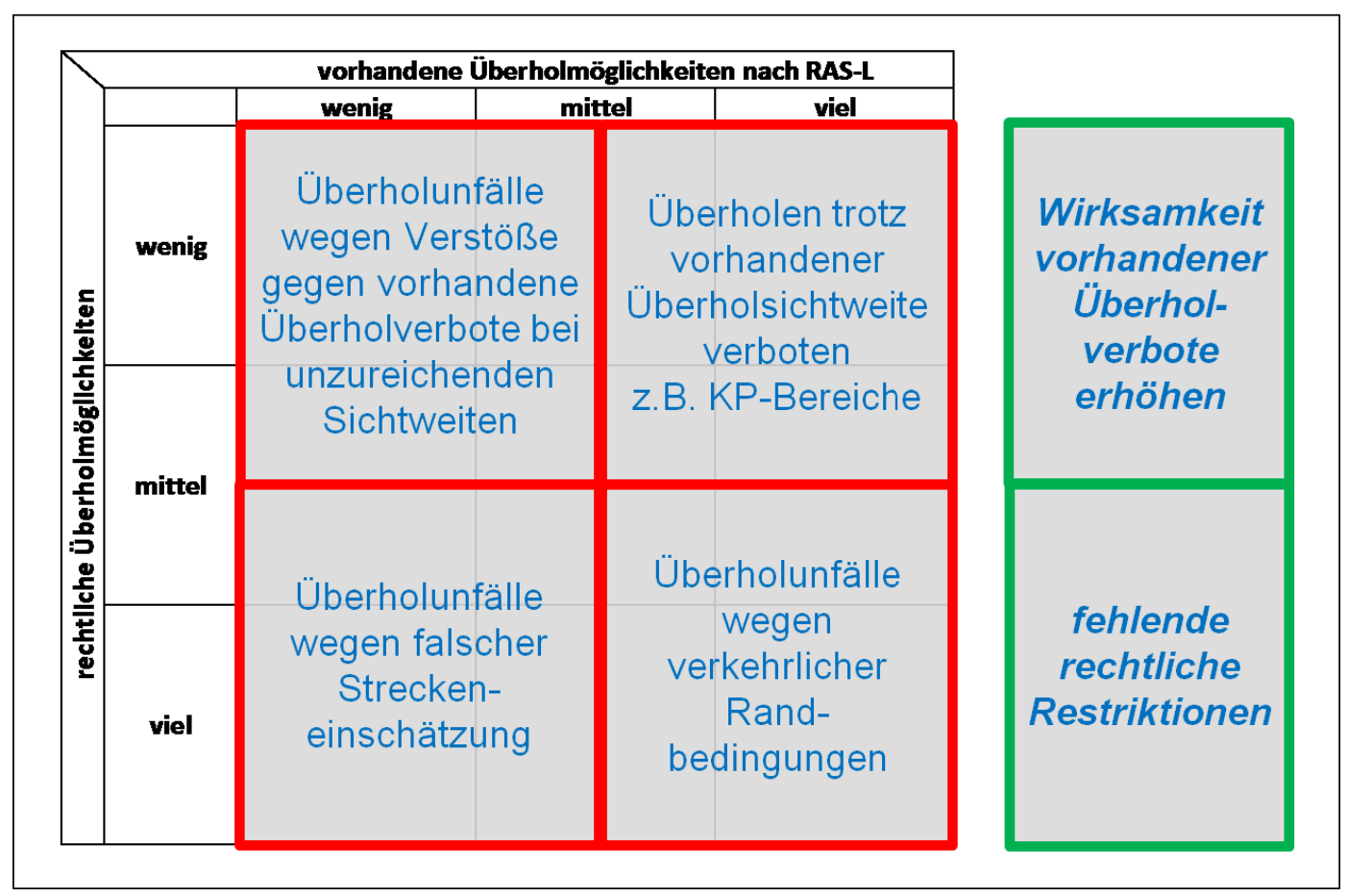

Abbildung 3.26: Ergebnis der Klasseneinteilung von Überholmöglichkeiten

Bei der Erstellung einer Matrix nach den vorgeschlagenen Kriterien ergibt sich Abbildung 3.26. Sind viele rechtliche Möglichkeiten dagegen aber nur wenig Überholmöglichkeiten nach RAS-L tatsächlich vorhanden, so entstehen Überholunfälle auf der Untersuchungsstrecke womöglich durch eine falsche Streckeneinschätzung. Sind sowohl rechtliche als auch tatsächliche Überholmöglichkeiten in ausreichendem Maße vorhanden, so geschehen die Überholunfälle möglicherweise wegen verkehrlicher Randbedingungen, da die Trassierung keine größeren Einschränkungen vorgibt. Ansatzbereiche für Maßnahmen in diesen beiden Gruppen stellt die Neuanordnung von rechtlichen Restriktionen dar. Sind wenig rechtliche Möglichkeiten vorhanden sowie wenig Überholmöglichkeiten nach RAS-L, so handelt es sich bei den Unfällen um Verstöße gegen bereits vorhandene Anordnungen der Verkehrsbehörden. Sind wenig rechtliche Überholmöglichkeiten vorhanden aber vergleichsweise viele Sichtweiten, so können Knotenpunktbereiche ursächlich für die Verbote sein. 
In diesen beiden Gruppen muss bei Unfällen aber über die Erhöhung der Wirksamkeit der vorhandenen Überholverbote nachgedacht werden.

Bei der Zuordnung der 100 Untersuchungsstecken zu der vorgeschlagenen Klasseneinteilung ergibt sich Anhang $\vee$. Hierbei ist innerhalb der $3 \times 3$ Matrix ein Gewicht in Richtung der freigegebenen Abschnitte (viel rechtliche Überholmöglichkeiten) entstanden. Dies entspricht aber auch den Ergebnissen der abgeschlossenen Netzanalyse und Unfallzuordnung, da tatsächlich durchschnittlich $70 \%$ der Untersuchungsstrecken freigegebene Streckenabschnitte aufweisen. Fraglich ist an dieser Stelle nur noch die tatsächliche Unfallposition. Denn bei einer Strecke mit $90 \%$ freigegebenen Abschnitten und 10 \% Überholverbot, bei der aber alle Überholunfälle auf den $10 \%$ mit Überholverbot passiert sind, sollte nicht zwangsläufig der freigegebene Abschnitt maßgebend sein. Um dies zu prüfen, wurden die Anteile der Unfälle berechnet, die tatsächlich in freigegebenen Abschnitten passiert sind und zur Clusterung herangezogen. Somit können die Wechselwirkungen zwischen der reinen Streckencharakteristik und dem tatsächlichen Überholunfallgeschehen überprüft werden. Dies bedeutet im Beispiel, dass Strecke BL5-298 wohl nicht zwangsläufig wegen ihrer großzügigen Überholmöglichkeiten auffällig für Überholunfälle geworden ist, da 80 \% der Überholunfälle im Überholverbot geschehen sind. Ein genau umgekehrtes Beispiel ist die Strecke BL5438. Sie weist wenig rechtliche Überholmöglichkeiten auf, allerdings sind $75 \%$ der Unfälle in freigegebenen Abschnitten geschehen, was ein Indiz für den Abbau von Überholdruck ist, der sich angestaut hat als man nicht überholen durfte und abgebaut wurde als die Überholverbote aufgehoben wurden.

Ein letzter vorbereitender Schritt zur Clusterung ist die Untersuchung der Streckenbänder auf Unfallhäufungsstellen, weil es grundsätzlich erstrebenswert ist, Streckenteile an denen sich aus bestimmten Ursachen Überholunfälle häufen vorrangig zu betrachten, um Maßnahmen abzuleiten. Hierbei werden drei unterschiedliche Definitionen von Unfallhäufungen festgelegt.

Definition 1: $\quad$ - 2 Überholunfälle auf weniger als $200 \mathrm{~m}$ Streckenlänge

Definition 2: $\quad$ - mehr als 2 Überholunfälle auf weniger als 200 m Streckenlänge oder - mehrere Unfallhäufungen nach Definition 1

Definition 3: - Unfallhäufungslinien (mehr als 2 Überholunfälle verteilt auf bis zu 1.000 m)

Insgesamt sind 57 Strecken mit Unfallhäufungen nach einer der drei Definitionen im Kollektiv der 100 unfallauffälligsten Untersuchungsstrecken vorhanden. Bei der Clusterung der Untersuchungsstrecken ist eine Vorauswahl von Strecken durchzuführen. Dies bedeutet, dass Strecken auf denen in der Projektbearbeitung bereits im Jahr 2011 eine Detailanalyse durchgeführt wurde, auch im Kollektiv der 50 Strecken weiterhin betrachtet werden. Die Erhebungen wurden hier auf Basis der unfallauffälligsten Untersuchungsstrecken in Bundesland 3 und Bundesland 4 auch ohne Clusterung begonnen, um den Projektverlauf durch die verspätet zur Auswertung verfügbaren Unfalldaten aus Bundesland 5 nicht unnötig zu verzögern. Hierbei wurden bereits auf 15 Strecken in den o.g. Bundesländern Erhebungen durchgeführt. Darüberhinaus werden Strecken bei der Clusterung vernachlässigt, deren Lage innerhalb der einzelnen Bundesländer bzw. zu anderen potentiellen 
Strecken für die Detailanalyse ungünstig ist. Von diesen Strecken ist aus forschungsökonomischen Gründen abzusehen, allerdings ist hier bei besonders interessanten Strecken ein vergleichbarer Ersatz zu suchen. Als letztes müssen Untersuchungstrecken vernachlässigt werden, auf denen sich aufgrund von Baumaßnahmen in der Vergangenheit die Überholsituation verändert hat. Der Fokus der Detailanalyse liegt auf Strecken mit Unfallhäufungen nach einer der drei Definitionen, um im Netz vorhandene Unfallhäufungsstellen entschärfen zu können. Die weitere Clusterung verläuft in 5 Schritten.

Beginnend mit Schritt 1 werden die 13 Strecken mit Unfallhäufungen nach Definition 2 als gesetzt für die folgende Untersuchung angesehen, da diese Definition die schwersten Unfallhäufungen ausweist. Zwischen den bereits vorhandenen erhobenen Strecken und Schritt 1 sind dabei durchaus Schnittmengen aufgetreten. In Schritt 2 werden zu dem bisherigen Kollektiv aus jeder Klasse nach Anhang $\vee$ mindestens eine Strecke ergänzt. In Schritt 3 wurden die Besonderheiten des Unfallgeschehens herangezogen (Anteil der Unfälle auf freigegebenen Abschnitten innerhalb der $3 x$ 3 - Matrix). Diese Prüfung hat jedoch zu keinem weiteren Ergebnis geführt, da die hier interessanten Strecken bereits im ausgewählten Kollektiv enthalten waren oder die Strecken keine Unfallhäufungen enthielten und somit grundsätzlich vernachlässigt werden. In Schritt 4 wurden Untersuchungsstecken ausgewählt, bei denen die Problembereiche des Unfallgeschehens auf den Strecken sowie auch potentielle Maßnahmen offensichtlich sind. Im Regelfall decken sich aber die Strecken mit offensichtlichen Defiziten auch mit der Auswahl der stärksten Unfallhäufungen, da hier die größten systematischen Mängel in der Landstraßengestaltung (vorhandene Überholsichtweiten vs. verkehrsrechtliche Anordnungen) bzw. bei der Durchführung von Überholvorgängen durch die verkehrlichen Randbedingungen (hohe Verkehrsstärke mit einhergehendem erhöhten Überholdruck) vorhanden sind. Durch die bereits durchgeführten Arbeitsschritte konnten 28 Strecken ausgewählt werden. In einem letzten Schritt mussten aus verbleibenden 27 Strecken mit Unfallhäufungen demnach nur noch 22 Strecken ausgewählt werden. Hier wurde im Ausschlussverfahren vorgegangen, da nur 5 weniger interessante Strecken entfernt werden müssen. Hierbei wurden 2 Strecken in Bundesland 4 vernachlässigt, da in diesem Bundesland bereits 10 Strecken erhoben wurden und zudem beide Strecken im überrepräsentierten 9. Matrixfeld angesiedelt sind. Außerdem wurde Strecke BL3-49 entfernt, da sich diese ebenfalls in diesem Matrixbereich befindet. Als Abschluss wurden die zwei Strecken mit den verbleibenden geringsten Unfallkostenraten innerhalb der Matrix vernachlässigt (BL5-378 und BL5-402).

Im Ergebnis der beschriebenen Clusterung (siehe Anhang W) sind im Kollektiv der 50 Untersuchungsstrecken, welche innerhalb der Detailanalyse näher untersucht werden, die Strecken mit vielen Überholunfällen zu einem Großteil enthalten. Innerhalb der 9 Matrixfelder überwiegt eine Gleichverteilung der Unfallkostenraten über die ausgewählten Strecken. Somit können beispielsweise Strecken mit vier Unfällen aber wenig und viel DTV (was sich in den UKR niederschlägt) gleichwertig betrachtet werden. Insgesamt sind bei Betrachtung der Verkehrsstärken und der Unfallzahlen vernünftige Verteilungen über alle gebildeten Klassen entstanden. Somit ergibt sich insgesamt ist ein sehr breites Spektrum verschiedenster Untersuchungsstrecken, auf denen im Rahmen der folgenden Detailanalyse weitere Erhebungen durchgeführt werden können. 


\subsubsection{Datenlage Verkehrsunfallanzeigen}

Um im Rahmen der nachfolgenden Detailanalyse einen mikroskopischen Einblick in die vorherrschende Unfallsituation der einzelnen Strecken bekommen und darüber hinaus zielgerichtet Maßnahmen ableiten zu können, sind Unfallhergangsbeschreibungen unerlässlich. Für die 50 Strecken der Detailanalyse konnten bis auf Bundesland 3 (für den vorliegenden Untersuchungszeitraum von 2007 bis 2009 sind keine Unterlagen mehr verfügbar, da die Anzeigen grundsätzlich nur für 3 Jahre aufbewahrt werden) im restlichen Untersuchungsgebiet in Kooperation mit den Polizeibehörden die erforderlichen Unfallhergangsbeschreibungen erfolgreich angefragt werden. 


\section{Detailanalyse}

In diesem Kapitel wird die Detailanalyse der geclusterten 50 Untersuchungsstrecken ausführlich erläutert. Die Ausführungen umfassen die Ergebnisse der mikroskopischen Unfallanalyse (Ergänzung der Streckenbandanalyse - vgl. Kapitel 3.5.5 - um eine Auswertung der Unfallhergangsbeschreibungen) sowie die Durchführung der Erhebungen und Auswertungen zum Überholverhalten.

\subsection{Mikroskopische Unfallanalyse}

Im Rahmen der mikroskopischen Unfallanalyse wurden die Unfallhergangsbeschreibungen der durch die Clusterung ausgewählten 50 Strecken angefordert und im Rahmen der Detailanalyse ausgewertet. Hierfür wurde an die einzelnen zuständigen Polizeipräsidien herangetreten.

Das Ziel ist es, die im Rahmen der Netzanalyse erstellten Streckenbänder mit den Auswertungen der Unfallhergangsbeschreibungen detailliert zu verschneiden. Hierzu sind aufbauend auf der in Kapitel 3.5.5 erstellten Datenbank auf Unfallebene weitere Unfallmerkmale zu erheben. Unter anderem ist zu prüfen, in welcher Phase des Überholvorganges (Ausscheren, Überholen, Einscheren) sich der Unfall ereignet hat, woraus sich auch unterschiedliche Anforderungen an die Sichtweiten ergeben. In welchem Umfang sich diese Phasen des Überholvorganges aus den Unfalltexten ableiten lassen, bleibt abzuwarten. Darüberhinaus werden die Unfallbeteiligten nach Fahrzeuggruppen ermittelt sowie weitere Besonderheiten des Unfallhergangs festgehalten.

\subsubsection{Ergebnisse der mikroskopischen Unfallanalyse}

In diesem Kapitel werden für insgesamt 166 Überholunfälle auf 43 Untersuchungsstrecken (ohne Bundesland 3, vgl. Kapitel 3.5.7) die Ergebnisse der mikroskopischen Unfallanalyse dargestellt. Bei möglichen Differenzen der Anzahl von Überholunfällen mit auswertbaren Einzelmerkmalen zu der genannten Grundgesamtheit konnten keine eindeutigen Merkmale zugewiesen werden, weswegen diese Unfälle bei den entsprechenden Teilauswertungen vernachlässigt wurden.

Nachfolgend werden die einzelnen Unfallbeteiligten sowie deren Verkehrsbeteiligung (Fahrzeugarten) beschrieben. In Abbildung 4.1 wird die Verkehrsbeteiligung der Unfallverursacher veranschaulicht. Als Unfallverursacher gelten hierbei die Unfallbeteiligten, welche verkehrsrechtlich die Unfallschuld zugewiesen bekommen haben. Im Regelfall kann das überholende Fahrzeug als Unfallverursacher genannt werden, da es oftmals ohne Überholvorgang nicht zu einem Unfall gekommen wäre. In lediglich 5 Fällen war die Unfallschuld nicht eindeutig zuweisbar, da sowohl Überholer als auch Hindernisfahrzeug eine Teilschuld zugesprochen bekamen. Hierbei handelt es sich aber ausschließlich um Konflikte beim Abbiegen mit den entsprechenden Unfallursachen „Fehler beim Abbiegen“ sowie „Überholen trotz unklarer Verkehrslage“. In den Ergebnissen zeigt sich, dass es sich bei den Unfallverursachern eines Überholunfalles zu 82 \% um einen Pkw gehandelt hat. Zu weiteren $13 \%$ waren die Krafträder beteiligt. Diese beiden genannten Fahrzeugarten müssen im Landstraßennetz auch als die potentiellen Überholer angesehen werden. Lediglich $5 \%$ der Überholer waren Lastkraftwagen bzw. Fahrzeuge des Schwerverkehrs, welche im Regelfall auch eher die Hindernisfahrzeuge darstellen. 


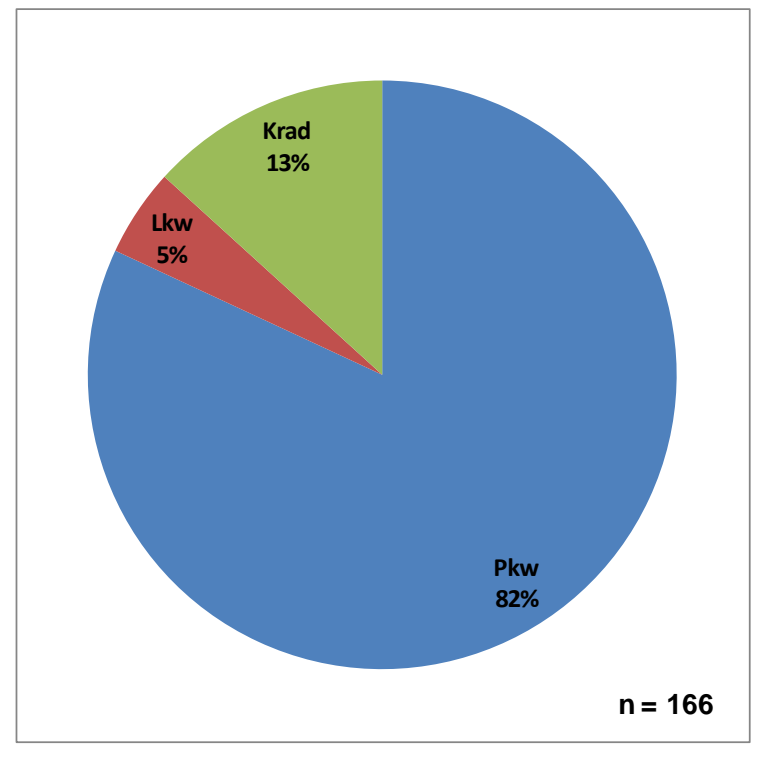

Abbildung 4.1: Fahrzeugart der Unfallverursacher (Überholer im Regelfall Unfallverursacher)

Die in der Unfallhergangsbeschreibung benannten Hindernisfahrzeuge, welche Ursache des Überholvorgangs waren, sind in Abbildung 4.2 darstellt. An dieser Stelle sei angemerkt, dass es sich hierbei nicht zwangsläufig um den Kollisionsgegner des Unfalles gehandelt hat. Diese Punkte werden aber nachfolgend ebenfalls betrachtet. Auch in dieser Auswertung besitzen die Pkw mit 54 Prozent den größten Anteil, weitere $31 \%$ entfallen auf Lastkraftwagen. Die verbleibenden $15 \%$ entfallen auf Fahrzeugarten, welche entweder eher potentielle Überholer darstellen (Krad), Fahrzeuge die im Landstraßennetz vergleichsweise selten auftreten (Radfahrer, Leichtkrafträder, Traktoren) oder Fahrzeuge deren Verkehrsbeteiligungen aus den Unfallhergangsbeschreibungen nicht ermittelt werden konnte.

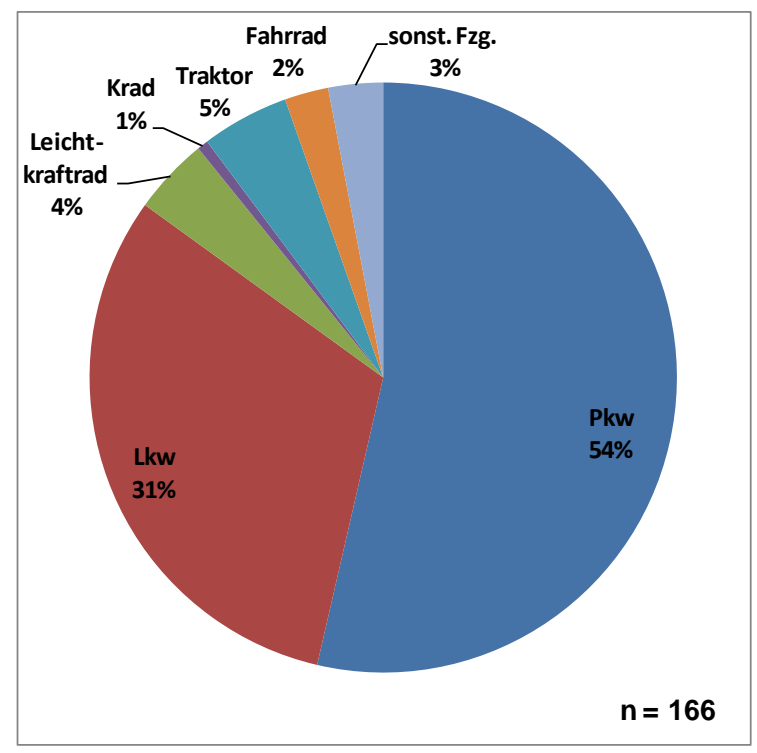

Abbildung 4.2: Unfallbeteiligtes Hindernisfahrzeug

Werden die beiden Fahrzeugkollektive bzw. die beiden Beteiligten des reinen Überholvorganges (bisher ohne Berücksichtigung der Fahrzeugart des Kollisionsgegners) miteinander verschnitten, so ergibt sich Abbildung 4.3. Maßgebende Überholmanöver bei Überholunfällen sind die Überho- 
lungen von Pkw an anderen Pkw sowie an Lkw oder weiteren unbekannten Fahrzeugen, darauf folgen die Überholungen durch Motorräder. Wurde ein Lkw als Überholer festgestellt, so handelte es sich überwiegend um Überholungen an Leichtkrafträdern. Oftmals war hier das Problem des zu geringen seitlichen Sicherheitsabstandes bzw. Konflikte beim Wiedereinscheren und eine Fehleinschätzung des Abstandes beider Fahrzeuge, was einen Kontakt und oftmals eine besonders hohe Unfallschwere (größtes Fahrzeug vs. kleinstes Fahrzeug) zur Folge hatte. Unter „weitere“ Konstellationen von Überholer und Hindernisfahrzeug wurden all diejenigen Verkehrsbeteiligungen zusammengefasst, welche im Rahmen dieser Zusammenstellung nur in Einzelfällen aufgetreten sind.

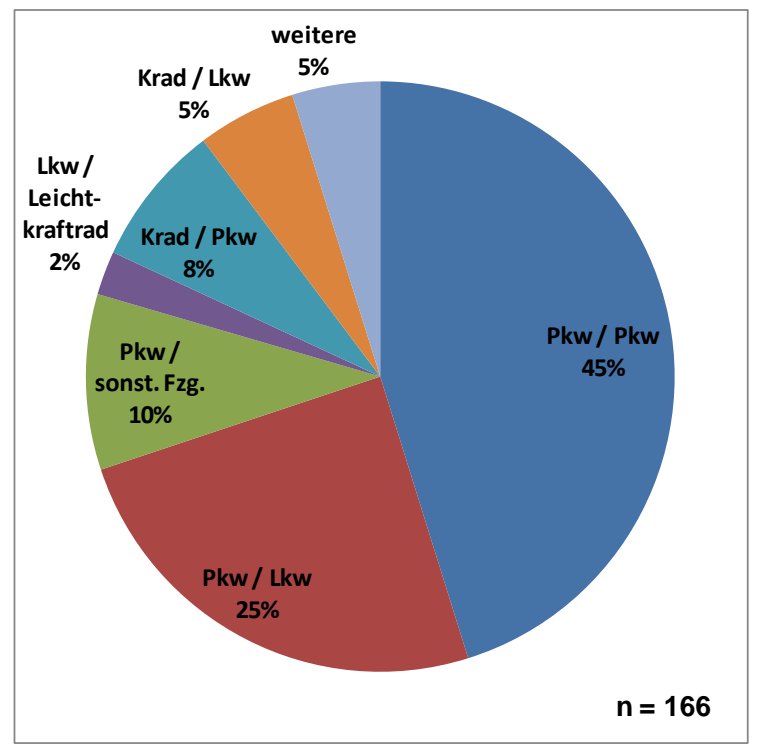

\section{Abbildung 4.3: Konstellation Überholer I Hindernisfahrzeug}

Betrachtet man die Kollisionsgegner des Überholunfalles bzw. die Fahrzeuge mit denen der Überholer zusammengestoßen ist, so ergibt sich Abbildung 4.4. Auch hier haben gemäß der Häufigkeit ihres Auftretens im Landstraßennetz die Pkw den größten Anteil mit 60 \%. Der nächst größere Teil der Kollisionsgegner entfällt hier auf Kollisionen mit anderen Objekten im Straßenumfeld.

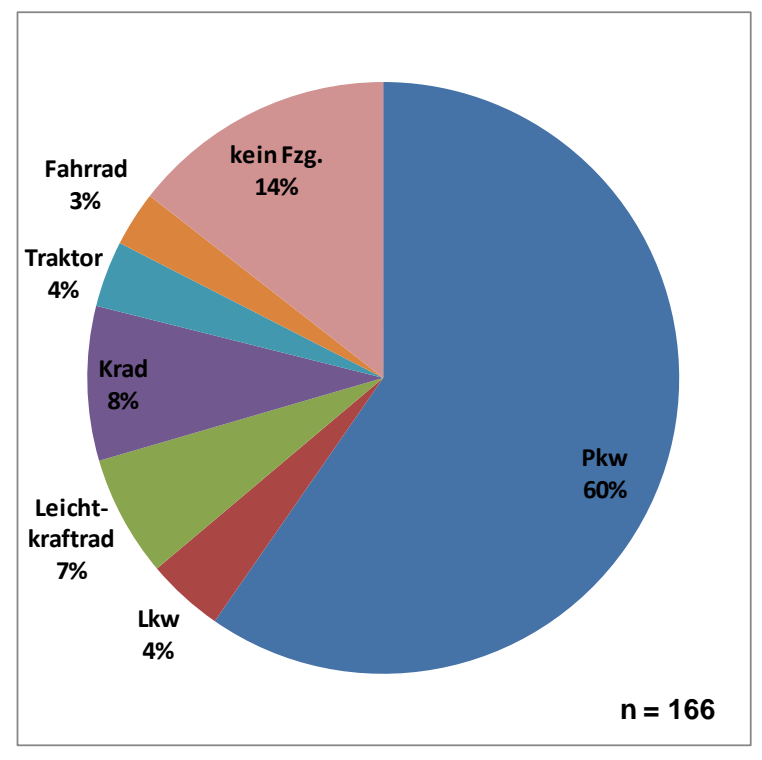

Abbildung 4.4: Kollisionsgegner des Überholunfalles 
In Anlehnung an die Unfallarten - „ob und wie Verkehrsteilnehmer kollidiert sind“ (vgl. FGSV, 2003) - werden für die Kollisionen der Beteiligten des Überholunfalles die Kollisionsarten nach Abbildung 4.5 definiert. Hier wird deutlich, dass bei den Überholunfällen überwiegend Konflikte mit entgegenkommenden Fahrzeugen identifiziert werden konnten. Dieses vielfältige Problem wird auch als der „klassische“ Überholunfall angesehen, da es aufgrund von Sichtweiten-, Entfernungsund Geschwindigkeitsabschätzungen zu Fehlentscheidungen beim Annehmen bzw. Ablehnen einer potentiellen Überholmöglichkeit gekommen ist. Alle weiteren Konflikte sind bei den analysierten Überholunfällen annähernd gleichverteilt. Hierzu zählen als nächst häufigste Kollisionsart der Überholunfall mit Abbiegern. Hierbei wird im Regelfall die Abbiegeabsicht des Hindernisfahrzeuges nicht erkannt, in dessen Folge es zu einer Überholung sowie zum Überholunfall gekommen ist. Es wird darauf verweisen, dass derartige Abbiegeunfälle hier nicht als Kollisionen mit dem Hindernisfahrzeug geführt werden, obwohl eine Kollision zwischen Hindernis und Überholer vorliegt. Ein weiterer Überholunfall ist die Kollision mit einem bereits überholenden Fahrzeuges. Hierbei wird beispielsweise im Kolonnenverkehr aus dritter Position eine Überholung durchgeführt und aus zweiter Position hinter dem Hindernisfahrzeug ebenfalls zum Überholen angesetzt. Bei dem folgenden Ausschervorgang kam es dann anschließend zu einer Kollision mit dem bereits rückwärtig Überholenden. Die bereits in Abbildung 4.4 dargestellten $14 \%$ der Unfälle ohne Kollisionen mit einem weiteren Fahrzeug sind auch hier mit gleichem Anteil vertreten. Die Unfälle mit Kollisionen mit dem Seitenraum bzw. des Straßenumfeldes entstehen hier häufig durch Kontrollverluste beim Überholvorgang (u.a. durch rasches Einscheren wegen plötzlich auftretendem Gegenverkehr). Diese Kontrollverluste sind im weiteren Unfallhergang mit einem Abkommen von der Fahrbahn und einer Kollision mit weiteren straßenseitigen Objekten verbunden. Kollisionen mit dem Hindernisfahrzeug beim Überholvorgang (Konflikte beim Ausscher-, Einschervorgang durch abgebrochene oder rasch beendete Überholungen sowie dem direkten Überholvorgang durch fehlende Sicherheitsabstände) schließen die Gruppe der maßgebenden Kollisionsarten. Alle weiteren Fälle betreffen nur Ausnahmen und werden an dieser Stelle nicht weiter berücksichtigt.

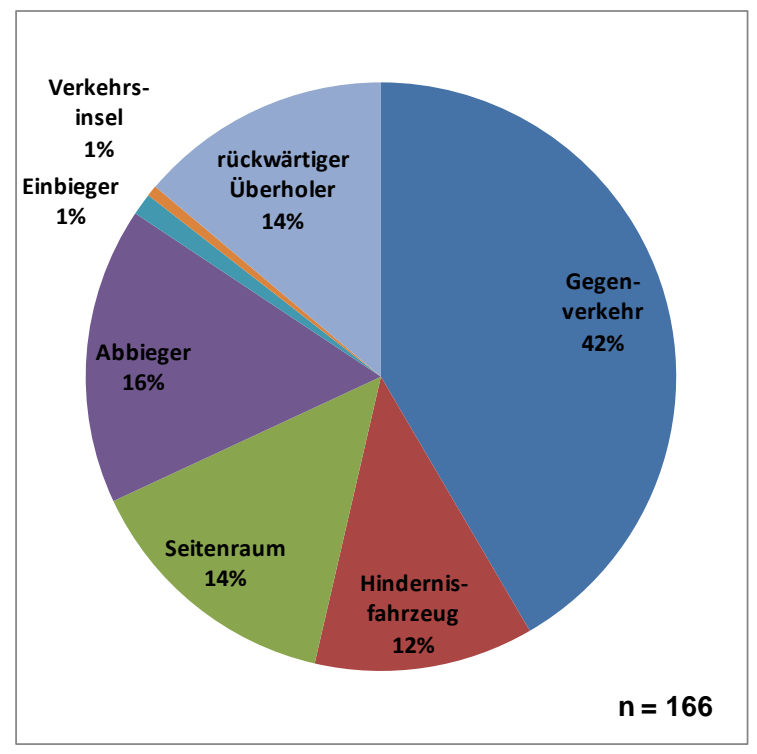

Abbildung 4.5: Beschreibung der Kollisionsart 
Werden die Kollisionsarten nach den Verkehrsbeteiligungen der Kollisionsgegner differenziert, so ergibt sich bei Zusammenstößen mit dem Gegenverkehr Abbildung 4.6. Nahezu bei allen Zusammenstößen mit dem Gegenverkehr war der Kollisionsgegner ein Pkw. Die vermuteten schlechten Erkennbarkeiten von eher kleinen Fahrzeugen wie den untersuchten zweispurigen Fahrzeugen ergaben hier allerdings keine besonderen Auffälligkeiten. Demnach ist bei Überholunfällen mit Zusammenstößen mit dem Gegenverkehr wohl eher die Abschätzung der Entfernungen und der gefahrenen Geschwindigkeiten das vorherrschende Problem. In Bezug auf diese mangelhaften Entfernungs- und Geschwindigkeitsabschätzungen ergeben sich fehlerhafte Überholentscheidungen bei ausreichenden bzw. vorhandenen Sichtweiten oder Überholunfälle durch Überholmanöver in eher schlechten Sichtweitenbereichen, bei denen aufgrund der unzureichenden Streckenübersicht der Gegenverehr plötzlich und unerwartet aufgetaucht ist.

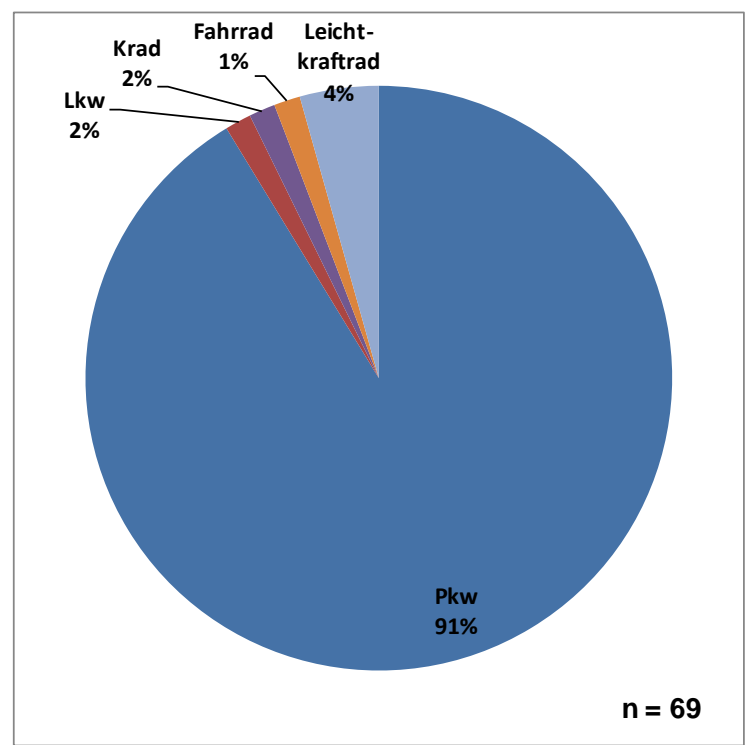

Abbildung 4.6: Differenzierung der Zusammenstöße mit dem Gegenverkehr nach Kollisionsgegnern

Bei der Differenzierung der Zusammenstöße mit dem rückwärtig bereits Überholenden (23 Überholunfälle) ergeben sich überwiegend Konflikte den eher schnellen und unscheinbaren oder schlecht erkennbaren Fahrzeugen wie den Motorrädern (52 \%). Probleme bei den Zusammenstößen mit dem rückwärtig Überholenden ist eine mangelnde Orientierung bzw. Verkehrsbeobachtung nach hinten. Hierbei muss vor dem Ausscheren der Raum hinter bzw. neben dem eigenen Fahrzeug auf andere Fahrzeuge geprüft werden (u.a. Schulterblick). Erst wenn die Prüfung von Gegenverkehr und rückwärtigem Verkehr erfolgreich war, kann eine positive Überholentscheidung getroffen werden. Missachtungen führen hierbei zu Unfällen. Bei den oft schnellen (sowohl bezogen auf Geschwindigkeit als auch auf das Beschleunigungsvermögen) Motorrädern kann aber im Zweifelsfall auch trotz ausreichender Orientierung an der Verkehrssituation ein Motorrad übersehen werden. Hierbei kann innerhalb von wenigen Sekundenbruchteilen auch nach der Prüfung des rückwärtigen Verkehrs ein Motorrad rasch ausgeschert und im „Toten Winkel“ des eigenen Fahrzeuges verschwunden sein. Alle weiteren Unfälle mit den rückwärtig Überholenden verteilen sich zu 44 \% auf Zusammenstöße mit Pkw's sowie zu 4 \% auf Konflikte mit Lkw's. Fahrzeuge des Schwerverkehrs zählen eher nicht zu den potentiellen Überholern und treten daher nur im Einzel- 
fall auf. Insgesamt kann hier unterstellt werden, dass bei Unfällen mit dem rückwärtigen Überholer grundsätzlich alle üblichen potentiellen Überholer (Pkw und Krad) betroffen sein können und die Unfälle durch mangelhafte Orientierung und Prüfung des umgebenen Verkehrs entstanden sind.

Werden die Zusammenstöße mit den Abbiegern differenziert nach den bekannten Verkehrsbeteiligungen, so ergibt sich Abbildung 4.7. Auch hier haben die häufig vertretenen Pkw's mit $55 \%$ den größten Anteil. Landwirtschaftliche Fahrzeuge und Lkw folgen mit weiteren 22 \% sowie $15 \%$. Die Abbiegekonflikte mit zweispurigen Fahrzeugen sind hier nur in Einzelfällen feststellbar gewesen. Generell besteht das Problem der Überholungen von Abbiegern darin, dass die Abbiegeabsicht nicht erkannt wird und im Gegenzug der Überholdruck schlagartig ansteigt. Ob an Knotenpunkten oder eher unscheinbaren Einmündungen von Wirtschaftswegen steigen prinzipiell auf der Landstraße die Unterschiede zwischen tatsächlich gefahrener und gewünschter Fahrtgeschwindigkeit rapide an, da die Abbiegegeschwindigkeiten eher im unteren Geschwindigkeitsbereich angesiedelt sind. Hier werden die Konflikte bzw. das Überholbedürfnis am größten, wenn die Geschwindigkeitsdifferenzen steigen, was bei fehlender Übersicht über die vorherrschende Verkehrssituation zu Fehlern und Unfällen führen kann.

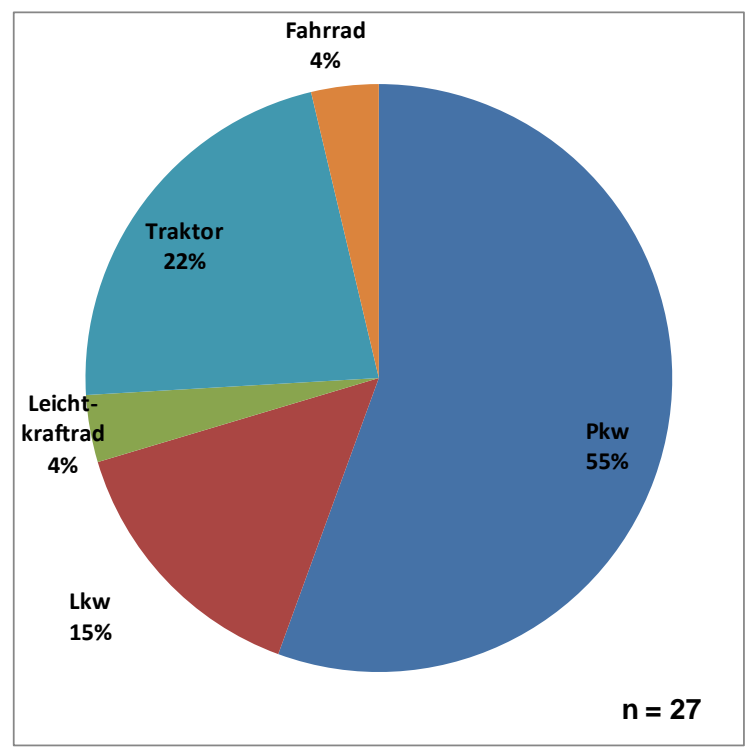

\section{Abbildung 4.7: Differenzierung der Zusammenstöße mit Abbiegern nach Kollisionsgegnern}

Eine Differenzierung der Kollisionsobjekte bei Zusammenstößen mit dem Seitenraum ist Abbildung 4.8 entnehmbar. Bei dem Abkommen von der Fahrbahn in Folge eines Überholvorganges kommen die Überholer in 50 \% der Fälle auf ein angrenzendes Feld bzw. eine Ackerfläche ab. In Abhängigkeit des Unfallverlaufes können sich hier beispielsweise durch überschlagende Pkw's oder die gering gesicherten Motorradfahrer trotzdem schwere Unfallfolgen ergeben. Kollisionen mit Böschungen (13\%) ergeben sich hier nur bei der Führung der Straße im Einschnitt. Bei Böschungen nach unten - also in Dammlage der Straße - wurden mit diesen Elementen keine Kollisionen vermerkt. Weitere $13 \%$ der Überholer kollidierten im Unfallverlauf mit einem angrenzenden Baum im Straßenseitenraum. Die Kollisionen der Unfallbeteiligten mit Brücken bzw. Widerlagern, Gräben, Mauern, Schutzplanken oder Verkehrsinseln konnten hier nur in Einzelfällen festgestellt werden und bedürfen daher keiner weiteren Aufmerksamkeit. 


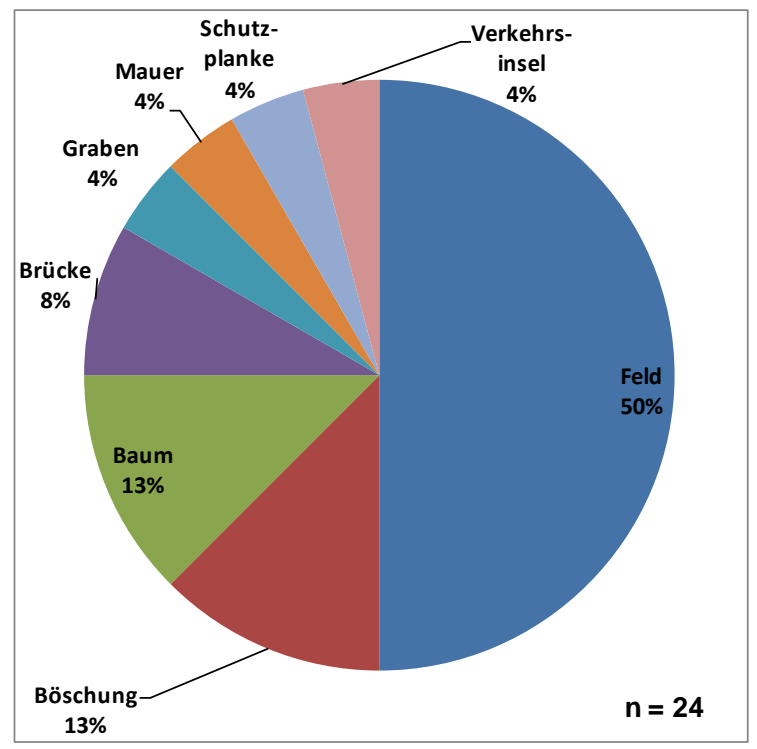

\section{Abbildung 4.8: Differenzierung der Zusammenstöße mit dem Seitenraum nach Kollisionsobjekten}

Werden die fünf bedeutsamen Kollisionsarten über den Unfallkategorien/Unfallschwereklassen dargestellt, dann ergibt sich Abbildung 4.9. Fast erwartungsgemäß steigt der Anteil der Überholunfälle mit Zusammenstößen mit dem Gegenverkehr bei schwereren Unfallfolgen an. Dagegen besteht bei Zusammenstößen mit abbiegenden Fahrzeugen eine umgekehrte Tendenz. Die Anteile von Zusammenstößen mit dem Seitenraum und den Hindernisfahrzeugen sind in allen vier Unfallkategorien nahezu gleich. Unfälle mit dem rückwärtigen Überholer stechen bei den leichten und schweren Unfällen hervor. Hier kann vermutet werden, dass die schweren Unfälle bei Motorradbeteiligung und die leichten Unfälle bei Pkw-Beteiligung entstanden sind.

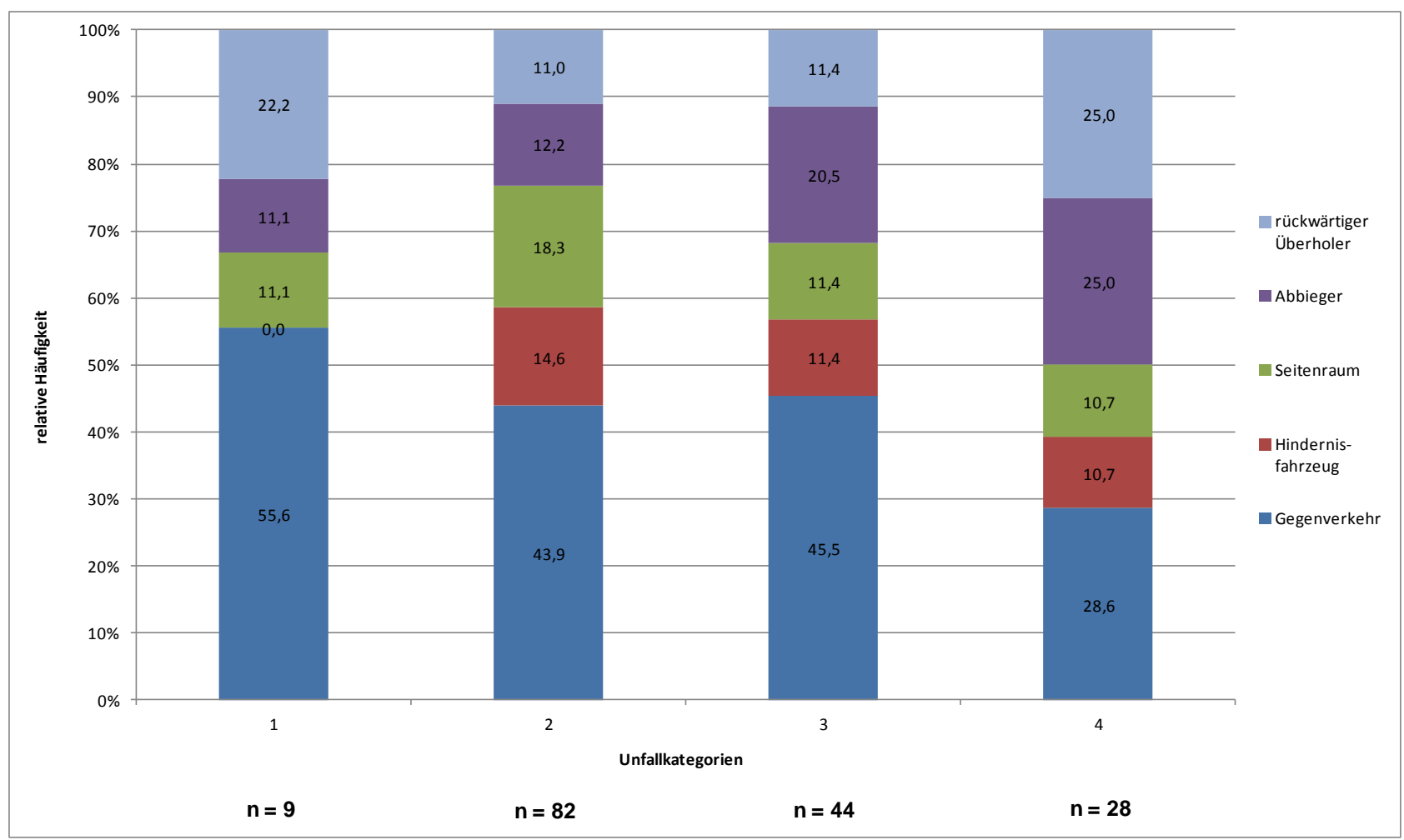

Abbildung 4.9: Kollisionsarten nach Unfallkategorien 
In Abbildung 4.10 sind die Abhängigkeiten zwischen der Unfallkategorie und der Art der Verkehrsbeteiligung des Unfallverursachers dargestellt. Der Anteil der Überholunfälle, bei denen ein Pkw das unfallverursachende bzw. überholende Fahrzeug war, nimmt mit geringerer Unfallschwere zu. Grund hierfür sind vorrangig die folgenden zwei Hintergründe. Überholunfälle mit Beteiligung von Motorrädern - also den schwächsten, ungeschützten Verkehrsteilnehmern auf Landstraßen - haben einen Anteil von 22 \% bei Unfällen mit Getöteten und von $20 \%$ bei Unfällen mit schwerem Personenschaden. Dagegen sind leichte Verletzungen oder Sachschäden bei Beteiligungen von Motorrädern relativ selten. Ist ein Lkw das überholende Fahrzeug bei einem Überholunfall, so kann durch deren hohe kinetische Energie egal bei welchem Kollisionsgegner auch eine hohe Unfallschwere erzeugt werden. Unfälle durch Lkw mit lediglich Sachschaden sind ebenfalls eher selten. Insgesamt ergeben sich die schwersten Unfallfolgen, wenn die größten und die schwächsten Verkehrsteilnehmer in einen Überholunfall verwickelt werden. Die sich ergebenden Zusammenhänge können als erwartungsgemäß angesehen werden.

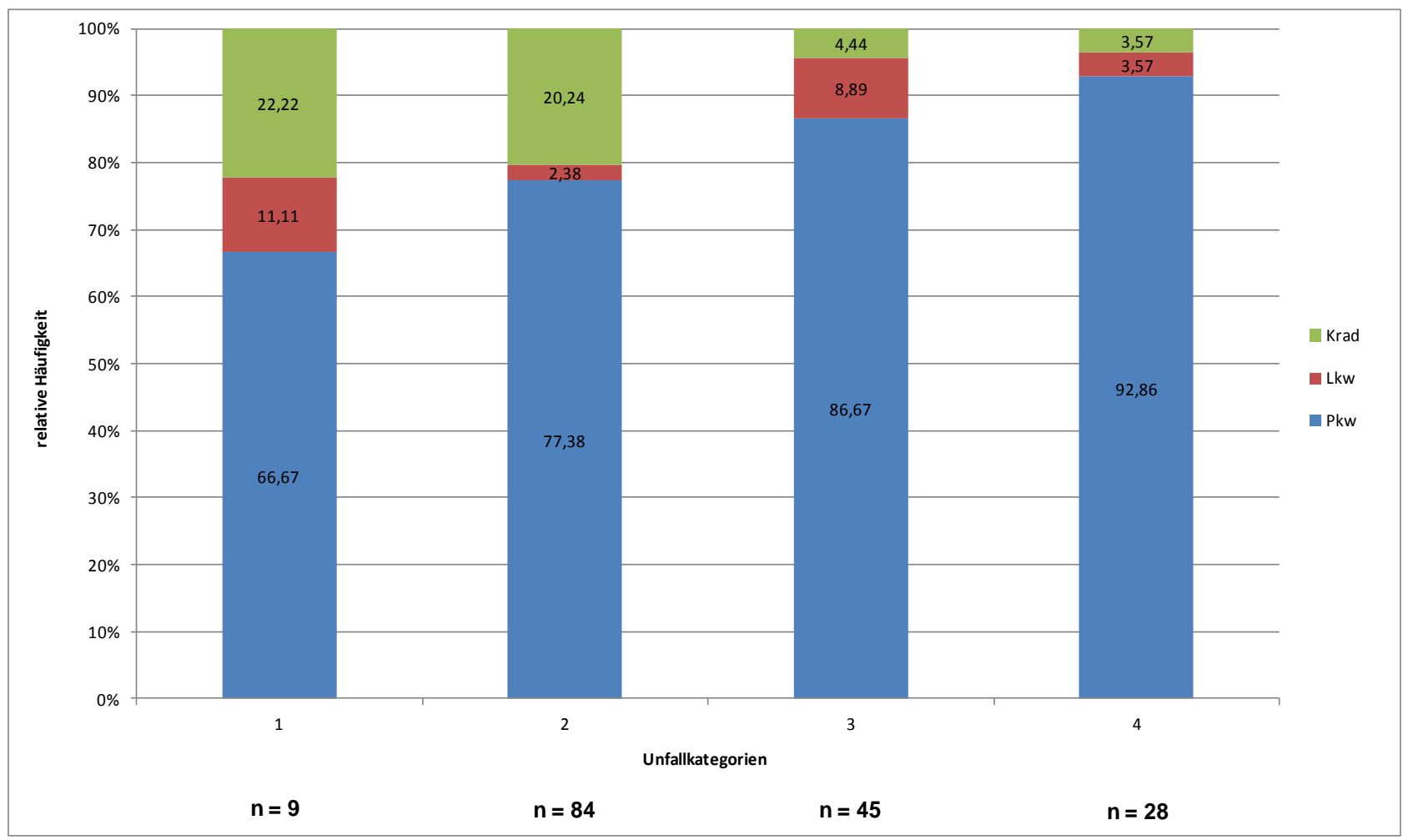

Abbildung 4.10: Art der Verkehrsbeteiligung des Unfallverursachers nach Unfallkategorien

In Abbildung 4.11 sind mögliche Besonderheiten der Unfallörtlichkeit dargestellt. Hier zeigt sich, dass zu 77 \% keine Besonderheiten vorhanden waren und die Überholunfälle überwiegend durch Fehleinschätzungen der Fahrzeugführer (vorhandene Sichtweiten, Gegenverkehrsentfernung und -geschwindigkeit sowie Orientierung nach rückwärtigem Verkehr) entstanden sein müssen. Die Unfallpositionen mit Knotenpunkteinfluss, an Einmündungen von Wirtschafts- bzw. Feldwegen sowie die Unfälle an Grundstückszufahrten sind überwiegend auf Abbiegekonflikte zurückzuführen. Differenzen zum Kapitel der Streckenbandanalyse (vgl. Kapitel 3.5.5) entstehen dadurch, dass durch die Unfalltextanalyse teilweise keine Einflüsse des Knotenpunktbereiches auf die Unfallentstehung erkennbar waren und der Unfall nur zufällig in einem solchen Bereich geschehen ist. Da- 
her sind in Ausnahmefällen in Knotenpunktbereichen auch Zusammenstöße mit dem Gegenverkehr prinzipiell denkbar. Alle weiteren vermerkten Fälle (Ortseingang mit Verkehrsinsel und Stau) sind ausgesprochene Sonderfälle und stark durch Zufallseinflüsse geprägt.

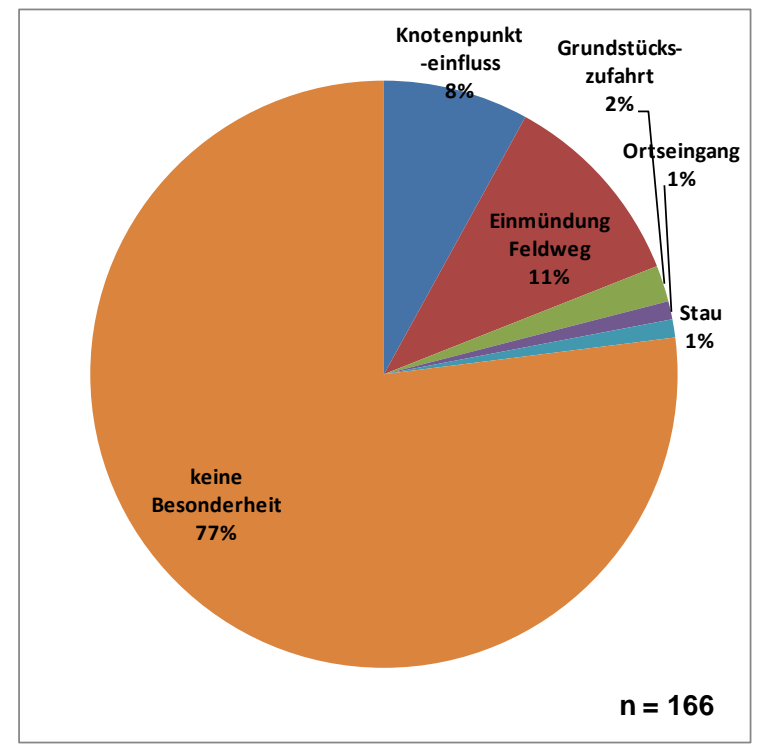

Abbildung 4.11: Besonderheit der Unfallörtlichkeit

Nachstehende Abbildung enthält die Anzahl der Fahrzeuge vor dem Überholer. Hierzu zählen das Hindernisfahrzeug sowie bei Kolonnenbildung bzw. gebundenem Verkehr die weiteren Fahrzeuge zwischen Überholer und Hindernis.

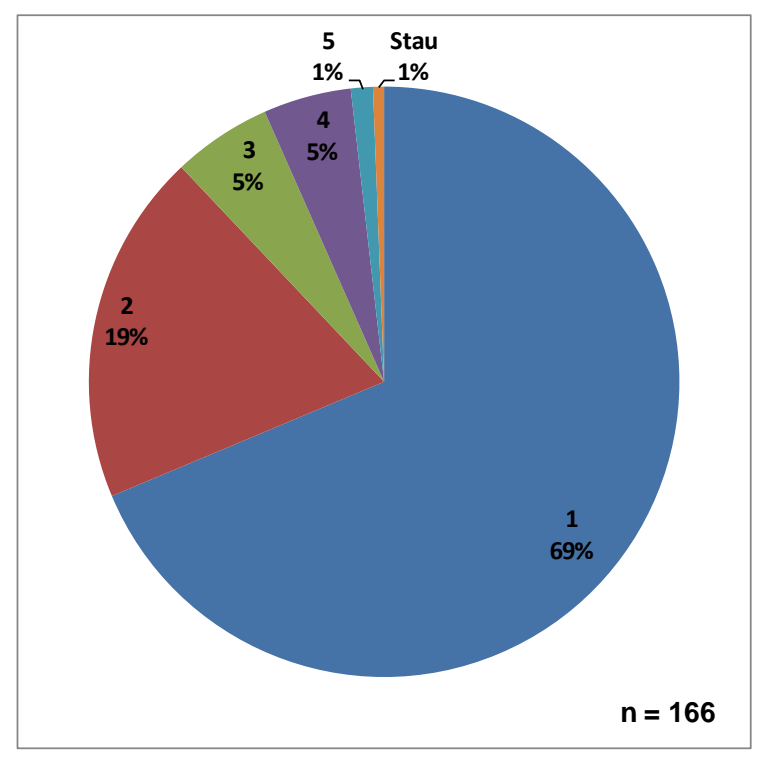

\section{Abbildung 4.12: Anzahl der Fahrzeuge vor dem Überholer (Kolonnenbildung)}

Im Großteil der Fälle (69 \%) wurde in der Unfallhergangsbeschreibung nur ein Hindernisfahrzeug direkt angegeben. Daher kam es lediglich zwischen Hindernis und Überholer zu Interaktionen (Abbau von Überholdruck). Zu 19 \% wurde bei der Überholung versucht, zwei langsamere Fahrzeuge zu überholen. Tatsächliche Überholunfälle bei Kolonnenbildung - mehr als zwei Fahrzeuge - sind dagegen eher selten. Dennoch besitzen die Überholungen aus höherer Kolonnenposition hinter dem Hindernisfahrzeug ein besonderes Gefährdungspotential. Hier können beispielsweise Über- 
holunfälle entstehen, da aus 4 Position vor einem Knotenpunkt zum Überholen angesetzt wurde und es durch die aus der Position gar nicht erkennbare Abbiegesituation im weiteren Verlauf zum Zusammenstoß mit dem linksabbiegenden Fahrzeug gekommen ist. Auch hier kann der Überholdruck des Überholers wegen zunehmender Geschwindigkeitsdifferenzen schlagartig ansteigen, allerdings ohne das die Möglichkeit der Erkennung der Abbiegeabsicht vorhanden ist, was bei Überholungen aus 1. Position nicht zwangsläufig der Fall sein muss. Insgesamt muss zu dieser Teilauswertung festgehalten werden, dass die Kolonnenverkehre nur sichtbar werden, wenn in den Unfallhergangsbeschreibungen der Polizei direkt von einer Überholabsicht des Unfallverursachers an mehreren Fahrzeugen gesprochen wird. Die Frage, welcher Anteil der hier ermittelten 69 \% der Überholunfälle auch wirklich nur ein Hindernisfahrzeug überholen wollten bzw. ob sich vor diesem Hindernis noch ein weiteres Fahrzeug befunden hat, kann nicht abschließend beantwortet werden. Die Ergebnisse sind bei Bewertung kritisch zu hinterfragen.

Die Ergebnisse der Zuordnung der Überholunfälle zu den unterschiedlichen Überholphasen nach Abbildung 2.5 sind in nachstehender Abbildung 4.13 veranschaulicht. Phase 1 und 5 des Überholmodells (Annäherungsphase an Hindernisfahrzeug sowie die Entfernung von Selbigen nach erfolgter Überholung) werden an dieser Stelle nicht berücksichtigt, da sie für die Unfallentstehung nicht maßgebend sind. Es zeigt sich, dass zu $48 \%$ die Überholunfälle während Phase 3 - des direkten Überholvorganges - geschehen sind. An zweiter Position ist Phase 2 - der Ausschervorgang - mit $27 \%$ unfallauffällig geworden. Phase 4 - der Einschervorgang - folgt mit $19 \%$ Anteil am Unfallgeschehen. Die verbleibenden $6 \%$ der Unfälle sind nicht eindeutig den Überholphasen zuordenbar gewesen.

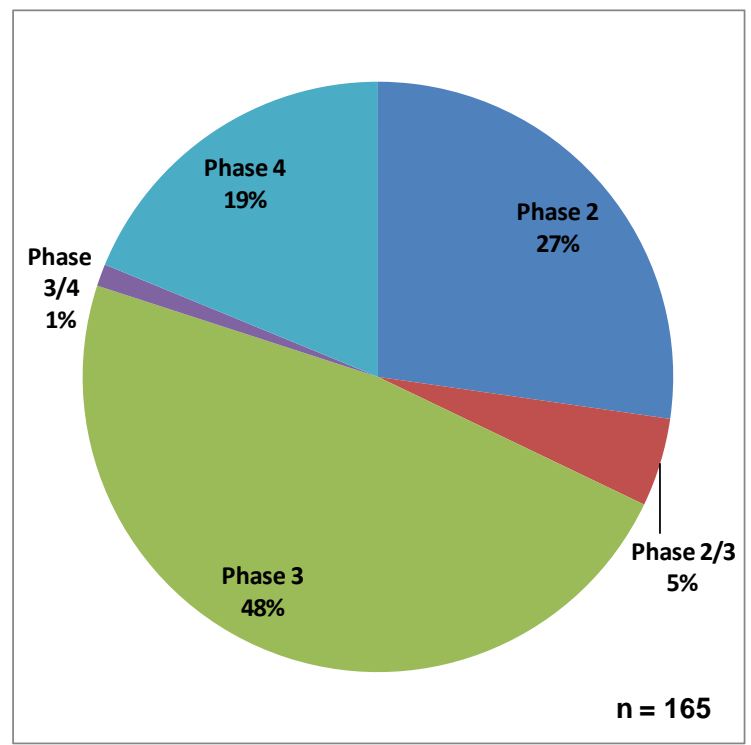

Abbildung 4.13: Unfallentstehung in Abhängigkeit der Überholphasen nach Durth/Habermehl, 1985

In Bezug zu den eben erläuterten Überholphasen ergeben sich weitere interessante Fragestellungen. Differenziert man beispielsweise die Überholphasen nach den in Abbildung 4.5 definierten Kollisionsarten beim Überholunfall, so ergibt sich die nachstehende Abbildung 4.14 aus der sich weitere Schlussfolgerungen ergeben. 


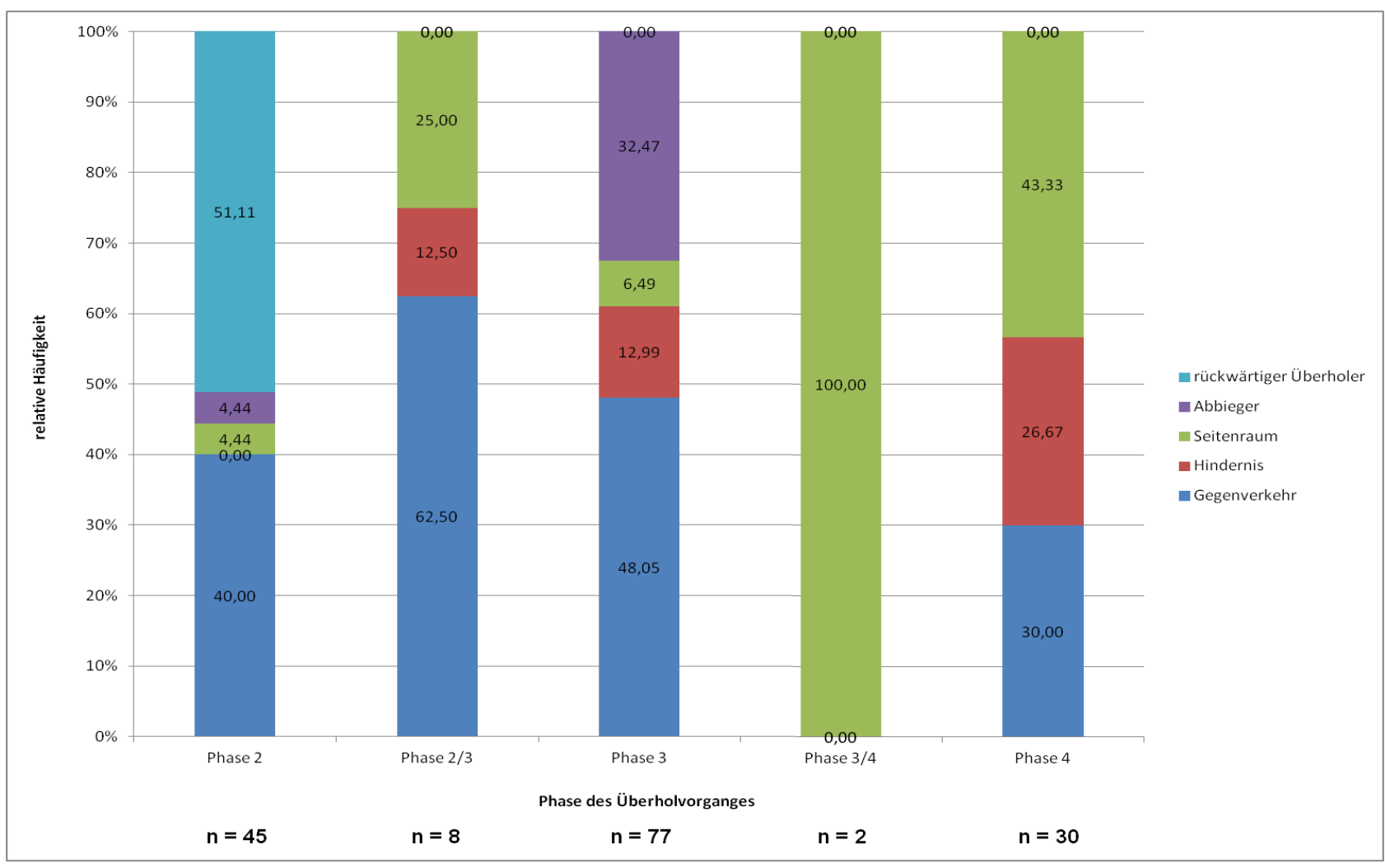

Abbildung 4.14: Kollisionsarten in Abhängigkeit der Überholphasen nach Durth/Habermehl, 1985

Betrachtet man die am häufigsten mit Überholunfällen belastete Überholphase 3, so überwiegen hier die Zusammenstöße mit dem Gegenverkehr aber auch die Konflikte mit den abbiegenden Fahrzeugen. Wird mit abbiegenden Fahrzeugen zusammengestoßen, so kommt es erwartungsgemäß erst dann zum Zusammenstoß, wenn bereits zum Überholvorgang angesetzt wurde und der Überholer sich in Phase 3 befindet. Die Zusammenstöße mit dem Gegenverkehr häufen sich, wenn der Überholvorgang nicht abgebrochen wird und die Fahrer stattdessen versuchen, die Überholung noch zu beenden. Allerdings wird sollte davon ausgegangen werden, dass bei plötzlich auftretenden Gegenverkehr die Überholer nicht reaktionslos auf das entgegenkommende Fahrzeug zusteuern. Ausschließlich bei Unfällen in der Überholphase 2 können Konflikte mit den rückwärtigen Überholern auftreten, welche in dieser Phase auch in den Vordergrund treten und hier als maßgebend angesehen werden müssen. Bei den hier auftretenden Zusammenstößen mit dem Gegenverkehr muss ebenfalls eine mangelhafte Orientierung im Verkehrsgeschehen unterstellt werden, da der Unfall während oder unmittelbar nach dem Aussscheren geschehen ist. Die Unfälle der Phase 4 enden häufig in Kollisionen mit dem Straßenseitenraum oder direkt mit dem Hindernis. Hierbei stellen sowohl das mangelhafte Abstandsverhalten zum rückwärtigen Hindernisfahrzeug als auch das rasche Einscheren durch plötzlich auftauchenden Gegenverkehr in Verbindung mit einem Kontrollverlust die problematischen Fahrmanöver dar. Wird dagegen direkt mit dem Gegenverkehr zusammengestoßen, so wurde womöglich versucht, den Überholvorgang noch zu beenden. Die in Ausnahmefällen nicht eindeutig zuordenbaren Überholphasen (Fälle zwischen zwei Überholphasen) müssen wegen der kleinen Grundgesamtheit an dieser Stelle nicht weiter betrachtet werden. 
Betrachtet man die Unfallsituation in Abhängigkeit der Überholphasen sowie der vorhandenen Überholsichtweiten, so ergibt sich Abbildung 4.15. Insgesamt können nur geringfügige Unterschiede der Überholphasen in verschiedenen Sichtweitenbereichen festgestellt werden. Es ergeben sich aber prinzipiell zwei wesentliche Tendenzen. Mit besser werdenden Sichtweitenbedingungen (von keinen Sichtweiten, über Grenzwert der RMS eingehalten bis zu Grenzwert nach RAS-L eingehalten) nehmen die Überholunfälle während Überholphase 3 ab. Grund hierfür ist, dass bei schlechten Sichtweiten die Wahrscheinlichkeit von unerwartet auftauchendem Gegenverkehr deutlich zunimmt. Bei ausreichenden Sichtweiten wird diese Wahrscheinlichkeit sinken und die Probleme entstehen dagegen überwiegend durch die Fehleinschätzung der Relativbewegung des Gegenverkehrs. Im Gegenzug zu den fallenden Anteilen von Überholphase 3 steigen die Anteile von Phase 2 und 4. Fraglich ist an dieser Stelle allerdings, warum bei nicht vorhandenen Sichtweiten (gemäß Grenzwert nach RMS) überhaupt Unfälle in Phase 2 entstehen können bzw. warum bei derart schlechten Sichtweitenbedingungen überhaupt noch zum Überholvorgang angesetzt wird. Unfälle in Phase 4 können hier in einem Sichtweitengefälle kurz vor dem Sichthindernis im Straßenseitenraum geschehen. Dies kann möglicherweise als Hinweis für eine mangelnde Frühankündigung der schlechten Sichtbedingungen verstanden werden. Die Zunahmen von Phase 2 bei guten Sichtweiten lassen sich beispielsweise durch sich bietende Überholmöglichkeiten bei guten Sichtweiten erklären, bei denen mehrere Fahrzeugführer die Überholmöglichkeit wahrnehmen wollen und bei deren beider Interaktionen ein Überholunfall entsteht (Konflikt mit rückwärtigem Überholer). Wie auch schon in Kapitel 3.5.5 festgestellt, geschehen die meisten Überholunfälle bei Sichtweitenbedingungen zwischen den Grenzwerten der RMS und der RAS-L.

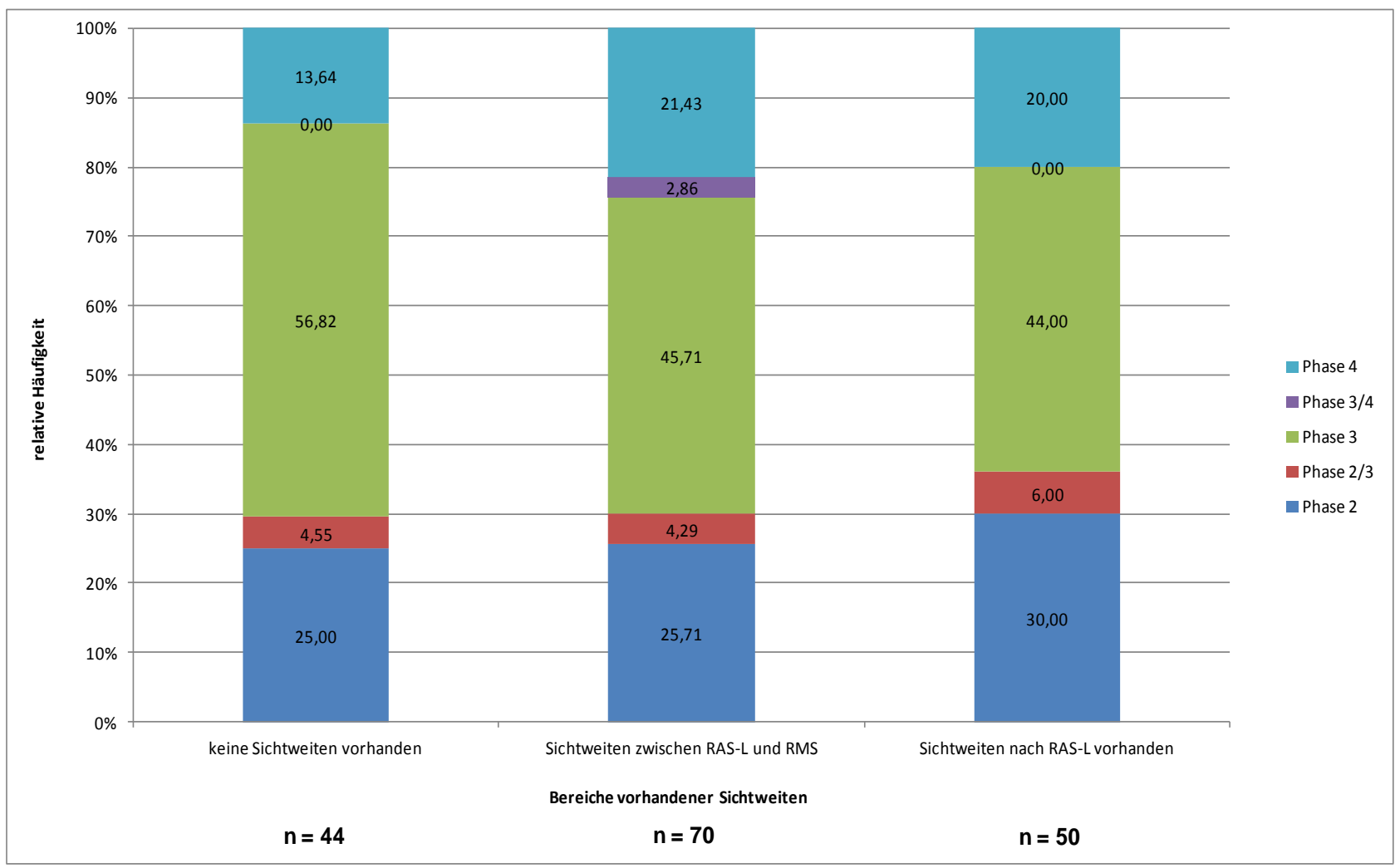

Abbildung 4.15: Überholphasen gemäß Durth/Habermehl (1985) nach Sichtweitendefinitionen der RMS/RAS-L 
Werden die eben erläuterten Sichtweitenbereiche noch feiner in einzelne Klassen zerlegt, so ergibt sich die Darstellung nach Anhang X/a. Grundsätzlich lassen sich aber auch durch die vorgenommene Verfeinerung hier keine wesentlich anderen Tendenzen erkennen.

Eine Differenzierung der Überholunfälle nach den Altersklassen und Geschlecht der Unfallverursacher enthält Abbildung 4.16. Es zeigt sich, dass von den 130 Unfallverursachern der Überholunfälle, zu denen entsprechende Angaben der Unfallhergangsbeschreibung entnommen werden konnten, $31 \%$ zwischen 20 und 30 Jahren alt sind. Aufgrund der Tatsache, dass sich die höchste Risikogruppe über 10 Altersjahre erstreckt und die Gruppe der Fahranfänger im Alter von 16 bis 19 Jahren über nur 4 Altersjahre (wobei 18 der 19 Überholunfälle von 18 bzw. 19 jährigen Fahrzeugführern verursacht wurden), muss denen im Ergebnis erreichten $15 \%$ der Unfallverursacher noch eine deutlich größere Bedeutung beigemessen werden. Auch innerhalb der Gruppe zwischen 20 und 30 Jahren besteht eine klare Tendenz zu bis zu 25 jährigen Fahrzeugführern von 80 \%, demzufolge ebenfalls noch junge Fahrer mit vergleichsweise wenig Fahrerfahrung. Unfallverursacher ab 60 Jahren sind relativ selten. Im Gesamtergebnis entsprechen die ermittelten Zusammenhänge den bereits in der Grundlagenstudie (vgl. Kapitel 2.3.3) ermittelten Ergebnissen. Demnach ist die Verteilung des Alters der Hauptverursacher gleich dem aller Unfallursachen mit Bezug zum Überholvorgang (unmittelbar Unfallbeteiligte mit einbezogen). Die Ergebnisse verschärfen sich bei Berücksichtigung der Kohortengrößen. Männliche Fahrzeugführer stellen mit insgesamt 84 \% der Unfallverursacher die klare Risikogruppe mit Bezug auf das Geschlecht dar.

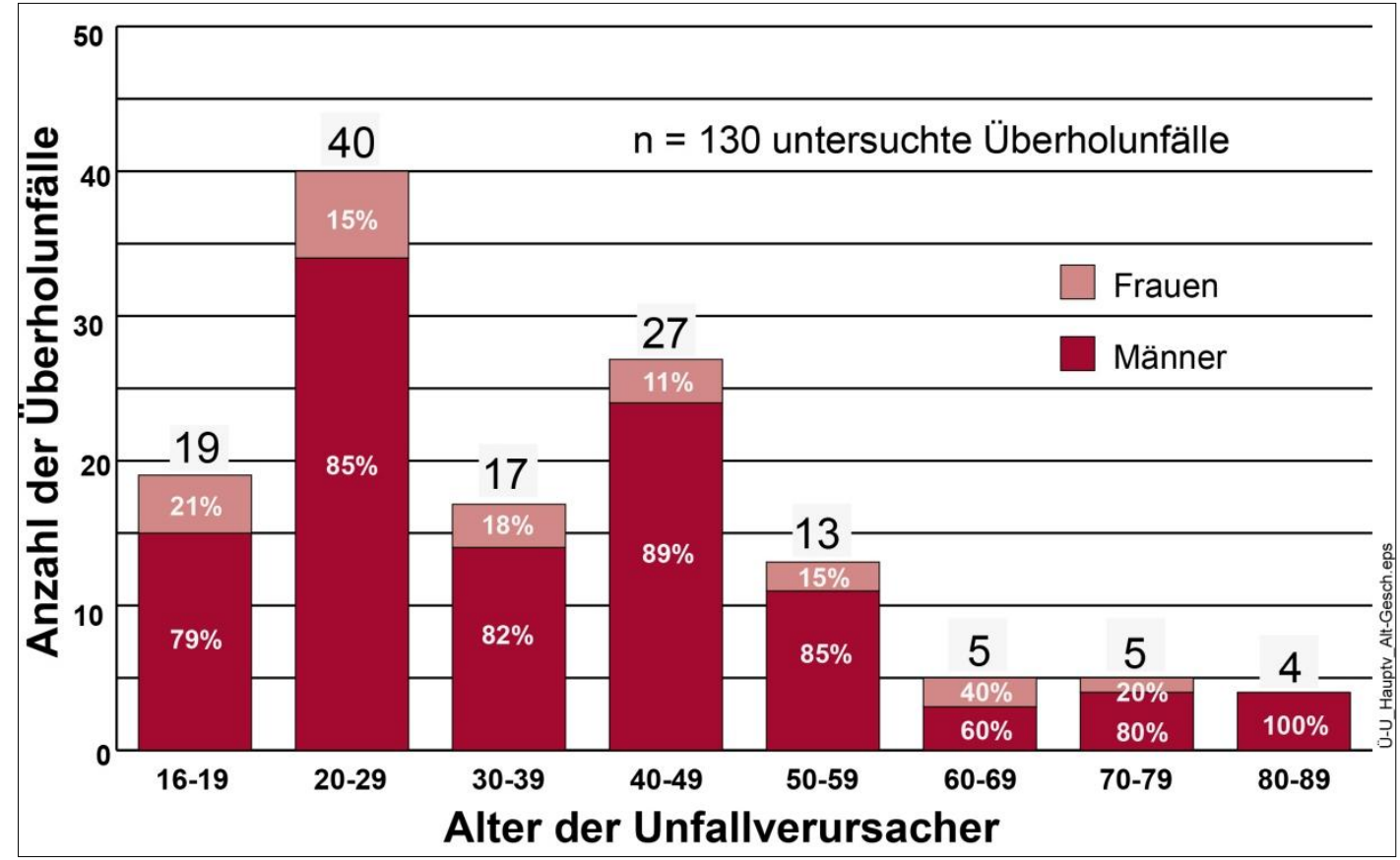

Abbildung 4.16: Altersklassen und Geschlecht der Hauptverursacher von Überholunfällen

Grundsätzlich müssen bei Überholunfällen junge Fahrzeugführer hervorgehoben werden. Als Ursachen können mangelnde Fahrerfahrung oder höhere Risikobereitschaft (zügigere Fahrweisen) genannt werden. Mit zunehmendem Alter wird dagegen von einer gemäßigteren Fahrweise ausgegangen, was zu weniger Überholdruck und auch zu weniger Überholunfällen führt. 
Abbildung 4.17 enthält die Altersstruktur nach den verkehrsrechtlichen Anordnungen in Bezug zum Überholen an den Unfallpositionen. Es zeigt sich - dies besonders gewichtet durch die hohen Anteile der jungen Fahrzeugführer an der Gesamtzahl der Unfallverursacher - deutlich vermehrte Verstöße gegen vorhandene Überholverbote im jungen Alter. Verstöße gegen vorhandene Überholverbote im höheren Alter der Unfallverursacher sind nur auf wenige Ausnahmen beschränkt.

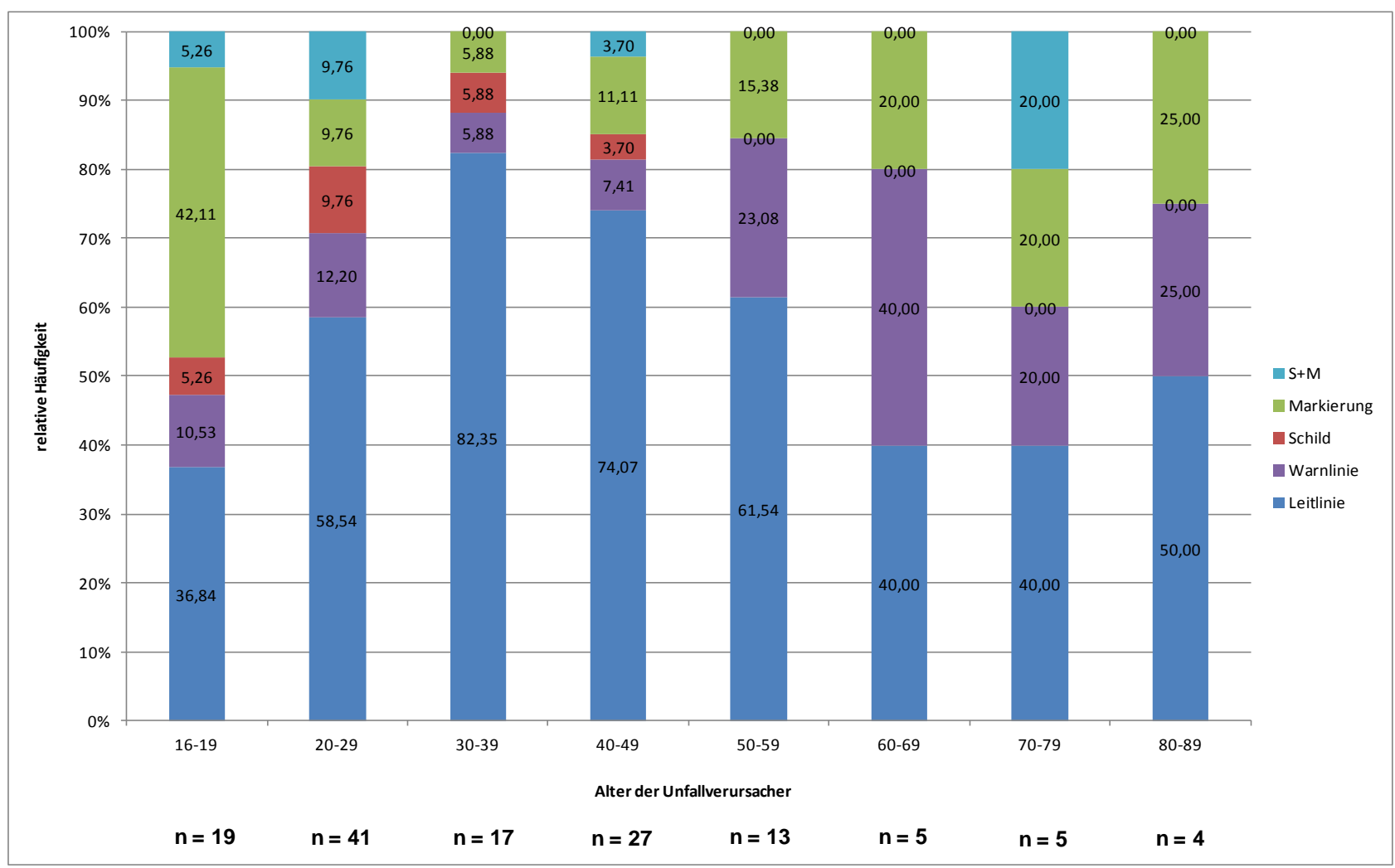

\section{Abbildung 4.17: Alter der Unfallverursacher und rechtliche Anordnungen an Unfallpositionen}

Weitere Auswertungen zur Altersstruktur können Anhang X entnommen werden. Es ergaben sich die folgenden Zusammenhänge. Bei der Verteilung der Altersstruktur auf die Art der Verkehrsbeteiligung wurde festgestellt, dass Lkw nur im Alter von 20 bis 60 als Unfallverursacher in Frage kommen. Dies entspricht dem gängigen Alter eines Berufskraftfahrers. Die Tendenzen sind mit zunehmendem Alter ebenfalls leicht steigend. Die Beteiligung von Motorrädern sticht besonders bei 20 bis 30 Jährigen und 40 bis 50 Jährigen hervor. Bei der Zuordnung der Altersstruktur zu den Überholphasen wurden hier nur die eindeutig zuordenbaren Überholphasen angesetzt. Grundsätzlich nehmen Unfälle beim Ausscher- sowie Einschervorgang mit zunehmendem Alter zu, Unfälle während des direkten Überholvorganges nehmen dagegen ab. Bei der Analyse der Altersstruktur in Bezug zu den vorhandenen Bereichen von Überholsichtweiten ergaben sich steigende Anteile von Überholunfällen bei guten Sichtweiten mit zunehmendem Alter. Hier können zunehmende Probleme mit der Einschätzung der Verkehrssituation (Geschwindigkeits- und Abstandsschätzung sowie Orientierung im verkehrlichen Umfeld) angenommen werden. Bei Fahranfängern scheint vor allem die Abschätzung von zur Verfügung stehenden Überholwegen Schwierigkeiten zu bereiten, da Erfahrungen für zur Überholentscheidung ausreichende Überholwege nur geringfügig vorhanden sind. Im Gegenzug kann auch vermutet werden, dass junge Fahrer aufgrund zügigeren Fahr- 
verhaltens auch zu Überholungen bei eher schlechten Sichtweiten bereit sind. Gleiches kann auch durch den sinkenden Anteil der Gegenverkehrsunfälle durch plötzliches Auftauchen von Gegenverkehr bestätigt werden. Bei Fahranfängern stellen die Zusammenstöße mit dem Gegenverkehr mit $65 \%$ die maßgebende Kollisionsart dar. Mit zunehmendem Alter steigen die Kollosionsarten an, die mit einer mangelhaften Orientierung im umgebenden verkehrlichen Umfeld einhergehen.

\subsubsection{Zusammenfassung}

Die Analyse von 166 Hergangsbeschreibungen von Überholunfällen auf 43 der 50 für die Detailanalyse ausgewählten Strecken ergibt zusammenfassend folgende Erkenntnisse. Die verkehrsrechtliche Unfallschuld ist grundsätzlich dem Überholenden zuzuordnen, da es ohne Überholvorgang womöglich auch nicht zu einem Unfall gekommen wäre. Hierbei handelt es sich überwiegend um die potentiellen Überholer im Landstraßennetz (Pkw und Motorrad). Die Hindernisfahrzeuge sind zu 54 \% Pkw und 31 \% Lkw. Grundsätzlich sind aber über alle Fahrzeugarten die Fahrzeuge vertreten, die potentielle Hindernisse aufgrund von Differenzen zwischen Fahr- und Wunschgeschwindigkeit darstellen können. Entsprechende Zusammenhänge ergeben sich auch bei der Verknüpfung von Überholer und Hindernisfahrzeug. Entsprechend ihres Auftretens im Landstraßennetz bilden auch bei Betrachtung der Kollisionsgegner beim Überholunfall die Pkw die größte Gruppe. Ein weiterer Großteil der auffälligen Kollisionen entfällt auf die Zusammenstöße mit dem Seitenraum bzw. Straßenumfeld.

Die Definition von Kollisionsarten in Anlehnung an die Unfallarten ergab 5 maßgebende Gruppen in Bezug zum Überholunfall. Die Zusammenstöße mit dem Gegenverkehr stellen hierbei mit 42 \% die größte Gruppe dar. Die grundsätzlichen Probleme sind hier Fehlentscheidungen beim Annehmen bzw. Ablehnen von potentiellen Überholmöglichkeiten aufgrund fehlerhafter Sichtweiten-, Entfernungs- und Geschwindigkeitsabschätzung. Die Konflikte mit abbiegenden Fahrzeugen (Nichterkennen der Abbiegeabsicht), bereits überholenden Fahrzeugen (rückwärtiger Überholer), dem Straßenumfeld (Kontrollverluste beim Überholvorgang mit Abkommen von der Fahrbahn) sowie dem Hindernisfahrzeug (Ein- und Ausschervorgang und mangelhafte Sicherheitsabstände) sind als weitere Kollisionsarten nahezu gleichverteilt.

Aufgrund der Fahrzeugbeteiligung bei Zusammenstößen mit dem Gegenverkehr ist davon auszugehen, dass die Probleme nicht durch eine schlechte Erkennbarkeit der Entgegenkommenden entstehen sondern vielmehr durch deren Entfernungs- und Geschwindigkeitsabschätzung. Von Zusammenstößen mit rückwärtigen Überholenden sind grundsätzlich die potentiellen Überholer (Pkw, Motorrad) betroffen, als Problem liegt oftmals eine mangelhafte Orientierung des umgebenden Verkehrs vor. Zusammenstöße mit abbiegenden Fahrzeugen entstehen dann, wenn an Knotenpunkten oder unscheinbaren Einmündungen von Wirtschaftwegen die Geschwindigkeitsdifferenzen (Abbiegegeschwindigkeit vs. Streckengeschwindigkeit) ansteigen und die Abbiegeabsicht nicht erkannt wird. Hiervon können grundsätzlich alle Fahrzeugarten betroffen sein. Wegen der entgegen gerichteten Geschwindigkeiten besitzen Zusammenstöße mit dem Gegenverkehr die schwersten Unfallfolgen, umgekehrte Tendenzen entstehen bei Kollisionen mit Abbiegern. Unter Berücksichtigung der Art der Fahrzeugbeteiligung des Unfallverursachers ergibt sich eine Tendenz 
zu schweren Unfallfolgen, wenn Motorräder als verhältnismäßig ungeschützte Verkehrsteilnehmer in einen Überholunfall verwickelt werden oder wenn Lkw beteiligt sind, welche die größten kinetischen Energien im Landstraßennetz verursachen.

Besonderheiten der Unfallstelle sind neben Knotenpunkten oder Einmündungen im Regelfall nicht vorhanden. Ca. 50 \% der Überholunfälle geschehen beim direkten Überholvorgang (Phase 3 überwiegend Konflikte mit Abbiegern und Entgegenkommenden), weitere ca. 30 \% der Unfälle entfallen auf den Ausschervorgang (Phase 2 - maßgebend sind hier Kollisionen mit rückwärtig Überholenden sowie dem Gegenverkehr) und die verbleibenden ca. $20 \%$ auf den Einschervorgang (Phase 4 - Kollisionen mit dem Straßenumfeld oder direkt dem Hindernisfahrzeug).

Bei den Auswertungen zur Altersstruktur der Unfallverursacher ergaben sich die gleichen Zusammenhänge, wie auch schon bei der Grundlagenstudie, somit also weniger Überholunfälle mit steigendem Alter. Insgesamt wurden 84 \% der Überholunfälle durch männliche Fahrzeugführer verursacht. Darüberhinaus wurden vermehrt Verstöße gegen vorhandene Überholverbote im jungen Alter festgestellt. Die Beteiligung von Motorrädern häuft sich ebenfalls bei Fahranfängern. Unfälle beim Ausscher- sowie Einschervorgang nehmen mit zunehmendem Alter zu, Unfälle während des direkten Überholvorganges dagegen ab. Des Weiteren ergaben sich steigende Anteile von Überholunfällen bei guten Sichtweiten mit zunehmendem Alter. Bei Fahranfängern stellen die Zusammenstöße mit dem Gegenverkehr mit 65 \% die maßgebende Kollisionsart dar. Insgesamt wird vermutet, dass bei Fahranfängern die Abschätzung der zur Verfügung stehenden Überholwege das Hauptproblem darstellt, da Erfahrungen für zur Überholentscheidung ausreichende Überholwege nur geringfügig vorhanden sind. Mit zunehmendem Alter nehmen dagegen Unfälle aufgrund mangelnder Orientierung im umgebenden verkehrlichen Umfeld zu. Demnach sind vor allem junge Fahrzeugführer als Risikogruppe zu nennen. Die Verkehrserziehung muss an dieser Stelle offensichtlich besondere Aufklärungsarbeit leisten.

Als grundlegende Probleme bei Überholunfällen müssen die Fehleinschätzungen der Fahrzeugführer (insbesondere vorhandene Sichtweiten, Gegenverkehrsentfernung und -geschwindigkeit sowie Orientierung zum rückwärtigen Verkehr) angenommen werden. Fehleinschätzungen der vorhandenen Sichtweiten - welche teilweise im Unfallbericht durch unfallaufnehmende Polizeibeamte ausgewiesen wurden - traten selbst in stehender Einschätzung auf. Es wird davon ausgegangen, dass die Möglichkeiten bzw. physischen Fähigkeiten der Fahrzeugführer zur Entfernungsbzw. Sichtweitenabschätzungen bei Bewegung im Straßenraum noch deutlich nachlassen. Zudem muss bei einer sich plötzlich bietenden Überholmöglichkeit die generelle Orientierung im umgebenden Verkehr als unzureichend angenommen und als weiteres Problem angesehen werden.

Bedingt durch die Clusterung sind teilweise unterschiedlichste Unfallkonstellationen in den einzelnen Bundesländern aufgetreten (in Bundesland 2 waren besonders Überholunfälle mit Abbiegern auffällig). Systematische Zusammenhänge zu Bunderländern können und sollen hier aber nicht ausgewiesen werden. Dennoch konnte durch die Clusterung eine Vielzahl von Besonderheiten und Problemsituationen des Überholvorganges sowie des daraus resultierenden Unfallgeschehens ermittelt und ausgewertet werden. 


\subsection{Analyse des Überholverhaltens}

In diesem Kapitel wird die Durchführung der empirischen Untersuchungen zum Fahrverhalten der 50 ausgewählten unfallauffälligen Strecken beschrieben. Ziel dieses Arbeitspaketes ist eine Überlagerung der im Rahmen der Netzanalyse erhobenen Strecken- und Unfallmerkmale mit den tatsächlich durchgeführten Überholvorgängen. Somit können die Zusammenhänge des Unfallgeschehens zu den realen Überholvorgängen sowie die inneren Abhängigkeiten zwischen Verkehrsstärke, Schwerverkehrsanteil und dem Überholverhalten analysiert werden. Im Ergebnis dieses Kapitels werden auf Streckenebene für die entsprechende Unfallsituation sowie die infrastrukturellen Gegebenheiten erläutert und die Problembereiche für die Unfallentstehung aufgedeckt sowie Lösungsmöglichkeiten vorgeschlagen.

\subsubsection{Abschnittsbildung und Messanordnung}

Für die Analyse von Überholvorgängen werden Videoerhebungen und Radarmessungen an ausgewählten Querschnitten in den Straßenräumen der 50 untersuchten Streckenabschnitte durchgeführt. Ziel einer solchen Erhebung muss es sein, dass Verkehrsverhalten unbeeinflusst erheben und analysieren zu können. Für die durchzuführenden Erhebungen steht eine umfangreiche Videoausrüstung und Verkehrsstatistikgeräte zur Verfügung.

Zur differenzierten Analyse der Überholvorgänge werden die Untersuchungsstrecken in Abschnitte mit bzw. ohne Überholmöglichkeiten eingeteilt. An freigegebenen Abschnitten mit ausreichenden Überholsichtweiten sind demzufolge Überholmöglichkeiten vorhanden, dagegen ermöglichen die erhobenen Überholverbote und eher unzureichende Sichtweiten keine sicheren Überholvorgänge. Für die Streckeneinteilung können die in Kapitel 3.5.2 erstellten Streckenbänder als Hilfestellung herangezogen werden. Zur Festlegung von Abschnitten mit bzw. ohne Überholmöglichkeiten werden die erforderlichen Überholsichtweiten der RMS unterstützend herangezogen, da die hohen Werte von erforderlichen Überholsichtweiten nach RAS-L in Verbindung mit der Streckencharakteristik nicht zwangsläufig ein Kriterium für eine positive Überholentscheidung sind.

Es gilt allerdings zu beachten, dass es sich bei den gefilterten Untersuchungsstrecken um ca. 3-4 km lange Landstraßenabschnitte handeln kann. Demzufolge ist es bei der Abschnittseinteilung nicht möglich, an jeder Änderung der verkehrsrechtlichen Situation innerhalb einer Untersuchungsstrecke einen separaten Abschnitt festzulegen. An kurvigen Strecken oder in bewegtem Gelände können zudem nicht an jeder Sichtweitenunterbrechung bzw. -änderung neue Messquerschnitte eingerichtet werden, da dies die technischen Möglichkeiten deutlich übersteigt. Grundsätzlich wurden die Erhebungen auf bestimmte Merkmale der Landstraßengestaltung sowie der verkehrsrechtlichen Situation konzentriert sowie auf die unfallauffälligen Teilbereiche von Untersuchungsstrecken begrenzt. Insgesamt ist die Anzahl der zu bildenden Teilabschnitte im Sinne der Aufgabenstellung und in Hinblick auf das zu erreichende Ziel sinnvoll abzuwägen.

In Abhängigkeit der ermittelten Abschnitte (Unfallsituation, infrastrukturelle und verkehrsrechtliche Bedingungen) wird die vorhandene Videoausrüstung auf der Untersuchungsstrecke verteilt. Die Beobachtung eines längeren Streckenabschnittes ist aus technischen, optischen aber auch oft- 
mals aus Gründen der Landstraßengestaltung (Seitenraumbepflanzung) nicht möglich. Demnach werden jeweils an den Abschnittsgrenzen Videokameras aufgestellt, um die Reihenfolge der Fahrzeugströme am Anfang und Ende eines betrachteten Teilabschnittes erfassen zu können. Besteht die Möglichkeit, einen eher kurzen Bereich mit Überholunfällen direkt einzusehen bspw. bei Überholungen in Knotenpunkten, so werden die Kameras dementsprechend angeordnet. Hierbei können Kameras mit erhöhtem Standpunkt (Teleskopmasten, siehe Abbildung 4.18 links) oder bodennahe Videokästen (dem System der Verkehrsstatistikgeräte nachempfunden, siehe Abbildung 4.18 Mitte) zum Einsatz kommen. Durch die Ermittlung der Fahrzeugreihenfolge an den Abschnittsgrenzen werden später bei der Datenauswertung die Anzahl der stattgefundenen Überholungen ermittelt. Befindet sich innerhalb der Untersuchungsstrecke ein Knotenpunkt an dem starke Abbiegebeziehungen zu erwarten sind, so muss an diesem Knotenpunkt ein Videostandort eingerichtet werden. Somit können Überholvorgänge auf einem Teilabschnitt durch einen danach abbiegenden Überholer oder ein abbiegendes Hindernisfahrzeug identifiziert werden, die ohne Zusatzposition nicht festgestellt werden können.
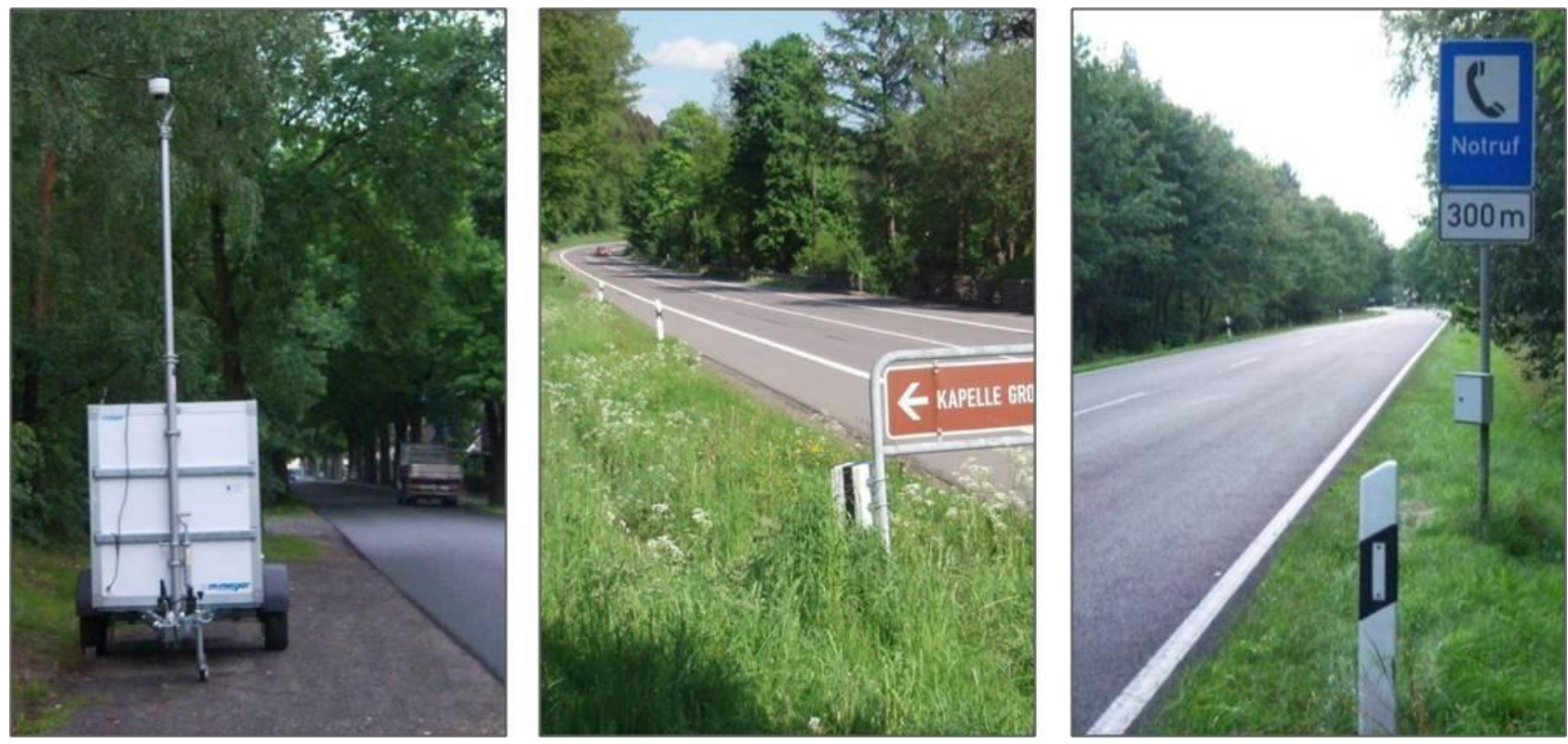

Abbildung 4.18: Eingesetzte Messausrüstung

Die Verkehrsstatistikgeräte (Abbildung 4.18 rechts) werden innerhalb eines gebildeten Abschnittes an einem geeigneten Verkehrsschild oder separaten, unabhängigen Standfuss montiert. Bei der Wahl des Messquerschnittes ist darauf zu achten, dass die erhobenen Geschwindigkeiten die realen Streckengeschwindigkeiten des Abschnittes widerspiegeln müssen. Demnach sind Messquerschnitte im Annäherungsbereich von Knotenpunkten (Geschwindigkeitsbeschränkungen, Wegweiser zur Vororientierung) wegen eines Einflusses auf die gefahrenen Geschwindigkeiten nicht repräsentativ für das Fahrverhalten auf der freien Strecke. Ist auf dem gesamten Untersuchungsabschnitt eine Geschwindigkeitsbeschränkung vorhanden, so können auch die diese Geschwindigkeit anordnenden Verkehrszeichen für die Montage genutzt werden. Die Erhebungen einer anfänglichen Pilotanalyse werden von 7 bis 19 Uhr durchgeführt. Wenn sich im Rahmen dieser Beispieluntersuchung andere Zeiträume von gesteigertem Interesse ergeben, ist dies bei weiteren Erhebungen zu berücksichtigen (vgl. hierzu Kapitel 4.2.3.2). 


\subsubsection{Datenauswertung}

Bei der Auswertung des erhobenen Videomaterials müssen die Untersuchungsstrecken entsprechend der oben beschriebenen Messanordnung betrachtet werden. Es wird darauf verwiesen, dass sich bei einer Untersuchungsstrecke mit 2 Teilabschnitten (3 Kamerapositionen) und einer notwendigen richtungsfeinen Auswertung der Überholvorgänge insgesamt 4 Untersuchungsrichtungen im Erhebungszeitraum ergeben können. Demnach muss jeder Abschnitt (Zwischenraum zweier Kameras) separat betrachtet werden, eine parallele Auswertung von mehreren aufeinanderfolgenden Abschnitten ist dagegen nicht praktikabel. Die Videos werden differenziert nach verschiedenen Überholergruppen ausgewertet. Hierfür wird stundenfein eine Matrix mit den zwei Beteiligten eines Überholmanövers (Überholer und Überholter) für die nachfolgend aufgezählten Fahrzeuggruppen angelegt:

- Pkw

- Lkw

- Kraftrad

- Leichtkraftrad

- Sonstige Fahrzeuge (Traktoren und Baufahrzeuge).

In der zu erstellenden Matrix müssen langsame, besondere Hindernisfahrzeuge berücksichtigt werden, da diese ein langes Pulk anstauen und auch überdurchschnittlich viele Überholvorgänge erzeugen können. Zudem können langsam fahrende Leichtkrafträder ohne Überholvorgänge im eigentlichen Sinne passiert werden. Wird das Auftreten dieser Fahrzeuge nicht gesondert betrachtet, so können sich verzerrte Auswertungen ergeben. Beispielsweise ist ein Vergleich zweier ähnlicher Strecken mit eigentlich wenigen Überholungen, wenn nur auf einer der beiden Strecken ein langsames Sonderfahrzeug gefahren ist, im Sinne der Aufgabenstellung nicht zweckmäßig. Demnach ist diese Abgrenzung der Sonderfahrzeuge von weiteren Fahrzeuggruppen zwingend erforderlich. Im Rahmen der folgenden Analysen wird demnach zwischen repräsentativen Überholungen (Pkw, Lkw, Krad) - welche auch den maßgebenden Anteil am Unfallgeschehen besitzen (vgl. Kapitel 4.1.1) - und Überholungen von Sonderfahrzeugen (Leichtkrafträder und sonstige Fahrzeuge) differenziert.

Im Rahmen der mikroskopischen Unfallanalyse (Unfallhergangsbeschreibungen vgl. Kapitel 4.1.1) konnten keine bedeutsamen Probleme durch Überholungen von Radfahrern auf den Landstraßenabschnitten festgestellt werden. Die Auswertung von Überholungen, die durch Fahrräder erzeugt werden, ist zudem äußerst schwierig. Es kann nicht überprüft werden, ob der Radfahrer zwischendurch abbiegt bzw. eine Pause macht oder gar auf Rad- oder Wirtschaftswegen fährt, daher ist eine auf Radfahrer bezogene Auswertung nicht sinnvoll. Zudem wäre der Informationsgehalt der Anzahl von überholten Radfahrern sehr gering, da bei schwachbelasteten Strecken eine Überholung als unkritisch angesehen werden muss und bei hohen Verkehrsstärken bzw. Geschwindigkeiten im Regelwerk bereits grundsätzlich ein begleitender Geh- und Radweg empfohlen wird. 
Durch die stundenweise Auswertung der Überholungen kann das Verkehrsverhalten zu unterschiedlichen Tageszeiten und somit verschiedenen Verkehrszuständen auf den Strecken analysiert werden. Über die Einzelstunden hinweg können die ermittelten Überholungen für die Gegenüberstellung der verschiedenen Strecken unter Beachtung der oben genannten Fahrzeuggruppen aggregiert werden. Somit können dann auch Schlussfolgerungen über das Überholverhalten bei unterschiedlichen trassierungstechnischen Randbedingungen gezogen werden.

\subsubsection{Ergebnisse der Pilotuntersuchung}

\subsubsection{Unfallzeitenverteilung}

Als erster Schritt für die Festlegung eines geeigneten Untersuchungszeitraumes wurden die Zeitangaben der Unfalldatenbanken zur Prüfung herangezogen. Hierbei sollten die Unfallzeiten aller 6.209 gefilterten Überholunfälle auf den Untersuchungsstrecken betrachtet werden. Wegen fehlender Zeitangaben in den Unfalldatenbanken konnten in Bundesland 4 für 2007 sowie für Bundesland 5 für 2007 und 2008 keine Auswertungen durchgeführt werden. Bei Betrachtung der Unfallzeiten ergab sich für die 4.314 verbleibenden Überholunfälle die nachstehende Verteilung.

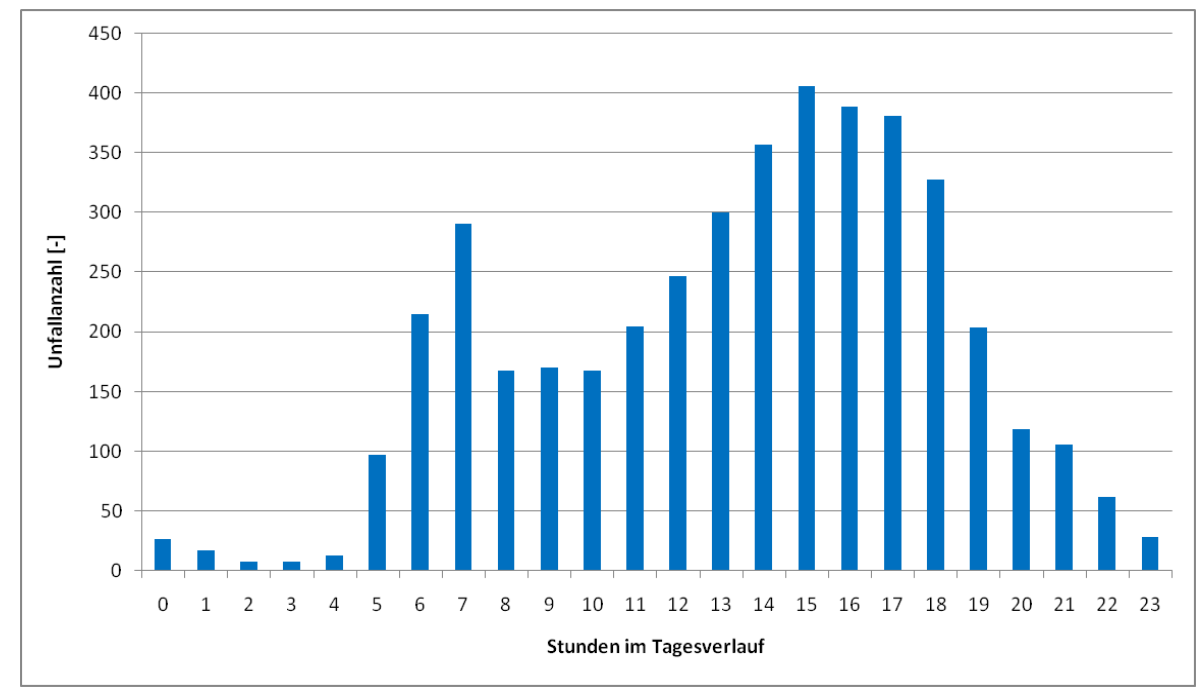

Abbildung 4.19: Zeitpunkte der Überholunfälle im Untersuchungsgebiet

Es wird deutlich, dass sich im Tagesverlauf der Unfallzeitpunkte 2 Maxima herauskristallisieren, Parallelen zur Tagesganglinie deuten sich an. In den Morgenstunden wird eine eher kleine Häufung von Überholunfällen sichtbar, wohingegen sich am Nachmittag im Rahmen des Pendler- bzw. Berufsverkehrs von 14 bis 18 Uhr die höchste Unfallauffälligkeit ergibt. Zwischen 8 und 11 Uhr ergibt sich ein vergleichsweise schwachbelasteter Zeitraum. In den Nachtstunden sind Überholunfälle dagegen eher selten. Ein geeigneter Untersuchungszeitraum soll aber nicht ausschließlich auf Basis der Überholunfälle festgelegt werden. Stattdessen war im Rahmen der Pilotanalyse die oben dargestellte Verteilung mit den ersten Ergebnissen der gezählten Überholvorgänge zu überlagern und erst in Abstimmung dieser beiden Parameter eine Entscheidung zu fällen. 


\subsubsection{Anpassung Untersuchungs- und Erhebungszeitraum}

Ein Überblick über die zeitliche Verteilung der Überholvorgänge wurde im Rahmen der Pilotanalyse in Bundesland 3 gewonnen. Die in der Pilotanalyse näher betrachteten Untersuchungsstrecken ergaben, dass die Überholungen zwar den Verlauf einer Tagesganglinie vermuten lassen, sich die Ausprägungen aber teilweise deutlich anders darstellen. Die Verteilungen sind hier deutlich abhängig von der Charakteristik der betrachteten Landstraße, allerdings deuten sich 2 Maxima im Zeitraum von 7 bis $19 \mathrm{Uhr}$ an. Es ist anzunehmen, dass eine Verkehrsverhaltensanalyse über eine Schwach- sowie eine Hauptverkehrszeit hinweg ausreichend sein wird. Durch die deutlich höhere Unfallauffälligkeit der Nachmittagsstunden sollten diese bevorzugt betrachtet werden, da sich ein höheres Untersuchungspotential im Vergleich zu der Morgenspitze bietet. Gleiches wird auch auf die Anzahl der durchgeführten Überholungen übertragen. Es bestehen Tendenzen zu mehr Überholungen in den Nachmittagsstunden. Hier konnten insgesamt mehr Überholungen über einen längeren Zeitraum identifiziert werden. Insgesamt treten somit Überholungen entsprechend dem Verlauf einer Tagesganglinie in der Nachmittagsspitze häufiger auf. Dieser Aspekt soll für die weiteren Erhebungen berücksichtigt werden. Durch die Zusammenhänge von Überholungen im Zusammenspiel mit den Verkehrsstärken und anderen Parametern ist ein schwachbelasteter und starkbelasteter Zeitraum von großem Interesse. Die Untersuchung zweier Maxima der Verkehrsstärken im Tagesverlauf scheint somit nicht zwangsläufig notwendig zu sein.

In der Projektidee dieser Untersuchung war angedacht, die Messungen auf den Untersuchungsstrecken an einem Werktag von 7 bis 19 Uhr durchzuführen. Durch die Ergebnisse der Pilotanalyse wird der Erhebungszeitraum aus forschungsökonomischen Gründen auf Zeiten von gesteigertem Interesse für das Unfallgeschehen (vgl. Abbildung 4.19) und den ermittelten Überholvorgängen angepasst. Der Untersuchungszeitraum soll sich demnach für die weiteren Erhebungen auf die Schwachverkehrszeit am Mittag und die Hauptverkehrszeit bzw. Verkehrsspitze am Nachmittag beschränken. Somit kann das unterschiedliche Überholverhalten in diesen beiden interessanten Zeiträumen untersucht werden. Ein Mehrwert durch eine 12 Stunden Messung und zusätzliche Abdeckung der Vormittagsspitze im Verkehrsaufkommen ist nicht vorhanden. Für die Erhebungen nach der Pilotanalyse ist der Zeitraum von 9 bis 19 Uhr vorgesehen, welcher die oben beschriebenen Schwach- und Hauptverkehrszeiten beinhaltet. Durch die Anpassung des Erhebungszeitraumes wird es ermöglicht, unter Berücksichtigung der technischen und personellen Ressourcen Messungen an aufeinanderfolgenden Tagen und somit auch mehrere Erhebungen pro Woche durchzuführen. 


\subsubsection{Ergebnisse der Fahrverhaltensanalysen}

\subsubsection{Generelle Zusammenhänge zwischen Überholverhalten und Unfallgeschehen}

Während der umfangreichen Analysen zum Überholverhalten auf den in Kapitel 3.5.6 ausgewählten und in Anhang W zusammengefassten 50 Untersuchungsstrecken wurden für jeden Untersuchungsabschnitt (vgl. Abschnittsbildung in Kapitel 4.2.1) Überholmatrizen ermittelt. Die Ergebnisse in Bezug zum Überholverhalten werden in diesem Kapitel ausführlich erläutert.

Insgesamt wurden auf den 50 Untersuchungsstrecken 78 Streckenabschnitte mit 150 Fahrtrichtungen ausgewertet. Das Gesamtergebnis aller in der Detailanalyse ermittelten und für die folgenden Auswertungen zur Verfügung stehenden Überholungen ist aggregiert über das gesamte Untersuchungsgebiet in Tabelle 4.1 dargestellt.

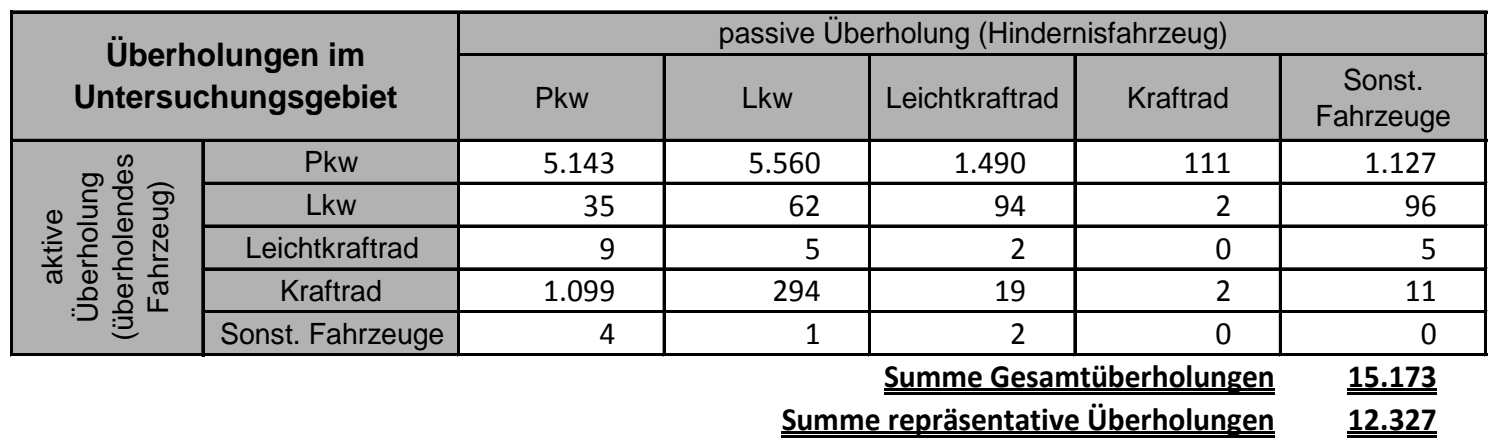

Tabelle 4.1: Erhobene Überholungen im Untersuchungsgebiet

Im Rahmen der Detailanalyse wurden auf den Untersuchungsabschnitten insgesamt 15.173 Überholungen festgestellt. Von dieser Gesamtanzahl verbleiben nach Vernachlässigung der besonderen Hindernisfahrzeuge (bspw. Leichtkrafträder und landwirtschaftliche Fahrzeuge) insgesamt 12.327 repräsentative Überholungen. Die Größenordnungen der festgestellten Überholungen sind in Abhängigkeit der verkehrlichen und infrastrukturellen Gegebenheiten der Untersuchungsabschnitte sehr verschieden ausgeprägt. Bei Gesamtbetrachtung der Überholmatrix zeigt sich, dass die Pkw/Pkw-Überholungen mit insgesamt $34 \%$ und die Pkw/Lkw-Überholungen mit $37 \%$ hier den Großteil aller Überholungen darstellen. Überholungen von Pkw an der Summe der besonderen Hindernisfahrzeuge sind mit $17 \%$ die dritthäufigste Überholer/Hindernis-Konstellation. Darauf folgen mit $7 \%$ die Krad/Pkw-Überholungen. Alle anderen Überholungen sind bei Betrachtung der Gesamtmatrix nur untergeordnet. Entsprechend der Häufigkeit des Auftretens der einzelnen Fahrzeugklassen im Landstraßennetz ergeben sich auch nach den bereits in Abbildung 4.3 angedeuteten Zusammenhängen hier zumindest in ähnlichen Größenordnungen vergleichbare Ergebnisse.

Wird die Anzahl der Überholungen mit den in der mikroskopischen Unfallanalyse ermittelten Konstellationen von Überholer und Hindernisfahrzeug bei den Überholunfällen überlagert, so ergibt sich Tabelle 4.2. Bei Betrachtung der Tabelle ist zu beachten, dass hier nur die Ergebnisse von 4 Bundesländern berücksichtigt werden konnten. Bei der mikroskopischen Unfallanalyse konnten aufgrund der Datenlage der Unfallanzeigen für Bundesland 3 keine Auswertungen durchgeführt und somit keine Überholer/Hindernis-Konstellationen ermittelt werden. Um eventuelle Verzerrungen zu 
vermeiden wurden demnach nur bei der nachstehenden Betrachtung die Ergebnisse der Detailanalysen in Bundesland 3 vernachlässigt.

\begin{tabular}{|c|c|c|c|c|c|c|}
\hline \multirow{2}{*}{\multicolumn{2}{|c|}{$\begin{array}{c}\text { Überholungen } 4 \\
\text { Bundesländer }\end{array}$}} & \multicolumn{5}{|c|}{ passive Überholung (Hindernisfahrzeug) } \\
\hline & & \multirow{2}{*}{$\frac{P k w}{3.737}$} & \multirow{2}{*}{$\frac{L k w}{4.212}$} & \multirow{2}{*}{$\begin{array}{c}\text { Leichtkraftrad } \\
1.231\end{array}$} & \multirow{2}{*}{$\begin{array}{r}\text { Kraftrad } \\
100\end{array}$} & \multirow{2}{*}{$\begin{array}{c}\begin{array}{c}\text { Sonst. } \\
\text { Fahrzeuge }\end{array} \\
887\end{array}$} \\
\hline \multirow{5}{*}{ 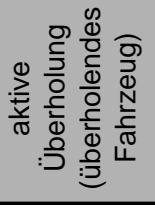 } & Pkw & & & & & \\
\hline & Lkw & 30 & 50 & 80 & 2 & 72 \\
\hline & Leichtkraftrad & 8 & 5 & 2 & 0 & 3 \\
\hline & Kraftrad & 914 & 249 & 16 & 2 & 9 \\
\hline & Sonst. Fahrzeuge & 4 & 1 & 2 & 0 & 0 \\
\hline \multirow{2}{*}{\multicolumn{2}{|c|}{$\begin{array}{c}\text { Überholunfälle } 4 \\
\text { Bundesländer }\end{array}$}} & \multicolumn{5}{|c|}{ passive Überholung (Hindernisfahrzeug) } \\
\hline & & Pkw & Lkw & Leichtkraftrad & Kraftrad & $\begin{array}{c}\text { Sonst. } \\
\text { Fahrzeuge }\end{array}$ \\
\hline \multirow{5}{*}{ 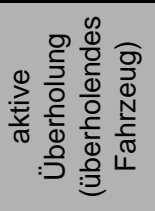 } & Pkw & 75 & 41 & 3 & 1 & 16 \\
\hline & Lkw & 1 & 2 & 4 & - & 1 \\
\hline & Leichtkraftrad & - & - & - & - & - \\
\hline & Kraftrad & 13 & 9 & - & - & - \\
\hline & Sonst. Fahrzeuge & - & - & - & - & - \\
\hline \multirow{2}{*}{\multicolumn{2}{|c|}{$\begin{array}{l}\text { Unfallrisiko bei } \\
\text { Überholungen } \\
{[(\mathrm{U} / 3 \mathrm{a}) /(\mathrm{U} / 10 \mathrm{~h})]}\end{array}$}} & \multicolumn{5}{|c|}{ passive Überholung (Hindernisfahrzeug) } \\
\hline & & Pkw & Lkw & Leichtkraftrad & Kraftrad & $\begin{array}{c}\text { Sonst. } \\
\text { Fahrzeuge }\end{array}$ \\
\hline \multirow{5}{*}{ 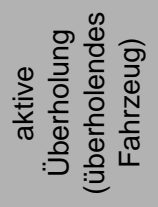 } & Pkw & 0,020 & 0,010 & 0,002 & 0,010 & 0,018 \\
\hline & Lkw & 0,033 & 0,040 & 0,050 & - & 0,014 \\
\hline & Leichtkraftrad & - & - & - & - & - \\
\hline & Kraftrad & 0,014 & 0,036 & - & - & - \\
\hline & Sonst. Fahrzeuge & - & - & - & - & - \\
\hline
\end{tabular}

Tabelle 4.2: Verknüpfung Überholunfälle mit Überholungen (BL1, BL2, BL4, BL5)

Analog zur dargestellten Überholmatrix der verbleibenden 4 Bundesländer wurde eine Matrix der Überholunfälle erstellt. Hier sind die im Rahmen der mikroskopischen Unfallanalyse ausgewerteten 166 Überholunfälle detailliert aufgeschlüsselt. Überlagert man die ermittelten Überholungen mit der Anzahl der Überholunfälle, so kann eine Kennzahl zur Beurteilung des Unfallrisikos angegeben werden. Bei der Interpretation des Unfallrisikos muss auf folgende Zusammenhänge ausdrücklich hingewiesen werden. Hinter der Anzahl der Überholungen in der oberen der drei Matrizen steckt ein Untersuchungszeitraum von 10 Stunden während der Detailanalysen. Die dargestellten Überholunfälle sind allerdings während eines Zeitraumes von 3 Jahren (2007 - 2009) geschehen. Lediglich der Bezug der beiden Zeiträume und eine folgende Gleichbehandlung ergeben falsche Rückschlüsse auf das Unfallrisiko. Die Aussage, dass $2 \%$ aller Pkw/Pkw-Überholungen in einem Überholunfall resultieren, wäre somit nicht korrekt. Es bestünde die Möglichkeit, durch einen Faktor die beiden Zeiträume aneinander anzugleichen. Hierbei müssten sowohl beim herunter rechnen des Unfallgeschehens auf 10 Stunden als auch bei der Hochrechnung der Überholungen auf 3 Jahre jeweils 4 verschiedene Verteilungen berücksichtigt werden. Demzufolge müssten die Verteilungen von Überholungen und Überholunfällen während eines Tages, während einer Woche, während der Monate und sogar über die 3 Jahre hinweg hinreichend genau bekannt sein. Dies muss für die Überholungen grundsätzlich ausgeschlossen werden, aber auch für die Berechnung eines Faktors für die Überholunfälle bestehen Unsicherheiten. 
Unabhängig von einem potentiellen anzusetzenden Faktor ist das Ergebnis des in der unteren Matrix in Tabelle 4.2 dargestellten Quotienten aus Überholunfällen und Überholungen ein definiertes Maß für das Unfallrisiko und somit ein grundsätzliches Indiz für die Gefährdungen, die bei Überholungen auf Landstraßen vorhanden sind. Grundsätzlich wird daher auf die Angleichung der beiden Zeiträume verzichtet. Bei der Argumentation mit dem generierten Unfallrisiko muss aber beachtet werden, dass in dieser Untersuchung auch nur die besonders unfallauffälligen Untersuchungsstrecken berücksichtigt wurden. Netzweite Rückschlüsse unter Einbeziehung von Abschnitten mit wenigen Unfällen oder sogar unfallfreier Abschnitte sind nicht möglich. Bei der Bewertung des Unfallrisikos müssen die eben erläuterten Bedingungen unbedingt beachtet werden, um Fehlinterpretationen zu vermeiden. Das berechnete Unfallrisiko kann unter Berücksichtigung der Einheit (U/3a)/(Ü/10h) korrekt verwendet werden.

In den Ergebnissen zeigt sich das größte Unfallrisiko bei Überholungen, bei denen Lastkraftwagen aktiv überholen. Der Grund für diese hohe Kennzahl liegt allerdings darin, dass Überholungen von Lastkraftwagen nur relativ selten festgestellt werden konnten, es in Bezug zum Unfallgeschehen aber zu einigen wenigen Unfällen gekommen ist. Dies verweist auf die besonders hohe Unfallgefahr, wenn Überholungen von großen, vergleichsweise trägen Fahrzeugen durchgeführt werden. Lkw/Pkw-Überholungen und Lkw/Lkw-Überholungen sind vergleichsweise selten, dagegen kam es zu häufigen Überholungen und auch dem größtem Unfallrisiko, wenn Lkw langsamere Leichtkrafträder überholen, die auch für den Lkw ein Hindernis darstellen. Die Problembereiche sind hier meist die unzureichenden Sicherheitsabstände, die entweder grundsätzlich nicht richtig eingeschätzt werden können oder bei unzureichender Überholmöglichkeit resultierend aus dem Gegenverkehr und dem falschen Einschätzen der Überholsituation mit dem langen, trägen Lastkraftwagen entstehen können. Die nächstgrößere Risikogruppe sind Überholungen von Motorrädern an Lkw.

Die Fahrzeugkonstellation mit den Ergebnissen die auch auf der größten Datenbasis beruhen sind generell die Überholungen von Pkw. Hierbei ist auffällig, dass aufgrund der größeren Geschwindigkeitsdifferenz zwischen Pkw und Lkw auch die meisten Überholungen durchgeführt werden, diese Überholungen aber möglicherweise aus dem gleichen Grund auch deutlich unauffälliger in Bezug zum Unfallgeschehen sind. Das größte Unfallrisiko bei Pkw entsteht bei Überholungen an anderen Pkw. Die Länge des zu überwindenden Hindernisses ist zwar im Vergleich zum Lkw deutlich geringer, allerdings führen die höheren Geschwindigkeiten in Summe auch zu einem längeren, nur noch schlecht einschätzbaren Überholweg. Dies kann bei unzureichenden Sichtweiten und Fehleinschätzungen zu Überholunfällen führen. Eine besondere Konfliktauffälligkeit besteht allerdings auch bei den Überholungen von Pkw an besonders langsamen landwirtschaftlichen Fahrzeugen. Hier muss aber unterstellt werden, dass die auffällig gewordenen Abbiegeunfälle hier einen entscheidenden Beitrag leisten.

Aufgrund des höheren Unfallrisikos von Krad/Lkw-Überholungen im Vergleich zu den Krad/PkwÜberholungen wird allerdings doch ein entscheidender Einfluss der Hindernislänge angenommen. Grund hierfür könnte das hohe Beschleunigungsvermögen von Motorrädern sein, da aus Sicht der 
Motorräder die Geschwindigkeiten der potentiellen Hindernisse (Pkw, Lkw) nicht wesentlich anders sind, jedoch ein Pkw wegen der kürzeren Überholwege sicherer überholt wird.

Nachfolgend werden weitere Abhängigkeiten der Überholungen, der Überholunfälle und des Unfallrisikos zu verkehrlichen und infrastrukturellen Randbedingungen auf Basis der einzelnen Untersuchungsabschnitt dargestellt.

\subsubsection{2 Überholverhalten in Abhängigkeit äußerer Bedingungen}

Für die vorliegenden Auswertungen wurde aus den ermittelten Überholmatrizen sowie den erhobenen Verkehrsdaten jeder untersuchten Fahrtrichtung der einzelnen Untersuchungsabschnitte eine Datenbank als Grundlage erstellt. Die Datenbank enthält demnach 150 fahrtrichtungsfeine Datensätze mit den folgenden Bestandteilen:

- Ergebnisse der Videoanalyse (Gesamtüberholungen, repräsentative Überholungen)

- Verkehrsstärken, Geschwindigkeiten

- Streckencharakteristik (Länge, mittlere Sichtweiten, maßgebender Sichtweitenbereich)

- verkehrsrechtliche Randbedingungen.

Zu den unter den beiden letzten Punkten genannten Angaben gibt es folgende Erläuterungen. Die Abschnittslänge der Videobeobachtungen ergibt sich als Abstand der abschnittsbegrenzenden Kamerapositionen, zwischen denen die Überholungen tatsächlich stattgefunden haben. Die mittlere Sichtweite im Abschnitt ist der Mittelwert der vorhandenen - bei der Nachtrassierung ermittelten - Sichtweiten. Hierbei kann grundsätzlich eine Bewertung der vorliegenden Streckencharakteristik vorgenommen werden. Darüberhinaus wurden die Sichtweiten im Abschnitt nochmals bewertet und den drei wesentlichen Sichtweitenbereichen (Grenzwert nach RAS-L eingehalten, Grenzwert nach RMS eingehalten und keiner der beiden Grenzwerte eingehalten) zugeordnet. Die Zuordnung zu den Sichtweitenbereichen richtet sich im Wesentlichen nach der Streckencharakteristik. Demzufolge zählt der überwiegend eingehaltene Grenzwert als maßgebendes Kriterium. Wenn die Sichtweiten nur kurz einen Grenzwert überschreiten (z.B. auch stark schwankende Sichtweiten), dann kann dies nicht als erfülltes Kriterium für den entsprechend größeren Sichtweitenbereich angesehen werden. Bei den verkehrsrechtlichen Randbedingungen wurden den einzelnen Fahrtrichtungen die aufgetretenen Längen der drei unterschiedlichen Überholverbote (Markierung, Beschilderung, Kombination aus beidem) zugeordnet. Durch einen Vergleich der Längen der unterschiedlichen Restriktionen wurde ein maßgebendes Überholverbot für den Fall bestimmt, dass sich unterschiedliche Anordnungen auf dem betrachteten Abschnitt abwechseln. Wechselnde Überholverbote sind allerdings auf wenige Ausnahmen beschränkt geblieben.

Beginnend mit Abbildung 4.20 werden die Differenzen zwischen Gesamtüberholungen und repräsentativen Überholungen dargestellt. Hier zeigt sich mit ausreichender statistischer Sicherheit ein linearer Zusammenhang zwischen diesen beiden Untersuchungskollektiven. Die Streuung der Wertepaare um die Regressionsgerade ist zudem sehr gering. Die größten Differenzen ergeben sich grundsätzlich bei einer geringen Anzahl von Überholungen. 


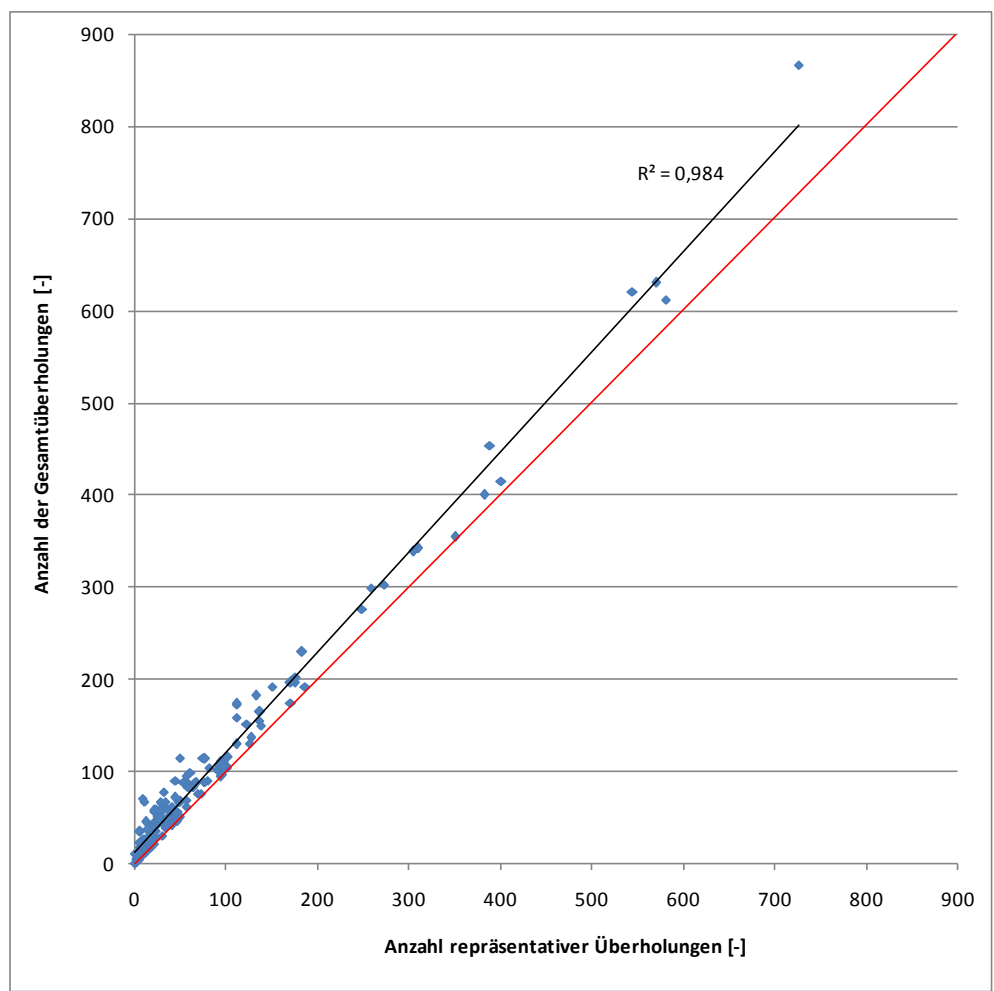

Abbildung 4.20: Zusammenhang zwischen Gesamtüberholungen und repräsentativen Überholungen Hintergrund dieser Gegenüberstellung beider Kollektive war die Vermutung, dass möglicherweise bei schlechten Sichtweiten die Überholungen an besonders langsamen oder kleinen Hindernissen zunehmen und hingegen die repräsentativen Überholungen von vergleichsweise schnelleren Hindernissen abnehmen. Dies hätte ein geringeres Unfallrisiko bei schlechten Sichtweiten zur Folge. In Abbildung 4.21 sind die Ergebnisse der entsprechenden Auswertung dargestellt.

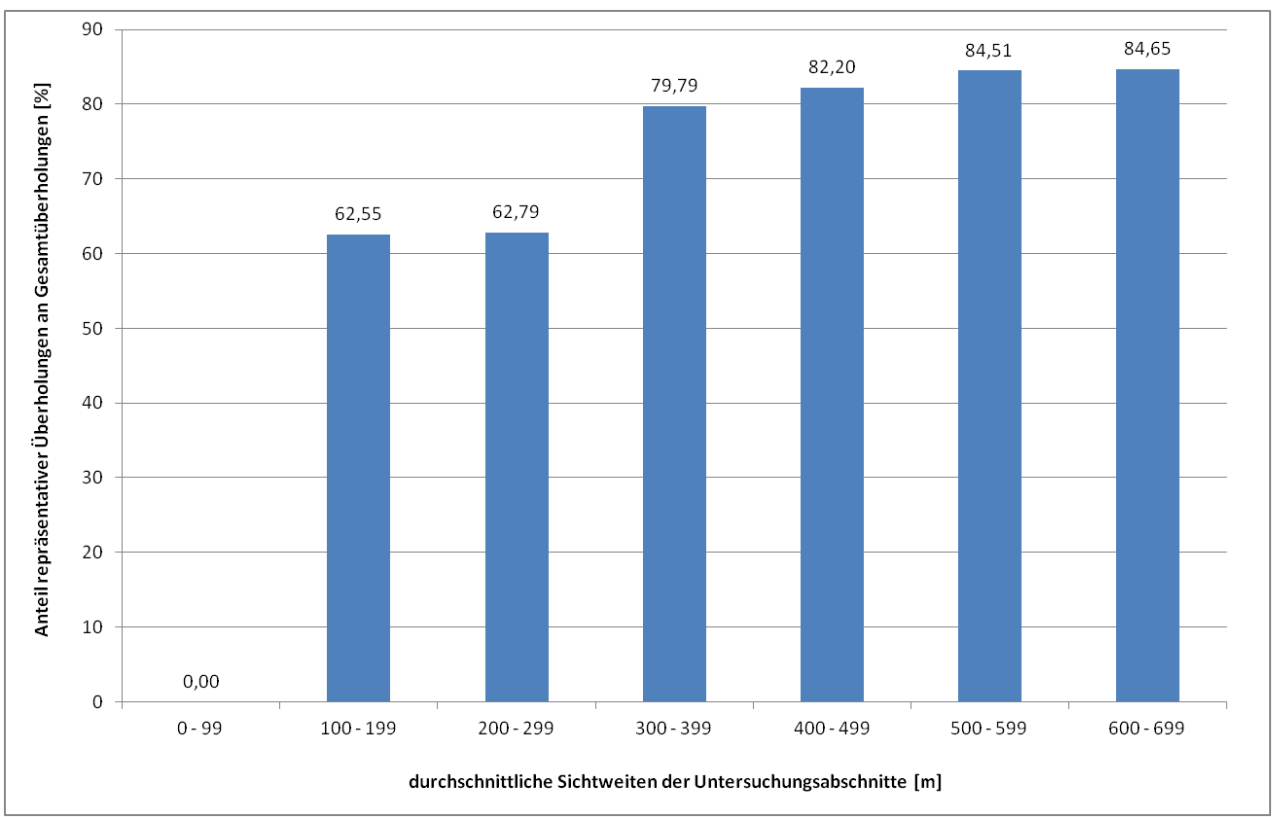

Abbildung 4.21: Zusammenhang zwischen Sichtweiten und beiden Überholkollektiven

Es zeigt sich, dass die Anteile der repräsentativen Überholungen an der Gesamtzahl der Überholungen im Abschnitt stetig ansteigen je größer die mittleren Sichtweiten im Abschnitt werden. Somit 
können die o.g. Vermutungen grundsätzlich bestätigt werden. Problematisch ist an dieser Stelle, dass in Bereichen mit schlechten Sichtweiten trotzdem noch über $60 \%$ repräsentative Überholungen stattfinden. Wird hier bei schlechten Sichtweiten durch einen Pkw ein Leichtkraftrad überholt, so kann dies vergleichsweise als unkritisch angesehen werden. Wird im gleichen Abschnitt dagegen eine Pkw/Pkw-Überholung durchgeführt, so steigt das Unfallrisiko deutlich an, da der benötigte Überholweg nicht eingesehen werden kann. Die Darstellung der Zusammenhänge zwischen der tatsächlichen Überholanzahl und den mittleren Sichtweiten enthält nachstehende Abbildung.

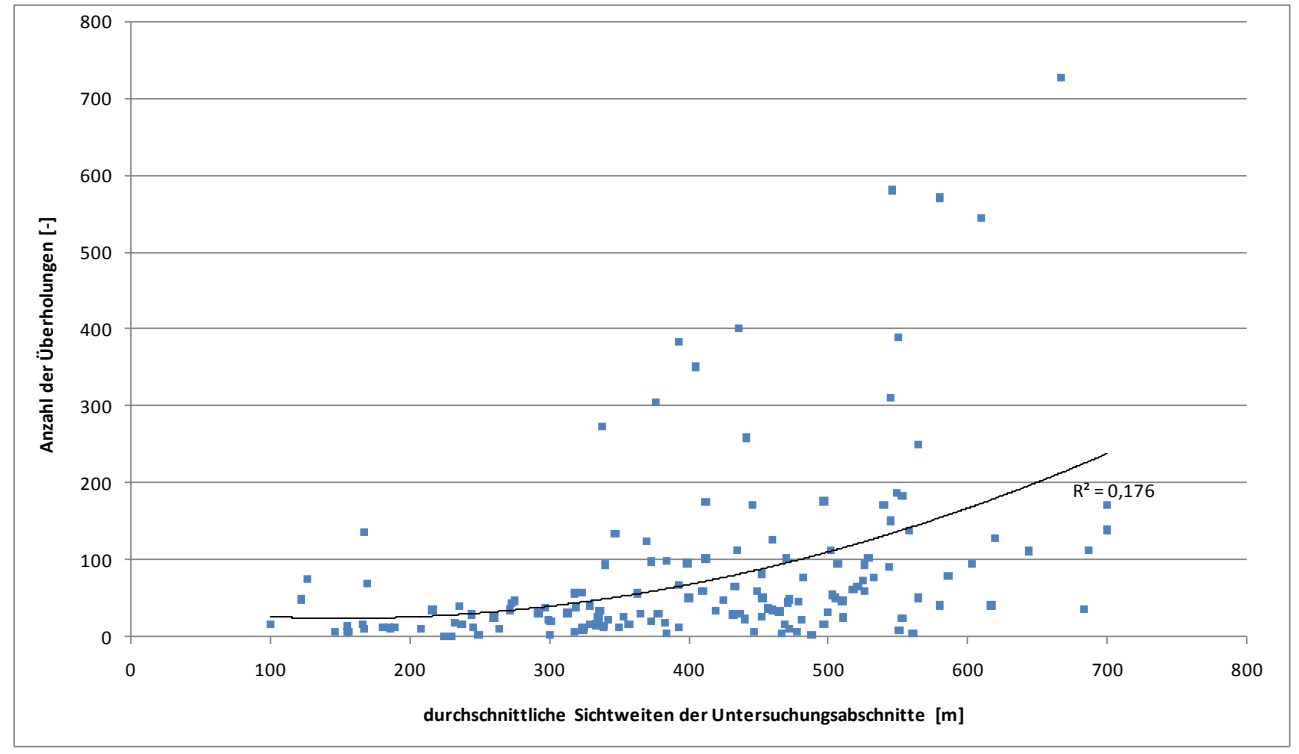

Abbildung 4.22: Zusammenhang zwischen repräsentativen Überholungen und Sichtweiten

Auch hier zeigt sich erwartungsgemäß eine steigende Tendenz zu Überholungen bei steigenden mittleren Sichtweiten im Untersuchungsabschnitt. Dennoch muss der Umstand, dass unabhängig von der Größenordnung bei schlechten Sichtweiten überhaupt eine Überholung stattfindet aus Sicht der Verkehrssicherheit als äußerst kritisch angesehen werden. Wenn hier auch nur 5 Überholungen in einem schlechten Sichtweitenbereich durchgeführt werden, so ist auch bei diesen wenigen Überholungen ein deutlich erhöhtes Unfallrisiko vorhanden. Dieser Tatsache muss zur Erhöhung der Verkehrssicherheit mit betrieblichen Maßnahmen entgegengewirkt werden.

Bei der Betrachtung der Anzahl von Überholungen muss allerdings auch die Länge des entsprechenden Untersuchungsabschnittes berücksichtigt werden. Grundsätzlich ergibt sich ähnlich den Unfalldichten bei Analysen zur Verkehrssicherheit auch ein Unterschied im Überholverhalten, wenn jeweils im gleichen Zeitraum 200 Überholungen auf 1 Kilometer oder auf 4 Kilometern durchgeführt werden. Entsprechend besitzt nach Brilon [1976] die reine Angabe der Anzahl von Überholungen keine besondere Aussagekraft. Daher müssen Bezugsgrößen wie die Streckenlänge und des entsprechenden Zeitintervalls stets mit betrachtet werden. Dadurch ergibt sich die Überholrate ÜR $=$ Ü / ( $\left.L^{\star} \mathrm{t}\right)\left[\ddot{U} /\left(\mathrm{km}^{\star} \mathrm{h}\right)\right]$. Durch die Berechnung der Überholrate kann auch eine vergleichende Betrachtung von Streckenabschnitten mit Ausfällen bei den Verkehrserhebungen (geringfügig aufgetretene technische Probleme bei der Videoerhebung) sichergestellt werden, was ohne relativen Bezug zum Zeitintervall zu Verzerrungen führen kann. 
Werden die Zusammenhänge der Überholungen und Sichtweiten aus Abbildung 4.22 mit der Überholrate ergänzt, so ergibt sich Abbildung 4.23. Die wesentlichen Zusammenhänge und Argumentationen haben sich allerdings im Vergleich zur Überholanzahl nicht wesentlich geändert. Grundsätzlich ist noch festzuhalten, dass die größte Anzahl von unfallauffälligen Untersuchungsstrecken im Bereich der mittleren Sichtweiten (zwischen Grenzwerten der RAS-L und RMS) zu finden ist. Ein weiterer Großteil der Untersuchungsabschnitte entfällt auf Strecken mit Sichtweiten unterhalb des RMS-Grenzwertes, dagegen sind nur wenige „Überholabschnitte“ mit ausreichenden Sichtweiten feststellbar. Unterhalb des Grenzwertes der RMS sind die Überholraten auf einem vergleichsweise konstanten Niveau, bevor sich bei größeren mittleren Sichtweiten auch steigende Überholraten ergeben.

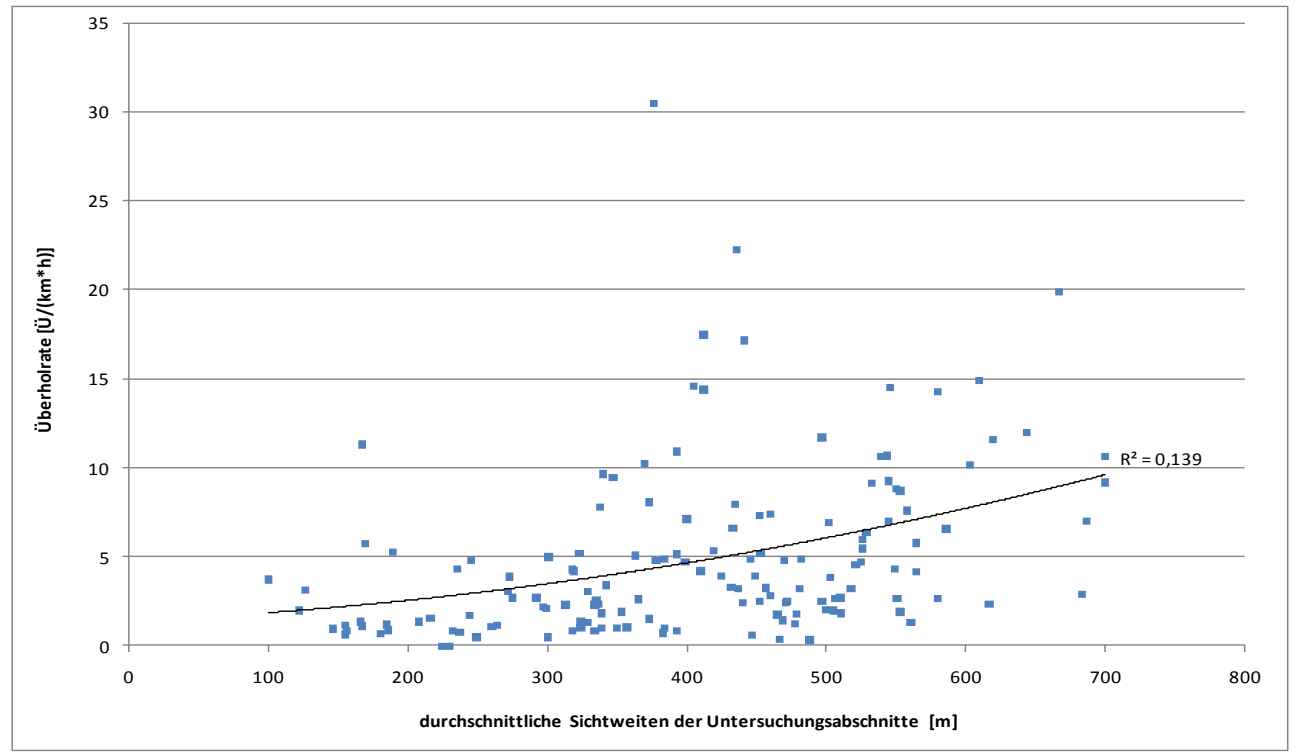

Abbildung 4.23: Zusammenhang zwischen repräsentativer Überholrate und Sichtweiten

Aufgrund der in Abbildung 4.20 dargestellten geringen Unterschiede bzw. starken Abhängigkeiten zwischen Gesamtüberholungen und repräsentativen Überholungen wird bei den nachfolgenden Auswertungen nur noch auf die repräsentativen Überholungen Bezug genommen.

Werden die anfänglichen allgemeinen Auswertungen aus Kapitel 4.2.4.1 mit den ermittelten drei Sichtweitenbereichen verschnitten, so ergibt sich nachstehend die Abbildung 4.24. Der vorstehend erläuterte Zusammenhang, dass mit steigenden Sichtweiten zwangsläufig mehr repräsentative Überholungen möglich und auch durchgeführt werden, ist auch bei Betrachtung der aggregierten Sichtweitenbereiche deutlich erkennbar. Darüberhinaus erhöht sich allerdings auch die Unfallanzahl mit besseren Sichtweitenbereichen. Es muss aber beachtet werden, dass die Ausprägungen beider Kenngrößen trotzdem gegenläufig sind.

Es wird darauf verwiesen, dass sich aufgrund der fortschreitenden Detaillierung der durchgeführten Untersuchung (Reduzierung der Untersuchungsstrecken von 100 nachtrassierten zu 50 im Detail untersuchten Strecken) auch geringfügige Änderungen in den Tendenzen der einzelnen Sichtweitenbereiche ergeben haben. So haben beispielsweise die Unfälle in guten Sichtweitenbereichen im Gegenzug zu den Unfällen bei schlechten Sichtweiten zugenommen, wohingegen der 
Anteil der Unfälle zwischen beiden Grenzwerten von Sichtweiten nahezu unverändert blieb (vgl. hierzu Abbildung 3.23).

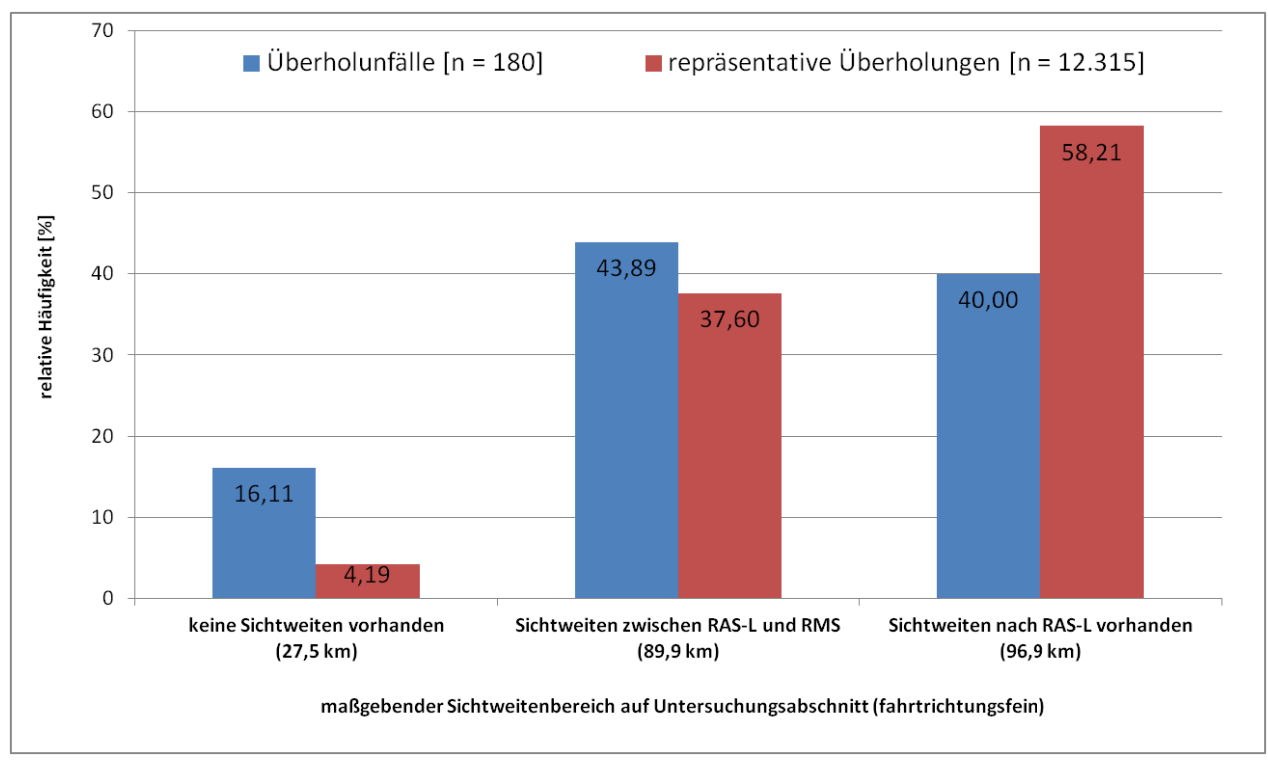

Abbildung 4.24: Zusammenhang zwischen Überholunfällen und repräsentativen Überholungen

Wird analog zu Kapitel 4.2.4.1 aus Anzahl der Überholunfälle und tatsächlichen Überholungen ein Unfallrisiko berechnet, so ergibt sich Abbildung 4.25. Hierzu kann festgehalten werden, dass erwartungsgemäß das Unfallrisiko mit besseren Sichtweiten abnimmt. Es ergeben sich nach Abbildung 4.24 zwar vergleichsweise wenige Überholungen in schlechten Sichtweitenbereichen, allerdings sind diese wenigen Überholungen auch durch ein besonders hohes Unfallrisiko gekennzeichnet. Im Vergleich ist das Unfallrisiko in schlechten Sichtweitenbereichen (unterhalb RMSGrenzwert) nahezu 6-mal so groß wie das Unfallrisiko bei ausreichenden Sichtweiten nach RAS-L. Bei der Verbesserung der Sichtweiten von eingehaltenem RMS-Grenzwert zu ausreichenden Sichtweiten nach RAS-L kann von einer Halbierung des Unfallrisikos gesprochen werden.

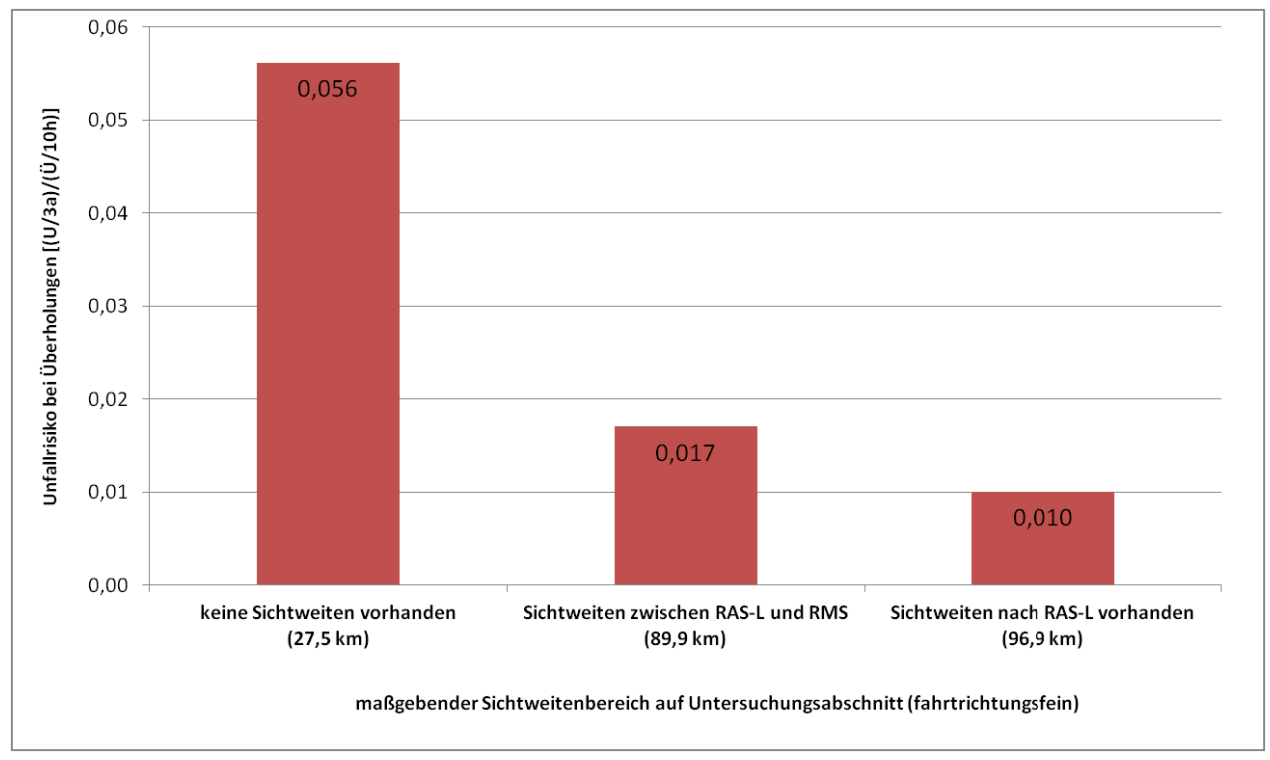

Abbildung 4.25: Unfallrisiko bei repräsentativen Überholungen in unterschiedlichen Sichtweitenbereichen 
Erweitert man die vorstehenden Auswertungen um eine Differenzierung nach vorhandenen Überholverboten, so ergibt sich nachstehende Abbildung 4.26. Neben den bereits ermittelten Zusammenhängen, dass mit steigenden Sichtweiten die Überholunfälle und auch Überholungen ansteigen, zeigt sich ein deutliches Bild in Hinblick auf Unfälle und Überholungen in Bereichen mit vorhandenen Überholverboten. Es wird ersichtlich, dass bei Markierungen, Beschilderungen oder deren beider Kombination das Unfallgeschehen und das Überholverhalten entschieden zurückgehen. Dieser Aspekt kann als deutlicher Sicherheitsgewinn angesehen werden.

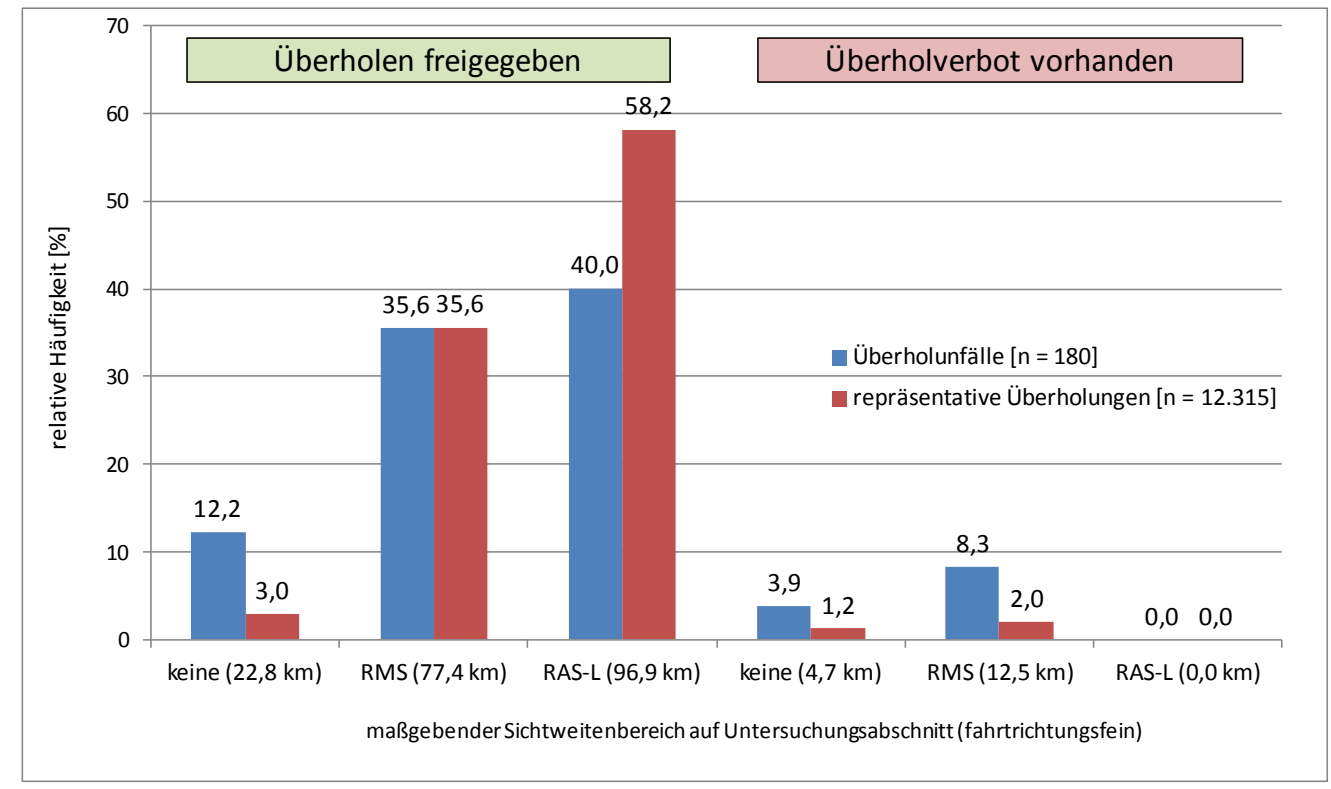

\section{Abbildung 4.26: Zusammenhang zwischen Überholunfällen und repräsentativen Überholungen} differenziert nach Überholverboten

Wird der bereits beschriebene Risikowert von Überholunfällen je Überholung berechnet, so ergibt sich nachfolgendes Bild.

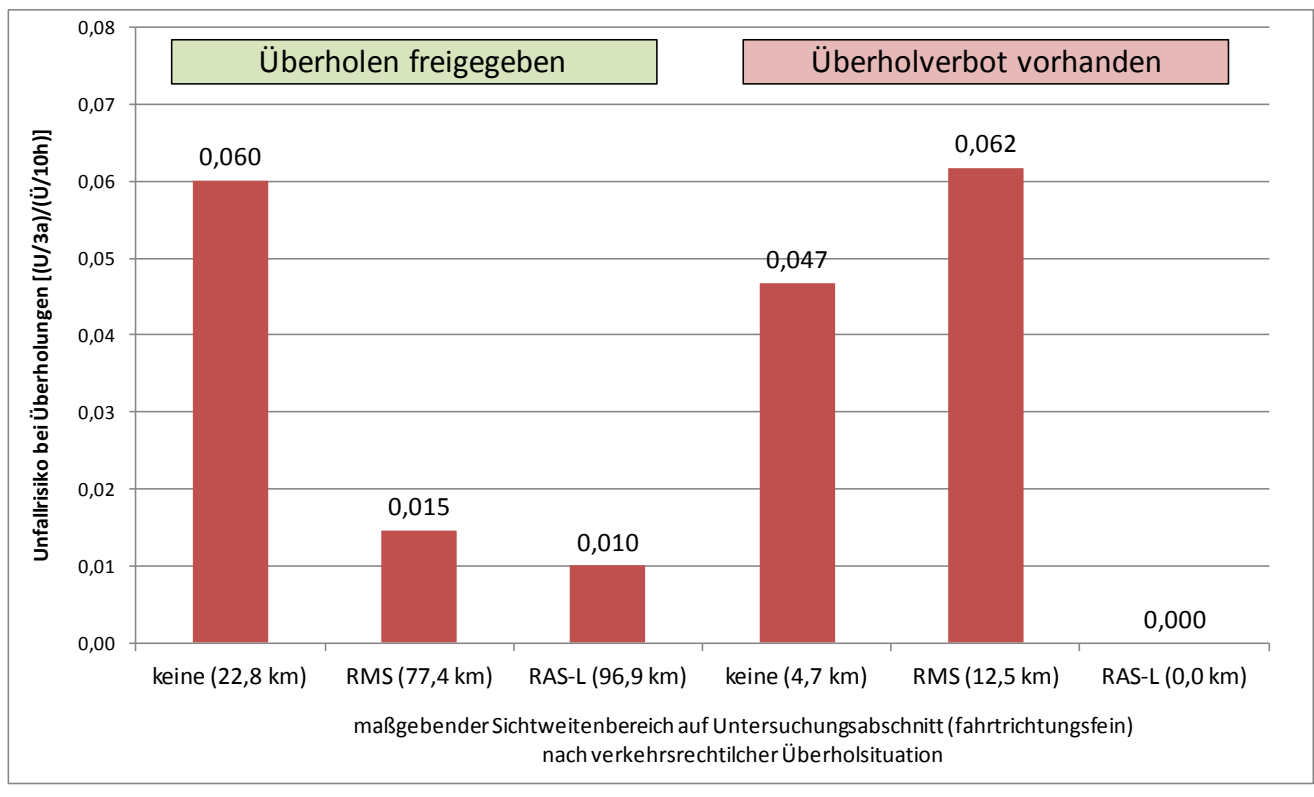

Abbildung 4.27: Unfallrisiko bei repräsentativen Überholungen nach Sichtweitenbereichen und verkehrsrechtlicher Überholsituation 
Zum Überholen freigegebene Abschnitte ergeben hier aufgrund ihrem großen Anteil an Überholungen und Überholunfallgeschehen auch die bereits aus Abbildung 4.25 bekannten Abhängigkeiten. Demnach fällt das Risiko eines Überholunfalles bei besseren Sichtweiten. Ist dagegen ein Überholverbot auf dem Untersuchungsabschnitt vorhanden, so ist gemessen an der vergleichsweise geringen Anzahl an Überholungen - da der Großteil der Verkehrsteilnehmer den rechtlichen Vorgaben folgt - das Risiko eines Überholunfalles teilweise größer als in freigegebenen Abschnitten. Die Risiken sinken entgegen der freien Abschnitte mit fallenden Sichtweiten, da hier offenbar die Akzeptanz von vorhandenen Überholverboten mit am größten ist.

Aufgrund der hier gewählten neuen Bezugsgröße in Form der tatsächlich durchgeführten Überholungen darf diese Tendenz aber nicht als Gegenargument zu bereits vorher getroffenen Aussagen angesehen werden. Die Verbindung der Überholungen mit dem Unfallgeschehen stellt hier allerdings nur eine fiktive Risikogröße dar und kann die netzweiten Sicherheitsbelange der im Rahmen der Analyse der verkehrlichen Randbedingungen (vgl. Kapitel 3.4) sowie der Analyse der vorhandenen Sichtweiten (vgl. Kapitel 3.5) keineswegs entkräften, da zwischen dem Bezug auf Streckenlängen und Verkehrsstärken (Unfallkenngrößen) und dem Bezug auf tatsächlich realisierte Überholungen deutlich unterschieden werden muss.

Abschnitte mit Überholverboten und vorhandenen Sichtweiten über den Grenzwerten der RAS-L konnten im Rahmen der Detailanalysen nicht ausgewertet werden, deshalb ergibt sich hier die Unfallanzahl sowie die Anzahl der Überholungen in einem solchen Bereich zu null. Es ist allerdings davon auszugehen, dass in diesen Bereichen die Akzeptanz der vorhandenen Überholverbote weiter fallen wird und es möglicherweise auf gehäuft zu Überholunfällen kommt (Beispiel Knotenpunktunfälle bei guten Sichtweiten).

In Anhang $Y$ sind die Betrachtungen der Überholungen und Überholunfälle in Bezug zur vorhandenen Verkehrsstärke auf der entsprechenden Fahrtrichtung der Untersuchungsabschnitte dargestellt. Anhang Y/a zeigt geringfügig steigende repräsentative Überholraten und auch Überholunfälle mit steigender Verkehrsstärke. Allerdings sind die statistischen Zusammenhänge sehr schwach ausgeprägt, die Streuungen sind sehr hoch und die Bestimmtheitsmaße äußerst gering. Bei geringen Verkehrsstärken wird vermutet, dass aufgrund des seltenen Aufeinandertreffens von Fahrzeugen in einer Richtung auch nur wenige Überholungen durchgeführt werden. Werden sie durchgeführt, so ist die Unfallhäufigkeit eben wegen dieser geringen Verkehrsstärken gering. Bei hohen Verkehrsstärken steigt die Wahrscheinlichkeit von potentiellen Überholungen und auch die des sich anstauenden Überholdruckes, da wegen der höheren Verkehrsstärke nur wenige Überholmöglichkeiten gegeben werden. Dies kann risikoreiche Überholmanöver fördern und Überholunfälle hervorrufen. Die bisher erläuterten Zusammenhänge sind allerdings losgelöst von den dazugehörigen vorhandenen Sichtweiten im Abschnitt. Diese Abhängigkeiten werden in Anhang Y/b- $d$ nachgetragen.

Grundsätzlich wird hier die Kategorisierung des Straßennetzes erkennbar. Demzufolge existieren Strecken mit Sichtweiten unterhalb des RMS-Grenzwertes nur bei geringen Verkehrsstärken. Steigen dagegen die Verkehrsstärken an, so kann auch vermehrt von einem besserem Ausbaustan- 
dard der Straße und somit besseren Sichtweiten ausgegangen werden. Bei Betrachtung von Anhang Y/b zeigen sich in allen drei Sichtweitenbereichen Maxima von Überholunfällen mit unterschiedlichen Ausprägungen bei mittleren Verkehrsstärken. Hiermit kann die Vermutung, dass bei geringen Verkehrsstärken wenige Unfälle wegen weniger Überholungen entstehen und bei hohen Verkehrsstärken nur noch wenige Überholungen möglich sind, bestätigt werden. Die wieder fallende Tendenz der Überholunfälle im Vergleich zu Anhang Y/a liegt womöglich im Übergewicht der Strecken mit mittleren Verkehrsstärken auf Landstraßen begründet. Die Summe der Unfälle ist demnach bei mittleren Verkehrsstärken am größten und fällt bei größeren Verkehrsstärken wieder ab. Insgesamt zeigt sich auch in Anhang Y/c die größte Überholhäufigkeit bei mittleren Verkehrsstärken.

Betrachtet man das Unfallrisiko in Anhang Y/d so wird grundlegend deutlich, dass unabhängig von der vorliegenden Verkehrsstärke das Unfallrisiko bei Überholmanövern in schlechten Sichtweitenbereichen am größten ist. Dies spricht erneut für strikte Überholverbote bei schlechten Sichtbedingungen. Folgend auf diesen schlechten Sichtweitenbereich sind die Sichtweiten im Zwischenbereich der Grenzwerte nach RMS und RAS-L ebenfalls unfallauffälliger als die am sichersten erscheinenden Abschnitte mit guten Überholsichtweiten. Insgesamt spricht dies erneut für gute Überholmöglichkeiten bei ausreichenden Sichtweiten und einem eher geringen Unfallrisiko.

Bei Betrachtung der fahrtrichtungsfeinen Verkehrsstärken und den Unfallzahlen kann noch folgender Ausblick in Bezug zum Entwurfsklassenprinzip der neuen Richtlinien für die Anlage von Landstraßen gegeben werden. Geht man davon aus, dass künftig bei Verkehrsstärken in der Größenordnung von 10.000 Fahrzeugen in 24 Stunden am Querschnitt (die in den Darstellungen von Anhang $Y / b-d$ enthaltenen fahrtrichtungsfeinen Verkehrsstärken werden für diese Betrachtung näherungsweise verdoppelt) die erhöhte Verbindungsfunktion sowie daraus resultierend mindestens die Entwurfsklasse 2 zum Einsatz kommt, so können bei der Markierung der Landstraßen nach EKL 2 und einem unterstellten regelkonformen Verhalten der Verkehrsteilnehmer grundsätzlich folgende Annahmen getroffen werden:

- Das Vermeidungspotential aller Überholunfälle durch die Markierung von Strecken mindestens nach EKL 2 liegt bei unzureichenden Sichtweiten (unterhalb den RAS-LGrenzwerten) bei $12,2 \%$.

- Das Vermeidungspotential aller Überholunfälle durch die Markierung von Strecken mindestens nach EKL 2 liegt bei guten Sichtweiten (oberhalb den RAS-L-Grenzwerten) bei $15,6 \%$.

- In Summe könnte durch die netzweite Anwendung der RAL beim Neubau sowie des M_EKLBEST im Bestandsnetz durch die Markierung der Entwurfsklassen 1 und 2 insgesamt $28 \%$ aller heutigen Überholunfälle vermieden werden.

Wird zudem bei Straßen der EKL 3 ein striktes Überholverbot angeordnet, wenn keine ausreichenden Sichtweiten zur Überholung eines Lastkraftwagens vorhanden sind (unterhalb $600 \mathrm{~m}$ entspricht den Vorgaben der RAS-L) und bei Straßen der EKL 4 gar nicht mehr überholt, so können 
weitere 47,8 \% der heutigen Überholunfälle vermieden werden. Wird gegen die vorgesehenen Maßnahmen regelwidrig verstoßen, sinkt das hier angegebene Vermeidungspotential und die Wirksamkeit muss erhöht werden.

Bei der Gegenüberstellung von Überholraten und berechneten Unfallkenngrößen differenziert nach en maßgebenden Sichtweitenbereichen ergeben sich die Ergebnisse nach Anhang Z. Die über die drei Sichtweitenbereiche aggregierten Ergebnisse der dargestellten Überholraten entsprechen tendenziell den Ergebnissen aus Abbildung 4.23. Die Ergebnisse der auf die Unfallanzahl sowie auf die Unfallkosten bezogenen Unfallkenngrößen zeigen alle die gleichen Zusammenhänge. Demnach verringern sich die Unfallanzahl und auch die Unfallkosten bei besser werdenden Sichtweiten. Die Ausprägungen der Unfall(kosten)raten ergeben hier noch deutlichere Zusammenhänge als die Unfall(kosten)dichten. Die Raten mit Bezug zur Verkehrsstärke und zur Streckenlänge haben sich zwischen schlechten (<RMS) und ausreichenden Sichtweiten ( $>$ RAS-L) mehr als halbiert, die größte Verbesserung zum Unfallgeschehen zeigt sich allerdings bereits zwischen Sichtweiten unterhalb des RMS Grenzwertes und den zu vermeidenden Sichtweitenbereichen zwischen RMS und RAS-L. Mit Bezug zur Unfalldichte zeigten sich dagegen eher gleichmäßige Verbesserungen der Verkehrssicherheit mit zunehmender Sichtweite.

In Anhang AA sind abschließend die Ergebnisse zum Überholverhalten und den Unfallkenngrößen bei bereits vorhandenen verkehrsrechtlichen Restriktionen dargestellt. Zum Überholverhalten ist festzuhalten, dass offensichtlich kein der bestehenden verkehrsrechtlichen Anordnungen zu einer absoluten Vermeidung von Überholungen führen. Die Überholrate ist mit 3,36 Überholungen pro Kilometer und Stunde bei vorhandenen Markierungen am größten. Die Überholrate halbiert sich bei der Anordnung von Überholverbotszeichen Z 276 und erreicht ihr Minimum von ca. 1 Überholung pro Kilometer und Stunde bei der Kombination aus Markierung und Beschilderung. In Bezug zu den Unfallkenngrößen ergibt sich kein einheitliches Bild. Die Unfallraten und -dichten sind in ihren Ergebnissen sehr unterschiedlich.

Die Unfallkostenraten und -kostendichten sind dagegen entsprechend der Tendenzen der Überholrate ebenfalls fallend. Werden die benannten Diagramme aus Anhang AA noch mit den freigegebenen Abschnitten ergänzt, so ergeben sich die geringsten Unfallkenngrößen in Landstraßenabschnitten ohne Überholverbote. Diese Tendenz ist erneut auf Verzerrungen der Unfallkenngrößenberechnung zurückzuführen, da es sich bei Überholverboten meist um kurze Abschnitte handelt, die grundsätzlich hohe Unfallkenngrößen ergeben, wohingegen freigegebene Abschnitte sehr lang sind und die Unfallkenngrößen verkleinern. Gleiches Ergebnis ist bereits bei der Netzanalyse aufgetreten (vgl. Kapitel 3.4.5), weshalb die Betrachtungen auf die unfallfreien Abschnitte erweitert wurden (vgl. Kapitel 3.4.6). Diese Erweiterung ist im Rahmen der Detailanalyse nicht möglich, weshalb auch auf die Darstellung der Unfallkenngrößen für die freigegebenen Abschnitte verzichtet wird, um Fehlinterpretationen grundsätzlich vorzubeugen. Ergänzend sei noch erwähnt, dass die Überholrate mit 6,45 Überholungen pro Kilometer und Stunde bei zum Überholen freigegebenen Abschnitten am größten ist. Es kann davon ausgegangen werden, dass aufgrund des Län- 
genbezuges auch bei den Überholraten ähnliche Verzerrungen wie bei den Unfallkenngrößen auftreten. Demnach sind die Überholraten der Überholverbote gegebenenfalls zu hinterfragen.

Insgesamt ist zu den vorhandenen Überholverboten festzuhalten, dass die hier berechneten Unfallkenngrößen nur eine geringe Aussagekraft besitzen. Eventuelle Unterschiede zwischen den Überholverboten sind im Vergleich zur Netzanalyse mit deren umfangreichen Datenbasis nicht besonders zu gewichten. Aufgrund der eher kleinen Datengrundlage von Überholverboten und dem Fokus des Projektes auf alle unfallauffälligen Bereiche (Großteil der Untersuchungsstrecken sind zum Überholen freigegeben, vgl. Matrizen der Netzanalyse in Kapitel 3.4.2) kann mit den hier erreichten Ergebnissen keine abschließende Empfehlung über die Wirksamkeit der Überholverbote gegeben werden. Die geringe Datengrundlage lässt keine genauen Rückschlüsse über die Sicherheitseffekte von Überholverboten zu. Zuverlässige Erkenntnisse zur Wirksamkeit von Maßnahmen gegen Überholungen und -unfälle könnten an unfallauffälligen Streckenabschnitten beispielsweise durch Vorher-Nachher-Untersuchungen gewonnen werden.

Betrachtet man die vorhandenen zulässigen Höchstgeschwindigkeiten in den Untersuchungsabschnitten, so wird eine Halbierung der Überholrate bei vorhandenen Geschwindigkeitsbeschränkungen im Vergleich zu freigegebenen Abschnitten deutlich. Die sich ergebenden Unfallkenngrößen zeigen keine wesentlichen Unterschiede, allerdings sind auch hier die Ergebnisse aufgrund der eher geringen Datenbasis nicht als relevant zu bezeichnen. Die Ergebnisse der Netzanalyse sind zur Bewertung der verkehrsrechtlichen Anordnungen wegen der umfangreichen Datengrundlage als maßgebend anzusehen. Alle weiteren Erkenntnisse über die Wirkung von Maßnahmen wären durch eine Vorher-Nachher-Untersuchungen zu ermitteln.

\subsubsection{Zusammenfassung}

Im Rahmen der Detailanalyse wurde durch umfangreiche Erhebungen das Überholverhalten in unterschiedlichen Landstraßenbereichen untersucht. Hierbei wurden die Untersuchungsstrecken in Abschnitte mit Überholmöglichkeiten (keine rechtlichen Restriktionen sowie gute Sichtweiten) und ohne Überholmöglichkeiten (Überholverbote oder unzureichende Sichtweiten) unterteilt. Die Ergebnisse der Videoanalysen der untersuchten Landstraßen (50 Strecken mit 78 Abschnitten und 150 Richtungen) wurden in Überholmatrizen zusammengefasst. Hierbei wurden Fahrzeugklassen und daraus abgeleitete repräsentative Überholungen ermittelt.

Personenkraftwagen bilden nach der Häufigkeit ihres Auftretens im Landstraßennetz auch die maßgebende Fahrzeuggruppe potentieller Überholer (88,5 \% aller Überholungen). Gemessen an der geringen Häufigkeit der Überholungen von Lkw, geht von ihnen jedoch das größte Unfallrisiko aus. Den Fokus der Analysen müssen allerdings die häufigen Überholer (Pkw, Krad) bilden. Aufgrund der geringen Geschwindigkeitsdifferenzen sind Pkw/Pkw-Überholungen im Vergleich zu Pkw/Lkw-Überholungen als vergleichsweise unsicher anzusehen. Überholungen von Motorrädern sind an Lkw auffällig geworden. Grundsätzlich steigen die Anzahl der Überholungen und auch die Überholrate mit besseren Sichtweiten. Das ausgewiesene Unfallrisiko sinkt mit steigenden Sichtweiten deutlich. Auch bei nur wenigen Überholungen ergibt sich somit die zwingende Notwendig- 
keit, dass Überholen in ungeeigneten Sichtweitenbereichen strikt zu untersagen. Die Annahme, dass Fahrzeugführer nicht zur Verfügung stehende Überholsichtweiten eigenständig erkennen können und demnach nicht zum Überholen ansetzen ist schlichtweg falsch, da bei auch noch so schlechten Sichtweiten zwar selten aber insgesamt trotzdem überholt wird. Der Fahrer muss bei unzureichenden Sichtweiten durch betriebliche Maßnahmen unterstützt werden.

Eine Überlagerung der Verkehrsstärken ergab in Bezug zu den Sichtweiten und dem damit verbundenen Überholraten und Unfallrisiko ähnliche Erkenntnisse. Durch diese weitere Differenzierung nach den Verkehrsstärken können folgende Annahmen bei der Anwendung der RAL sowie des M_EKLBEST und der damit einhergehenden Einführung des Entwurfsklassenprinzips getroffen werden. Unterstellt man regelkonformes Verhalten, so könnten bei der Markierung von EKL 1 und EKL 2 ca. $28 \%$ sowie bei Strecken der EKL 3 und EKL 4 weitere $48 \%$ der heutigen Überholunfälle vermieden werden. Bei Regelverstößen verringert sich diese Potentialabschätzung.

Die Ergebnisse der Unfallkenngrößen lassen aufgrund der geringen Datenbasis im Rahmen der Detailanalysen keine eindeutigen bzw. aussagekräftigen Schlussfolgerungen zu. Daher sind die auf einer größeren Datenbasis beruhenden Ergebnisse der Netzanalyse für die Unfallkenngrößen als maßgebend anzusehen. Das Überholverhalten - beschrieben durch die Überholrate - wird durch Überholverbote und Geschwindigkeitsbeschränkungen auf Landstraßen eingegrenzt, aber in Abhängigkeit der vorherrschenden Streckencharakteristik nicht ausnahmslos unterbunden. VorherNachher-Untersuchungen könnten die Wirkungen von Überholverboten direkt verdeutlichen. Hierbei müssten auf ausgewählten Strecken in Abstimmung mit den Landesverwaltungen verkehrsrechtliche Maßnahmen umgesetzt und die Wirkungen nach einer Eingewöhnungsphase beurteilt werden. 


\subsection{Besonderheiten und Maßnahmenvorschläge der Untersuchungsstrecken}

Im Rahmen dieses Kapitels werden grundsätzliche Empfehlungen aus Sicht der Verkehrssicherheit für die betrachteten Untersuchungsstrecken zusammengetragen. Dieser abschließende Bearbeitungsschritt ergänzt die vorhergehende Gesamtbetrachtung der Zusammenhänge zwischen Unfallgeschehen, Überholverhalten sowie den straßenseitigen Merkmalen. Da es sich im Großteil der Fälle um Unfallhäufungen handelt (vgl. Definition der Clusterung in Kapitel 3.5.6), werden die Problembereiche nachfolgend kurz beschrieben - um möglichst viele Besonderheiten aufzuzeigen und individuelle Lösungsvorschläge für die entsprechend vorherrschende Unfallsituation gegeben. Die detaillierten Ergebnisse der Erhebungen der Strecken sind Anhang BB zu entnehmen.

\subsubsection{Untersuchungsstrecken in Bundesland 1}

Das offensichtliche Problem der Untersuchungsstrecke BL1-3 im westlichen Abschnitt ist die geringe Überholsichtweite. Dennoch werden im Bereich der Unfallpositionen bereits vorhandene markierte Überholverbote und Geschwindigkeitsbeschränkungen für einen $600 \mathrm{~m}$ langen Teilabschnitt unterbrochen, in dem die Sichtweitenbedingungen nicht wesentlich besser sind. Möglicherweise suggeriert die Unterbrechung und die kurzzeitig ansteigende Sichtweite eine potentielle Überholmöglichkeit, welche tatsächlich nicht vorhanden ist. Da in diesem Bereich bereits 2 schwere Überholunfälle geschehen sind, welche ohne den Überholvorgang möglicherweise hätten verhindert werden können, sollten hier klare verkehrsrechtliche Restriktionen den Fahrer bei seiner Fahraufgabe unterstützen. Im zweiten Abschnitt fallen anfängliche vorhandene Sichtweiten im Streckenverlauf ab. Hier kann die rechtzeitige Ankündigung von schlechten Überholsichtweiten die Unfallsituation verbessern.

Bei Untersuchungsstrecke BL1-18 geschahen die 3 ersten Unfälle alle in Überholphase 2. Bei derart fallenden Sichtweiten sollte aber generell nicht mehr zum Überholen ausgeschert werden. Möglicherweise wären die Unfälle durch eine Frühankündigung der schlechten Sichtweiten vermeidbar gewesen. Die nächste Unfallhäufung lässt sich ursächlich auf eine eher unscheinbare Einmündung zurückführen. Die Wirksamkeit der bereits vorhandenen Markierung muss verstärkt und rechtzeitig angekündigt werden. Möglicherweise besteht hier aufgrund der guten Sichtverhältnisse wenig Einsicht für die angeordneten Verbote, da auch der Knotenpunkt nicht ausreichend erkennbar ist. Sinken dann hier die Geschwindigkeiten aufgrund von Abbiegern, kann dies die hier gehäuften Überholungen aus dem Kolonnenverkehr (Position 2 bis 4) und Kollisionen mit dem Abbieger zur Folge haben. Im Bereich des letzten Unfalles wurde eine vorhandene Markierung trotz schlechter Sichtweiten durch eine 200 m lange Warnlinie unterbrochen. Dies kann Überholmöglichkeiten suggerieren und zu Unfällen führen. Die Lücke sollte geschlossen werden.

Die Untersuchungsstrecke BL1-72 ist nahezu vollständig mit Überholverboten versehen. Hierbei wurden sowohl Beschilderungen als auch Markierungen verwendet. Im Bereich der Unfallpositionen wurde die Sperrlinie für 200 m allerdings durch eine Warnlinie ersetzt, was beim Verkehrsteilnehmer gegebenenfalls zu Missverständnissen führen kann. Da in diesen Bereichen dennoch 46 
repräsentative Überholungen festgestellt wurden, muss entweder die Wirksamkeit der Überholverbote oder der Zweck der 200 m langen Unterbrechung (Warnlinie) in Frage gestellt werden.

Der erste Überholunfall auf Untersuchungsstrecke BL1-148 geschah bei guten Sichtweitenbedingungen aber dennoch vorhandenem Überholverbot im Knotenpunktbereich. Zwischen den hier mehreren Knotenpunkten mit Markierung und Beschilderung sind die rechtlichen Restriktionen erneut kurzzeitig unterbrochen. Nähere Aussagen sind aufgrund fehlender Unfallanzeigen nicht möglich. Der zweite unfallauffällige Abschnitt ist nur mit Überholverboten beschildert, Leit- und Warnlinien wechseln hier in Lageplankurven. Wegen der verhältnismäßig guten Sichtweiten führt das Überholverbot möglicherweise zu Unverständnis und trotzdem zu Überholungen. Die Fahrbahnbeschaffenheit war zu den Unfallzeitpunkten sehr schlecht, aufgrund der Fahrbahnerneuerung konnten im zweiten Abschnitt wegen fehlender Markierung und Baustellenbeschilderung keine Messungen während der Detailanalysen vorgenommen werden.

Der erste Unfall auf Untersuchungsstrecke BL1-151 ereignete sich bei theoretisch guten Sichtweitenbedingungen. Aus dem Unfallhergang war ableitbar, dass der Pkw den Gegenverkehr allerdings aufgrund des Hindernisfahrzeuges gar nicht sehen konnte. Trassierungstechnisch sind zwar gute Sichtverhältnisse vorhanden, dennoch werden bei der Sichtweitenberechnung - mit der Entwurfssoftware Card/1 oder Vestra - im Planungsprozess keine Behinderungen durch Hindernisfahrzeuge berücksichtigt. Auf derartige Risiken muss im Straßenverlauf hingewiesen werden, vor allem wenn es bereits zu schweren Unfällen gekommen ist. Die verbleibenden beiden Unfälle sind durch Abbiegekonflikte entstanden. Beide Unfälle wären bei einer vorausschauenden Fahrweise womöglich nicht entstanden. Die „klassischen“ Überholunfälle waren diese 2 Fälle jedoch nicht.

Bei der Untersuchungsstrecke BL1-199 handelt es sich um einen überbreiten Querschnitt von 15,1 m Fahrbahnbreite (inkl. Mehrzweckstreifen). Der erste Unfall ist aufgrund zufälliger Einflüsse (Stau) nicht genauer zu betrachten. Bei beiden folgenden Unfälle sind möglicherweise dem überbreiten Querschnitt geschuldet. Beide überholten trotz Gegenverkehr und kollidierten mit diesem. Bei derartigen Querschnitten konnte oftmals ein Überholen trotz Gegenverkehr beobachtet werden, der Gegenverkehr ist hier demnach nicht zwangsläufig ein Kriterium für eine negative Überholentscheidung. Inwieweit überbreite Querschnitte einen negativen Einfluss auf das Überholunfallgeschehen haben, kann hier aufgrund des Einzelfalles nicht geklärt werden. Der letzte Unfall stellt erneut einen Sonderfall dar, da bereits sämtliche verkehrsrechtliche Restriktionen im Knotenpunktbereich vorhanden sind. Der Unfall hatte aber nur geringe Folgen und wäre bei Befolgung der vorhandenen Regeln nicht geschehen.

Im ersten Abschnitt der Untersuchungsstrecke BL1-252 liegt eine Unfallhäufung mit 5 Unfällen durch Abbiegekonflikte an einer Einmündung eines Wirtschaftsweges vor. Bei derartigem Unfallgeschehen muss die Unterbrechung der vorhandenen Überholverbote wegen nur kurzzeitig ausreichenden Sichtweiten in Frage gestellt werden. Langfristig können Aufstellfächen dazu beitragen, die Abbiegekonflikte zu entschärfen. Beim folgenden Unfall kollidierte ein Motorradfahrer mit der Mittelinsel in einer Ortsdurchfahrt. Die vorhergehende $200 \mathrm{~m}$ lange Unterbrechung der vorhande- 
nen Sperrlinie durch eine Warnlinie kann eine Überholmöglichkeit suggerieren. Bei den beiden Unfällen nach der Ortsdurchfahrt kann eine Besonderheit in der Trassierung festgestellt werden. Durch das Zusammenspiel von Lageplan und Seitenraumgestaltung (Höhenplan ohne Einfluss) können sichtbare Gegenverkehre für wenige Sekunden hinter dem Seitenraum verschwinden. Dies führt zu einem gefährlichen Sichtweitensprung nach unten, demzufolge halbieren sich die vorhandenen Sichtweiten innerhalb weniger Meter, worauf aus Sicht der Verkehrssicherheit hinzuweisen ist. Die 3 Überholunfälle im letzten Abschnitt sind alle bei vorhandener Beschilderung durch Z 276 geschehen. Auch die geringe Anzahl festgestellter Überholungen (15 in 10 h) muss durch verkehrsrechtliche Maßnahmen unterbunden werden, die Wirksamkeit ist zu erhöhen.

Auf der Untersuchungsstrecke BL1-455 wurden 3 Überholunfälle registriert. Zwei Unfälle sind durch Abbiegekonflikte und ein weiterer durch ungenügenden Sicherheitsabstand zum überholten Radfahrer entstanden. Demnach handelt es sich hierbei nicht zwangsläufig um ein klassisches Überholunfallgeschehen. Dennoch müssen bei einer derartigen Häufung und auch begründet durch die nur kurzzeitig ausreichenden Überholsichtweiten Maßnahmen zur Vermeidung von Überholungen (insgesamt 91 Überholungen beobachtet) getroffen werden. Die beiden Unfälle mit schwerem Personenschaden sind im Bereich fallender Sichtweiten geschehen, die kurz vor dem RMS-Grenzwert liegen. Die fallenden Sichtweiten sind mindestens anzukündigen.

Die Untersuchungsstrecke BL1-528 ist durch zwei Überholunfälle bei ausreichenden Sichtweiten gekennzeichnet. Hierbei wurde ein Abbiegekonflikt an einem Wirtschaftweg festgestellt und eine Kolonnenüberholung eines Motorrades, dass bei Gegenverkehr zwischen den Fahrzeugen einscheren musste und ins Schleudern geriet. Auf die Gefährlichkeit von unscheinbaren Einmündungen wurde bereits verwiesen, dies gilt auch wenn diese keinem übergeordneten Wegeziel dienen. Bei dem Motorradunfall wird möglicherweise die fehlerbehaftete Entfernungsschätzung zum Gegenverkehr deutlich, welche hier ein rasches Einscheren erforderte. Der dritte Unfall auf dieser Strecke wurde bei schlechten Sichtweiten durchgeführt, auch hier muss von einer Fehleinschätzung der Situation gesprochen werden. Warum keine betrieblichen Maßnahmen das Überholen untersagen bzw. die schlechten Sichtweiten verdeutlichen, ist nicht erkennbar.

Auf Untersuchungsstrecke BL1-710 zeigen sich besonders die Zufälligkeit von Unfällen und die Vielzahl potentieller Einflussgrößen (Streckencharakteristik, Verkehrsgeschehen). Bei der Strecke handelt es sich um zwei identische Teilabschnitte (gleiche Länge, gleiche Sichtweitensituation) die durch eine Kurve voneinander getrennt werden können. Warum nun auf dem einen Abschnitt zwei und auf dem äquivalenten zweiten Abschnitt kein Überholunfall geschehen ist, kann nur durch andere Einflussgrößen in der Schnittstelle zwischen Fahrer, Fahrzeug und Umgebung erklärt werden. Grundsätzlich ist für bei Abschnitte aufgrund der nur kurz vorhandenen Überholmöglichkeit ein Überholverbot denkbar.

\subsubsection{Untersuchungsstrecken in Bundesland 2}

Auf der Untersuchungsstrecke BL2-337 konnte bei 4 von 5 Überholunfällen ein Einfluss von Knotenpunkten bzw. Einmündungen festgestellt werden. Beim ersten Überholunfall wurde auf ei- 
ner Sperrfläche zum Überholen an einer Kolonne angesetzt, an dessen Spitze mit einem Linksabbieger kollidiert wurde. Hier müssen die Überholverbote verlängert werden. Der folgende Überholunfall entstand aufgrund fehlerbehafteter Verkehrseinschätzung. Bei den folgenden beiden Überholunfällen sollte das Überholverbot auf die Bereiche der unfallverursachenden Einmündungen erweitert werden. Auch die beim letzten Überholunfall durchgeführte Überholung im Knotenpunktbereich muss durch frühzeitige Anordnung von Zeichen 295 verhindert werden. Das bisherige Zeichen 276 scheint nur unzureichend beachtet zu werden. Bei diesem Unfall wurde ein seltener Unfallhergang festgestellt, bei dem der Überholer auf der übergeordneten Straße mit dem Linkseinbieger der untergeordneten Straße kollidierte.

Im ersten Abschnitt der Untersuchungsstrecke BL2-537 sind schwankende Sichtweiten mit nur kurzzeitigen Sichtweitenspitzen (Sichtweite überschreitet erforderlichen Grenzwert nur für wenige Streckenmeter und fällt direkt wieder ab) feststellbar. Warum im Sinne einer konsistenten und auch von den Verkehrsteilnehmern nachvollziehbaren Anordnung von Überholverboten trotzdem bei gleichbleibender Streckencharakteristik einmal ein Verbot angeordnet wird und im folgenden Streckenteil keine Restriktionen vorhanden sind, ist nicht nachvollziehbar. Auf dem nördlichen zweiten Untersuchungsabschnitt wurde ein Überholunfall registriert. Auf die deutlich schlechten Sichtweiten ist mit Überholverboten hinzuweisen, um dem Fahrzeugführer die Entscheidung zur vermeintlichen Überholmöglichkeit grundlegend abzunehmen. In diesem Abschnitt konnten bisher 35 Überholungen festgestellt werden.

Bei der Untersuchungsstrecke BL2-967 handelt es sich um eine $600 \mathrm{~m}$ lange Verbindungsstraße zwischen zwei Ortsdurchfahrten, die durch zwei Knotenpunkte in nahezu 3 gleichlange Teile zerlegt wird. Die schweren Überholunfälle sind durch Abbiege/Einbiegekonflikte entstanden, hätten aber dennoch durch die Verhinderung von Überholungen vermieden werden können. Die bisher angeordneten Überholverbote sollten aufgrund der Streckencharakteristik durch Markierungen verstärkt und auch auf den Gesamtabschnitt ausgedehnt werden. Grundsätzlich sind auf der Strecke $50 \mathrm{~km} / \mathrm{h}$ zugelassen. Das Geschwindigkeitsniveau ist mit einer v85 von $62 \mathrm{~km} / \mathrm{h}$ und Maximalgeschwindigkeiten von über $100 \mathrm{~km} / \mathrm{h}$ deutlich zu hoch. Daher kann auch bereits eine Geschwindigkeitsüberwachung die gewünschte Vermeidung der in der Analyse festgestellten 14 Gesamtund 2 repräsentativen Überholungen mit sich bringen.

Die Untersuchungsstrecke BL2-974 verfügt über die gesamte Streckenlänge über eine überbreiten Querschnitt mit Mehrzweckstreifen (in Summe 11,60 m Fahrbahnbreite). Alle sich darauf befindenden vier Überholunfälle sind auf Abbiegekonflikte zurückzuführen, bei denen trotz Überholverbots zu einem Überholvorgang angesetzt wurde. Womöglich geschuldet dem überbreiten Querschnitt werden hier auch in ausreichendem Umfang Überholungen durchgeführt. Die Gefahr von Überholungen in bereits unfallauffälligen Streckenabschnitten muss durch weitere verkehrsrechtliche Maßnahmen verdeutlicht werden. Neben diesen strikten Verboten kann möglicherweise auch im Streckenverlauf die Ummarkierung des Mehrzweckstreifens zu wechselseitigen Überholfahrstreifen mit sicheren Überholmöglichkeiten hilfreich sein, um Angebote für die Senkung des Überholdruckes zu schaffen. 
Auf der Untersuchungsstrecke BL2-993 ist im ersten Abschnitt zu Beginn einer $600 \mathrm{~m}$ langen Geraden von zwei Verkehrsteilnehmern die auftauchende Überholmöglichkeit hinter einer Kurve wahrgenommen worden. Hierbei kam es zu einer Kollision zwischen beiden Überholenden. Obwohl die Markierung bis hinter die Kurve reicht, wurde schon im Vorfeld zum Überholen angesetzt. Die Wirksamkeit des Überholverbotes ist zu erhöhen. Warum bei eher schlechten Sichtweiten im Folgeabschnitt häufig Unterbrechungen von vorhandenen Restriktionen zu finden sind, ist nicht erklärbar. Im Zuge einer solchen Unterbrechung kam es im zweiten Abschnitt zu einer Häufung von 3 Überholunfällen nach einer scharfen Linkskurve. Die Linkskurve ist durch einen äußerst kleinen Radius gekennzeichnet (ca. $30 \mathrm{~m}$ ) und auch im Vorfeld sind keine ausreichenden Sichtweiten vorhanden. Hinter der Linkskurve wird ein kurzes weiträumiges Tal geöffnet, welches den Eindruck einer guten Sichtweite suggerieren kann. Durch die Unterbrechung der Markierung (Z 295) wird der Effekt verstärkt. Die Markierung ist zur Unterstützung der Fahrzeugführer beizubehalten, damit auch die wenigen festgestellten 41 Überholungen in diesem kritischen Bereich vermieden werden.

\subsubsection{Untersuchungsstrecken in Bundesland 3}

Aufgrund der fehlenden Unfallhergangsbeschreibungen in Bundesland 3 konnte für dieses Bundesland keine umfassende Analyse des Unfallgeschehens durchgeführt werden. Dennoch ist davon auszugehen, dass es unabhängig von der tatsächlichen Unfallentstehung mit präventiven verkehrsrechtlichen Vorgaben in kritischen Bereichen nicht zu Überholungen und schlussendlich nicht zu Überholunfällen gekommen wäre.

Im ersten Abschnitt der Untersuchungsstrecke BL3-73 sind auf einer ca. 200 m langen Geraden zwischen zwei Kurven 3 schwere Überholunfälle geschehen. Warum bei derartigem Unfallgeschehen noch keine Maßnahmen umgesetzt wurden ist nicht nachvollziehbar. Die Sichtweiten schwanken im gesamten ersten Abschnitt um den Grenzwert der RMS herum, dennoch sind nur Leitlinien bzw. Warnlinien vorhanden. 120 Fahrzeugführer haben während des Analysezeitraumes überholt, was bei diesen Sichtweiten nicht haltbar ist. Überholverbote sind zwingend nachzutragen. Kritisch zu bewerten sind zudem mehrere beobachtete Überholungen links einer Verkehrsinsel im Knotenpunktbereich, was zu Konflikten mit einbiegenden Fahrzeugen führen kann. Im zweiten Abschnitt mit guten Sichtweiten ist nur ein Überholunfall im Vorfeld einer Kurve geschehen, der durch Frühankündigung ggf. hätte vermieden werden können.

Die Untersuchungsstrecke BL3-128 besitzt auf beiden Abschnitten kurzzeitig ausreichende und danach fallende Sichtweiten. Eine Geschwindigkeitsbeschränkung von $80 \mathrm{~km} / \mathrm{h}$ ist generell vorhanden, Überholverbote existieren nur im unfallfreien ersten Abschnitt bei Sichtweiten unterhalb RMS. Die Vermutung liegt nahe, dass eine frühzeitige Ankündigung von schlechten Sichtweiten bzw. des Knotenpunktbereiches zu einer Verringerung der Unfallauffälligkeit geführt hätte. Trotz der Geschwindigkeitsbeschränkung wurde im südlichen Abschnitt 227-mal überholt und im nördlichen Abschnitt 144-mal. Die bisherige Lücke einer an beiden Streckenenden bereits angrenzenden vierstreifig ausgebauten Bundesstraße wird künftig durch eine Ortsumfahrung geschlossen werden und die Überholsituation auf dieser Landstraße gänzlich entschärft. 
Auf der Untersuchungsstrecke BL3-195 sind bis auf wenige - durch Einzelkurven und kleine Kuppen verursachte - geringe Sichthindernisse überwiegend gute Sichtweiten vorhanden. Die Kurven- und Kuppenbereiche sind bereits durch Überholverbote gesichert. Alle drei Überholunfälle können aufgrund der Lage damit in Verbindung gebracht werden, dass bei aufgehobenen Überholverboten sofort eine Überholmöglichkeit gesehen und ohne ausreichende Orientierung im verkehrlichen Umfeld zum Überholen angesetzt wird. Gesicherte Aussagen können aber wegen fehlender Unfallhergangsbeschreibungen nicht getroffen werden.

Die Untersuchungsstrecke BL3-1156 ist durch gute Sichtweiten gekennzeichnet bei denen insgesamt 3 Überholunfälle geschehen sind. Insgesamt wurden - vermutlich aufgrund der sehr hohen Verkehrsstärke - auch nur 131 Überholungen durchgeführt. Maßnahmenempfehlungen sind auch bei dieser Strecke nicht mehr erforderlich, da bereits mit einem vierstreifigen Ausbau der Straße begonnen wurde.

Untersuchungsstrecke BL3-1184 ist ein 1.200 m langer Landstraßenabschnitt mit anfänglich ausreichenden und danach fallenden Sichtweiten. Beide Überholunfälle sind in den fallenden Sichtweiten entstanden. Derart späte Überholungen vor dem Sichthindernis können zu Unfällen führen, wenn bei Annäherung an das Hindernis aus der Kurve heraus Gegenverkehr auftaucht. Diese Überholungen müssen durch eine rechtzeitige Ankündigung der Sichtweiteneinschränkung verhindert werden.

Auf der Untersuchungsstrecke BL3-1185 konnte eine eher schlechte Sichtweitensituation festgestellt werden. Die Sichtweiten schwanken um den Grenzwert der RMS, Überholverbote sind bisher nicht vorhanden. Insgesamt wurde hier 60-mal in 10 Stunden überholt, dabei waren allerdings nur 15 repräsentative Überholungen vorhanden. Allerdings kann auch diese geringe Anzahl von Überholungen in kritischen Situationen zu Unfällen führen. Überholverbote sind bei derartigen Streckencharakteristiken unerlässlich und sollten auch hier nachgetragen werden.

Die Untersuchungsstrecke BL3-1197 ist überwiegend durch gute Sichtweiten mit wenigen Unterbrechungen gekennzeichnet. Beim ersten Überholunfall ist die Unterbrechung der vorhandenen Überholverbote bei eher unzureichenden Sichtweiten nicht nachvollziehbar und zu beseitigen. $\mathrm{Zu}$ den folgenden drei Überholunfällen bei guten Sichtweiten kann aufgrund fehlender Detailinformationen keine gesicherte Aussage getroffen werden. Der letzte Unfall vor einer Kuppe hätte gegebenenfalls durch präventive Maßnahmen verhindert werden können. Bisher sind jedoch keine verkehrsrechtlichen Restriktionen vorhanden, welche auf die folgende Kuppe sowie die damit verbundene Sichtweiteneinschränkung hinweisen.

\subsubsection{Untersuchungsstrecken in Bundesland 4}

Der erste Überholunfall auf der Untersuchungsstrecke BL4-4 ist bei guten Sichtweiten geschehen. Der Überholer geriet aufgrund von Glätte ins Schleudern, was auf eine - der Situation nicht angepassten - Fahrweise schließen lässt. Maßnahmen scheinen hier wenig zweckmäßig. Der zweite schwere Überholunfall dieser Strecke geschah bei schlechten Sichtweiten zwischen zwei Kurven. Auf die schlechten Sichtweiten wird in beiden Richtungen mit Warnlinien versucht hinzu- 
weisen, Verbote existieren nicht. Die schlechten Sichtweiten sind durch klare Verbote zu kennzeichnen, die Warnlinien zu ersetzen, um dem Fahrzeugführer klare Vorgaben zu geben. Der Verursacher versuchte, sich im bevorstehenden Überholabschnitt hinter der Kurve früh zu orientieren und kollidierte mit dem Gegenverkehr. Daher sollten die Überholverbote über eine bestimmte Länge in den Abschnitt mit guten Sichtweiten hineinragen, um derart frühe Ausscherversuche zu unterbinden.

Auf der Untersuchungsstrecke BL4-157 sind nahezu alle Unfälle bei ausreichenden Sichtweiten geschehen. Die Kollisionsgegner waren hierbei überwiegend die Gegenverkehre, was die Fehleinschätzung von Entfernungen und Geschwindigkeiten des Gegenverkehrs verdeutlicht. Tritt hier ein vermehrtes Unfallgeschehen auf, so müssen kurzfristig restriktive Maßnahmen bzw. bei derart langen Abschnitten langfristig Überholfahrstreifen in Betracht gezogen werden. Ausnahmen bilden hier zwei Unfälle beim Linksabbiegen im Knotenpunktbereich, wobei bereits Geschwindigkeitsbeschränkungen und Markierungen vorhanden waren. Die letzten vier Unfälle geschahen in einem sehr kurvenreichen Abschnitt mit guten Sichtweiten, aber allen bereits vorhanden rechtlichen Restriktionen. Hier müssen zur Minderung der Überholvorgänge polizeiliche Überwachungsmaßnahmen unterstützend eingesetzt werden.

Bei der Untersuchungsstrecke BL4-232 zeigt sich eine ähnliche Streckencharakteristik mit guten Sichtweiten. Die ersten beiden Überholunfälle sind auf falsche Einschätzungen von verkehrlichen Randbedingungen zurückzuführen. Viele dieser Unfälle geschehen in den Spitzenstunden bei großer Verkehrsbelastung. Neben der generellen Empfehlung von Überholfahrstreifen auf Abschnitten mit derartiger Charakteristik sowie auffälligem Überholverhalten (1.486 Überholungen in $10 \mathrm{~h}$ ) können gegebenenfalls auch dynamische Überholverbote in Abhängigkeit der Verkehrssituation eine Verbesserung bringen. Die Besonderheit dieser Strecke ist eine Unfallhäufung mit 4 Unfällen im Umfeld einer geringfügig beeinflussenden Kuppe, die nur durch eine Warnlinie hervorgehoben wird. Die Einschränkung führt zu einer nicht ausreichenden Übersicht über den notwendigen Überholweg, was hier zu Kollisionen mit dem Gegenverkehr führte. Dies ist durch Überholverbote zu verdeutlichen. Der letzte Überholunfall im Vorfeld eines Knotenpunktes ist durch frühzeitige Überholverbote zu verdeutlichen und ggf. die Knotenpunktgeschwindigkeit zu überwachen.

Die Untersuchungsstrecke BL4-236 sind erneut alle Unfälle bei ausreichenden Sichtweiten geschehen. Auffällig sind hier Unfälle mit rückwärtig Überholenden sowie Zusammenstöße mit dem Gegenverkehr, die alle auf verkehrliche Randbedingungen zurückzuführen sind. Zwei Unfälle geschahen durch linksabbiegende Fahrzeuge, welche überholt wurden. Auch bei den hier vorhandenen längeren Abschnittslängen sowie in Summe 467 Überholungen in 10 Stunden können Überholfahrstreifen zur Sicherung der Überholvorgänge in Frage kommen.

Das Unfallgeschehen auf der Untersuchungsstrecke BL4-260 ist auf einem Abschnitt mit eher schlechten Sichtweiten gekennzeichnet. Der erst Überholunfall geschah mit dem rückwärtig Überholenden bei einer sich kurzzeitig bietenden Überholmöglichkeit. Hier ist vor allem aufgrund des folgenden Knotenpunktes ein Überholverbot anzuordnen, um zu vermeiden, dass Überholungen in 
den Knotenpunktbereich hineinragen. Der zweite Unfall im ungeeigneten Abschnitt hätte womöglich durch klare verkehrsrechtliche Restriktionen verhinder werden können.

Die Überholunfälle im ersten Abschnitt von Untersuchungsstrecke BL4-264 sind im Bereich eines vorhandenen Bahnüberganges und eine inn umgebende Überholverbotsmarkierung geschehen. Jeweils in beiden Fahrtrichtungen ist das vorhandene Überholverbot wegen der fallenden Sichtweiten nach dem Bahnübergang nicht aufzuheben und sollte durchgehend angeordnet werden. Der eine zufällige Überholunfall mit lediglich Sachschaden im Bereich guter Sichtweiten bedarf hier keiner gesonderten Aufmerksamkeit.

Der erste Überholunfall auf Untersuchungsstrecke BL4-280 ist durch eine Kolonnenüberholung und der folgenden Kollision mit dem Gegenverkehr entstanden. Bei der Überholung von mehreren Fahrzeugen sind der benötigte Überholweg sowie die Entfernungen und Geschwindigkeiten des Gegenverkehrs auch bei guten Sichtweiten nur schwer abschätzbar. Auch der letzte Unfall dieses Abschnittes ist auf eine Kolonnenüberholung zurückzuführen, hierbei kam es zu einer Kollision des Überholenden mit einem weiteren ausscherenden Fahrzeug. Kolonnenüberholungen sind aufgrund der schwer einzuschätzenden Randbedingungen zu unterbinden. Die beiden verbleibenden Unfälle sind in fallenden, ungenügenden Sichtweiten entstanden, auf welche durch klare Überholverbote rechtzeitig hinzuweisen ist.

Die Untersuchungsstrecke BL4-314 lässt sich grundsätzlich in 2 Abschnitte unterteilen. Im ersten Abschnitt sind auf einer sehr kurvigen Strecke kurzzeitig ausreichende Sichtweiten vorhanden, was sich auch in 201 Überholungen in 10 Stunden widerspiegelt. Der zweite Abschnitt besitzt schlechte Sichtweiten und im Bereich der Unfälle auch ein Überholverbot. Trotz der schlechten Sichtweiten wurde in dem freigegebenen Abschnitt 34 überholt. Unabhängig von der Überholsituation sind in beiden Abschnitten klare rechtliche Vorgaben anzuordnen.

Die Untersuchungsstrecke BL4-358 erzeugt nochmals den Eindruck einer Überholstrecke mit überwiegend guten Sichtweiten. Die wenigen schlechten Sichtweiten sind hier durch Überholverbote um die entsprechenden Kuppen herum vergleichsweise gut umgesetzt. Die Unfallauffälligkeit liegt nur in Bereichen mit guten Sichtweiten. Der erste Unfall geschah durch geringe Sicherheitsabstände zum überholten Radfahrer. Die vorhandene Markierung sowie die folgende Ortsdurchfahrt sind aber grundsätzlich durch eine Geschwindigkeitsbeschränkung zu hervorzuheben. Die beiden verbleibenden Unfälle sind Kolonnenüberholungen, die generell als kritisch anzusehen sind. Bei der Gesamtanzahl von 795 Überholungen und der großen Abschnittslänge können sich langfristig Überholfahrstreifen anbieten.

Untersuchungsstrecke BL4-358 ist eine 1 Kilometer lange Verbindung zwischen zwei Ortschaften an der Landesgrenze von Bundesland 4. Hier bieten sich nur zu Beginn der jeweiligen Fahrrichtung kurzzeitig Überholmöglichkeiten. Beide Überholunfälle sind jedoch bei fallenden Sichtweiten zwischen RAS-L und RMS geschehen. Erwähnenswert ist an dieser Stelle, dass trotz der fallenden Sichtweiten beide Unfälle durch Überholungen an mehreren Fahrzeugen entstanden sind. Die fallenden Sichtweiten sind durch klare verkehrsrechtliche Vorgaben rechtzeitig anzukündigen, um derartige Überholungen und Unfälle vermeiden zu können. 


\subsubsection{Untersuchungsstrecken in Bundesland 5}

Bei der Untersuchungsstrecke BL5-39 handelt es sich um eine $400 \mathrm{~m}$ lange Verbindung zwischen zwei Ortsdurchfahrten. Die Sichtweiten sind aufgrund der Seitenraumgestaltung und Kurvigkeit des Abschnittes als unzureichend einzustufen. Der Knotenpunktbereich kann nur bei einem der Überholunfälle als ursächlich angesehen werden, wobei es zum Konflikt mit einem Linksabbieger gekommen ist. Beim anderen Unfall kam es aufgrund der schlechten Sichtweitensituation zur Kollision mit dem Gegenverkehr. Der erforderliche Überholweg ist auf dieser Strecke grundsätzlich nicht einsehbar, weswegen verkehrsrechtliche Regelungen den Fahrer bei der Fahraufgabe unterstützen sollten und das Überholen generell verbieten (insgesamt 49 Überholungen beobachtet).

Untersuchungsstrecke BL5-115 ist durch vergleichsweise gute Sichtweiten gekennzeichnet. Dennoch sind zwei der drei Überholunfälle in unzureichenden Sichtweiten bzw. in Sichtweitengefällen geschehen. Derartige Situationen müssen im Streckenverlauf durch die frühzeitige Ankündigung von schlechten Sichtweitenbereichen verdeutlicht werden. Der Unfall mit tödlichem Ausgang war eine Kollision mit dem Gegenverkehr im Bereich von ausreichenden Sichtweiten. Möglicherweise wird durch die in dem Fall vorhandene schlagartige Sichtweitenverbesserung eine Überholmöglichkeit suggeriert, welche bei nicht ausreichender Orientierung im verkehrlichen Umfeld zu einer unbedachten Überholung führen kann. Aufgrund der schwankenden Sichtweiten und dem vorliegenden Unfallgeschehen sollten Überholverbote in Betracht gezogen werden. Langfristig können auf dem langen Abschnitt auch Überholfahrstreifen in Frage kommen.

Der erste Abschnitt von Untersuchungsstrecke BL5-126 ist in beiden Fahrtrichtungen durch nur kurzzeitige Überholmöglichkeiten und danach fallende Sichtweiten bis hin zum Grenzwert der RMS gekennzeichnet und zeigt eine deutliche Unfallhäufung. Die kurzeitig vorhandenen Sichtweiten (ca. für 200 m) können aber nicht als ausreichende Überholmöglichkeit angesehen werden, da die physischen Fähigkeiten der Fahrzeugführer zur Entfernungsschätzung begrenzt sind. Drei der vier Unfälle wurden durch den Gegenverkehr beeinflusst. Auf dem gesamten Abschnitt ist aufgrund der Streckencharakteristik und des Unfallgeschehens durchgängig ein Überholverbot anzuordnen. Auch der Unfall im zweiten Abschnitt ist bei geringen, fallenden Sichtweiten und einer Kollision mit dem Gegenverkehr entstanden. Die Maßnahmenempfehlungen gelten hier analog zum ersten Streckenabschnitt.

Die Untersuchungsstrecke BL5-225 konnte wegen einer Vollsperrung sowie einer neugeplanten Umgehungsstraße nicht in der Detailanalyse untersucht werden. Dennoch gibt es auf Basis des Unfallgeschehens folgende Anmerkungen. Die Unfallhäufung mit 5 Überholunfällen liegt in einem weiträumigen Tal zwischen zwei Abschnitten mit Überholverbot (doppelter Schmalstrich auf jeweils $1 \mathrm{~km}$ Länge). Diese nach einem Kilometer als erste Überholmöglichkeit wahrnehmbare Situation und die Unterbrechung der Überholverbote kann aufgrund der Sichtweiten nicht nachvollzogen werden. Das Überholverbot sollte durchgezogen werden. Im zweiten Abschnitt wird eine vorhandene Überholverbotsmarkierung für $300 \mathrm{~m}$ bei eher unzureichenden Sichtweiten durch eine Warnlinie unterbrochen und durch ein Verbot nach Zeichen 276 ersetzt. Bei derartigen Sichtweiten ist diese Freigabe eher fraglich, zumal im folgenden Abschnitt ein Überholfahrstreifen vorhanden ist. 
Untersuchungsstrecke BL5-228 verfügt im ersten Abschnitt über vergleichsweise gute Sichtweiten. Dennoch sind die Unfälle bei eher schwankenden Sichtweiten im Zwischenbereich der RAS-L und RMS entstanden und wurden durch die fehlerbehafteten Entfernungseinschätzungen zum Gegenverkehr begünstigt. Dieser unzureichend abschätzbare Zwischenbereich sollte durch Überholverbote gesichert werden. Im zweiten Abschnitt sind grundsätzlich Sichtweiten unterhalb des RMS-Grenzwertes feststellbar. Zur Verdeutlichung der Situation sind lediglich Warnlinien vorhanden. In der Rückrichtung existiert wegen des folgenden Knotenpunktes ein Verbot nach Zeichen 276. Warum in diesem Abschnitt dennoch pro Richtung jeweils 20 Überholungen feststellbar waren, ist nicht erklärbar. Wegen der denkbar schlechten Sichtweiten und des vorliegenden Unfallgeschehens sind deutliche Überholverbote zwingend erforderlich.

Eine deutliche Unfallhäufung befindet sich auf Untersuchungsstrecke BL5-298 im ersten Abschnitt. In beiden Fahrtrichtungen sind fallende Überholsichtweiten erkennbar, die überwiegend zwischen RMS und RAS-L angesiedelt sind. Jedoch besteht nur in einer der beiden Fahrtrichtungen ein durch Z 296 angeordnetes Überholverbot. Dies kann womöglich durch einen sich dort befindlichen Parkplatz erklärt werden. Drei der vier Überholunfälle sind in der bereits markierten Fahrtrichtung geschehen. Grundsätzlich ist wegen der Sichtweiten das Überholen in beiden Richtungen zu untersagen bzw. die Wirksamkeit des vorhandenen Verbotes durch Beschilderungen und Geschwindigkeitsbeschränkungen (Parkplatz) zu verstärken. Im zweiten Abschnitt wurde nur ein Sachschadensunfall bei schlechten Sichtweiten und markierter Warnlinie festgestellt. Die Warnlinie ist frühzeitig durch einen Schmalstrich zu ersetzen.

Untersuchungsstrecke BL5-306 ist im unfallauffälligen Bereich durch ausreichende Sichtweiten gekennzeichnet. Alle 4 Überholunfälle sind aufgrund verkehrlicher Randbedingungen und einer mangelnden Orientierung zum Gegenverkehr (3 Unfälle) sowie zum rückwärtigen Verkehr (1 Unfall) geschehen. Aufgrund der überwiegend schweren Unfallsituation müssen Überholverbote trotz der guten Sichtweiten oder alternativ Geschwindigkeitsbeschränkungen angeordnet werden, um den Überholdruck zu senken.

Im ersten Abschnitt der Untersuchungsstrecke BL5-376 kollidierte ein Lkw durch mangelnden Sicherheitsabstand mit dem überholten Leichtkraftrad. Hierbei handelt es sich aber nur um einen zufälligen Unfall. Grundsätzlich müssen aber die Überholungen von Lkw wegen ihrer Größen und der fahrdynamischen Eigenschaften als kritisch angesehen werden. Im zweiten Abschnitt müssen die vorhandenen Überholverbote bei fallenden Sichtweiten verstärkt werden, da hier die Abschätzung der für die Überholung notwendigen Wege nur unzureichend möglich ist. Die Unterbrechung des Schmalstriches nach Z 295 steht möglicherweise auch im Widerspruch zum vorhandenen Zeichen 276 und wird fälschlicherweise als potentielle Überholmöglichkeit gedeutet.

Auf der Untersuchungsstrecke BL5-394 ist eine Tendenz zu Sichtweiten in der Nähe des RMSGrenzwertes vorhanden, demnach existieren keine ausreichenden Überholmöglichkeiten. Auf dem gesamten Abschnitt ist Tempo $70 \mathrm{~km} / \mathrm{h}$ zugelassen, Überholverbote existieren nicht. Von den insgesamt 115 festgestellten Überholungen waren zwar nur 21 repräsentative Überholungen, dennoch können bei ungünstigen Konstellationen auch diese wenigen Überholungen zu Unfällen füh- 
ren. Da vor allem im Zwischenbereich von RAS-L und RMS Schwierigkeiten zur sicheren Einschätzung der Entfernungen bestehen, müssen hier unabhängig von der Unfallentstehung wegen der schlechten Sichtweiten zwingend Überholverbote nachgetragen werden.

Die Untersuchungsstrecke BL5-428 kann aufgrund mehrerer Knotenpunkte auch in mehrere Teilabschnitte unterteilt werden. Die Sichtweiten und Unfallsituationen sind aber in allen Abschnitten ähnlich. Demnach sind stark schwankende Sichtweiten feststellbar gewesen, die nur kurzeitig tatsächliche Überholmöglichkeiten aufweisen. Grundsätzlich muss auch hier auf fallende Überholsichtweiten rechtzeitig hingewiesen werden bzw. dürfen vorhandene Überholverbote nicht wegen kurzzeitiger Sichtweitenspitzen (Sichtweitensprung nach oben wegen der Möglichkeit des Vorbeischauens an nahen Sichtweitenhindernissen, aber sofortiges Sichtweitengefälle wegen eines folgenden Hindernisses im Streckenverlauf) aufgehoben werden. Im gleichen Sinne sind auch schlechte Sichtweiten wie im letzten Abschnitt grundsätzlich mit einem Überholverbot zu belegen.

Auf der Untersuchungsstrecke BL5-438 sind alle vier Überholunfälle bei ausreichenden Sichtweiten geschehen. Für diese Strecke liegen allerdings keine Unfallhergangsbeschreibungen vor. Dennoch werden hier verkehrliche Ursachen angenommen und eine mangelhafte Orientierung des Überholenden im verkehrlichen Umfeld (inkl. falscher Entfernungs- und Geschwindigkeitsschätzungen des Gegenverkehrs) unterstellt. Wenn in guten Sichtweitenbereichen aufgrund verkehrlicher Gegebenheiten (hier beispielsweise hoher DTV mit $10.000 \mathrm{Kfz} / 24 \mathrm{~h}$ ) ein nur unter erhöhtem Risiko abbaubarer Überholdruck entsteht, dann müssen Überholverbote oder unter entsprechenden Gegebenheiten Angebote für Überholungen durch Überholfahrstreifen vorgesehen werden. Möglicherweise besteht auch die Möglichkeit einer dynamischen Signalisierung von Überholverboten in Abhängigkeit der momentan vorhandenen Verkehrsstärke.

Bei der ersten Unfallhäufung auf Untersuchungsstrecke BL5-460 ist ein Unfall auf den Einfluss der Einmündung eines Wirtschaftsweges zurückzuführen, in den links abgebogen wurde. Beim anderen Unfall handelt es sich um einen Überholversuch von mehreren Fahrzeugen und einer folgenden Kollision zwischen zwei Überholenden. Die grundsätzlich angeordneten $80 \mathrm{~km} / \mathrm{h}$ werden nicht in ausreichendem Maße eingehalten, da die v85 im Mittel beider Fahrtrichtungen bei 100 km/h liegt. Demzufolge könnten Geschwindigkeitsüberwachungen zu einer Minderung der gefahrenen Geschwindigkeiten sowie des Überholdruckes wegen geringer Geschwindigkeitsstreuungen führen. Der Unfall im zweiten Abschnitt ist bei äußerst schlechten Sichtweiten geschehen. Warum hier nicht bereits Überholverbote vorhanden sind, ist nicht nachvollziehbar.

Der erste Abschnitt der Untersuchungsstrecke BL5-550 ist durch einen - sich aus Lageplan und Seitenraumgestaltung ergebenden - plötzlichen Sichtweitensprung nach unten (Verringerung der Sichtweiten) gekennzeichnet, dessen Effekt sich durch das Hindernisfahrzeug noch verstärken kann. Die in dem Bereich vorhandenen Überholverbote müssen auf die vorhergehenden Bereiche erweitert und die Wirksamkeit erhöht werden. Auch im zweiten Abschnitt sind alle drei Überholunfälle in bereits vorhandenen Überholverboten in unzureichenden Sichtweitenbereichen geschehen. Warum trotz gleichbleibend mangelhafter Sichtweiten die vorhandenen Überholverbote für $700 \mathrm{~m}$ unterbrochen werden, ist nicht erklärbar. Dies kann wohl auch bei den Verkehrsteilnehmern zu 
Missverständnissen bzw. einer mangelnden Akzeptanz für offensichtliche willkürliche vorhandene Überholverbote führen. Die Überholverbote sind entsprechend der Streckencharakteristik einheitlich und nachvollziehbar anzuordnen, um den Sinn der Regelungen nicht in Frage zu stellen.

Die Streckencharakteristik der Untersuchungsstrecke BL5-577 ist mit der Strecke BL5-394 vergleichbar. Überwiegend können eher unzureichende Sichtweiten festgestellt werden (im Vergleich zur BL5-394 sind allerdings zwei Sichtweitenspitzen vorhanden) und die rechtlichen Vorgaben sind identisch (Tempo 70, kein Überholverbot). Das aufgrund der geringen Sichtweitenspitzen in der sonst unzureichenden Streckencharakteristik insgesamt 230-mal in 10 Stunden überholt wurde, ist nicht hinnehmbar. Entsprechend der Vergleichsstrecke sind Überholverbote nachzutragen.

Auf den zwei Abschnitten der Untersuchungsstrecke BL5-667 ist die Streckencharakteristik ähnlich und die Sichtweiten zwischen RAS-L und RMS angesiedelt. Dennoch besteht im ersten Abschnitt eine Tendenz hin zum Grenzwert der RMS. Überholholverbote sind in beiden Abschnitten bisher nicht vorhanden, sollten aber aufgrund der Streckencharakteristik und des vorherrschenden Unfallgeschehens nachträglich angeordnet werden. Möglicherweise können auf dem langen zweiten Abschnitt auch Überholungen langfristig auf gesicherte Überholfahrstreifen verlagert werden. Insgesamt wurden auf diesem 2.400 m langen Abschnitt 708 Überholungen beobachtet.

Die Untersuchungsstrecke BL5-673 lässt sich in einen Abschnitt ohne Überholverbote und einen zweiten Abschnitt mit Überholverboten unterteilen. Hierbei ist festzustellen, dass im freigegebenen ersten Abschnitt die Sichtweiten tendenziell noch schlechter als im zweiten Abschnitt sind. Der zweite Abschnitt verfügt über ein sprunghaftes Sichtweitengefälle, welches die vorhandene Sichtweite durch das ungünstige Zusammenspiel von Trassierung und Seitenraumgestaltung innerhalb weniger Meter halbiert. Hier können Fahrzeuge im Sichtschatten der verursachenden Böschung kurzzeitig verschwinden. Beim Auswerten der Unfallhergangsbeschreibungen wurde in diesem Einzelfall eine reaktive Anordnung der Überholverbote in Folge des Unfallgeschehens erkennbar. Warum die Überholverbote im Sinne von konsistenten und nachvollziehbaren rechtlichen Restriktionen nicht auf den gesamten Abschnitt ausgedehnt wurden, ist nicht erklärbar.

Auch die Untersuchungsstrecke BL5-965 kann in einen Abschnitt ohne und einen folgenden Abschnitt mit Überholverbot unterteilt werden. Die Sichtweiten sind in beiden Abschnitten nahezu identisch, dennoch wurde nicht der Gesamtabschnitt mit einem Überholverbot versehen. Die rechtlichen Anordnungen spiegeln sich auch im Überholverhalten der beiden Abschnitte wider. Im freigegebenen ersten Abschnitt wurde in Summe 155-mal überholt, im Abschnitt mit Überholverbot auch 13-mal. Gerade der erste Abschnitt ist allerdings auch durch zwei schwere Überholunfälle die in Kollisionen mit dem Gegenverkehr endeten, gekennzeichnet. Das gerade hier die Verbote bei bestehender Unfallauffälligkeit fehlen ist mehr als unverständlich. Die Überholverbote sind auf den Gesamtabschnitt auszudehnen und bei Missachtung sind zusätzlich wegen der Kurvenfolge Geschwindigkeitsbeschränkungen vorzusehen.

Untersuchungsstrecke BL5-1001 kann erneut in zwei Streckenabschnitte zerlegt werden. Auf dem ersten Abschnitt sind die vorhandenen Sichtweiten äußerst schlecht, Überholverbote bestehen nur teilweise. Bei Lesen der Unfallhergangsbeschreibungen sind Formulierungen von unfall- 
aufnehmenden Beamten aufgefallen, welche die Fähigkeiten der Entfernungsschätzung deutlich in Frage stellen. Demnach war auf dieser Strecke von zwei Unfällen in einem geraden, übersichtlichen Teilstück die Rede. Aufgrund der tatsächlichen Sichtweiten kann dies nicht ausgemacht werden. Dennoch stellt die Entfernung den Menschen schon bei statischer Schätzung vor Probleme, welche sich beim Fahren noch verstärken. Auch hier sind die Überholverbote auf den gesamten Abschnitt auszudehnen. Im zweiten Abschnitt geschah ein leichter Unfall im Zusammenspiel mit einem Linksabbieger in einen Wirtschaftweg. Besonderer Beachtung bedürfen hier aber die beiden letzten schweren Unfälle. Diese sind im Vorfeld eines Knotenpunktes geschehen. Hier können bei vermeintlich guten Sichtweiten (suggeriert durch die freie Tallage) Überholungen vor dem Knotenpunkt durchgeführt werden, bei denen durch Abbieger am Knotenpunkt plötzlich Gegenverkehr auftauchen kann (zweimalige Situation). Der Knotenpunkt ist rechtzeitig durch Überholverbote und Geschwindigkeitsbeschränkungen anzukündigen und späte Überholmanöver zu unterbinden.

\subsubsection{Zusammenfassung wesentlicher Handlungsfelder}

Nach Analyse der einzelnen Strecken und deren Unfallgeschehen können die wesentlichen Handlungsfelder für die Vermeidung von Überholunfällen auf Landstraßen in Anlehnung an Abbildung 3.26 wie folgt zusammengefasst werden. Hierbei gilt es im Wesentlichen, nicht vorhandene rechtliche Restriktionen nachzutragen sowie die Wirksamkeit bereits vorhandener Überholverbote in unfallauffälligen bzw. zum Überholen ungeeigneten Landstraßenabschnitten zu erhöhen.

Bei guten (unterhalb RMS) sowie mittleren Sichtweiten (zwischen RAS-L und RMS) muss der Fahrzeugführer in seiner Fahraufgabe unterstützt werden. Hierbei sind Überholverbote unerlässlich. Bei Gesamtbetrachtung der vorherigen Streckenanalyse kann die Empfehlung von nachzutragenden Überholverboten am häufigsten ausgesprochen werden. Diese Neuanordnung betrifft überwiegend das generelle Verbot von bisher möglichen Überholungen in eigentlich ungeeigneten Bereichen. Ein weiterer Teil der zu ergänzenden Überholverbote betrifft den Lückenschluss zwischen vorhandenen Überholverboten mit kurzzeitigen Unterbrechungen bzw. Freigeben des Überholens. Ein dritter Aspekt der Neuanordnungen betrifft die frühzeitige Ankündigung von folgenden Sichtweiteneinschränkungen bzw. von Überholverboten.

Neben zum Überholen ungeeigneten Abschnitten können Überholunfälle aber auch in Bereichen mit ausreichenden Sichtweiten geschehen. Liegen hier Unfallhäufungen bzw. Unfallhäufungslinien vor, so müssen auch hier Maßnahmen getroffen werden, um die Unfallauffälligkeit einzudämmen.

Ungefähr ein Viertel der Empfehlungen verweisen auf die Wirksamkeitserhöhung von bereits vorhandenen rechtlichen Restriktionen, was annähernd auch der Verteilung der Gesamtunfallanzahl im gesamten Untersuchungsgebiet nach Abbildung 3.8 entspricht.

Durch diese Betrachtungen der Einzelstrecken konnten die Problembereiche und Besonderheiten der einzelnen Unfallpositionen erläutert und die wesentlichen Handlungsfelder beschrieben werden. Welche direkten Maßnahmenempfehlungen für die verschiedenen Handlungsfelder vorgeschlagen werden können, ist dem nachfolgenden Kapitel 5 zu entnehmen. 


\section{Maßnahmenzusammenfassung}

Nach den umfassenden Analysen zum Projekt „Untersuchung von Maßnahmen zur Prävention von Überholunfällen auf einbahnigen Landstraßen“ sollen nun abschließend auch konkrete Maßnahmenvorschläge abgeleitet werden. Entsprechend des Zusammenspiels von Fahrer, Fahrzeug und Fahrumgebung bei der Fahraufgabe, können auch differenziert für diese drei Bereiche Maßnahmen vorgeschlagen werden, welche nachfolgend erläutert werden.

\subsection{Maßnahmenansatz Verkehrsinfrastruktur}

\subsubsection{Generelle Empfehlungen}

Die infrastrukturellen Maßnahmen zur Vermeidung von Überholunfällen unterscheiden sich im Allgemeinen in bauliche und betriebliche Maßnahmen. Zu baulichen Maßnahmen zählt vorrangig die Anlage von Zusatz- bzw. Überholfahrstreifen, auf denen die Überholungen sicher durchgeführt und Überholunfälle vermieden werden können. Da derartige Maßnahmen nur mit größeren Investitionen langfristig umsetzbar sind und diese deutlich über den vorliegenden Untersuchungsgegenstand einer einbahnig zweistreifigen Landstraße hinausgehen, werden diese Maßnahmen hier nur untergeordnet betrachtet. Einbauten auf vorhandenen Strecken, wie beispielsweise Bischofsmützen, Querschwellen oder bauliche Richtungstrennungen werden hier grundsätzlich ausgeschlossen, da dieser Ansatz bereits im Entwurfsstadium der Richtlinien für die Anlage von Landstraßen verworfen wurde.

Betriebliche Maßnahmen gegen Überholunfälle bzw. gegen Überholungen selbst unterscheiden sich grundsätzlich in Bereiche, wo bisher kein Überholverbot vorhanden ist und in Bereiche, wo derzeit zwar Überholverbote angeordnet sind und dies aber offensichtlich nicht ausreichend beachtet wird (siehe auch Abbildung 3.26).

Als Grundsatz von betrieblichen Maßnahmen muss gelten, dass der Verkehrsteilnehmer durch klare verkehrsrechtliche Restriktionen bei seiner Fahraufgabe unterstützt wird und das eine Einheit mit den baulichen Gegebenheiten der Landstraßen vorliegt. Bei bisher nicht vorhandenen Überholverboten müssen die unterschiedlichen Randbedingungen durch verschiedene vorliegende Sichtweitenbereiche beachtet werden. Grundsätzlich muss in Abschnitten mit unzureichenden Sichtweiten (unterhalb der RMS) die strikte präventive Anordnung von Überholverboten vorgenommen werden. Eine erst reaktive Anordnung als Maßnahme gegen bereits geschehene Unfälle ist deutlich unzureichend. Die für diesen eher unzureichenden Sichtweitenbereich vorhandene Philosophie der bisherigen StVO ist aufzugeben, da die Fahrzeugführer wegen fehlerbehafteter Entfernungsschätzungen nicht in der Lage sind, allein zu erkennen, wo kein Überholen möglich ist.

Direkt nach den unzureichenden Sichtweiten muss auch auf die mittleren Sichtweiten eingegangen werden. Diese Bereiche zwischen der halben und der vollen Überholsichtweite können sich negativ auf die Verkehrssicherheit auswirken, da hier die Sichtweiten ebenfalls nicht genügend abgeschätzt werden können. Die Sichtweiten unterhalb der RAS-L Grenzwerte schließen die RMS Grenzwerte mit ein. Für die sichere Durchführung eines Überholmanövers muss der gesamte be- 
nötigte Überholweg vorhanden und einsehbar sein, bei kleineren Sichtweiten darf nicht mehr zum Überholen ausgeschert werden, da durch plötzlichen Gegenverkehr kritische Verkehrssituationen entstehen können. Hierbei ist allerdings zwischen repräsentativen Überholungen und Überholungen an landwirtschaftlichen Fahrzeugen zu unterscheiden.

Deswegen muss grundsätzlich für das Vorhandensein von repräsentativen Überholmöglichkeiten ein einheitlicher und akzeptabler Grenzwert zwischen den Regelwerken des Straßenentwurfs (RAS-L) und des Straßenbetriebs (RMS) definiert werden. Wird dieser Grenzwert unterschritten, so muss dem Fahrzeugführer - der durch fehlerbehaftete Entfernungs- und Geschwindigkeitsschätzung gekennzeichnet ist - die Überholentscheidung grundsätzlich abgenommen werden. Welcher Grenzwert für die neuen Regelwerke des Landstraßenentwurfs (RAL) festzulegen ist, wird in weiteren - bereits laufenden Untersuchungen der Bundesanstalt für Straßenwesen zum Überholmodell auf Landstraßen - zu klären sein. Danach sind die bisher vorgesehenen $600 \mathrm{~m}$ der RAL gegebenenfalls anzupassen.

Die Tatsache, dass selbst in bereits unfallauffällig gewordenen Landstraßenabschnitten zum Großteil keine rechtlichen Restriktionen vorhanden sind, ist nicht hinnehmbar. Dieser Missstand muss bei der Markierung von Straßen nach dem Entwurfsklassenprinzip nach den RAL behoben werden, um den Hintergrund der selbsterklärenden Straße und das entsprechende Überholprinzip zu verdeutlichen. Auch bei der Anwendung des neuen Entwurfsklassenprinzips auf das Bestandsnetz (M_EKLBEST) müssen klare präventive Maßnahmen vorgesehen werden. Hierbei sind vor allem Straßen zu berücksichtigen, die weder nach den RAL noch nach dem M_EKLBEST kurz- oder mittelfristig nach dem Entwurfsklassenprinzip gekennzeichnet werden können. Durch die Anwendung der neuen Richtliniengeneration im Landstraßennetz wurde im Rahmen dieser Untersuchung ein erhöhtes Vermeidungspotential von Überholunfällen abgeschätzt.

Für neu anzuordnende Überholverbote muss beachtet werden, dass hierbei kein Konflikt mit den bisherigen rechtlichen Vorgaben entsteht. Wird beispielsweise auf einem unfallauffälligen Abschnitt auf $400 \mathrm{~m}$ Länge bei mittleren Sichtweiten (zwischen RAS-L und RMS) ein Überholverbot markiert, so müssen Ausnahmeregelungen für potentielle langsame Fahrzeuge (landwirtschaftlicher Verkehr) getroffen werden. Es ist nicht anzunehmen, dass Fahrzeugführer über mehrere hundert Meter hinweg einem Traktor aufgrund einer Markierung folgen, obwohl Sichtweiten vorhanden sind, die lediglich für eine Lkw Überholung unzureichend sind. Allerdings besteht zwischen beiden potentiellen Hindernissen eine erhebliche Geschwindigkeitsdifferenz. Im schlechtesten Fall wird hier weiterer Überholdruck aufgebaut oder weitere Gefahren generiert, wenn 2 Pkw dem Traktor folgen und der vierte Beteiligte den gesamten Pulk überholt. Die Möglichkeit einer Ausnahmeregelung für landwirtschaftliche Fahrzeuge durch Zusatzzeichen, wie für Zeichen 276 denkbar, besteht bei Markierungen nicht. Jedoch besteht die Möglichkeit, Bereiche die selbst zum Überholen eines langsamen Traktors ungeeignete Sichtweiten aufweisen, besonders hervorzuheben. Diese Maßnahmen sind jedoch von der Frequenz der landwirtschaftlichen Fahrzeuge abhängig.

Liegt bei Landstraßen mit eigentlich ausreichenden Überholsichtweiten ein erhöhtes Unfallgeschehen aufgrund von verkehrlichen Randbedingungen vor (hoher Überholdruck wegen hoher Ver- 
kehrsstärken) so müssen auch hier trotzdem Überholverbote angeordnet werden. Bei diesen Abschnitten stehen die Entfernungs- und Geschwindigkeitsschätzungen des Gegenverkehrs im Vordergrund. Da diese Schätzungen der Verkehrsteilnehmer grundlegend fehlerbehaftet sind, müssen bei Unfallhäufungen ebenfalls Maßnahmen erfolgen. Gegebenenfalls findet sich hier Potential für die Entwicklung technischer Elemente, die den Fahrer bei der Fahraufgabe unterstützen. Hierbei sind Fahrerassistenzsysteme oder aber auch dynamische Überholverbote denkbar, bei denen nur unter bestimmten verkehrlichen Randbedingungen Überholverbote angezeigt werden (Spitzenbelastung) und in der Schwachverkehrszeit keine Restriktionen vorliegen (vgl. Brilon, 1976 sowie Künzelmann, 2012).

Insgesamt muss bei der Neuanordnung von Überholverboten allerdings auch darauf geachtet werden, dass durch umfangreiche Überholverbote nicht eine Vielzahl von Überholungen in kurze freigegebene Abschnitte verlagert werden, die dann unter noch größeren Überholdruck weitere bzw. neue Gefahrensituationen hervorrufen können. Demzufolge müssen entsprechend Rohloff [1999] nicht nur Verbote umgesetzt, sondern auch Angebote geschaffen werden (Zusatzfahrstreifen).

Wo derzeit schon Überholverbote angeordnet sind, müssen Maßnahmen definiert werden, die das vorhandene Überholverbot stärker durchsetzen oder die Kraftfahrer anderweitig vom Überholen abhalten. Denkbar sind hier profilierte Markierungen oder Geschwindigkeitsüberwachungsanlagen, um die Geschwindigkeitsstreuung zu minimieren und dem Fahrzeugführer somit den Überholbedarf zu nehmen.

Unabhängig von Neuanordnung oder Wirksamkeitserhöhung ist ein wichtiger Bestandteil der verkehrsrechtlichen Anordnungen die ausreichende und frühzeitige Ankündigung von vorhandenen oder von potentiellen neuen Überholvorboten. Diese Maßnahmen werden im Übergangsbereich von Abschnitten mit guten Sichtweiten und Abschnitten mit unzureichenden Sichtweiten erforderlich. Zweck dieser frühzeitigen Ankündigung von vorliegenden Gefährdungen muss es sein, dass eine im Vorfeld begonnene Überholung noch abgeschlossen werden kann, aber ein neues Ausscheren rechtlich vermieden wird (Warnlinien mit Pfeilmarkierungen im Zusammenspiel mit einseitigen Fahrstreifenbegrenzungen).

Unabhängig von allen drei bisher angesprochenen Sichtweitenbereichen müssen auch klare und wirksame Überholverbote in Knotenpunktbereichen präventiv angeordnet werden, da in der Untersuchung eine Vielzahl von Abbiegekonflikten aufgetreten sind. Bei untergeordneten Wegezielen mit eher unbedeutender Abbiegeranzahl sollen Maßnahmen erst bei Unfallauffälligkeit vorgesehen werden, falls die Einmündungen nicht ohnehin schon in einem Bereich mit präventiv angeordneten Maßnahmen fallen.

Im Verlauf von gegenwärtigen Landstraßen finden sich häufiger Abschnitte, in denen eine bereits vorhandene Markierung trotz schlechter Sichtweiten durch eine kurze Warnlinie (ca. $200 \mathrm{~m}$ lange Warnlinien wurden mehrfach festgestellt) unterbrochen wird. Dies kann Überholmöglichkeiten suggerieren, die in Wirklichkeit gar nicht vorhanden sind. Der erneute Beginn von Markierungen nach Zeichen 295 ist in 200 m Entfernung für den Fahrzeugführer nicht zwangsläufig erkennbar. Die Un- 
terbrechung führt zu Missverständnissen und ist als Unfallrisiko einzuschätzen. Derartige Lücken müssen grundsätzlich geschlossen werden.

Generell müssen die Effekte von Warnlinien als Hinweis für die Fahrzeugführer auf schlechtere Sichtweiten bzw. ungeeignete Überholabschnitte als unzureichend angesehen werden. Es ist klar zu differenzieren, ob Bereiche mit oder ohne ausreichende Sichtweiten vorliegen und danach die Entscheidung über eine Überholstrecke oder ein Überholverbot zu fällen. Zwischenstufen sind hier nicht notwendig und führen auch durch deren mangelhafte rechtliche Wirkung nicht zu wünschenswerten Effekten. Durch Warnlinien können lediglich folgende Überholverbote angekündigt werden. In diesem Fall sind die Warnlinien allerdings durch Pfeilmarkierungen zu ergänzen.

Bei ungünstigen Konstellationen von Lageplan, Höhenplan und Querschnittsgestaltung können sich sprunghafte Sichtweitengefälle ergeben (plötzlicher Sichtweitenabfall um $200 \mathrm{~m}$ bis $300 \mathrm{~m}$ ). Diesen ungünstigen Randbedingungen bzw. Elementfolgen innerhalb der Landstraßentrassierung muss ein erhöhtes Konfliktpotential zugeschrieben werden, da Sichtweiten oder Fahrzeuge entsprechend dem Tauchen in nicht Standardraumelementen plötzlich verschwinden bzw. wieder auftauchen können. Derartige Bereiche sind ausnahmslos mit Überholverboten zu versehen.

Insgesamt variieren die Schwerpunkte von potentiellen Maßnahmen in Abhängigkeit der vorgegebenen Topographie bzw. der daraus resultierenden Sichtweiten. In der vorliegenden Untersuchung konnte aber auch eine Zufälligkeit von Überholunfällen ebenfalls bestätigt werden. Hier waren vergleichbare Landstraßenabschnitte vorhanden, bei denen auf einer Strecke ein Unfallgeschehen vorhanden war, aber im äquivalenten Fall nicht. Bei derartigen Fällen muss auch beachtet werden, dass hier auch konsistente, für den Verkehrsteilnehmer nachvollziehbare Überholverbote anordnet werden. Unterschiedliche Anordnungen unter ähnlichen Randbedingungen führen zu Akzeptanzverlust und Regelverstößen bei vorhandenen Überholverboten.

\subsubsection{Konkretisierung der infrastrukturellen Maßnahmen}

\subsubsection{Wirksamkeitsabschätzung}

Grundsätzlich wird davon ausgegangen, dass in Abhängigkeit der Streckencharakteristik gegebenenfalls schon vorhandene Überholverbote bereits ausreichend befolgt werden. Dagegen ist auch davon auszugehen, dass die präventive Anordnung von bestimmten Überholverboten in guten Sichtweitenbereichen nicht durchsetzbar zu sein scheint und hier gegebenenfalls konventionelle Überholverbote bei bestehender Unfallauffälligkeit nicht mehr ausreichen.

Bei den Analysen der verkehrsrechtlichen Anordnungen (500 Untersuchungsstrecken) sowie der Analysen der vorhandenen Sichtweiten (100 Untersuchungsstrecken) konnte in Bereichen, in denen das Überholen durch Überholverbote geregelt ist, ein deutlicher Sicherheitsgewinn festgestellt werden. Demnach sinkt das Risiko und auch die Schwere eines potentiellen Überholunfalles.

Nach Abbildung 3.11 kann vermutet werden, dass die Wirksamkeit von Markierungen größer ist als die von reinen Beschilderungen. Grund hierfür ist möglicherweise die stete Sichtbarkeit der Markierung und somit die Erinnerung an das gegebene Verbot. Beschilderungen können dagegen in Ein- 
zelfällen sogar übersehen werden. Die Frage, warum Beschilderungen und gleichzeitige Markierungen in Abbildung 3.11 eher schlecht abschneiden, kann mit den Knotenpunkten - in denen diese Anordnungen häufig vertreten sind - und deren kurzer Längenausdehnung erklärt werden.

In den Detailanalysen wurde festgestellt, dass Überholverbote sich deutlich auf das Überholverhalten auswirken. In vorhandenen Überholverboten wird weniger überholt als in freigegebenen Streckenabschnitten, allerdings ist innerhalb von Überholverboten das Einzelrisiko von wenigen Überholungen vergleichsweise hoch.

Grundlegend kann auch den Geschwindigkeitsbeschränkungen im Vergleich zu den Überholverboten eine deutliche Wirkung auf das Überholunfallgeschehen (vgl. ebenfalls Abbildung 3.11) und auch auf das Überholverhalten zugeschrieben werden. Insgesamt sind hier die Sicherheitsgewinne am größten, wenn sowohl Überholverbote als auch Geschwindigkeitsbeschränkungen vorhanden bzw. angeordnet sind. Darüber hinaus können Geschwindigkeitsbeschränkungen mit konventionellen Mitteln polizeilich überwacht werden. Das Projekt AOSI hat hier bereits die Potentiale von Geschwindigkeitsüberwachungsanlagen aufzeigen können. Die Durchsetzung und anschließende Überwachung von Überholverboten erscheint dagegen vergleichsweise schwierig und mit geläufigen Mitteln nicht möglich.

\subsubsection{Modularer Aufbau von Überholverboten}

Bei der Umsetzung von Überholverboten kann ein modularer Aufbau der rechtlichen Restriktionen angewendet werden. Grundsätzlich muss bei den Maßnahmenempfehlungen auch auf die Anwendung des Entwurfsklassenprinzips nach RAL hingearbeitet werden. Demnach gelten die folgenden Empfehlungen differenziert nach den Entwurfsklassen.

Bei einbahnig zweistreifigen Querschnitten nach RAL muss - auch zur Berücksichtigung der Belange von landwirtschaftlichen Verkehren - zwischen Sichtweiten unterhalb und oberhalb des heutigen RMS Grenzwertes unterschieden werden. Insgesamt wird der folgende modulare Aufbau von Überholverboten vorgeschlagen, der im Rahmen der einzelnen Entwurfsklassen untereinander erweiterbar ist.

\section{EKL1:}

Für diese Entwurfsklasse werden keine Maßnahmenvorschläge abgeleitet, da das Überholen grundsätzlich auf den vorgesehenen RQ 15,5 sicher möglich ist.

\section{EKL 2:}

Bei Strecken der Entwurfsklasse zwei besteht für den Fall, dass eine hinreichende Anzahl von Überholfahrstreifen nicht zu verwirklichen ist, die Möglichkeit, in ausreichenden Sichtweitenbereichen das Überholen im Fahrstreifen des Gegenverkehrs zuzulassen. Da landwirtschaftliche Verkehre auf diesen Strecken nach Möglichkeit auf gesonderten Wegen fahren sollen, werden diese hier nicht berücksichtigt. 


\section{Sichtweiten unterhalb $600 \mathrm{~m}$ :}

Strikte Überholverbote, da keine sicheren Überholungen mehr durchgeführt werden können.

1. Doppelte Fahrstreifenbegrenzung nach Zeichen 295

2. Doppelte Fahrstreifenbegrenzung nach Zeichen 295 mit profiliertem Zwischenraum

\section{Sichtweiten oberhalb 600 m:}

Für den Fall von Unfallhäufungen muss gegebenenfalls die gewährte Ausnahmeregelung der Freigabe des Überholens im Fahrstreifen des Gegenverkehrs streckenweise entzogen oder weitere Überholfahrstreifen zur Erhöhung der Verkehrssicherheit und -qualität vorgesehen werden.

\section{EKL 3:}

Auf Straßen der Entwurfsklasse 3 werden künftig einbahnig zweistreifige Querschnitte die Regellösung sein. Hierfür gelten die folgenden Empfehlungen.

\section{Sichtweiten unterhalb $300 \mathrm{~m}$ :}

Strikte Überholverbote, da auch langsame landwirtschaftliche Fahrzeuge nicht mehr sicher überholt werden können:

1. Einfache Fahrstreifenbegrenzung nach Zeichen 295

2. Anordnungen um Z 276 erweiterbar

3. Geschwindigkeitsbeschränkungen unterhalb der vorgesehenen $100 \mathrm{~km} / \mathrm{h}$ bei Unfallauffälligkeit

4. Geschwindigkeitsüberwachung bei Missachtungen (vorzugsweise stationär durch OGÜ, alternativ temporär durch Polizei)

\section{Sichtweiten oberhalb $300 \mathrm{~m}$ :}

Grundsätzliche präventive Überholverbote bei Sichtweiten bis $600 \mathrm{~m}$ mit Berücksichtigung landwirtschaftlicher Verkehre:

1. Überholverbot nach Zeichen 276 mit Zusatzzeichen 1026-36

Bei Missachtung der vorgesehenen Überholverbote nach Z 276 oder grundsätzlichem Ausschluss von landwirtschaftlichen Verkehren:

1. Überholverbot nach Zeichen 276 ohne Zusatzzeichen 1026-36, ergänzt durch einfache Fahrstreifenbegrenzung nach Zeichen 295

2. Geschwindigkeitsbeschränkungen unterhalb der vorgesehenen $100 \mathrm{~km} / \mathrm{h}$ bei Unfallauffälligkeit

3. Geschwindigkeitsüberwachung bei Missachtungen (vorzugsweise stationär durch OGÜ, alternativ temporär durch Polizei)

4. Alternativ Überholfahrstreifen bei erhöhter Verkehrsbedeutung

Bei der Anwendung des M_EKLBEST auf das Bestandsnetz muss allerdings auch beachtet werden, dass nicht ausnahmslos alle Bestandsstrecken nach dem Entwurfsklassenprinzip gekennzeichnet werden können. Da diese Strecken auch nicht die Mindestkriterien zur Kennzeichnung ei- 
ner Entwurfsklasse erfüllen können - beispielsweise eine Fahrbahnbreite von 6,0 m oder mehr muss ein generelles Überholverbot in Betracht gezogen werden.

\section{EKL 4:}

Auf Straßen der künftigen Entwurfsklasse 4 wird aufgrund der untergeordneten Verkehrsbedeutung der Straße kein Überholbedarf gesehen. Ist das dem Fahrzeugführer in Einzelfällen nicht vermittelbar, so gelten folgende Maßnahmen.

1. Überholverbot nach Zeichen 276

2. Anordnung einer Geschwindigkeitsbeschränkung von $70 \mathrm{~km} / \mathrm{h}$

3. Geschwindigkeitsüberwachung bei Missachtungen der angeordneten $70 \mathrm{~km} / \mathrm{h}$ (vorzugsweise stationär durch OGÜ, alternativ temporär durch Polizei)

Mittelmarkierungen müssen bei dieser Entwurfsklasse grundsätzlich ausgeschlossen werden, um den Hintergrund der EKL 4 Markierung (abmarkierte Kernfahrbahn durch Leitlinien am Rand ohne Mittelmarkierung) zu wahren.

\section{Grundlegende Vorgaben für Straßen der Entwurfsklassen 2 bis 4:}

- Überholverbote sind in schlechten Sichtweitenbereichen (unterhalb $600 \mathrm{~m}$ ) zwingend notwendig. Der Grenzwert ist in Abhängigkeit noch ausstehender Forschungsergebnisse zum Überholmodell noch anzupassen.

- Aus der oben gennannten Forderung ergibt sich der Bedarf an Überholverboten in Kurvenund Kuppenbereichen und deren direktem Umfeld, da in dieser Untersuchung ein Sichtweiteneinfluss bei bestimmten Entwurfsparametern und Seitenraumgestaltungen nachgewiesen werden konnte.

- Neben den entwurfstechnischen Überholverboten aufgrund der Trassierungselemente ergibt sich ein Erfordernis von Überholverboten in Knotenpunktbereichen, da auch hier Überholunfälle auffällig geworden sind.

Bei bisher fehlenden Überholverboten kann in Anhängigkeit der potentiellen Entwurfsklasse sowie der Streckencharakteristik und der erwarteten Akzeptanz eine Maßnahme des Modulkataloges direkt ausgewählt werden. Bei bereits vorhandenen Überholverboten aber deren stetiger Missachtung kann an der Stelle der gegenwärtig vorhandenen Überholverbote eingestiegen und die nächst höhere Restriktion angeordnet werden.

Abschließende Empfehlungen über die Wirksamkeit verschiedener rechtlicher Restriktionen in Bezug zum Überholvorgang können bisher nicht gegeben werden. Gesicherte Erkenntnisse zur Wirkung von Überholverboten können dagegen von einer Vorher-Nachher-Untersuchungen erwartet werden. Hierbei könnte der eben beschriebene modulare Aufbau angewendet werden.

\subsection{Maßnahmenansatz Verkehrsteilnehmer}

In Bezug zum Verkehrsteilnehmer hat die vorliegende Untersuchung gezeigt, dass besonders die Entfernungs- und Geschwindigkeitsschätzungen der Verkehrsteilnehmer fehlerbehaftet sind. Die physischen Fähigkeiten der Fahrzeugführer sind hier nicht ausreichend und können vor allem bei 
jungen Fahranfängern mit wenig Fahrerfahrung zu Fehlern und überwiegend schweren Überholunfällen führen. Neben den bereits beschriebenen infrastrukturellen Hilfsmitteln können hier die folgenden Ansätze direkt am Fahrzeugführer eine Verbesserung der Verkehrssicherheit auf Landstraßen mit sich bringen.

Grundsätzlich muss bereits in der Verkehrserziehung auf den komplexen Überholvorgang und dessen Gefahren hingewiesen werden. Die Fahrschule kann alle jungen bzw. neuen Verkehrsteilnehmer erreichen, da sie Grundlage für den Erwerb des Führerscheins ist. Die fahrdynamischen Grundlagen, verkehrlichen Zusammenhänge sowie erforderlichen Handlungen bis zur positiven Überholentscheidung müssen hier verdeutlicht werden. Aber auch neben den Fahranfängern müssen die bereits erfahreneren Verkehrsteilnehmer über die Risiken des Überholvorganges aufgeklärt werden. Öffentlichkeitsarbeit und Sicherheitskampagnen zur Verbreitung der grundsätzlich vorhandenen Risiken eines Überholvorganges und dessen potentielle Folgen sind hierbei ein geeignetes Mittel.

Wesentlicher Bestandteil einer sicheren Überholung ist die ausreichende Orientierung im umgebenden verkehrlichen Umfeld. Hierzu zählt vorrangig die ausreichende Orientierung nach vorn zum Gegenverkehr aber auch die Orientierung nach hinten zum rückwärtigen Verkehr (inklusive der Überprüfung des „Toten Winkels“), um auch Kollisionen mit bereits Überholenden vermeiden zu können. Bei den Überholunfällen mit rückwärtigen Überholern spielt aber auch die Thematik der Kolonnenüberholung eine entscheidende Rolle. Bei der Aufklärungsarbeit sind die grundsätzlichen Gefahren von Kolonnenüberholungen und die noch wesentlich schwierigeren Einschätzungen derartiger Verkehrssituationen hervorzuheben. Insbesondere durch sprunghafte Sichtweitenerhöhungen, die mehrere Fahrzeugführer gleichzeitig zum Abbau von Überholdruck nach längeren unzureichenden Sichtweiten nutzen wollen oder aber auch durch Abbieger an Knotenpunkten, deren Abbiegeabsicht aus höherer Kolonnenposition nicht erkennbar ist, können Kolonnenüberholungen begünstigt werden. Prinzipiell wäre auch ein Verbot von Kolonnenüberholungen angebracht.

Ein Abschnitt auf dem nicht überholt wurde, wurde in dieser Untersuchung nicht festgestellt, egal ob mit oder ohne vorhandene Überholverbote. Auf die besonderen Gefahren und Risiken von Überholungen in bereits vorhandenen Überholverboten muss zwingend hingewiesen werden. Wenn gegen das verbotswidrige Überholen beispielsweise härtere Strafen in Betracht gezogen werden, dann müssen auch Überlegungen zur Kontrolle und Überwachung des Verkehrsverhaltens angestellt werden. Hierzu sind allerdings bislang keine konventionellen Methoden verfügbar.

Insgesamt kann ein bewusstes und rücksichtsvolles bzw. umsichtiges Fahren in vielen Fällen bereits Unfälle vermeiden. Dies muss auch bei dem besonders komplexen Überholvorgang verdeutlicht werden.

\subsection{Maßnahmenansatz Fahrzeug}

Wie bereits in vielen anderen Bereichen der Fahrzeugtechnik ist auch die fahrzeugseitige Unterstützung der Fahrzeugführer beim Überholvorgang durch Fahrerassistenzsysteme prinzipiell denk- 
bar. Hierbei kann beispielsweise die Verkehrszeichenerkennung oder aber die bereits vorhandenen Spurführungsassistenten genutzt werden, um auch vorhandene Überholverbote hinzuweisen.

Die durch Kayser/Otten/Hahn 1988 im Simulator getestete Unterstützung der Fahrzeugführer beim Fällen einer Überholentscheidung durch das Aufzeigen potentieller Möglichkeiten oder das Hinweisen auf kritische Gegenverkehrsabstände wird in Hinblick auf die folgende Richtliniengeneration nicht als zielführend angesehen. Zudem ist die technische Umsetzung eines solchen Systems bisher nicht erprobt worden.

Bei der Nutzung von Navigationsgeräten besteht grundsätzlich noch die Möglichkeit der Hervorhebung bzw. der Ankündigung von folgenden gesicherten Überholabschnitten durch Überholfahrstreifen im vorgesehenen Routenverlauf. Hierbei können die Fahrzeugführer in ihrem Überholdruck gebremst und die Überholungen in sichere Landstraßenabschnitte verlagert werden, was im Ergebnis auch Überholunfälle vermeiden kann.

Bei derartigen technischen Lösungen müssen aber auch die damit verbundenen Nachteile berücksichtigt werden. Hierzu zählt beispielsweise die Erreichbarkeit der breiten Masse von Fahrzeugen bzw. Fahrzeugführern, welche bei Fahrerassistenzsystemen meist nur eingeschränkt möglich ist. 


\section{Zusammenfassung}

Überholunfälle gehören insgesamt zu den folgeschwersten Unfällen auf deutschen Straßen. Das Ziel des vorliegenden Projektes war es daher, die infrastrukturellen und verkehrlichen Einflussgrößen auf das Überholverhalten und -unfallgeschehen zu bestimmen, um geeignete Maßnahmen zur Vermeidung dieser schweren Unfälle ableiten zu können.

Bereits in der anfänglichen Grundlagenstudie konnten eine Vielzahl von Einflussgrößen und Zusammenhänge auf das Überholverhalten ermittelt werden. Hierzu wurden in einer Literaturanalyse das Unfallgeschehen, das Fahrverhalten sowie existierende Maßnahmenempfehlungen vergangener Untersuchungen beleuchtet, der Stand der Technik im Planungsregelwerk dargestellt und in einer Datenbankabfrage beim Statistischen Bundesamt die ersten Zusammenhänge aufgezeigt.

In einer umfangreichen Netzanalyse in den Bundesländern Baden-Württemberg, Brandenburg, Nordrhein-Westfalen, Rheinland-Pfalz und Sachsen-Anhalt wurden die in Bezug zum Überholvorgang unfallauffälligsten Landstraßenabschnitte ermittelt. Hierzu wurden Unfalldatenbanken der Jahre 2007 bis 2009 mit den Straßeninformationsbanken der 5 Bundesländer verschnitten und für die folgenden Arbeitsschritte aufbereitet. Im Ergebnis wurde über das Kriterium der Unfallkostendichte eine Rangfolge der 500 am auffälligsten mit Überholunfällen belasteten Landstraßen erstellt und als Grundlage der weiteren Untersuchungsschritte herangezogen.

Auf den ausgewählten 500 Untersuchungsstrecken wurden in der weiteren Netzanalyse die angeordneten verkehrsrechtlichen Anordnungen (Überholverbote und Geschwindigkeitsbeschränkungen unterschiedlicher Ausprägungen) durch Streckenbefahrungen auf insgesamt 2.235 Kilometer Bestandsnetz erhoben und ausgewertet. Nach den Befahrungen wurden den einzelnen erhobenen Streckenmerkmalen insgesamt 1.557 Überholunfälle direkt zugeordnet. Durch die Verknüpfung der verkehrsrechtlichen Anordnungen mit dem Unfallgeschehen sowie der ermittelten Fahrbahnbreiten konnten Unfallkenngrößen zur Beschreibung der Unfallauffälligkeit berechnet werden. Hierbei wurden wegen des verzerrenden Einflusses kurzer Merkmalslängen auch unfallfreie Abschnitte einbezogen, wodurch auch eine Bewertung des Gesamtnetzes ermöglicht wurde. Die Güte der berechneten Ergebnisse wurde in umfangreichen Signifikanztests geprüft.

In der weiteren Netzanalyse wurde in verkleinertem Rahmen mittels einer Nachtrassierung der 100 unfallauffälligsten Untersuchungsstrecken der Rangfolge überprüft, ob die erhobenen verkehrsrechtlichen Anordnungen den tatsächlich vorhandenen Sichtweiten den auf den Landstraßenabschnitten entsprechen. Hierzu wurden für die 100 Untersuchungsstrecken während der Befahrungen geografische Punktfolgen mittels GPS erhoben und mit einer Entwurfssoftware nachtrassiert. Ergebnis der Nachtrassierung waren Strecken- und Sichtweitenbändern, die mit dem Unfallgeschehen und verkehrsrechtlichen Randbedingungen überlagert wurden, um weitere Hinweise auf unfallbegünstigende Streckenmerkmale und bereits ergriffene Maßnahmen bekommen zu können. Dabei sollte geprüft werden, inwieweit die Einheit von Bau (vorhandene Sichtweiten) und Betrieb (rechtliche Restriktionen) im Bestandsnetz sichergestellt ist. 
Nach Abschluss der Streckenbandanalyse, in der die Beziehungen zwischen Unfallgeschehen, Streckencharakteristik und straßenseitigen verkehrsrechtlichen Restriktionen umfangreich dargestellt wurden, konnte auf Grundlage der Trassierungsinformationen eine Clusterung innerhalb der 100 nachtrassierten Strecken vorgenommen werden. Dadurch konnten auf Basis von vorhandenen und verkehrsrechtlichen Überholmöglichkeiten, den Verkehrsstärken und dem Unfallgeschehen die 50, in der folgenden Detailanalyse näher zu untersuchenden Strecken ausgewählt werden. Zur Erhöhung des Untersuchungspotentials wurde auch vorrangig nach Unfallhäufungen gesucht.

In den Detailanalysen wurde auf den ausgewählten 50 Untersuchungsstrecken eine mikroskopische Unfallanalayse durchgeführt, um genauere Kenntnisse zum Unfallhergang der Überholunfälle zu erhalten. Hierzu wurden in Kooperation mit den Polizeibehörden die Unfallhergangsbeschreibungen von 166 Überholunfällen angefragt und analysiert. Aufgrund der Datenlage konnte Bundesland 3 nicht in den mikroskopischen Unfallanalysen untersucht werden. In den mikroskopischen Unfallanalysen wurden weitere Zusammenhänge von Streckenmerkmalen und den speziellen Unfallgegebenheiten sowie den Fahrzeugklassen und Fahrzeugführern hergestellt und ausgewertet.

Während der Detailanalysen wurden zudem Verkehrsverhaltensanalysen durch 10 stündige Erhebungen auf den 50 Untersuchungsstrecken durchgeführt, um Hinweise darüber zu bekommen, in welchen Streckenabschnitten Überholungen überhaupt stattfinden. Hierbei wurde zwischen Abschnitten mit bzw. ohne Überholmöglichkeiten differenziert und die Zusammenhänge der Überholanzahl zu den Streckencharakteristiken und verkehrsrechtlichen Vorgaben hergestellt.

Bei den Erhebungen wurden auf den 50 Untersuchungsstrecken insgesamt 78 Streckenabschnitte sowie 150 Fahrtrichtungen analysiert. Durch den Vergleich der Fahrzeugreihenfolge an den unterschiedlichen Messquerschnitten wurde eine Matrix mit aktiven und passiven Überholern nach Fahrzeugklassen erstellt. Dabei konnten insgesamt 15.173 Überholungen ermittelt und mit den Streckenmerkmalen verknüpft werden. Im Ergebnis wurden Unfallrisiken und Überholraten für verschiedene Merkmale der Untersuchungsstrecken ausgewiesen.

Nach Abschluss sämtlicher Untersuchungen wurden auf Basis der Ergebnisse Maßnahmenvorschläge für die Prävention von Überholunfällen gegeben. Hierbei standen vor allem infrastrukturelle Maßnahmen in Vordergrund, aus denen in Anlehnung an die kommende Richtliniengeneration und die Anwendung des Entwurfsklassenprinzips ein modularer Aufbau von Maßnahmen abgeleitet wurde. Darüberhinaus wurden auch Ansätze am Fahrzeug und Fahrzeugführer angesprochen.

Im Rahmen dieses Projektes lag der Fokus der Analysen auf den Ursachen und Randbedingungen von Überholunfällen auf Landstraßen und nicht wie in vielen älteren Untersuchungen auf dem Überholvorgang selbst. Dabei ist es gelungen, die vielfältigen Zusammenhänge der betrieblichen und baulichen Merkmale der Untersuchungsstrecken zum Überholunfallgeschehen und Überholverhalten herzustellen und Maßnahmen gegen diese schweren Unfälle abzuleiten.

Die wesentlichen Erkenntnisse der Untersuchung werden in nachstehendem Kapitel 7 kurz zusammengefasst. 


\section{Fazit der Untersuchung}

Aus den Ergebnissen des Projektes „Untersuchung von Maßnahmen zur Prävention von Überholunfällen auf einbahnigen Landstraßen“ können die folgenden Schlussfolgerungen prägnant zusammengefasst werden. Die Darstellungen orientieren sich dabei chronologisch am Arbeitsablauf und den wesentlichen Hauptbestandteilen des Projektes.

\section{Literaturanalyse}

- Das Überholen ist ein sehr komplexer Verkehrsvorgang mit einer Vielzahl von Einflussfaktoren [Netzer, 1966].

- Der Mensch ist physisch und psychisch gar nicht in der Lage, alle Einflussfaktoren rational zu erfassen und eine Entscheidung zu fällen, weshalb es auch zahlreiche Möglichkeiten gibt, wie es beim Überholen zu Fehlern und Unfällen kommen kann [Netzer, 1966].

- Die Überlagerung verschiedener ungünstiger Eigenschaften von Fahrer, Fahrzeug, Fahrbahn und deren Umgebung kann Fehler hervorrufen.

- Bauliche und betriebliche Maßnahmen können die Wahrnehmung von situativen Schwierigkeiten verbessern und die Aufmerksamkeit der Fahrzeugführer auf Problembereiche lenken [Kämpfe/Schlag/Weller, 2005].

- Bei sicherheitsgefährdenden Handlungen muss nach unbeabsichtigten (z.B. Aufmerksamkeits- und Informationsfehler) und beabsichtigen Handlungen (bewusste Verstöße gegen vorhandene Restriktionen) unterschieden werden [Reason, 1994].

- Das Überholbedürfnis nimmt mit wachsender Geschwindigkeitsstreuung und steigender Verkehrsbelastung zu, angestauter Überholdruck kann risikobehaftete Überholungen hervorrufen [Steierwald/Jacobs/Feier, 1985].

- Häufungen von Überholungen korrelieren mit den vorhandenen Überholsichtweiten und werden von aktueller Verkehrssituation mitbestimmt [Kayser/Otten/Hahn, 1986].

- Infrastrukturelle Maßnahmen gegen Überholungen unterscheiden sich in positiv (Zusatzfahrstreifen mit Hinweisschildern) und negativ wirkende Maßnahmen (Überholverbote durch Markierung, Beschilderung und Geschwindigkeitsbeschränkung) [Kayser/Struif, 1993].

- Weitere Ansatzpunkte zur Erhöhung der Verkehrssicherheit ist die Verkehrserziehung [Runkel, 1970] und Fahrerassistenzsysteme (z.B. Spurwechselassistenten) [Gründl, 2006].

- Die Definition von 4 Entwurfsklassen wird in den künftig gültigen RAL auch mit grundsätzlichen Überholprinzipien verbunden sein, deren Ziel es ist, Überholungen auf Überholfahrstreifen sicherzustellen und bei kritischen Sichtweiten zu vermeiden [FGSV, 2012b].

- Bei der Übertragung des Entwurfsklassenprinzips muss ein längerer Übergangsprozess berücksichtigt werden, daher müssen kurz- und mittelfristig Maßnahmen im Bestandsnetz erfolgen, um folgenschwere Überholunfälle zu vermeiden [Richter/Zierke 2010]. 


\section{Statistische Hintergründe - Unfallgeschen Destatis 2009}

- 20 \% aller Unfälle in Deutschland im Jahr 2009 geschahen außerhalb geschlossener Ortschaften und abseits von Bundesautobahnen [Statistisches Bundesamt, 2010a].

- Auf Landstraßen zeigt sich durch den hohen Anteil von getöteten (59 \%) und schwerverletzten (40 \%) Menschen eine besondere Unfallschwere [Statistisches Bundesamt, 2010a].

- $6 \%$ der Unfälle mit Personenschaden auf Landstraßen sind ursächlich auf Überholvorgänge zurückzuführen [Statistisches Bundesamt, 2010a].

- $\quad$ Die hohen Anteile der Unfallursache „Überholen“ bei Getöteten (8,8 \%) und Schwerverletzten $(7,7 \%)$ verdeutlichen eine besondere Unfallschwere [Statistisches Bundesamt, 2010a].

- $66 \%$ der Überholunfälle mit Personenschaden sind Unfälle im Längsverkehr, $21 \%$ Abbiegeunfälle und 10 \% Fahrunfälle [Statistisches Bundesamt, 2011].

- $24 \%$ der Überholunfälle mit Personenschaden sind Zusammenstöße mit entgegenkommenden Fahrzeugen, weitere $24 \%$ Unfälle mit Fahrzeugen in gleicher Richtung, $14 \%$ mit vorrausfahrenden Fahrzeugen und $11 \%$ mit einbiegenden/kreuzenden Fahrzeugen. Auf die Begegnungsunfälle entfällt die höchste Unfallschwere [Statistisches Bundesamt, 2011].

- Die maßgebenden Ursachen bei Überholunfällen mit Personenschaden sind Überholen trotz Gegenverkehr (28\%) und Überholen trotz unklarer Verkehrslage (26\%) [Statistisches Bundesamt, 2011].

- Die Fahrzeugklassen bei Überholunfällen entsprechen den erwartungsgemäßen Überholern auf Landstraßen. $76 \%$ der Unfallbeteiligten mit einer Teilschuld führten Personenkraftwagen, 16 \% Motorräder sowie 8 \% Lastkraftwagen (Statistisches Bundesamt, 2010a).

- Risikogruppen bei Überholunfällen mit Personenschaden sind mit ca. 80 \% Männer sowie junge Fahrzeugführer (18 - 30 Jahre alt) [Statistisches Bundesamt, 2011].

- Bei Berücksichtigung der Kohortengröße ergibt sich ein fallendes Unfallrisiko mit Bezug zum Überholen mit zunehmendem Alter [Statistisches Bundesamt, 2010b].

- Zeitliche Auffälligkeiten von Überholunfällen mit Personenschaden zeigen sich steigend von Montag bis hin zum Freitag und vorrangig in den Sommermonaten (April - September mit $64 \%$ der Überholunfälle mit Personenschaden) [Statistisches Bundesamt, 2011].

- $81 \%$ der Überholunfälle mit Personenschaden geschehen bei Tageslicht, $77 \%$ bei trockener Fahrbahn, insgesamt also bei guten äußeren Bedingungen [Statistisches Bundesamt, 2011]. 


\section{Streckenaufbereitung - Makroskopische Unfallanalyse}

- In Baden-Württemberg, Brandenburg, Nordrhein-Westfalen, Rheinland-Pfalz und SachsenAnhalt wurden aus $81.599 \mathrm{~km}$ Straßennetz insgesamt $58.269 \mathrm{~km}$ einbahnig, zweistreifige Außerortsstraßen gefiltert.

- Dem Untersuchungsgebiet wurden für den Zeitraum von 2007 bis 2009 insgesamt 85.345 Unfälle der Kategorien 1 bis 4 zugewiesen, davon 6.209 Überholunfälle (Ursachen 16 - 23).

- $68 \%$ aller Überholunfälle (Unfallkategorie 1 bis 4) sind Unfälle im Längsverkehr, $20 \%$ Abbiegeunfälle, 9 \% Fahrunfälle. Alle anderen Unfalltypen haben untergeordnete Bedeutung.

- $25 \%$ aller Überholunfälle (Unfallkategorie 1 bis 4) sind Unfälle mit Entgegenkommenden, $23 \%$ kollidieren mit in gleicher Richtung fahrenden Fahrzeugen, $18 \%$ kommen von der Fahrbahn ab, $13 \%$ stoßen mit vorrausfahrenden Fahrzeugen und weitere $11 \%$ mit einbiegenden, kreuzenden Fahrzeugen zusammen. Alle anderen Unfallarten sind unauffällig.

- Überholunfälle haben schwere Unfallfolgen. Die Anpassung der Unfallkostensätze ergab bei Überholunfällen im Mittel ca. $44.000 €$ höhere Unfallkosten pro Unfall als bei allen Landstraßenunfällen mit Personenschaden.

- Zwischen Gesamtunfallkollektiv und Überholunfällen auf Landstraßen bestehen nur äußerst geringe Abhängigkeiten. Schlussfolgerungen auf Zusammenhänge sind nicht zulässig.

\section{Erhebung der verkehrlichen Randbedingungen}

- Die 500 unfallauffälligsten Untersuchungsstrecken im Untersuchungsgebiet verteilen sich auf 2.235 Kilometer Streckenlänge.

- Über alle 5 Bundesländer ergeben sich vergleichbare, klare Tendenzen in Bezug zu den angeordneten Überholverboten.

- Im Mittel verfügen $69 \%$ der befahrenen Strecken nicht über ein Überholverbot bzw. nicht über rechtliche Restriktionen in Bezug zum Überholvorgang.

- Einseitige Überholverbote (Z 296) treten nur zu 1 \% und somit vergleichsweise selten auf.

- Ist bei den verbleibenden $30 \%$ des Netzes ein beidseitiges Überholverbot vorhanden, so handelt es sich zu $56 \%$ um eine reine Markierung ( $Z$ 295), zu $22 \%$ um eine reine Beschilderung ( $Z$ 276) und zu weiteren $22 \%$ um eine Kombination aus beidem.

- $67 \%$ der befahrenen Strecken verfügen über eine Höchstgeschwindigkeit von $100 \mathrm{~km} / \mathrm{h}$. Auf den verbleibenden $33 \%$ gilt eine niedrigere Geschwindigkeitsbeschränkung.

- Auf den 500 unfallauffälligsten Untersuchungsstrecken im Untersuchungsgebiet ereigneten sich insgesamt 1.557 Überholunfälle.

- Die Anteile von Überholunfällen nach rechtlichen Anordnungen sind mit dem Vorhandensein der Merkmale (Überholverbote, Geschwindigkeitsbeschränkung) im Netz vergleichbar. 
- $74 \%$ der Überholunfälle geschehen in Abschnitten ohne Überholverbote, $72 \%$ in Bereichen ohne Geschwindigkeitsbeschränkung.

- Bei Betrachtung der reinen Unfallzahlen besteht nur eine Tendenz zu Überholunfällen in freigegeben Abschnitten (keine Überholverbote oder Geschwindigkeitsbeschränkungen).

- Im zugrundegelegten Straßennetz ergibt sich mit $5 \%$ statistischer Sicherheit eine signifikante Verringerung der Unfallkenngrößen durch Geschwindigkeitsbeschränkungen.

- Auf gleichem Signifikanzniveau sorgen auch Überholverbote (aggregierte Betrachtungsweise) für eine Senkung der Unfallraten und -dichten. Die Verringerung der Unfallkostenraten und -dichten kann wegen zusätzlicher zufälliger Einflüsse (Unfallschwere) nur mit geringerer statistischer Sicherheit angenommen werden.

- Statistisch sichere Aussagen beim Vergleich verschiedener Überholverbote sind nicht möglich, da mit zunehmendem Detaillierungsgrad der Kollektive die Signifikanzen abnehmen.

- 57 \% der Strecken entsprechen einem Regelquerschnitt nach RAS-Q (1996), 30 \% einem Regelquerschnitt nach RAS-Q (1982) und $13 \%$ keinem Regelquerschnitt der vergangenen Richtliniengenerationen.

- Statistisch abgesicherte Aussagen über die Unfallauffälligkeit verschiedener Querschnittsbreiten sind nicht möglich. Querschnittsbreiten genügen somit nicht als alleiniges Merkmal zur Beschreibung des Überholunfallgeschehens.

\section{Analyse der vorhandenen Sichtweiten}

- Die Darstellung der gültigen Sichtweitendefinitionen (RMS vs. RAS-L) ergibt 4 Bereiche (ausreichende Sichtweiten nach RAS-L, Sichtweiten zwischen halber und voller Überholsichtweite, Sichtweiten unterhalb des RMS-Grenzwertes, dazwischenliegende Grauzone).

- Im Mittel geschahen 71 \% der untersuchten 333 Überholunfälle im Einflussbereich von Lageplankurven. Mit zunehmendem bewegtem Gelände erhöht sich der Kurvenanteil.

- Rechtskurven zeigen eine geringfügig höhere Unfallauffälligkeit als Linkskurven.

- Überholunfälle häufen sich mit sinkendem Kurvenradius. Hierbei nehmen die Richtungsänderungswinkel und somit die Einflüsse auf die vorhandenen Sichtweiten zu.

- 38 \% der Überholunfälle geschehen im direkten Umfeld von Kuppen, 33 \% in Wannen und $28 \%$ in Höhenplangeraden (Einzeleinflüsse ohne Berücksichtigung des Umfeldes).

- 24 \% der Überholunfälle geschehen in Sichtweitenbereichen, die den Grenzwert RMS und somit das Mindestkriterium unterschreiten.

- $34 \%$ der Überholunfälle liegen in Bereichen zwischen der halben und vollen Überholsichtweite nach RAS-L, $12 \%$ sind in der Grauzone zwischen RAS-L und RMS angesiedelt.

- $30 \%$ der Überholunfälle geschehen in Abschnitten mit ausreichenden Überholsichtweiten. 
- Die Anteile der Überholunfälle differenziert nach den verkehrsrechtlichen Anordnungen entsprechen den Ergebnissen der Matrizen der 500 Untersuchungsstrecken (vgl. Punkt 4).

- Unabhängig von den vorhandenen Sichtweiten (alle benannten Sichtweitenbereiche) geschehen mindestens $72 \%$ der Überholunfälle in freigegebenen Streckenabschnitten.

- Der Anteil von verkehrsrechtlichen Restriktionen nimmt nur geringfügig mit fallenden Sichtweiten zu, der Anteil von Warnlinien an den Leitlinien (Z 340) steigt dagegen an.

- Unfallkenngrößen nach Sichtweitenbereichen und freigegebenen Abschnitten sowie Überholverboten bestätigen die erhöhte Sicherheitswirkung rechtlicher Restriktionen.

- Unter 600 m Sichtweiten führen Überholverbote zu einer deutlichen Erhöhung der Verkehrssicherheit.

- $\quad 73 \%$ der unfallauffälligen Lageplankurven, $71 \%$ der unfallauffälligen Kuppen sowie $45 \%$ der unfallauffälligen Knotenpunkte enthalten keine Überholverbote.

- 39 \% der Überholunfälle könnten theoretisch durch die Anwendung bestehender Vorgaben (Überholverbote bei Sichtweitenkriterien unterhalb RAS-L) vermieden werden (75\% aller Unfälle ohne rechtliche Restriktionen inkl. $25 \%$ Wahrscheinlichkeit der Missachtung).

\section{Mikroskopische Unfallanalyse}

- Im Regelfall wird der Überholer als Unfallverursacher angenommen. Bei $97 \%$ der Unfälle hatte der Überholer die Unfallschuld, die verbleibenden $3 \%$ entsprechen einer Teilschuld.

- 82 \% der Unfallverursacher sind Pkw, 13 \% Krafträder und 5 \% Lkw.

- Die maßgebenden unfallbeteiligten Hindernisfahrzeuge (Ursache der Überholung) waren zu 54 \% Pkw, 31 \% Lkw, 5 \% landwirtschaftliche Fahrzeuge und 4 \% Leichtkrafträder.

- Auffällige Konstellationen von Überholer und Hindernisfahrzeug sind zu $45 \%$ Pkw / Pkw, 25 \% Pkw / Lkw, 10 \% Pkw / andere Fahrzeuge, 8 \% Krad / Pkw und 5 \% Krad / Lkw.

- $60 \%$ der maßgebenden Kollisionsgegner sind Personenkraftwagen, $14 \%$ das Straßenumfeld, $8 \%$ Krafträder und $7 \%$ Leichtkrafträder.

- Bei Überholunfällen konnten 5 Kollisionsarten festgestellt werden. $42 \%$ der Überholenden kollidieren mit dem Gegenverkehr, $16 \%$ mit Abbiegern, $14 \%$ mit dem Straßenumfeld, weitere $14 \%$ mit rückwärtig Überholenden und $12 \%$ mit dem Hindernisfahrzeug.

- Erkennbarkeitsprobleme des Gegenverkehrs sind nur untergeordnet, maßgebend sind fehlerbehaftete Entfernungs- und Geschwindigkeitsschätzungen.

- Kollisionen mit bereits überholenden Fahrzeugen betreffen überwiegend potentielle Überholer, demnach 52 \% Motorräder und 44 \% Pkw (mangelhafte Orientierung - Schulterblick). 
- Die Kollisionsgegner bei Überholunfällen mit Abbiegern verteilen sich auf 55 \% Pkw, 22 \% landwirtschaftliche Fahrzeuge und $15 \%$ Lkw.

- Der Überholdruck wird am größten, wenn Differenzen zwischen gefahrener und gewünschter Geschwindigkeit steigen (Abbieger vs. Überholer auch bei unscheinbaren Wegezielen).

- Bei Beteiligung von Motorrädern (ungeschützte Verkehrsteilnehmer) und Lastkraftwagen (hohe kinetische Energie) steigt die Unfallschwere erwartungsgemäß an.

- $\quad 77 \%$ der Unfallpositionen weisen keine Besonderheiten auf, 21 \% der Unfälle geschahen im Bereich von Knotenpunkten oder Einmündungen von Wirtschaftswegen.

- Bei 69 \% der Unfälle wurde nur ein Hindernisfahrzeug benannt, bei weiteren $19 \%$ wurden zwei und bei $12 \%$ mehrere Hindernisfahrzeuge (Kolonnenverkehr) direkt angegeben.

- $48 \%$ der Überholunfälle geschehen während des direkten Überholvorganges, 27 \% beim Ausscheren und $19 \%$ beim Wiedereinscheren.

- Kollisionen mit rückwärtigen Überholern bestimmen das Unfallgeschehen beim Ausscheren, die Kollisionen mit dem Gegenverkehr die Unfälle beim tatsächlichen Überholvorgang und das Abkommen in den Straßenseitenraum die Unfälle beim Einscheren.

- Unfälle beim direkten Überholvorgang nehmen mit schlechter werdenden Sichtweiten zu, dagegen nehmen die Anteile beim Aus- und Einscheren ab.

- Fahranfänger sind besonders unfallgefährdet. $47 \%$ der Unfallverursacher sind jünger als 30 Jahre.

- Der Anteil von Überholunfällen durch Verstöße gegen bereits vorhandene Überholverbote ist bei Fahranfängern (bis 20 Jahre) mit $53 \%$ am größten.

- Bei Fahranfängern bestehen Schwierigkeiten bei der Abschätzung ausreichender Überholwege, ältere Menschen neigen zu mangelnder Orientierung im verkehrlichen Umfeld.

- Insgesamt werden Probleme bei der Sichtweiten-, Entfernungs- und Geschwindigkeitsabschätzung, Nichterkennen der Abbiegeabsicht, Kontrollverluste, mangelhafte Orientierung zu rückwärtigen Verkehren und Konflikte beim Ein-/Ausscheren sowie mangelnde Sicherheitsabstände als die maßgebenden Unfallursachen angesehen.

\section{Detailanalyse zum Überholverhalten}

- Im Rahmen der Detailanalysen wurden insgesamt 15.173 Überholungen ermittelt.

- 34 \% der festgestellten Überholungen sind Pkw/Pkw-Überholungen, 37 \% Pkw/LkwÜberholungen, 17 \% Überholungen durch Pkw an Leichtkrafträdern oder sonstigen Fahrzeugen und $7 \% \mathrm{Krad} / \mathrm{Pkw}$-Überholungen. 
- Das größte Unfallrisiko ergibt sich bei Überholungen durch Lastkraftwagen, wobei 50 \% der Überholungen an langsamen Leichtkrafträdern stattfinden und Unfälle durch mangelnde Sicherheitsabstände zu verzeichnen waren.

- Aufgrund der hohen Geschwindigkeitsdifferenzen zählen Pkw/Lkw-Überholungen und Überholungen von Pkw an Leichtkrafträdern zu den vergleichsweise sicheren Überholer/Hindernis-Konstellation.

- Durch ähnliche Geschwindigkeitsniveaus sind Pkw/Pkw vergleichsweise unsicher. PkwÜberholungen an sonst. Fahrzeugen (im Regelfall landwirtschaftliche Verkehre) sind durch die Abbiegekonflikte auffällig.

- Krad-Überholungen an Lkw sind aufgrund längerer Überholwege risikobehafteter als KradPkw-Überholungen.

- Zwischen Gesamtüberholungen und repräsentativen Überholungen (Leichtkrafträder und sonst. Fahrzeuge als Hindernisse ausgeschlossen) existiert ein linearer Zusammenhang.

- Mit größeren Sichtweiten nimmt der Anteil repräsentativer Überholungen an Gesamtüberholungen zu. Dennoch ist der Mindestanteil von 62 \% repräsentativer Überholungen vor allem bei schlechten Sichtweiten als äußerst kritisch anzusehen.

- Anzahl der Überholungen und Überholrate steigen mit besseren Sichtweiten, dennoch muss auch wenigen Überholungen in kritischen Bereichen entgegengewirkt werden.

- Fahrzeugführer können bedingt durch die fehlerbehaftete Entfernungsschätzung nicht vorhandene Überholmöglichkeiten nicht eigenständig erkennen.

- Bei Überlagerung mit den Überholunfällen ergibt sich ein besonders hohes Unfallrisiko auf Landstraßenabschnitten mit schlechten Sichtweiten $(0,056(\mathrm{U} / 3 \mathrm{a}) /(\mathrm{U} / 10 \mathrm{~h}))$ beim Vergleich mit ausreichenden Sichtweiten (0,010 (U/3a)/(Ü/10h)).

- Entsprechend der Häufigkeit ihres Auftretens im Landstraßennetz sind Überholunfälle und Überholungen auf Strecken mit mittleren Verkehrsstärken am häufigsten.

- Unabhängig von der Verkehrsstärke sind Überholungen bei schlechten Sichtweiten am gefährlichsten. Das Risiko in den anderen Sichtweitenbereichen schwankt geringfügig mit der vorliegenden Verkehrsstärke allerdings ohne eindeutige Tendenzen.

- Durch Anwendung des Entwurfsklassenprinzips der RAL und regelkonformes Verhalten könnten bei der Markierung von EKL 1 und EKL 2 ca. $28 \%$ sowie weitere $48 \%$ der heutigen Überholunfälle bei Strecken der EKL 3 und EKL 4 vermieden werden.

- Mit steigenden Sichtweiten sinken die Unfallkenngrößen, die Überholraten steigen.

- Überholverbote verringern die Anzahl von Überholungen auf Landstraßen, können sie aber nicht ausnahmslos unterbinden.

- Durch Geschwindigkeitsbeschränkungen kann sich die Überholrate halbieren. 
- Die Effekte der verkehrsrechtlichen Anordnungen (Regelakzeptanz) sind abhängig von den örtlichen Gegebenheiten der Untersuchungsstrecken.

- Die Ergebnisse der Unfallkenngrößen sind aufgrund der geringen Datengrundlage nicht als maßgebend anzusehen.

\section{Maßnahmen gegen Überholunfälle}

- Bei infrastrukturellen Maßnahmen gegen Überholunfälle kann zwischen baulichen und betrieblichen Maßnahmen unterschieden werden.

- Langfristige bauliche Maßnahmen (Überholfahrstreifen) können Überholunfälle vermeiden. Kurzfristige bauliche Maßnahmen (Bischofsmützen) werden dagegen ausgeschlossen.

- Betriebliche Maßnahmen unterscheiden sich in Bereiche mit fehlenden Restriktionen und Bereiche mit bereits vorhandenen Maßnahmen.

- Bei unzureichenden Sichtweiten müssen strikte präventive Anordnungen von Überholverboten vorgesehen werden, um die Verkehrsteilnehmer bei der Fahraufgabe zu unterstützen.

- Die Philosophie der bisherigen StVO ist aufzugeben, da Fahrzeugführer nicht in der Lage sind, allein zu erkennen, wo kein Überholen möglich ist.

- Bei mittleren Sichtweiten müssen grundsätzlich Überholungen verhindert werden, hierbei sind aber die Belange von landwirtschaftlichen Fahrzeugen zu berücksichtigen.

- Für repräsentative Überholungen muss ein einheitlicher, akzeptabler Grenzwert definiert werden, bei dessen Unterschreitung dem Fahrzeugführer die Überholentscheidung grundsätzlich abzunehmen ist.

- Bisher sind auch bei bereits unfallauffälligen Landstraßenabschnitten oftmals keine Restriktionen vorhanden. Diese Missstände sind bei der Einführung der RAL zu beseitigen.

- Auch auf Landstraßen mit ausreichenden Sichtweiten müssen bei Unfallhäufungen dennoch Maßnahmen erfolgen. Gegebenenfalls sind hier dynamische Überholverbote in Abhängigkeit der aktuellen Verkehrssituation denkbar.

- Nicht beachtete, bereits vorhandene Überholverbote, müssen mit ergänzenden Maßnahmen in ihrer Wirkung verstärkt werden.

- Die frühzeitige Ankündigung von Überholverboten durch Warnlinien mit Pfeilmarkierungen ist ein wichtiger Bestandteil für Hinweise auf bevorstehende Gefährdungen.

- Die Wirkung von Warnlinien als Hinweis auf unzureichende Sichtweiten (anstelle konkreter Verbote) wird dagegen als unzureichend angesehen.

- In Knotenpunktbereichen sind klare und wirksame Überholverbote präventiv anzuordnen. 
- Kurzzeitigen Unterbrechungen vorhandener Überholverbote sind im Landstraßennetz zu beseitigen. Hierdurch können dem Fahrer Überholmöglichkeiten suggeriert werden.

- Bei sprunghaften Sichtweitengefällen müssen zwingend verkehrsrechtliche Maßnahmen erfolgen.

- Im Landstraßennetz sind konsistente, dem Fahrzeugführer verständliche Überholverbote anzuordnen, um dessen Akzeptanz zu erhöhen und Regelverstößen vorzubeugen.

- In Abhängigkeit der Streckencharakteristik werden Überholverbote unterschiedlich befolgt.

- Insgesamt wird auch den Geschwindigkeitsbeschränkungen ein deutlicher Effekt auf das Überholverhalten und -unfallgeschehen zugeschrieben, die auch mit konventionellen Mitteln überwacht werden können.

- Für die infrastrukturellen Maßnahmen wird ein modularer Aufbau von rechtlichen Restriktionen in Anlehnung an das Entwurfsklassenprinzip der RAL empfohlen.

- Der Maßnahmenansatz am Verkehrsteilnehmer fokussiert die Verkehrserziehung von jungen Fahranfängern sowie Sicherheitskampagnen und Öffentlichkeitsarbeit bei erfahreneren Verkehrskehrsteilnehmern.

- Hierbei besonders auf die fahrdynamischen Grundlagen, die verkehrlichen Zusammenhänge und den komplexen Überholvorgang einzugehen.

- Auf die Gefahren von Kolonnenüberholungen muss hingewiesen werden. Diese sind gegebenenfalls zu verbieten.

- Verbotswidriges Überholen muss hart geahndet werden, allerdings fehlen bisher Methoden zu dessen Überwachung.

- Durch die Fahrzeugtechnik und Fahrerassistenzsysteme (Verkehrszeichenerkennung, Spurführungsassistenten) kann auf vorhandene Überholverbote hingewiesen werden.

- Mit Navigationsgeräten kann auf - im vorgeschlagenen Routenverlauf kommende - sichere Überholmöglichkeiten (Überholfahrstreifen) hingewiesen werden, um Überholdruck abzubauen. 


\section{Ausblick}

Das Ziel der vorliegenden Untersuchung war die Detektion von unfallauffälligen Strecken und das Ableiten von Wirkungsfaktoren, die das Vorkommen von Überholunfällen forcieren. Bezogen auf die Wirksamkeit von einzelnen Überholverboten auf das Überholverhalten konnten aus den Detailanalysen allerdings keine gesicherten Erkenntnisse abgeleitet werden.

Mit Hilfe von Vorher-Nachher-Untersuchungen könnten dagegen die Wirkungen von einzelnen Präventionsmaßnahmen gegen Überholunfälle direkt untersucht und bewertet werden. Ziel einer solchen Vorher-Nachher-Untersuchung wären verkehrstechnische Untersuchungen an Streckenabschnitten, wo Maßnahmen zur Prävention von Überholunfällen ergriffen wurden. Dabei sind nicht nur die unfallauffälligen Streckenabschnitte zu ermitteln, sondern nach Umsetzung eine Wirkungsanalyse der Maßnahmen durchzuführen.

Das Überholverhalten kann auf die in diesem Bericht erläuterten Art und Weise in einem Vorhersowie einem Nachher-Szenario ermittelt werden. Bei der Umsetzung der Maßnahmen auf den Untersuchungsstrecken sind entsprechend der verkehrlichen und baulichen Situation verschiedene Überholverbote in Betracht zu ziehen, die auch untereinander modular erweitert werden können (vgl. hierzu Kapitel 5.1.2). Die Richtlinien für die Anlage von Landstraßen, das M_EKLBEST sowie die Ergebnisse dieser Untersuchung bilden eine sehr gute Grundlage für die Identifizierung von potentiell geeigneten Maßnahmen. Die Maßnahmen wären mit den Vertretern der Straßenbaubehörden sowie den Verkehrsbehörden abzustimmen und nach erfolgter Maßnahmenumsetzung sowie einer Eingewöhnungsphase die entsprechende Nachher-Erhebung und eine Wirksamkeitsabschätzung auf das Überholverhalten durchzuführen.

Da im Untersuchungszeitraum des Nachher-Szenarios im Rahmen der Detailanalysen keine ausreichenden Zeiträume für Unfalluntersuchungen vorhanden sind, können über die direkten sicherheitstechnischen Wirkungen zunächst keine Aussagen getroffen werden. Diese können aber über die Vermeidung von beobachtbaren Überholmanövern und über eine Veränderung der gefahrenen Geschwindigkeiten vorab abgeschätzt werden. Ist darüber hinaus ein ausreichender Zeitraum nach Maßnahmenumsetzung vorhanden, so können die Abschätzungen anhand des Überholverhaltens durch eine weitere Unfallanalyse untermauert werden. Somit könnten im Gesamtergebnis zum Thema der Überholunfälle nicht nur unfallauffällige Strecken und deren Mängel identifiziert sowie unfallbegünstigende Einflussgrößen aufgezeigt sondern auch direkt Maßnahmen sowie deren Wirksamkeit beschrieben werden. 


\section{Literaturverzeichnis}

bfu - Beratungsstelle für Unfallverhütung:

Gigaliner - Auswirkungen der Anhebung der Gewichtslimite für Lastwagen von 40 auf 60 Tonnen, bfu-Positionspapier, Bern, 2010

Brannolte, U; et al.:

Sicherheitsbewertung von Querschnitten außerörtlicher Straßen, Berichte der Bundesanstalt für Straßenwesen, Heft V5, Bergisch Gladbach, 1993

Brilon, W:

Unfallgeschehen und Verkehrsablauf - Warteschlangenmodell des Verkehrsablaufs auf zweispurigen Landstraßen, in: Forschung Straßenbau und Straßenverkehrstechnik, Heft 201, Bonn-Bad Godesberg, 1976

Brosius, F.:

SPSS 8 - Professionelle Statistik unter Windows, Hamburg, 1998, Online unter URL:

http://www.molar.unibe.ch/help/statistics/ [Stand: 10.12.2012]

Bundesanstalt für Straßenwesen:

Starenkästen und Überholfahrstreifen im Praxistest, Pressemitteilung 23/2008 - Langfassung, Bergisch-Gladbach, 2008

Bundesministerium für Verkehr, Bau und Stadtentwicklung:

Anweisung Straßeninformationsbank (ASB), Teilsystem Netzdaten, Bergisch Gladbach, 2009

Durth, W.:

Ein Beitrag zur Erweiterung des Modells für Fahrer, Fahrzeug und Straße in der Straßenplanung, in: Straßenbau und Straßenverkehrstechnik, Heft 163, Bonn, 1974

Durth, W/Bald, S.:

Risikoanalysen im Straßenwesen, in: Forschung Straßenbau und Straßenverkehrstechnik, Heft 531, Bonn-Bad Godesberg, 1988

Durth, W./Habermehl, K.:

Überholvorgänge auf einbahnigen Straßen, in: Forschung Straßenbau und Straßenverkehrstehnik, Heft 489, Bonn-Bad Godesberg, 1985

Ebersbach, D./Schüller, H.:

Praktische Abwendung der Empfehlungen für die Sicherheitsanalyse von Straßennetzen (ESN) Erfahrungen mit den Verfahren der Abschnittsbildung, in: Straßenverkehrstechnik, Heft 9, Seiten 515-527, 2008

Elvik, R./Vaa, T.:

The handbook of road safety measures, Amsterdam u.a., 2004

Forschungsgesellschaft für Straßen- und Verkehrswesen:

Empfehlungen für die Sicherheitsanalyse von Straßennetzen (ESN), Köln, 2003, (zit. 2003a) 
Forschungsgesellschaft für Straßen- und Verkehrswesen:

Handbuch für die Bemessung von Straßenverkehrsanlagen (HBS), Köln, 2001, (zit. 2001b)

Forschungsgesellschaft für Straßen- und Verkehrswesen:

Merkblatt für die Auswertung von Straßenverkehrsunfällen, Teil 1: Führen und Auswerten von Unfalltypen-Steckkarten, Köln, 2003, (zit. 2003b)

Forschungsgesellschaft für Straßen- und Verkehrswesen:

Merkblatt für die Auswertung von Straßenverkehrsunfällen, Teil 2: Maßnahmen gegen Unfallhäufungen, Köln, 2001, (zit. 2001a)

Forschungsgesellschaft für Straßen- und Verkehrswesen:

Merkblatt zur Örtlichen Unfalluntersuchung in Unfallkommissionen (M Uko), Köln, 2012, (zit. 2012a)

Forschungsgesellschaft für Straßen- und Verkehrswesen:

Richtlinien für die Anlage von Landstraßen (RAL), unveröffentlichter Entwurf (Stand 12/2010), 2010

Forschungsgesellschaft für Straßen- und Verkehrswesen:

Richtlinien für die Anlage von Landstraßen (RAL), unveröffentlichter Entwurf (Stand 08/2012), 2012, (zit. 2012b)

Forschungsgesellschaft für Straßen- und Verkehrswesen:

Richtlinien für integrierte Netzgestaltung (RIN), Köln, 2008

Forschungsgesellschaft für Straßen- und Verkehrswesen:

Richtlinien für die Anlage von Straßen, Teil: Knotenpunkte, Abschnitt 1: Plangleiche Knotenpunkte (RAS-K-1) Köln, 1988

Forschungsgesellschaft für Straßen- und Verkehrswesen:

Richtlinien für die Anlage von Straßen, Teil: Linienführung, Abschnitt 1: Elemente der Linienführung (RAS-L-1), Köln, 1984

Forschungsgesellschaft für Straßen- und Verkehrswesen:

Richtlinien für die Anlage von Straßen, Teil: Linienführung (RAS-L), Köln, 1995

Forschungsgesellschaft für Straßen- und Verkehrswesen:

Richtlinien für die Anlage von Straßen, Teil: Querschnitte (RAS-Q), Bonn, 1982

Forschungsgesellschaft für Straßen- und Verkehrswesen:

Richtlinien für die Anlage von Straßen, Teil: Querschnitte (RAS-Q), Köln, 1996

Forschungsgesellschaft für Straßen- und Verkehrswesen:

Richtlinien für die Markierung von Straßen, Teil 2: Anwendung von Fahrbahnmarkierungen (RMS2), Köln, 1980 
Glaeser, K.-P./Kaschner, R./Lerner, M./Roder, C.K./Weber, R./Wolf, A./Zander, U.:

Auswirkungen von neuen Fahrzeugkonzepten auf die Infrastruktur des Bundesfernstraßennetzes, Schlussbericht der Bundesanstalt für Straßenwesen, 2. Auflage, Bergisch Gladbach, 2006

Gründl, M.:

Fehler und Fehlverhalten als Ursache von Verkehrsunfällen und Konsequenzen für das Unfallvermeidungspotenzial und die Gestaltung von Fahrerassistenzsystemen, Dissertation, Institut für Psychologie der Universität Regensburg, 2005

Gründl, M.:

Analyse des Fahrerverhaltens vor dem Unfall - eine Methode für eine verbesserte Fehleranalyse bei der Untersuchung realer Verkehrsunfälle, Paper zum 38. BDP-Kongress für Verkehrspsychologie Universität Regensburg, 2006, Online unter URL:

http://psydok.sulb.uni-saarland.de/volltexte/2006/721/ [Stand: 24.02.2011]

Hartkopf, G.Meber, R.:

Die neuen Richtlinien für Landstraßen - Ein Schritt zu selbsterklärenden Straßen, in: Straßenverkehrstechnik, Heft 1, Seiten 10-18, 2005

Hecht, C.:

Sichere Landstraßen in Deutschland, ADAC e.V., Ressort Verkehr, 1. Auflage, München, 2012 Hegewald, A.Meber, R.:

Unfälle auf schmalen Landstraßenquerschnitten; in: Straßenverkehrstechnik, Heft 11, Seiten 677683,2008

Herz, R./Schlichter, G./Siegener, W.:

Angewandte Statistik für Verkehrs- und Regionalplaner, 2. Auflage, Düsseldorf, 1992

Hiersche, E.-U.:

Die Bedeutung und Ermittlung der Sichtweiten von Straßen, in: Straßenbau und Straßenverkehrstechnik, Heft 67, Bonn, 1968

Kämpfe, B./Schlag, B./Weller, G.:

Streckencharakteristik und Fahrfehler, in: Straßenverkehrstechnik, Heft 11, Seiten 564-571, 2005

Kayser, H. J./Otten, N./Hahn, S.:

Simulatorversuche zum Überholverhalten von Kraftfahrern auf einbahnigen Außerortsstraßen, Lehrstuhl und Institut für Straßenwesen, Erd- und Tunnelbau der RWTH Aachen, Aachen, 1986 Kayser, H. J./Otten, N./Hahn, S.:

Simulatorversuche zur Beeinflussung des Überholverhaltens auf einbahnigen Außerortsstraßen, Lehrstuhl und Institut für Straßenwesen, Erd- und Tunnelbau der RWTH Aachen, Aachen, 1988 Kayser, H. J./Struif, R.:

Maßnahmen zur Beeinflussung des Überholverhaltens, in: Forschung Straßenbau und Straßenverkehrstehnik, Heft 690, Bonn-Bad Godesberg, 1993 
Kuczora, V.:

Straßenentwurf mit CARD/1 - Grundlagen, Wiesbaden, 2004

Künzelmann, M.:

Verkehrssicherheit und Verkehrsablauf bei Überholvorgängen auf Landstraßen, Masterarbeit, Fachgebiet Straßenplanung und Straßenbetrieb der Technischen Universität Berlin, Berlin, 2012

Laffont, S./Schmidt, G.:

Analyse des Überholdrucks - zur Sicherheitsbewertung von Landstraßen, Auswertung des FEVorhabens 02.148 G92F, Aachen, 1993

Lamm, R./Beck, A./Zumkeller, K.:

Analyse von Zusammenhängen zwischen Verkehrssicherheit und Straßenentwurf auf Außerortsstraßen, in: Straßen- und Tiefbau, Heft 12, Seiten 6-12, 1999

Lamm, R./Psarianos, B./Mailänder, T.:

Highway design and traffic safety engineering handbook, New York u.a., 1999

Leutzbach, W./Zoellmer, J.:

Zusammenhang zwischen der Verkehrssicherheit und den Elementen des Straßenentwurfs, in: Forschung Straßenbau und Straßenverkehrstechnik, Heft 545, Bonn-Bad Godesberg, 1989

Lippold, Ch./Schulz, R./Krüger, H.-P./Scheuchenpflug, R./Lorenz, Ch.:

Einfluss der Straßenseitenraumbepflanzung auf Fahrverhalten und Verkehrssicherheit, in: Forschung Straßenbau und Straßenverkehrstechnik, Heft 1018, Bonn, 2009

Matena, S. et.al.:

Road categorization and design of self explaining roads, RIPCORD-ISEREST-Projekt, Internal Report No. D 3.1, 2006

Ministerium für Stadtentwicklung, Wohnen und Verkehr (MSWV):

Hinweise zur Verkehrslenkung und optischen Orientierung durch Bepflanzung an Bundes- und Landesstraßen (außerorts) im Land Brandenburg (HVO), Runderlass des Landes Brandenburg, 2002

Netzer, M.:

Der Überholvorgang auf Landstraßen unter Berücksichtigung der Verkehrssicherheit, in: Straßenbau und Straßenverkehrstechnik, Heft 50, Bonn, 1966

Otte, D.:

Charakteristika von Unfällen auf Landstraßen - Analyse aus Erhebungen am Unfallort, Berichte der Bundesanstalt für Straßenwesen, Heft M 122, Bergisch Gladbach, 2000

Palm, I./Schmidt, G.:

Querschnittsbreiten einbahniger Außerortsstraßen und Verkehrssicherheit - und Sonderuntersuchung zum Querschnittstyp b2+1, Berichte der Bundesanstalt für Straßenwesen, Heft V 64, Bergisch Gladbach, 1999 
Pfundt, K.:

Unfälle auf Landstraßen - bauliche Verbesserung oder Verbesserung junger Fahrer?, in: Zeitschrift für Verkehrssicherheit, Heft 47, Seiten 15-20, 2001

Reason, J.:

Human Error, deutsch von Grabowski, J., Menschliches Versagen - psychologische Risikofaktoren und moderne Technologien, Heidelberg, 1994

Retzko, H.-G.:

Vergleichende Bewertung verschiedener Arten der Verkehrsregelung an städtischen Straßenverkehrsknotenpunkten, in: Straßenbau und Straßenverkehrstechnik, Heft 12, Bonn, 1961

Richter, T./Zierke, B.:

Merkblatt für die Übertragung des Prinzips der Entwurfsklassen nach den RAL auf bestehende Straßen (M_EKLBEST), unveröffentlichter Entwurf (Version 4.0, Stand 25.06.2009), Berlin, 2009

Richter, T./Zierke, B.:

Ergänzungen der Richtlinien für die Anlage von Landstraßen (RAL) zur Anwendung beim am Bestand orientierten Um- und Ausbau (BASt-Projekt FE 02.0293/2007/FRB), unveröffentlichter Schlussbericht, Berlin, 2010

Rohloff, M.:

Verbesserung der Verkehrssicherheit auf Landstraßen, in: Straße und Autobahn, Heft 2, Seiten 8184, 1999

Runkel, M.:

Die Bedeutung der Sichtbehinderung durch Lastkraftwagen für Überholvorgänge auf zweispurigen Landstraßen, in: Straßenbau und Straßenverkehrstechnik, Heft 97, Bonn, 1970

Statistisches Bundesamt:

Merkblatt zur Erhebung von Unfallmerkmalen der bundeseinheitlichen Verkehrsunfallanzeige, Wiesbaden, 2008

Statistisches Bundesamt:

Verkehrsunfälle 2009, Fachserie 8, Reihe 7, Wiesbaden, 2010 (zit. 2010a)

Statistisches Bundesamt:

Statistisches Jahrbuch 2010 - Für die Bundesrepublik Deutschland mit »Internationalen Übersichten«, Wiesbaden, 2010 (zit. 2010b)

Statistisches Bundesamt:

Individuelle Datenanfrage zu Unfällen des Jahres 2009 mit den Ursachen 16-23 (Überholunfälle), Wiesbaden, 2011

Steierwald, G./Jacobs, F./Feier, H.:

Überholverhalten und Qualität auf zweispurigen Landstraßen mit Gegenverkehr, in: Forschung Straßenbau und Straßenverkehrstechnik, Heft 472, Bonn-Bad Godesberg, 1983 
Stolz, M.:

Sichtweiten und Verkehrsablauf, Schriftreihe der Deutschen Akademie für Verkehrswissenschaft Hamburg, Band 3, Hamburg, 1967

StVO:

Straßenverkehrs-Ordnung vom 16. November 1970 (BGBI. I S. 1565), zuletzt geändert durch Artikel 1 der Verordnung vom 1. Dezember 2010 (BGBI. I S. 1737), 2010, Online unter URL:

http://www.gesetze-im-internet.de/stvo/index.html [Stand: 21.11.2012]

StVO-VwV:

Allgemeine Verwaltungsvorschrift zur Straßenverkehrs-Ordnung vom 22. Oktober 1998 in der Fassung vom 17. Juli 2009, 2009, Online unter URL:

http://www.verwaltungsvorschriften-im-internet.de/bsvwvbund 26012001 S3236420014.htm

[Stand: 18.10.2012]

Topp, $\mathrm{H}$.:

Wie schnell ist sicher? - Geschwindigkeit und Verkehrssicherheit, in: Straßenverkehrstechnik, Heft 7, Seiten 426-431, 2008

Weinert, R./Vengels, S.:

Pilotanwendung der Empfehlungen für die Sicherheitsanalyse von Straßennetzen (ESN), Berichte der Bundesanstalt für Straßenwesen, Heft V 171, Bergisch Gladbach, 2008

Weise, G./Durth, W.:

Straßenbau - Planung und Entwurf, 3. Auflage, Berlin, 1997

Wirth, W.:

Sicherheitsaspekte des Straßenentwurfs - Das deutsche Trassierungsregelwerk im Wandel der Zeit, in: Straße und Autobahn, Heft 3, Seiten 173-183, 2000 


\section{Anhang A}

Grundbegriffe der Verkehrssicherheitsarbeit 


\section{Beschreibung Unfalltyp 1}

\section{Fahrunfall (F)}

Der Unfall wurde ausgelöst durch den Verlust der Kontrolle über das Fahrzeug (wegen nicht angepasster Geschwindigkeit oder falscher Einschätzung des Straßenverlaufs, des Straßenzustandes o.Ä.), ohne dass andere Verkehrsteilnehmer dazu beigetragen haben. Infolge unkontrollierter Fahrzeugbewegungen kann es dann aber zum Zusammenstoß mit anderen Verkehrsteilnehmern gekommen sein.

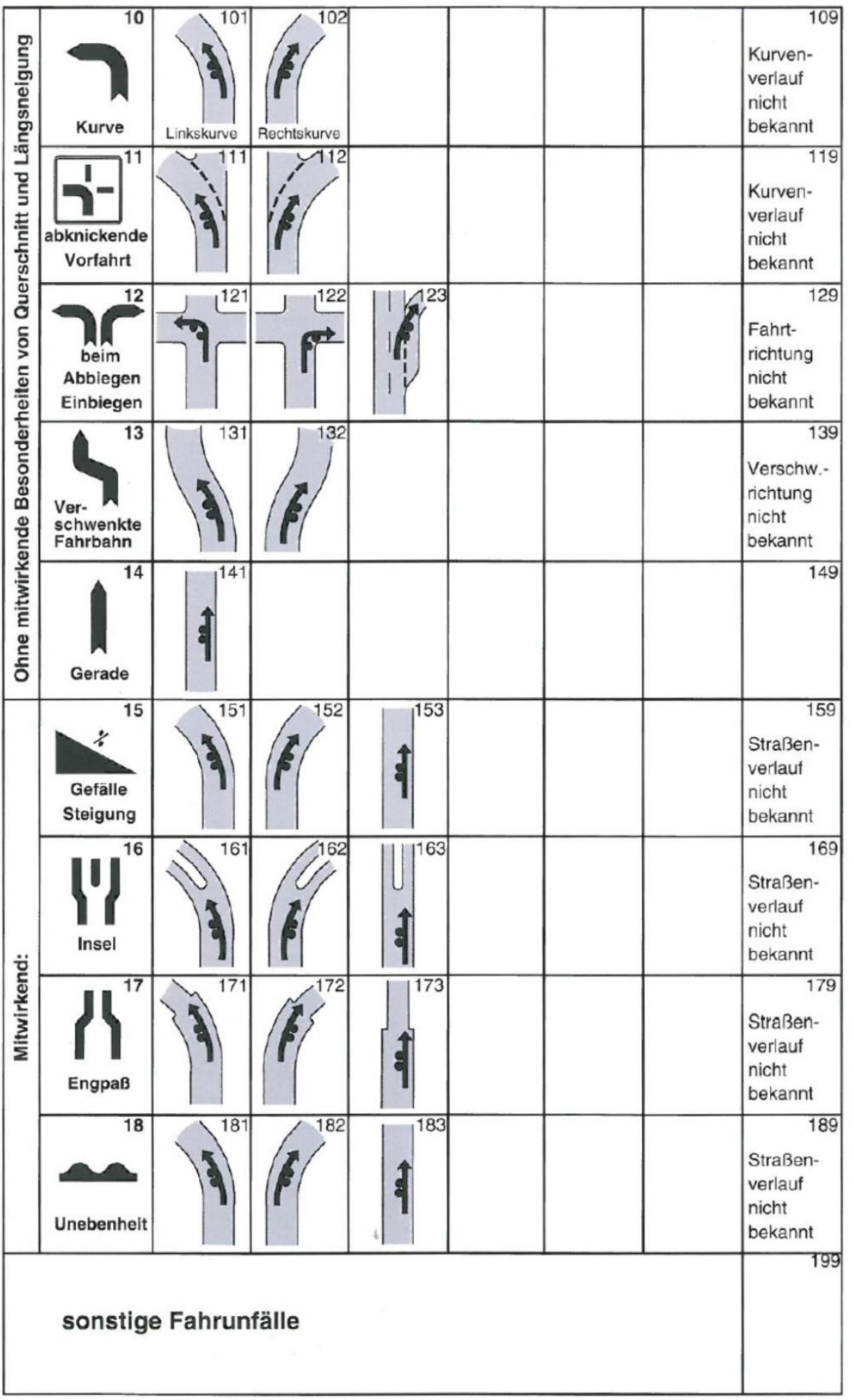

(Quelle: FGSV, 2003b) 


\section{Beschreibung Unfalltyp 2}

\section{Abbiege-Unfall $(A B)$}

Der Unfall wurde ausgelöst durch einen Konflikt zwischen einem Abbieger und einem aus gleicher oder entgegengesetzter Richtung kommenden Verkehrsteilnehmer (auch Fußgänger!) an Kreuzungen, Einmündungen, Grundstücks- oder Parkplatzzufahrten.

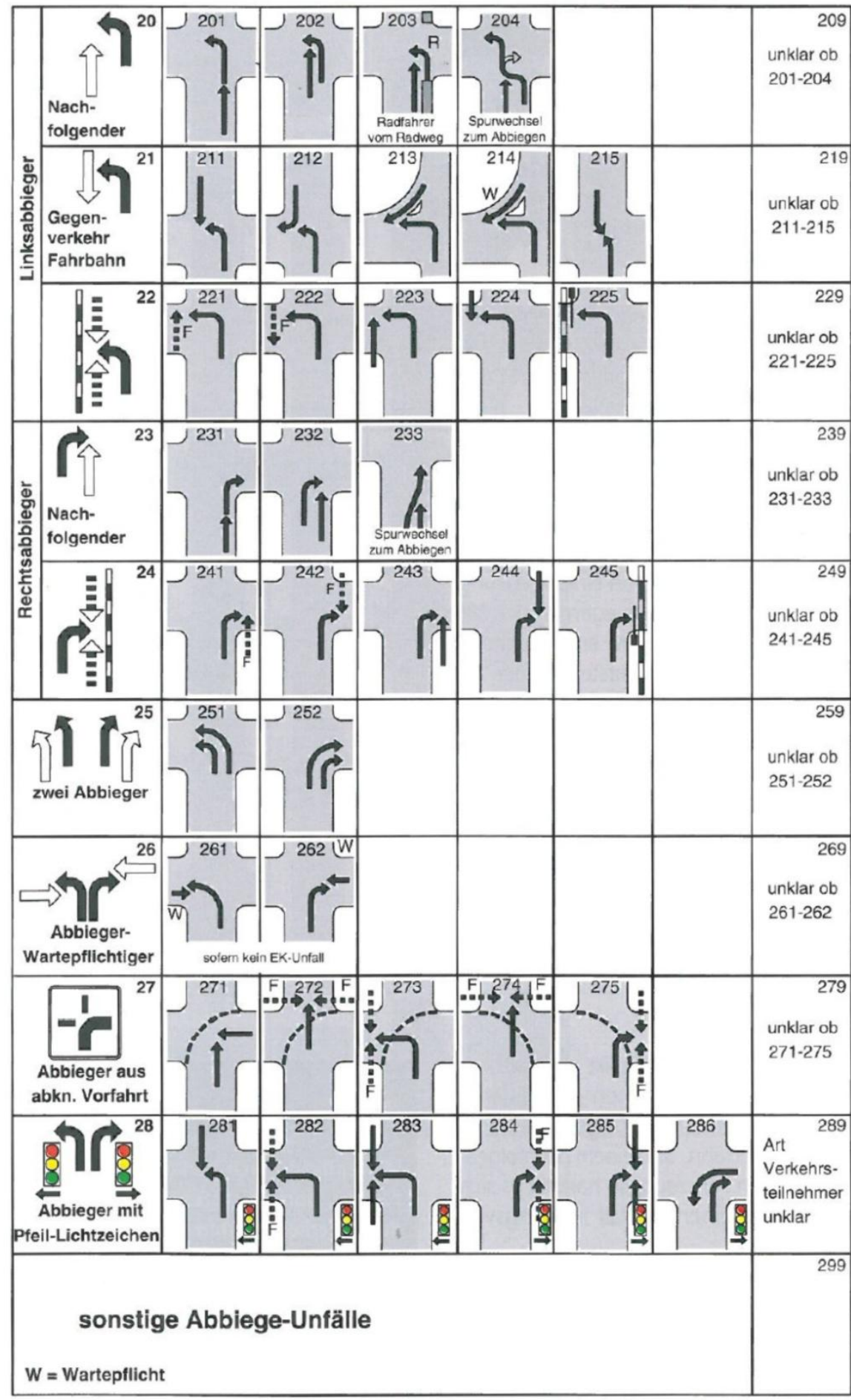

(Quelle: FGSV, 2003b) 


\section{Beschreibung Unfalltyp 3}

\section{Einbiegen/Kreuzen-Unfall (EK)}

Der Unfall wurde ausgelöst durch einen Konflikt zwischen einem einbiegen den der kreuzenden Wartepflichtigen und einem vorfahrtberechtigten Fahrzeug an Kreuzungen, Einmündungen, oder Ausfahrten von Grundstücken und Parkplätzen.

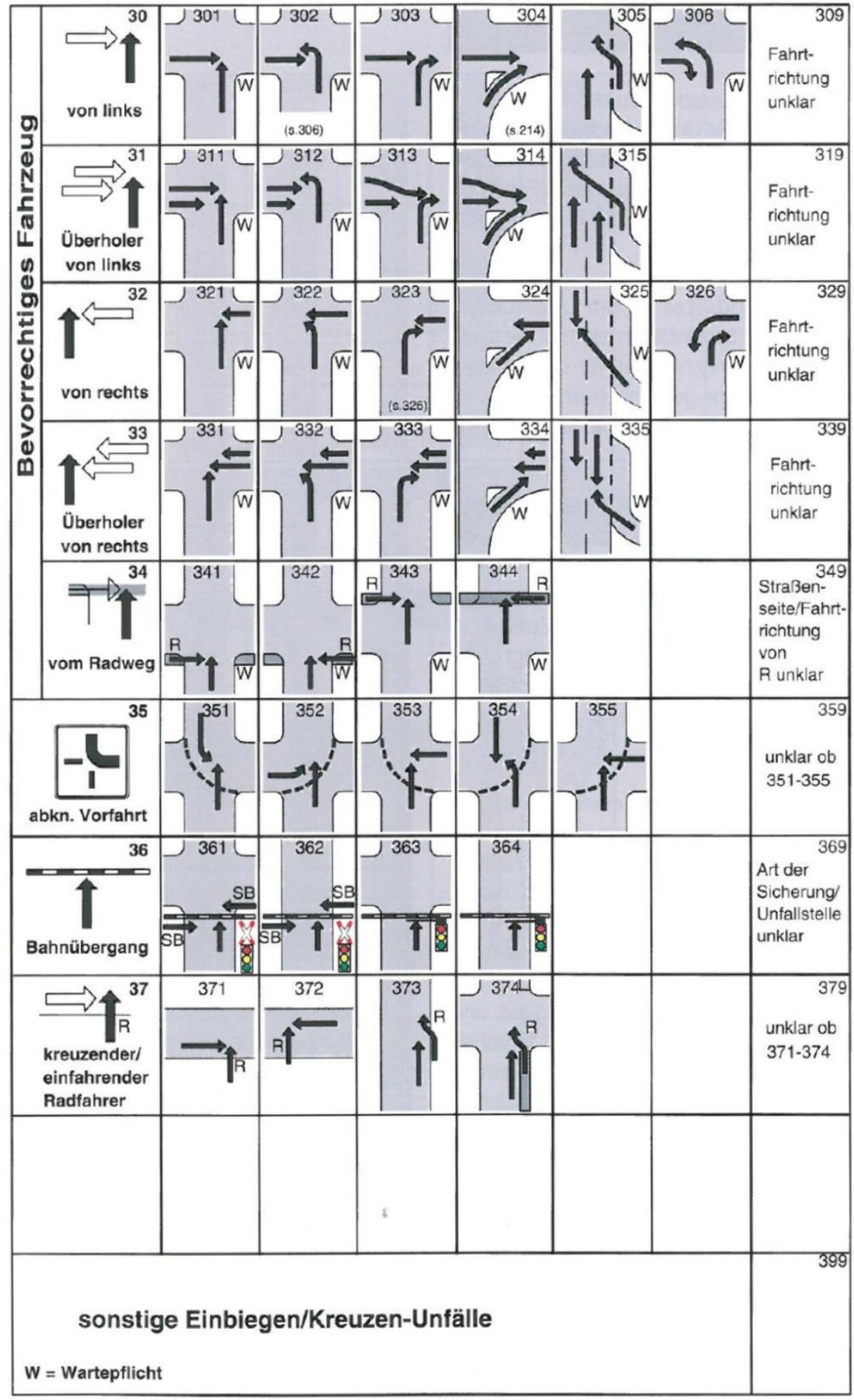

(Quelle: FGSV, 2003b) 


\section{Beschreibung Unfalltyp 4}

\section{Überschreiten-Unfall (ÜS)}

Der Unfall wurde ausgelöst durch einen Konflikt zwischen einem Fahrzeug und einem Fußgänger auf der Fahrbahn, sofern dieser nicht in Längsrichtung ging und sofern das Fahrzeug nicht abgebogen ist. Dies gilt auch, wenn der Fußgänger nicht angefahren wurde.

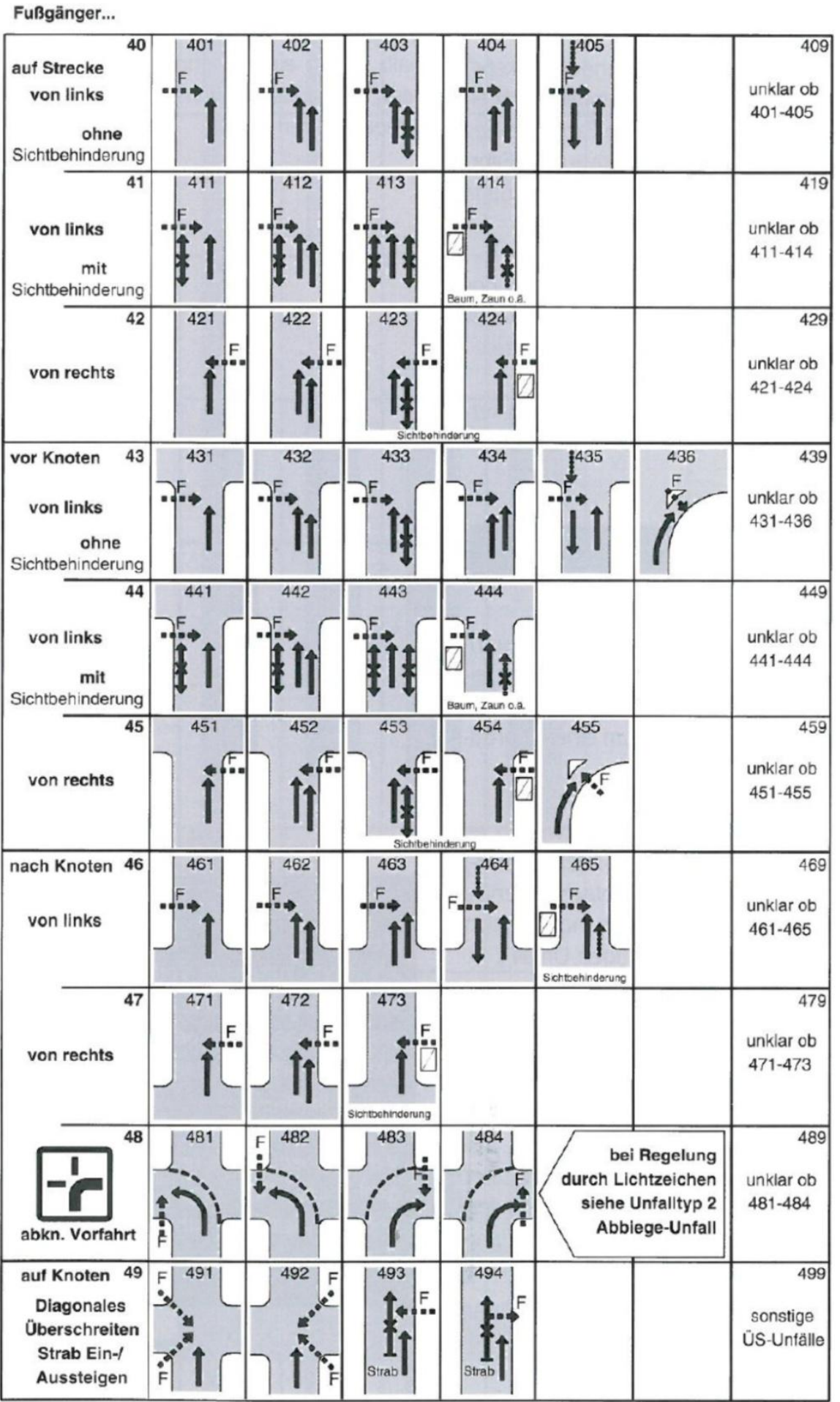

$\rightarrow$ Parker auf Fahrbahn oder Gehweg, Aufstellung längs oder quer

(Quelle: FGSV, 2003b) 


\section{Beschreibung Unfalltyp 5}

\section{Unfall durch ruhenden Verkehr (RV)}

Der Unfall wurde ausgelöst durch einen Konflikt zwischen einem Fahrzeug des fließenden Verkehrs und einem Fahrzeug, das parkt/hält bzw. Fahrmanöver im Zusammenhang mit dem Parken/Halten durchführte.

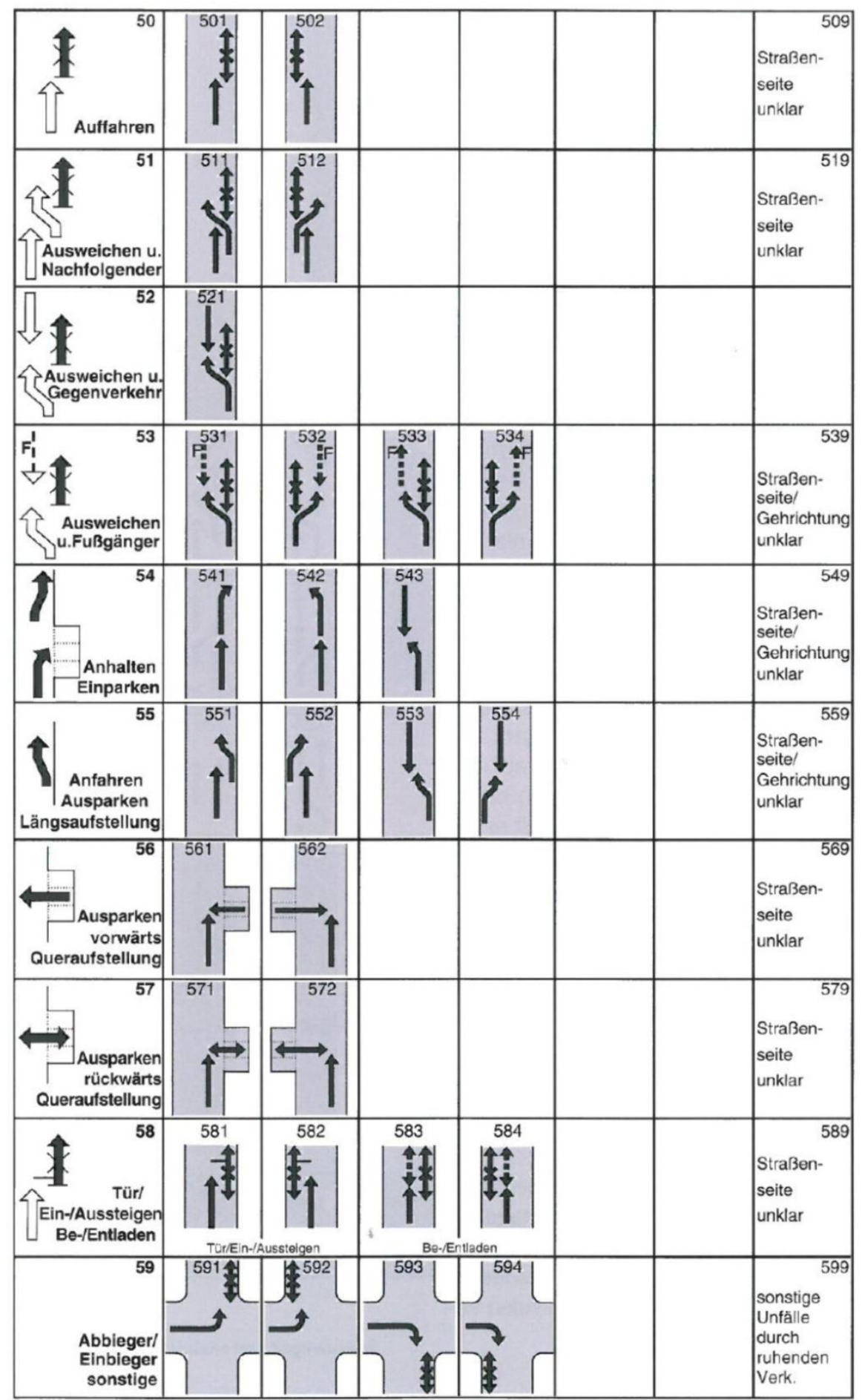

$\leftrightarrow$ Parker Aufstellung längs oder quer zur Fahrbahn

(Quelle: FGSV, 2003b) 


\section{Beschreibung Unfalltyp 6}

\section{Unfall im Längsverkehr (LV)}

Der Unfall wurde ausgelöst durch einen Konflikt zwischen Verkehrsteilnehmern, die sich in gleicher oder entgegengesetzter Richtung bewegten, sofern dieser Konflikt nicht einem andern Unfalltyp entspricht.

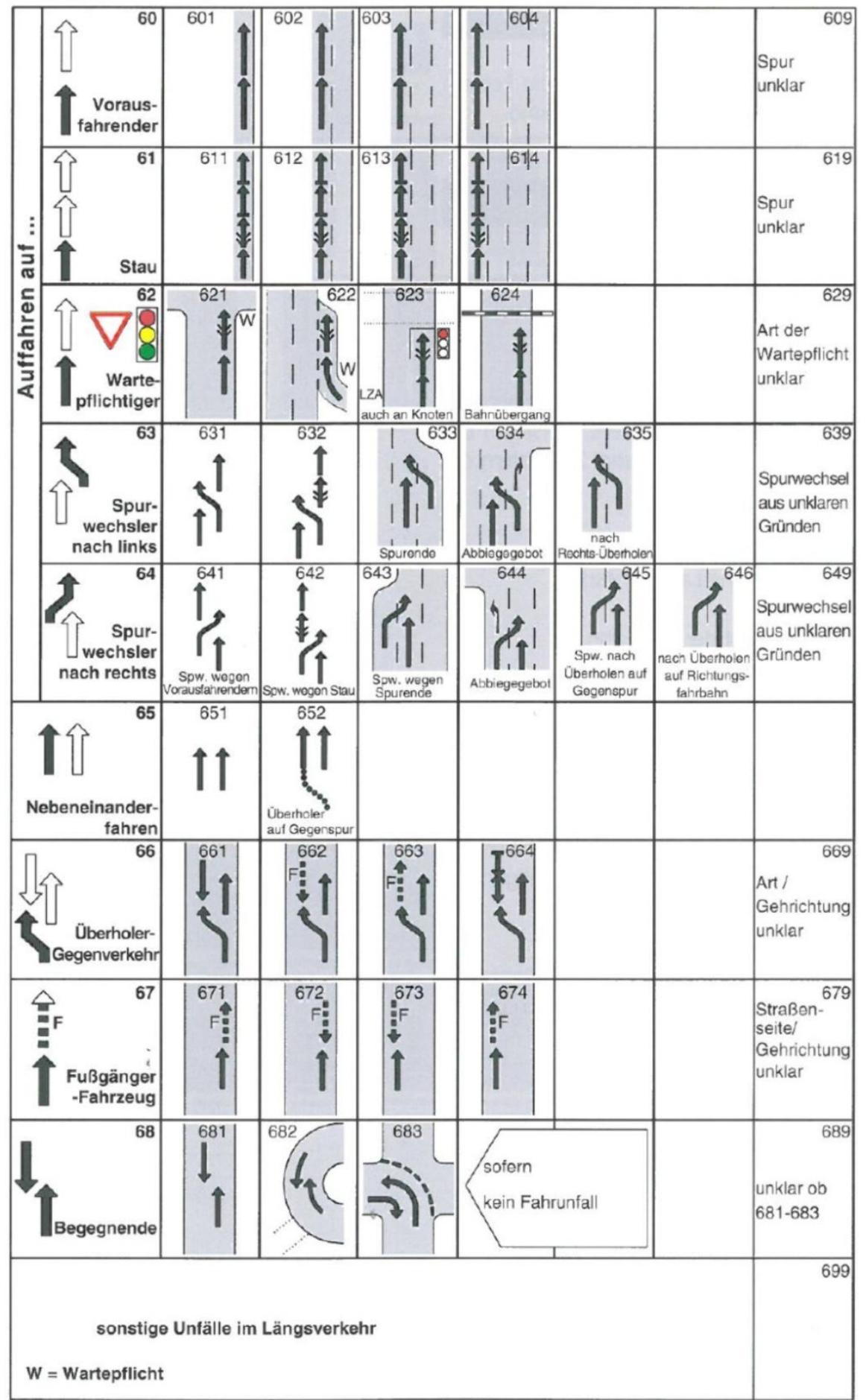

(Quelle: FGSV, 2003b) 


\section{Beschreibung Unfalltyp 7}

\section{Sonstiger Unfall (SO)}

Unfall, der sich nicht den Typen 1 - 6 zuordnen lässt. Beispiele: Wenden, Rückwärtsfahren, Parker untereinander, Hindernis oder Tier auf der Fahrbahn, plötzlicher Fahrzeugschaden (Bremsversagen, Reifenschaden o.Ä.)

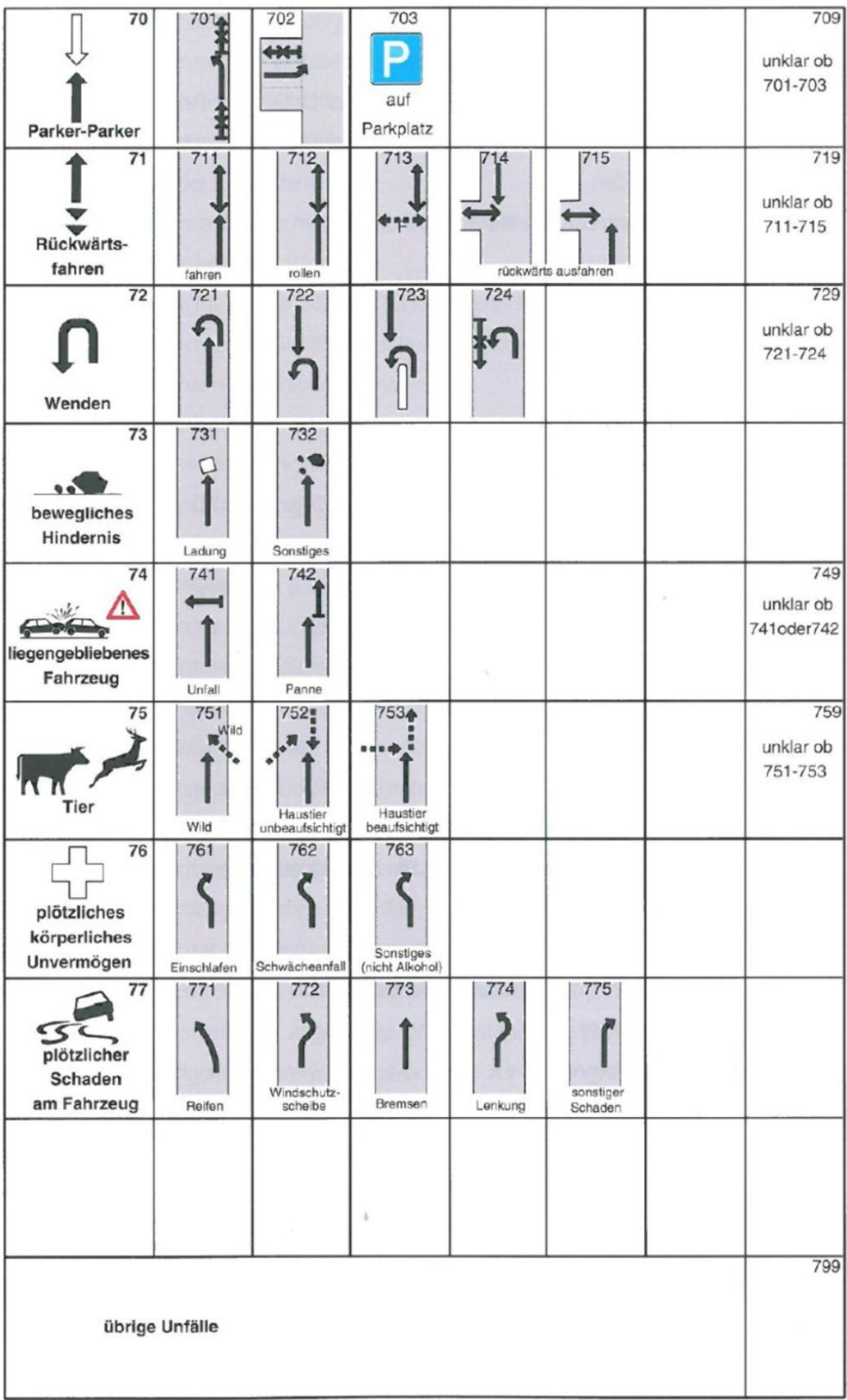

(Quelle: FGSV, 2003b) 


\section{Beschreibung der Unfallkategorien}

\begin{tabular}{l|l|l}
$\begin{array}{l}\text { Schwerste } \\
\text { Unfallfolge }\end{array}$ & $\begin{array}{l}\text { Unfall- } \\
\text { kategorie }\end{array}$ & Beschreibung* \\
\hline $\begin{array}{l}\text { Unfall mit } \\
\text { Getöteten }\end{array}$ & Kategorie 1 & Mindestens ein getöteter Verkehrsteilnehmer. \\
\hline $\begin{array}{l}\text { Unfall mit } \\
\text { Schwerverletzten }\end{array}$ & Kategorie 2 & $\begin{array}{l}\text { Mindestens ein schwerverletzter Verkehrsteilnehmer, } \\
\text { aber keine Getöteten. }\end{array}$ \\
\hline $\begin{array}{l}\text { Unfall mit } \\
\text { Leichtverletzten }\end{array}$ & Kategorie 3 & $\begin{array}{l}\text { Mindestens ein leichtverletzter Verkehrsteilnehmer, } \\
\text { aber keine Getöteten und keine Schwerverletzten. }\end{array}$ \\
\hline $\begin{array}{l}\text { schwerwiegender } \\
\text { Unfall mit } \\
\text { Sachschaden }\end{array}$ & Kategorie 4 & $\begin{array}{l}\text { Unfälle mit Sachschaden und Straftatbestand oder } \\
\text { Ordnungswidrigkeits-Anzeige (unfallursächlich), bei } \\
\text { denen mind. ein Kraftfahrzeug nicht mehr fahrbereit } \\
\text { ist (abschleppen). }\end{array}$ \\
\hline $\begin{array}{l}\text { Sonstiger } \\
\text { Unfall mit } \\
\text { Sachschaden }\end{array}$ & Kategorie 5 & $\begin{array}{l}\text { Sachschadenunfälle } \\
\text {-mit Straftatbestand oder Ordnungswidrigkeits- } \\
\text { Anzeige ohne Alkohol, bei denen alle Kraftfahrzeuge } \\
\text { fahrbereit sind, } \\
\text {-mit lediglich geringfügiger Ordnungswidrigkeit } \\
\text { (Verwarnung), unabhängig, ob ein Kfz fahrbereit oder } \\
\text { nicht fahrbereit. }\end{array}$ \\
\hline Alle übrigen Sachschadenunfälle mit Alkohol.
\end{tabular}

*Statistisches Bundesamt, Wiesbaden 1995

Unfälle der Kategorien 1 und 2 stellen Unfälle mit schwerem Personenschaden U(SP) und Unfälle der Kategorie 3 Unfälle mit leichtem Personenschaden U(LV) dar. Zusammengefasst ergeben Kategorie 1 bis 3 Unfälle mit Personenschaden $U(P)$.

Unfälle der Kategorie 4 sind Unfälle mit schwerwiegendem Sachschaden U(SS). Kategorie 5 und 6 betreffen alle Unfälle mit leichtem Sachschaden U(LS), Kategorie 6 hierbei allerdings mit Alkoholeinfluss. Unfälle der Kategorien 4 bis 6 bezeichnet man allgemein als Unfälle mit Sachschaden $\mathrm{U}(\mathrm{S})$.

(Quelle: FGSV, 2003b) 


\section{Beschreibung der Unfallarten}

1. Zusammenstoß mit anderem Fahrzeug, das anfährt, anhält oder im ruhenden Verkehr steht.

Anfahren oder Anhalten ist hier im Zusammenhang mit einer gewollten Fahrtunterbrechung zu sehen, die nicht durch die Verkehrslage veranlasst ist. Ruhender Verkehr im Sinne dieser Unfallart ist das Halten oder Parken am Fahrbahnrand, auf Seitenstreifen, auf den markierten Parkstellen unmittelbar am Fahrbahnrand, auf Gehwegen oder auf Parkplätzen. Der Verkehr von und zu Parkplätzen mit eigenen Zufahrten gehört zur Unfallart 5.

2. Zusammenstoß mit anderem Fahrzeug, das vorausfährt oder wartet.

Unfälle durch Auffahren auf ein Fahrzeug, das selbst noch fuhr oder verkehrsbedingt hielt. Auffahren auf anfahrende bzw. anhaltende Fahrzeuge gehören zur Unfallart 1.

3. Zusammenstoß mit anderem Fahrzeug, das seitlich in gleicher Richtung fährt. Unfälle beim Nebeneinanderfahren (Streifen) oder beim Fahrstreifenwechsel (Schneiden).

4. Zusammenstoß mit anderem Fahrzeug, das entgegenkommt.

Zusammenstöße im Begegnungsverkehr, ohne das ein Kollisionspartner die Absicht hatte, über die Gegenspur abzubiegen.

5. Zusammenstoß mit anderem Fahrzeug, das einbiegt oder kreuzt.

Zu dieser Unfallart gehören Zusammenstöße mit dem Querverkehr und Kollisionen mit Fahrzeugen die aus anderen Straßen, Wegen oder Grundstücken einbiegen oder dorthin abbiegen wollen. Das Auffahren auf wartende Abbieger gehört zur Unfallart 2.

6. Zusammenstoß zwischen Fahrzeug und Fußgänger.

Personen, die sich arbeitsbedingt auf der Fahrbahn aufhalten oder noch in enger Verbindung zu einem Fahrzeug stehen, wie Straßenarbeiter, Polizeibeamte bei der Verkehrsregelung oder ausgestiegene Fahrzeuginsassen bei Pannen zählen nicht als Fußgänger. Zusammenstöße mit innen gehören zur Unfallart 10.

7. Aufprall auf ein Hindernis auf der Fahrbahn.

Zu den Hindernissen zählen z.B. umgestürzte Bäume, Steine, verlorene Fracht sowie freilaufende Tiere oder Wild. Zusammenstöße mit geführten Tieren oder Reitern gehören zur Unfallart 10.

\subsection{Abkommen von der Fahrbahn nach rechts/links.}

Bei diesen Unfallarten ist es nicht zu einem Zusammenstoß mit anderen Verkehrsteilnehmern gekommen. Es kann jedoch weitere Unfallbeteiligte geben, z.B. wenn das verunglückte Fahrzeug von der Straße abgekommen ist, weil es einem anderen Verkehrsteilnehmer ausgewichen ist, ohne inn zu berühren.

10. Unfall anderer Art.

Hier werden alle Unfälle erfasst, die sich nicht einer der Unfallarten von 1 bis 9 zuordnen lassen.

(Quelle: FGSV, 2003b) 


\section{Unfallursachenverzeichnis}

Nr. Ursachenbezeichnung

Verkehrstüchtigkeit

01 Alkoholeinfluss

02 Einfluss anderer berauschender Mittel (z.B.

Drogen, Rauschgift)

03 Übermüdung

04 Sonstige körperliche oder geistige Mängel

Fehler der Fahrzeugführer

Straßenbenutzung

10 Benutzung der falschen Fahrbahn (auch

Richtungsfahrbahn) oder verbotswidrige

Benutzung anderer StraBenteile

11 Versto8 gegen das Rechtsfahrgebot

Geschwindigkeit

Nicht angepasste Geschwindigkeit

12 mit gleichzeitigem Überschreiten der

zulässigen Hōchstgeschwindigkeit

13 in anderen Fällen

\section{Abstand}

14 Ungenügender Sicherheitsabstand (Sonstige Ursachen, die zu einem Verkehrsunfall führen, sind den zutreffenden Positionen, wie Geschwindigkeit, Übermüdung usw. zuzuordnen)

15 Starkes Bremsen des Vorausfahrenden ohne zwingenden Grund

\section{Oberholen}

16 Unzulässiges Rechtsüberholen

17 Überholen trotz Gegenverkehrs

18 Überholen trotz unklarer Verkehrslage

19 Überholen trotz unzureichender

Sichtverhältnisse

20 Überholen ohne Beachtung des nachfolgenden Verkehrs und/oder ohne rechtzeitige und deutliche Ankündigung des Ausscherens

21 Fehler beim Wiedereinordnen nach rechts

22 Sonstige Fehler beim Überholen (z.B. ohne genügenden Seitenabstand; an

Fußgängerüberwegen s. Pos. 38, 39)

23 Fehler beim Überholtwerden

\section{Vorbeifahren}

24 Nichtbeachten des Vorranges entgegenkommender Fahrzeuge beim Vorbeifahren an haltenden Fahrzeugen, Absperrungen oder Hindernissen (\$ 6) (ausgenommen Pos. 32)
Nichtbeachten des nachfolgenden Verkehrs beim Vorbeifahren an haltenden Fahrzeugen, Absperrungen oder Hindemissen und/oder ohne rechtzeitige und deutliche Ankündigung des Ausscherens

\section{Nebeneinanderfahren}

Fehlerhaftes Wechseln des Fahrstreifens beim Nebeneinanderfahren oder Nichtbeachten des ReiBverschlussverfahrens ( $\$ 7$ ) (ausgenommen Pos. 20, 25)

\section{Vorfahrt, Vorrang}

Nichtbeachten der Regel "rechts vor links" Nichtbeachten der die Vorfahrt regelnden Verkehrszeichen (\$ 8) (ausgenommen Pos. 29) Nichtbeachten der Vorfahrt des

durchgehenden Verkehrs auf Autobahnen oder Kraftfahrstraßen (\$18, Abs. 3)

Nichtbeachten der Vorfahrt durch Fahrzeuge, die aus Feld- und Waldwegen kommen

31 Nichtbeachten der Verkehrsregelung durch Polizeibeamte oder Lichtzeichen

(ausgenommen Pos. 39)

32 Nichtbeachten des Vorranges entgegenkommender Fahrzeuge (Zeichen 208 StVO)

33 Nichtbeachten des Vorranges von Schienenfahrzeugen an Bahnübergängen

Abbiegen, Wenden, Rückwärtsfahren, Ein- und Anfahren Fehler beim Abbiegen ( 59 ) (ausgenommen Pos. 33,40 )

Fehler beim Wenden oder Rückwärtsfahren Fehler beim Einfahren in den flieBenden Verkehr (z.B. aus einem Grundstück, von einem anderen Straßenteil oder beim Anfahren vom Fahrbahnrand)

Falsches Verhalten gegenüber Fưßgängern an Fưgängerüberwegen an Fußgängerfurten beim Abbiegen an Haltestellen (auch haltenden Schulbussen mit eingeschaltetem Wamblinklicht) 
Anhang B

Berechnung von Unfallkenngrößen und angepassten Unfallkostensätzen 
Unfallkenngrößen für einzelne Streckenabschnitte

$$
\begin{array}{ll}
\mathrm{UR}=\frac{10^{6} * \mathrm{U}}{365 * \mathrm{DTV} * \mathrm{~L} * \mathrm{t}} & {\left[\frac{\mathrm{U}}{10^{6} \mathrm{Kfz} * \mathrm{~km}}\right]} \\
\mathrm{UKR}=\frac{1000 * \mathrm{UK}}{365 * \mathrm{DTV} * \mathrm{~L} * \mathrm{t}} & {\left[\frac{\mathrm{Euro}}{1000 \mathrm{Kfz} * \mathrm{~km}}\right]} \\
\mathrm{UD}=\frac{\mathrm{U}}{\mathrm{L} * \mathrm{t}} & {\left[\frac{\mathrm{U}}{\mathrm{km} * \mathrm{a}}\right]} \\
\mathrm{UKD}=\frac{\mathrm{UK}}{1000 * \mathrm{~L} * \mathrm{t}} & {\left[\frac{1000 \text { Euro }}{\mathrm{km} * \mathrm{a}}\right]} \\
\mathrm{SIPO}=\mathrm{UKD}-\mathrm{gUKD} & {\left[\frac{1000 \text { Euro }}{\mathrm{km} * \mathrm{a}}\right]} \\
\mathrm{gUKD}=\frac{\mathrm{gUKR} * \mathrm{DTV} * 365}{10^{6}} & {[}
\end{array}
$$

$\begin{array}{ll}\text { UR } & \text { Unfallrate } \\ \text { UKR } & \text { Unfallkostenrate } \\ \text { UD } & \text { Unfalldichte } \\ \text { UKD } & \text { Unfallkostendichte } \\ \text { SIPO } & \text { Sicherheitspotential } \\ \text { gUKD } & \text { Grundunfallkostendichte } \\ \text { gUKR } & \text { Grundunfallkostenrate [Euro/1000 Kfz * km] } \\ \text { U } & \text { Unfallanzahl [-] } \\ \text { UK } & \text { Unfallkosten [Euro] } \\ \text { DTV } & \text { Durchschnittliche tägliche Verkehrsstärke [Kfz/24h] } \\ \text { L } & \text { Länge des Streckenabschnittes [km] } \\ t & \text { Länge des Untersuchungszeitraumes [a] }\end{array}$




\section{Unfallkenngrößen für zusammengefasste Straßenzüge}

$\mathrm{UR}=\frac{10^{6} * \sum\left(\frac{\mathrm{U}}{\mathrm{t}}\right)}{\sum(365 * \mathrm{DTV} * \mathrm{~L})}$

$\left[\frac{\mathrm{U}}{10^{6} \mathrm{Kfz} * \mathrm{~km}}\right]$

$\mathrm{UKR}=\frac{1000 * \sum\left(\frac{\mathrm{UK}}{\mathrm{t}}\right)}{\sum(365 * \mathrm{DTV} * \mathrm{~L})}$

$\left[\frac{\text { Euro }}{1000 \mathrm{Kfz} * \mathrm{~km}}\right]$

$\mathrm{UD}=\frac{\sum\left(\frac{\mathrm{U}}{\mathrm{t}}\right)}{\sum(\mathrm{L})}$

$\left[\frac{\mathrm{U}}{\mathrm{km} * \mathrm{a}}\right]$

$\mathrm{UKD}=\frac{\sum\left(\frac{\mathrm{UK}}{\mathrm{t}}\right)}{\sum(1000 * \mathrm{~L})}$

$\left[\frac{1000 \text { Euro }}{\mathrm{km} * \mathrm{a}}\right]$

SIPO $=$ UKD - gUKD

$\left[\frac{1000 \text { Euro }}{\mathrm{km} * \mathrm{a}}\right]$

$\operatorname{gUKD}=\frac{365 * \sum_{1}(\mathrm{gUKR} * \mathrm{DTV} * \mathrm{~L})}{\left(10^{6} * \sum \mathrm{L}\right)}$

$\left[\frac{1000 \text { Euro }}{\mathrm{km} * \mathrm{a}}\right]$

UR

Unfallrate

UKR

Unfallkostenrate

UD

Unfalldichte

UKD

Unfallkostendichte

SIPO

Sicherheitspotential

gUKD

Grundunfallkostendichte

gUKR

Grundunfallkostenrate [Euro/1000 Kfz * km]

$\mathrm{U}$

Unfallanzahl [-]

UK

Unfallkosten [Euro]

DTV

Durchschnittliche tägliche Verkehrsstärke [Kfz/24h]

L

Länge des Streckenabschnittes [km]

$\mathrm{t}$

Länge des Untersuchungszeitraumes [a] 


\section{Anpassung der Unfallkostensätze}

$$
\begin{array}{lll}
\mathrm{WUa}(\mathrm{SP}) & =\frac{\mathrm{V}(\mathrm{GT}) * \mathrm{WV}(\mathrm{GT})+\mathrm{V}(\mathrm{SV}) * \mathrm{WV}(\mathrm{SV})+\mathrm{V}(\mathrm{LV}) * \mathrm{WV}(\mathrm{LV})+\mathrm{U}(\mathrm{SP}) * \mathrm{WUS}(\mathrm{SP})}{\mathrm{U}(\mathrm{SP})} & {\left[\frac{\text { Euro }}{\mathrm{U}}\right]} \\
\mathrm{WUa}(\mathrm{LV})=\frac{\mathrm{V}(\mathrm{LV}) * \mathrm{WV}(\mathrm{LV})+\mathrm{U}(\mathrm{LV}) * \mathrm{WUS}(\mathrm{LV})}{\mathrm{U}(\mathrm{LV})} & {\left[\frac{\text { Euro }}{\mathrm{U}}\right]}
\end{array}
$$

\section{Berechnung der angepassten Unfallkosten}

$$
\begin{array}{lr}
\mathrm{UKa}(\mathrm{P})=\mathrm{U}(\mathrm{SP}) * \mathrm{WUa}(\mathrm{SP})+\mathrm{U}(\mathrm{LV}) * \mathrm{WUa}(\mathrm{LV}) & {[\text { Euro] }} \\
\mathrm{UK}(\mathrm{SS})=\mathrm{U}(\mathrm{SS}) * \mathrm{WU}(\mathrm{SS}) & {[\text { Euro] }} \\
\mathrm{UKa}=\mathrm{UKa}(\mathrm{P})+\mathrm{UK}(\mathrm{SS}) & {[\text { Euro }]}
\end{array}
$$

WUa(SP) angepasster Unfallkostensatz für Unfälle mit schwerem Personenschaden

WUa(LV) angepasster Unfallkostensatz für Unfälle mit leichtem Personenschaden

WUS(SP/LV/SS) Unfallkostensatz für Sachschaden bei Unfällen mit schwerem Personenschaden/leichtem Personenschaden/schwerem Sachschaden [Euro/U]

V(GT/SV/LV) Anzahl der Getöteten/Schwerverletzten/Leichtverletzten [-]

WV(GT/SV/LV) Kostensatz für Getötete/Schwerverletzte/Leichtverletzte [Euro/Person]

U(SP/LV/SS) Anzahl der Unfälle mit schwerem Personenschaden/leichtem Personenschaden/schwerem Sachschaden [-]

$\mathrm{UKa}(\mathrm{P}) \quad$ angepasste Unfallkosten für Unfälle mit Personenschaden [Euro]

UK(SS) angepasste Unfallkosten für Unfälle schwerem Sachschaden [Euro]

UKa angepasste Unfallkosten

\begin{tabular}{|l|c|}
\hline Schwere der Verletzung & Kostensatz WV [Euro/Person] \\
\hline GT: Getötet & 1.250 .000 \\
\hline SV: Schwerverletzt & 85.000 \\
\hline LV: Leichtverletzt & 3.750 \\
\hline
\end{tabular}

Kostensätze für Verunglückte - Preisstand 2000 (Quelle: FGSV, 2003b)

\begin{tabular}{|l|c|}
\hline \multicolumn{1}{|c|}{ Unfallkategorie } & Kostensatz WV [Euro/U] \\
\hline SP: Unfall mit Getöteten oder Schwerverletzten & 17.000 \\
\hline LV: Unfall mit Leichtverletzten & 13.000 \\
\hline SS: Schwerwiegender Unfall mit Sachschaden & 13.000 \\
\hline
\end{tabular}

Kostensätze für Sachschäden bei Unfällen auf Landstraßen (Quelle: FGSV, 2003b) 


\section{Anhang C \\ Zusammenhänge zwischen dem Gesamtunfallgeschehen und dem Kollektiv der Überholunfälle}


7) Überholunfälle auf Landstraßen - Anhänge zum Abschlussbericht

Unfallanzahl $(n=6.209)$

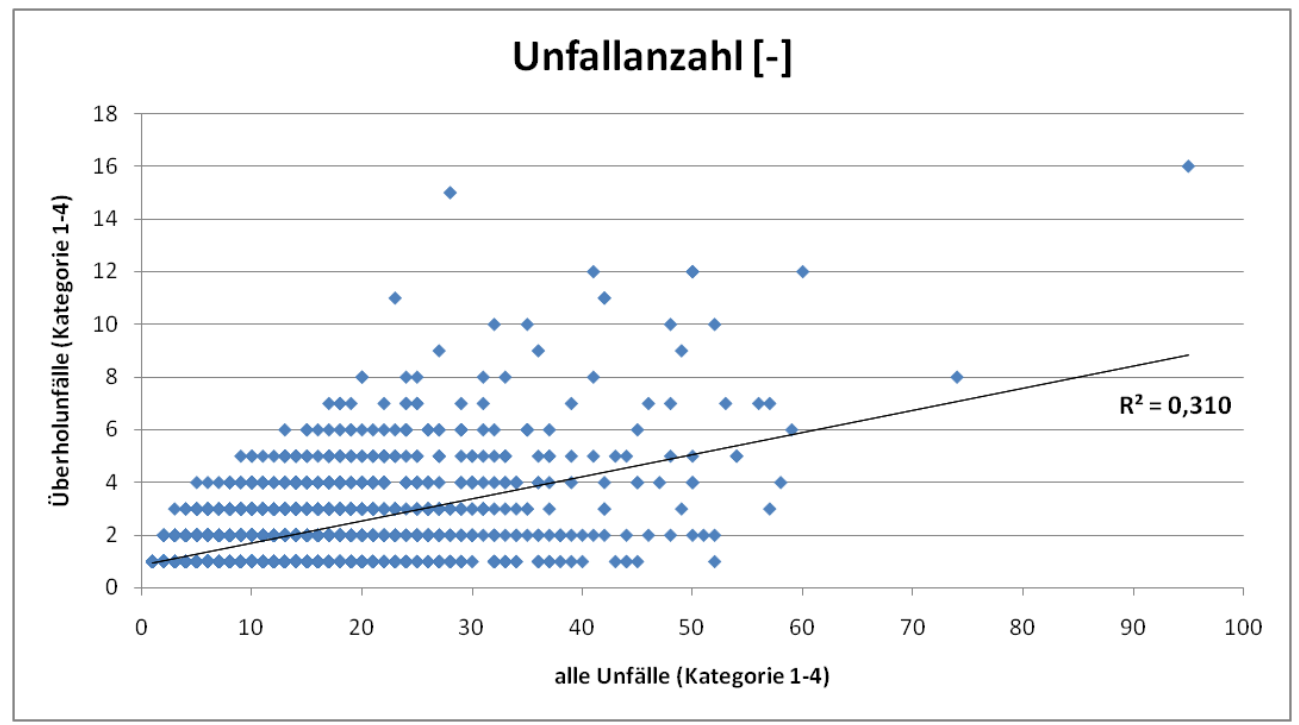

Anzahl Untersuchungsstrecken $(n=2.412)$

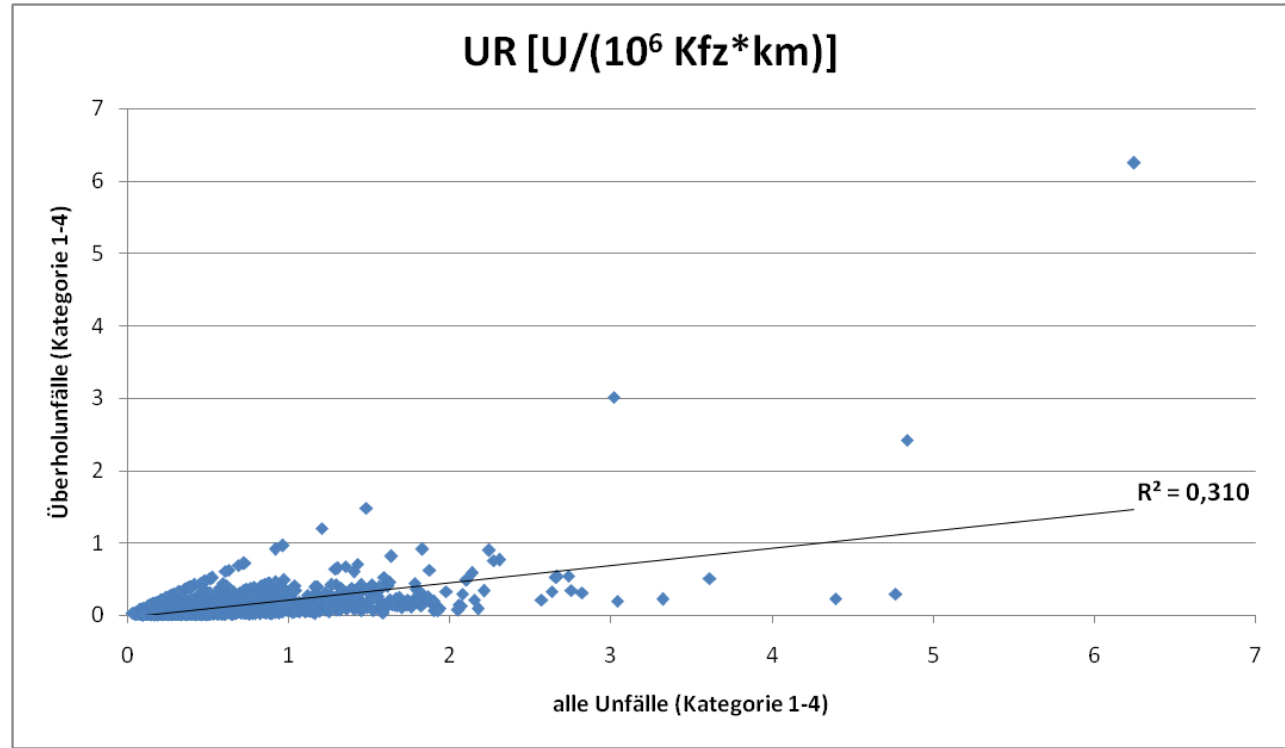

Anzahl Untersuchungsstrecken $(n=2.412)$

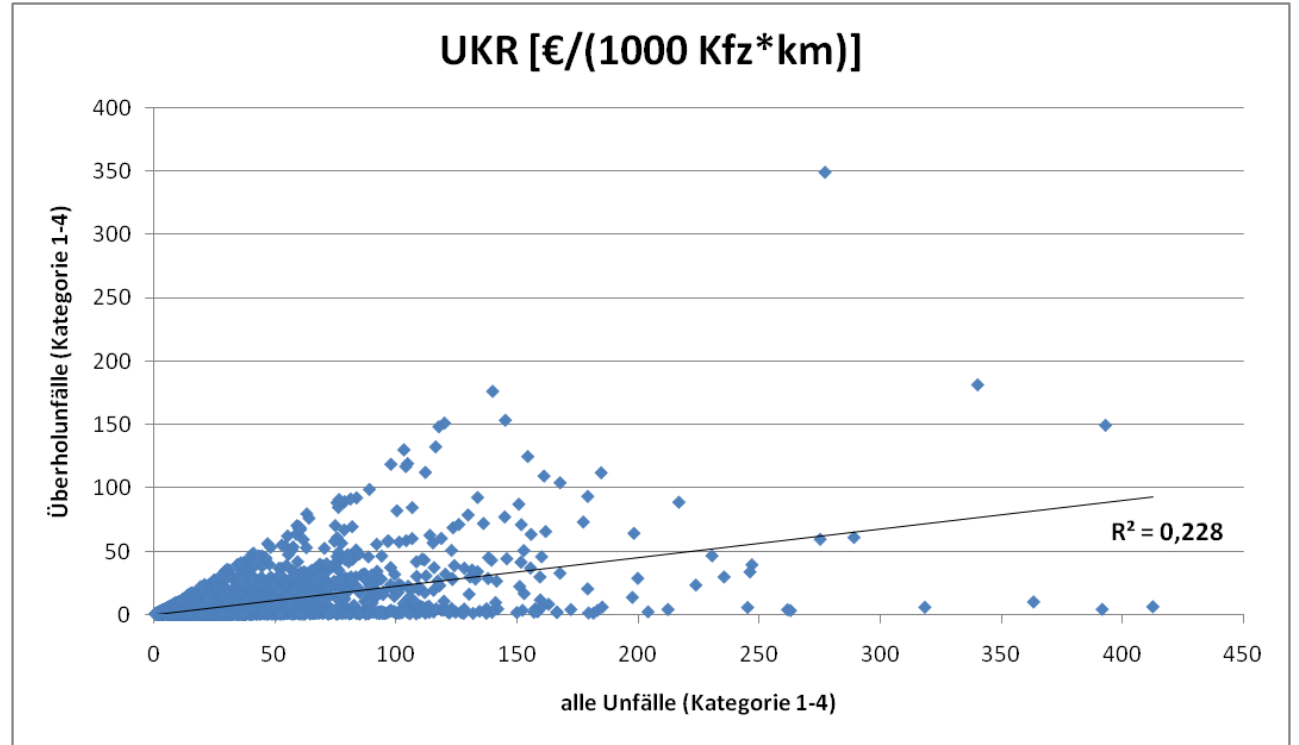


7) Überholunfälle auf Landstraßen - Anhänge zum Abschlussbericht

Anzahl Untersuchungsstrecken $(n=3.445)$

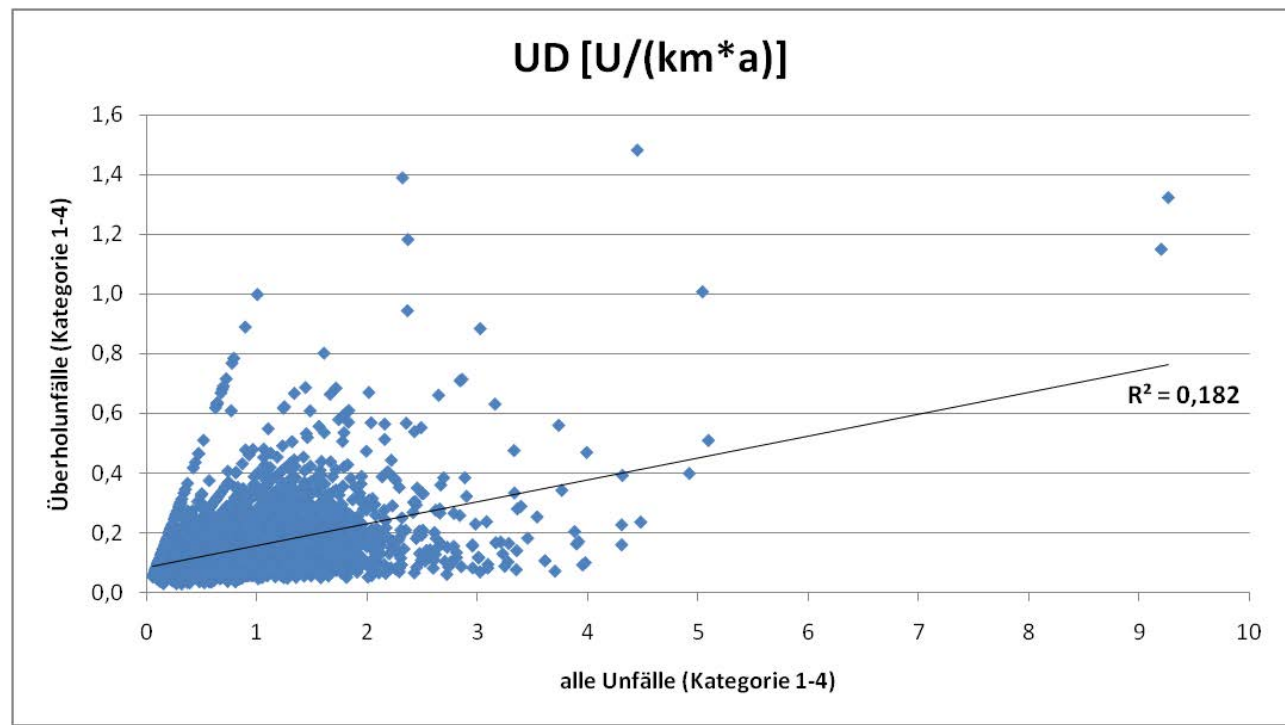

Anzahl Untersuchungsstrecken $(n=3.445)$

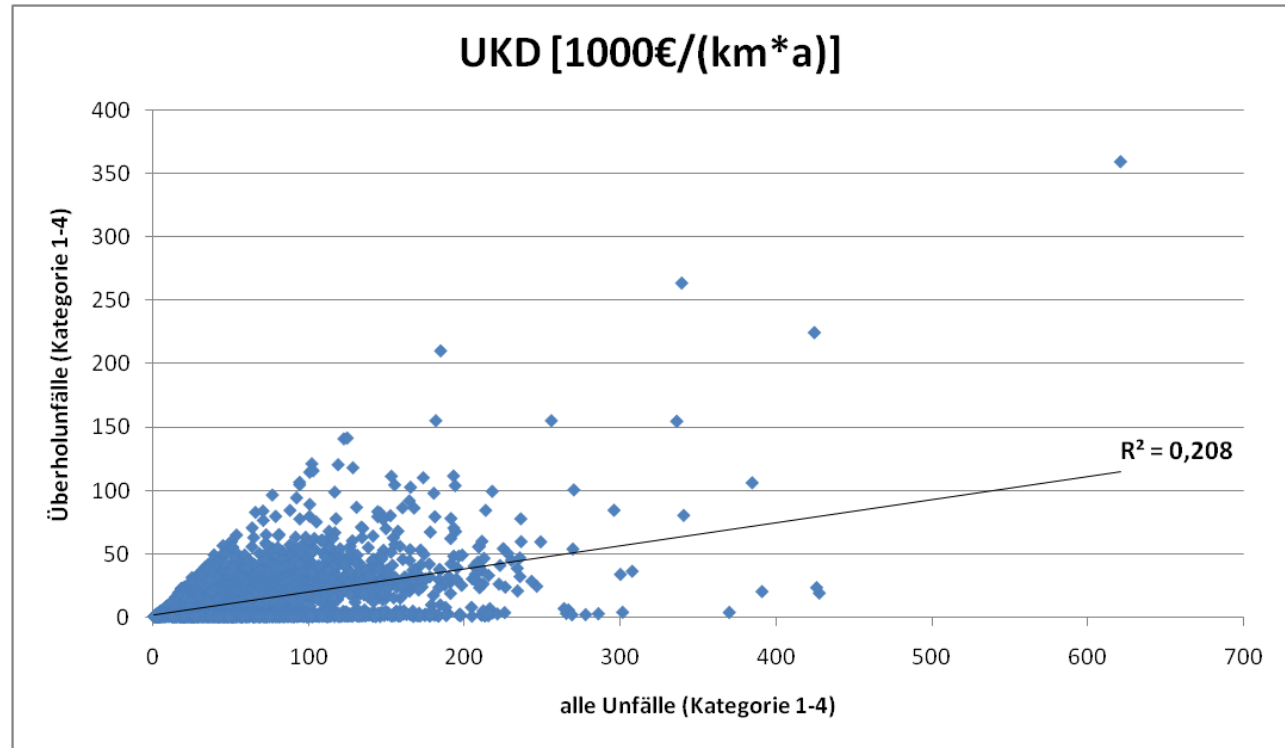

Anzahl Untersuchungsstrecken $(n=2.412)$

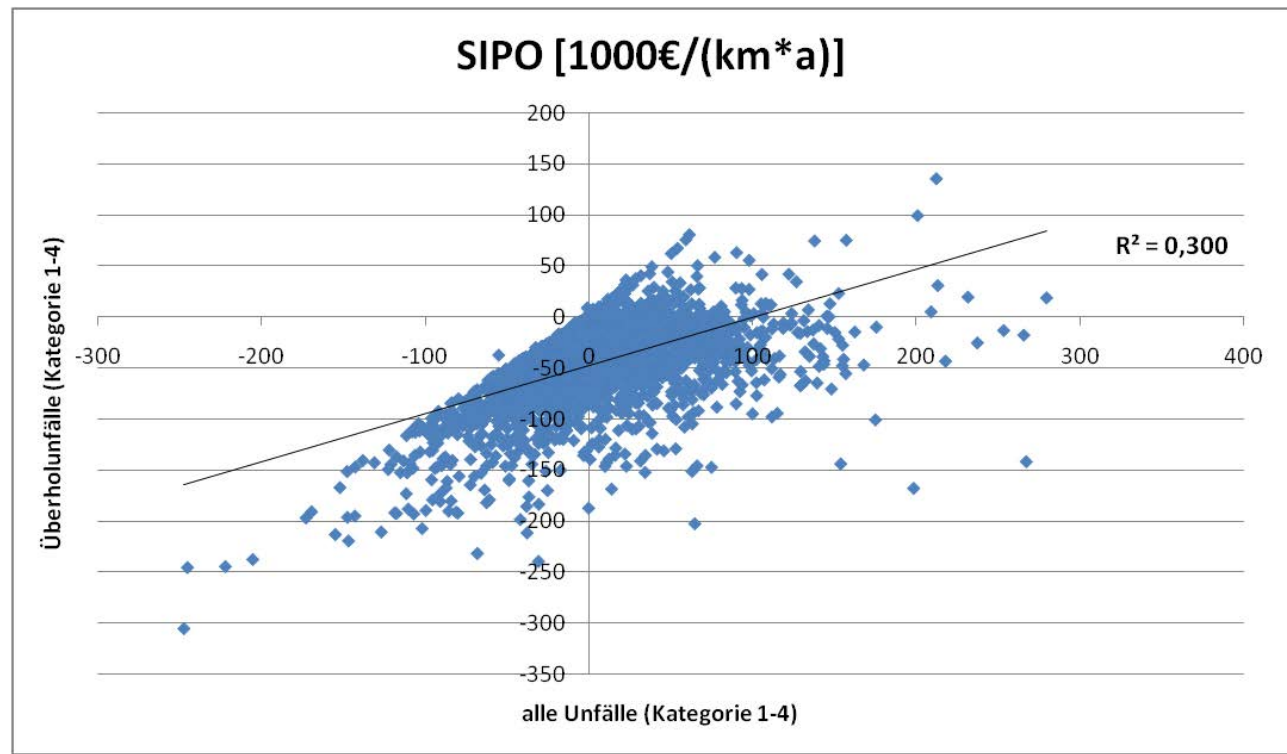




\section{Anhang D \\ Rangfolge der $\mathbf{5 0 0}$ mit Überholunfällen auffälligsten Untersuchungsstrecken}




\begin{tabular}{|c|c|c|c|c|c|c|c|c|c|c|c|c|c|c|c|c|}
\hline $\begin{array}{l}\frac{N}{\pi} \\
\frac{\pi}{0} \\
\frac{0}{0} \\
\frac{0}{0} \\
\frac{0}{5} \\
\frac{0}{\pi} \\
\widetilde{x}\end{array}$ & 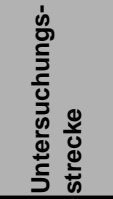 & 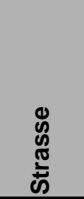 & 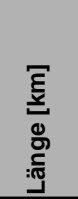 & 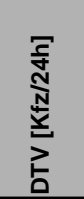 & 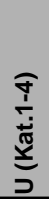 & 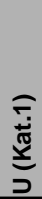 & 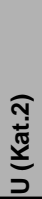 & 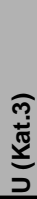 & 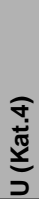 & $\begin{array}{l}\underset{\Psi}{\Psi} \\
\text { y }\end{array}$ & 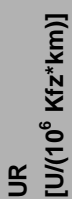 & 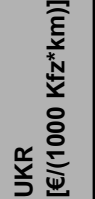 & ○ & 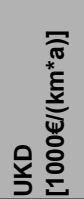 & 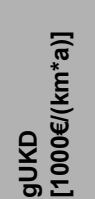 & 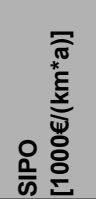 \\
\hline 1. & BL2-967 & L512 & 0,720 & 12467 & 3 & 0 & 2 & 0 & 1 & 569.132 & 0,31 & $57, \overline{90}$ & 1,39 & 263,49 & 127,41 & 136,07 \\
\hline 2. & BL1-688 & L389 & 1,869 & 9121 & 3 & 0 & 3 & 0 & 0 & 869.544 & 0,16 & 47,45 & 0,54 & 155,08 & 91,51 & 63,57 \\
\hline 3. & BL5-306 & B 32 & 2,191 & 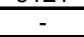 & 4 & 0 & 3 & 1 & 0 & 929.381 & טג, & 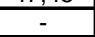 & 0,61 & 141,39 & & - \\
\hline 4. & BL5-3380 & B 33 & 0,750 & 17402 & 2 & 0 & 1 & 0 & 1 & 316.784 & 0,14 & 22,17 & 0,89 & 140,79 & 177,85 & $-37,06$ \\
\hline 5. & BL1-710 & L356 & 1,662 & 5873 & 2 & 0 & 2 & 0 & 0 & 579.696 & 0,14 & 40,91 & 0,40 & 116,26 & 79,57 & 36,70 \\
\hline 6. & BL5-275 & L 181 & 3,678 & 5409 & 5 & 1 & 3 & 0 & 1 & 1.228 .136 & 0,23 & 56,38 & 0,45 & 111,30 & 55,28 & 56,02 \\
\hline 7. & BL5-55 & L 200 & 2,759 & - & 3 & 0 & 3 & 0 & 0 & 911.352 & - & - & 0,36 & 110,11 & 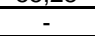 & \\
\hline 8. & BL4-387 & L 24 & 1,078 & 4300 & 2 & 0 & 1 & 0 & 1 & 344.537 & 0,39 & 67,88 & 0,62 & 106,54 & 43,95 & 62,59 \\
\hline 9. & BL1-18 & B8 & 3,898 & 10639 & 8 & 1 & 3 & 2 & 2 & 1.221 .356 & 0,18 & 27,03 & 0,68 & 104,44 & 108,21 & $-3,77$ \\
\hline 10. & BL5-403 & L 1192 & 1,949 & 13128 & 2 & 0 & 2 & 0 & 0 & 607.568 & 0,08 & 23,86 & 0,34 & 103,91 & 121,96 & $-18,04$ \\
\hline 11. & BL1-471 & K67 & 1,000 & 2700 & 2 & 0 & 1 & 1 & 0 & 307.830 & 0,68 & 104,12 & 0,67 & 102,61 & 27,59 & 75,02 \\
\hline 12. & BL3-183 & K7150 & 1,108 & - & 2 & 0 & 1 & 1 & 0 & 334.269 & - & 2 & 0,60 & 100,56 & - & - \\
\hline 13. & BL4-236 & B 79 & 5,847 & 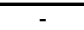 & 10 & 0 & 5 & 4 & 1 & 1.743 .601 & - & - & 0,57 & 99,40 & - & - \\
\hline 14. & BL1-151 & L322 & 2,933 & 3900 & 3 & 0 & 3 & 0 & 0 & 869.544 & 0,24 & 69,42 & 0,34 & 98,82 & 39,86 & 58,97 \\
\hline 15. & BL5-208 & B 30 & 2,068 & - & 2 & 2 & 0 & 0 & 0 & 607.568 & - & 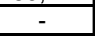 & 0,32 & 97,93 & 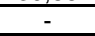 & 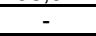 \\
\hline 16. & BL5-197 & L 151 & 2,211 & - & 3 & 0 & 2 & $\frac{1}{1}$ & 0 & 625.597 & - & - & 0,45 & 94,32 & - & - \\
\hline 17. & BL5-91 & L 201 & 2,203 & - & 2 & 0 & 2 & 0 & 0 & 607.568 & - & - & 0,30 & 91,93 & - & - \\
\hline 18. & BL5-228 & B 311 & 3,524 & - & 5 & 1 & 2 & 1 & 1 & 942.381 & - & 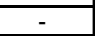 & 0,47 & 89,14 & - & - \\
\hline 19. & BL2-210 & L591 & 3,202 & 8067 & 3 & 0 & 3 & 0 & $\frac{1}{0}$ & 834.198 & 0,11 & 29,49 & 0,31 & 86,84 & 82,44 & 4,40 \\
\hline 20. & BL5-376 & $L 371$ & 3,583 & - & 4 & 0 & 3 & 1 & 0 & 929.381 & - & - & 0,37 & 86,46 & - & - \\
\hline 21. & BL4-232 & B 81 & 4,105 & 16026 & 7 & 1 & 2 & 3 & 1 & 1.062 .298 & 0,10 & 14,75 & 0,57 & 86,26 & 163,79 & $-77,53$ \\
\hline 22. & BL3-1184 & L743 & 1,318 & 6323 & 2 & 0 & 1 & 1 & 0 & 334.269 & 0,22 & 36,63 & 0,51 & 84,54 & 64,62 & 19,92 \\
\hline 23. & BL2-440 & L763 & 2,195 & 3907 & 2 & 0 & 2 & 0 & 0 & 556.132 & 0,21 & 59,22 & 0,30 & 84,45 & 39,93 & 44,52 \\
\hline 24. & BL5-394 & $L 1250$ & 1,413 & 8799 & 4 & 0 & 1 & 3 & 0 & 357.871 & 0,29 & 26,29 & 0,94 & 84,42 & 89,93 & $-5,50$ \\
\hline 25. & BL3-1197 & L79 & 6,449 & 3951 & 6 & 0 & 5 & 0 & 1 & 1.595 .405 & 0,22 & 57,28 & 0,31 & 82,46 & 40,31 & 42,15 \\
\hline 26. & BL5-577 & B 39 & 2,517 & 6051 & 2 & 0 & 2 & 0 & 0 & 607.568 & 0,12 & 36,74 & 0,26 & 80,46 & 61,33 & 19,14 \\
\hline 27. & BL4-264 & B 86 & 2,809 & 7142 & 3 & 0 & 2 & 0 & 1 & 676.074 & 0,13 & 30,25 & 0,36 & 80,23 & 74,27 & 5,96 \\
\hline 28. & BL5-550 & L592 & 3,887 & & 4 & 0 & 3 & $\frac{1}{1}$ & $\frac{1}{0}$ & 929.381 & 0,10 & & 0,34 & 79,70 & $t \rightarrow, 2$ & 0,00 \\
\hline 29. & BL2-428 & L679 & 1,238 & 10606 & 2 & 0 & 1 & $\frac{1}{1}$ & 0 & 295.894 & 0,14 & 20,58 & 0,54 & 79,67 & 108,39 & $-28,72$ \\
\hline 30. & BL3-1185 & L40 & 1,403 & 7374 & 2 & 0 & 1 & 1 & 0 & 334.269 & 0,18 & 29,51 & 0,48 & 79,42 & 75,36 & 4,06 \\
\hline 31. & BL4-280 & L 172 & 4,326 & 9057 & 4 & 0 & 3 & 1 & 0 & 1.012 .840 & 0,09 & 21,98 & 0,31 & 78,04 & 99,40 & $-21,35$ \\
\hline 32. & BL4-314 & L 205 & 4,258 & 8771 & 3 & 0 & 3 & 0 & 0 & 994.611 & 0,07 & 24,32 & 0,23 & 77,86 & 89,64 & $-11,78$ \\
\hline 33. & BL5-12 & $L 320$ & 3,912 & & 3 & 0 & 3 & 0 & 0 & 911.352 & & & 0,26 & 77,65 & 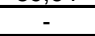 & \\
\hline 34. & BL5-115 & L 185 & 3,969 & 3302 & 3 & 1 & 2 & 0 & 0 & 911.352 & 0,21 & 63,51 & 0,25 & 76,54 & 33,75 & 42,79 \\
\hline 35. & BL5-126 & B 27 & 5,539 & - & 6 & 0 & 4 & 2 & 0 & 1.251 .194 & - & $\frac{1}{-}$ & 0,36 & 75,30 & - & A. \\
\hline 36. & BL5-673 & B 292 & 4,385 & - & 4 & 0 & 3 & 1 & 0 & 929.381 & - & - & 0,30 & 70,65 & - & - \\
\hline 37. & BL5-648 & L 1088 & 4,325 & - & 3 & 0 & 3 & 0 & 0 & 911.352 & - & - & 0,23 & 70,24 & - & - \\
\hline 38. & BL2-614 & L163 & 2,648 & 2700 & 2 & 0 & 2 & 0 & 0 & 556.132 & 0,26 & 71,04 & 0,25 & 70,01 & 27,59 & 42,41 \\
\hline 39. & BL5-667 & B 27 & 4,703 & - & 6 & $\frac{1}{1}$ & 2 & $\frac{2}{2}$ & 1 & 960.410 & $\frac{5, L}{-}$ & - & 0,43 & 68,07 & - & - \\
\hline 40. & BL5-391 & L 1209 & 2,978 & - & 2 & 0 & 2 & 0 & 0 & 607.568 & - & - & 0,22 & 68,01 & - & - \\
\hline 41. & BL4-370 & B 242 & 1,721 & 5905 & 2 & 0 & 1 & 1 & 0 & 349.766 & 0,18 & 31,43 & 0,39 & 67,74 & 60,35 & 7,40 \\
\hline 42. & BL5-298 & B 313 & 4,729 & - & 6 & 0 & 3 & 1 & 2 & 955.381 & - & & 0,42 & 67,34 & 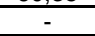 & \\
\hline 43. & BL1-455 & L428 & 2,981 & 7300 & 3 & 0 & 2 & 1 & 0 & 597.678 & 0,13 & 25,08 & 0,34 & 66,83 & 74,61 & $-7,77$ \\
\hline 44. & BL3-1135 & L96 & 4,839 & 1436 & 3 & 0 & 3 & 0 & 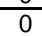 & 949.443 & 0,39 & 124,78 & 0,21 & 65,40 & 14,68 & 50,73 \\
\hline 45. & BL5-225 & B 311 & 6,349 & 8721 & 6 & 1 & 3 & 0 & 2 & 1.241 .136 & 0,10 & 20,47 & 0,32 & 65,16 & 89,13 & $-23,97$ \\
\hline 46. & BL1-381 & L205 & 2,973 & 1500 & 2 & 0 & 2 & 0 & 0 & 579.696 & 0,41 & 118,71 & 0,22 & 65,00 & 15,33 & 49,67 \\
\hline 47. & BL3-1133 & L88 & 4,900 & 2914 & 3 & 0 & 0 & 0 & 0 & 949.443 & 0,19 & 60,73 & 0,20 & 64,59 & 29,78 & 34,81 \\
\hline 48. & BL1-528 & L493 & 3,098 & 7421 & 3 & 0 & 2 & 1 & 0 & 597 & 0,12 & 23,74 & 0,32 & 64,31 & 75,84 & \begin{tabular}{|l|l|}
$-11,53$ \\
\end{tabular} \\
\hline 49. & BL3-135 & B101 & 5,204 & 5736 & 6 & 0 & 3 & 3 & 0 & 1.002 .807 & 0,18 & 30,68 & 0,38 & 64,23 & 58,62 & 5,61 \\
\hline 50. & BL5-1001 & L 387 & 5,081 & & 6 & 0 & 3 & 3 & 0 & 96 & 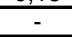 & 10 & 0,39 & 63,34 & , & \\
\hline 51. & BL1-148 & L335 & 6,114 & 3519 & 4 & 0 & 4 & 0 & 0 & 1.159 .392 & 0,17 & 49,21 & 0,22 & 63,21 & 35,96 & 27,25 \\
\hline 52. & BL4-4 & B 190 & 3,508 & 4371 & 2 & 0 & 2 & 0 & 0 & & 0,12 & 39,49 & 0,19 & 63,01 & 44,67 & 18,33 \\
\hline 53. & BL3-73 & B102 & 6,702 & 6050 & 4 & 2 & 2 & 0 & 0 & 1.265 .924 & 0,09 & 28,51 & 0,20 & 62,96 & 61,83 & 1,13 \\
\hline 54. & BL1-403 & B48 & 1,635 & 2714 & 2 & 0 & 1 & 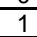 & & 307.830 & 0,41 & 63,35 & 0,41 & 62,76 & 27,74 & 35,02 \\
\hline 55. & BL2-984 & B236 & 3,154 & 8675 & 4 & 0 & 2 & $\frac{2}{2}$ & 0 & 591. & 0,13 & 19,75 & 0,42 & 62,54 & 88,66 & $-26,11$ \\
\hline 56. & BL5-53 & L 201 & 3,244 & & 2 & 0 & 2 & 0 & 0 & 607 & & & 0,21 & 62,43 & & \\
\hline 57. & BL1-252 & B259 & 5,343 & 5427 & 11 & 0 & 3 & 5 & 3 & 998.454 & 0,34 & 31,11 & 0,69 & 62,29 & 56,06 & 6,24 \\
\hline 58. & BL2-993 & L735 & 3,119 & 3788 & 4 & 0 & 2 & 0 & 2 & 582.132 & 0,31 & 45,00 & 0,43 & 62,21 & 38,71 & 23,50 \\
\hline 59. & BL2-679 & B51 & 3,035 & 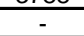 & 2 & 1 & 1 & 0 & 0 & 556.132 & - & , & 0,22 & 61,08 & - & , \\
\hline 60. & BL2-337 & B61 & 3,301 & 10867 & 5 & 0 & 2 & 1 & 2 & 599.960 & 0,13 & 15,27 & 0,50 & 60,58 & 111,06 & $-50,48$ \\
\hline 61. & BL4-358 & B 185 & 5,485 & 5661 & 3 & 1 & 2 & 0 & 0 & & 0,09 & 29,25 & 0,18 & 60,44 & 57,86 & 2,59 \\
\hline 62. & BL5-193 & B 34 & 3,474 & 19118 & 3 & 0 & 2 & $\frac{1}{1}$ & 0 & 625.597 & 0,04 & 8,60 & 0,29 & 60,03 & 195,39 & $-135,36$ \\
\hline 63. & BL4-157 & B 185 & 6,343 & 7240 & 12 & 1 & 2 & 5 & 4 & 1.137 .756 & 0,24 & 22 & 0,63 & 59,79 & 74,06 & $-14,27$ \\
\hline 64. & BL3-128 & B101 & 3,613 & 10395 & $\frac{15}{3}$ & $\frac{1}{0}$ & $\frac{L}{2}$ & 0 & $\frac{7}{1}$ & 645.962 & 0,07 & 15,80 & 0,28 & 59,60 & 105,64 & $\begin{array}{l}-46,04 \\
-46,\end{array}$ \\
\hline 65. & BL4-260 & B 85 & 1,958 & 5678 & 2 & 0 & $\frac{L}{1}$ & 0 & $\frac{1}{1}$ & 344.537 & 0,16 & 28,30 & 0,34 & 58,65 & 58,03 & 0,63 \\
\hline 66. & BL1-296 & K47 & 3,377 & 2886 & 3 & 0 & $\frac{1}{2}$ & 0 & 1 & 592.696 & 0,28 & 55,54 & 0,30 & 58,50 & 29,49 & 29,01 \\
\hline 67. & BL2-938 & L551 & 1,720 & 6415 & 2 & 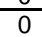 & 1 & 1 & 0 & 295.894 & 0,17 & 24,49 & 0,39 & 57,34 & 65,56 & $-8,22$ \\
\hline 68. & BL5-776 & B 294 & 4,117 & 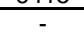 & 7 & 0 & 2 & 4 & 1 & 692.684 & - & 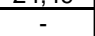 & 0,57 & 56,08 & - & - \\
\hline 69. & BL4-108 & B 1 & 4,390 & 4724 & 7 & 0 & 2 & 2 & 3 & 738.532 & 0,29 & 30,99 & 0,53 & 56,08 & 50,66 & 5,42 \\
\hline 70. & BL2-985 & B236 & 3,417 & 11634 & 3 & 0 & 2 & 1 & 0 & 573.960 & 0,07 & 13,21 & 0,29 & 55,99 & 118,68 & $\begin{array}{l}-62,69 \\
\end{array}$ \\
\hline 71. & BL2-881 & L195 & 1,769 & 14742 & 2 & 1 & 0 & 1 & 0 & 295.894 & 0,06 & 9,34 & 0,38 & 55,76 & 167,13 & $-111,38$ \\
\hline 72. & BL5-378 & L 372 & 1,896 & 15255 & 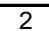 & 1 & 0 & 0 & 1 & 316 & 0,06 & 10,00 & 0,35 & 55,69 & 155,91 & $-100,21$ \\
\hline 73. & BL1-565 & L507 & $\frac{1,030}{3,473}$ & 2933 & $\frac{4}{2}$ & $\frac{1}{0}$ & $\frac{\pi}{2}$ & 0 & $\frac{1}{0}$ & 579.696 & 0,18 & 52,36 & 0,19 & 55,64 & $\frac{13,71}{29,75}$ & 25,88 \\
\hline 74. & BL4-294 & B 87 & 3,992 & 3630 & $\frac{4}{2}$ & 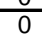 & 2 & 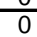 & 0 & 663.074 & 0,13 & 41,79 & 0,17 & 55,37 & 37,10 & 18,27 \\
\hline 75. & BL1-3 & B62 & 3,800 & 6054 & 5 & 0 & 2 & 2 & 1 & 628.660 & 0,20 & 24,96 & 0,44 & 55,15 & 61,87 & $-6,73$ \\
\hline
\end{tabular}




\begin{tabular}{|c|c|c|c|c|c|c|c|c|c|c|c|c|c|c|c|c|}
\hline $\begin{array}{l}\frac{N}{\pi} \\
\frac{\pi}{0} \\
\frac{0}{0} \\
\frac{0}{0} \\
\frac{0}{5} \\
\frac{1}{\pi} \\
\frac{\pi}{\simeq} \\
\end{array}$ & 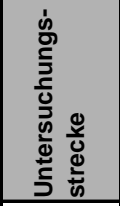 & 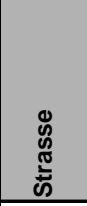 & 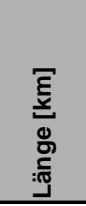 & $\begin{array}{l}\frac{F}{d} \\
\frac{N}{N} \\
\frac{1}{2} \\
\frac{D}{0}\end{array}$ & 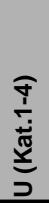 & 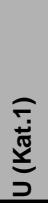 & 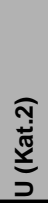 & 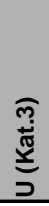 & 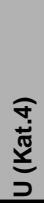 & $\begin{array}{l}\mathbf{\Psi} \\
\text { 号 }\end{array}$ & 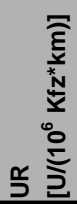 & 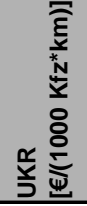 & 올 & 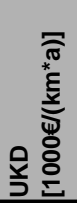 & 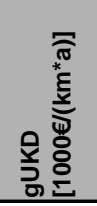 & 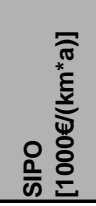 \\
\hline 76. & BL1-199 & B9 & 2,019 & 16879 & 4 & 1 & 0 & 1 & 2 & 333.830 & 0,11 & 8,95 & 0,66 & 55,11 & 172,50 & $-117,39$ \\
\hline 77. & BL1-72 & $\mathrm{L} 254$ & 1,833 & 6445 & 2 & 0 & 1 & 0 & 1 & 302.848 & 0,15 & 23,41 & 0,36 & 55,07 & 65,87 & $-10,79$ \\
\hline 78. & BL5-428 & L 1060 & 3,975 & - & 5 & 1 & 1 & 2 & 1 & 656.626 & - & - & 0,42 & 55,06 & - & - \\
\hline 79. & BL4-21 & B 189 & 6,314 & 8464 & 5 & 0 & 3 & 2 & 0 & 1.031 .069 & 0,09 & 17,62 & 0,26 & 54,43 & 86,50 & $-32,07$ \\
\hline 80. & BL3-11 & B189 & 3,878 & 4072 & 2 & 0 & 2 & 0 & 0 & 632.962 & 0,12 & 36,61 & 0,17 & 54,41 & 41,62 & 12,79 \\
\hline 81. & BL3-1156 & L33 & 3,993 & 18296 & 3 & 0 & 2 & 1 & 0 & 650.750 & 0,04 & 8,29 & 0,25 & 54,32 & 183,59 & $-129,26$ \\
\hline 82. & BL1-83 & L258 & 5,427 & - & 4 & 0 & 3 & 0 & 1 & 882.544 & - & - & 0,25 & 54,21 & - & - \\
\hline 83. & \begin{tabular}{|l|} 
BL4-298 \\
\end{tabular} & L 198 & 4,085 & 1355 & 2 & 0 & 2 & 0 & 0 & 663.074 & 0,33 & 109,40 & 0,16 & 54,11 & 13,85 & 40,26 \\
\hline 84. & BL5-39 & L 328 B & 1,988 & - & 2 & 0 & 1 & 1 & 0 & 321.813 & - & - & 0,34 & 53,96 & - & - \\
\hline 85. & BL2-974 & L539 & 5,244 & 6576 & 4 & 0 & 3 & 0 & 1 & 847.198 & 0,11 & 22,44 & 0,25 & 53,85 & 67,21 & \begin{tabular}{|l|}
$-13,35$ \\
\end{tabular} \\
\hline 86. & BL2-54 & L475 & 3,470 & 7825 & 2 & 0 & 2 & 0 & 0 & 556.132 & 0,07 & 18,70 & 0,19 & 53,42 & 79,97 & $-26,55$ \\
\hline 87. & BL5-265 & L 104 & 3,807 & - & 2 & 1 & 1 & 0 & 0 & 607.568 & - & - & 0,18 & 53,20 & - & - \\
\hline 88. & BL2-14 & B8 & 3,568 & 6549 & 3 & 0 & 2 & 0 & 1 & 569.132 & 0,12 & 22,24 & 0,28 & 53,17 & 66,93 & $-13,76$ \\
\hline 89. & BL5-438 & L 2218 & 4,020 & 9525 & 4 & 1 & 1 & 1 & 1 & 638.597 & 0,10 & 15,23 & 0,33 & 52,95 & 97,35 & $-44,39$ \\
\hline 90. & BL5-627 & B 290 & 5,857 & 6689 & 4 & 0 & 3 & 1 & 0 & 929.381 & 0,09 & 21,66 & 0,23 & 52,89 & 68,36 & $-15,47$ \\
\hline 91. & BL3-49 & B167 & 6,097 & 5487 & 4 & 0 & 3 & 1 & 0 & 967.231 & 0,11 & 26,40 & 0,22 & 52,88 & 56,08 & $-3,20$ \\
\hline 92. & BL2-537 & L927 & 3,676 & 6076 & 3 & 0 & 2 & 1 & 0 & 573.960 & 0,13 & 25,08 & 0,27 & 52,05 & 58,11 & $-6,06$ \\
\hline 93. & BL3-195 & B87 & 6,092 & 6899 & 3 & 0 & 3 & 0 & 0 & 949.443 & 0,07 & 20,63 & 0,16 & 51,95 & 70,51 & $-18,56$ \\
\hline 94. & BL5-983 & B 466 & 3,902 & - & 2 & 0 & 2 & 0 & 0 & 607.568 & - & - & 0,17 & 51,90 & - & - \\
\hline 95. & \begin{tabular}{|l|} 
BL5-440 \\
\end{tabular} & B 290 & 4,053 & - & 3 & 0 & 2 & 1 & 0 & 625.597 & - & - & 0,25 & 51,45 & - & - \\
\hline 96. & BL2-774 & L109 & 1,919 & 4805 & 2 & 0 & 1 & 1 & 0 & 295.894 & 0,20 & 29,05 & 0,35 & 51,40 & 49,53 & 1,87 \\
\hline 97. & BL5-402 & L 1201 & 3,949 & 12919 & 2 & 0 & 2 & 0 & 0 & 607.568 & 0,04 & 10,88 & 0,17 & 51,28 & 132,03 & $-80,75$ \\
\hline 98. & BL5-965 & B 312 & 4,073 & - & 3 & 0 & 2 & 1 & 0 & 625.597 & - & - & 0,25 & 51,20 & - & - \\
\hline 99. & BL5-460 & L 1127 & 4,084 & 6684 & 3 & 0 & 2 & 0 & 1 & 620.568 & 0,10 & 20,76 & 0,24 & 50,65 & 68,31 & $-17,66$ \\
\hline 100. & BL5-996 & B 465 & 2,121 & - & 2 & 0 & 1 & 1 & 0 & 321.813 & - & - & 0,31 & 50,58 & - & - \\
\hline 101. & BL3-109 & B246 & 4,260 & 4683 & 3 & 1 & 1 & 0 & 1 & 645.962 & 0,14 & 29,57 & 0,23 & 50,54 & 47,86 & 2,68 \\
\hline 102. & BL5-907 & L 1157 & 2,090 & - & 2 & 0 & 1 & 0 & 1 & 316.784 & - & - & 0,32 & 50,52 & - & - \\
\hline 103. & BL5-482 & $\mathrm{L} 611$ & 4,102 & - & 3 & 0 & 2 & 0 & 1 & 620.568 & - & - & 0,24 & 50,43 & - & - \\
\hline 104. & BL5-347 & L 370 & 8,143 & - & 5 & 0 & 4 & 0 & 1 & 1.228 .136 & - & - & 0,20 & 50,27 & - & - \\
\hline 105. & BL4-306 & B 180 & 4,416 & 6596 & 2 & 0 & 2 & 0 & 0 & 663.074 & 0,06 & 20,79 & 0,15 & 50,05 & 67,41 & $-17,36$ \\
\hline 106. & BL2-763 & B56 & 3,824 & 9801 & 3 & 1 & 1 & 1 & 0 & 573.960 & 0,07 & 13,99 & 0,26 & 50,03 & 100,17 & $-50,13$ \\
\hline 107. & BL2-330 & L947 & 3,730 & 5265 & 2 & 0 & 2 & 0 & 0 & 556.132 & 0,09 & 25,86 & 0,18 & 49,70 & 53,81 & $-4,11$ \\
\hline 108. & BL2-707 & K11(NE & 3,730 & - & 2 & 0 & 2 & 0 & 0 & 556.132 & - & - & 0,18 & 49,70 & - & - \\
\hline 109. & BL1-576 & L532 & 2,033 & 8795 & 2 & 0 & 1 & 0 & 1 & 302.848 & 0,10 & 15,46 & 0,33 & 49,66 & 89,91 & $-40,25$ \\
\hline 110. & BL4-366 & B 180 & 4,890 & 9173 & 6 & 1 & 1 & 2 & 2 & 725.532 & 0,12 & 14,77 & 0,41 & 49,46 & 93,75 & \begin{tabular}{|l|}
$-44,29$ \\
\end{tabular} \\
\hline 111. & BL1-697 & L363 & 3,919 & 4700 & 2 & 0 & 2 & 0 & 0 & 579.696 & 0,10 & 28,74 & 0,17 & 49,31 & 48,03 & 1,27 \\
\hline 112. & BL4-308 & B 87 & 4,492 & 8829 & 2 & 0 & 2 & 0 & 0 & 663.074 & 0,05 & 15,27 & 0,15 & 49,20 & 90,23 & $-41,03$ \\
\hline 113. & BL4-362 & L 228 & 4,541 & 1384 & 2 & 0 & 2 & 0 & 0 & 663.074 & 0,28 & 92,46 & 0,15 & 48,67 & 14,74 & 33,93 \\
\hline 114. & BL5-122 & B 313 & 4,162 & 5532 & 2 & 2 & 0 & 0 & 0 & 607.568 & 0,08 & 24,10 & 0,16 & 48,66 & 56,54 & $-7,88$ \\
\hline 115. & BL5-268 & $\mathrm{L} 115$ & 2,218 & - & 2 & 0 & 1 & 1 & 0 & 321.813 & - & - & 0,30 & 48,36 & - & - \\
\hline 116. & BL4-335 & B 183 & 7,467 & 6314 & 9 & 0 & 3 & 2 & 4 & 1.083 .069 & 0,18 & 21,12 & 0,40 & 48,35 & 64,10 & $-15,75$ \\
\hline 117. & BL4-339 & L 159 & 7,109 & 4016 & 5 & 0 & 3 & 2 & 0 & 1.031 .069 & 0,16 & 32,98 & 0,23 & 48,35 & 41,04 & 7,30 \\
\hline 118. & BL1-337 & B51 & 4,177 & 14331 & 4 & 0 & 2 & 0 & 2 & 605.696 & 0,06 & 9,31 & 0,32 & 48,34 & 145,39 & $-97,06$ \\
\hline 119. & BL1-613 & L167 & 2,108 & 2000 & 2 & 0 & 1 & 0 & 1 & 302.848 & 0,43 & 65,60 & 0,32 & 47,89 & 20,44 & 27,45 \\
\hline 120. & BL5-497 & L 560 & 4,486 & 12699 & 4 & 1 & 1 & 2 & 0 & 643.626 & 0,06 & 10,25 & 0,30 & 47,82 & 130,70 & $-82,88$ \\
\hline 121. & BL5-950 & B 492 & 4,366 & 11429 & 3 & 0 & 2 & 1 & 0 & 625.597 & 0,05 & 11,45 & 0,23 & 47,76 & 116,80 & $-69,04$ \\
\hline 122. & BL4-227 & B 81 & 4,739 & 12286 & 3 & 0 & 2 & 0 & 1 & 676.074 & 0,05 & 10,60 & 0,21 & 47,55 & 125,56 & \begin{tabular}{|l|}
$-78,01$ \\
\end{tabular} \\
\hline 123. & BL5-949 & B 311 & 5,054 & - & 9 & 1 & 1 & 4 & 3 & 718.684 & - & - & 0,59 & 47,40 & - & - \\
\hline 124. & BL4-297 & B 180 & 4,767 & 5874 & 3 & 0 & 2 & 0 & 1 & 676.074 & 0,10 & 22,05 & 0,21 & 47,27 & 60,03 & $-12,76$ \\
\hline 125. & BL5-913 & L 1084 & 4,503 & 8757 & 4 & 0 & 2 & 1 & 1 & 638.597 & 0,09 & 14,79 & 0,30 & 47,27 & 89,50 & $-42,22$ \\
\hline 126. & BL1-34 & L266 & 4,612 & 4550 & 6 & 0 & 2 & 3 & 1 & 646.642 & 0,28 & 30,04 & 0,43 & 46,74 & 43,56 & 3,18 \\
\hline 127. & BL4-107 & B 71 & 5,219 & 15099 & 6 & 0 & 2 & 3 & 1 & 730.761 & 0,07 & 8,47 & 0,38 & 46,67 & 154,31 & $-107,64$ \\
\hline 128. & BL1-549 & L499 & 4,317 & 2761 & 3 & 0 & 2 & 1 & 0 & 597.678 & 0,23 & 45,79 & 0,23 & 46,15 & 28,22 & 17,93 \\
\hline 129. & BL5-319 & B 462 & 4,854 & - & 6 & 1 & 1 & 2 & 2 & 669.626 & - & - & 0,41 & 45,98 & - & - \\
\hline 130. & BL2-220 & L591 & 4,161 & 6164 & 3 & 0 & 2 & 1 & 0 & 573.960 & 0,11 & 20,44 & 0,24 & 45,98 & 63,00 & \begin{tabular}{|l|}
$-17,02$ \\
\end{tabular} \\
\hline 131. & BL3-174 & B169 & 4,591 & 8817 & 2 & 0 & 2 & 0 & 0 & 632.962 & 0,05 & 14,28 & 0,15 & 45,96 & 90,11 & $-44,15$ \\
\hline 132. & BL1-23 & B413 & 4,446 & 8864 & 4 & 0 & 2 & 1 & 1 & 610.678 & 0,09 & 14,15 & 0,30 & 45,78 & 90,59 & $-44,81$ \\
\hline 133. & BL5-369 & L 410 & 4,441 & 7841 & 2 & 0 & 2 & 0 & 0 & 607.568 & 0,05 & 15,93 & 0,15 & 45,60 & 80,14 & $-34,53$ \\
\hline 134. & BL4-363 & L 151 & 4,848 & 4188 & 2 & 0 & 2 & 0 & 0 & 663.074 & 0,09 & 29,82 & 0,14 & 45,59 & 42,80 & 2,79 \\
\hline 135. & BL1-19 & L255 & 4,248 & 5400 & 2 & 0 & 2 & 0 & 0 & 579.696 & 0,08 & 23,08 & 0,16 & 45,49 & 55,19 & $-9,70$ \\
\hline 136. & BL3-31 & B198 & 4,739 & 4243 & 3 & 0 & 2 & 0 & 1 & 645.962 & 0,14 & 29,34 & 0,21 & 45,44 & 43,36 & 2,07 \\
\hline 137. & BL5-289 & L 283 & 4,459 & - & 2 & 0 & 2 & 0 & 0 & 607.568 & - & - & 0,15 & 45,42 & - & - \\
\hline 138. & BL4-333 & B 183 & 4,879 & - & 2 & 0 & 2 & 0 & 0 & 663.074 & - & - & 0,14 & 45,30 & - & - \\
\hline 139. & BL4-83 & B 1 & 7,823 & 7530 & 7 & 1 & 2 & 3 & 1 & 1.062 .298 & 0,11 & 16,47 & 0,30 & 45,26 & 76,96 & $-31,69$ \\
\hline 140. & BL5-595 & L 1107 & 2,343 & - & 2 & 0 & 1 & 0 & 1 & 316.784 & - & - & 0,28 & 45,07 & - & - \\
\hline 141. & BL5-359 & L 415 & 2,386 & 10082 & 2 & 0 & 1 & 1 & 0 & 321.813 & 0,08 & 12,22 & 0,28 & 44,96 & 103,04 & $-58,08$ \\
\hline 142. & BL1-201 & B258 & 11,110 & 4265 & 8 & 2 & 3 & 2 & 1 & 1.498 .204 & 0,15 & 29,00 & 0,24 & 44,95 & 43,41 & 1,54 \\
\hline 143. & BL1-711 & K9 & 2,285 & 1500 & 2 & 0 & 1 & 1 & 0 & 307.830 & 0,53 & 82,02 & 0,29 & 44,91 & 15,33 & 29,58 \\
\hline 144. & BL5-644 & B 19 & 4,530 & 3165 & 2 & 0 & 2 & 0 & 0 & 607.568 & 0,13 & 38,70 & 0,15 & 44,71 & 32,35 & 12,36 \\
\hline 145. & BL2-677 & B265 & 2,209 & 14384 & 2 & 0 & 1 & 1 & 0 & 295.894 & 0,05 & 8,08 & 0,30 & 44,65 & 154,82 & $-110,17$ \\
\hline 146. & BL5-697 & L 362 & 4,676 & - & 3 & 0 & 2 & 1 & 0 & 625.597 & - & - & 0,21 & 44,60 & - & - \\
\hline 147. & BL3-1035 & $\mathrm{L} 21$ & 5,088 & 4167 & 5 & 1 & 1 & 1 & 2 & 676.750 & 0,22 & 29,15 & 0,33 & 44,34 & 42,59 & 1,75 \\
\hline 148. & BL1-360 & L55 & 4,496 & 7067 & 3 & 0 & 2 & 1 & 0 & 597.678 & 0,10 & 19,89 & 0,22 & 44,31 & 62,37 & $-18,06$ \\
\hline 149. & BL1-1 & B42 & 9,740 & 12203 & 12 & 0 & 4 & 6 & 2 & 1.293 .284 & 0,09 & 10,15 & 0,41 & 44,26 & 122,09 & $-77,83$ \\
\hline 150. & BL5-721 & B 462 & 4,724 & - & 3 & 0 & 2 & 1 & 0 & 625.597 & - & - & 0,21 & 44,14 & - & - \\
\hline
\end{tabular}


7) Überholunfälle auf Landstraßen - Anhänge zum Abschlussbericht

\begin{tabular}{|c|c|c|c|c|c|c|c|c|c|c|c|c|c|c|c|c|}
\hline 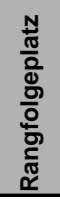 & 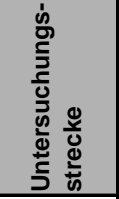 & 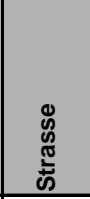 & 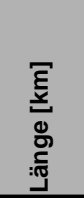 & 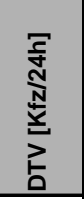 & 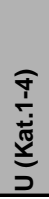 & 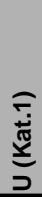 & 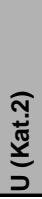 & 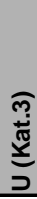 & 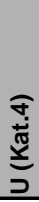 & $\begin{array}{l}\mathbb{\Psi} \\
\frac{\mathbf{y}}{J}\end{array}$ & 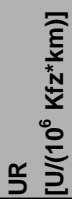 & 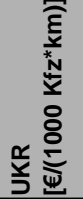 & ○ & 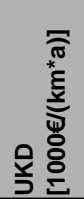 & 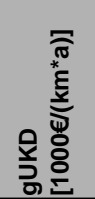 & 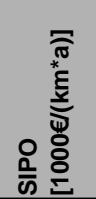 \\
\hline 151. & \begin{tabular}{|l|} 
BL5-559 \\
\end{tabular} & 1103 & 2,441 & 5361 & 2 & 0 & 1 & 1 & 0 & 321.813 & 0,14 & 22,46 & 0,27 & 43,95 & 54,79 & $-10,84$ \\
\hline 152. & BL2-86 & B58 & 4,223 & 8046 & 2 & 0 & 2 & 0 & 0 & 556.132 & 0,05 & 14,95 & 0,16 & 43,90 & 82,23 & $-38,33$ \\
\hline \begin{tabular}{|l|}
153. \\
\end{tabular} & \begin{tabular}{|l|} 
BL5-986 \\
\end{tabular} & L 1217 & 4,634 & 9758 & 2 & 1 & 1 & 0 & 0 & $\begin{array}{l}607.568 \\
\end{array}$ & 0,04 & 13,03 & 0,14 & 43,70 & 93,89 & $-50,18$ \\
\hline 154. & \begin{tabular}{|l|} 
BL5-563 \\
\end{tabular} & L 1103 & 4,638 & 200 & 2 & 0 & 2 & 0 & 0 & 607.568 & - & & 0,14 & 43,67 & 0,0 & 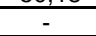 \\
\hline 155. & \begin{tabular}{|l|} 
BL5-506 \\
\end{tabular} & L536 & 4,658 & 12447 & 2 & 0 & 2 & 0 & 0 & 607.568 & 0,03 & 9,58 & 0,14 & 43,48 & 127,03 & $-83,55$ \\
\hline \begin{tabular}{|l|}
156. \\
\end{tabular} & BL1-46 & B414 & 4,446 & 10167 & 2 & 1 & 1 & 0 & 0 & 579.696 & 0,04 & 11,70 & 0,15 & 43,46 & 104,04 & $-60,58$ \\
\hline 157. & \begin{tabular}{|l|} 
BL5-979 \\
\end{tabular} & B 28 & 4,783 & - & 3 & 0 & 2 & 0 & 1 & 620.568 & - & 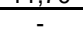 & 0,21 & 43,25 & tor & $0,0,0$ \\
\hline 158. & \begin{tabular}{|l|}
$\mathrm{BL} 2-116$ \\
\end{tabular} & B226 & 2,283 & 9378 & 2 & 0 & 1 & 1 & 0 & 295.894 & 0,09 & 12,62 & 0,29 & 43,20 & 95,84 & $-52,64$ \\
\hline \begin{tabular}{|l|}
159. \\
\end{tabular} & $\begin{array}{l}\text { BL5-613 } \\
\end{array}$ & B 45 & 4,690 & 4386 & 2 & 0 & 2 & 0 & 0 & 607.568 & 0,09 & 26,97 & 0,14 & 43,18 & 44,82 & $-1,64$ \\
\hline 160. & \begin{tabular}{|l|} 
BL5-257 \\
\end{tabular} & L 103 & 2,522 & 2459 & 2 & 1 & 0 & 1 & 0 & 321.813 & 0,29 & 47,39 & 0,26 & 42,53 & 25,13 & 17,40 \\
\hline \begin{tabular}{|l|}
161. \\
\end{tabular} & BL3-1081 & L51 & 5,104 & 6290 & 3 & 0 & 2 & 1 & 0 & 650.750 & 0,09 & 18,51 & 0,20 & 42,50 & 64,28 & $-21,78$ \\
\hline \begin{tabular}{|l|}
162. \\
\end{tabular} & \begin{tabular}{|l|} 
BL1-156 \\
\end{tabular} & K107 & 2,438 & 2378 & 2 & 0 & 1 & 1 & 0 & 307.830 & 0,32 & 48,49 & 0,27 & 42,09 & 24,30 & 17,78 \\
\hline 163. & \begin{tabular}{|l|} 
BL5-883 \\
\end{tabular} & L564 & 4,818 & 14014 & 2 & 0 & 2 & 0 & 0 & $\begin{array}{l}607.568 \\
\end{array}$ & 0,03 & 8,46 & 0,14 & 42,03 & 139,07 & $-97,03$ \\
\hline 164. & \begin{tabular}{|l|} 
BL2-315 \\
\end{tabular} & B65 & 2,310 & 9375 & 2 & 0 & 1 & 0 & 1 & 291.066 & 0,08 & 11,87 & 0,29 & 42,00 & 99,05 & $-57,05$ \\
\hline \begin{tabular}{|l|}
165. \\
\end{tabular} & \begin{tabular}{|l|} 
BL5-619 \\
\end{tabular} & B 27 & 4,836 & 7569 & 2 & 0 & 2 & 0 & 0 & 607.568 & 0,05 & 15,23 & 0,14 & 41,88 & 76,97 & $-35,09$ \\
\hline 166. & BL5-247 & B 500 & 4,950 & - & 3 & $\frac{\pi}{1}$ & $\frac{4}{1}$ & 0 & 1 & 620.568 & - & - & 0,20 & 41,79 & דינד & U \\
\hline 167. & BL3-47 & \begin{tabular}{|l|} 
B167 \\
\end{tabular} & 5,158 & 7494 & 3 & 0 & 2 & 0 & 1 & 645.962 & 0,07 & 15,26 & 0,19 & 41,74 & 76,59 & $-34,84$ \\
\hline 168. & \begin{tabular}{|l|} 
BL5-462 \\
\end{tabular} & \begin{tabular}{|l|l|} 
L 1144 \\
\end{tabular} & 2,530 & 12437 & 2 & 0 & 1 & 0 & 1 & 316.784 & 0,06 & 9,19 & 0,26 & 41,74 & 127,11 & $-85,37$ \\
\hline \begin{tabular}{|l|}
169. \\
\end{tabular} & \begin{tabular}{|l|} 
BL1-251 \\
\end{tabular} & L98 & 5,089 & 4384 & 6 & 1 & 1 & 1 & 3 & 636.678 & 0,25 & 26,06 & 0,39 & 41,70 & 44,80 & $-3,10$ \\
\hline \begin{tabular}{|l|}
170. \\
\end{tabular} & \begin{tabular}{|l|} 
BL5-349 \\
\end{tabular} & B 463 & 7,788 & & 7 & 1 & 2 & 2 & 2 & 973.410 & 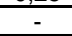 & & 0,30 & 41,66 & & \\
\hline 171. & \begin{tabular}{|l|} 
BL4-224 \\
\end{tabular} & L 85 & 5,749 & 5550 & 5 & 0 & 2 & 3 & 0 & $\begin{array}{l}717.761 \\
\end{array}$ & 0,16 & 23,65 & 0,29 & 41,62 & 49,28 & $-7,66$ \\
\hline 172. & \begin{tabular}{|l|} 
BL1-511 \\
\end{tabular} & L490 & 2,468 & 2233 & 2 & 0 & 1 & 1 & 0 & 307.830 & 0,33 & 51,01 & 0,27 & 41,58 & 22,82 & 18,75 \\
\hline 173. & \begin{tabular}{|l|} 
BL3-172 \\
\end{tabular} & B96 & 5,190 & 9970 & 3 & 0 & 2 & 0 & 1 & 645.962 & 0,05 & 11,40 & 0,19 & 41,49 & 101,89 & $-60,41$ \\
\hline \begin{tabular}{|l|}
174. \\
\end{tabular} & \begin{tabular}{|l|} 
BL1-466 \\
\end{tabular} & B422 & 4,662 & 3094 & 2 & 0 & 2 & 0 & 0 & 579.696 & 0,13 & 36,70 & 0,14 & 41,45 & 31,62 & 9,83 \\
\hline 175. & \begin{tabular}{|l|} 
BL1-448 \\
\end{tabular} & L437 & 4,811 & 4600 & 3 & 0 & $\frac{4}{2}$ & 1 & 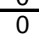 & 597.678 & 0,12 & 24,66 & 0,21 & 41,41 & 47,01 & $\frac{-1,050}{-5,60}$ \\
\hline 176. & $\begin{array}{ll}\text { BL4-323 } \\
\end{array}$ & L 189 & 2,963 & 4715 & 3 & 0 & 1 & $\frac{1}{2}$ & 0 & 367.995 & 0,20 & 24,06 & 0,34 & 41,40 & 48,19 & $-6,79$ \\
\hline \begin{tabular}{|l|}
177. \\
\end{tabular} & BL3-1039 & L304 & 5,248 & 5064 & 3 & 1 & 1 & 1 & 0 & 650.750 & 0,10 & 22,36 & 0,19 & 41,33 & 51,75 & $-10,42$ \\
\hline 178. & \begin{tabular}{|l|} 
BL4-281 \\
\end{tabular} & L 172 & 2,788 & 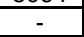 & 2 & 1 & 0 & 0 & 1 & 344.537 & 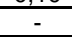 & - & 0,24 & 41,19 & & \\
\hline \begin{tabular}{|l|}
179. \\
\end{tabular} & $\begin{array}{l}\text { BL1-235 } \\
\end{array}$ & L29 & 2,601 & 3309 & 3 & 0 & 1 & 1 & 1 & 320.830 & 0,39 & 41,63 & 0,38 & 41,12 & 27,65 & 13,46 \\
\hline 180. & \begin{tabular}{|l|}
$\mathrm{BL} 2-338$ \\
\end{tabular} & $\mathrm{~B} 61$ & 2,509 & 17339 & 3 & 0 & 1 & 1 & 1 & 308.894 & 0,07 & 6,76 & 0,40 & 41,04 & 169,94 & $-128,90$ \\
\hline 181. & \begin{tabular}{|l|} 
BL3-189 \\
\end{tabular} & B96 & 5,258 & 3663 & 3 & 0 & 2 & 0 & 1 & 645.962 & 0,14 & 30,63 & 0,19 & 40,95 & 37,44 & 3,52 \\
\hline 182. & \begin{tabular}{|l|} 
BL2-708 \\
\end{tabular} & L142 & 4,977 & - & 5 & 0 & 2 & 3 & 0 & 609.616 & $\frac{1}{-}$ & - & 0,33 & 40,83 & in & - \\
\hline \begin{tabular}{|l|}
183. \\
\end{tabular} & \begin{tabular}{|l|} 
BL5-227 \\
\end{tabular} & B 313 & 4,975 & - & 2 & 0 & 2 & 0 & 0 & 607.568 & - & - & 0,13 & 40,71 & - & - \\
\hline 184. & \begin{tabular}{|l|l} 
BL3-140 \\
\end{tabular} & B101 & 5,188 & 2778 & $\frac{4}{2}$ & 1 & 1 & 0 & 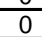 & 632.962 & 0,13 & 40,11 & 0,13 & 40,67 & 28,39 & 12,28 \\
\hline 185. & \begin{tabular}{|l|} 
BL4-159 \\
\end{tabular} & B 184 & 8,709 & 8206 & 7 & 0 & 3 & 3 & 1 & 1.062 .298 & 0,09 & 13,57 & 0,27 & 40,66 & 83,87 & $-43,21$ \\
\hline 186. & \begin{tabular}{|l|} 
BL4-384 \\
\end{tabular} & L 239 & 3,030 & 7175 & 3 & 0 & 1 & $\frac{2}{2}$ & 0 & 367.995 & 0,12 & 15,27 & 0,33 & 40,48 & 74,23 & \begin{tabular}{|l|l}
$-33,74$ \\
\end{tabular} \\
\hline \begin{tabular}{|l|}
187. \\
\end{tabular} & \begin{tabular}{|l|} 
BL5-736 \\
\end{tabular} & L564 & 7,505 & 4759 & 3 & 1 & 2 & 0 & 0 & 911.352 & 0,08 & 23,30 & 0,13 & 40,48 & 48,64 & $-8,16$ \\
\hline 188. & \begin{tabular}{|c|}
$B L 2-958$ \\
\end{tabular} & L336 & 4,607 & 4370 & 2 & 1 & 1 & 0 & 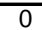 & 556.132 & 0,08 & 22,75 & 0,14 & 40,24 & 49,53 & $-9,30$ \\
\hline 189. & \begin{tabular}{|l|} 
BL1-120 \\
\end{tabular} & B417 & 4,992 & 2586 & 3 & 0 & 2 & 1 & 0 & 597.678 & 0,18 & 36,57 & 0,20 & 39,91 & 30,55 & 9,36 \\
\hline 190. & BL5-317 & B 294 & 5,231 & - & 3 & 0 & 2 & 1 & 0 & 625.597 & - & $\frac{1}{-}$ & 0,19 & 39,86 & - & 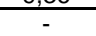 \\
\hline 191. & \begin{tabular}{|l|}
$\mathrm{BL} 2-751$ \\
\end{tabular} & B56 & 5,101 & - & 5 & 0 & 2 & 3 & 0 & 609.616 & - & - & 0,33 & 39,84 & - & - \\
\hline \begin{tabular}{|l|}
192. \\
\end{tabular} & \begin{tabular}{|l|} 
BL5-241 \\
\end{tabular} & L 125 & 5,122 & - & 2 & 0 & 2 & 0 & 0 & 607.568 & - & - & 0,13 & 39,54 & 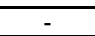 & - \\
\hline 193. & \begin{tabular}{|l|} 
BL5-922 \\
\end{tabular} & \begin{tabular}{|l|} 
B 466 \\
\end{tabular} & 5,324 & - & $\frac{5}{3}$ & 0 & $\frac{4}{2}$ & 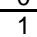 & 0 & 625.597 & - & - & 0,19 & 39,17 & - & - \\
\hline 194. & BL3-1155 & L33 & 5,400 & 11218 & 2 & 0 & $\frac{4}{2}$ & 0 & 0 & 632.962 & 0,03 & 9,54 & 0,12 & 39,07 & 114,65 & $-75,58$ \\
\hline 195. & \begin{tabular}{|l|l|} 
BL2-620 \\
\end{tabular} & B399 & 4,750 & 3491 & 2 & 0 & $\angle$ & 0 & 0 & 556.132 & 0,11 & 30,63 & 0,1 & 39,03 & 35,68 & 3,35 \\
\hline 196. & \begin{tabular}{|c|} 
BL4-89 \\
\end{tabular} & L54 & 2,996 & 2623 & 2 & 1 & 0 & 1 & 0 & 349.766 & 0,23 & 40,65 & 0,22 & 38,91 & 26,81 & 12,11 \\
\hline 197. & \begin{tabular}{|l|} 
BL5-169 \\
\end{tabular} & \begin{tabular}{|l|}
$\mathrm{L} 139$ \\
\end{tabular} & 2,833 & - & 3 & 0 & 1 & 0 & 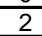 & 329.784 & - & - & 0,35 & 38,80 & - & - \\
\hline \begin{tabular}{|l|}
198. \\
\end{tabular} & \begin{tabular}{|l|} 
BL3-45 \\
\end{tabular} & B109 & 5,450 & 4292 & 2 & 0 & 2 & 0 & 0 & 632.962 & 0,08 & 24,71 & 0,12 & 38,71 & 43,86 & $-5,15$ \\
\hline \begin{tabular}{|l|}
199. \\
\end{tabular} & \begin{tabular}{|l|} 
BL2-721 \\
\end{tabular} & B477 & 4,793 & - & 2 & 0 & 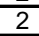 & 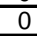 & 0 & 556 & - & 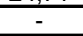 & 0,12 & 38,68 & 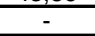 & 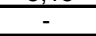 \\
\hline 200. & BL2-971 & B54 & 2,509 & - & 2 & 0 & 1 & 0 & 1 & & - & - & 0,2 & 38,67 & - & - \\
\hline \begin{tabular}{|l|}
201. \\
\end{tabular} & $\begin{array}{l}\mathrm{BL} 2-221 \\
\end{array}$ & L811 & 4,795 & 1253 & 2 & 0 & 2 & 0 & 0 & 556.132 & 0,30 & 84,53 & 0,14 & 38,66 & 12,81 & 25,85 \\
\hline 202. & \begin{tabular}{|l|l} 
BL1-522 \\
\end{tabular} & L493 & 5,007 & 4887 & $\frac{4}{2}$ & 0 & $\frac{5}{2}$ & 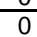 & 0 & 579.696 & 0,07 & 21,73 & 0,1 & 38,59 & $\begin{array}{l} \pm<, 01 \\
49,73 \\
\end{array}$ & $\frac{20,05}{-11,14}$ \\
\hline 203. & \begin{tabular}{|l} 
BL1-587 \\
\end{tabular} & L525 & 5,127 & 3213 & 3 & 0 & $\frac{4}{2}$ & 0 & $\frac{\pi}{1}$ & 592.696 & 0,18 & 34,62 & 0,20 & 38,53 & 31,17 & 7,37 \\
\hline 204. & BL4-48 & \begin{tabular}{|l|} 
B 188 \\
\end{tabular} & 5,738 & 6798 & 2 & $\frac{1}{1}$ & $\frac{1}{1}$ & 0 & 0 & 663.074 & 0,05 & 15,52 & $\frac{0,12}{0,12}$ & 38,52 & 69,48 & $-30,96$ \\
\hline 205. & \begin{tabular}{|l|} 
BL2-832 \\
\end{tabular} & B480 & 4,971 & 7921 & 3 & 1 & 1 & $\frac{1}{1}$ & 0 & 573.960 & 0,07 & 13,91 & 0,20 & 38,49 & 77,46 & $-38,97$ \\
\hline 206. & \begin{tabular}{|l|} 
BL5-777 \\
\end{tabular} & L 621 & 5,423 & - & 3 & 0 & 2 & 1 & 0 & 625.597 & - & 0 & 0,18 & 38,45 & - & - \\
\hline \begin{tabular}{|l|}
207. \\
\end{tabular} & $\begin{array}{l}\text { BL4-295 } \\
\end{array}$ & $\begin{array}{l}L 203 \\
\end{array}$ & 3,046 & 1743 & 2 & 0 & 1 & $\frac{1}{1}$ & $\mathrm{c}$ & 349 & 0,34 & 60,16 & 0,22 & 38,28 & 17,81 & 20,46 \\
\hline \begin{tabular}{|l|}
208. \\
\end{tabular} & \begin{tabular}{|l|} 
BL5-690 \\
\end{tabular} & B 36 & 5,457 & 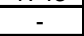 & 3 & 0 & 2 & 1 & 0 & 625.597 & & & 0,18 & 38,21 & & \\
\hline \begin{tabular}{|l|}
209. \\
\end{tabular} & \begin{tabular}{|l|} 
BL4-230 \\
\end{tabular} & L 82 & 4,018 & 7889 & 8 & 0 & 1 & 7 & 0 & 459 & 0,23 & 13,23 & 0, & 38,09 & 80,63 & $-42,54$ \\
\hline 210. & \begin{tabular}{|l|} 
BL5-664 \\
\end{tabular} & B 292 & 5,433 & - & 3 & 0 & 2 & 0 & 1 & 620.568 & 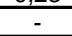 & & 0,1 & 38,07 & & \\
\hline 211. & \begin{tabular}{|l|l|} 
BL1-207 \\
\end{tabular} & B257 & $\frac{1,405}{10,559}$ & 3887 & $\frac{5}{7}$ & 0 & $\frac{4}{4}$ & 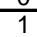 & $\frac{1}{2}$ & 1.20 & 0,17 & 28,50 & 0,2 & 37,99 & 37,33 & 0,66 \\
\hline 212. & BL5-578 & B 39 & 3,213 & & 5 & $\frac{\pi}{1}$ & 0 & $\frac{1}{2}$ & $\frac{4}{2}$ & 365.842 & & & 0,52 & 37,95 & & \\
\hline 213. & \begin{tabular}{|l|} 
BL4-269 \\
\end{tabular} & B 180 & 3,837 & 10166 & 7 & $\frac{1}{1}$ & 0 & $\frac{5}{5}$ & 1 & 435.682 & 0,16 & $\overline{0,2}$ & 0,61 & 37,85 & 103,90 & $-66,05$ \\
\hline 214. & $\begin{array}{l}\mathrm{BL} 2-382 \\
\end{array}$ & L663 & 5,056 & 1846 & 3 & 0 & 2 & 1 & 0 & 573.960 & 0,26 & 50,50 & 0,20 & 37,84 & 20,98 & 16,86 \\
\hline 215. & \begin{tabular}{|l|} 
BL4-211 \\
\end{tabular} & $L 24$ & 3,471 & 4175 & 5 & 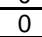 & 1 & $\frac{12}{2}$ & 2 & 393.995 & 0,32 & 24,83 & 0,48 & 37,84 & 42,67 & $-4,83$ \\
\hline 216. & $\begin{array}{l}\text { BL2-392 } \\
\end{array}$ & L670 & 2,997 & 4488 & 5 & 0 & 1 & $\frac{2}{2}$ & 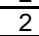 & 339.722 & 0,34 & 23,07 & 0,56 & 37,78 & 45,87 & $-8,08$ \\
\hline 217. & \begin{tabular}{|l|} 
BL4-383 \\
\end{tabular} & $\begin{array}{l}L 242 \\
\end{array}$ & 6,496 & 9417 & 6 & 0 & 2 & 4 & 0 & 735.990 & 0,09 & 10,91 & 0,31 & 37,77 & 96,93 & $-59,16$ \\
\hline \begin{tabular}{|l|}
218. \\
\end{tabular} & \begin{tabular}{|l|} 
BL5-492 \\
\end{tabular} & $\begin{array}{l}\text { L } 571 \\
\end{array}$ & 5,562 & - & 3 & 1 & $\perp$ & 1 & 0 & 625.597 & - & - & 0,18 & 37,49 & - & \\
\hline 219. & \begin{tabular}{|l|} 
BL2-157 \\
\end{tabular} & B70 & 7,539 & 5128 & 4 & 0 & 3 & 0 & 1 & 847.198 & 0,09 & 20,01 & 0,18 & 37,46 & 52,41 & $-14,95$ \\
\hline 220. & \begin{tabular}{|l|} 
BL2-547 \\
\end{tabular} & L758 & 5,503 & 10807 & 6 & 0 & 2 & 2 & 2 & 617.788 & 0,09 & 9,49 & 0,36 & 37,42 & 110,45 & $-73,03$ \\
\hline \begin{tabular}{|l|}
221. \\
\end{tabular} & \begin{tabular}{|l|} 
BL5-898 \\
\end{tabular} & B 29 & 5,691 & & 4 & 0 & 2 & 1 & 1 & 638.597 & & & 0,23 & 37,40 & & \\
\hline 222. & \begin{tabular}{|l|}
$\mathrm{BL} 2-488$ \\
\end{tabular} & $\mathrm{~L} 758$ & 2,598 & 2871 & 2 & 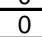 & $\angle$ & \pm & $\frac{1}{1}$ & 291. & 0,24 & 35, & 0,26 & 37,34 & 29,34 & 8,00 \\
\hline 223. & $\begin{array}{ll}\text { BL2-531 } \\
\end{array}$ & L793 & 4,970 & 5007 & $\frac{2}{2}$ & 0 & $\frac{1}{2}$ & 0 & 0 & 556.132 & 0,07 & 20,41 & 0,13 & 37,30 & 51,17 & $-13,87$ \\
\hline 224. & \begin{tabular}{|l|} 
BL4-300 \\
\end{tabular} & B 180 & 4,527 & 5720 & 12 & 0 & 1 & 6 & 5 & 505.911 & 0,42 & 17,84 & 0,88 & 37,25 & 58,46 & $-21,21$ \\
\hline \begin{tabular}{|l|}
225. \\
\end{tabular} & \begin{tabular}{|l|} 
BL1-169 \\
\end{tabular} & B256 & 6,502 & 10864 & 11 & 0 & 2 & 6 & 3 & 726.588 & 0,13 & 8,89 & 0,56 & 37,25 & 117,37 & $-80,12$ \\
\hline
\end{tabular}


7) Überholunfälle auf Landstraßen - Anhänge zum Abschlussbericht

\begin{tabular}{|c|c|c|c|c|c|c|c|c|c|c|c|c|c|c|c|c|}
\hline 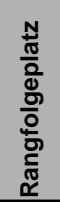 & 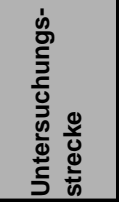 & 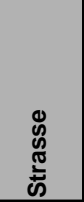 & 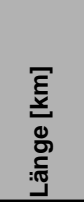 & 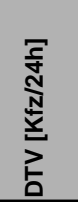 & 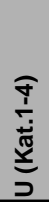 & 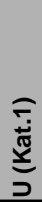 & 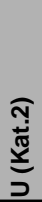 & 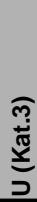 & 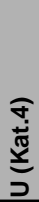 & $\begin{array}{l}\underset{\Psi}{\Psi} \\
\frac{y}{J}\end{array}$ & 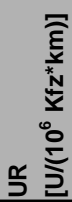 & 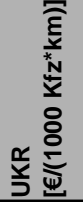 & ○ & 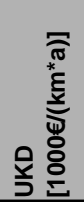 & 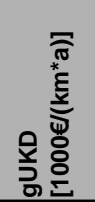 & 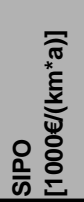 \\
\hline 226. & \begin{tabular}{|l|} 
BL3-181 \\
\end{tabular} & B169 & 5,782 & 7399 & 3 & 0 & 2 & 0 & 1 & 645.962 & 0,06 & 13,79 & 0,17 & 37,24 & 75,62 & $-38,38$ \\
\hline 227. & \begin{tabular}{|l|} 
BL1-279 \\
\end{tabular} & B53 & 5,472 & 3925 & 4 & 0 & 2 & 1 & 1 & 610.678 & 0,17 & 26,02 & 0,24 & 37,20 & 40,03 & $-2,83$ \\
\hline 228. & \begin{tabular}{|l|} 
BL5-404 \\
\end{tabular} & L 1201 & 2,902 & 12060 & 2 & 1 & 0 & 1 & 0 & 321.813 & 0,06 & 8,94 & 0,23 & 36,96 & 115,75 & $-78,79$ \\
\hline \begin{tabular}{|l|}
229. \\
\end{tabular} & \begin{tabular}{|l|} 
BL1-339 \\
\end{tabular} & L150 & 8,124 & 4793 & 5 & 0 & 3 & 1 & 1 & 900.526 & 0,12 & 21,48 & 0,21 & 36,95 & 48,17 & $-11,22$ \\
\hline 230. & \begin{tabular}{|c|} 
BL3-91 \\
\end{tabular} & B168 & 5,714 & 2607 & 2 & 0 & 2 & 0 & 0 & 632.962 & 0,12 & 38,80 & 0,12 & 36,92 & 26,64 & 10,28 \\
\hline 231. & \begin{tabular}{|l|} 
BL5-987 \\
\end{tabular} & L 1217 & 5,664 & - & 3 & 0 & 2 & $\frac{1}{1}$ & 0 & 625.597 & - & - & 0,18 & 36,82 & - & - \\
\hline \begin{tabular}{|l|}
232. \\
\end{tabular} & $\begin{array}{l}\text { BL4-302 } \\
\end{array}$ & B 2 & 3,575 & - & 5 & 1 & 0 & 2 & 2 & 393.995 & - & - & 0,47 & 36,74 & - & - \\
\hline \begin{tabular}{|l|}
233. \\
\end{tabular} & BL3-1123 & L38 & 6,303 & 6874 & 6 & 0 & 2 & 2 & 2 & 694.538 & 0,13 & 14,64 & 0,32 & 36,73 & 70,25 & $-33,52$ \\
\hline 234. & BL3-1175 & L31 & 6,421 & 5184 & 7 & 0 & 2 & 2 & 3 & 707.538 & 0,19 & 19,41 & 0,36 & 36,73 & 52,98 & $-16,25$ \\
\hline 235. & BL3-1174 & L30 & 2,991 & - & 2 & 0 & 1 & 0 & 1 & 329.481 & - & - & 0,22 & 36,72 & - & - \\
\hline \begin{tabular}{|l|}
236. \\
\end{tabular} & \begin{tabular}{|l|} 
BL5-203 \\
\end{tabular} & B 312 & 3,087 & 6923 & 3 & 0 & 1 & 2 & 0 & 339.842 & 0,13 & 14,52 & 0,32 & 36,70 & 70,75 & $-34,06$ \\
\hline 237. & \begin{tabular}{|l|} 
BL4-334 \\
\end{tabular} & B 183 & 6,025 & 7708 & 2 & 0 & 2 & 0 & 0 & 663.074 & 0,04 & 13,04 & 0,11 & 36,68 & 78,78 & $-42,09$ \\
\hline \begin{tabular}{|l|}
238. \\
\end{tabular} & \begin{tabular}{|l|} 
BL1-237 \\
\end{tabular} & B410 & 5,431 & 3182 & 3 & 0 & 2 & 1 & 0 & 597.678 & 0,16 & 31,07 & 0,18 & 36,68 & 33,06 & 3,62 \\
\hline 239. & BL5-1030 & B 10 & 2,940 & & 2 & 0 & 1 & 1 & 0 & 321.813 & 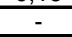 & & 0,23 & 36,49 & , & \\
\hline 240. & \begin{tabular}{|l|l} 
BL1-598 \\
\end{tabular} & L522 & 8,138 & 4890 & 4 & 1 & $\frac{1}{2}$ & $\frac{1}{1}$ & 0 & 887.526 & 0,09 & 20,00 & 0,16 & 36,35 & 50,89 & $-14,54$ \\
\hline \begin{tabular}{|l|}
241. \\
\end{tabular} & \begin{tabular}{|l|l} 
BL4-225 \\
\end{tabular} & L 100 & 6,328 & 2630 & 3 & 1 & 1 & 1 & 0 & 681.303 & 0,16 & 37,39 & 0,16 & 35,89 & 26,88 & 9,01 \\
\hline 242. & \begin{tabular}{|l|} 
BL1-529 \\
\end{tabular} & L540 & 2,876 & 4226 & 2 & 0 & 1 & 1 & 0 & 307.830 & 0,15 & 23,13 & 0,23 & 35,68 & 43,19 & $-7,51$ \\
\hline \begin{tabular}{|l|}
243. \\
\end{tabular} & \begin{tabular}{|l|} 
BL3-147 \\
\end{tabular} & B246 & 5,961 & 3853 & 2 & 0 & 2 & 0 & 0 & 632.962 & 0,08 & 25,17 & 0,11 & 35,39 & 39,38 & $-3,98$ \\
\hline 244. & \begin{tabular}{|l|} 
BL1-411 \\
\end{tabular} & B50 & 5,638 & - & 3 & 0 & 2 & 1 & 0 & 597.678 & - & - & 0,18 & 35,34 & - & - \\
\hline 245. & $\begin{array}{l}\text { BL2-959 } \\
\end{array}$ & B256 & 3,252 & - & 5 & 0 & 1 & 3 & 1 & 344.550 & - & - & 0,51 & 35,32 & - & - \\
\hline 246. & \begin{tabular}{|l|} 
BL2-731 \\
\end{tabular} & B221 & 5,663 & 10791 & 5 & 0 & 2 & 1 & 2 & 599.960 & 0,07 & 8,89 & 0,29 & 35,31 & 11,28 & $-75,97$ \\
\hline \begin{tabular}{|l|}
247. \\
\end{tabular} & \begin{tabular}{|l|} 
BL2-178 \\
\end{tabular} & L590 & 6,178 & 7710 & 8 & 0 & 2 & 4 & 2 & 653.444 & 0,15 & 12,53 & 0,43 & 35,26 & 78,80 & $-43,54$ \\
\hline 248. & \begin{tabular}{|l|} 
BL4-54 \\
\end{tabular} & B 189 & 13,422 & 8330 & 10 & 2 & 2 & 2 & 4 & 1.414 .606 & 0,08 & 11,66 & 0,25 & 35,13 & 84,38 & $-49,24$ \\
\hline 249. & BL2-145 & L889 & 5,284 & 5697 & 2 & 0 & 2 & 0 & 0 & 556.132 & 0,06 & 16,87 & 0,13 & 35,08 & 58,22 & $-23,14$ \\
\hline \begin{tabular}{|l|}
250. \\
\end{tabular} & \begin{tabular}{|l|} 
BL2-900 \\
\end{tabular} & L286 & 2,939 & - & 3 & 0 & 1 & 1 & 1 & 308.894 & - & - & 0,34 & 35,03 & - & - \\
\hline 251. & \begin{tabular}{|l|} 
BL5-182 \\
\end{tabular} & L $163 \mathrm{~A}$ & 3,062 & 2426 & 2 & 0 & 1 & 1 & 0 & 321.813 & 0,25 & 39,56 & 0,22 & 35,03 & 24,79 & 10,24 \\
\hline \begin{tabular}{|l|}
252. \\
\end{tabular} & \begin{tabular}{|l|} 
BL1-100 \\
\end{tabular} & L265 & 5,687 & 3300 & 3 & 0 & 2 & 1 & 0 & 597.678 & 0,15 & 29,08 & 0,18 & 35,03 & 33,73 & 1,31 \\
\hline 253. & \begin{tabular}{|l|}
$\mathrm{BL} 2-264$ \\
\end{tabular} & L585 & 5,384 & 4382 & 2 & 0 & 2 & 0 & 0 & 556.132 & 0,08 & 21,53 & 0,12 & 34,43 & 44,78 & $-10,35$ \\
\hline 254. & BL5-910 & L 1158 & 3,079 & 6258 & 2 & 0 & 1 & 0 & 1 & 316.784 & 0,09 & 15,01 & 0,22 & 34,30 & 63,96 & $-29,66$ \\
\hline 255. & \begin{tabular}{|l|} 
BL5-180 \\
\end{tabular} & L 157 & 5,922 & - & 2 & 0 & 2 & 0 & 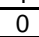 & 607.568 & - & - & 0,11 & 34,20 & - & - \\
\hline \begin{tabular}{|l|}
256. \\
\end{tabular} & \begin{tabular}{|l|} 
BL5-993 \\
\end{tabular} & B 28 & 6,455 & - & 5 & 1 & 1 & 3 & 0 & 661.655 & - & - & 0,26 & 34,17 & - & - \\
\hline \begin{tabular}{|l|}
257. \\
\end{tabular} & \begin{tabular}{|l|} 
BL1-561 \\
\end{tabular} & L515 & 5,794 & 3646 & 3 & 1 & 1 & 0 & 5 & 592.696 & 0,11 & 21,68 & 0,17 & 34,10 & 44,04 & $-9,94$ \\
\hline 258. & \begin{tabular}{|l|} 
BL5-988 \\
\end{tabular} & L 1214 & 3,100 & 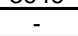 & 2 & 0 & 1 & 0 & 1 & 316.784 & , & $2, \infty, \infty$ & 0,22 & 34,06 & 西 & דיה, \\
\hline \begin{tabular}{|l|}
259. \\
\end{tabular} & \begin{tabular}{|l|} 
BL3-64 \\
\end{tabular} & B167 & 3,273 & 5738 & 2 & 0 & 1 & 1 & 0 & 334.269 & 0,09 & 15,30 & 0,20 & 34,04 & 62,31 & $-28,27$ \\
\hline 260. & BL4-243 & L92 & 3,428 & 4589 & 2 & 0 & 1 & 1 & 0 & 349.766 & 0,12 & 20,31 & 0,19 & 34,01 & 46,90 & $-12,89$ \\
\hline 261. & \begin{tabular}{|l|} 
BL3-105 \\
\end{tabular} & B168 & 9,340 & 8997 & 3 & 0 & 3 & 0 & 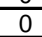 & 949.443 & 0,03 & 10,44 & 0,11 & 33,88 & 90,89 & $-57,01$ \\
\hline 262. & \begin{tabular}{|l|} 
BL4-369 \\
\end{tabular} & L 226 & 3,639 & 1990 & 3 & 0 & 1 & 2 & 0 & 367.995 & 0,38 & 46,41 & 0,27 & 33,71 & 20,34 & 13,37 \\
\hline \begin{tabular}{|l|}
263. \\
\end{tabular} & \begin{tabular}{|l|} 
BL1-560 \\
\end{tabular} & B39 & 9,139 & 9536 & 6 & 0 & 3 & 3 & 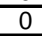 & 923.490 & 0,06 & 9,82 & 0,22 & 33,68 & 96,04 & $-62,36$ \\
\hline 264. & \begin{tabular}{|l|} 
BL1-495 \\
\end{tabular} & L554 & 5,901 & 10533 & 3 & $\frac{1}{1}$ & $\frac{1}{1}$ & 0 & 1 & 592.696 & 0,04 & 8,35 & 0,17 & 33,48 & 112,32 & $-78,84$ \\
\hline 26. & \begin{tabular}{|l|} 
BL5-716 \\
\end{tabular} & L 88 & 3,218 & - & 2 & 0 & 1 & 1 & 0 & 321.813 & . & - & 0,21 & 33,33 & 5 & 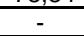 \\
\hline 266. & \begin{tabular}{|l|} 
BL2-872 \\
\end{tabular} & L655 & 5,562 & 10877 & 2 & 1 & 1 & 0 & 0 & 556.132 & 0,03 & 8,40 & 0,12 & 33,33 & 111,16 & $-77,83$ \\
\hline \begin{tabular}{|l|}
267. \\
\end{tabular} & BL4-39 & L23 & 6,639 & 2918 & 2 & 0 & 2 & 0 & 0 & 663.074 & 0,09 & 31,26 & 0,10 & 33,29 & 29,82 & 3,47 \\
\hline 268. & \begin{tabular}{|l|} 
BL5-244 \\
\end{tabular} & B 31 & 6,115 & - & 2 & 0 & 2 & 0 & 0 & 607.568 & - & - & 0,11 & 33,12 & - & - \\
\hline 269. & \begin{tabular}{|l|} 
BL4-289 \\
\end{tabular} & $L 212$ & 3,478 & 4319 & 2 & 0 & 1 & 0 & 1 & 344.537 & 0,12 & 20,95 & 0,19 & 33,02 & 44,14 & $-11,12$ \\
\hline 270. & \begin{tabular}{|l|} 
BL1-600 \\
\end{tabular} & L527 & 3,472 & 11817 & 4 & 0 & 1 & 3 & 0 & 343.794 & 0,09 & 7,77 & 0,38 & 33,01 & 119,02 & $-86,01$ \\
\hline \begin{tabular}{|l|}
271. \\
\end{tabular} & \begin{tabular}{|l|} 
BL4-36 \\
\end{tabular} & L 19 & 7,046 & 3217 & 4 & 0 & 2 & 1 & 1 & 694.303 & 0,16 & 28,01 & 0,19 & 32,85 & 32,83 & 0,01 \\
\hline 272. & \begin{tabular}{|l|} 
BL1-281 \\
\end{tabular} & B53 & 6,211 & 4560 & 4 & 0 & 2 & 1 & 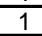 & 610.678 & 0,12 & 18,88 & 0,21 & 32,77 & 48,62 & $-15,84$ \\
\hline \begin{tabular}{|l|}
273. \\
\end{tabular} & \begin{tabular}{|l|} 
BL2-898 \\
\end{tabular} & L284 & 5,658 & - & 2 & 0 & 2 & 0 & 0 & 556.132 & - & - & 0,12 & 32,76 & - & - \\
\hline 274. & BL5-97 & B 34 & 6,367 & - & 3 & 0 & 2 & 1 & 0 & $\begin{array}{l}625.597 \\
\end{array}$ & - & - & 0,1 & 32,75 & - & - \\
\hline 275. & \begin{tabular}{|l|} 
BL2-716 \\
\end{tabular} & L183 & 5,662 & - & 2 & 0 & 2 & 0 & 0 & 556.132 & - & $\ldots$ & 0,12 & 32,74 & - & - \\
\hline \begin{tabular}{|l|}
276. \\
\end{tabular} & BL4-40 & B 71 & 6,888 & 5221 & 3 & 2 & 0 & 0 & 1 & 676.074 & 0,08 & 18,26 & 0,15 & 32,72 & 50,16 & $-17,44$ \\
\hline 277. & \begin{tabular}{|l|} 
BL5-643 \\
\end{tabular} & B 19 & 3,418 & - & 3 & $\frac{4}{1}$ & 0 & $\frac{1}{1}$ & $\frac{1}{1}$ & 334.813 & - & $\frac{s+2}{-}$ & 0,29 & 32,65 & - & - \\
\hline 278. & BL5-334 & L 433 & 3,249 & - & 2 & 0 & 1 & 0 & 1 & 316.784 & - & - & 0,21 & 32,50 & - & - \\
\hline 279. & \begin{tabular}{|l|}
$\mathrm{BL} 2-908$ \\
\end{tabular} & B506 & 3,220 & - & 3 & 0 & + & $\frac{2}{2}$ & 0 & 313.722 & - & - & 0,31 & 32,48 & - & - \\
\hline 280. & \begin{tabular}{|c|} 
BL5-13 \\
\end{tabular} & L 265 & 3,492 & 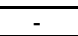 & 3 & 1 & 0 & 2 & 0 & 339.842 & - & 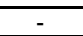 & 0,29 & 32,44 & - & - \\
\hline 281. & \begin{tabular}{|l|} 
BL4-379 \\
\end{tabular} & B 185 & 7,137 & 1860 & 4 & 0 & 2 & 2 & 1 & $\begin{array}{l}694.303 \\
\end{array}$ & 0,28 & 47,76 & 0,19 & 32,43 & 19,01 & 13,42 \\
\hline \begin{tabular}{|l|}
282. \\
\end{tabular} & $\begin{array}{l}\text { BL2-355 } \\
\end{array}$ & L782 & 2,999 & 7111 & 2 & 0 & 1 & 0 & 1 & 291. & 0,10 & 14,38 & 0,22 & 32,35 & 62,99 & $-30,64$ \\
\hline 283. & \begin{tabular}{|l|} 
BL5-406 \\
\end{tabular} & L 1199 & 3,269 & - & 2 & 0 & 1 & 0 & 1 & 316.784 & - & - & 0,20 & 32,30 & -1 & - \\
\hline 284. & \begin{tabular}{|l|} 
BL1-543 \\
\end{tabular} & B48 & 9,550 & 2622 & 6 & 0 & 3 & 3 & 0 & & 0,22 & 33,68 & 0,21 & 32,23 & 26,80 & 5,44 \\
\hline 285. & $\begin{array}{ll}\text { BL4-354 } \\
\end{array}$ & B 6 & 7,055 & 3518 & 3 & 1 & $\frac{5}{1}$ & $\frac{1}{1}$ & 0 & 681.303 & 0,11 & 25,07 & 0,14 & 32,19 & 35,95 & $-3,76$ \\
\hline 286. & \begin{tabular}{|l|} 
BL3-138 \\
\end{tabular} & B101 & 6,757 & 7758 & 3 & 0 & 2 & 1 & 0 & 650.750 & 0,05 & 11,34 & 0,15 & 32,10 & 79,29 & $-47,18$ \\
\hline 287. & BL5-2 & B 31 & 3,811 & - & 5 & 0 & 1 & $\frac{1}{2}$ & 2 & 365.842 & - & $\frac{x+1}{-}$ & 0,44 & 32,00 & - & 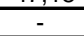 \\
\hline 288. & \begin{tabular}{|l|} 
BL4-178 \\
\end{tabular} & L 133 & 3,644 & 4134 & 2 & 0 & 1 & 1 & 0 & 349.766 & 0,12 & 21,20 & 0,18 & 31,99 & 42,25 & $-10,25$ \\
\hline \begin{tabular}{|l|}
289. \\
\end{tabular} & \begin{tabular}{|l|} 
BL2-782 \\
\end{tabular} & B477 & 8,892 & te & 4 & 1 & 2 & 1 & 0 & 852.026 & - & 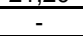 & 0,15 & 31,94 & - & - \\
\hline 290. & \begin{tabular}{|l|} 
BL5-763 \\
\end{tabular} & L 1180 & 6,352 & & 2 & 0 & 2 & 0 & 0 & 607.568 & & & 0,10 & 31,88 & & \\
\hline 29. & BL5-76 & $\angle 275$ & 6,356 & 3616 & 2 & 0 & 2 & 0 & 0 & 607 & 0,08 & 24,14 & 0,10 & 31,86 & 36,96 & $-5,09$ \\
\hline \begin{tabular}{|l|}
292. \\
\end{tabular} & BL3-1080 & L51 & 3,787 & 6290 & 4 & 0 & 1 & 1 & 2 & 360.269 & 0,15 & 13,81 & 0,35 & 31,71 & 64,28 & $-32,57$ \\
\hline 293. & BL2-36 & L581 & 3,302 & 6573 & 3 & 1 & 0 & 2 & 0 & 313.722 & 0,12 & 12,20 & 0,30 & 31,67 & 72,69 & $-41,02$ \\
\hline \begin{tabular}{|l|}
294. \\
\end{tabular} & BL3-79 & B1 & 6,663 & 7465 & 2 & 1 & 1 & 0 & 0 & 632.962 & 0,04 & 11,62 & 0,10 & 31,67 & 76,29 & $-44,63$ \\
\hline 295. & \begin{tabular}{|l|} 
BL5-100 \\
\end{tabular} & L 226 & 3,477 & - & 3 & 0 & 1 & 0 & 2 & 329. & & - & 0,29 & 31,62 & & 7 \\
\hline 296. & \begin{tabular}{|l|} 
BL4-343 \\
\end{tabular} & B 185 & 3,690 & 7856 & 2 & 0 & $\frac{1}{1}$ & 1 & 0 & 349.766 & 0,06 & 11,08 & 0,18 & 31,60 & 79,83 & $-48,23$ \\
\hline 297. & \begin{tabular}{|l|} 
BL1-542 \\
\end{tabular} & L542 & 6,118 & 1975 & $\frac{5}{2}$ & 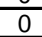 & $\frac{1}{2}$ & 0 & 0 & 579 & 0,14 & 41, & 0,11 & 31,58 & 21,18 & 10,41 \\
\hline \begin{tabular}{|l|}
298. \\
\end{tabular} & \begin{tabular}{|l|} 
BL1-407 \\
\end{tabular} & L419 & 6,261 & 9463 & 3 & 0 & 2 & 0 & 1 & 592.696 & 0,08 & 15,60 & 0,16 & 31,55 & 56,63 & $-25,08$ \\
\hline 299. & BL3-1054 & L17 & 3,722 & 7534 & 3 & 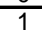 & 0 & $\frac{2}{2}$ & U & 352.057 & 0,10 & 11,38 & 0,27 & 31,53 & 77,55 & $-46,02$ \\
\hline 300. & BL1-97 & L292 & 3,203 & 2900 & 2 & 0 & 1 & 0 & 1 & 302.848 & 0,20 & 29,78 & 0,21 & 31,52 & 29,64 & 1,88 \\
\hline
\end{tabular}


7) Überholunfälle auf Landstraßen - Anhänge zum Abschlussbericht

\begin{tabular}{|c|c|c|c|c|c|c|c|c|c|c|c|c|c|c|c|c|}
\hline 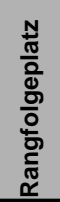 & 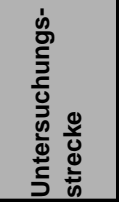 & 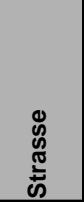 & 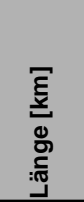 & 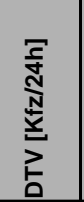 & 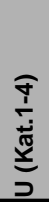 & 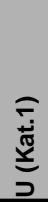 & 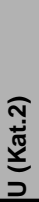 & 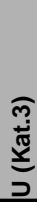 & 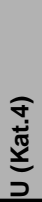 & $\begin{array}{l}\underset{\Psi}{\Psi} \\
\frac{y}{J}\end{array}$ & 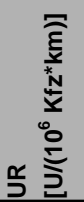 & 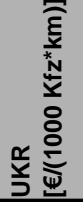 & ○ & 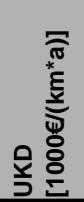 & 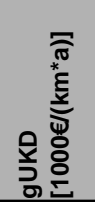 & 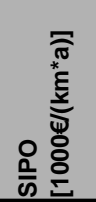 \\
\hline 301. & \begin{tabular}{|l|} 
BL2-754 \\
\end{tabular} & L264 & 5,892 & - & 2 & 0 & 2 & 0 & 0 & 556.132 & & & 0,11 & 31,46 & & \\
\hline 302. & \begin{tabular}{|l|} 
BL2-458 \\
\end{tabular} & B83 & 3,089 & 5500 & 2 & 0 & 1 & 0 & 1 & 291.066 & 0,11 & 15,65 & 0,22 & 31,41 & 56,21 & $-24,80$ \\
\hline 303. & \begin{tabular}{|l|} 
BL2-998 \\
\end{tabular} & L697 & 5,908 & 3639 & 2 & 0 & 2 & 0 & 0 & 556.132 & 0,09 & 26,19 & 0,11 & 31,38 & 33,55 & $-2,17$ \\
\hline 304. & \begin{tabular}{|l|} 
BL5-222 \\
\end{tabular} & L 456 & 6,481 & & 2 & 1 & 1 & 0 & 0 & 607.568 & & & 0,10 & 31,25 & & \\
\hline 305. & BL1-89 & L255 & 7,062 & 5400 & 7 & 1 & 1 & 3 & 2 & 659.642 & 0,17 & 15,80 & 0,33 & 31,14 & 55,19 & $-24,05$ \\
\hline 306. & BL2-21 & $\mathrm{B} 67$ & 6,177 & 11702 & 3 & 1 & 1 & 1 & 0 & 573.960 & 0,04 & 7,11 & 0,16 & 30,97 & 122,02 & $\begin{array}{l}-91,05 \\
\end{array}$ \\
\hline 307. & \begin{tabular}{|l|} 
BL4-146 \\
\end{tabular} & B 180 & 7,162 & 5278 & 2 & 1 & 1 & 0 & 0 & 663.074 & 0,05 & 16,02 & 0,09 & 30,86 & 53,94 & $-23,08$ \\
\hline 308. & \begin{tabular}{|l|} 
BL2-744 \\
\end{tabular} & L230 & 3,337 & 7232 & 3 & 0 & 1 & 1 & 1 & 308.894 & 0,11 & 11,43 & 0,30 & 30,86 & 75,59 & $-44,73$ \\
\hline 309. & BL2-698 & L26 & 3,341 & 4903 & 3 & 0 & 1 & 1 & 1 & 308.894 & 0,17 & 17,22 & 0,30 & 30,82 & 50,11 & $-19,29$ \\
\hline 310. & \begin{tabular}{|l|} 
BL5-918 \\
\end{tabular} & L 1165 & 6,772 & - & 3 & 0 & 2 & 1 & 0 & 625.597 & - & - & 0,15 & 30,79 & 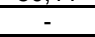 & 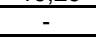 \\
\hline 311. & BL5-514 & $L 722$ & 6,779 & 14632 & 3 & 1 & 1 & 1 & 0 & 625.597 & 0,03 & 5,88 & 0,15 & 30,76 & 146,57 & $-115,81$ \\
\hline 312. & \begin{tabular}{|l|} 
BL5-159 \\
\end{tabular} & B 3 & 3,683 & - & 3 & 0 & 1 & $\frac{2}{2}$ & 0 & 339.842 & - & - & 0,27 & 30,76 & - & - \\
\hline 313. & \begin{tabular}{|l|} 
BL5-372 \\
\end{tabular} & $L 370$ & 6,933 & - & 4 & 0 & 2 & 1 & 1 & 638.597 & - & - & 0,19 & 30,70 & - & - \\
\hline 314. & \begin{tabular}{|l|} 
BL1-259 \\
\end{tabular} & B49 & 7,256 & 4722 & 8 & 0 & 2 & $\frac{1}{2}$ & $\frac{1}{4}$ & 667.660 & 0,21 & 17,54 & 0,37 & 30,67 & 48,96 & $-18,29$ \\
\hline 315. & \begin{tabular}{|l|} 
BL2-278 \\
\end{tabular} & B58 & 6,238 & 12762 & 3 & 1 & 1 & 1 & 0 & 573.960 & 0,03 & 6,69 & 0,16 & 30,67 & 128,32 & $\begin{array}{l}-97,65 \\
\end{array}$ \\
\hline 316. & \begin{tabular}{|l|} 
BL2-823 \\
\end{tabular} & L617 & 3,364 & 4717 & 3 & 0 & 1 & 1 & 1 & 308.894 & 0,17 & 17,78 & 0,30 & 30,61 & 48,21 & $-17,60$ \\
\hline 317. & \begin{tabular}{|l|} 
BL1-429 \\
\end{tabular} & L433 & 3,360 & 1434 & 2 & 0 & 1 & 1 & 0 & 307.830 & 0,38 & 58,35 & 0,20 & 30,54 & 14,66 & 15,88 \\
\hline 318. & \begin{tabular}{|l|} 
BL5-42 \\
\end{tabular} & B 33 & 3,468 & 11280 & 2 & 0 & 1 & 0 & 1 & 316.784 & 0,05 & 7,40 & 0,19 & 30,45 & 115,28 & $-84,83$ \\
\hline 319. & \begin{tabular}{|l|} 
BL2-297 \\
\end{tabular} & B482 & 3,189 & 13690 & 2 & 0 & 1 & 0 & 1 & 291.066 & 0,04 & 5,37 & 0,21 & 30,42 & 158,68 & $-128,25$ \\
\hline 320. & BL5-86 & B 32 & 3,535 & - & $\frac{4}{2}$ & 1 & 0 & 1 & 0 & 321.813 & , & 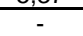 & 0,19 & 30,35 & D. & $x_{2}$ \\
\hline 321. & \begin{tabular}{|l|}
$\mathrm{BL} 2-689$ \\
\end{tabular} & L422 & 3,448 & 17874 & 3 & 0 & 1 & 2 & 0 & 313.722 & 0,04 & 3,82 & 0,29 & 30,33 & 222,42 & $-192,09$ \\
\hline 322. & \begin{tabular}{|l|} 
BL5-962 \\
\end{tabular} & B 32 & 3,540 & 4462 & 2 & 1 & 0 & 1 & 0 & 321.813 & 0,12 & 18,61 & 0,19 & 30,30 & 45,60 & $-15,30$ \\
\hline 323. & $\begin{array}{l}\mathrm{BL} 2-384 \\
\end{array}$ & B233 & 3,260 & 12607 & $\frac{4}{2}$ & 0 & 1 & $\frac{1}{1}$ & 0 & 295.894 & 0,05 & 6,87 & 0,20 & 30,26 & 123,28 & \begin{tabular}{|l|}
$-93,03$ \\
\end{tabular} \\
\hline 324. & BL4-276 & B 6 & 4,346 & 9912 & 5 & 0 & $\frac{t}{1}$ & $\frac{1}{2}$ & $\frac{5}{2}$ & 393.995 & 0,11 & 8,35 & 0,38 & 30,22 & 101,30 & \begin{tabular}{|l|}
$-71,08$ \\
\end{tabular} \\
\hline 325. & \begin{tabular}{|l|} 
BL1-409 \\
\end{tabular} & L414 & 3,400 & 1876 & 2 & 0 & 1 & 1 & 0 & 307.830 & 0,29 & 44,07 & 0,20 & 30,18 & 19,17 & 11,01 \\
\hline 326. & \begin{tabular}{|l|} 
BL4-106 \\
\end{tabular} & L 24 & 3,812 & 2877 & 2 & 0 & 1 & 0 & 1 & 344.537 & 0,17 & 28,69 & 0,17 & 30,13 & 29,40 & 0,72 \\
\hline 327. & \begin{tabular}{|l|} 
BL2-155 \\
\end{tabular} & L600 & 3,274 & 7614 & 2 & 0 & 1 & 1 & 0 & 295.894 & 0,07 & 10,78 & 0,20 & 30,13 & 78,26 & $-48,13$ \\
\hline 328. & \begin{tabular}{|l|}
$\mathrm{BL} 2-263$ \\
\end{tabular} & L811 & 3,222 & 7017 & 2 & 0 & 1 & 0 & 1 & 291.066 & 0,08 & 11,76 & 0,21 & 30,11 & 71,71 & $-41,60$ \\
\hline 329. & BL5-1000 & $\mathrm{L} 230$ & 4,107 & 4985 & 5 & 0 & 1 & 3 & 1 & 370.871 & 0,22 & 16,54 & 0,41 & 30,10 & 50,95 & $-20,85$ \\
\hline 330. & \begin{tabular}{|l|} 
BL3-206 \\
\end{tabular} & B101 & 3,710 & 3684 & 2 & 0 & 1 & 1 & 0 & 334.269 & 0,13 & 22,30 & 0,18 & 30,03 & 37,71 & $\begin{array}{l}-7,67 \\
\end{array}$ \\
\hline \begin{tabular}{|l|}
331. \\
\end{tabular} & \begin{tabular}{|l|} 
BL3-93 \\
\end{tabular} & B1 & 22,229 & 7721 & 12 & 2 & 4 & 5 & 1 & 2.000 .826 & 0,06 & 10,29 & 0,18 & 30,00 & 81,67 & $-51,67$ \\
\hline 332. & BL4-85 & L 52 & 3,898 & 1966 & 2 & 0 & 1 & 1 & + & 349.766 & 0,24 & 41,68 & 0,17 & 29,91 & 20,09 & 9,82 \\
\hline 333. & BL5-945 & L 1261 & 3,597 & & $\frac{4}{2}$ & 0 & $\frac{1}{1}$ & $\frac{1}{1}$ & 0 & 321.813 & & & 0,19 & 29,82 & & $0,0<$ \\
\hline 334. & \begin{tabular}{|l|} 
BL1-184 \\
\end{tabular} & B257 & 21,142 & 8345 & 16 & 0 & $\frac{1}{6}$ & 4 & $\frac{6}{6}$ & 1.889 .016 & 0,08 & 9,89 & 0,25 & 29,78 & 84,35 & $-54,57$ \\
\hline 335. & BL2-775 & L240 & 6,901 & - & 6 & 0 & 2 & 1 & 3 & 612.960 & - & , & 0,29 & 29,61 & - & 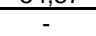 \\
\hline 336. & BL1-33 & K52 & 3,670 & 1975 & 3 & 0 & 1 & $\frac{1}{2}$ & 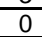 & 325.812 & 0,29 & 31,28 & 0,27 & 29,59 & 26,49 & 3,10 \\
\hline \begin{tabular}{|l|}
337. \\
\end{tabular} & BL3-1181 & L30 & 4,370 & 5649 & 5 & 0 & 1 & 4 & 0 & 387.633 & 0,19 & 15,06 & 0,38 & 29,57 & 54,98 & $-25,42$ \\
\hline 338. & \begin{tabular}{|l|} 
BL4-128 \\
\end{tabular} & B 245 & 3,944 & 6203 & 2 & 0 & 1 & 1 & (2) & 349.766 & 0,07 & 13,06 & 0,17 & 29,56 & 63,39 & $-33,83$ \\
\hline 339. & \begin{tabular}{|l|} 
BL2-182 \\
\end{tabular} & B70 & 3,441 & 12268 & 3 & 1 & 0 & 0 & 2 & 304.066 & 0,06 & 6,58 & 0,29 & 29,46 & 125,38 & $-95,92$ \\
\hline 340. & \begin{tabular}{|l|} 
BL5-968 \\
\end{tabular} & B 311 & 6,878 & - & 2 & 1 & 1 & 0 & 0 & $\begin{array}{l}607.568 \\
\end{array}$ & - & - & 0,10 & 29,44 & - & - \\
\hline 341. & \begin{tabular}{|l|} 
BL2-691 \\
\end{tabular} & L441 & 3,353 & 5997 & 2 & 0 & 1 & 1 & U & 295.894 & 0,09 & 13,44 & 0,20 & 29,42 & 61,29 & $-31,87$ \\
\hline 342. & \begin{tabular}{|l|} 
BL2-445 \\
\end{tabular} & B252 & 3,305 & 6969 & 2 & 0 & 1 & 0 & 1 & 291.066 & 0,08 & 11,05 & 0,20 & 29,36 & 74,37 & $-45,01$ \\
\hline 343. & \begin{tabular}{|l|}
$\mathrm{BL} 2-463$ \\
\end{tabular} & L886 & 3,370 & 4668 & 2 & 0 & $\perp$ & 1 & 0 & 295.894 & 0,11 & 17,00 & 0,20 & 29,27 & 48,22 & $-18,95$ \\
\hline 344. & \begin{tabular}{|l|} 
BL1-693 \\
\end{tabular} & B270 & 3,512 & 11666 & 2 & 0 & 1 & 1 & 0 & 307.830 & 0,04 & 6,75 & 0,19 & 29,22 & 121,11 & $-91,90$ \\
\hline 345. & \begin{tabular}{|l|} 
BL5-624 \\
\end{tabular} & B 290 & 3,824 & - & 3 & 0 & 1 & $\frac{1}{1}$ & 1 & 334.813 & - & - & 0,26 & 29,19 & - & - \\
\hline 346. & \begin{tabular}{|l|} 
BL1-274 \\
\end{tabular} & L158 & 11,152 & 3000 & 10 & 0 & 3 & 3 & 4 & 975.490 & 0,27 & 26,63 & 0,30 & 29,16 & 30,66 & $-1,50$ \\
\hline 347. & BL5-260 & L 105 & 4,106 & - & 4 & 0 & 1 & 3 & 0 & 357.871 & s & 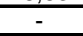 & 0,32 & 29,05 & - & 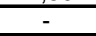 \\
\hline 348. & \begin{tabular}{|l|} 
BL1-249 \\
\end{tabular} & B49 & 7,220 & 6074 & 5 & 0 & 2 & 2 & 1 & 628.660 & 0,10 & 13,09 & 0,23 & 29,02 & 62,08 & $-33,05$ \\
\hline 349. & BL3-1105 & L64 & 3,841 & 2201 & 2 & 0 & 1 & 1 & 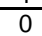 & 334.269 & 0,22 & 36,11 & 0,17 & 29,01 & 22,49 & 6,51 \\
\hline 350. & \begin{tabular}{|l|} 
BL5-190 \\
\end{tabular} & L 151 & 3,653 & - & 2 & 0 & 1 & 0 & 1 & 316.784 & - & - & 0,18 & 28,91 & - & - \\
\hline $\begin{array}{l}351 . \\
351 .\end{array}$ & \begin{tabular}{|l|} 
BL5-274 \\
\end{tabular} & B 33 & 3,729 & - & 2 & 0 & 1 & 1 & 0 & 321.813 & - & - & 0,18 & 28,77 & - & - \\
\hline 352. & \begin{tabular}{|l|} 
BL4-311 \\
\end{tabular} & L 207 & 4,054 & 4114 & 2 & 0 & 1 & $\perp$ & 0 & 349.766 & 0,11 & 19,15 & 0,1 & 28,76 & 42,05 & $-13,29$ \\
\hline 353. & \begin{tabular}{|l|} 
BL1-10 \\
\end{tabular} & B414 & 4,138 & 7218 & 5 & 0 & $\frac{1}{1}$ & $\frac{1}{3}$ & 1 & 356.794 & 0,15 & 10,91 & $0,4 \mathrm{~d}$ & 28,74 & 73,77 & $\begin{array}{l}+45,03 \\
\end{array}$ \\
\hline 354. & BL3-81 & B102 & 3,879 & 14165 & 2 & 0 & $\frac{1}{1}$ & 1 & 0 & 334.269 & 0,03 & 5,56 & 0,1 & 28,72 & 144,77 & $-116,04$ \\
\hline 355. & \begin{tabular}{|l|} 
BL3-170 \\
\end{tabular} & B156 & 3,828 & 5356 & 2 & 0 & 1 & 0 & 1 & 329 & 0,09 & 14,68 & 0,17 & 28,69 & 54,74 & $-26,05$ \\
\hline 356. & \begin{tabular}{|l|} 
BL2-200 \\
\end{tabular} & L595 & 6,465 & 3030 & 2 & 0 & 2 & 0 & 0 & 556.132 & 0,09 & 25,93 & 0,10 & 28,67 & 30,97 & $-2,29$ \\
\hline \begin{tabular}{|l|}
357. \\
\end{tabular} & \begin{tabular}{|l|} 
BL3-117 \\
\end{tabular} & B102 & 3,890 & 3433 & 2 & 0 & 1 & 1 & 0 & 334.269 & 0,14 & 22,86 & 0,17 & 28,64 & 35,09 & $-6,44$ \\
\hline 358. & \begin{tabular}{|l|} 
BL4-330 \\
\end{tabular} & B 184 & 4,438 & 5406 & 4 & 0 & 1 & 2 & 1 & 380.995 & 0,15 & 14,50 & 030 & 28,62 & 55,25 & $-26,63$ \\
\hline 359. & \begin{tabular}{|l|} 
BL5-102 \\
\end{tabular} & $\mathrm{L} 193$ & 3,702 & - & 2 & 0 & 1 & 0 & 1 & & -5 & - & 0,18 & 28,52 & - & - \\
\hline 360. & \begin{tabular}{|l|} 
BL3-143 \\
\end{tabular} & B102 & 3,920 & 3638 & 2 & 1 & 0 & 1 & 0 & 334.269 & 0,13 & 21,41 & 0,17 & 28,42 & 37,18 & $-8,76$ \\
\hline 361. & \begin{tabular}{|l|l} 
BL4-273 \\
\end{tabular} & B 6 & 4,103 & 8579 & $\frac{4}{2}$ & 0 & $\frac{\pi}{1}$ & $\frac{1}{1}$ & $\frac{0}{0}$ & & 0,05 & 9 & 0,1 & 28,42 & 87,68 & $\frac{-0,10}{-59,26}$ \\
\hline 362. & \begin{tabular}{|l|} 
BL1-669 \\
\end{tabular} & L395 & 3,823 & 9822 & 3 & 0 & $\frac{1}{1}$ & $\frac{1}{2}$ & 0 & 325.812 & 0,07 & 7,92 & 0,26 & 28,41 & 100,38 & $\begin{array}{l}-71,97 \\
-1,97\end{array}$ \\
\hline 363. & \begin{tabular}{|l|} 
BL4-116 \\
\end{tabular} & $\mathrm{L} 65$ & 8,001 & 6317 & 3 & 0 & $\frac{1}{2}$ & $\underline{E}$ & 0 & 681.303 & 0,05 & 12,31 & $\frac{1,12}{0,12}$ & 28,38 & 64,56 & $-36,18$ \\
\hline 364. & \begin{tabular}{|l|} 
BL5-952 \\
\end{tabular} & B 311 & 4,308 & - & 5 & 0 & 1 & $\frac{2}{2}$ & 2 & 365.842 & - & - & 0,39 & 28,31 & - & - \\
\hline 365. & \begin{tabular}{|l|} 
BL5-488 \\
\end{tabular} & B 35 & 4,005 & - & 3 & 0 & 1 & 2 & 0 & 339.842 & - & - & 0,25 & 28,28 & - & - \\
\hline 366. & \begin{tabular}{|l|} 
BL5-603 \\
\end{tabular} & L 508 & 3,947 & - & 3 & 0 & 1 & 1 & 1 & 334.813 & - & - & 0,25 & 28,28 & - & - \\
\hline 367. & \begin{tabular}{|l|} 
BL1-372 \\
\end{tabular} & L400 & 3,631 & 1088 & 2 & 0 & 1 & 1 & 0 & 307.830 & 0,46 & 1,16 & 0,18 & 28,26 & 11,12 & 17,14 \\
\hline 368. & BL3-1042 & L200 & 7,830 & 4274 & 4 & 0 & 2 & 1 & 1 & 663.750 & 0,11 & 18,11 & 0,17 & 28,26 & 43,68 & $-15,42$ \\
\hline 369. & \begin{tabular}{|l|} 
BL2-726 \\
\end{tabular} & B509 & 3,434 & 8831 & 2 & 0 & 1 & 0 & 1 & 291.066 & 0,06 & 8,77 & 0,19 & 28,25 & 90,25 & $-62,00$ \\
\hline 370. & \begin{tabular}{|l|} 
BL3-161 \\
\end{tabular} & B156 & 3,945 & 3331 & 2 & 0 & 1 & 1 & 0 & 334.269 & 0,14 & 22,71 & 0,17 & 28,24 & 34,83 & $-6,58$ \\
\hline 371. & $\begin{array}{l}\text { BL5-14 } \\
\end{array}$ & L 318 & 3,739 & & $\frac{4}{2}$ & 0 & $\frac{1}{1}$ & 0 & 1 & 316.784 & & & 0,18 & 28,24 & & \\
\hline 372. & BL3-1096 & L702 & 3,948 & 1770 & $\frac{4}{2}$ & 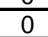 & \pm & 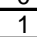 & $\frac{1}{0}$ & 334.269 & 0,27 & 45,25 & 0,17 & 28,22 & 17,46 & 10,76 \\
\hline 373. & \begin{tabular}{|l|} 
BL1-485 \\
\end{tabular} & L134 & 3,578 & 1100 & 2 & 0 & 1 & 0 & 1 & 302.848 & 0,46 & 70,27 & 0,19 & 28,21 & 11,24 & 16,97 \\
\hline 374. & BL5-24 & B 32 & 3,804 & - & 2 & 0 & 1 & 1 & 0 & 321.813 & - & $\frac{1}{-}$ & 0,18 & 28,20 & - & 0,0 \\
\hline 375. & \begin{tabular}{|l|} 
BL2-994 \\
\end{tabular} & B229 & 7,517 & 7679 & 7 & 0 & 2 & 3 & 2 & 635.616 & 0,10 & 9,44 & 0,31 & 28,19 & 83,60 & $-55,42$ \\
\hline
\end{tabular}


7) Überholunfälle auf Landstraßen - Anhänge zum Abschlussbericht

\begin{tabular}{|c|c|c|c|c|c|c|c|c|c|c|c|c|c|c|c|c|}
\hline 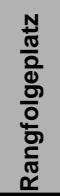 & 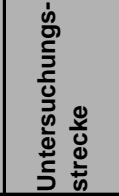 & 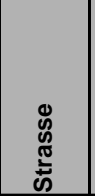 & 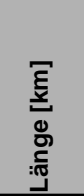 & 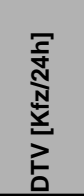 & 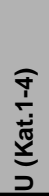 & 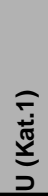 & 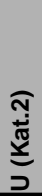 & 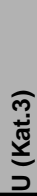 & 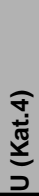 & $\begin{array}{l}\mathbb{\Psi} \\
\text { ๖ }\end{array}$ & 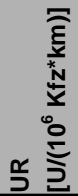 & 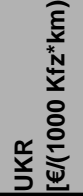 & ○ & 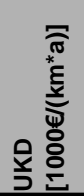 & 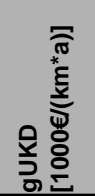 & 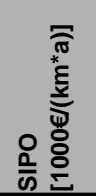 \\
\hline 376. & \begin{tabular}{|l|} 
BL2-1001 \\
\end{tabular} & B229 & 3,715 & 10537 & 3 & 0 & 1 & 2 & 0 & 313.722 & 0,07 & 7,26 & 0,27 & 28,15 & 108,53 & $-80,38$ \\
\hline 377. & \begin{tabular}{|l|} 
BL2-953 \\
\end{tabular} & L336 & 3,514 & - & 2 & 0 & 1 & 1 & 0 & 295.894 & -1 & - & 0,19 & 28,07 & - & 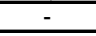 \\
\hline 378. & \begin{tabular}{|l|} 
BL2-877 \\
\end{tabular} & L539 & 3,518 & 8188 & 2 & 0 & 1 & 1 & 0 & 295.894 & 0,07 & 10,45 & 0,19 & 28,04 & 75,10 & $-47,06$ \\
\hline 379. & BL4-13 & \begin{tabular}{|l|} 
B 248 \\
\end{tabular} & 4,469 & 6436 & 4 & 0 & 1 & 1 & 2 & 375.766 & 0,13 & 11,93 & 0,30 & 28,03 & 65,78 & $-37,75$ \\
\hline 380. & BL5-9 & \begin{tabular}{|l|}
$\mathrm{L} 320$ \\
\end{tabular} & 3,829 & - & 2 & 0 & 1 & 1 & 0 & 321.813 & 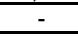 & - & 0,17 & 28,02 & & \\
\hline 381. & BL5-599 & \begin{tabular}{|l|l|}
$\mathrm{L} 2310$ \\
\end{tabular} & 7,391 & 3587 & 3 & 0 & 2 & 0 & 1 & 620.568 & 0,10 & 21,38 & 0,14 & 27,99 & 36,66 & $-8,67$ \\
\hline 382. & BL1-406 & B420 & 7,225 & 7968 & 4 & 0 & 2 & 0 & 2 & 605.696 & 0,06 & 9,56 & 0,18 & 27,94 & 81,82 & $-53,88$ \\
\hline 383. & BL2-91 & L491 & 3,473 & 8812 & 2 & 0 & 1 & 0 & 1 & 291.066 & 0,06 & 9,05 & 0,19 & 27,94 & 86,43 & $-58,49$ \\
\hline 384. & BL5-585 & B 19 & 3,858 & - & 2 & 0 & 1 & 1 & 0 & 321.813 & - & 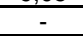 & 0,17 & 27,80 & - & 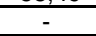 \\
\hline 385. & BL2-507 & 2822 & 6,713 & - & 2 & 0 & 2 & 0 & 0 & 556.132 & - & - & 0,10 & 27,61 & - & - \\
\hline 386. & BL2-15 & L41 & 3,672 & 4519 & 3 & 0 & 1 & 0 & 2 & 304.066 & 0,17 & 16,92 & 0,27 & 27,60 & 45,68 & $-18,08$ \\
\hline 387. & BL5-480 & \begin{tabular}{|l|l|}
$L$ & 1134 \\
\end{tabular} & 3,888 & 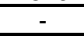 & 2 & 0 & 1 & 1 & 0 & 321.813 & - & . & 0,17 & 27,59 & 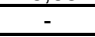 & 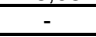 \\
\hline 388. & BL5-54 & L $200 \mathrm{~A}$ & 4,326 & 5780 & 4 & 0 & 1 & 3 & 0 & 357.871 & 0,15 & 13,07 & 0,31 & 27,58 & 59,07 & $-31,50$ \\
\hline 389. & BL5-10 & B 12 & 3,835 & 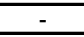 & 2 & 0 & 1 & 0 & 1 & 316.784 & - & + & 0,17 & 27,53 & 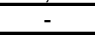 & - \\
\hline 390. & \begin{tabular}{|l}
$B L 3-1176$ \\
\end{tabular} & L200 & 4,635 & 8403 & 5 & 0 & 1 & 3 & 1 & 382.845 & 0,11 & 8,75 & 0,36 & 27,53 & 88,08 & $-60,54$ \\
\hline 391. & \begin{tabular}{|l|l|} 
BL4-103 \\
\end{tabular} & $\mathrm{L} 25$ & 4,235 & 1410 & 2 & 0 & 1 & 1 & 0 & 349.766 & 0,31 & 53,49 & 0,16 & 27,53 & 14,41 & 13,12 \\
\hline 392. & BL4-62 & B 71 & 4,557 & 7330 & 4 & 0 & 1 & 1 & 2 & 375.766 & 0,11 & 10,27 & 0,29 & 27,49 & 74,91 & $-47,43$ \\
\hline 393. & BL3-63 & B158 & 4,280 & 11445 & 3 & 0 & 1 & 2 & 0 & 352.057 & 0,06 & 6,56 & 0,23 & 27,42 & 116,97 & $-89,55$ \\
\hline 394. & BL2-193 & L504 & 6,983 & 3903 & 3 & 0 & 2 & 1 & 0 & 573.960 & 0,11 & 20,31 & 0,14 & 27,40 & 37,78 & $-10,38$ \\
\hline 395. & BL3-1020 & L23 & 8,240 & 2975 & 5 & 0 & 2 & 1 & 2 & 676.750 & 0,18 & 24,60 & 0,20 & 27,38 & 31,17 & $-3,79$ \\
\hline 396. & BL4-92 & \begin{tabular}{|l|} 
B 189 \\
\end{tabular} & 4,196 & & 2 & 1 & 0 & 0 & 1 & 344.537 & - & - & 0,16 & 27,37 & 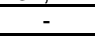 & , \\
\hline 397. & BL1-164 & B9 & 7,781 & 8068 & 6 & 1 & 1 & 1 & 3 & 636.678 & 0,09 & 9,26 & 0,26 & 27,27 & 82,45 & $-55,18$ \\
\hline 398. & $\mathrm{BL2}-928$ & $L 355$ & 3,618 & 8233 & 2 & 0 & 1 & 1 & 0 & 295.894 & 0,06 & 9,08 & 0,18 & 27,26 & 84,04 & $-56,78$ \\
\hline 399. & BL1-408 & L214 & 4,146 & 6175 & 4 & 0 & 1 & 2 & 1 & 338.812 & 0,15 & 12,45 & 0,32 & 27,24 & 61,27 & $-34,03$ \\
\hline 400. & BL2-873 & B229 & 3,572 & 8177 & 2 & 0 & 1 & 0 & 1 & 291.066 & 0,06 & 9,11 & 0,19 & 27,16 & 83,46 & $-56,29$ \\
\hline 401. & BL5-461 & \begin{tabular}{|l|l|} 
L 1127 \\
\end{tabular} & 3,960 & & 2 & 1 & 0 & 1 & 0 & 321.813 & 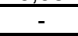 & & 0,17 & 27,09 & -1 & 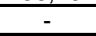 \\
\hline 402. & \begin{tabular}{|l|} 
BL4-293 \\
\end{tabular} & \begin{tabular}{|l|}
$\mathrm{L} 210$ \\
\end{tabular} & 4,309 & 1950 & 2 & 0 & 1 & 1 & 0 & 349.766 & 0,22 & 38,01 & 0,15 & 27,06 & 19,93 & 7,13 \\
\hline 403. & BL5-128 & L 171 & 4,285 & & 4 & 0 & 1 & 1 & 2 & 347.813 & & & 0,31 & 27,06 & & 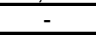 \\
\hline 404. & BL5-47 & \begin{tabular}{|l|}
$\mathrm{L} 220$ \\
\end{tabular} & 3,967 & 5987 & 2 & 0 & 1 & 1 & 0 & 321.813 & 0,08 & 12,37 & 0,17 & 27,04 & 61,19 & $-34,15$ \\
\hline 405. & BL5-605 & B 27 & 4,414 & - & 4 & 0 & 1 & 3 & 0 & 357.871 & - & - & 0,30 & 27,03 & - & 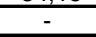 \\
\hline 406. & BL2-899 & L296 & 7,300 & - & 4 & 0 & 2 & 2 & 0 & 591.788 & - & - & 0,18 & 27,02 & - & - \\
\hline 407. & BL1-342 & B269 & 3,798 & 3569 & 2 & 1 & 0 & 1 & 0 & 307.830 & 0,13 & 20,74 & 0,18 & 27,02 & 36,48 & $-9,46$ \\
\hline 408. & \begin{tabular}{|l|}
$B L 5-1029$ \\
\end{tabular} & B 10 & 3,909 & & 2 & 0 & 1 & 0 & 1 & 316.784 & - & & 0,17 & 27,01 & & \\
\hline 409. & \begin{tabular}{|l|} 
BL2-411 \\
\end{tabular} & B516 & 10,297 & 4401 & 3 & 0 & 3 & 0 & 0 & 834.198 & 0,06 & 16,81 & 0,10 & 27,00 & 44,98 & $-17,97$ \\
\hline 410. & BL4-25 & B 71 & 4,639 & 7953 & 4 & 1 & 0 & 1 & 2 & 375.766 & 0,10 & 9,30 & 0,29 & 27,00 & 81,28 & $-54,28$ \\
\hline 411. & BL5-915 & B 29 & 4,356 & 15901 & 4 & 0 & 1 & $\frac{1}{2}$ & 1 & 352.842 & 0,05 & 4,65 & 0,31 & 27,00 & 162,51 & $-135,51$ \\
\hline 412. & BL2-16 & L174 & 3,655 & 3011 & 2 & 0 & 1 & 1 & 0 & 295.894 & 0,20 & 29,79 & 0,18 & 26,99 & 25,37 & 1,62 \\
\hline 413. & BL2-983 & B55 & 3,659 & 9603 & 2 & 0 & 1 & 1 & 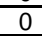 & 295.894 & 0,05 & 7,67 & 0,18 & 26,96 & 98,44 & $-71,49$ \\
\hline 414. & BL5-454 & \begin{tabular}{|l|l|}
$L 1115$ \\
\end{tabular} & 3,983 & - & 2 & 0 & 1 & 1 & 0 & 321.813 & - & - & 0,17 & 26,93 & - & -1 \\
\hline 415. & BL4-142 & \begin{tabular}{|l|} 
B 81 \\
\end{tabular} & 8,620 & 9843 & 4 & 1 & 1 & 1 & 1 & 694.303 & 0,04 & 7,48 & 0,15 & 26,85 & 100,47 & $-73,62$ \\
\hline 416. & BL2-848 & B229 & 4,057 & 9048 & 4 & 0 & 1 & 2 & 1 & 326.722 & 0,10 & 8,10 & 0,33 & 26,84 & 92,79 & $-65,94$ \\
\hline 417. & BL4-97 & B 188 & 4,672 & 5662 & 4 & 0 & 1 & 1 & 2 & 375.766 & 0,14 & 13,10 & 0,29 & 26,81 & 57,29 & $-30,48$ \\
\hline 418. & BL1-66 & K8 & 3,769 & 1275 & 2 & 1 & 0 & 0 & 1 & 302.848 & 0,38 & 58,24 & 0,18 & 26,78 & 12,88 & 13,91 \\
\hline 419. & \begin{tabular}{|l|} 
BL2-837 \\
\end{tabular} & $\mathrm{L} 740$ & 7,103 & 4338 & 3 & 1 & 1 & 0 & 1 & 569.132 & 0,09 & 16,87 & 0,14 & 26,71 & 44,33 & $-17,63$ \\
\hline 420. & \begin{tabular}{|l|} 
BL3-1192 \\
\end{tabular} & L79 & 4,395 & 8453 & 3 & 1 & 0 & 2 & 0 & 352.057 & 0,07 & 8,71 & 0,23 & 26,70 & 85,81 & $-59,10$ \\
\hline 421. & BL2-438 & L763 & 6,949 & 1561 & 2 & 0 & 2 & 0 & 0 & 556.132 & 0,17 & 46,82 & 0,10 & 26,68 & 15,95 & 10,72 \\
\hline 422. & \begin{tabular}{|l|} 
BL2-197 \\
\end{tabular} & L595 & 3,638 & 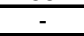 & 2 & 0 & 1 & 0 & 1 & 291.066 & 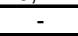 & - & 0,18 & 26,67 & 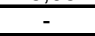 & 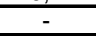 \\
\hline 423. & BL2-365 & $\mathrm{B} 61$ & 3,861 & 17185 & 3 & 0 & 1 & 1 & 1 & 308.894 & 0,04 & 4,59 & 0,26 & 26,67 & 162,69 & $-136,02$ \\
\hline 424. & BL2-944 & B226 & 7,788 & - & 6 & 0 & 2 & 3 & 1 & 622.616 & - & - & 0,26 & 26,65 & - & - \\
\hline 425. & BL1-81 & L304 & 3,790 & 7900 & 2 & 0 & 1 & 0 & 1 & 302.848 & 0,06 & 9,24 & 0,18 & 26,64 & 80,74 & $-54,10$ \\
\hline 426. & BL5-446 & \begin{tabular}{|l|l|} 
L 1124 \\
\end{tabular} & 3,966 & - & 2 & 1 & 0 & 0 & 4 & 316.784 & - & & 0,17 & 26,62 & & \\
\hline 427. & BL1-664 & B271 & 3,860 & 7018 & 2 & 0 & 1 & 1 & 0 & 307.830 & 0,07 & 10,53 & 0,17 & 26,58 & $\begin{array}{l}70,68 \\
\end{array}$ & $-44,10$ \\
\hline 428. & BL2-747 & L19 & 3,658 & - & 2 & 0 & 4 & 0 & 1 & 291.066 & - & - & 0,1 & 26,52 & 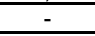 & 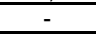 \\
\hline 429. & BL5-703 & L 87 & 4,054 & - & 2 & 0 & 1 & 1 & 0 & & - & - & 0, & 26,46 & - & - \\
\hline 430. & \begin{tabular}{|l|l|} 
BL3-1196 \\
\end{tabular} & L793 & 4,375 & - & 3 & 1 & 0 & 1 & 1 & 347.269 & - & - & 0,23 & 26,46 & 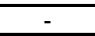 & - \\
\hline 431. & \begin{tabular}{|l|} 
BL5-111 \\
\end{tabular} & L 191 & 4,286 & & 3 & 1 & 0 & $\frac{2}{2}$ & 0 & 339.842 & - & - & 0,23 & 26,43 & - & - \\
\hline 432. & BL4-357 & B 6 & 4,592 & 8815 & 3 & 0 & 1 & 1 & 1 & 362.766 & 0,07 & 7,97 & 0,22 & 26,33 & 92,47 & $-66,14$ \\
\hline 433. & \begin{tabular}{|l|} 
BL3-1154 \\
\end{tabular} & L34 & 8,013 & 4747 & 2 & 0 & 2 & 0 & 0 & 632.962 & 0,05 & 15,20 & 0,08 & 26,33 & 48,51 & $-22,18$ \\
\hline 434. & \begin{tabular}{|l|} 
BL5-592 \\
\end{tabular} & \begin{tabular}{|l|l|}
$L 1036$ \\
\end{tabular} & 4,239 & & 3 & 0 & 1 & 1 & 1 & 334.813 & - & - & 0,24 & 26,33 & - & - \\
\hline 435. & BL4-148 & $\mathrm{L} 66$ & 4,433 & 2997 & 2 & 0 & 1 & 1 & 0 & 349.766 & 0,14 & 24,04 & 0,15 & 26,30 & 30,63 & $-4,33$ \\
\hline 436. & \begin{tabular}{|l|} 
BL3-171 \\
\end{tabular} & $\mathrm{B} 156$ & 4,402 & 5356 & 3 & 0 & 1 & 1 & 1 & 347 & 0,12 & 13,45 & 0,23 & 26,30 & 54,74 & $-28,44$ \\
\hline 437. & BL2-400 & B7 & 4,146 & 9582 & 4 & 0 & 1 & 2 & 1 & 326.722 & 0,10 & 7,96 & 0,32 & 26,27 & 92,41 & $-66,14$ \\
\hline 438. & BL5-1041 & \begin{tabular}{|l|l|}
$L$ & 1079 \\
\end{tabular} & 4,025 & 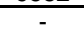 & 2 & 0 & 1 & 0 & 1 & & - & 40 & 0,17 & 26,23 & - & 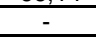 \\
\hline 439. & \begin{tabular}{|l|} 
BL2-442 \\
\end{tabular} & B64 & 3,988 & 8043 & 3 & 0 & 1 & 2 & 0 & 313.722 & 0,09 & 8,93 & 0,25 & 26,22 & 82,20 & $-55,98$ \\
\hline 440. & \begin{tabular}{|l|} 
BL3-1036 \\
\end{tabular} & L21 & 8,503 & 8449 & 4 & 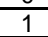 & 1 & 2 & 0 & 668.538 & 0,05 & 8,25 & 0,16 & 26,21 & 88,95 & $\begin{array}{l}-62,74 \\
\end{array}$ \\
\hline 441. & \begin{tabular}{|l|} 
BL2-975 \\
\end{tabular} & L539 & 7,698 & 10790 & 5 & 0 & 2 & 2 & 1 & 604.788 & 0,06 & 7,09 & 0,22 & 26,19 & 103,35 & $-77,16$ \\
\hline 442. & BL1-312 & B410 & 4,154 & 2479 & 3 & 0 & 1 & 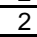 & 0 & 325.812 & 0,25 & 27,60 & 0,24 & 26,14 & 26,52 & $-0,38$ \\
\hline 443. & BL2-683 & L353 & 3,960 & 13533 & 3 & 0 & 1 & 1 & 1 & 308.894 & 0,05 & 4,98 & 0,25 & 26,00 & 146,18 & $-120,18$ \\
\hline 444. & BL5-937 & B 465 & 4,127 & 7295 & 2 & 0 & 1 & 1 & 0 & 321.813 & 0,06 & 9,81 & 0,16 & 25,99 & 74,17 & $-48,18$ \\
\hline 445. & BL5-568 & \begin{tabular}{|l|l} 
L 1111 \\
\end{tabular} & 4,073 & 18955 & 2 & 1 & 0 & 0 & 1 & 316.784 & 0,02 & 3,76 & 0,16 & 25,93 & 193,27 & $-167,35$ \\
\hline 446. & BL2-988 & L687 & 7,777 & 2767 & 5 & 1 & 1 & $\pi$ & 1 & 604.788 & 0,21 & 25,67 & 021 & 25,92 & 28,28 & $-2,36$ \\
\hline 447. & BL4-66 & B 71 & 4,667 & 6566 & 3 & 0 & 1 & 1 & 1 & 362. & 0,09 & 10,81 & 0,21 & 25,91 & 67,10 & $-41,19$ \\
\hline 448. & BL1-190 & B412 & 3,961 & 4267 & 2 & 0 & 1 & 1 & 0 & 307.830 & 0,11 & 16,63 & 0,17 & 25,91 & 43,61 & $-17,70$ \\
\hline 449. & BL3-14 & \begin{tabular}{|l|} 
K6825 \\
\end{tabular} & 4,241 & $=0$ & 2 & 5 & 1 & 0 & 1 & 329.481 & - & 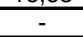 & 0,16 & 25,90 & 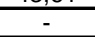 & \\
\hline 450. & BL1-508 & \begin{tabular}{|l|l|} 
B4427 \\
\end{tabular} & 7,697 & 3512 & 3 & 0 & 2 & 1 & 0 & 597.678 & 0,10 & 20,19 & 0,13 & 25,88 & 35,89 & $-10,01$ \\
\hline
\end{tabular}




\begin{tabular}{|c|c|c|c|c|c|c|c|c|c|c|c|c|c|c|c|c|}
\hline $\begin{array}{l}\frac{N}{\pi} \\
\frac{\pi}{0} \\
\frac{0}{0} \\
\frac{0}{0} \\
\frac{0}{0} \\
\frac{\pi}{\pi} \\
\underline{x}\end{array}$ & 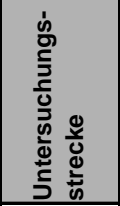 & 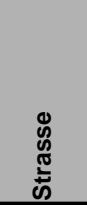 & 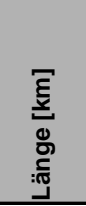 & $\begin{array}{l}\frac{F}{d} \\
\frac{T}{N} \\
\frac{1}{2} \\
Z \\
\end{array}$ & 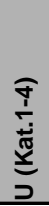 & 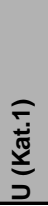 & 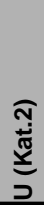 & $\begin{array}{l}\text { m } \\
\stackrel{\pi}{\pi} \\
\underline{\Sigma} \\
د\end{array}$ & 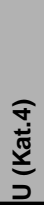 & $\begin{array}{l}\Psi \\
\stackrel{\Psi}{J}\end{array}$ & 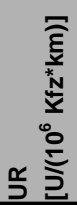 & 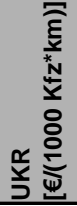 & ○ & 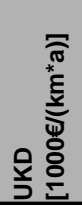 & 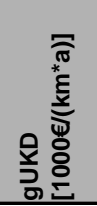 & 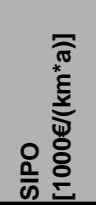 \\
\hline 451. & BL1-400 & L108 & 3,967 & 1900 & 2 & 0 & 1 & 1 & 0 & 307.830 & 0,24 & 37,30 & $0, \overline{17}$ & 25,87 & 19,42 & 6,45 \\
\hline 452. & BL1-602 & K3 & 3,906 & - & 2 & 0 & 1 & 0 & 1 & 302.848 & - & - & 0,17 & 25,84 & - & - \\
\hline 453. & BL5-254 & L 186 & 4,156 & - & 2 & 0 & 1 & 1 & 0 & 321.813 & - & - & 0,16 & 25,81 & - & - \\
\hline 454. & \begin{tabular}{|l|} 
BL5-899 \\
\end{tabular} & B 29 & 4,328 & 20733 & 3 & 1 & 0 & 1 & 1 & 334.813 & 0,04 & 3,97 & 0,23 & 25,79 & 181,70 & $-155,91$ \\
\hline 455. & BL5-720 & L 362 & 4,160 & - & 2 & 0 & 1 & 1 & 0 & 321.813 & - & - & 0,16 & 25,79 & - & - \\
\hline 456. & BL5-476 & B 10 & 4,095 & - & 2 & 0 & 1 & 0 & 1 & 316.784 & - & - & 0,16 & 25,79 & - & - \\
\hline 457. & BL1-266 & B269 & 7,743 & 3392 & 3 & 0 & 2 & 1 & 0 & 597.678 & 0,09 & 18,42 & 0,13 & 25,73 & 39,11 & $-13,38$ \\
\hline 458. & BL3-1158 & L23 & 4,565 & 13219 & 3 & 0 & 1 & 2 & 0 & 352.057 & 0,05 & 5,33 & 0,22 & 25,71 & 135,10 & $-109,39$ \\
\hline 459. & BL5-239 & L 181 & 4,175 & 8659 & 2 & 0 & 1 & 1 & 0 & 321.813 & 0,05 & 8,13 & 0,16 & 25,69 & 88,49 & $-62,80$ \\
\hline 460. & BL2-148 & L652 & 3,779 & 5708 & 2 & 0 & 1 & 0 & 1 & 291.066 & 0,08 & 12,32 & 0,18 & 25,67 & 58,34 & $-32,66$ \\
\hline 461. & BL5-20 & B 32 & 4,689 & - & 5 & 0 & 1 & 1 & 3 & 360.813 & - & - & 0,36 & 25,65 & - & - \\
\hline 462. & BL5-336 & B 294 & 8,308 & 4683 & 4 & 0 & 2 & 1 & 1 & 638.597 & 0,09 & 14,99 & 0,16 & 25,62 & 47,86 & $-22,24$ \\
\hline 463. & \begin{tabular}{|l|} 
BL5-58 \\
\end{tabular} & L 195 & 4,193 & 7651 & 2 & 1 & 0 & 1 & 0 & 321.813 & 0,06 & 9,16 & 0,16 & 25,58 & 78,19 & $-52,61$ \\
\hline 464. & BL2-776 & L240 & 3,859 & - & 2 & 1 & 0 & 1 & 0 & 295.894 & - & - & 0,17 & 25,56 & - & - \\
\hline 465. & BL5-342 & B 28 & 4,206 & 5501 & 2 & 0 & 1 & 1 & 0 & 321.813 & 0,08 & 12,70 & 0,16 & 25,50 & 56,22 & $-30,72$ \\
\hline 466. & \begin{tabular}{|l|} 
BL1-703 \\
\end{tabular} & L465 & 3,2069 & 4210 & 2 & 0 & $\frac{1}{1}$ & 0 & 1 & 302.848 & 0,12 & $\begin{array}{l}1 L, 10 \\
17,79\end{array}$ & 0,17 & 25,43 & 40,03 & $-14,59$ \\
\hline 467. & BL3-176 & B169 & 4,319 & 8473 & 2 & 1 & 0 & 0 & 1 & 329.481 & 0,05 & 8,22 & 0,15 & 25,43 & 86,59 & $-61,17$ \\
\hline 468. & BL2-255 & L844 & 3,818 & 3979 & 2 & 0 & 1 & 0 & 1 & 291.066 & 0,12 & 17,50 & 0,17 & 25,41 & 40,67 & $-15,25$ \\
\hline 469. & BL5-407 & L 1151 & 4,156 & 4059 & 2 & 1 & 0 & 0 & 1 & 316.784 & 0,11 & 17,15 & 0,16 & 25,41 & 41,48 & $-16,08$ \\
\hline 470. & BL4-192 & B 187 & 5,238 & 7893 & 5 & 0 & 1 & 3 & 1 & 399.224 & 0,11 & 8,74 & 0,32 & 25,41 & 81,43 & $-56,02$ \\
\hline 471. & BL4-210 & L 50 & 4,523 & 8294 & 2 & 0 & 1 & 0 & 1 & 344.537 & 0,05 & 8,39 & 0,15 & 25,39 & 84,76 & $-59,37$ \\
\hline 472. & \begin{tabular}{|l|} 
BL5-930 \\
\end{tabular} & B 466 & 4,467 & - & 3 & 0 & 1 & 2 & 0 & 339.842 & - & - & 0,22 & 25,36 & - & - \\
\hline 473. & BL4-256 & L 151 & 4,839 & 5672 & 3 & 0 & 1 & 2 & 0 & 367.995 & 0,10 & 12,24 & 0,21 & 25,35 & 57,97 & $-32,62$ \\
\hline 474. & BL2-541 & L757 & 3,891 & 9037 & 2 & 0 & 1 & 1 & 0 & 295.894 & 0,05 & 7,68 & 0,17 & 25,35 & 92,36 & $-67,01$ \\
\hline 475. & BL5-81 & L 290 & 4,238 & - & 2 & 0 & 1 & 1 & 0 & 321.813 & - & - & 0,16 & 25,31 & - & - \\
\hline 476. & BL5-1018 & L 1239 & 4,241 & - & 2 & 0 & 1 & 1 & 0 & 321.813 & - & - & 0,16 & 25,29 & - & - \\
\hline 477. & \begin{tabular}{|l|} 
BL2-932 \\
\end{tabular} & L439 & 4,137 & - & 3 & 0 & 1 & 2 & 0 & 313.722 & - & - & 0,24 & 25,28 & - & - \\
\hline 478. & BL5-32 & B 33 & 4,183 & 17316 & 2 & 0 & 1 & 0 & 1 & 316.784 & 0,03 & 4,05 & 0,16 & 25,24 & 174,56 & $-149,31$ \\
\hline 479. & BL3-145 & B102 & 4,359 & 5231 & 2 & 0 & 1 & 0 & 1 & 329.481 & 0,08 & 13,20 & 0,15 & 25,20 & 53,46 & $-28,27$ \\
\hline 480. & BL1-423 & B420 & 8,386 & 9813 & 5 & 0 & 2 & 3 & 0 & 633.642 & 0,06 & 7,21 & 0,20 & 25,19 & 97,76 & $-72,57$ \\
\hline 481. & BL1-320 & B50 & 4,247 & 2167 & 3 & 1 & 0 & 1 & 1 & 320.830 & 0,30 & 31,75 & 0,24 & 25,18 & 22,21 & 2,97 \\
\hline 482. & BL2-712 & L183 & 4,090 & - & 3 & 1 & 0 & 1 & 1 & 308.894 & - & - & 0,24 & 25,17 & - & - \\
\hline 483. & BL2-164 & L555 & 3,918 & 7009 & 2 & 0 & 1 & 1 & 0 & 295.894 & 0,07 & 9,84 & 0,17 & 25,17 & 71,63 & $-46,46$ \\
\hline 484. & BL1-426 & L422 & 4,011 & 7100 & 2 & 0 & 1 & 0 & 1 & 302.848 & 0,06 & 9,05 & 0,17 & 25,17 & 77,89 & $-52,72$ \\
\hline 485. & BL4-144 & L 66 & 9,267 & 3636 & 4 & 0 & 2 & 2 & 0 & 699.532 & 0,11 & 18,96 & 0,14 & 25,16 & 37,16 & $-12,00$ \\
\hline 486. & BL2-962 & L351 & 4,157 & 1322 & 3 & 0 & 1 & 2 & 0 & 313.722 & 0,58 & 60,91 & 0,24 & 25,16 & 11,56 & 13,59 \\
\hline 487. & BL4-149 & B 184 & 5,884 & 5453 & 8 & 0 & 1 & 4 & 3 & 443.453 & 0,22 & 12,09 & 0,45 & 25,12 & 58,19 & $-33,07$ \\
\hline 488. & BL3-1166 & L20 & 4,440 & 7650 & 2 & 1 & 0 & 1 & 0 & 334.269 & 0,05 & 8,99 & 0,15 & 25,10 & 78,18 & $-53,09$ \\
\hline 489. & BL4-291 & B 176 & 4,651 & 3593 & 2 & 1 & 0 & 1 & 0 & 349.766 & 0,11 & 19,11 & 0,14 & 25,07 & 36,72 & $-11,65$ \\
\hline 490. & BL1-439 & K16 & 4,270 & 1850 & 3 & 1 & 0 & 1 & 1 & 320.830 & 0,35 & 37,13 & 0,23 & 25,05 & 18,88 & 6,16 \\
\hline 491. & BL4-72 & B 246 & 4,900 & 2445 & 3 & 0 & 1 & 2 & 0 & 367.995 & 0,23 & 28,05 & 0,20 & 25,03 & 24,99 & 0,05 \\
\hline 492. & BL5-173 & L 169 & 4,286 & - & 2 & 0 & 1 & 1 & 0 & 321.813 & - & - & 0,16 & 25,03 & - & - \\
\hline 493. & \begin{tabular}{|l|} 
BL1-500 \\
\end{tabular} & \begin{tabular}{|l|l|}
$\mathrm{L} 546$ \\
\end{tabular} & 4,340 & 3733 & 3 & 0 & 1 & 2 & 0 & 325.812 & 0,18 & 19,34 & 0,23 & 25,02 & 36,23 & $-11,21$ \\
\hline 494. & BL5-623 & B 19 & 4,287 & - & 2 & 0 & 1 & 1 & 0 & 321.813 & - & - & 0,16 & 25,02 & - & - \\
\hline 495. & BL3-92 & B1 & 4,711 & 10049 & 3 & 0 & 1 & 2 & 0 & 352.057 & 0,06 & 7,01 & 0,21 & 24,91 & 99,52 & $-74,61$ \\
\hline 496. & BL2-562 & B64 & 3,895 & 14128 & 2 & 0 & 1 & 0 & 1 & 291.066 & 0,03 & 4,82 & 0,17 & 24,91 & 144,65 & $-119,74$ \\
\hline 497. & BL4-143 & B 180 & 4,708 & 5913 & 2 & 0 & 1 & 1 & 0 & 349.766 & 0,07 & 11,47 & 0,14 & 24,76 & 60,43 & $-35,67$ \\
\hline 498. & BL4-359 & B 180 & 4,963 & 5510 & 3 & 1 & 0 & 2 & 0 & 367.995 & 0,10 & 12,29 & 0,20 & 24,72 & 56,31 & $-31,60$ \\
\hline 499. & \begin{tabular}{|l|} 
BL4-329 \\
\end{tabular} & \begin{tabular}{|l|} 
B 100 \\
\end{tabular} & 4,719 & 10513 & 2 & 0 & 1 & 1 & 0 & 349.766 & 0,04 & 6,44 & 0,14 & 24,71 & 107,44 & $-82,74$ \\
\hline 500. & \begin{tabular}{|l|} 
BL2-789 \\
\end{tabular} & B59 & \begin{tabular}{|l|}
3,928 \\
\end{tabular} & - & 2 & 0 & 1 & 0 & 1 & 291.066 & - & - & 0,17 & 24,70 & - & - \\
\hline
\end{tabular}




\section{Anhang $\mathrm{E}$}

Ergebnisse der verkehrsrechtlichen Anordnungen 
a) verkehrsrechtliche Anordnungen in Bundesland 1 (89 Strecken mit 434 km)

\begin{tabular}{|c|c|c|c|}
\hline & $57,7 \%$ & $11,5 \%$ & $69,2 \%$ \\
\hline & $1,1 \%$ & $0,4 \%$ & $1,5 \%$ \\
\hline & $6,5 \%$ & $10,1 \%$ & $16,6 \%$ \\
\hline 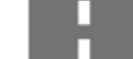 & $1,9 \%$ & $2,8 \%$ & $4,7 \%$ \\
\hline & $0,8 \%$ & $7,2 \%$ & $7,9 \%$ \\
\hline & $68,0 \%$ & $32,0 \%$ & $100,0 \%$ \\
\hline
\end{tabular}

c) verkehrsrechtliche Anordnungen in Bundesland 3 (62 Strecken mit 315 km)

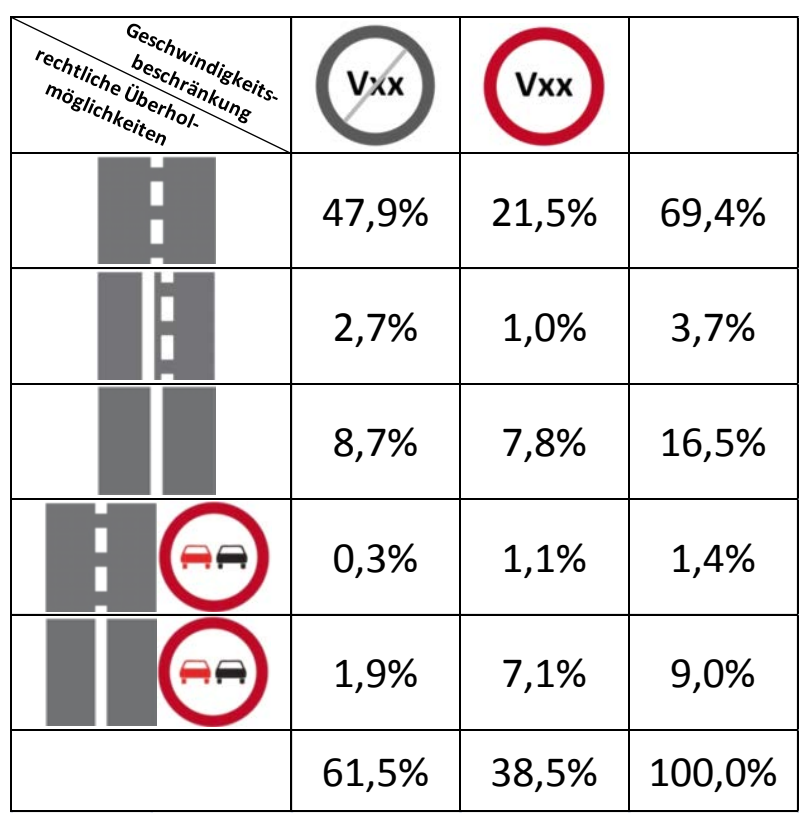

b) verkehrsrechtliche Anordnungen in Bundesland 2 (109 Strecken mit 443 km)

\begin{tabular}{|c|c|c|c|}
\hline I & $41,2 \%$ & $18,2 \%$ & $59,4 \%$ \\
\hline & $0,6 \%$ & $0,6 \%$ & $1,3 \%$ \\
\hline & $6,9 \%$ & $13,9 \%$ & $20,9 \%$ \\
\hline I & $1,2 \%$ & $10,9 \%$ & $12,2 \%$ \\
\hline & $0,2 \%$ & $6,1 \%$ & $6,3 \%$ \\
\hline & $50,2 \%$ & $49,8 \%$ & $100,0 \%$ \\
\hline
\end{tabular}

d) verkehrsrechtliche Anordnungen in Bundesland 4 (84 Strecken mit 405 km)

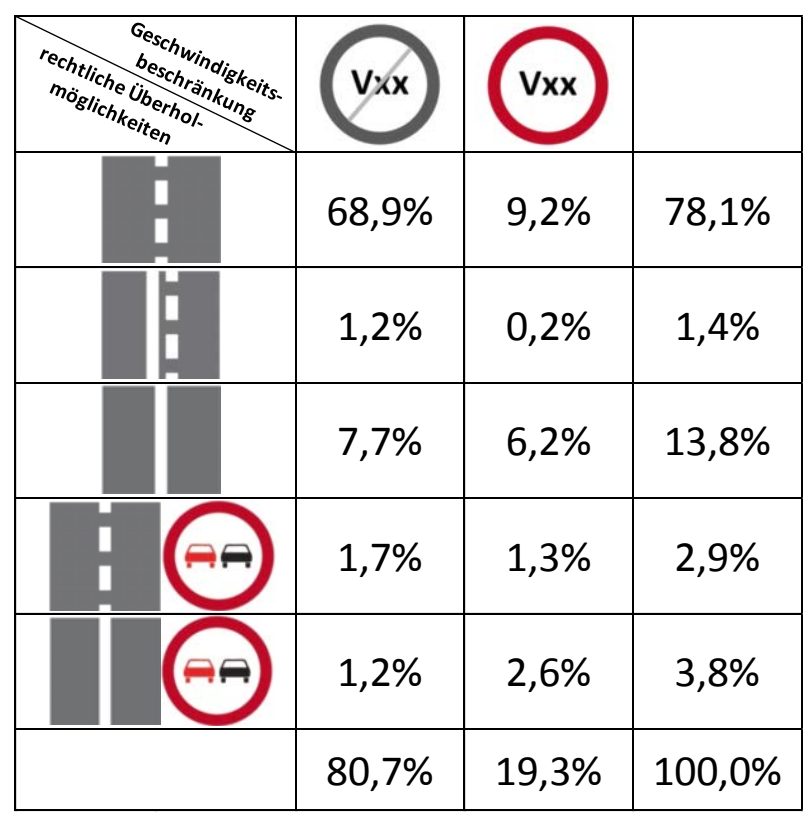


7) Überholunfälle auf Landstraßen - Anhänge zum Abschlussbericht

e) verkehrsrechtliche Anordnungen in Bundesland 5 (156 Strecken mit 638 km)

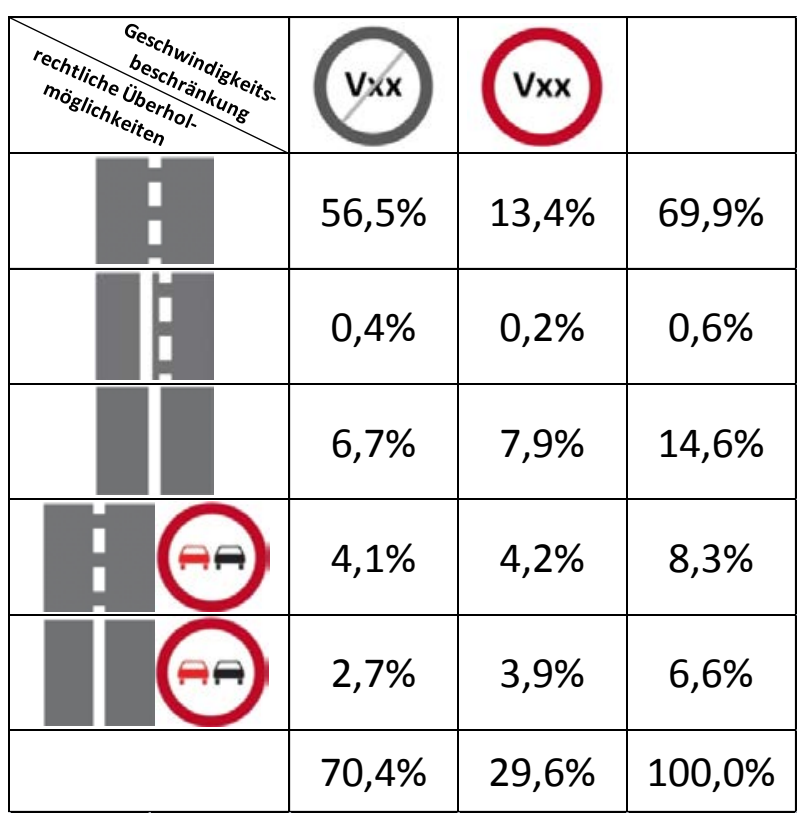




\section{Anhang $\mathbf{F}$ \\ Ergebnisse der Unfallzuordnung}


7) Überholunfälle auf Landstraßen - Anhänge zum Abschlussbericht

a) Unfallzuordnung in Bundesland 1 (332 Überholunfälle)

\begin{tabular}{|c|c|c|c|}
\hline & $63,3 \%$ & $12,3 \%$ & $75,6 \%$ \\
\hline & $1,5 \%$ & $0,6 \%$ & $2,1 \%$ \\
\hline & $6,3 \%$ & $4,5 \%$ & $10,8 \%$ \\
\hline 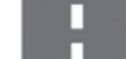 & $2,1 \%$ & $3,0 \%$ & $5,1 \%$ \\
\hline & $1,2 \%$ & $5,1 \%$ & $6,3 \%$ \\
\hline & $74,4 \%$ & $25,6 \%$ & $100,0 \%$ \\
\hline
\end{tabular}

c) Unfallzuordnung in Bundesland 3 (195 Überholunfälle)

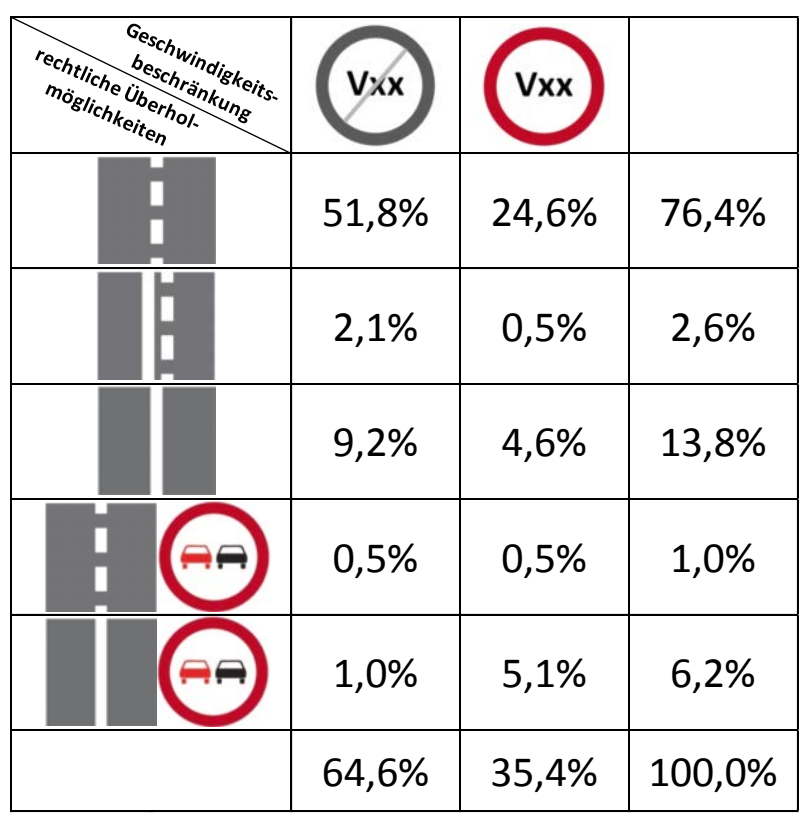

b) verkehrsrechtliche Anordnungen in Bundesland 2 (299 Überholunfälle)

\begin{tabular}{|c|c|c|c|}
\hline I & $46,2 \%$ & $17,7 \%$ & $63,9 \%$ \\
\hline & $0,7 \%$ & $0,7 \%$ & $1,3 \%$ \\
\hline & $3,7 \%$ & $11,0 \%$ & $14,7 \%$ \\
\hline 1 & $2,3 \%$ & $10,4 \%$ & $12,7 \%$ \\
\hline & $0,7 \%$ & $6,7 \%$ & $7,4 \%$ \\
\hline & $53,5 \%$ & $46,5 \%$ & $100,0 \%$ \\
\hline
\end{tabular}

d) Unfallzuordnung in Bundesland 4 (301 Überholunfälle)

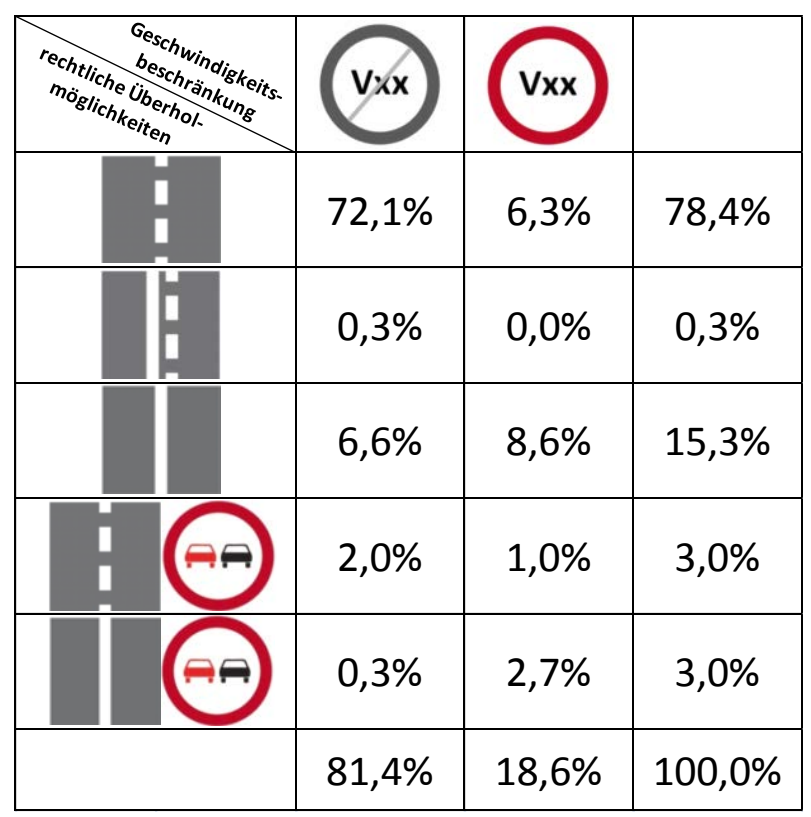


7) Überholunfälle auf Landstraßen - Anhänge zum Abschlussbericht

e) Unfallzuordnung in Bundesland 5 (430 Überholunfälle)

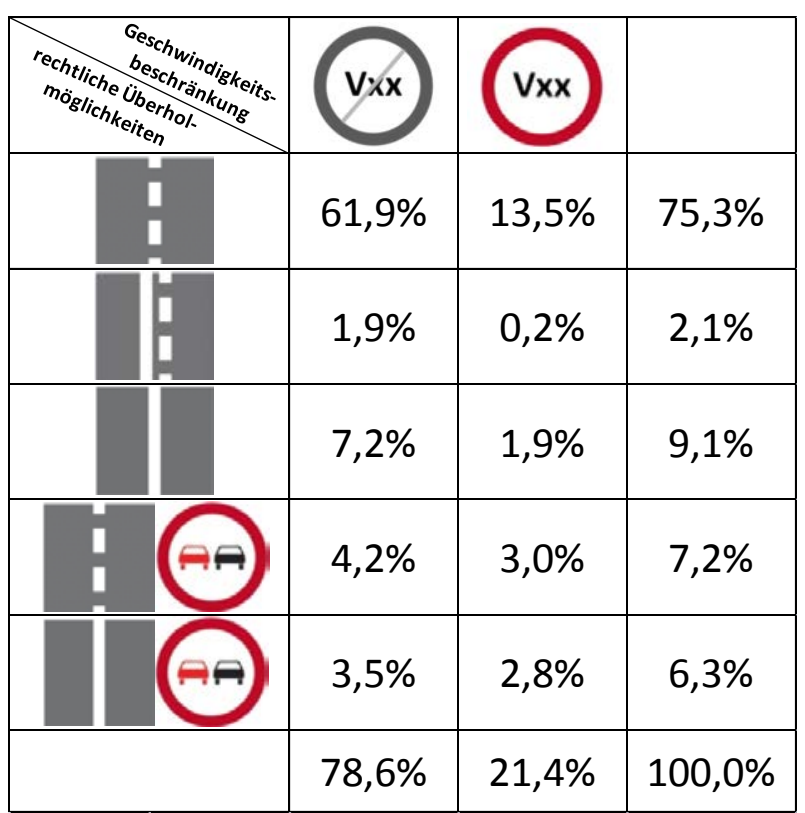




\section{Anhang G}

Unfallkategorien der Überholunfälle mit Bezug zu Merkmalslängen 
a) Unfallkategorie 1 (103 Unfälle auf 2.235 Kilometern Streckennetz)

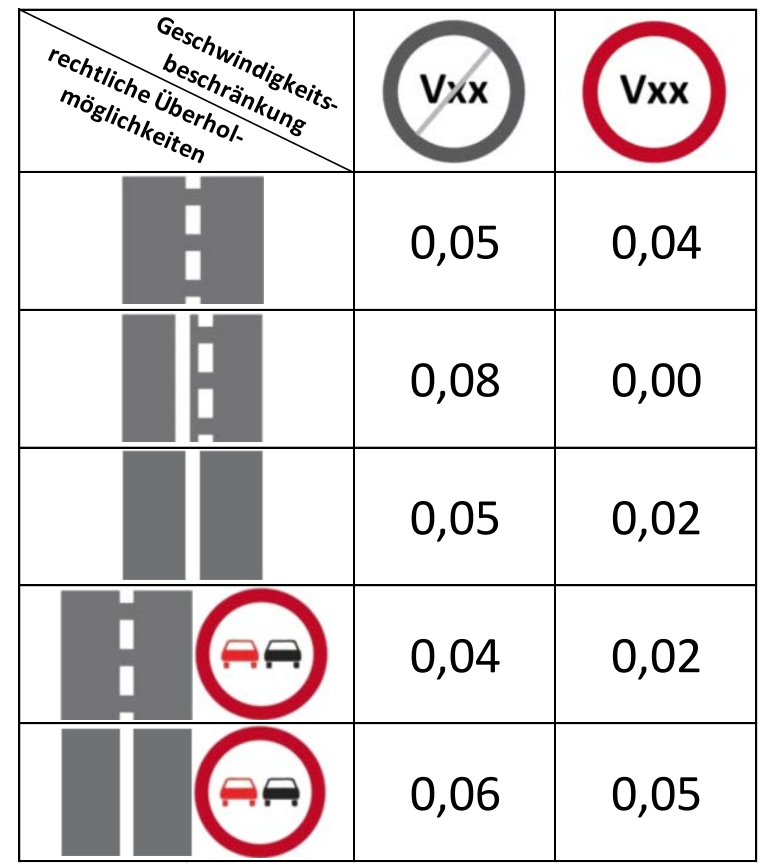

c) Unfallkategorie 3 (469 Unfälle auf 2.235 Kilometern Streckennetz)

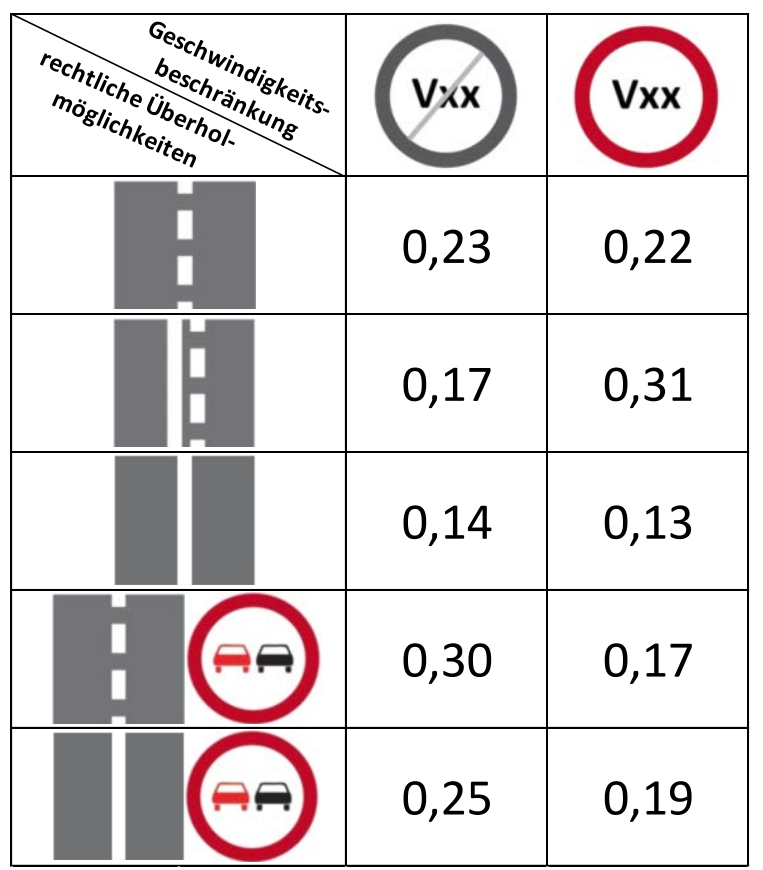

b) Unfallkategorie 2 (701 Unfälle auf 2.235 Kilometern Streckennetz)

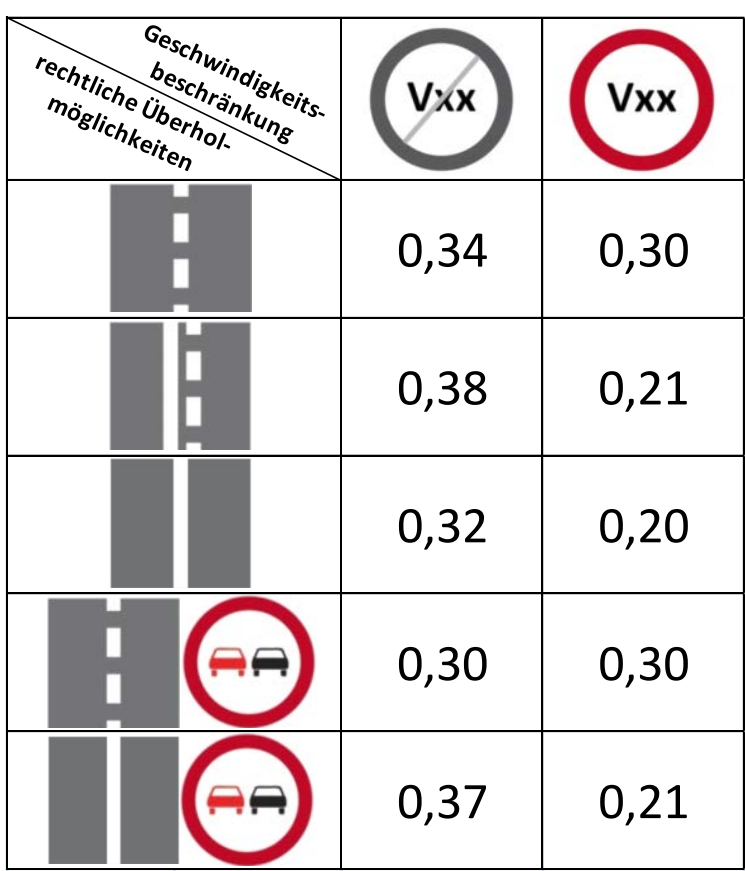

d) Unfallkategorie 4 (284 Unfälle auf 2.235 Kilometern Streckennetz)

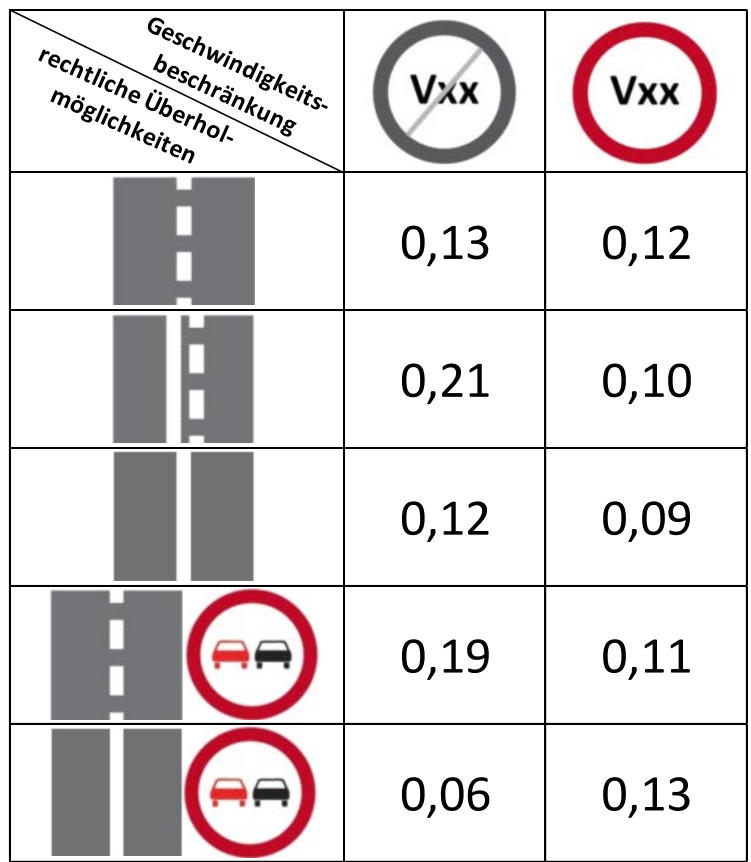




\section{Anhang $\mathrm{H}$ \\ Unfallkenngrößen der Überholunfälle mit Bezug zu unfallauffälligen Merkmalslängen}


7) Überholunfälle auf Landstraßen - Anhänge zum Abschlussbericht

a) Verteilung der Unfallkosten (Gesamtsumme $247.892 .208,98 €$ )

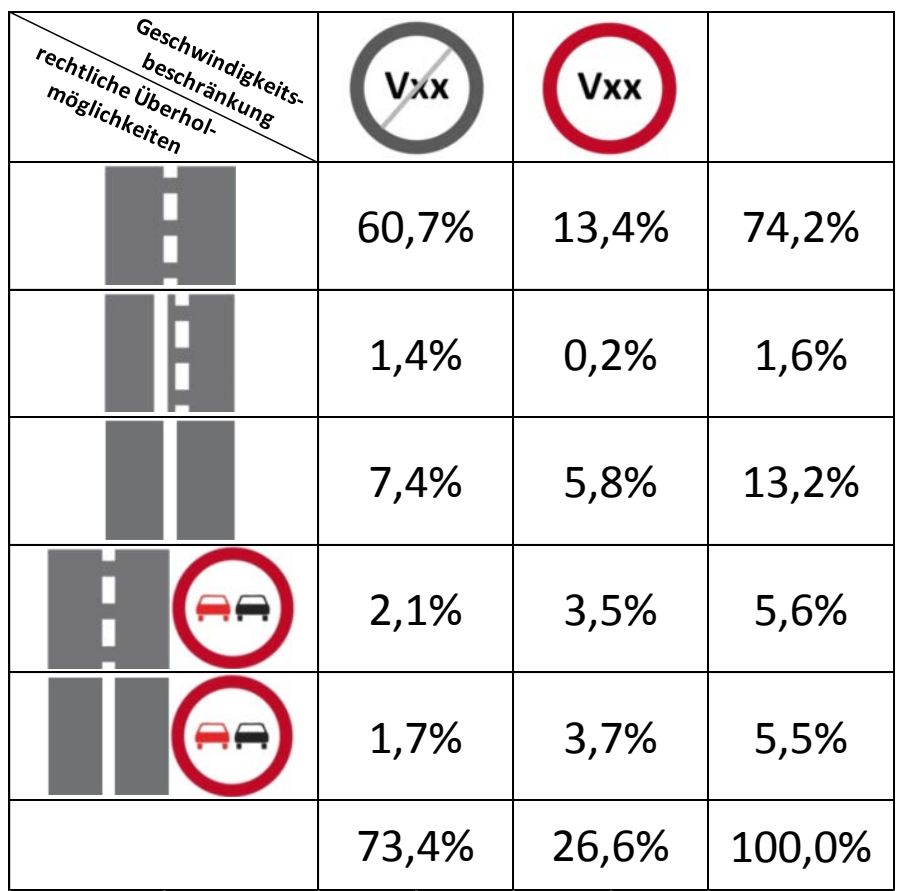

b) Bezugswerte der Unfallkenngrößen

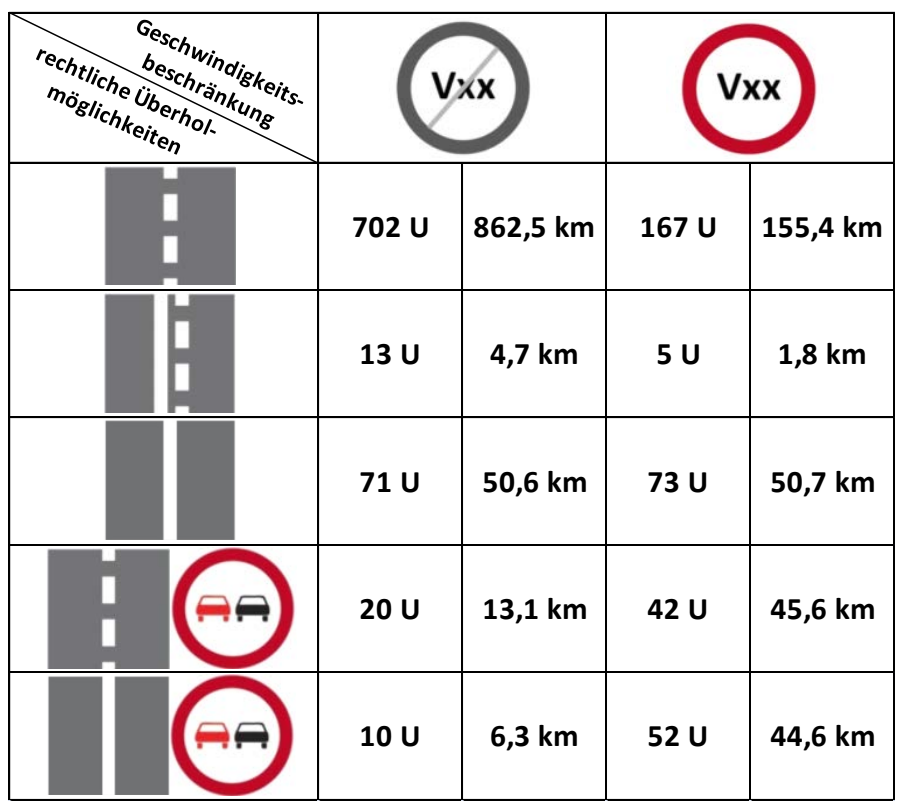




\section{c) Unfallrate $\left[\mathrm{U} /\left(10^{6} \mathrm{Kfz}^{*} \mathrm{~km}\right)\right]$}

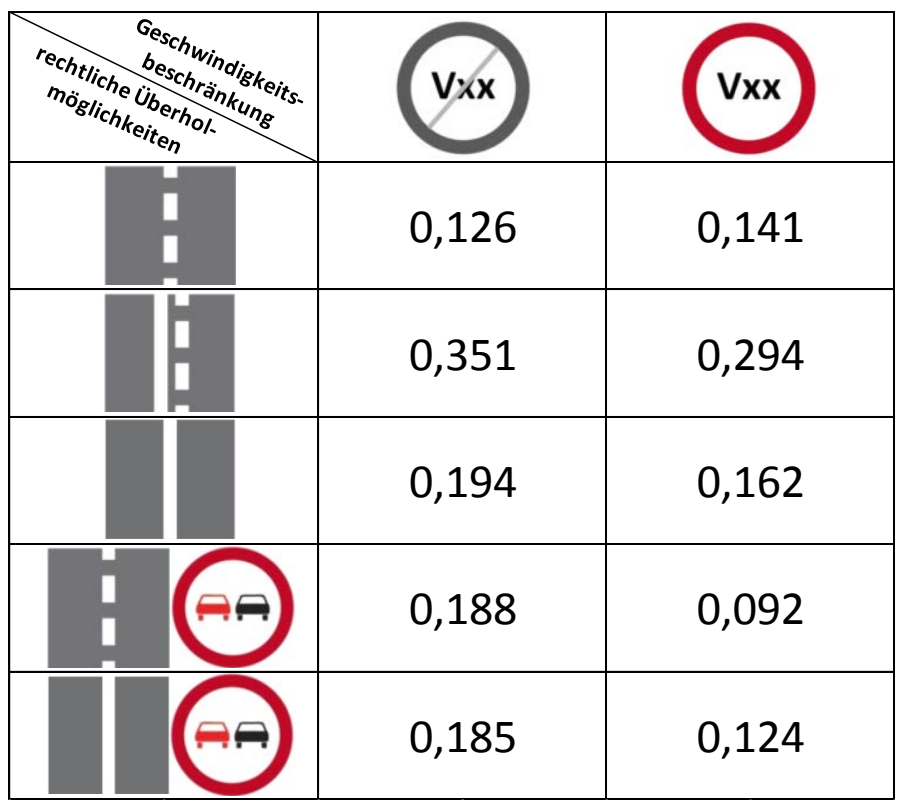

d) Unfallkostenrate $\left[€ /\left(1000 * K f z^{*} \mathrm{~km}\right)\right]$

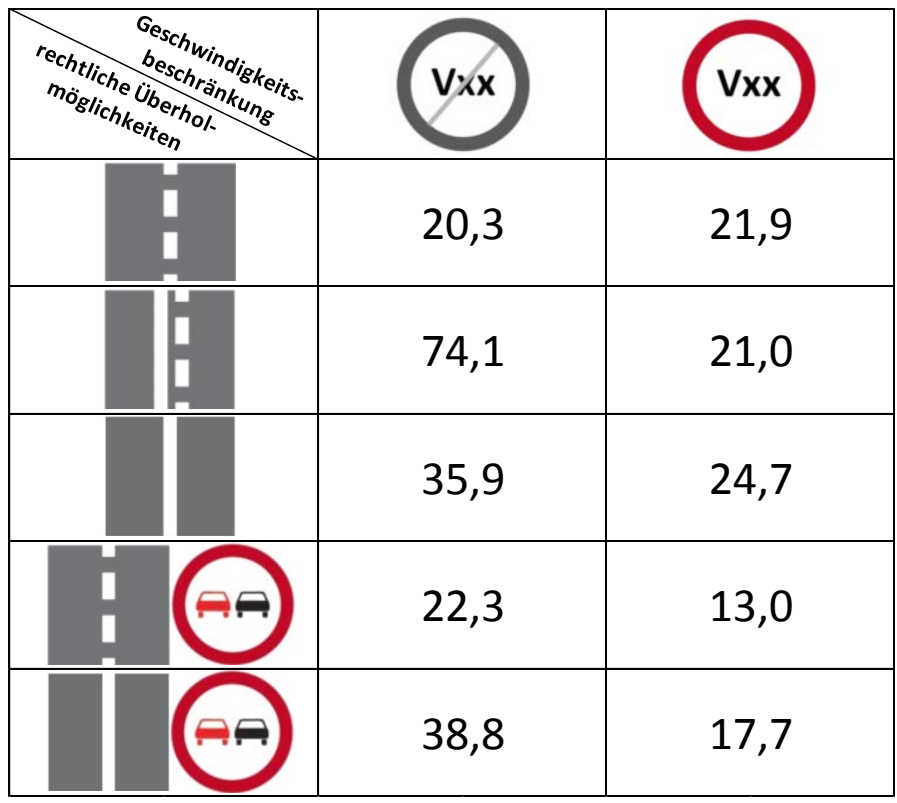


e) Unfalldichte $[\mathrm{U} /(\mathrm{km} * \mathrm{a})]$

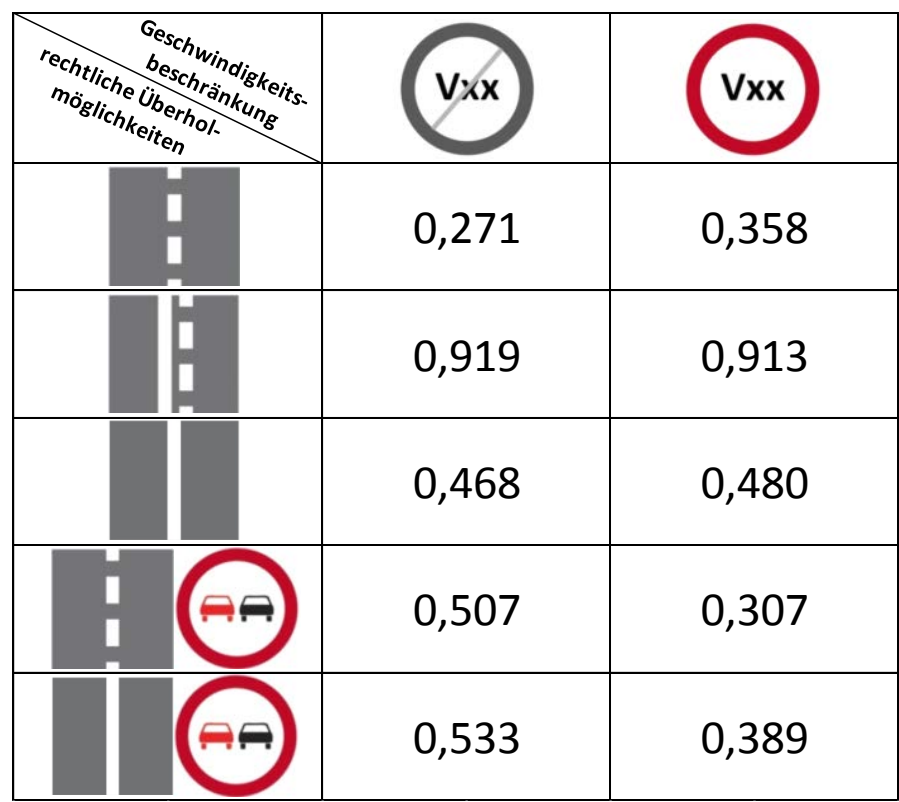

f) Unfallkostendichte $\left[1000 € /\left(\mathrm{km}^{*} \mathrm{a}\right)\right]$

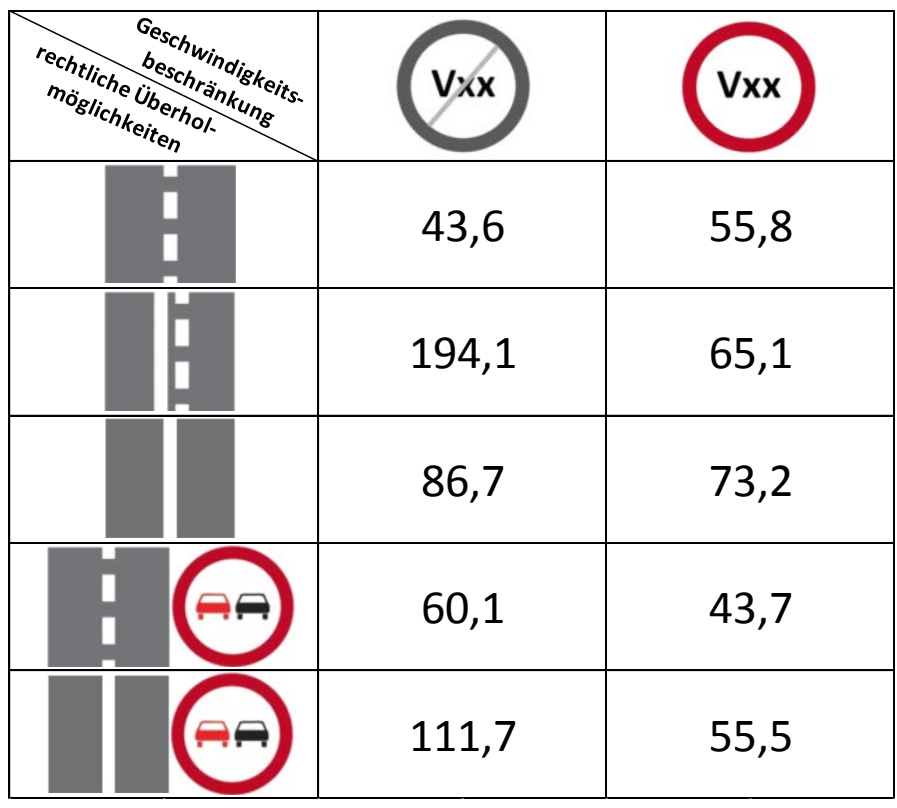




\section{Anhang I \\ Unfallkenngrößen der Überholunfälle mit Bezug zur Gesamtlänge der Untersuchungsmerkmale im Streckennetz}


7) Überholunfälle auf Landstraßen - Anhänge zum Abschlussbericht

a) Verteilung der Unfallkosten (Gesamtsumme $247.892 .208,98 €$ )

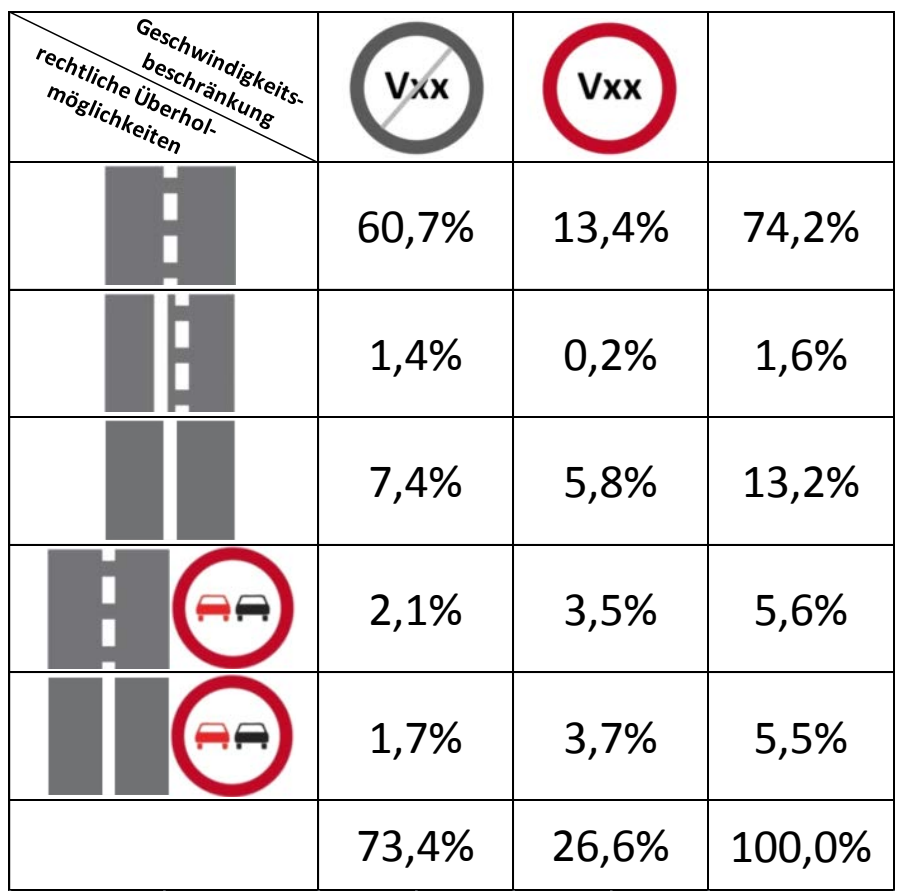

b) Bezugswerte der Unfallkenngrößen

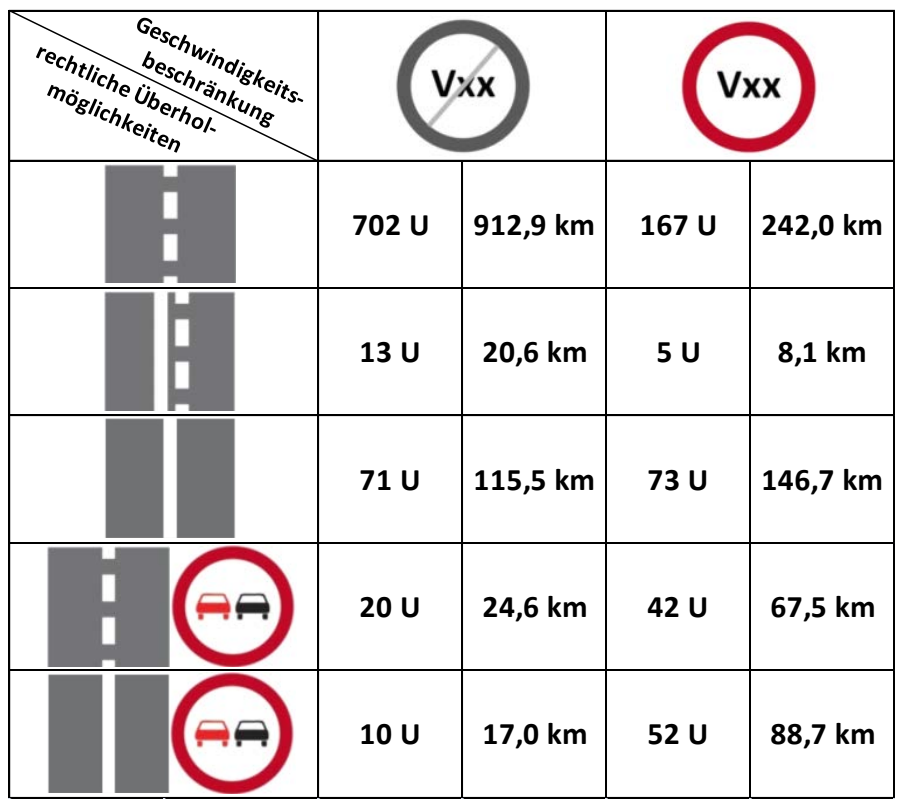




\section{c) Unfallrate $\left[\mathrm{U} /\left(10^{6 *} \mathrm{Kfz}^{*} \mathrm{~km}\right)\right]$}

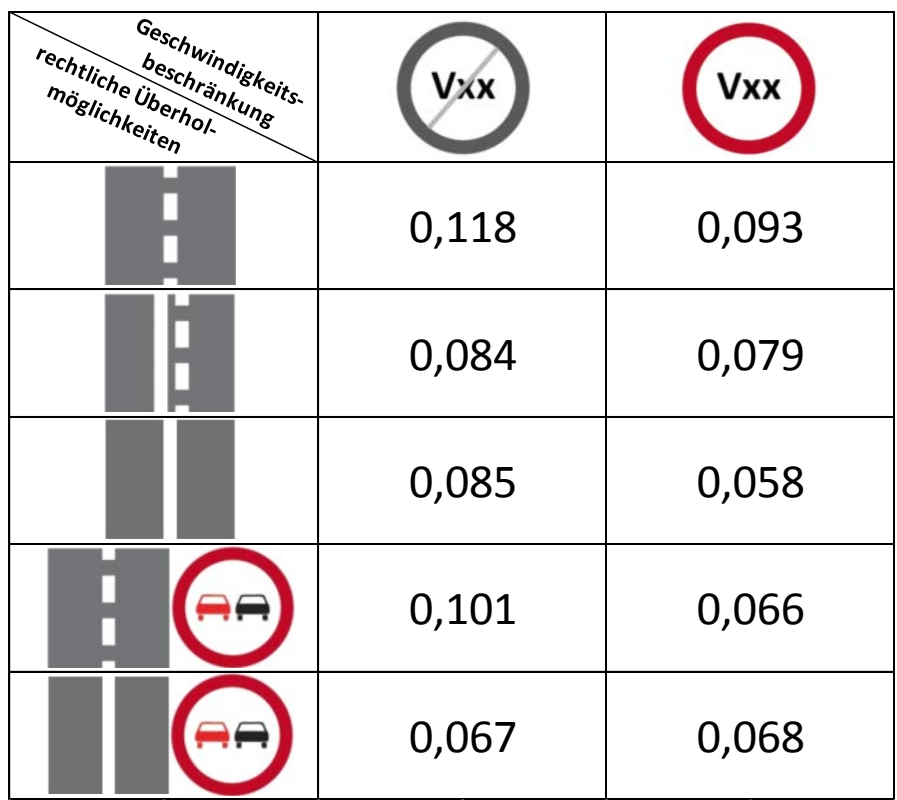

d) Unfallkostenrate $\left[€ /\left(1000 * K f z^{*} \mathrm{~km}\right)\right]$

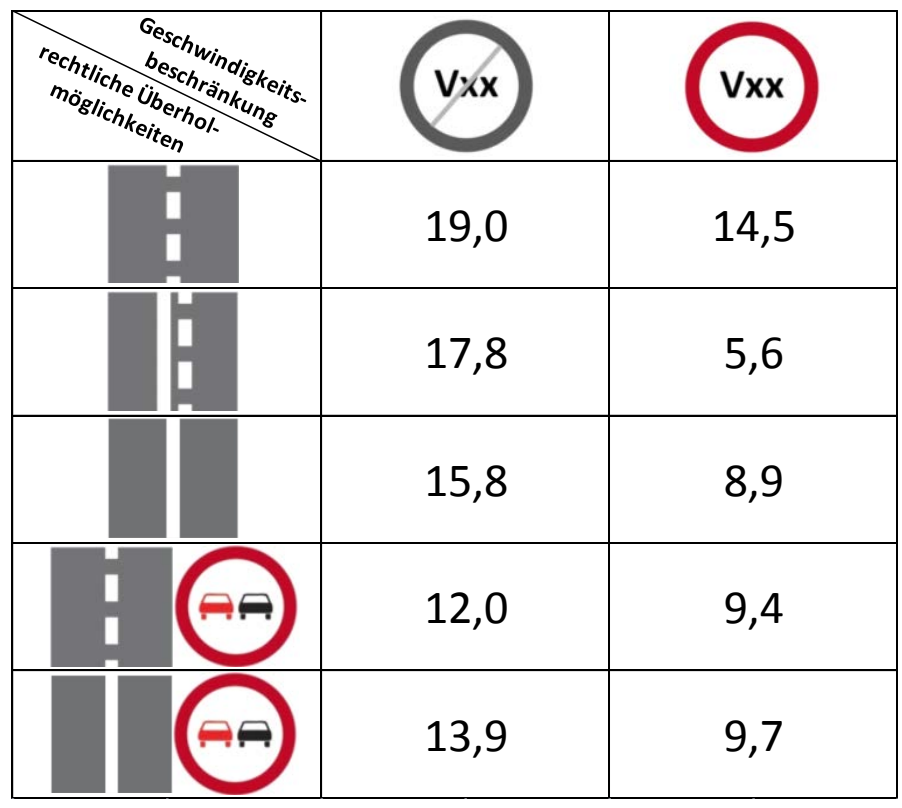


e) Unfalldichte $[\mathrm{U} /(\mathrm{km} * \mathrm{a})]$

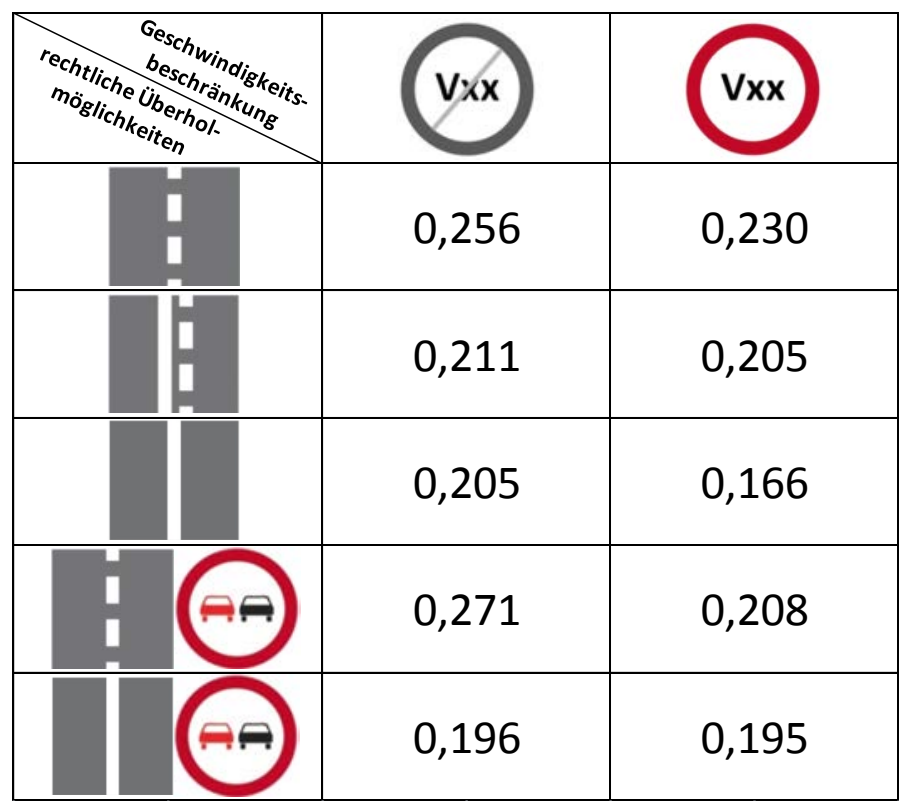

f) Unfallkostendichte $\left[1000 € /\left(\mathrm{km}^{*} \mathrm{a}\right)\right]$

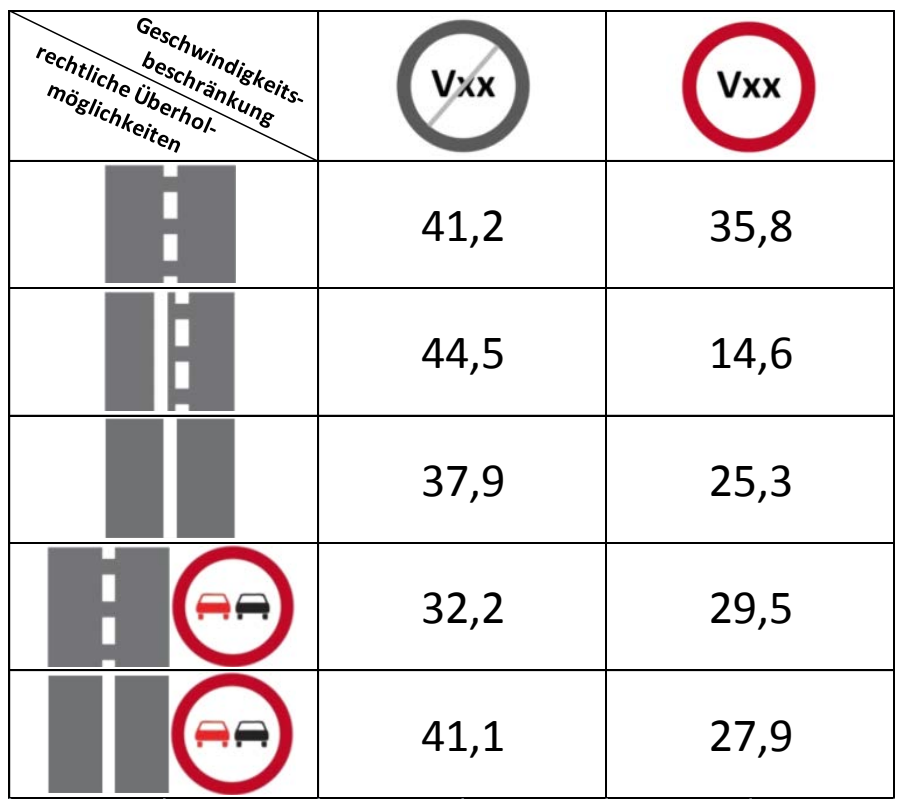


Anhang J

Signifikanztest der Unfallkenngrößen nach verkehrsrechtlichen Anordnungen 
a) Eigenschaften der Bezugsgrößen für Unfallkenngrößenberechnung (Streckenmerkmale)

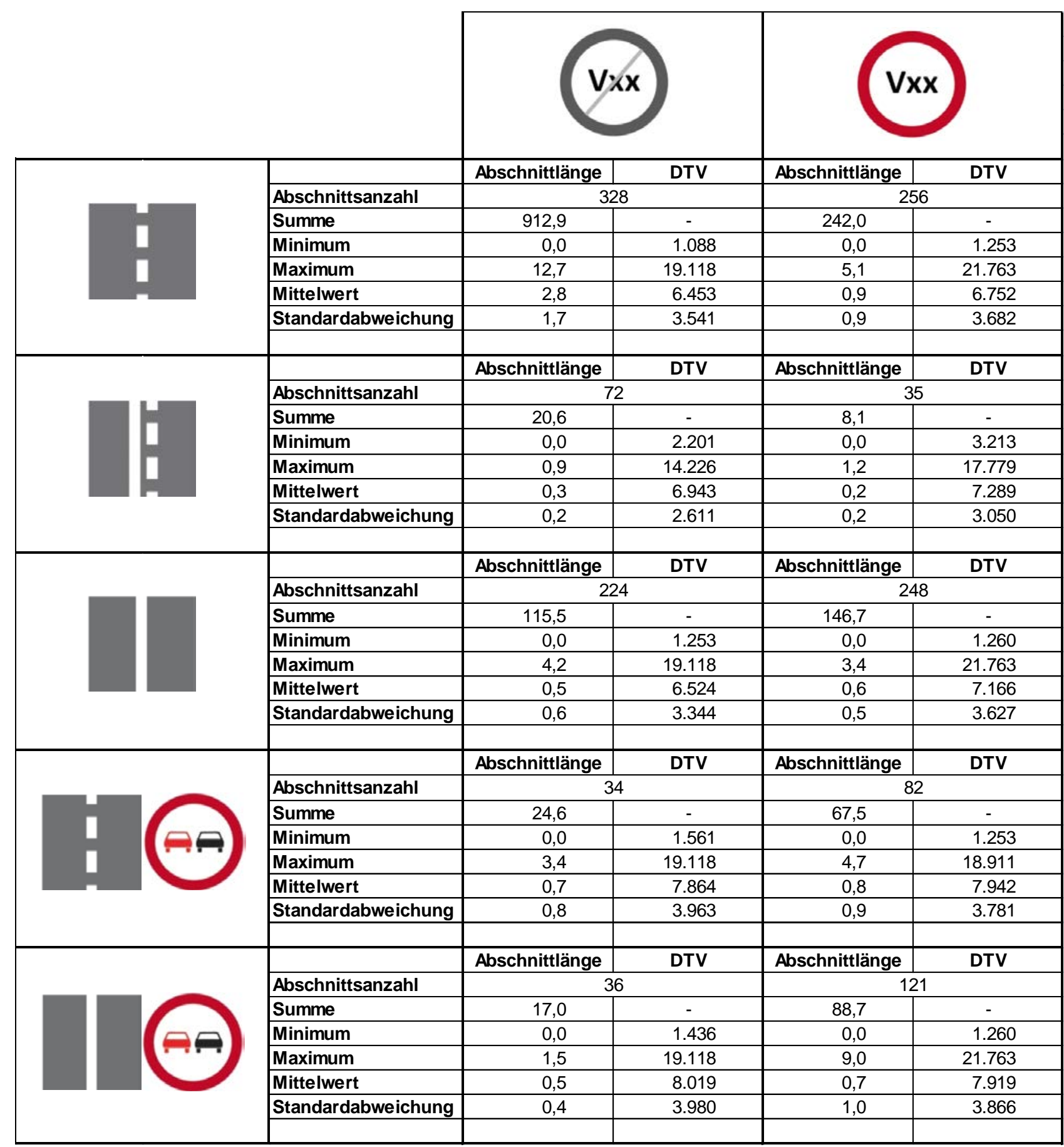


T1 Überholunfälle auf Landstraßen - Anhänge zum Abschlussbericht

b) Verteilungstest der Datengrundlagen (Streckenmerkmale)

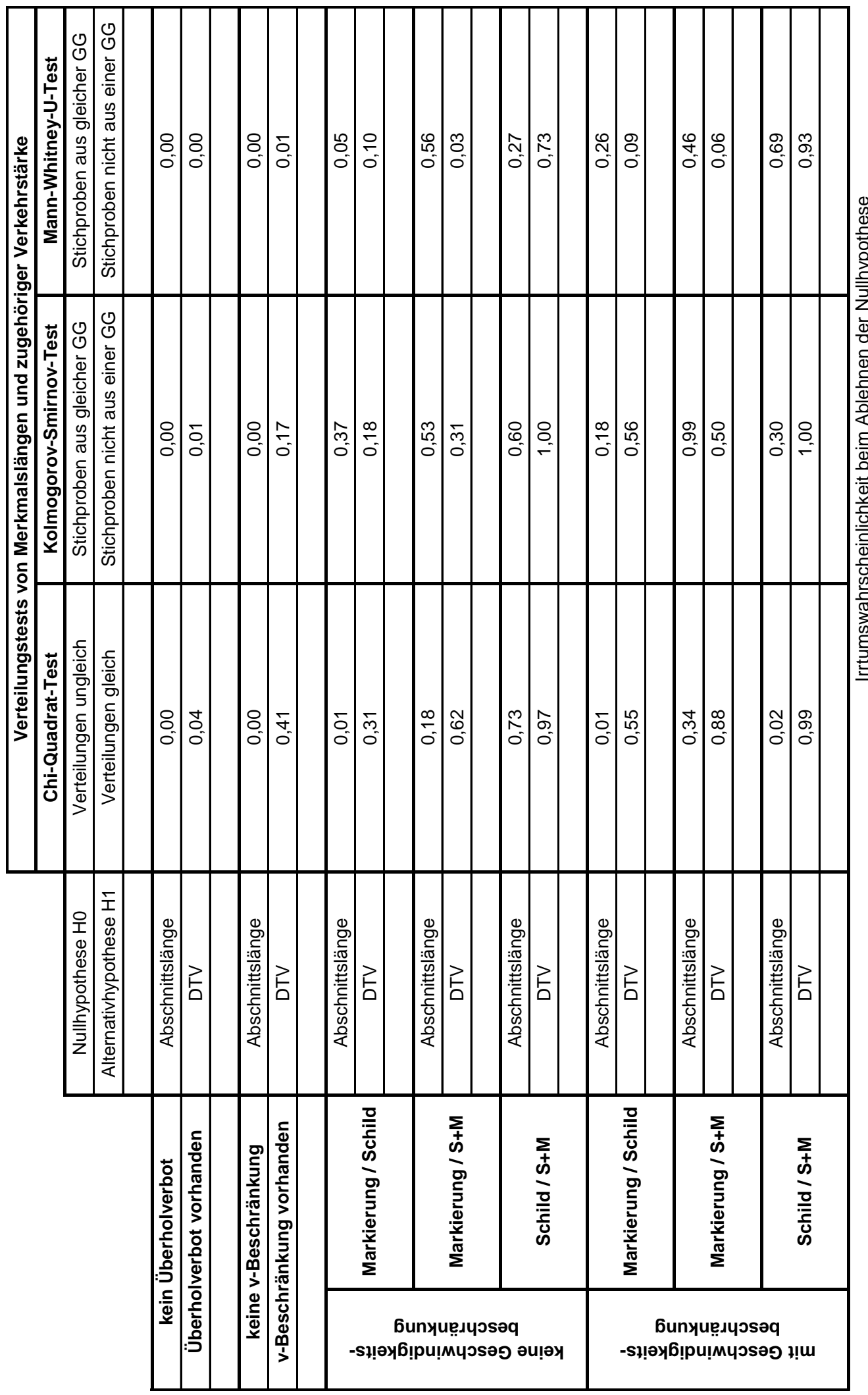




\section{Anhang $\mathrm{K}$ \\ Unfallkenngrößen des Gesamtunfallgeschehens (Unfallkategorie 1-4) differenziert nach Fahrbahnbreiten}


7) Überholunfälle auf Landstraßen - Anhänge zum Abschlussbericht

a) Unfallrate nach Fahrbahnbreiten auf den Untersuchungsstrecken $(n=341)$

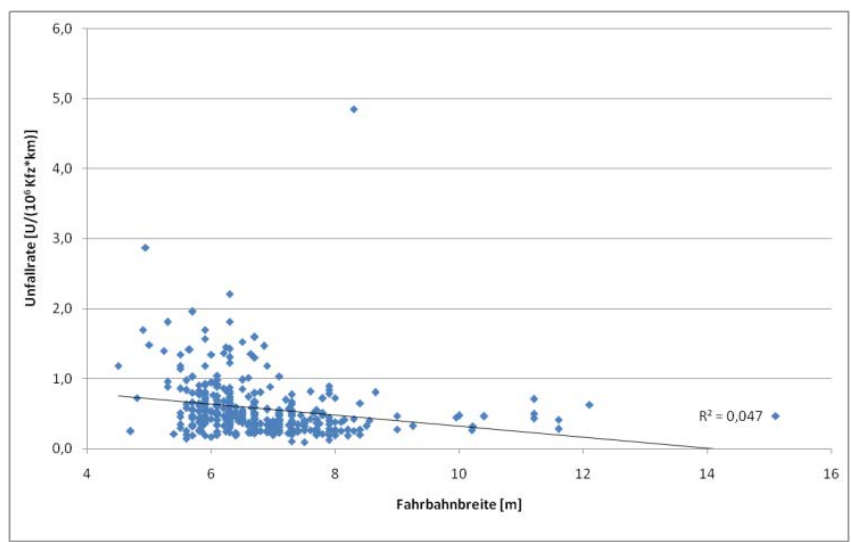

b) Unfallkostenrate nach Fahrbahnbreiten auf den Untersuchungsstrecken $(n=341)$

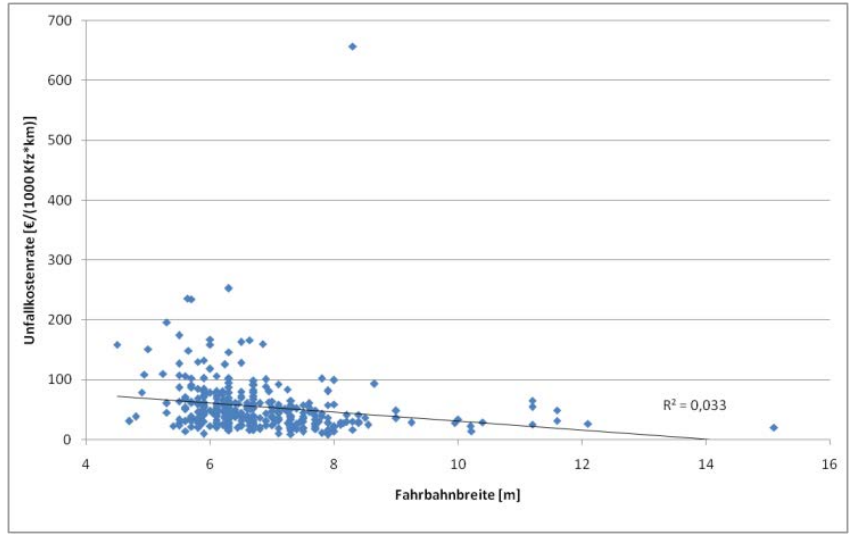

c) Unfalldichte nach Fahrbahnbreiten auf den Untersuchungsstrecken $(n=341)$

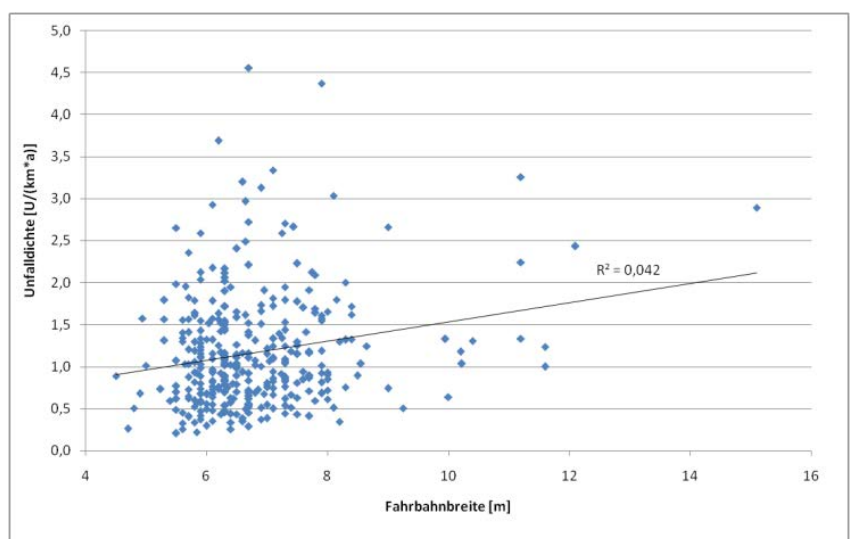

d) Unfallkostendichte nach Fahrbahnbreiten auf den Untersuchungsstrecken $(n=341)$

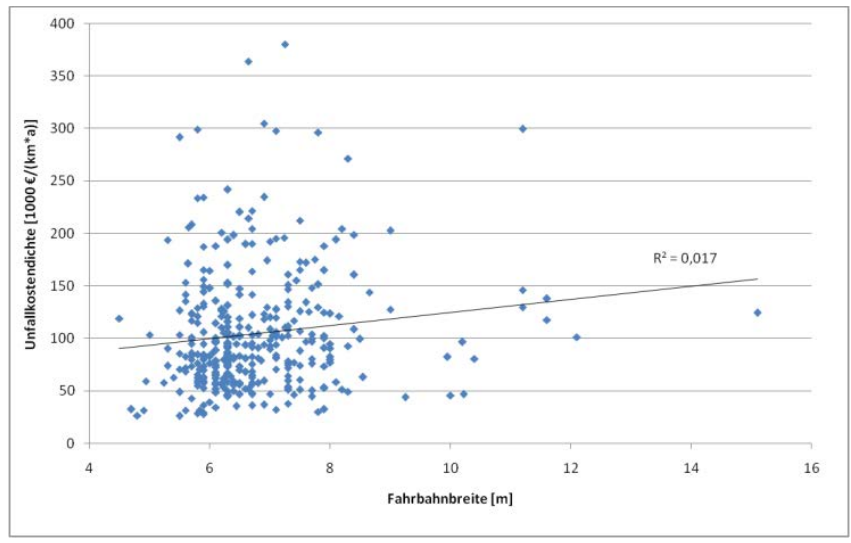




\section{Anhang L \\ Unfallkenngrößen der Überholunfälle differenziert nach Fahrbahnbreiten}


7) Überholunfälle auf Landstraßen - Anhänge zum Abschlussbericht

a) Unfallrate nach Fahrbahnbreiten auf den Untersuchungsstrecken $(n=341)$

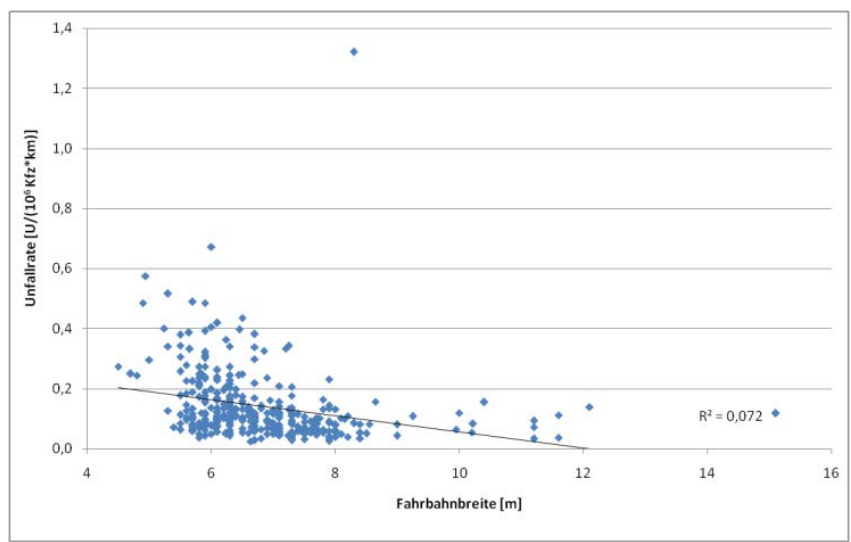

b) Unfallkostenrate nach Fahrbahnbreiten auf den Untersuchungsstrecken $(n=341)$

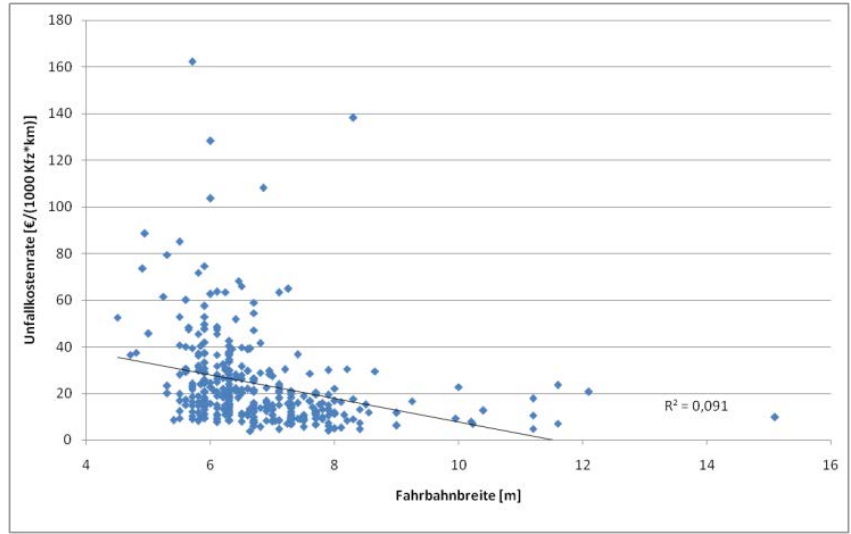

c) Unfalldichte nach Fahrbahnbreiten auf den Untersuchungsstrecken $(n=341)$

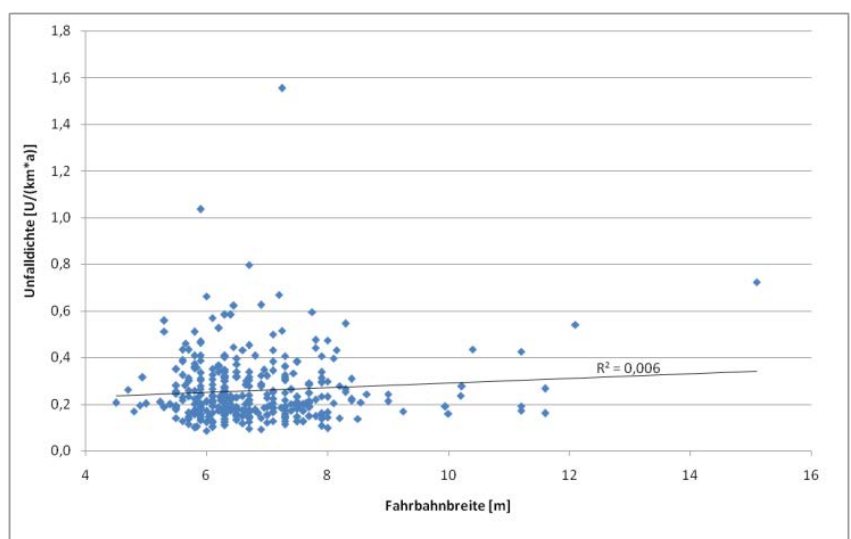

d) Unfallkostendichte nach Fahrbahnbreiten auf den Untersuchungsstrecken $(n=341)$

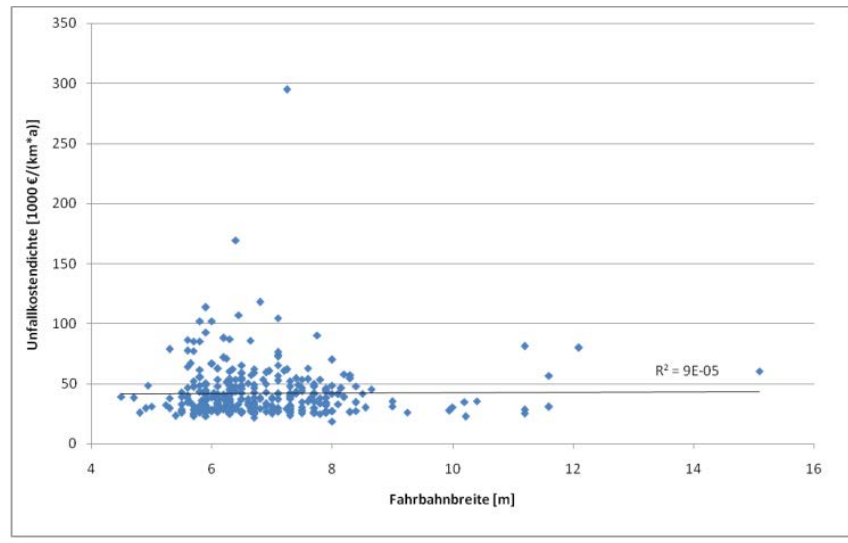




\section{Anhang M}

Unfallkenngrößen des Gesamtunfallgeschehens (Unfallkategorie 1-4) differenziert nach Straßenraumbreiten 
7) Überholunfälle auf Landstraßen - Anhänge zum Abschlussbericht

a) Unfallrate nach Straßenraumbreiten auf den Untersuchungsstrecken $(n=318)$

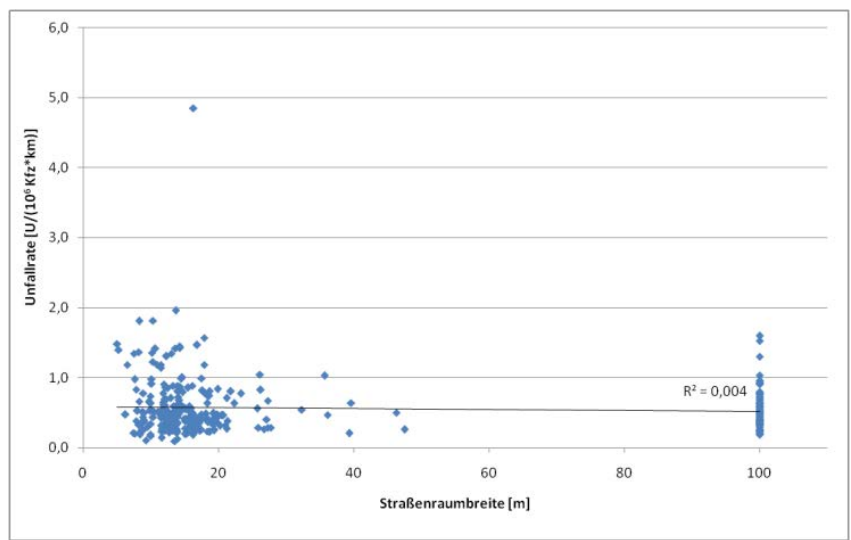

b) Unfallkostenrate nach Straßenraumbreiten auf den Untersuchungsstrecken $(n=318)$

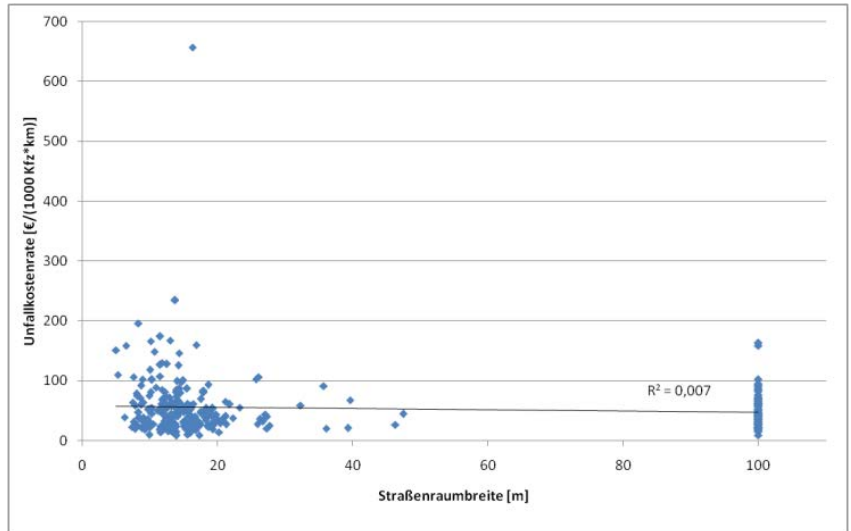

c) Unfalldichte nach Straßenraumbreiten auf den Untersuchungsstrecken $(n=318)$

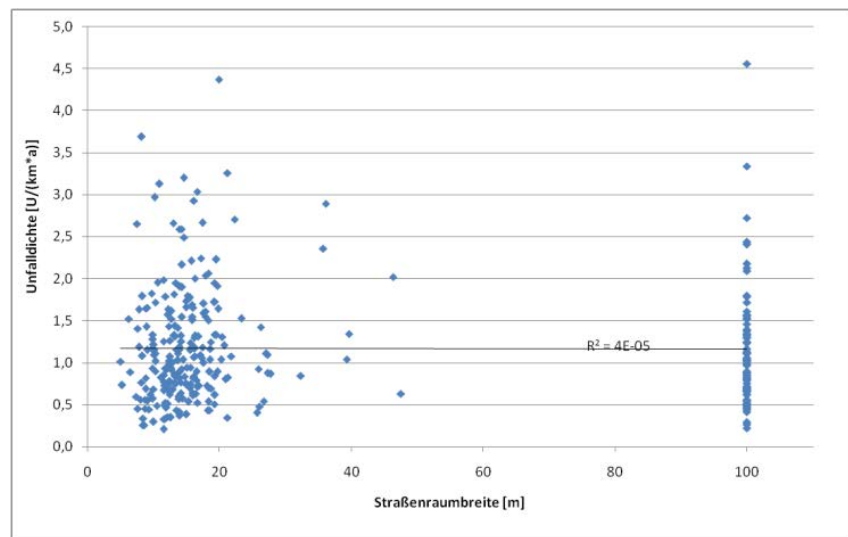

d) Unfallkostendichte nach Straßenraumbreiten auf den Untersuchungsstrecken $(n=318)$

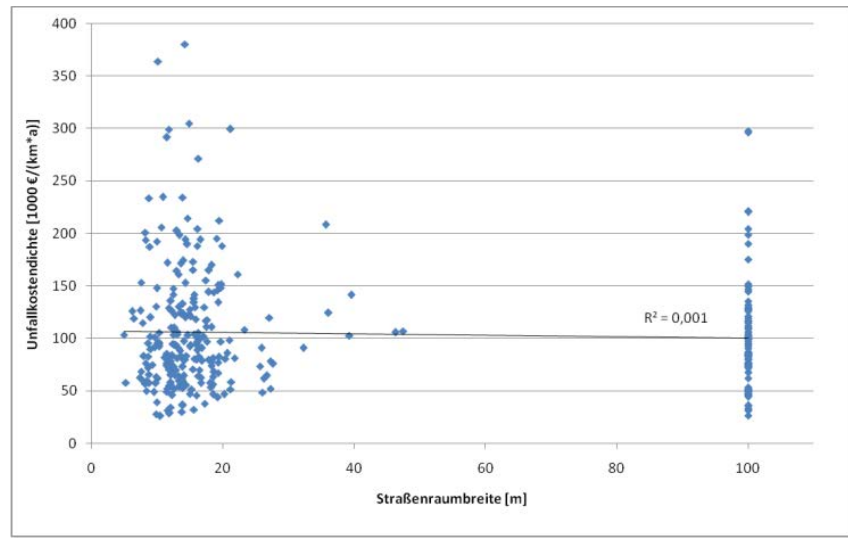




\section{Anhang N \\ Unfallkenngrößen der Überholunfälle differenziert nach Straßenraum- breiten}


7) Überholunfälle auf Landstraßen - Anhänge zum Abschlussbericht

a) Unfallrate nach Straßenraumbreiten auf den Untersuchungsstrecken $(n=318)$

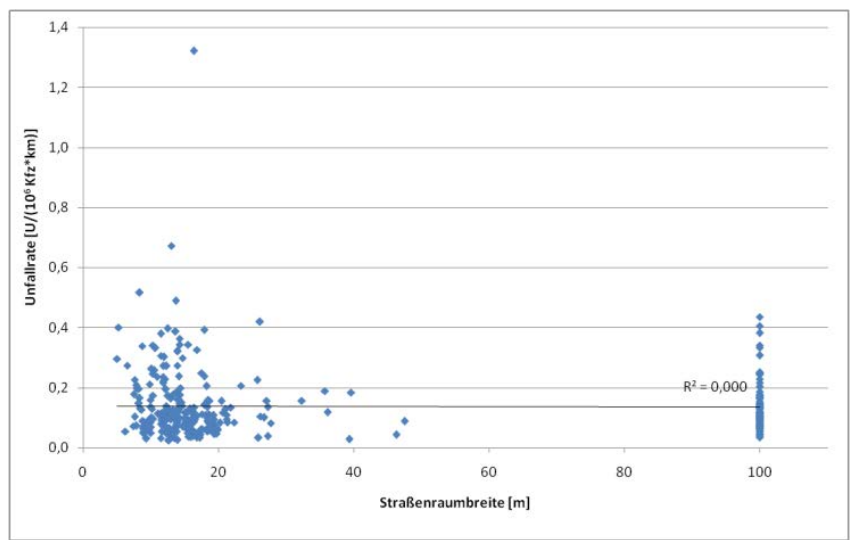

b) Unfallkostenrate nach Straßenraumbreiten auf den Untersuchungsstrecken $(n=318)$

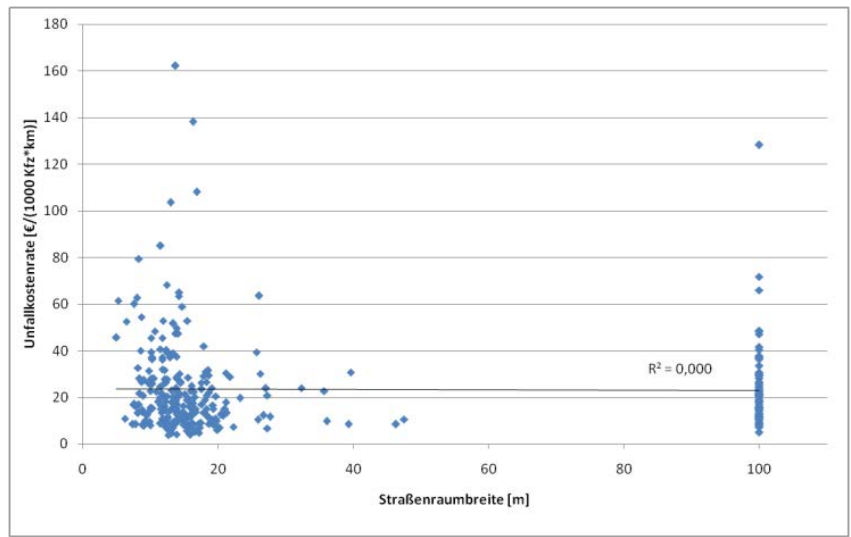

c) Unfalldichte nach Straßenraumbreiten auf den Untersuchungsstrecken $(n=318)$

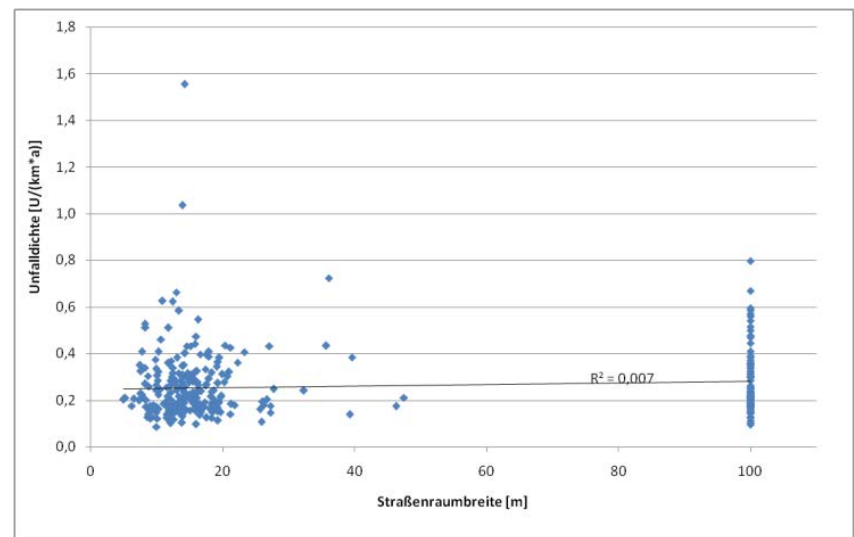

d) Unfallkostendichte nach Straßenraumbreiten auf den Untersuchungsstrecken $(n=318)$

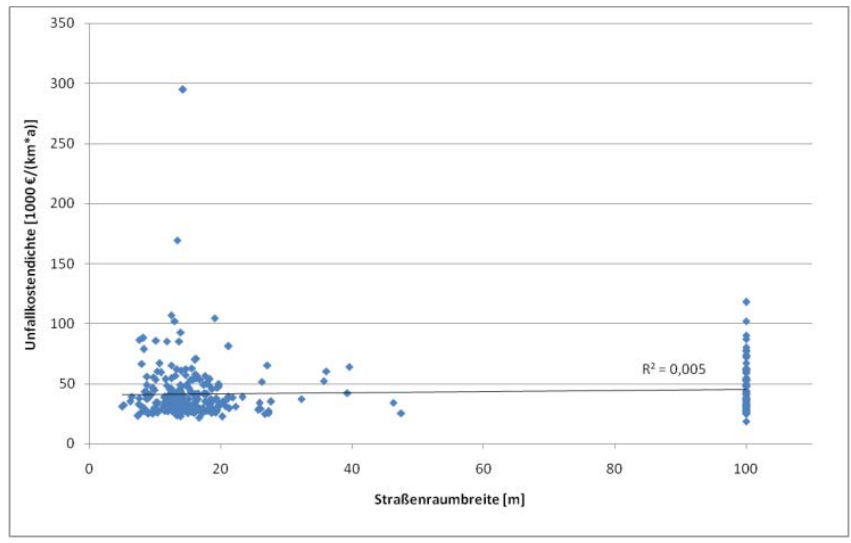




\section{Anhang 0}

Unfallkenngrößen des Gesamtunfallgeschehens (Unfallkategorie 1-4) differenziert nach Regelquerschnitten 
7) Überholunfälle auf Landstraßen - Anhänge zum Abschlussbericht

a) Unfallrate nach Regelquerschnitten

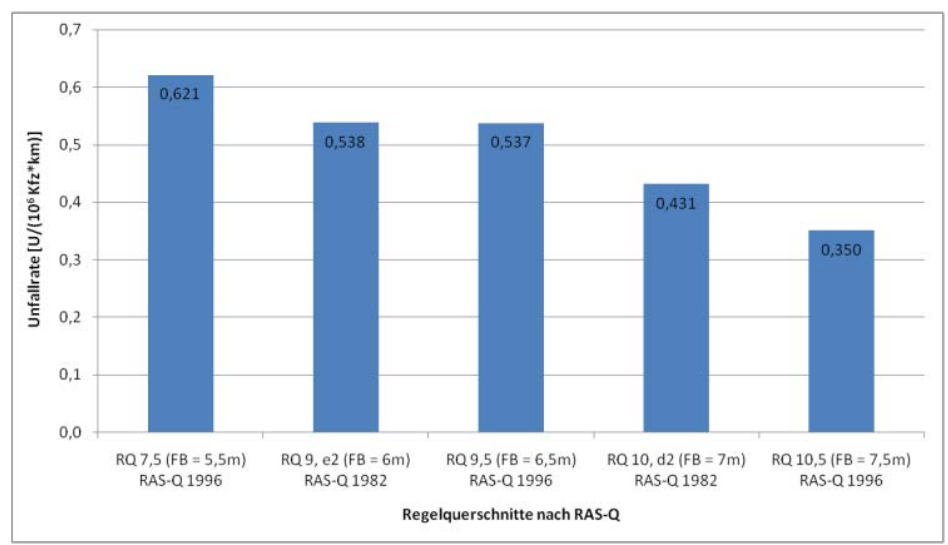

b) Unfallkostenrate nach Regelquerschnitten

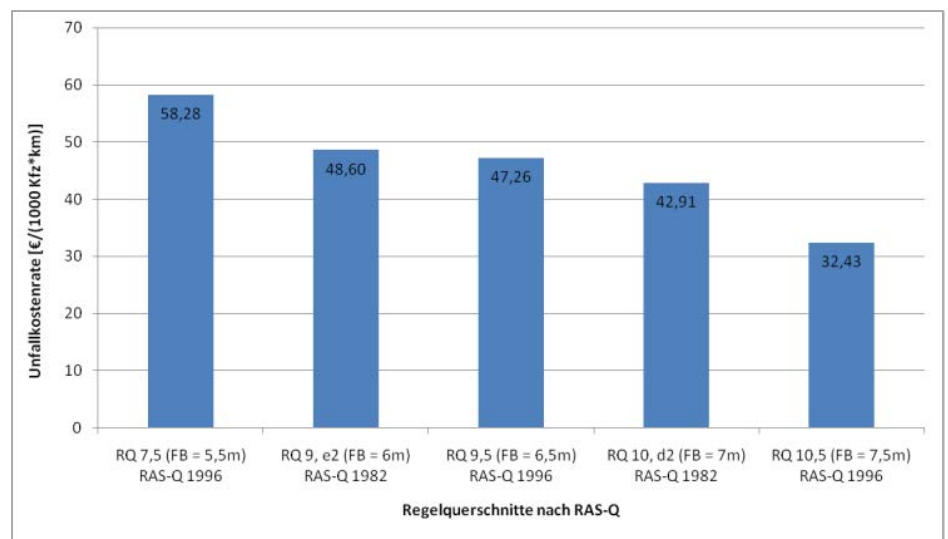

c) Unfalldichte nach Regelquerschnitten

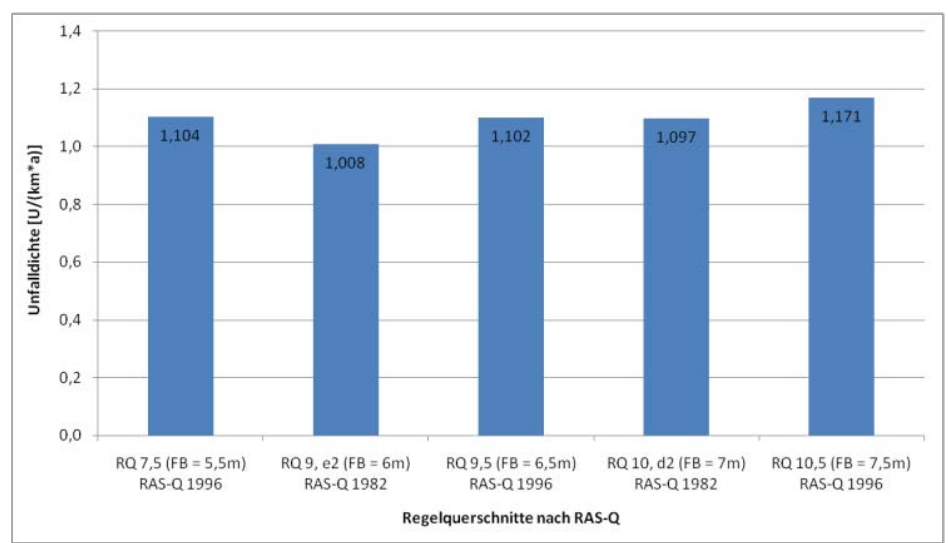

d) Unfallkostendichte nach Regelquerschnitten

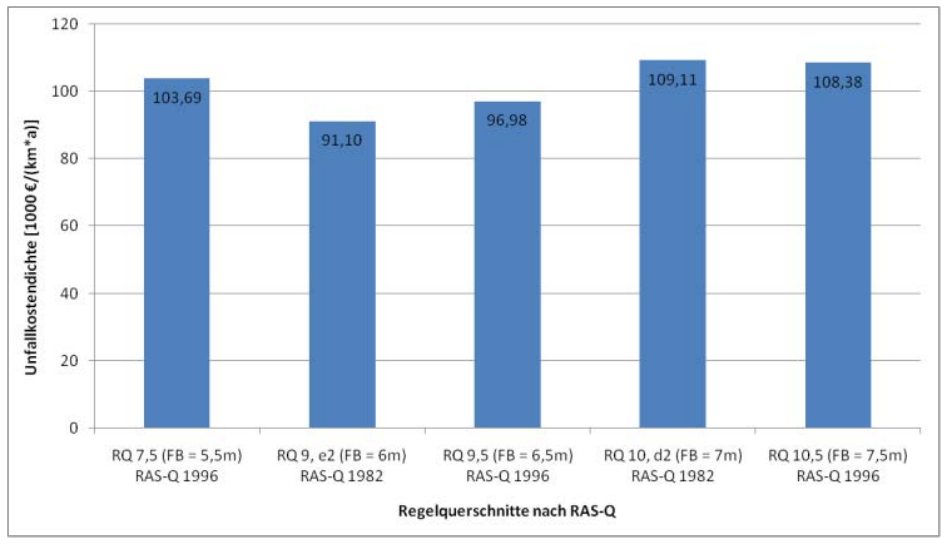




\section{Anhang $\mathbf{P}$ \\ Unfallkenngrößen der Überholunfälle differenziert nach Regelquer- schnitten}


7) Überholunfälle auf Landstraßen - Anhänge zum Abschlussbericht

a) Unfallrate nach Regelquerschnitten

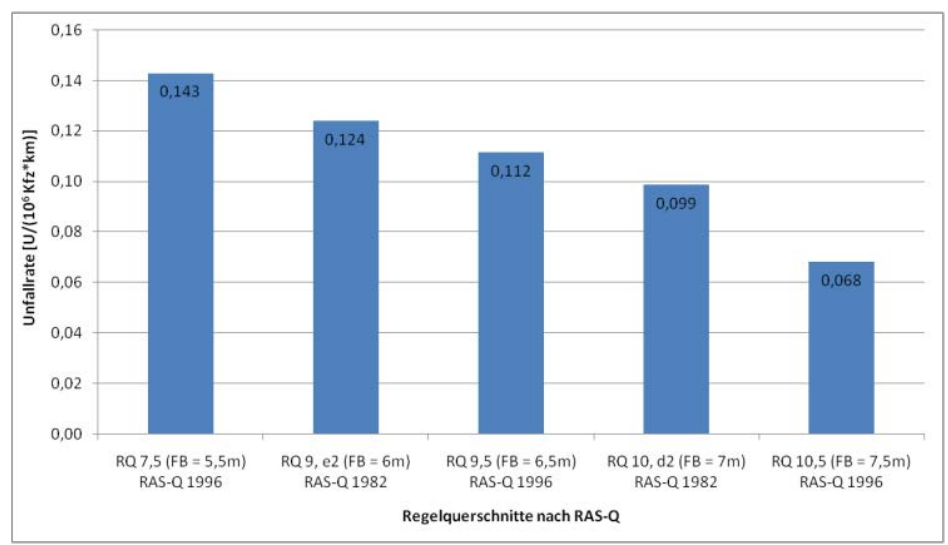

b) Unfallkostenrate nach Regelquerschnitten

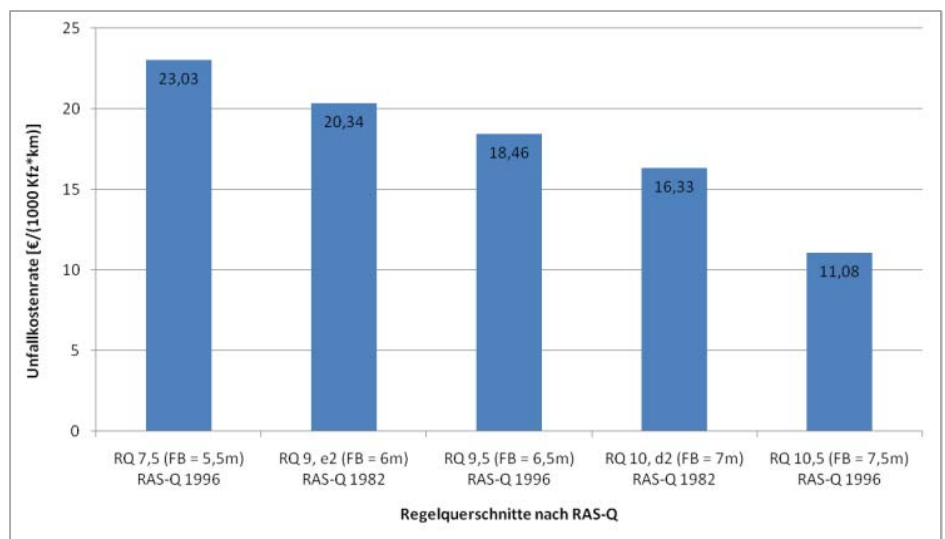

c) Unfalldichte nach Regelquerschnitten

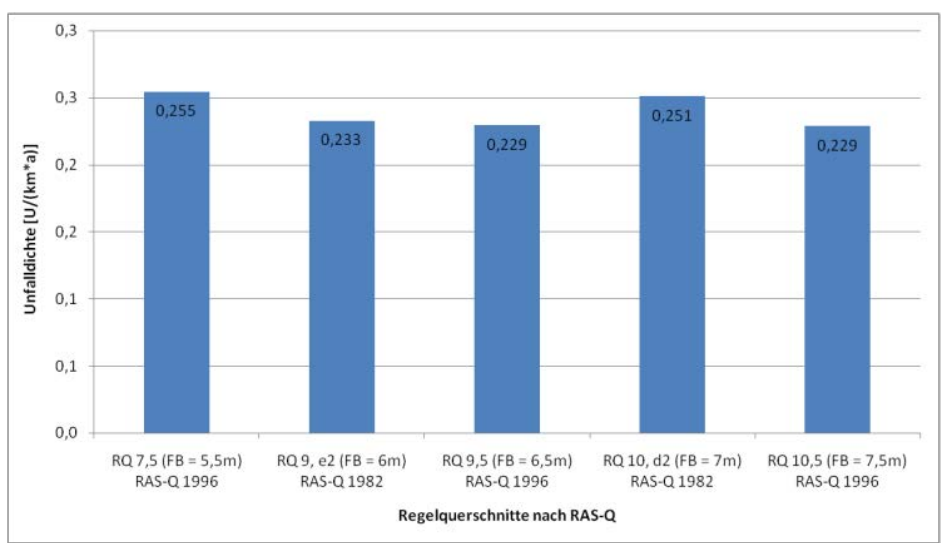

d) Unfallkostendichte nach Regelquerschnitten

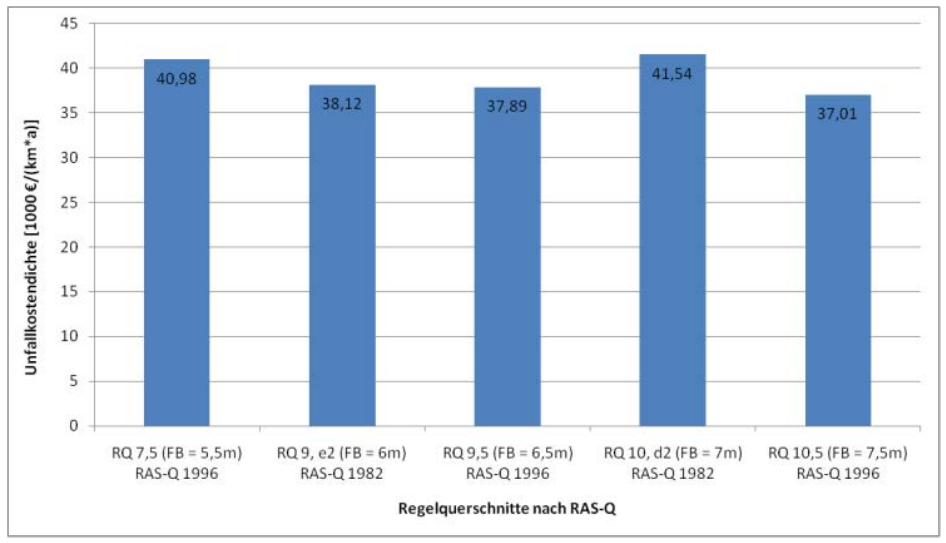




\section{Anhang Q}

Unfallkenngrößen der Überholunfälle differenziert nach verkehrsrechtlichen Anordnungen und Regelquerschnitten 
7) Überholunfälle auf Landstraßen - Anhänge zum Abschlussbericht

a) Bezugswerte der Unfallkenngrößen

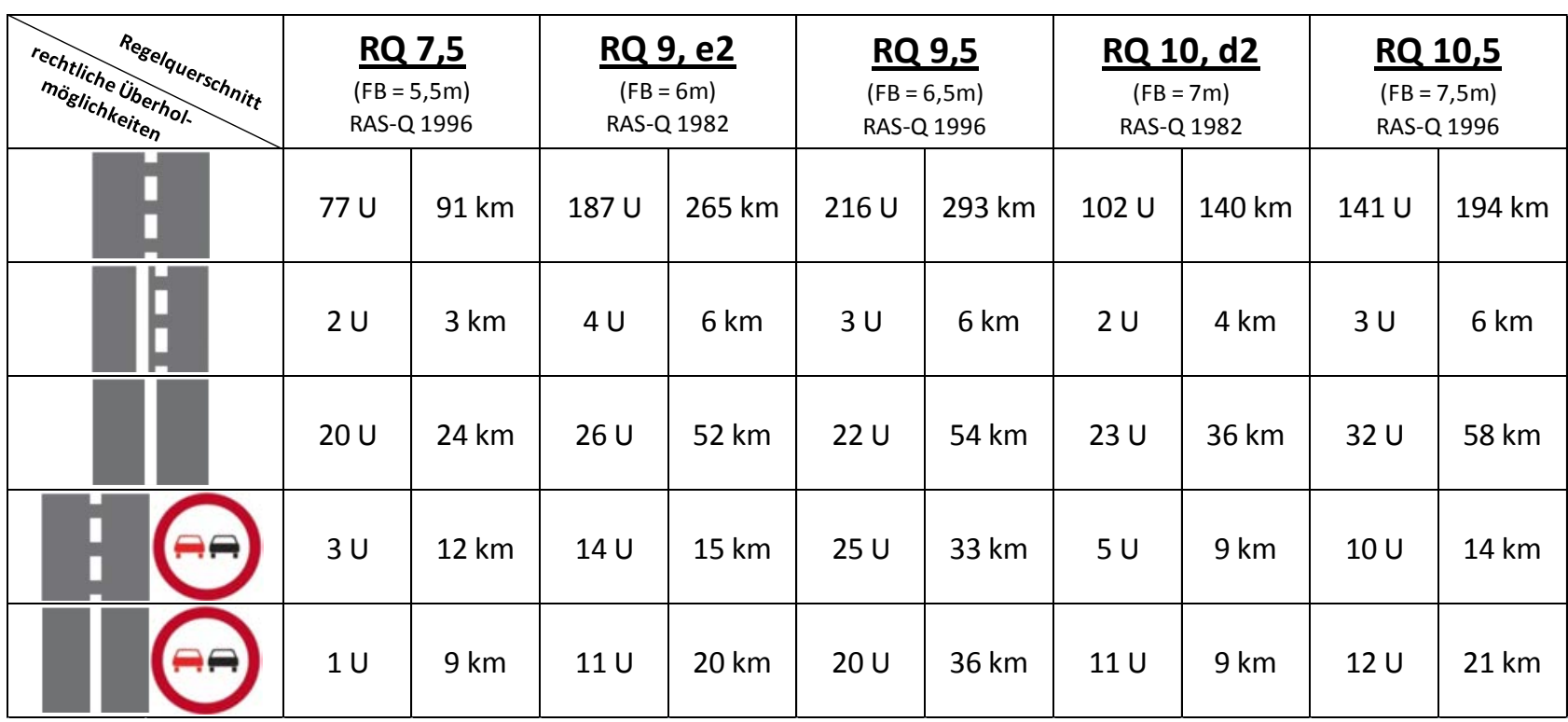

\section{b) Unfallrate $\left[\mathrm{U} /\left(10^{6 *} \mathrm{Kfz} * \mathrm{~km}\right)\right]$}

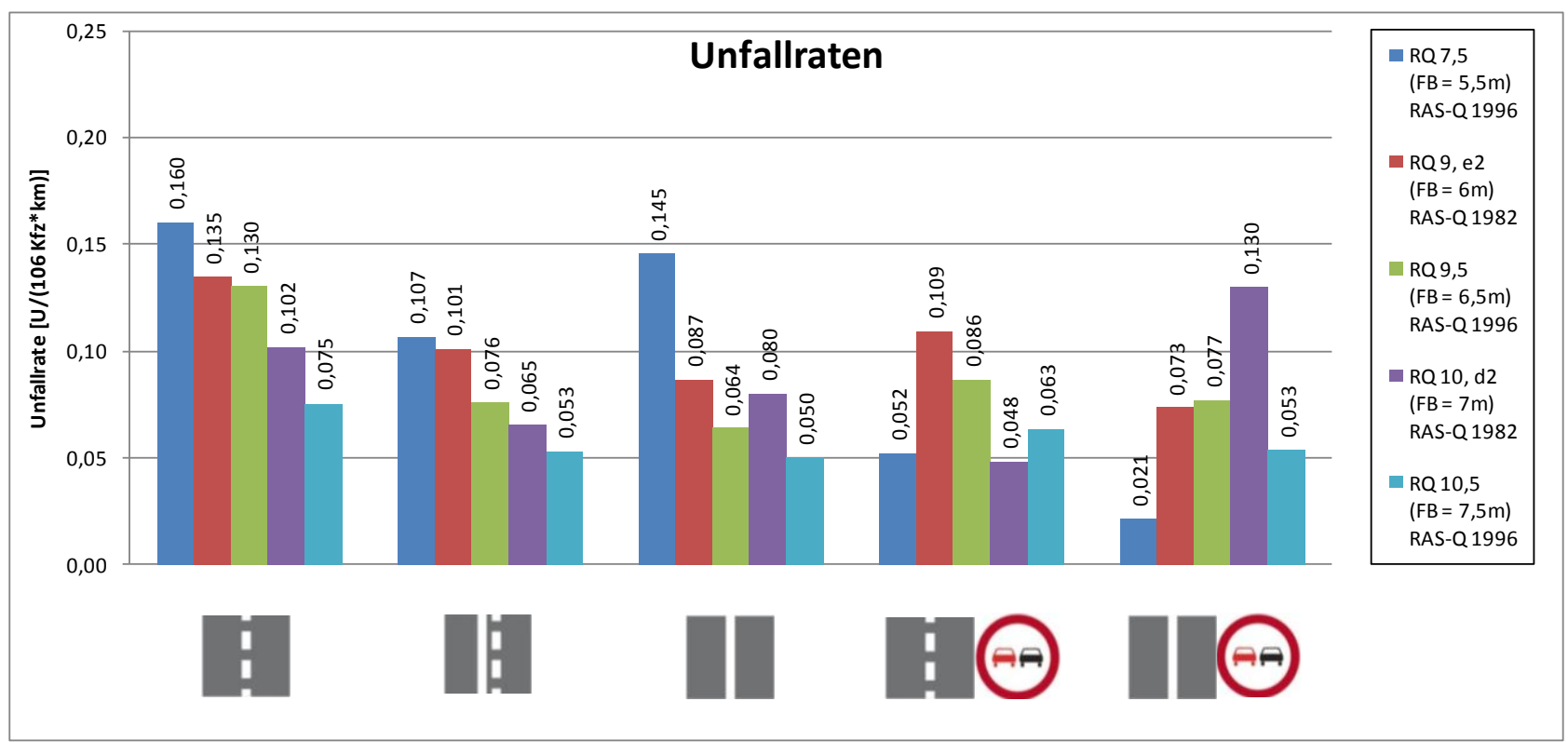


7) Überholunfälle auf Landstraßen - Anhänge zum Abschlussbericht

c) Unfallkostenrate $\left[€ /\left(1000 * K f z^{*} \mathrm{~km}\right)\right]$

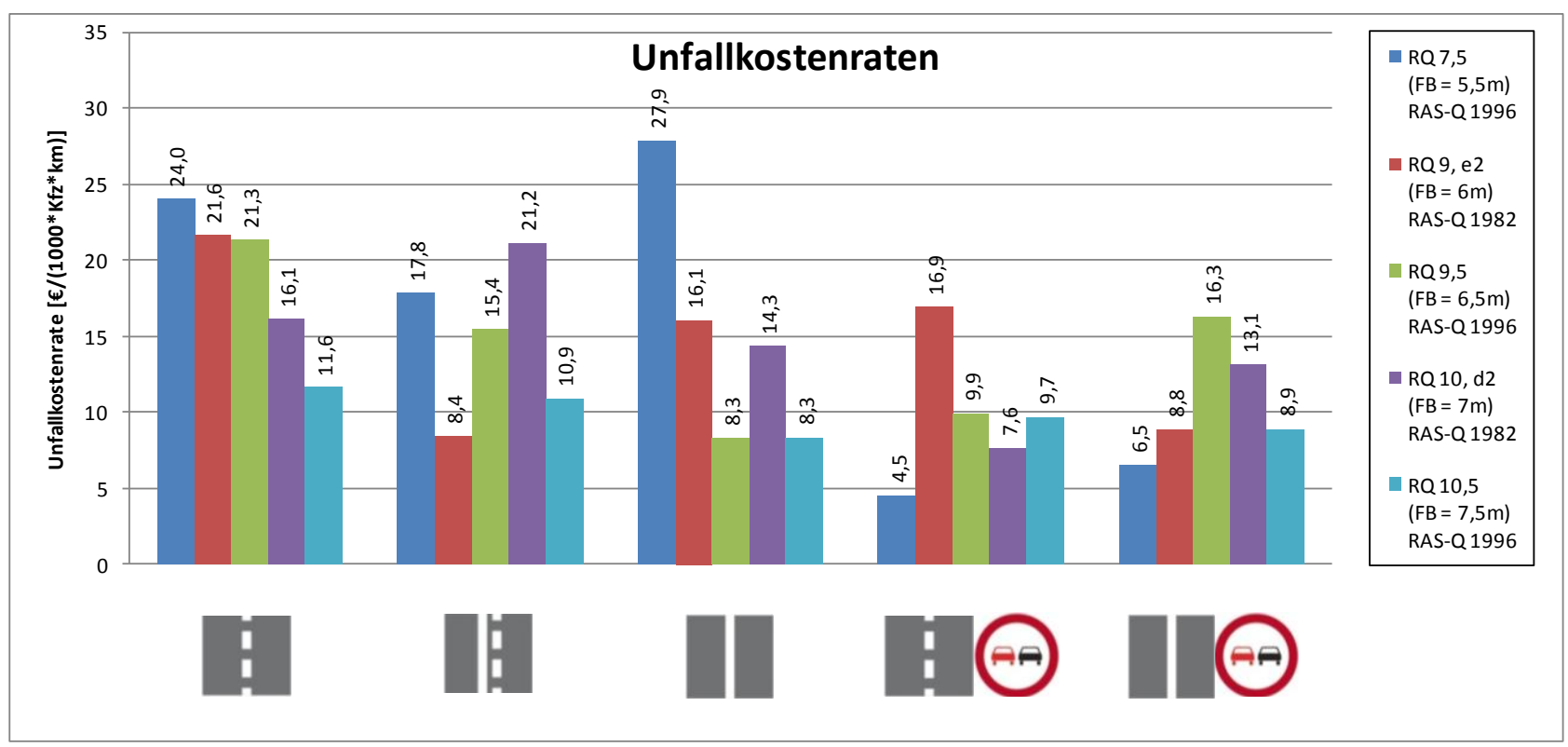

d) Unfalldichte $[\mathrm{U} /(\mathrm{km} * \mathrm{a})]$

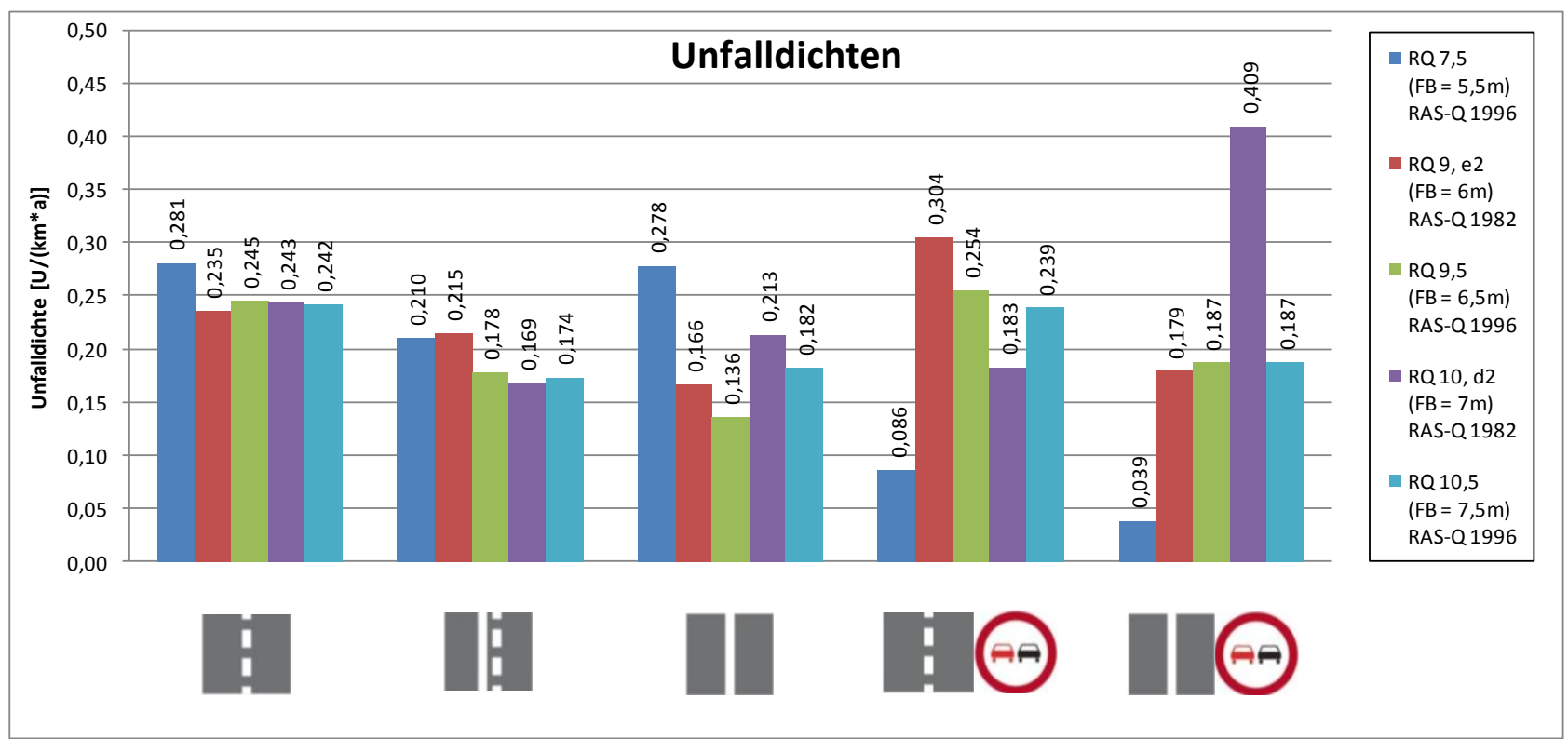


7) Überholunfälle auf Landstraßen - Anhänge zum Abschlussbericht

e) Unfallkostendichte $\left[1000 € /\left(\mathrm{km}^{*} \mathrm{a}\right)\right]$

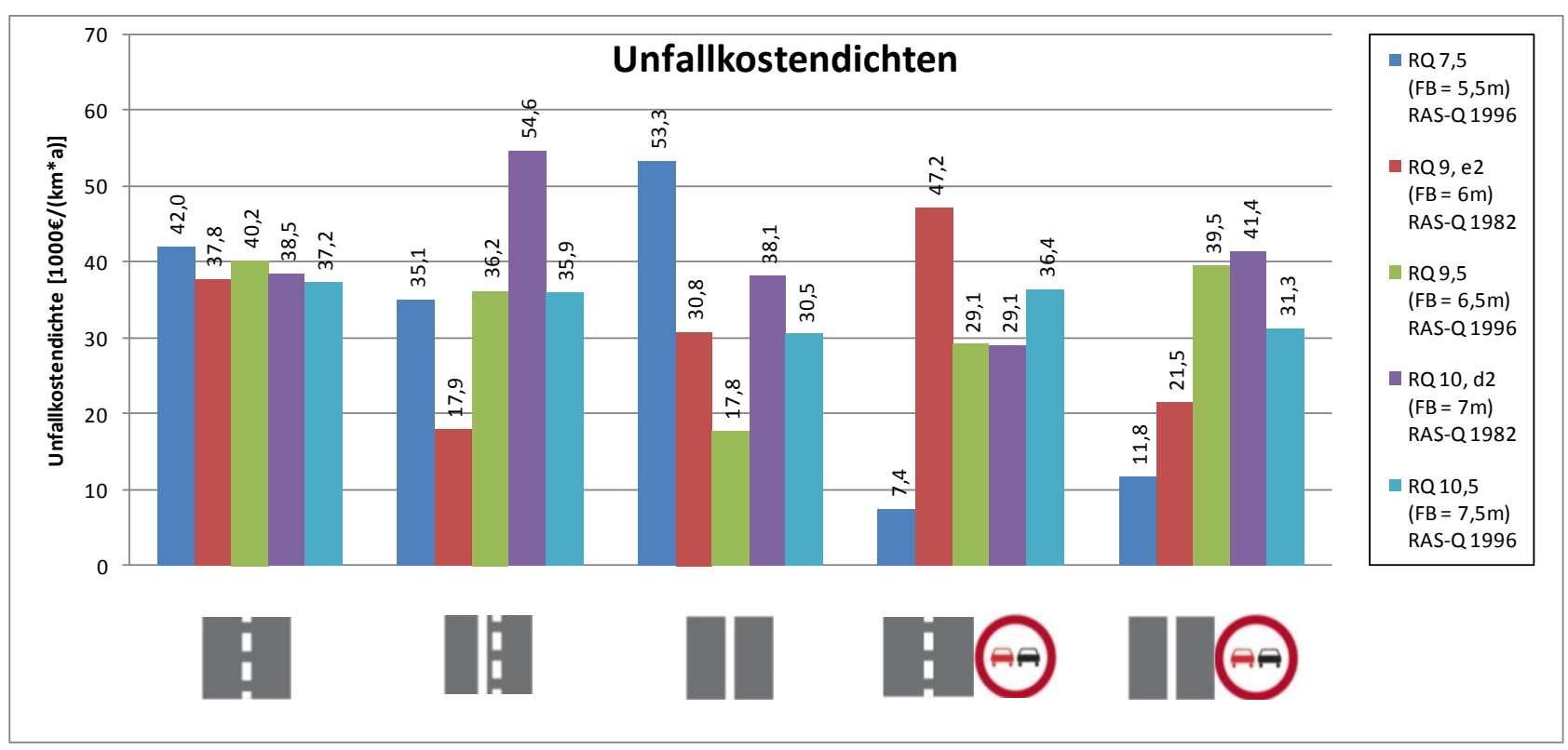




\section{Anhang $\mathbf{R}$ \\ Signifikanztest der Unfallkenngrößen nach \\ Fahrbahnbreiten}


7) Überholunfälle auf Landstraßen - Anhänge zum Abschlussbericht

a) Eigenschaften der Bezugsgrößen für Unfallkenngrößenberechnung (Regelquerschnitte)

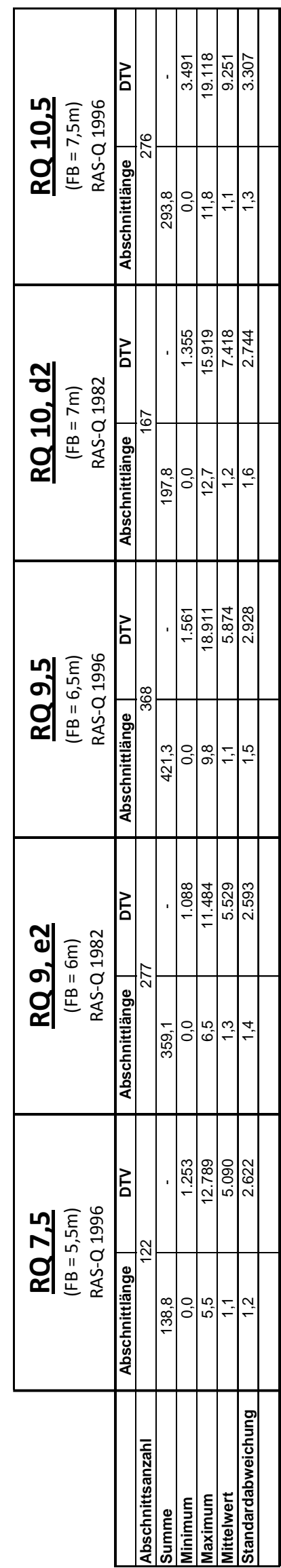




\section{b) Verteilungstest der Datengrundlagen (Regelquerschnitte)}

\begin{tabular}{|c|c|c|c|c|}
\hline & & \multicolumn{3}{|c|}{ Verteilungstests von Merkmalslängen und zugehöriger Verkehrstärke } \\
\hline & & Chi-Quadrat-Test & Kolmogorov-Smirnov-Test & Mann-Whitney-U-Test \\
\hline & Nullhypothese $\mathrm{HO}$ & Verteilungen ungleich & Stichproben aus gleicher GG & Stichproben aus gleicher GG \\
\hline & Alternativhypothese $\mathrm{H} 1$ & Verteilungen gleich & Stichproben nicht aus einer GG & Stichproben nicht aus einer GG \\
\hline \multirow[b]{2}{*}{ RQ 7,5 / RQ 9, e2 } & Abschnittslänge & 0,31 & 0,71 & 0,58 \\
\hline & DTV & 0,00 & 0,14 & 0,01 \\
\hline \multirow[b]{2}{*}{ RQ 7,5 / RQ 9,5 } & Abschnittslänge & 0,54 & 0,53 & 0,32 \\
\hline & DTV & 0,00 & 0,02 & 0,00 \\
\hline \multirow[b]{2}{*}{ RQ 7,5 / RQ 10, d2 } & Abschnittslänge & 0,87 & 0,99 & 0,68 \\
\hline & DTV & 0,00 & 0,00 & 0,00 \\
\hline \multirow[b]{2}{*}{ RQ 7,5 / RQ 10,5 } & Abschnittslänge & 0,69 & 0,87 & 0,44 \\
\hline & DTV & 0,00 & 0,00 & 0,00 \\
\hline \multirow[b]{2}{*}{ RQ 9, e2 / RQ 9,5 } & Abschnittslänge & 0,43 & 0,04 & 0,05 \\
\hline & DTV & 0,04 & 0,99 & 0,51 \\
\hline \multirow[b]{2}{*}{ RQ 9, e2 I RQ 10, d2 } & Abschnittslänge & 0,44 & 0,29 & 0,21 \\
\hline & DTV & 0,00 & 0,00 & 0,00 \\
\hline \multirow[b]{2}{*}{ RQ 9, e2 / RQ 10,5 } & Abschnittslänge & 0,45 & 0,10 & 0,27 \\
\hline & DTV & 0,00 & 0,00 & 0,00 \\
\hline \multirow[b]{2}{*}{ RQ 9,5 / RQ 10,d2 } & Abschnittslänge & 0,28 & 0,53 & 0,65 \\
\hline & DTV & 0,00 & 0,00 & 0,00 \\
\hline \multirow[b]{2}{*}{ RQ 9,5 / RQ 10,5 } & Abschnittslänge & 0,91 & 1,00 & 0,80 \\
\hline & DTV & 0,00 & 0,00 & 0,00 \\
\hline \multirow{3}{*}{ RQ 10, d2 / RQ 10,5 } & Abschnittslänge & 0,44 & 0,91 & 0,80 \\
\hline & DTV & 0,00 & 0,00 & 0,00 \\
\hline & & & & \\
\hline
\end{tabular}




\section{Anhang S \\ Zusammenhänge zwischen Überholunfällen und Landstraßeneigenschaften}


a) Unfallanzahl - Nettostreckenlänge

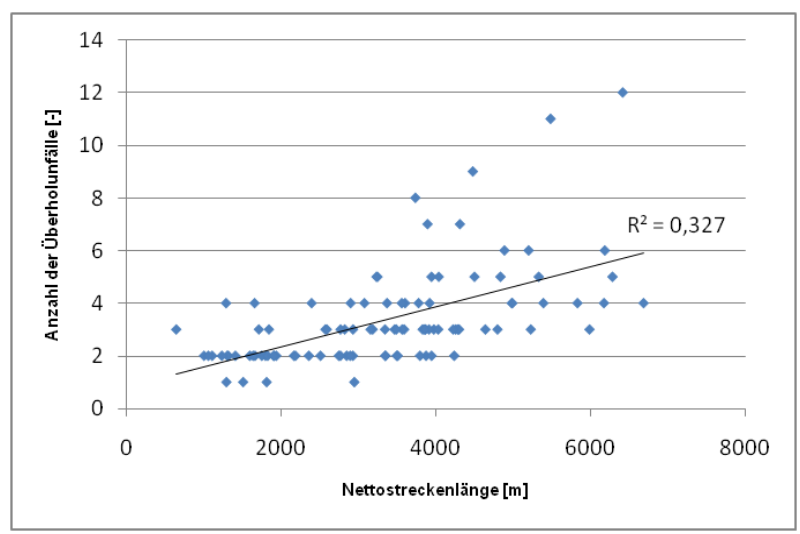

b) Unfallanzahl - Streckenanteil mit rechtlichen Überholmöglichkeiten

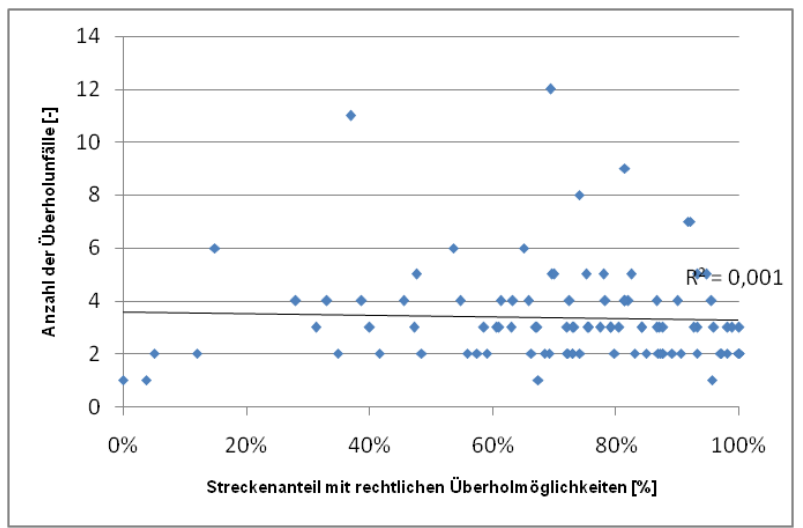

d) Unfallanzahl - Streckenanteil mit Überholmöglichkeiten nach RAS-L

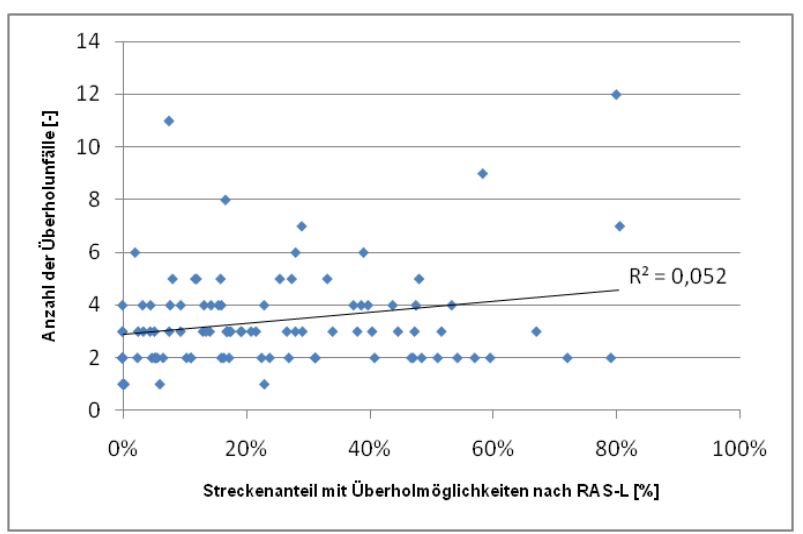

c) Unfallanzahl - Streckenlänge mit rechtlichen Überholmöglichkeiten

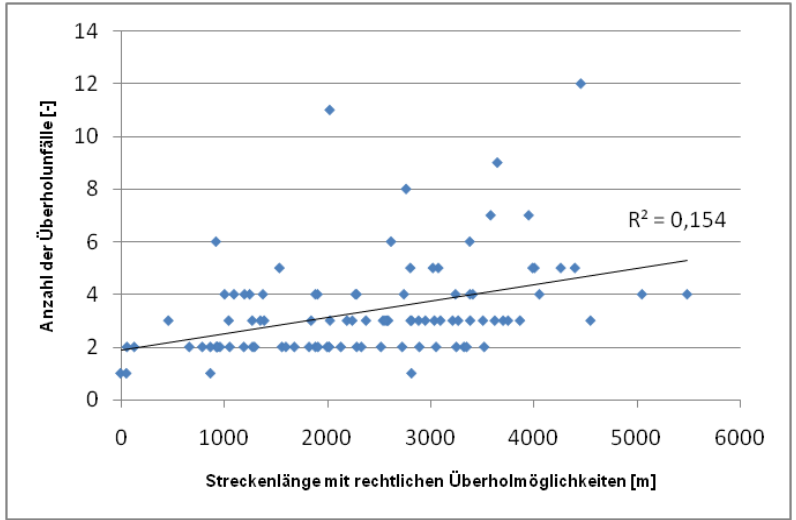

e) Unfallanzahl - Streckenlänge mit Überholmöglichkeiten nach RAS-L

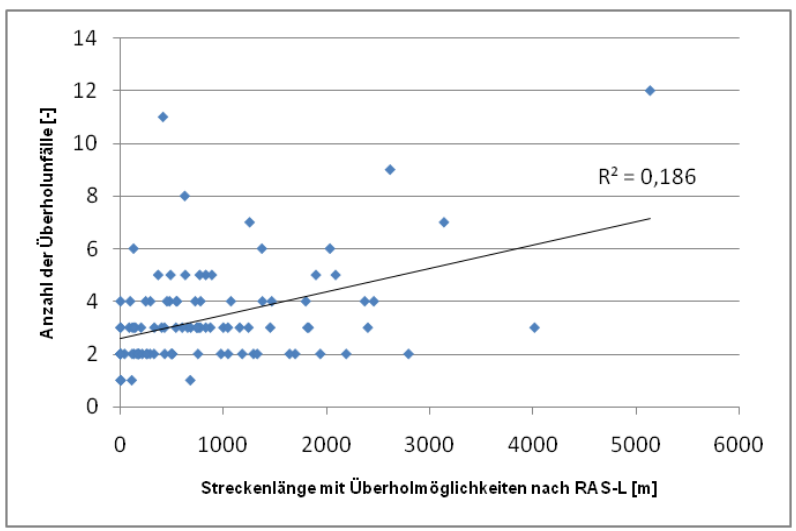


7) Überholunfälle auf Landstraßen - Anhänge zum Abschlussbericht

f) Unfallanzahl - Streckenanteil mit Überholmöglichkeiten nach RMS

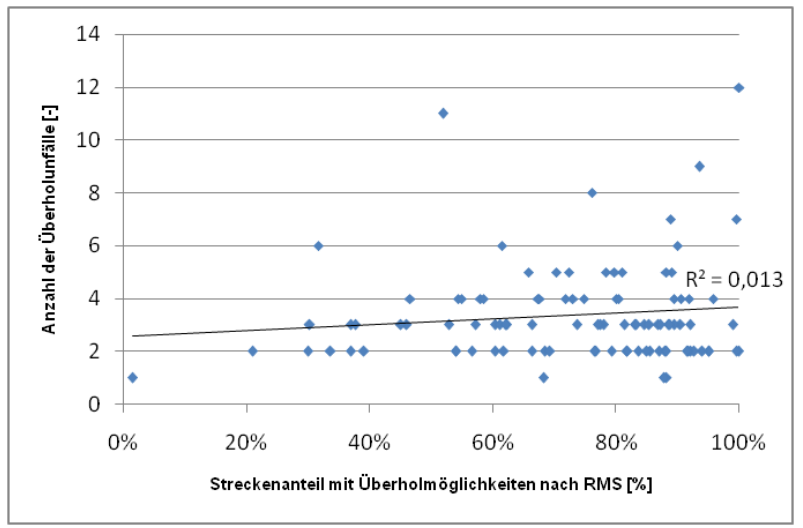

h) Unfallanzahl - Streckenanteil ohne Geschwindigkeitsbeschränkung

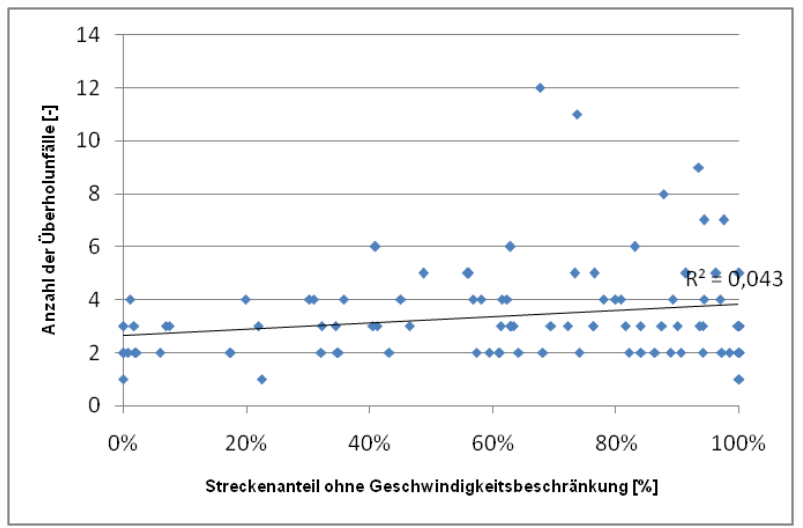

j) Unfallanzahl - DTV

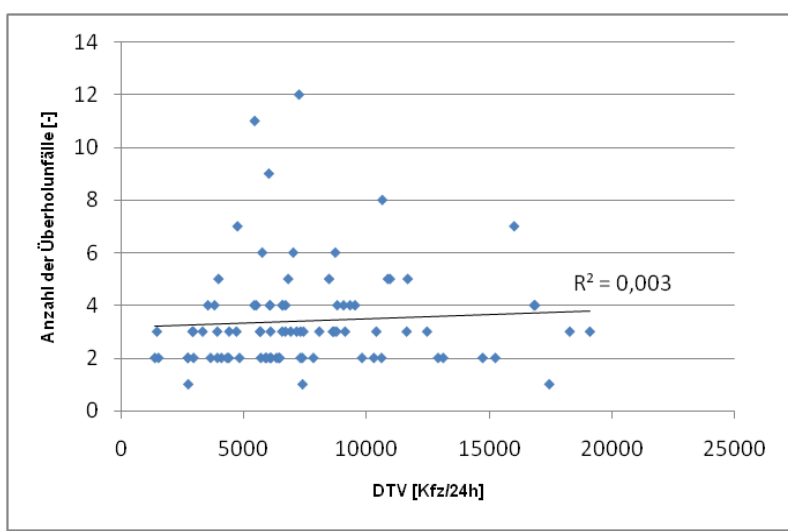

g) Unfallanzahl - Streckenlänge mit Überholmöglichkeiten nach RMS

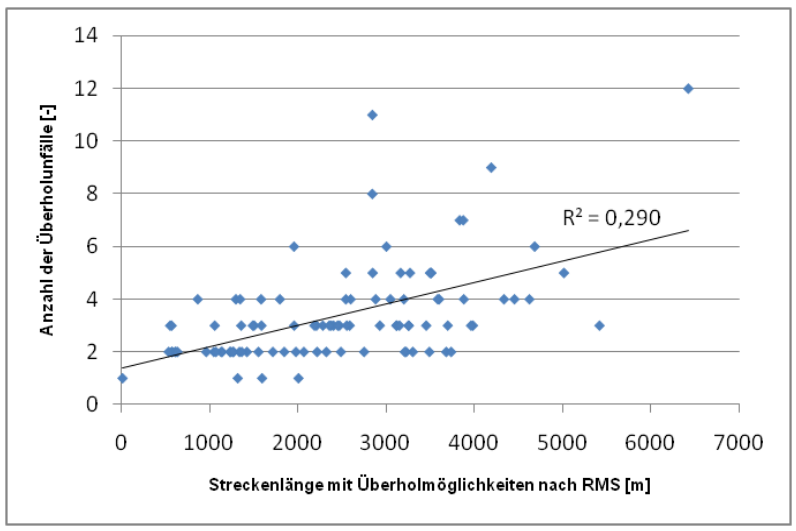

i) Unfallanzahl - Streckenlänge ohne Geschwindigkeitsbeschränkung

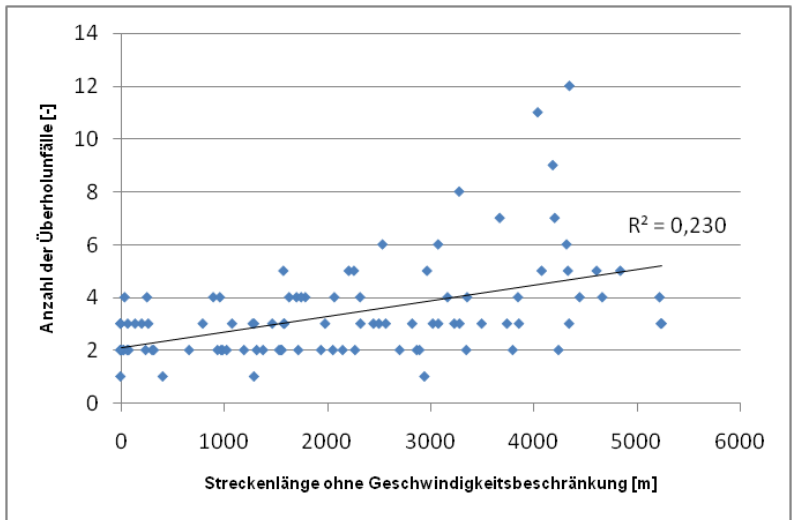

k) Unfallanzahl - Schwerverkehrsanteil

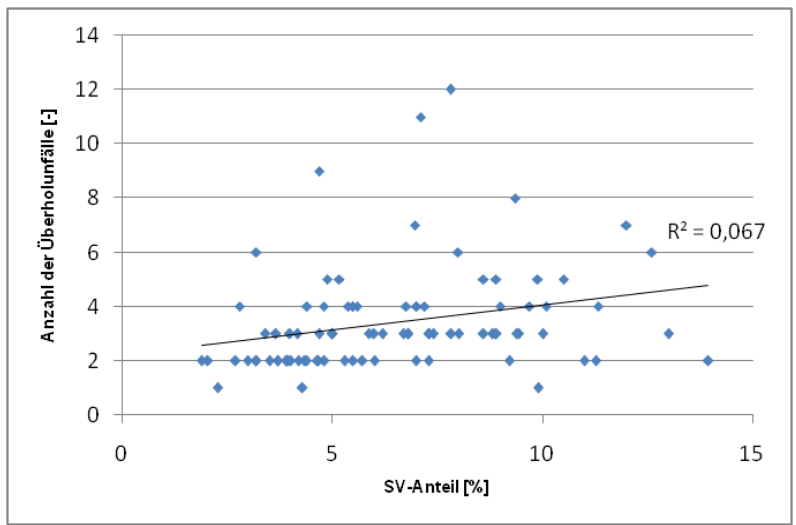




\section{Anhang $T$ \\ Analyse korrelierender Variablen}


7) Überholunfälle auf Landstraßen - Anhänge zum Abschlussbericht

a) vorhandene Überholmöglichkeiten nach RAS-L - rechtliche Randbedingungen

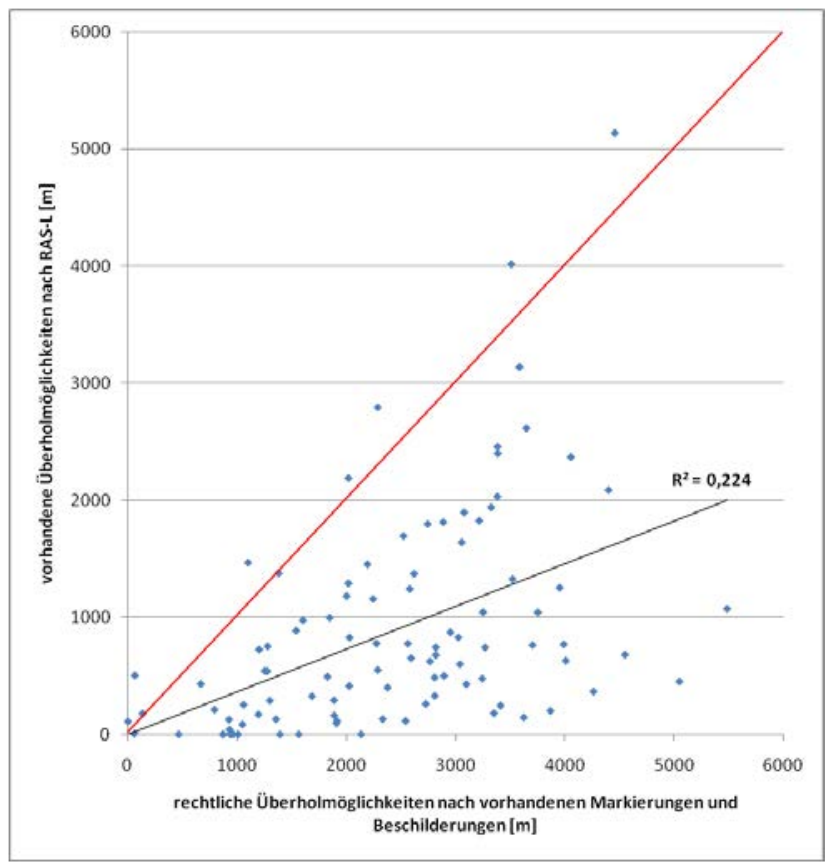

c) vorhandene Überholmöglichkeiten nach RAS-L - Nettostreckenlänge

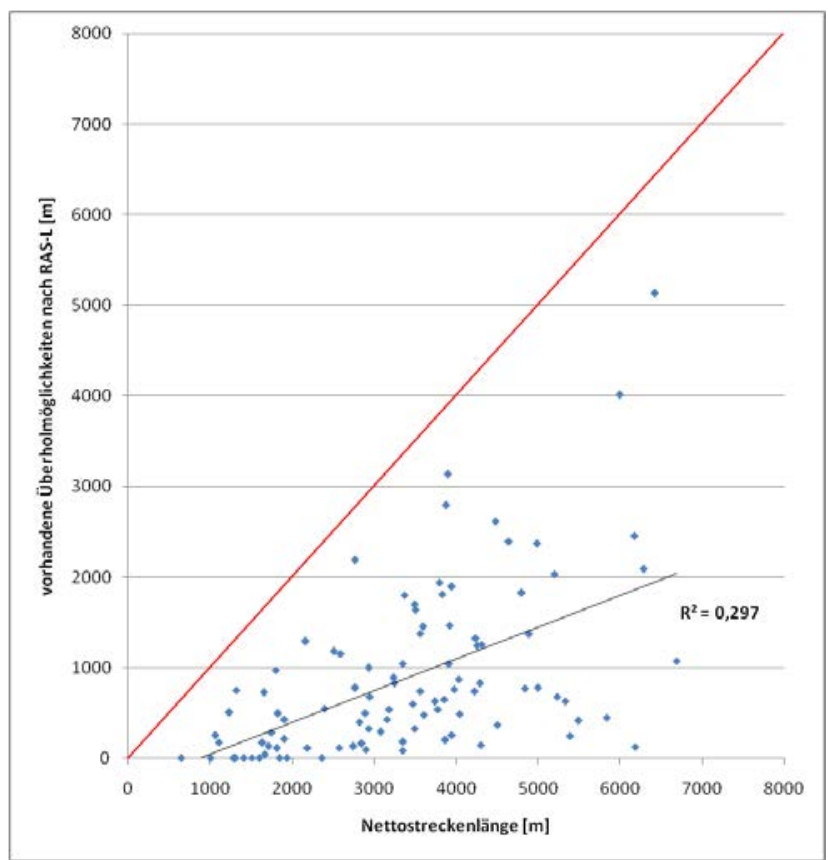

b) vorhandene Überholmöglichkeiten nach RMS - rechtliche Randbedingungen

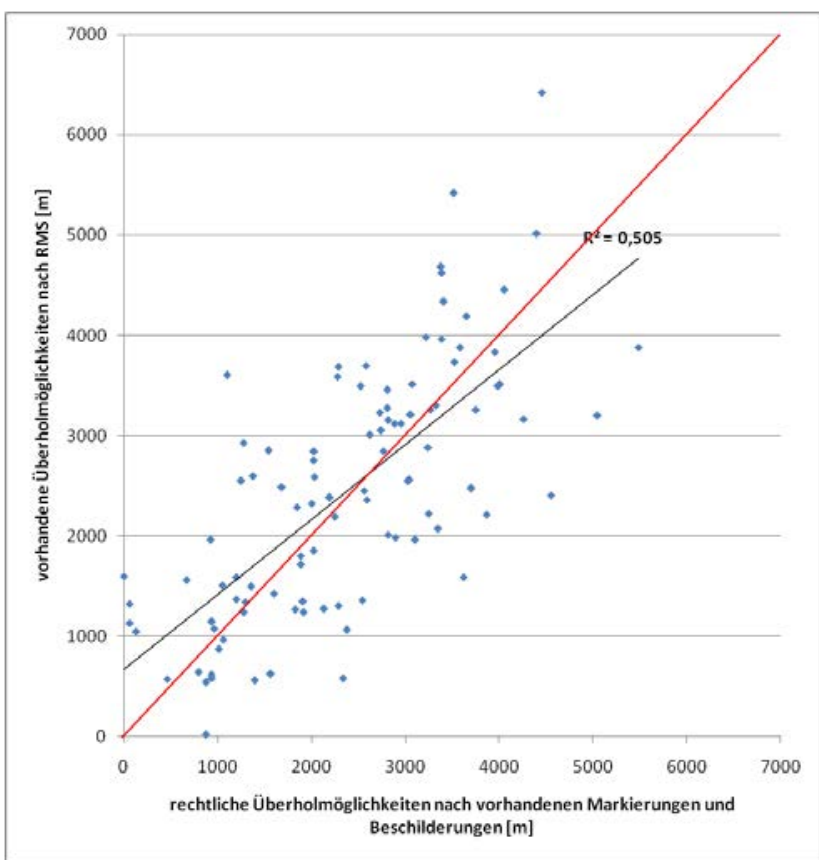

d) vorhandene Überholmöglichkeiten nach RMS - Nettostreckenlänge

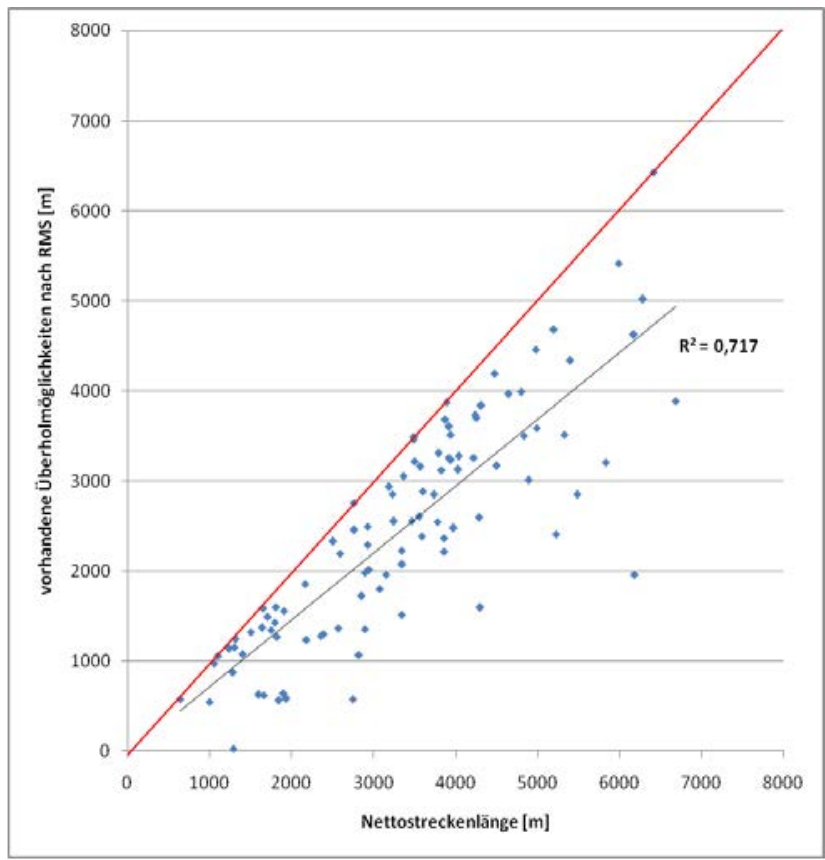


7) Überholunfälle auf Landstraßen - Anhänge zum Abschlussbericht

e) rechtliche Überholmöglichkeiten - Nettostreckenlänge

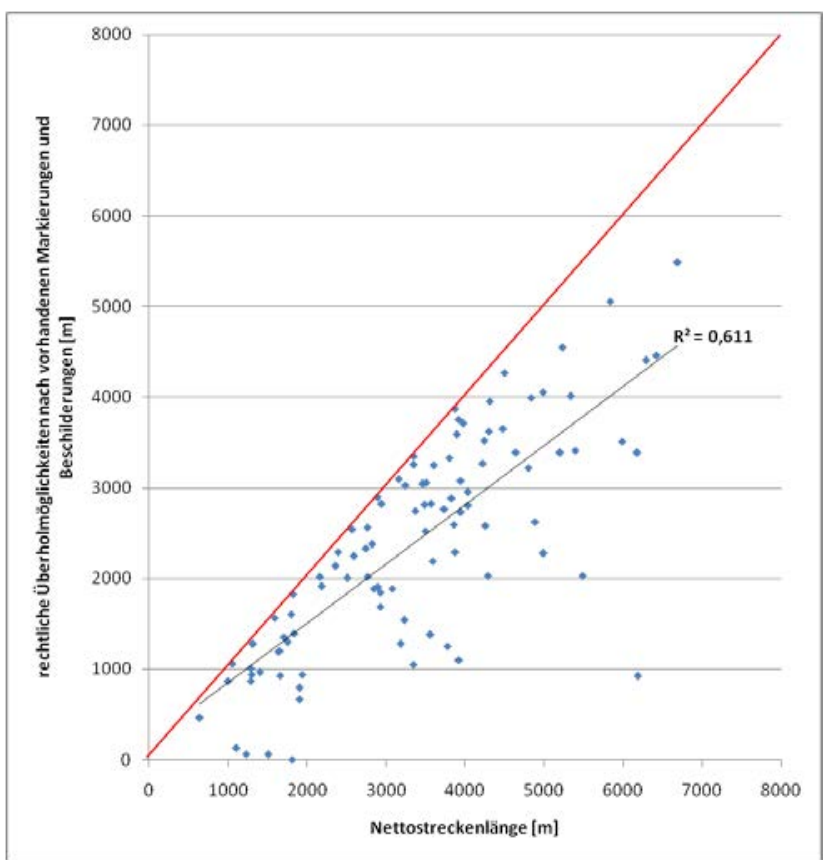




\section{Anhang $U$}

Zusätzliche Ergebnisse der Streckenbandanalyse 
7) Überholunfälle auf Landstraßen - Anhänge zum Abschlussbericht

a) Lageplanelemente differenziert nach Bundesländern $(n=333)$

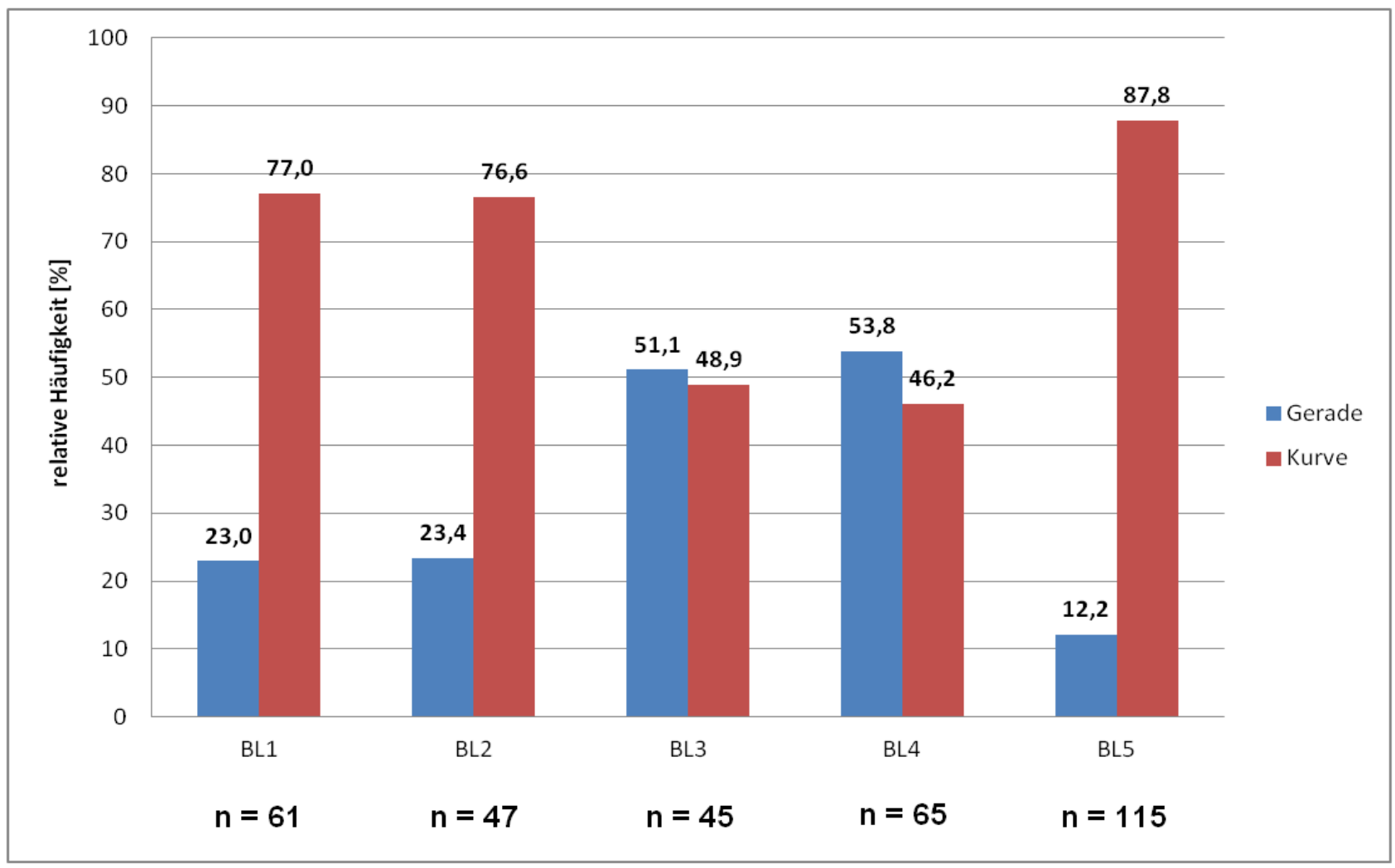

b) Höhenplanelemente differenziert nach Bundesländern $(n=329)$

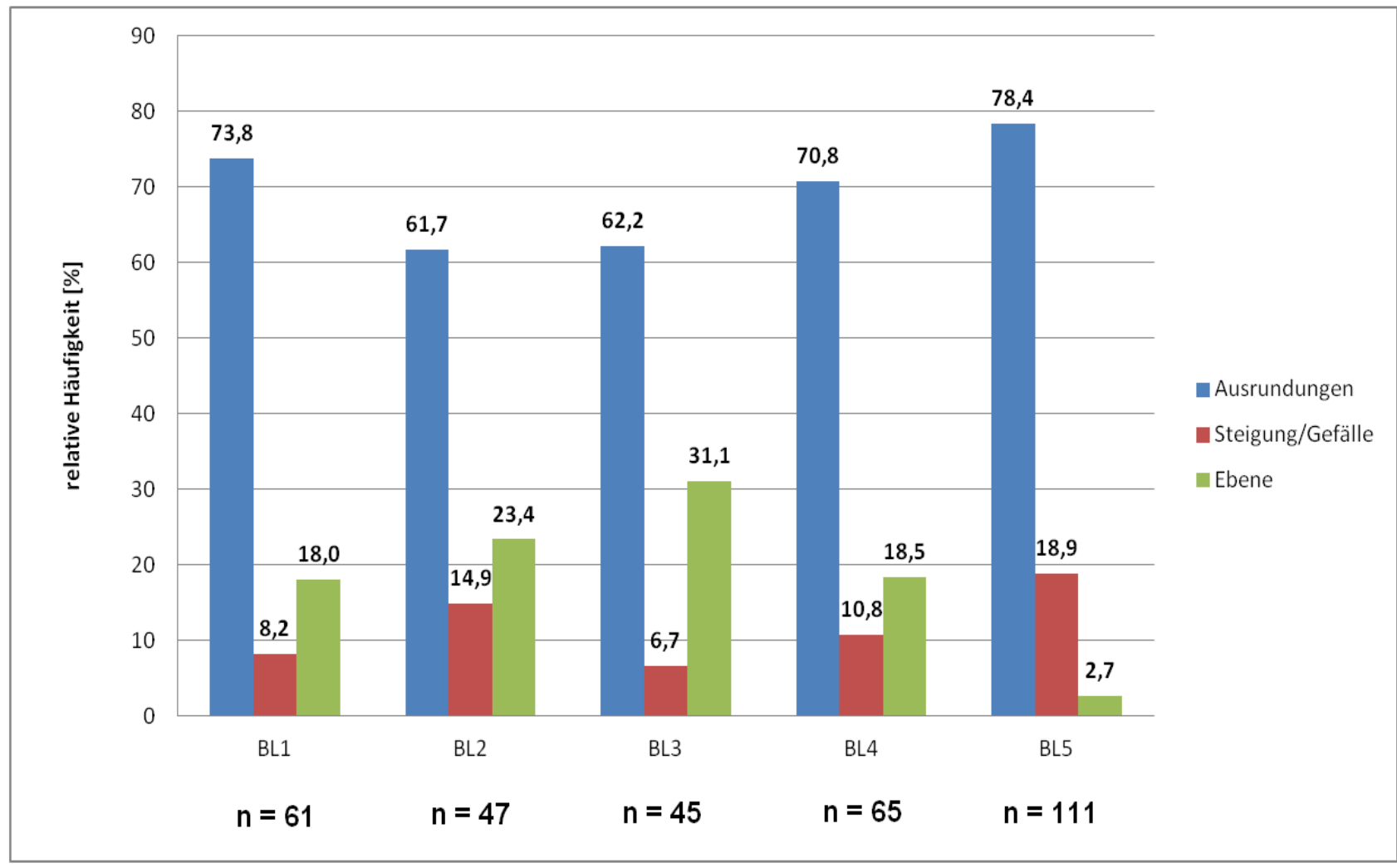


7) Überholunfälle auf Landstraßen - Anhänge zum Abschlussbericht

c) Eingehaltene Sichtweitenkriterien differenziert nach Bundesländern ( $n=332)$

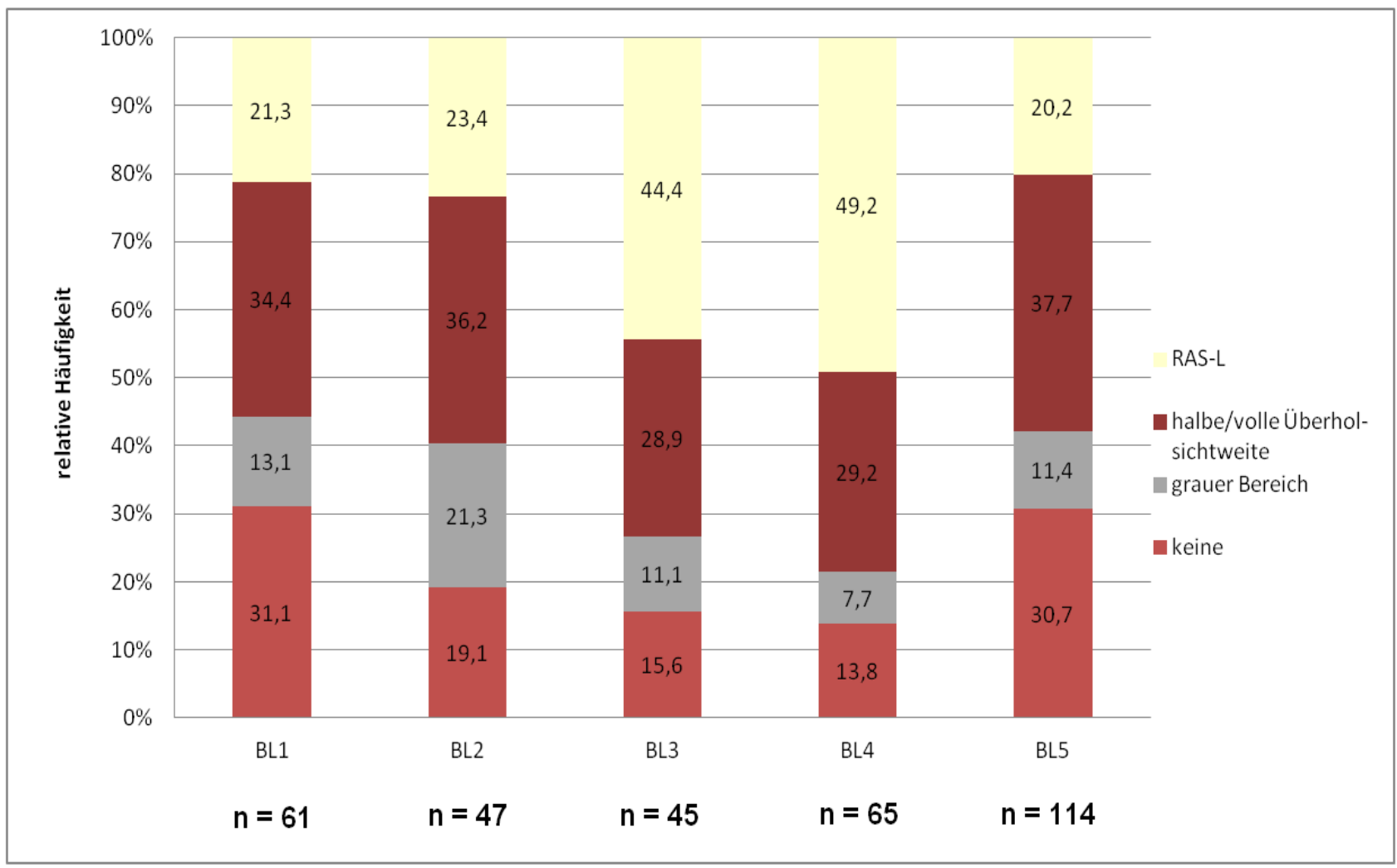

d) Elementkombinationen und resultierende eingehaltene Sichtweitenkriterien

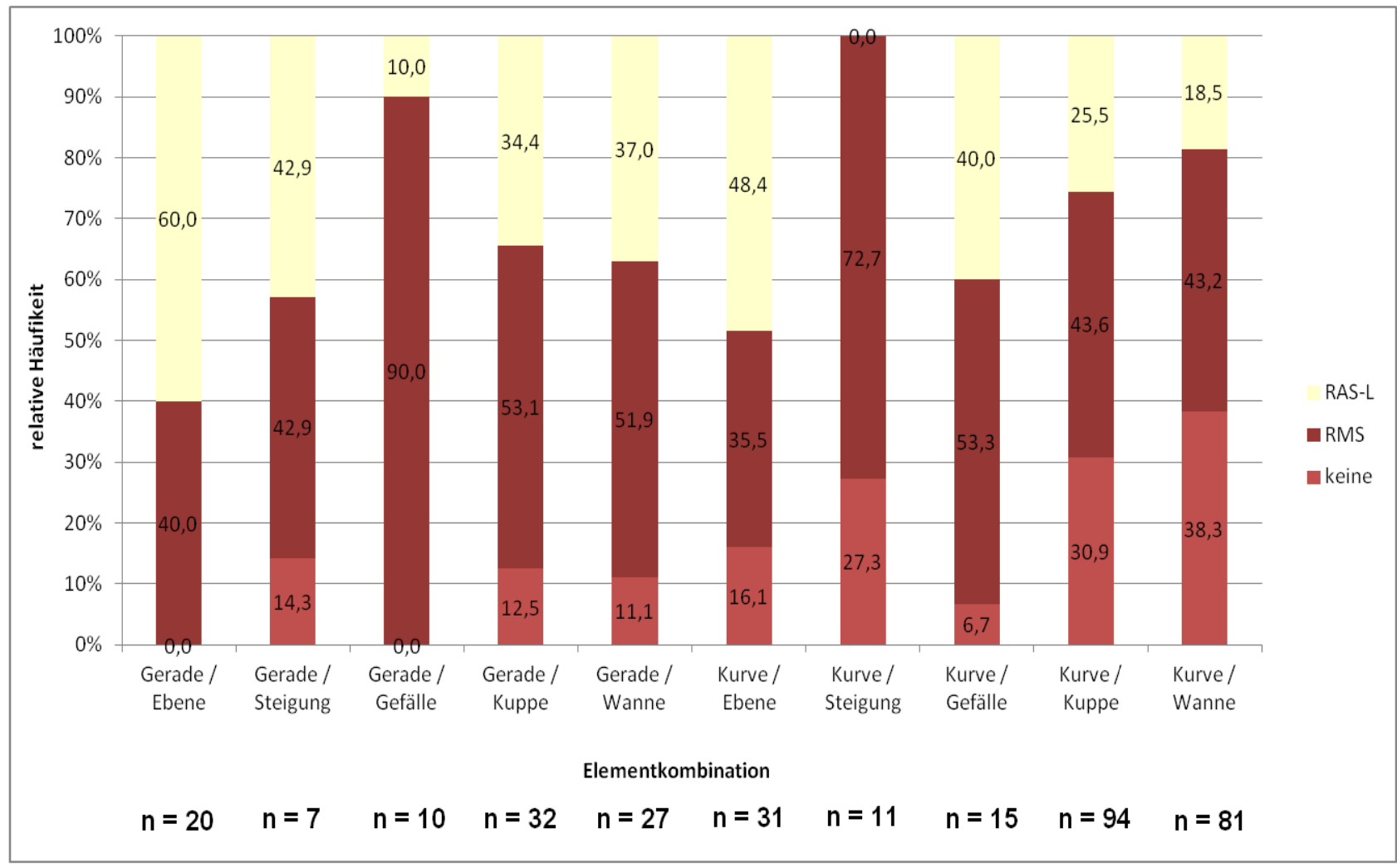


7) Überholunfälle auf Landstraßen - Anhänge zum Abschlussbericht

e) Rechtliche Anordnungen bei Unfällen in Kurven $(n=236)$

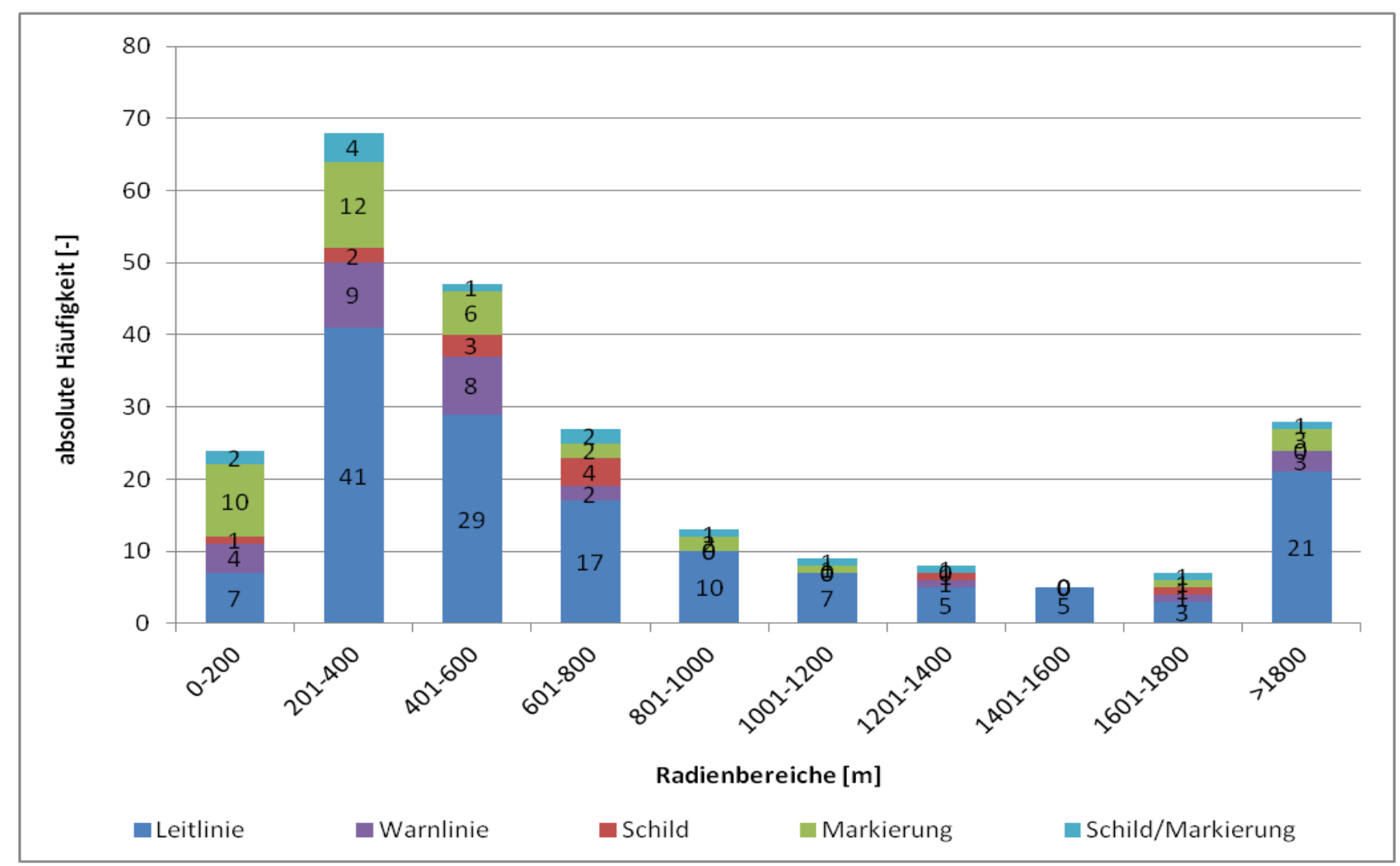

\section{f) Sichtweitenbereiche nach Radienklassen}

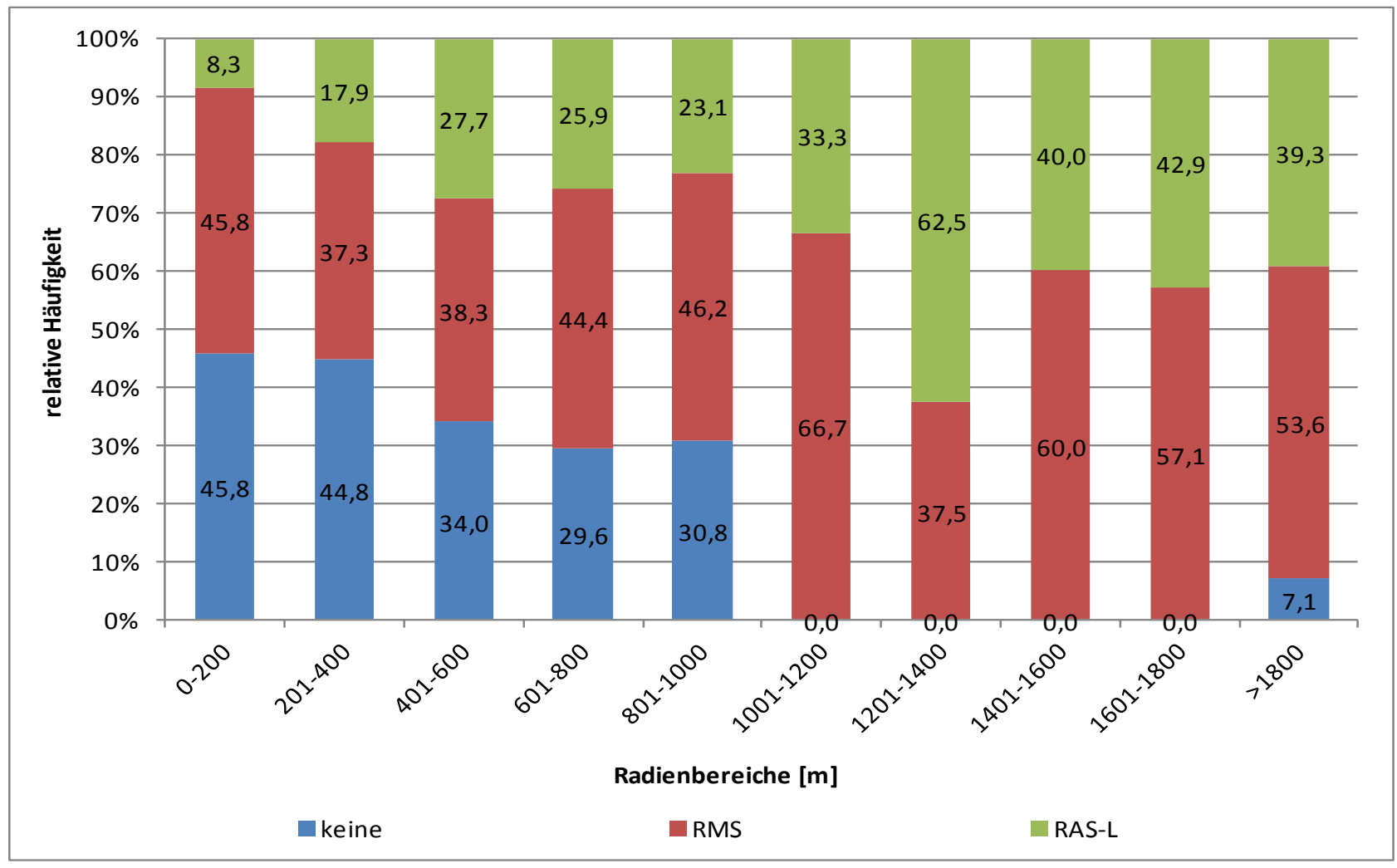


7) Überholunfälle auf Landstraßen - Anhänge zum Abschlussbericht

g) Rechtliche Anordnungen bei Unfällen in Kurven ohne Sichtweiten ( $n=71)$

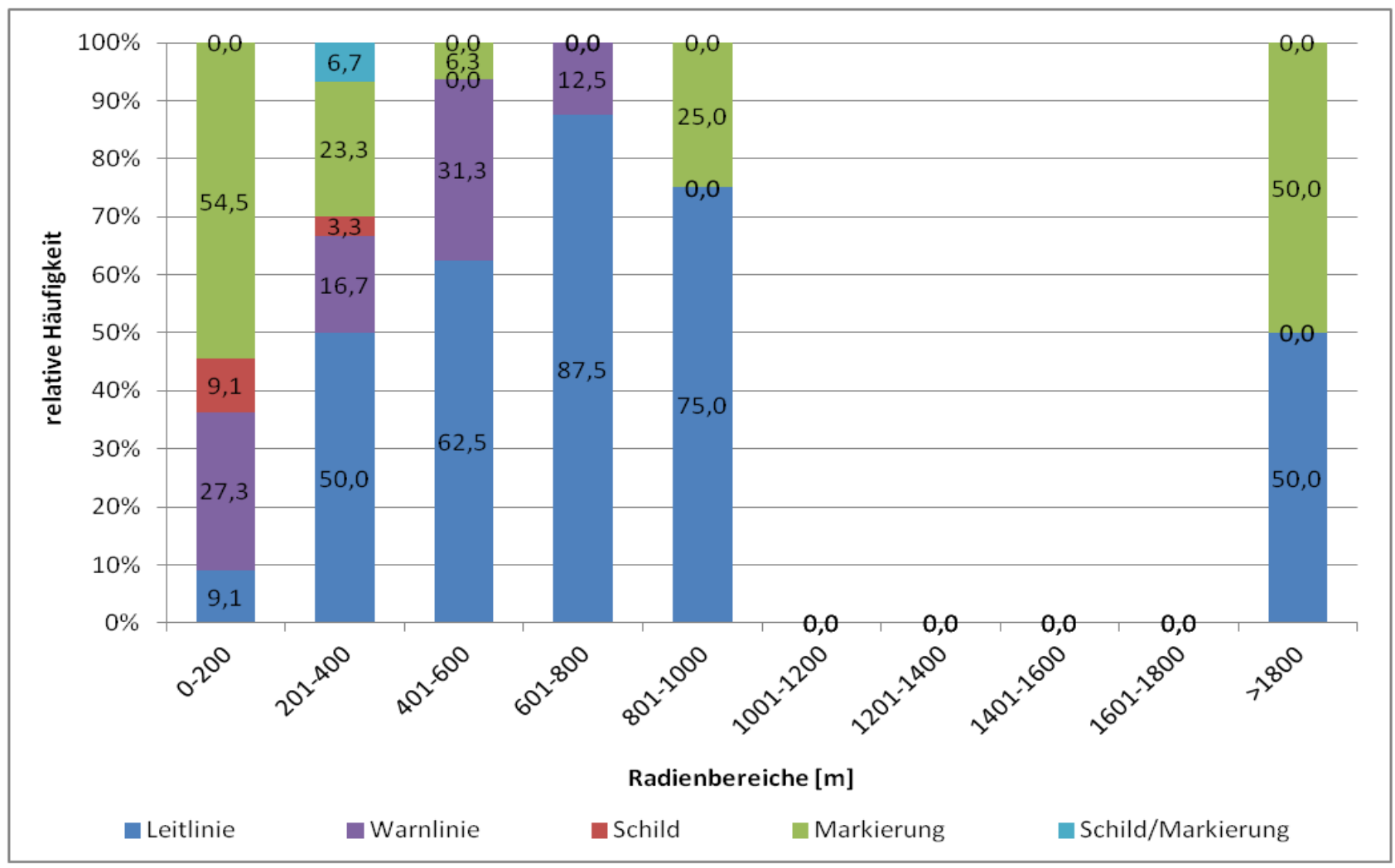

h) Rechtliche Anordnungen bei Unfällen in Kurven mit Sichtweiten nach RMS ( $n=103)$

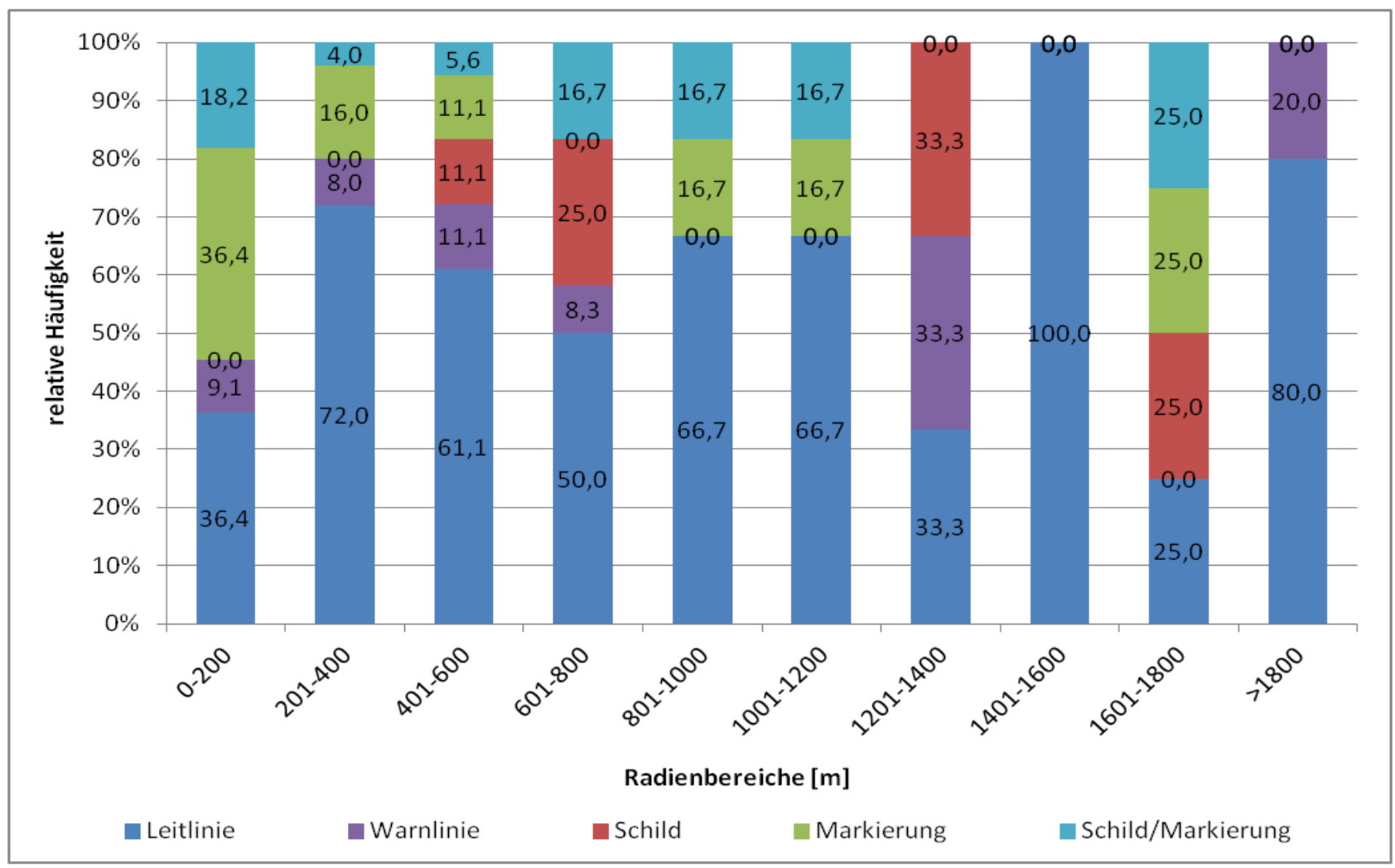


i) Rechtliche Anordnungen bei Unfällen in Kurven mit Sichtweiten nach RAS-L $(n=61)$

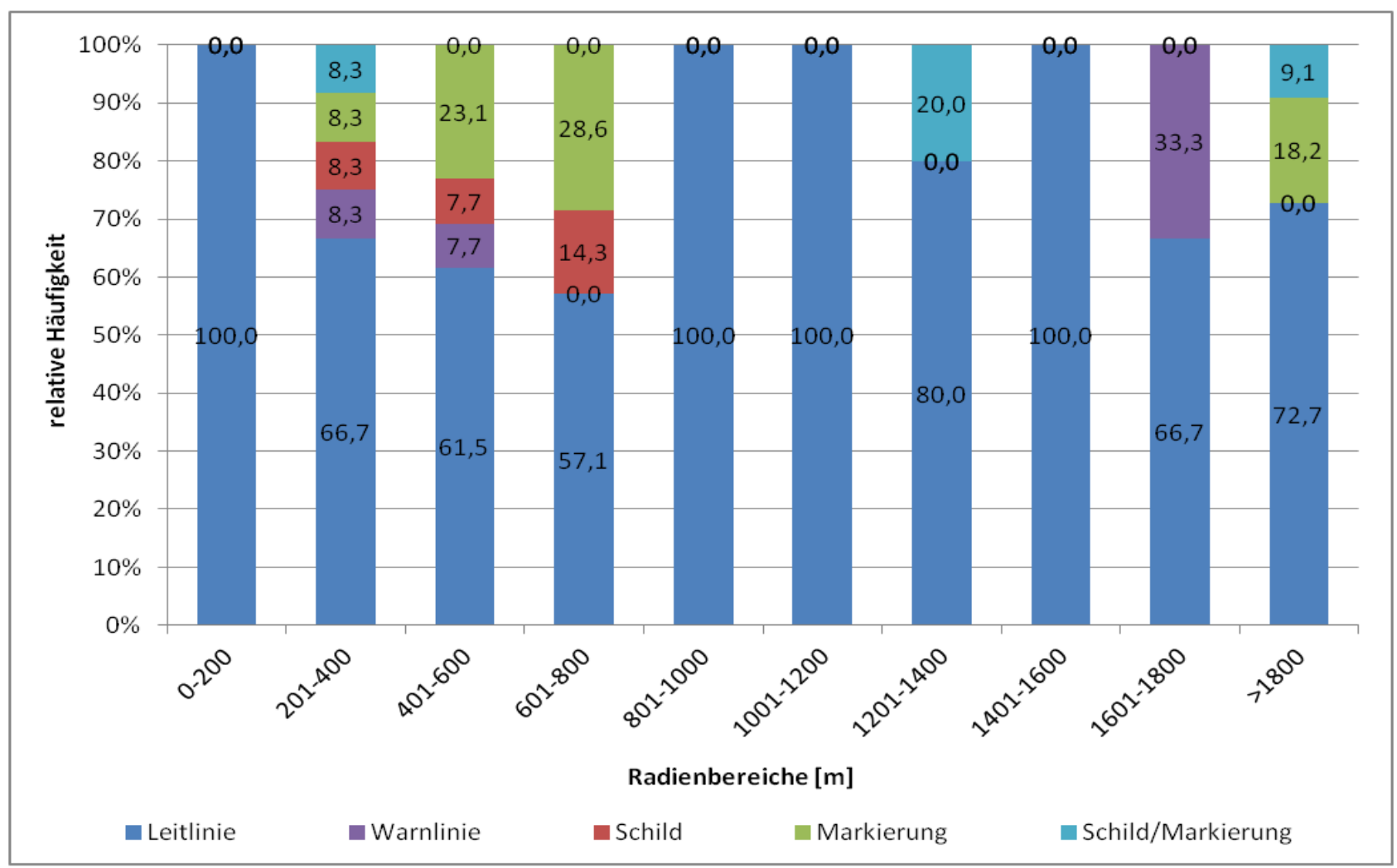

\section{j) Geschwindigkeitsbeschränkungen bei Unfällen in Kurven nach Sichtweitenbereichen}

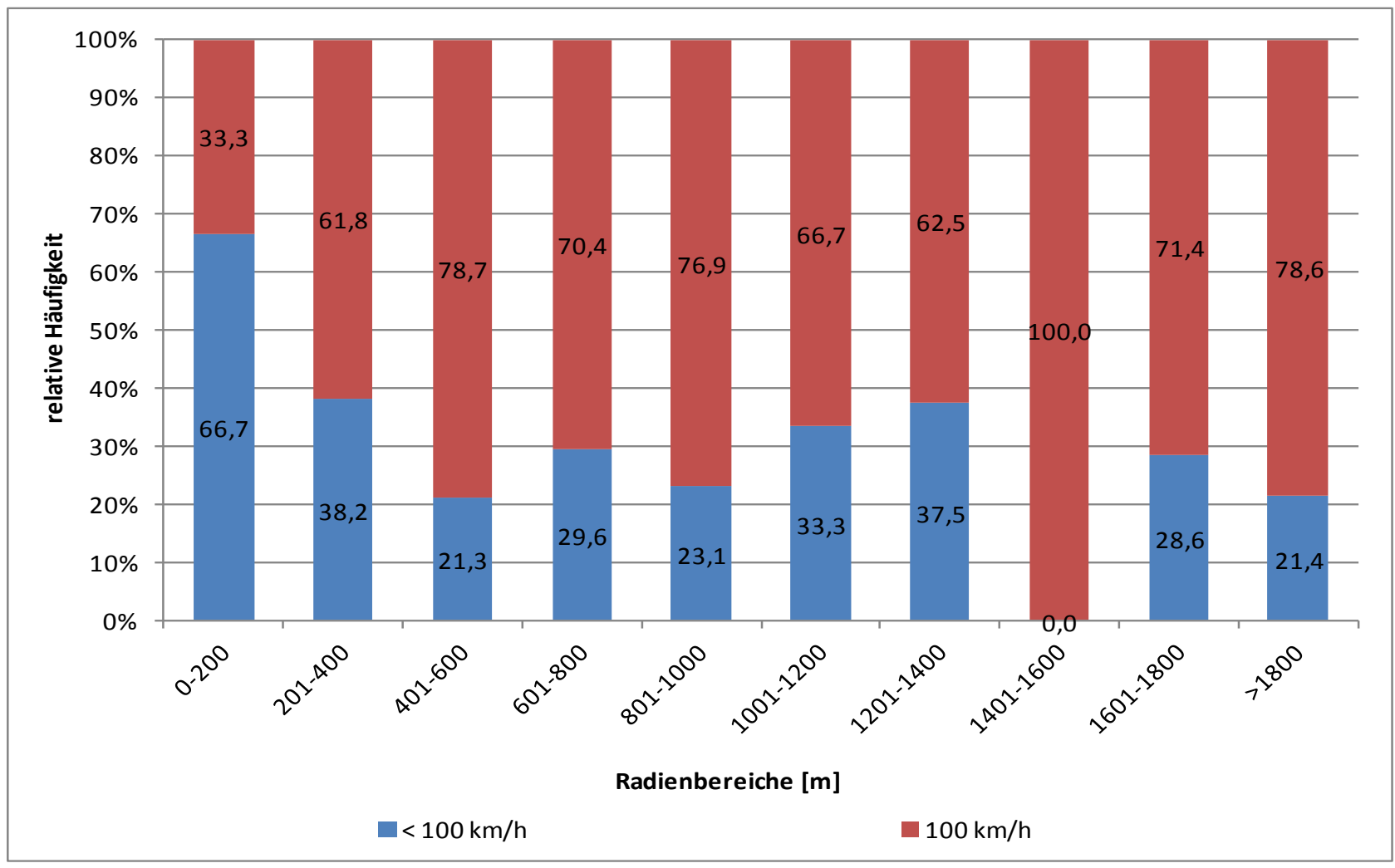




\section{Anhang $\mathrm{V}$}

Streckenzuordnung zu vorhandenen und rechtlichen Überholmöglichkeiten 


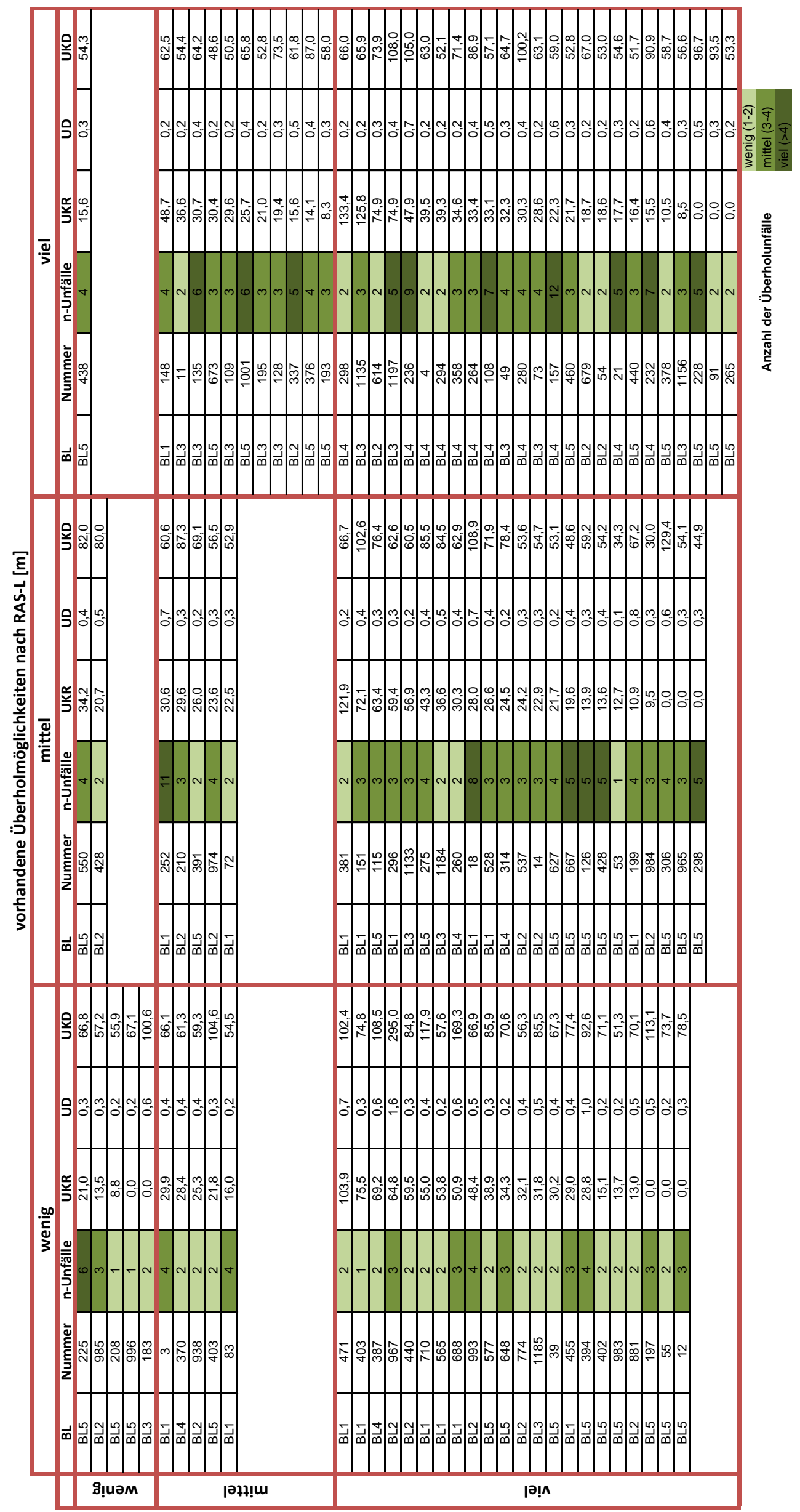

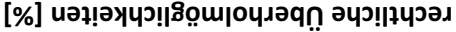




\section{Anhang W \\ Ausgewählte Strecken für Detailanalyse}




\begin{tabular}{|c|c|c|c|c|c|c|c|}
\hline 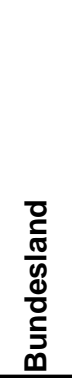 & 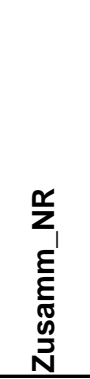 & 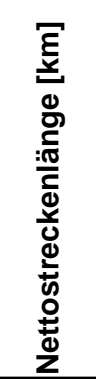 & 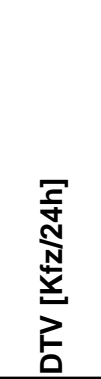 & 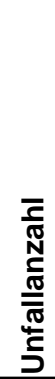 & 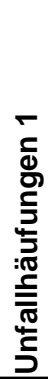 & 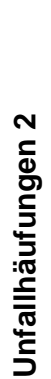 & 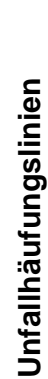 \\
\hline BL1 & 3 & 3,079 & 6054 & 4 & ja & & \\
\hline BL1 & 18 & 3,738 & 10639 & 8 & $\mathrm{ja}$ & $\mathrm{ja}$ & ja \\
\hline BL1 & 72 & 1,907 & 6445 & 2 & $\mathrm{ja}$ & & \\
\hline BL1 & 148 & 6,179 & 3519 & 4 & $\mathrm{ja}$ & & \\
\hline BL1 & 151 & 2,824 & 3900 & 3 & ja & & ja \\
\hline BL1 & 199 & 1,657 & 16879 & 4 & $\mathrm{ja}$ & & ja \\
\hline BL1 & 252 & 5,488 & 5427 & 11 & $\mathrm{ja}$ & ja & ja \\
\hline BL1 & 455 & 2,574 & 7300 & 3 & ja & & ja \\
\hline BL1 & 528 & 2,769 & 7421 & 3 & ja & & \\
\hline BL1 & 710 & 1,639 & 5873 & 2 & $\mathrm{ja}$ & & \\
\hline BL2 & 337 & 3,234 & 10867 & 5 & & & ja \\
\hline BL2 & 537 & 3,567 & 6076 & 3 & & & $\mathrm{ja}$ \\
\hline BL2 & 967 & 0,643 & 12467 & 3 & ja & & ja \\
\hline BL2 & 974 & 4,994 & 6576 & 4 & $\mathrm{ja}$ & & \\
\hline BL2 & 993 & 2,900 & 3788 & 4 & $\mathrm{ja}$ & ja & \\
\hline BL3 & 73 & 6,692 & 6050 & 4 & ja & ja & \\
\hline BL3 & 128 & 2,931 & 10395 & 3 & 3 & & \\
\hline BL3 & 195 & 5,992 & 6899 & 3 & ja & & \\
\hline BL3 & 1156 & 3,832 & 18296 & 3 & ja & & ja \\
\hline BL3 & 1184 & 1,318 & 6323 & 2 & ja & & \\
\hline BL3 & 1185 & 1,303 & 7374 & 2 & ja & & \\
\hline BL3 & 1197 & 3,947 & 3951 & 5 & ja & & \\
\hline BL4 & 4 & 3,508 & 4371 & 2 & & & \\
\hline BL4 & 157 & 6,423 & 7240 & 12 & ja & ja & ja \\
\hline BL4 & 232 & 3,896 & 16026 & 7 & $\mathrm{ja}$ & ja & $\mathrm{ja}$ \\
\hline BL4 & 236 & 4,482 & 6008 & 9 & $\mathrm{ja}$ & ja & $\mathrm{ja}$ \\
\hline BL4 & 260 & 1,827 & 5678 & 2 & & & \\
\hline BL4 & 264 & 2,592 & 7142 & 3 & ja & & \\
\hline BL4 & 280 & 3,371 & 9057 & 4 & ja & ja & ja \\
\hline BL4 & 314 & 4,227 & 8771 & 3 & ja & & \\
\hline BL4 & 358 & 4,644 & 5661 & 3 & & & \\
\hline BL4 & 387 & 1,058 & 4300 & 2 & & & \\
\hline BL5 & 39 & 1,595 & 6099 & 2 & ja & & \\
\hline BL5 & 115 & 3,978 & 3302 & 3 & ja & & \\
\hline BL5 & 126 & 5,335 & 11677 & 5 & ja & & ja \\
\hline BL5 & 225 & 6,190 & 8721 & 6 & ja & ja & ja \\
\hline BL5 & 228 & 3,249 & & 5 & $\mathrm{ja}$ & ja & \\
\hline BL5 & 298 & 4,840 & & 5 & ja & ja & \\
\hline BL5 & 306 & 2,395 & & 4 & ja & & ja \\
\hline BL5 & 376 & 3,562 & 16841 & 4 & ja & & $\mathrm{ja}$ \\
\hline BL5 & 394 & 1,288 & 8799 & 4 & ja & & ja \\
\hline BL5 & 428 & 4,041 & 10950 & 5 & & & ja \\
\hline BL5 & 438 & 3,922 & 9525 & 4 & & & ja \\
\hline BL5 & 460 & 3,915 & 6684 & 3 & ja & & \\
\hline BL5 & 550 & 3,780 & 6556 & 4 & ja & & \\
\hline BL5 & 577 & 2,359 & 6051 & 2 & ja & & \\
\hline BL5 & 667 & 4,503 & 6796 & 5 & ja & & ja \\
\hline BL5 & 673 & 4,289 & 4386 & 3 & & & ja \\
\hline BL5 & 965 & 3,858 & & 3 & ja & & $\mathrm{ja}$ \\
\hline BL5 & 1001 & 4,891 & 7004 & 6 & ja & ja & ja \\
\hline
\end{tabular}




\section{Anhang $X$}

Zusätzliche Ergebnisse der mikroskopischen Unfallanalyse 
7) Überholunfälle auf Landstraßen - Anhänge zum Abschlussbericht

a) Überholphasen nach vorhandenen Sichtweiten

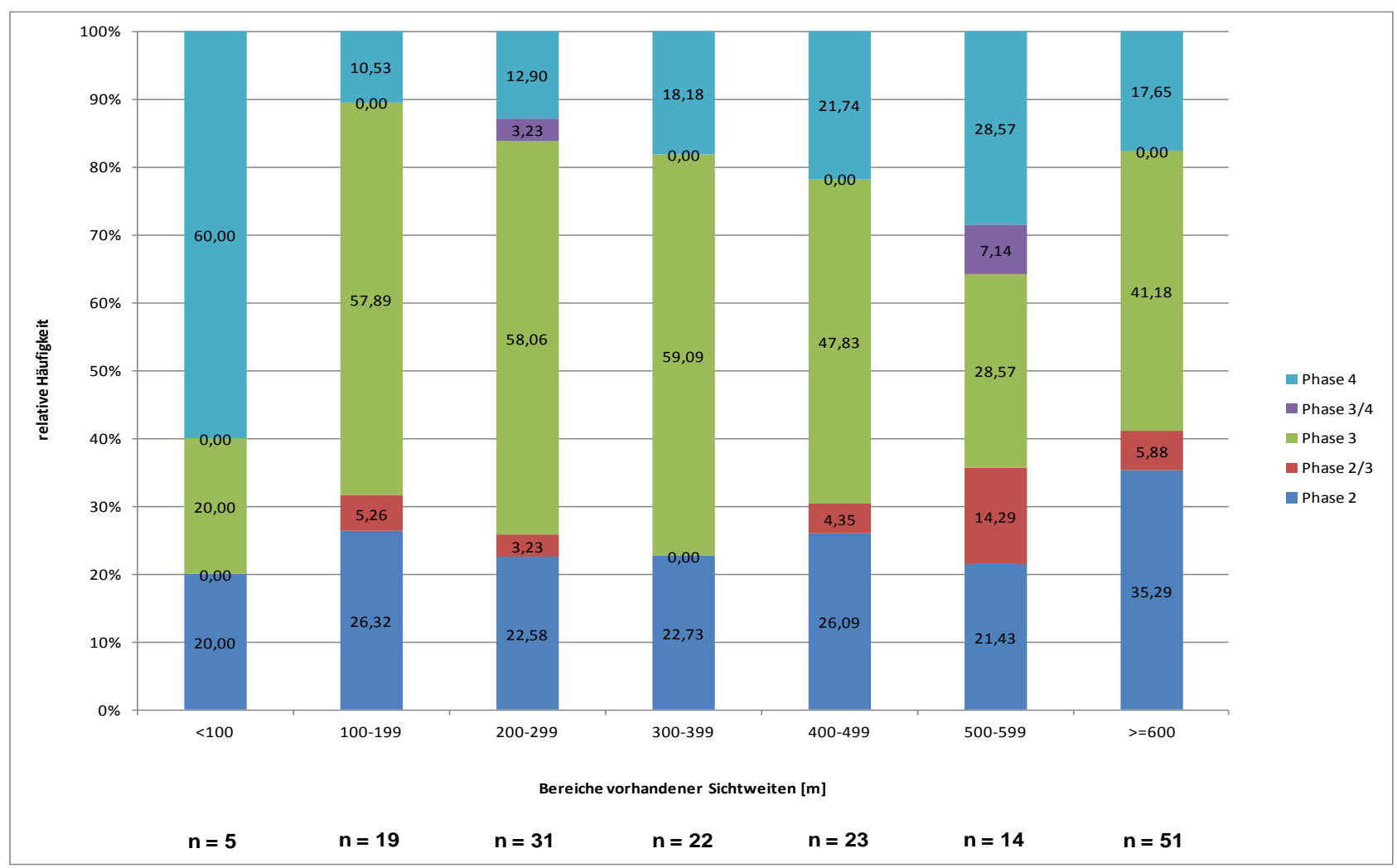

b) Alter der Unfallverursacher nach Art der Verkehrsbeteiligung

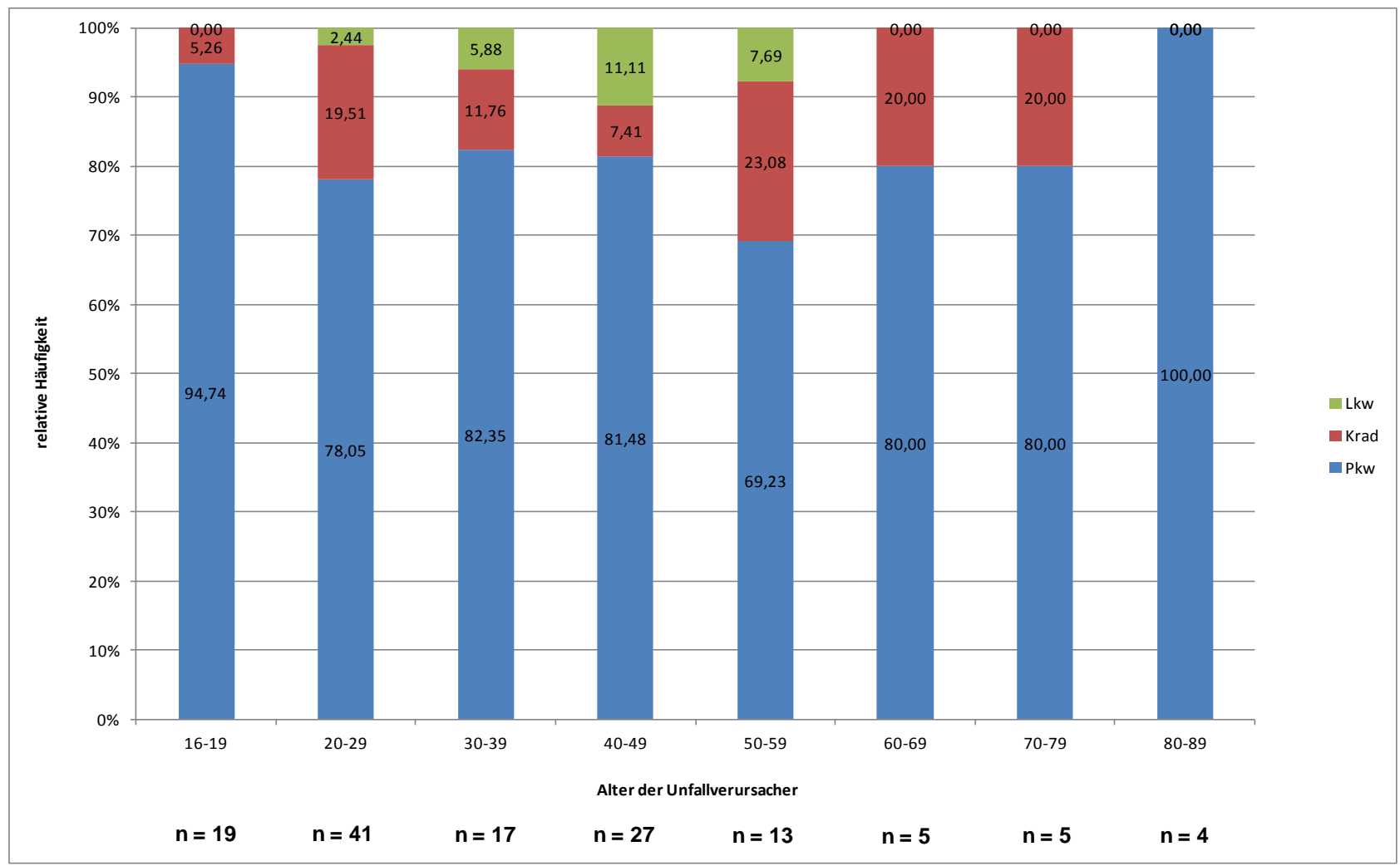


7) Überholunfälle auf Landstraßen - Anhänge zum Abschlussbericht

c) Alter der Unfallverursacher nach Überholphasen

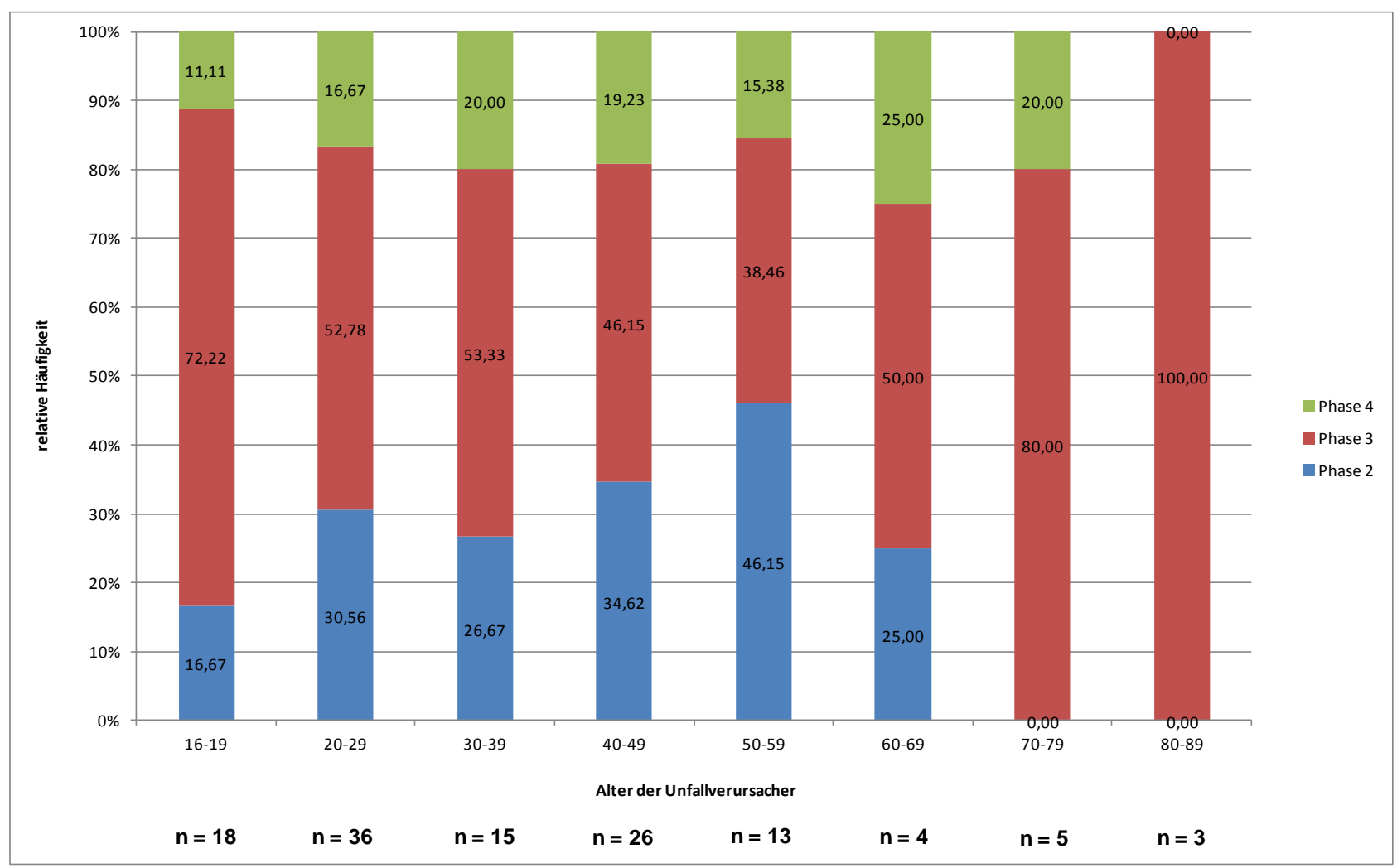

d) Alter der Unfallverursacher nach vorhandenen Sichtweiten

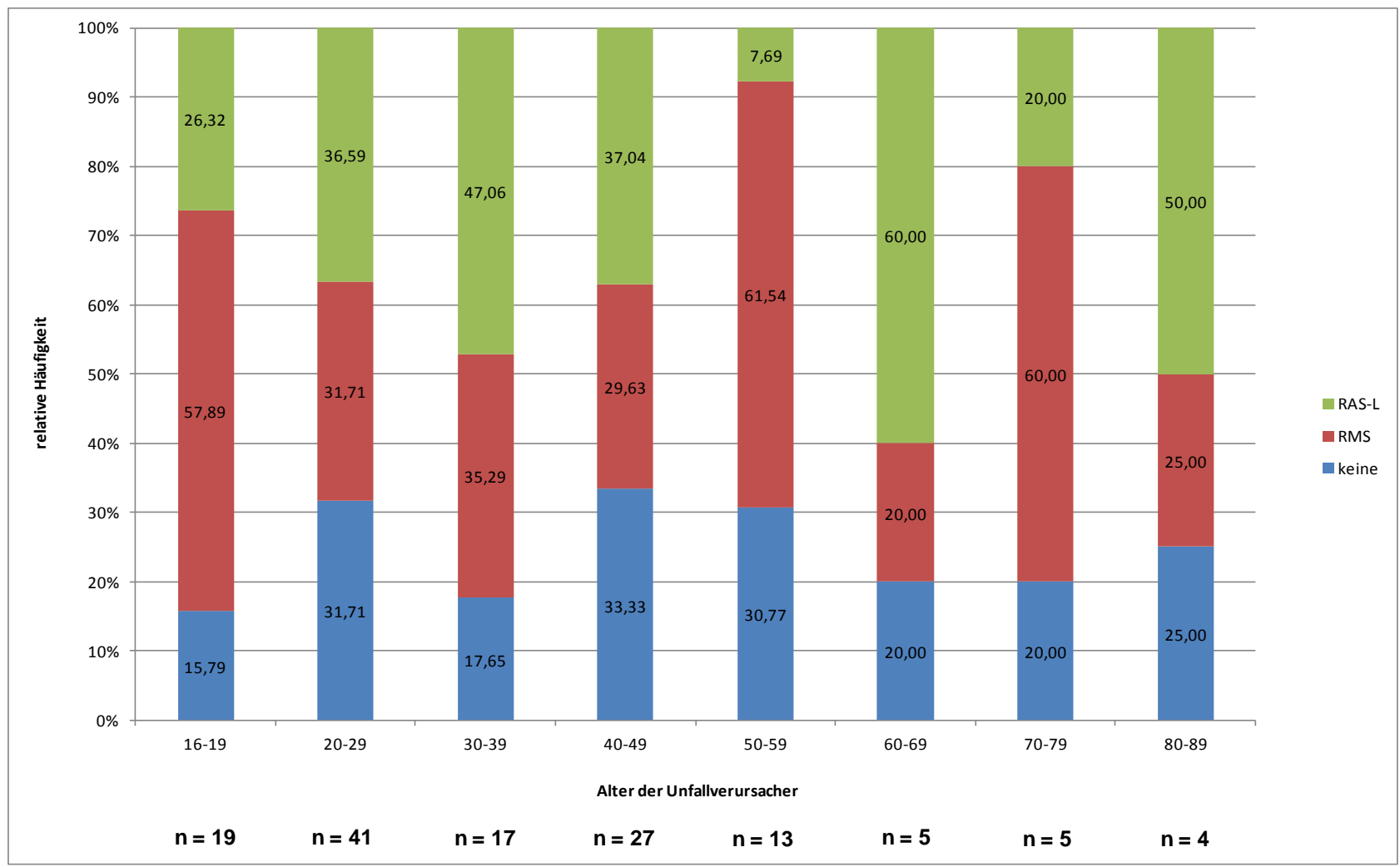


7) Überholunfälle auf Landstraßen - Anhänge zum Abschlussbericht

e) Alter der Unfallverursacher nach Kollisionsarten

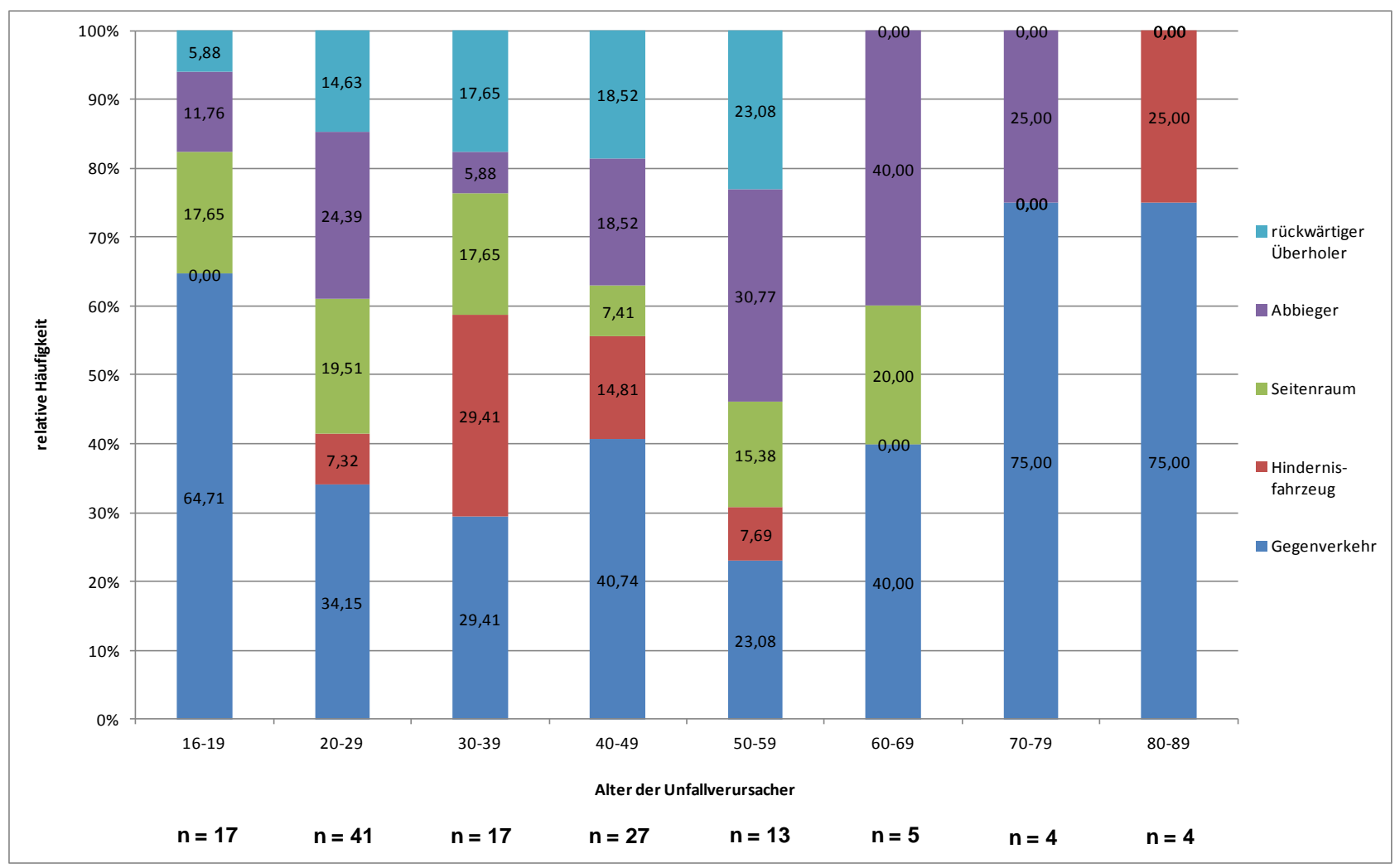




\section{Anhang $Y$ \\ Überholverhalten und Unfallgeschehen in \\ Abhängigkeit der Verkehrsstärken}


7) Überholunfälle auf Landstraßen - Anhänge zum Abschlussbericht

a) Repräsentative Überholrate und Überholunfälle nach Verkehrsstärken

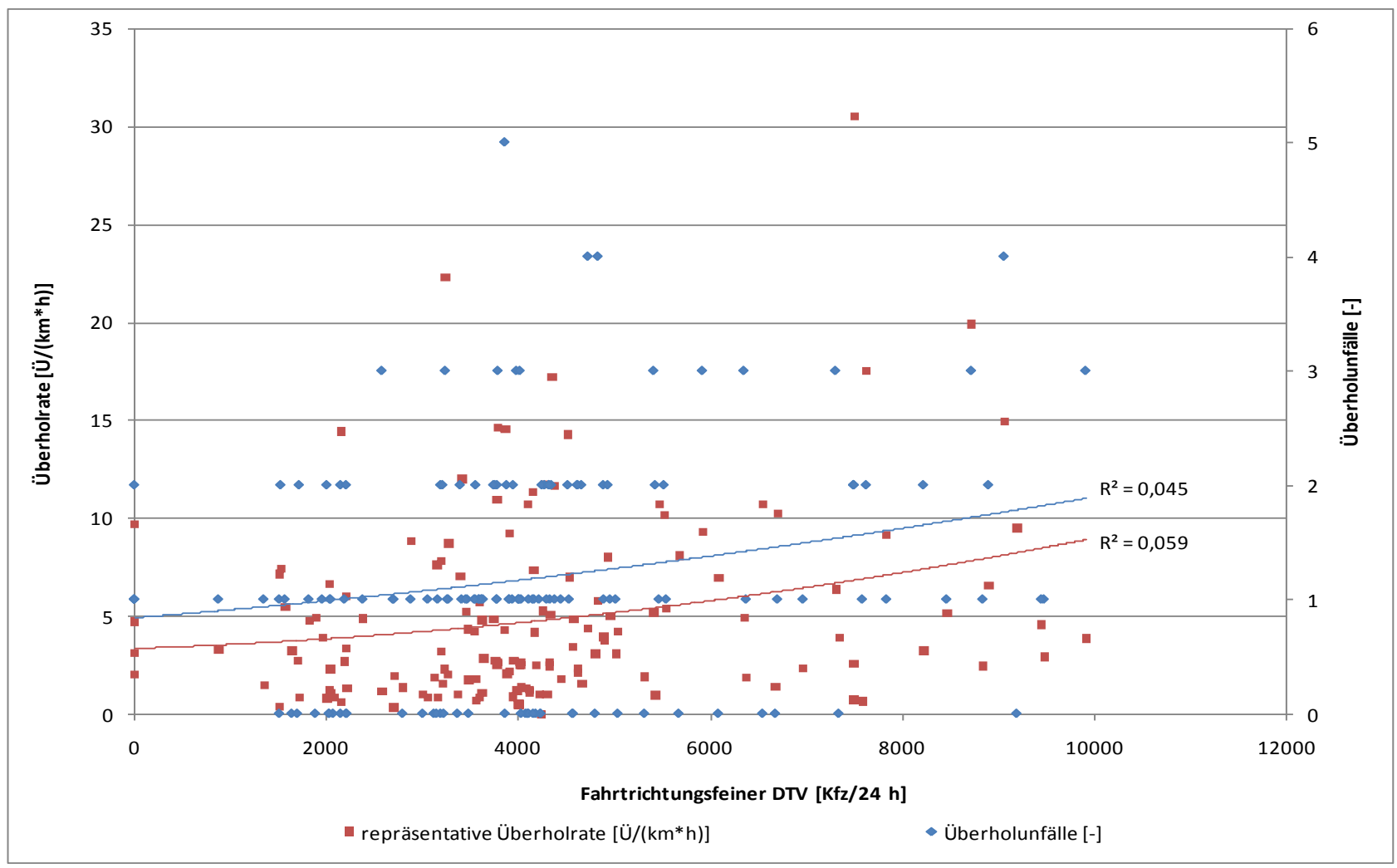

b) Überholunfälle nach Sichtweitenbereichen und Verkehrsstärken

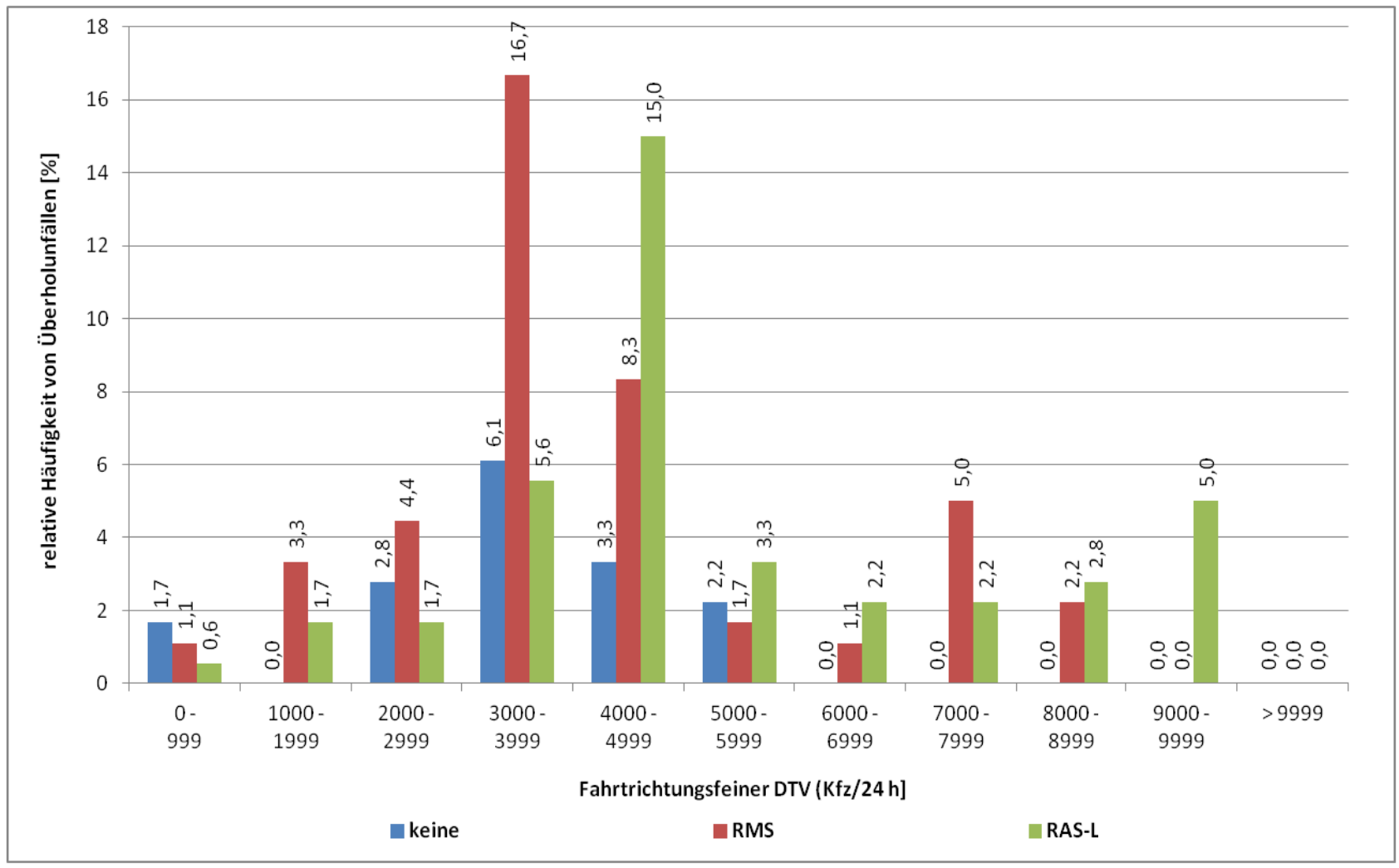


7) Überholunfälle auf Landstraßen - Anhänge zum Abschlussbericht

c) Repräsentative Überholungen nach Sichtweitenbereichen und Verkehrsstärken

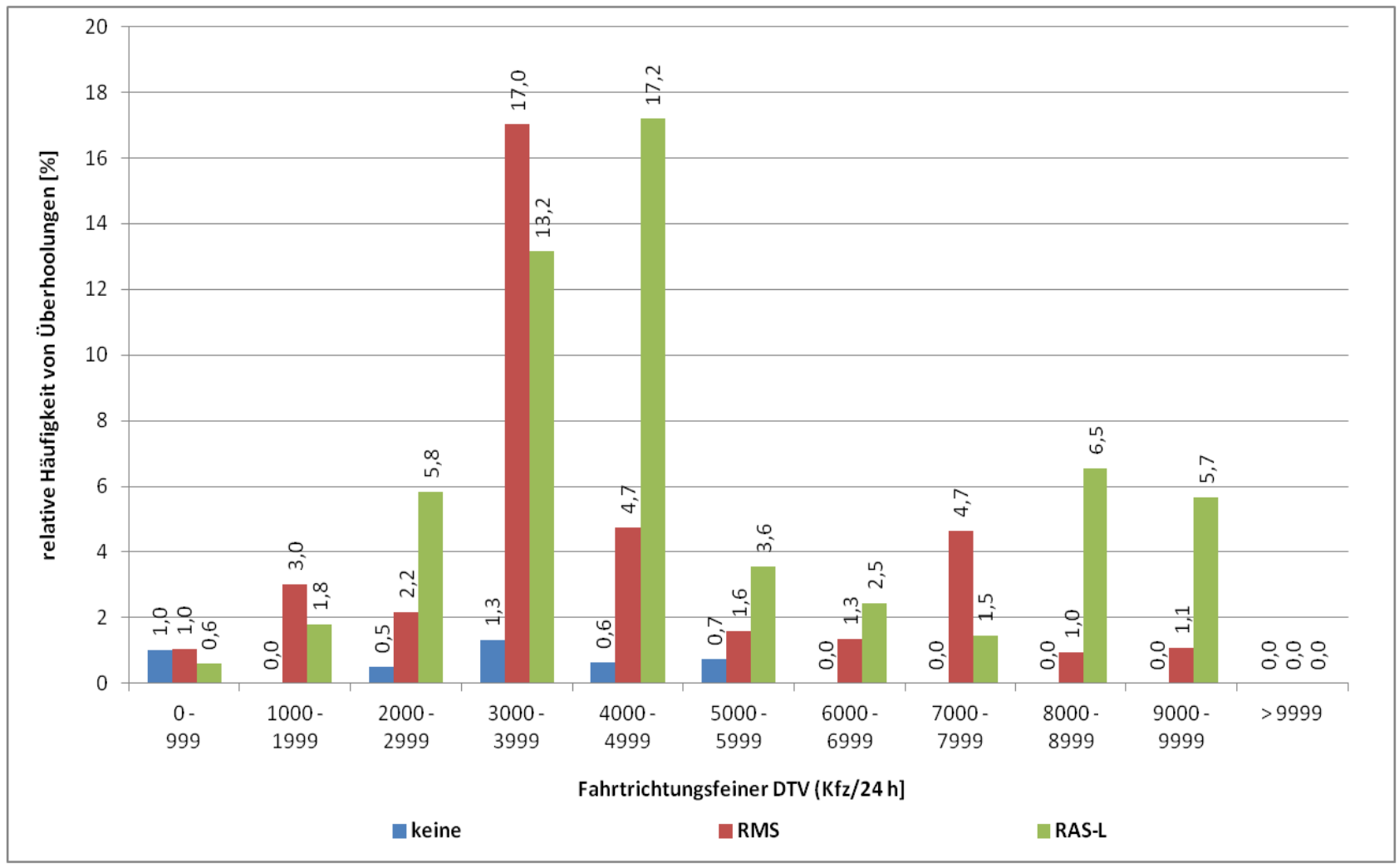

d) Unfallrisiko bei repräsentativen Überholungen nach Sichtweitenbereichen und Verkehrsstärken

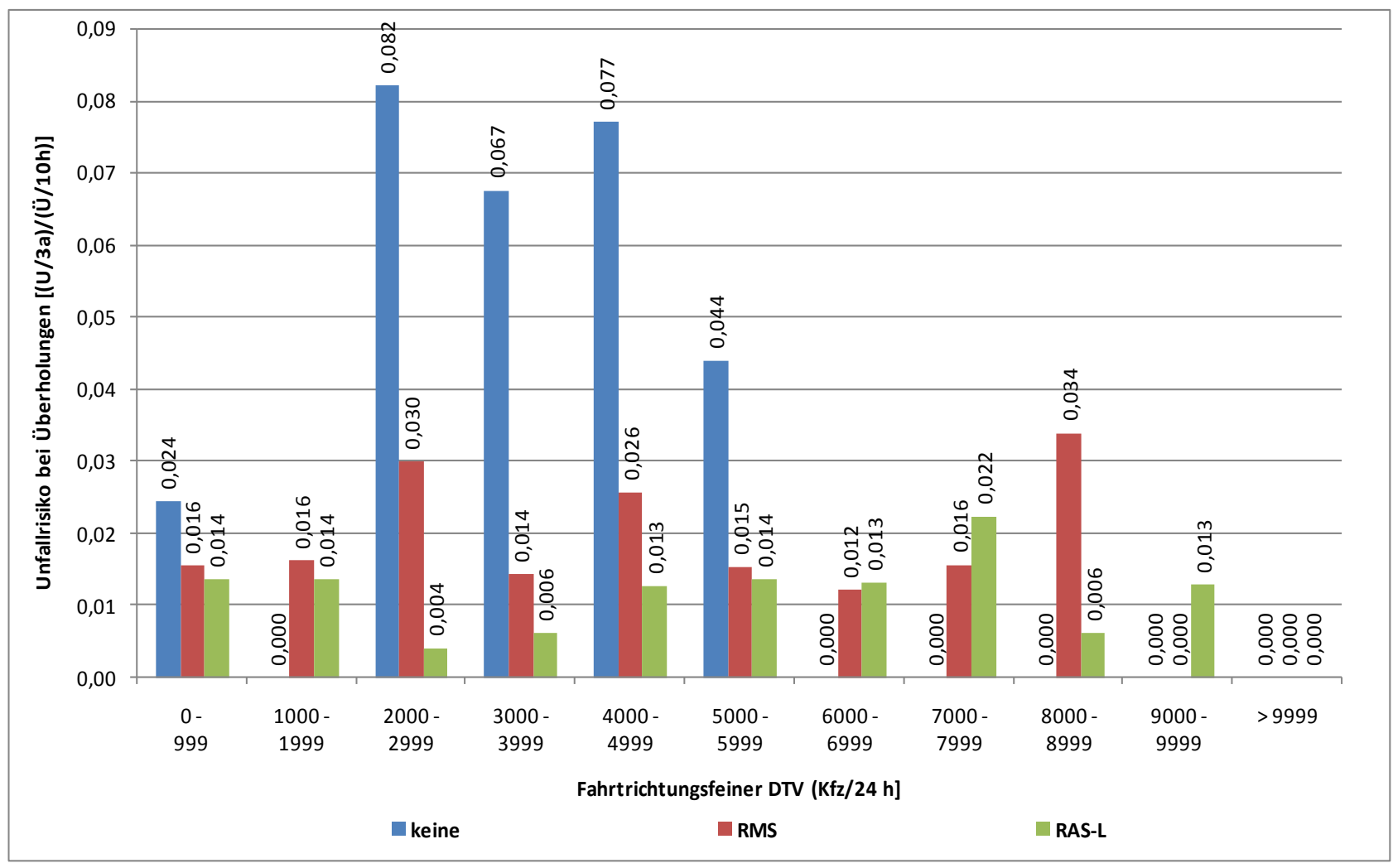


Anhang Z

Überholverhalten und Unfallgeschehen in Abhängigkeit maßgebender Sichtweitenbereiche 
7) Überholunfälle auf Landstraßen - Anhänge zum Abschlussbericht

a) Repräsentative Überholrate und Unfallrate nach Sichtweitenbereichen

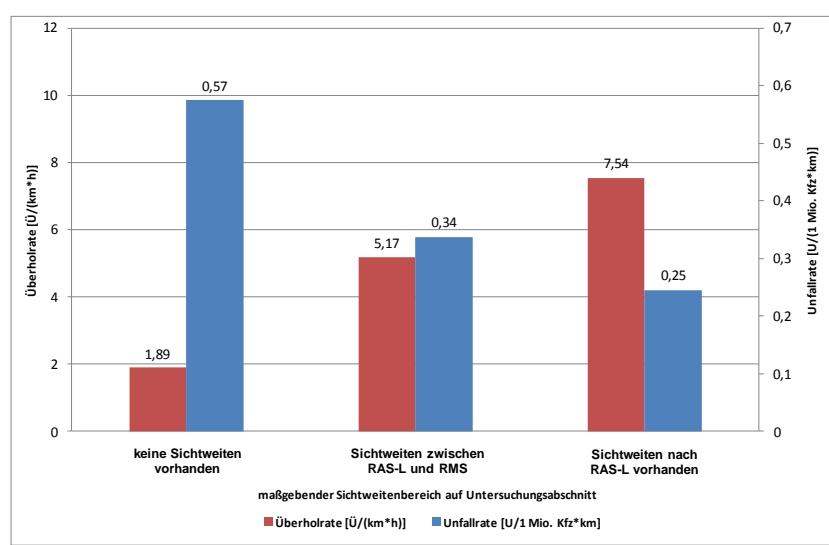

b) Repräsentative Überholrate und Unfallkostenrate nach Sichtweitenbereichen

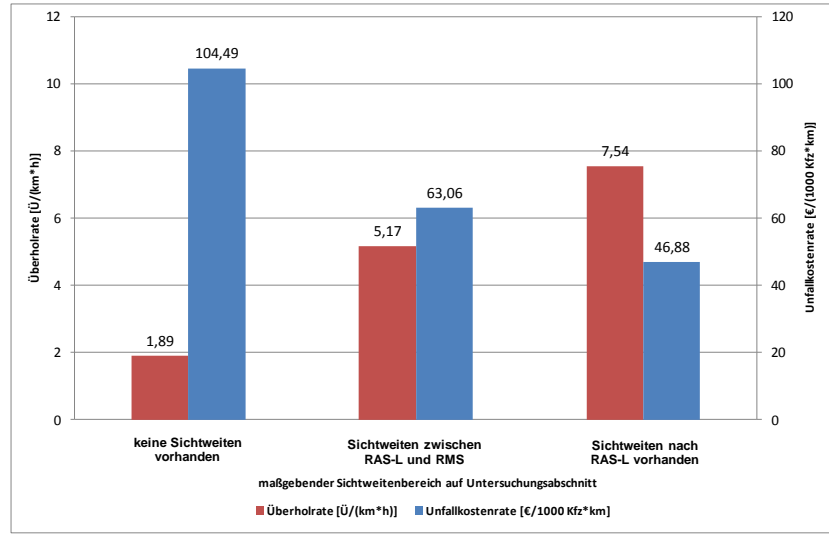

c) Repräsentative Überholrate und Unfalldichte nach Sichtweitenbereichen

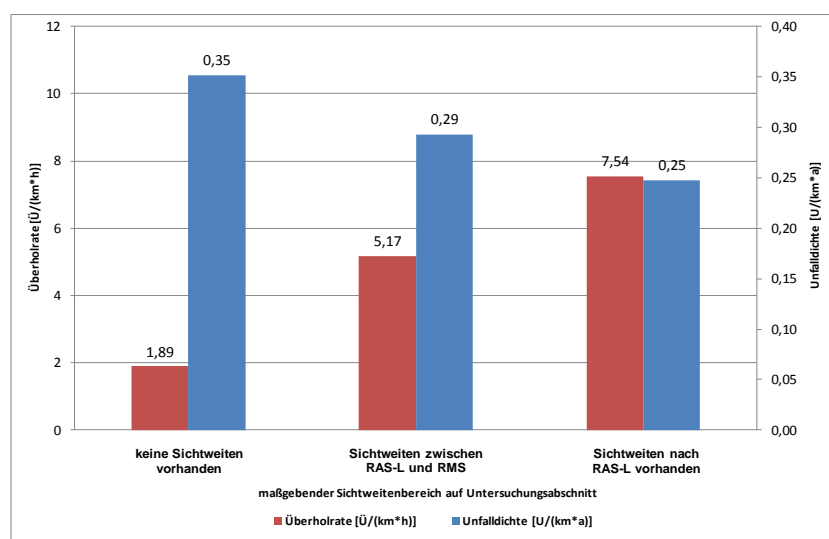

d) Repräsentative Überholrate und Unfallkostendichte nach Sichtweitenbereichen

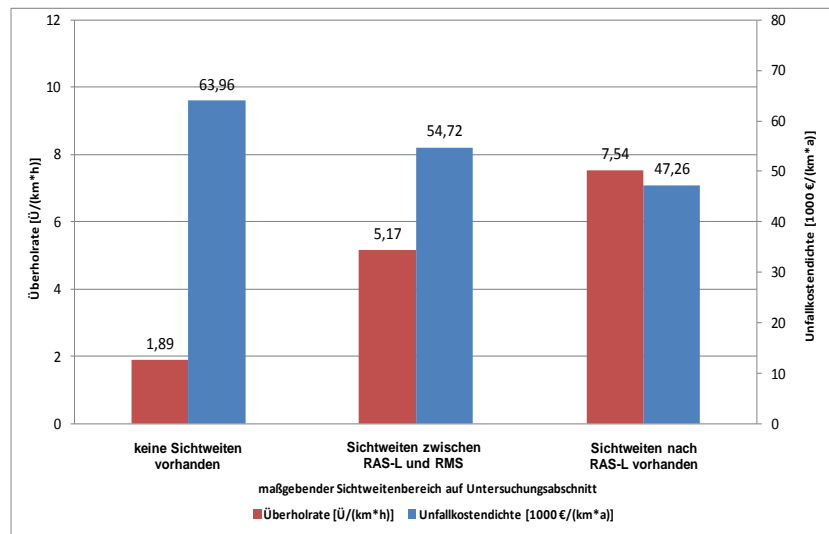


Anhang AA

Überholverhalten und Unfallgeschehen in Abhängigkeit verschiedener Überholverbote 
7) Überholunfälle auf Landstraßen - Anhänge zum Abschlussbericht

a) Repräsentative Überholrate und Unfallrate nach vorhandenen Überholverboten

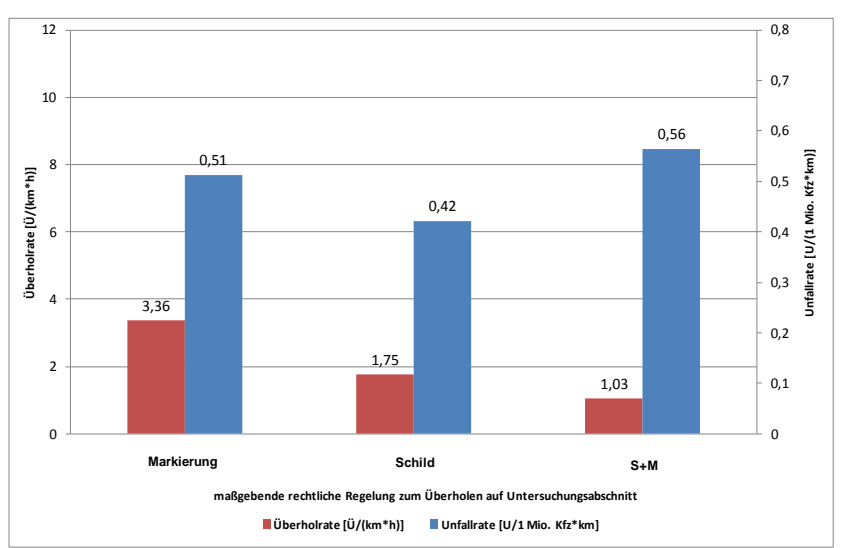

b) Repräsentative Überholrate und Unfallkostenrate nach vorhandenen Überholverboten

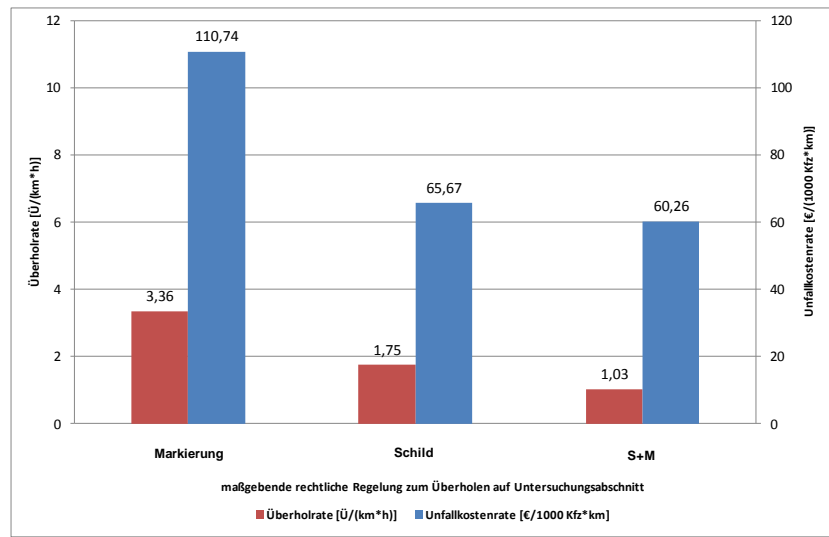

c) Repräsentative Überholrate und Unfalldichte nach vorhandenen Überholverboten

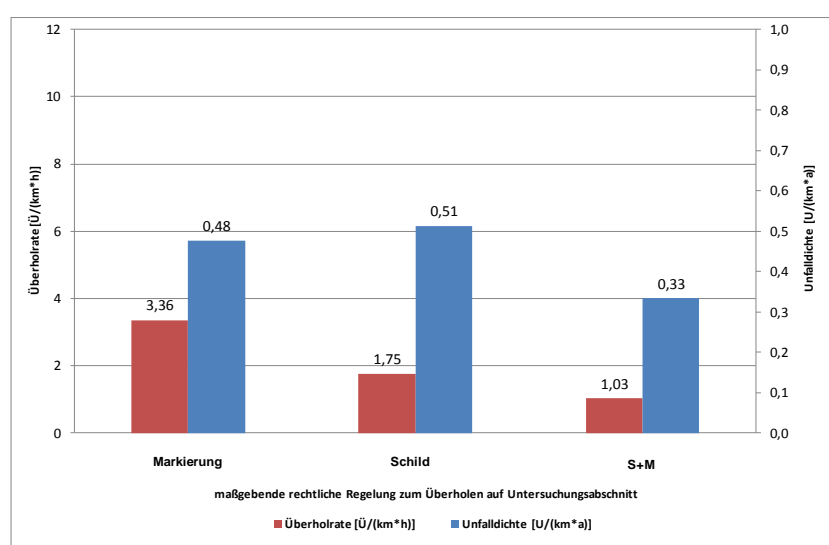

d) Repräsentative Überholrate und Unfallkostendichte nach vorhandenen Überholverboten

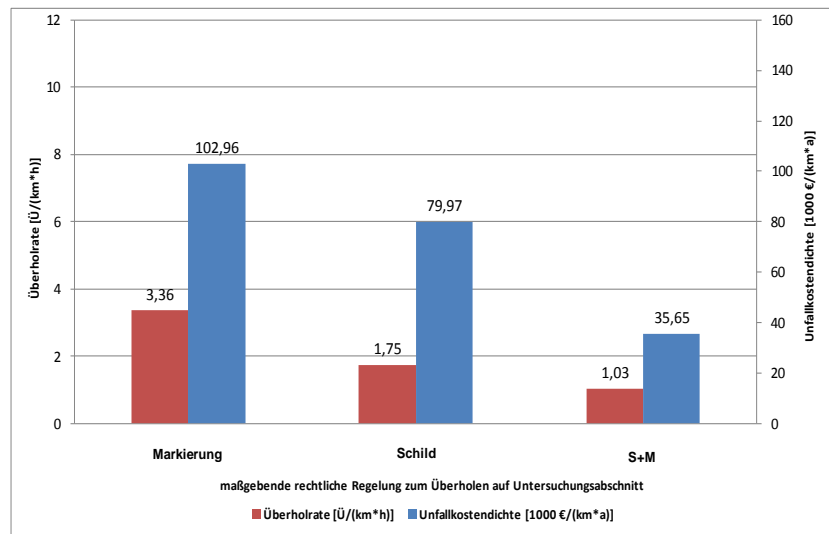


7) Überholunfälle auf Landstraßen - Anhänge zum Abschlussbericht

a) Repräsentative Überholrate und Unfallrate nach zulässigen Geschwindigkeiten

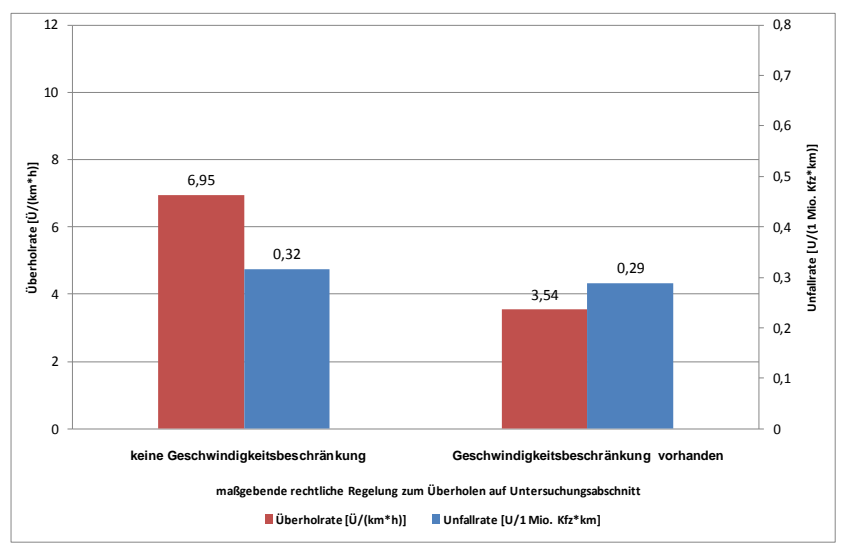

b) Repräsentative Überholrate und Unfallkostenrate nach zulässigen Geschwindigkeiten

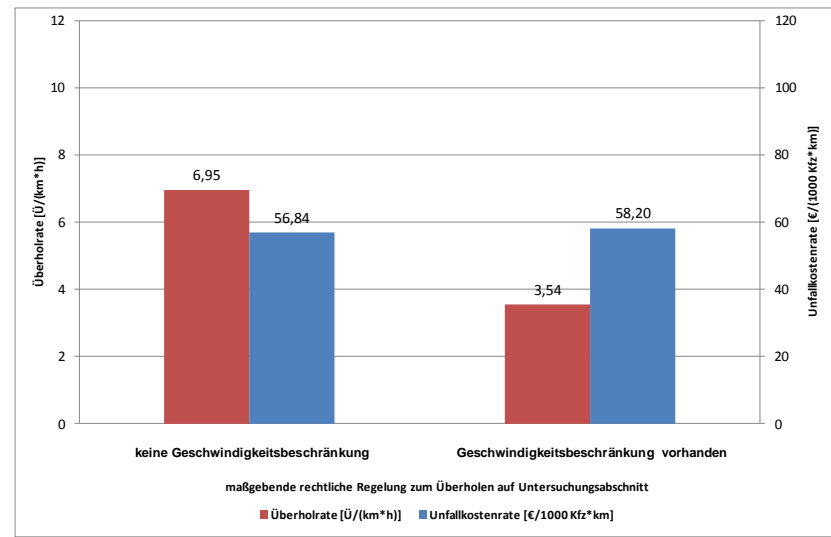

c) Repräsentative Überholrate und Unfalldichte nach zulässigen Geschwindigkeiten

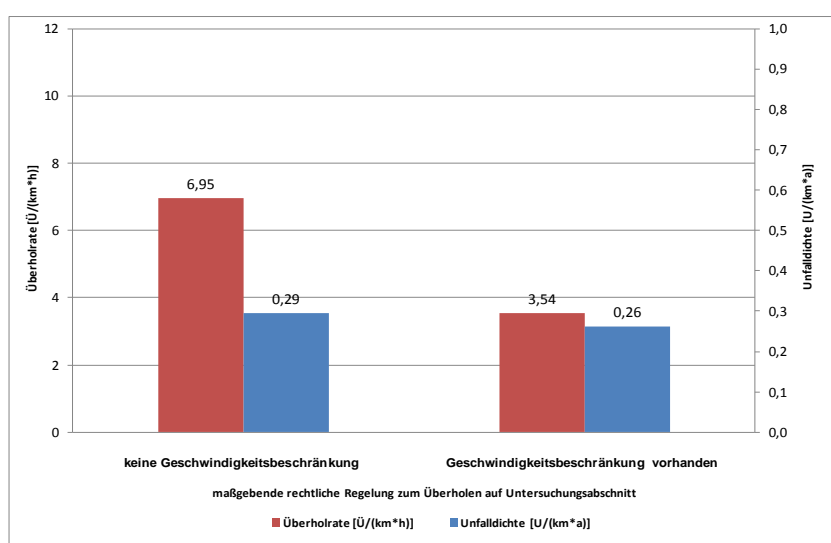

d) Repräsentative Überholrate und Unfallkostendichte nach zulässigen Geschwindigkeiten

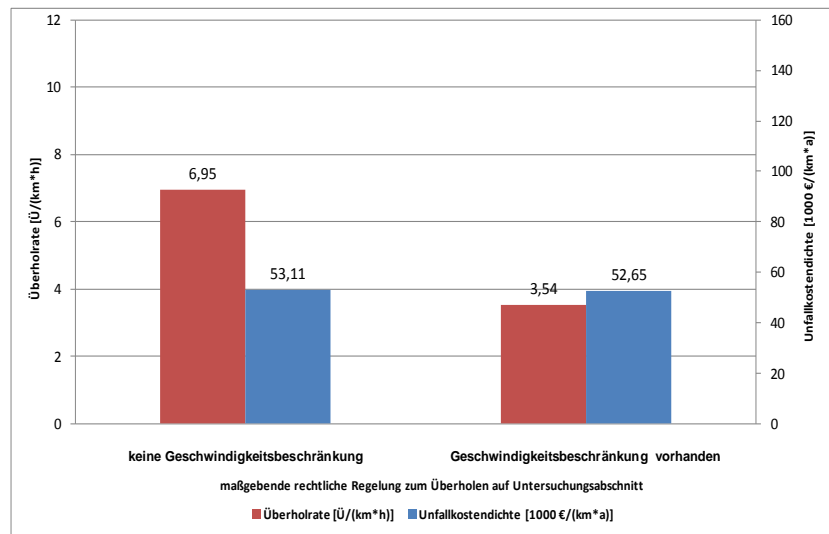




\section{Anhang BB \\ Gesamtergebnisse der Detailanalyse}




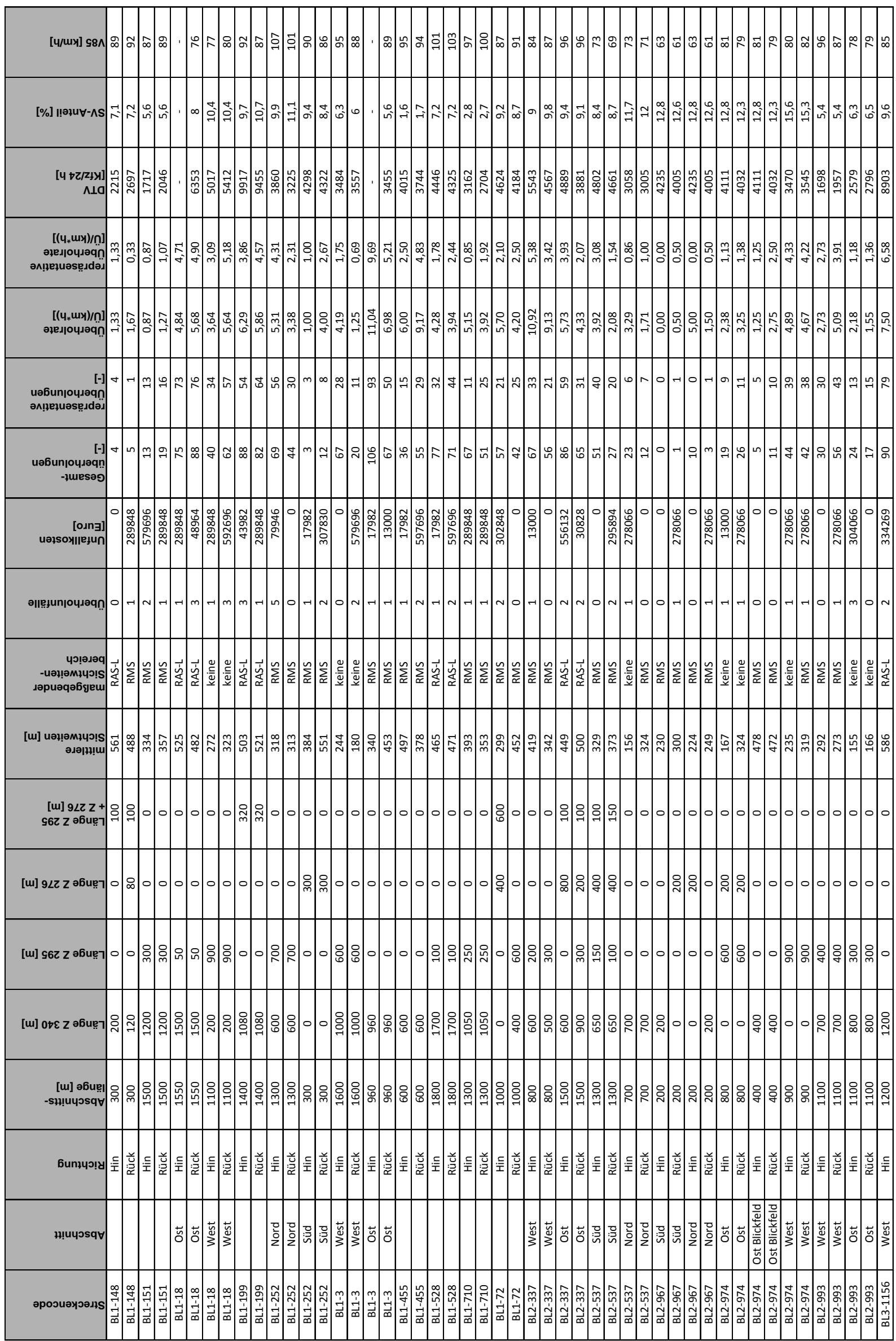




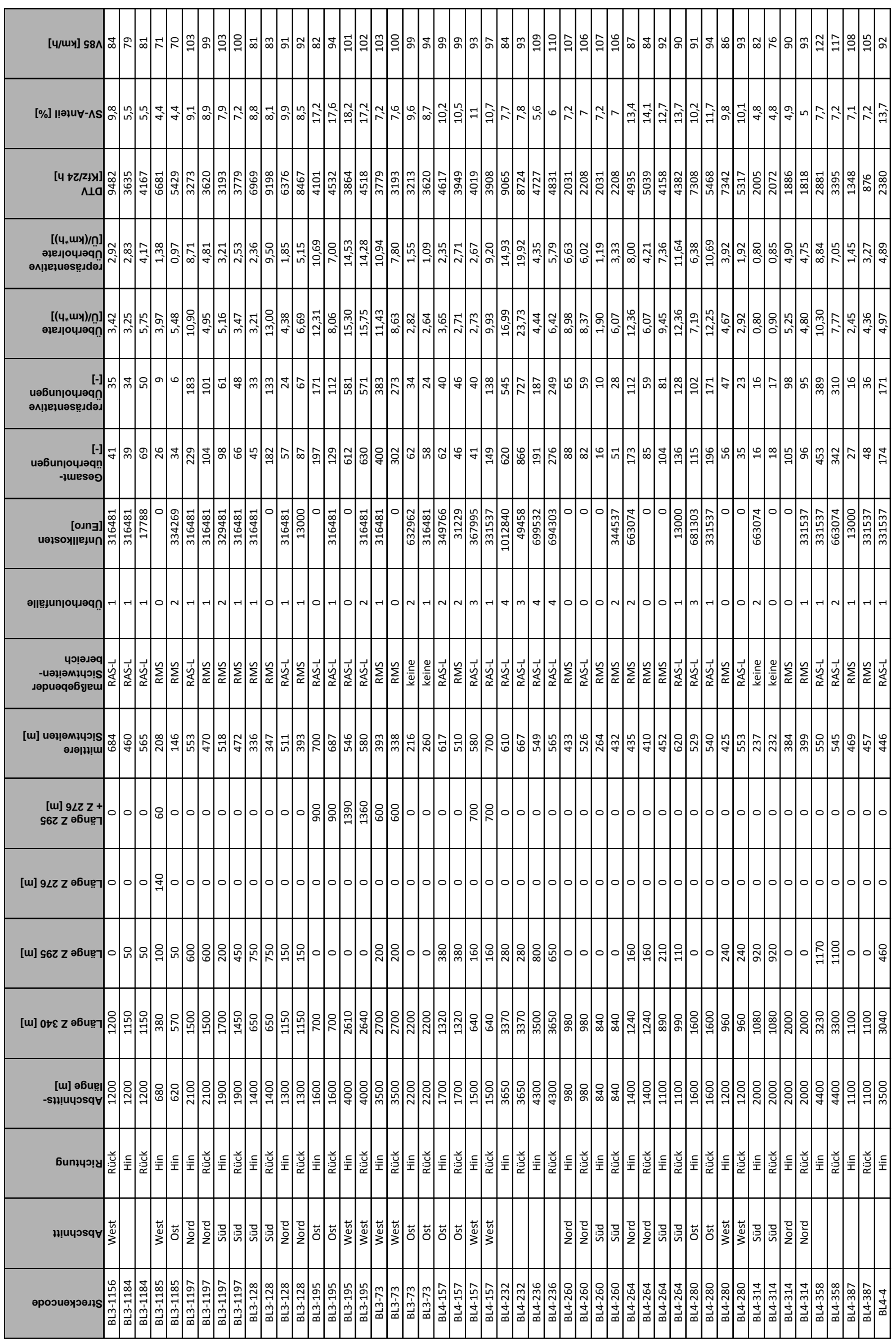




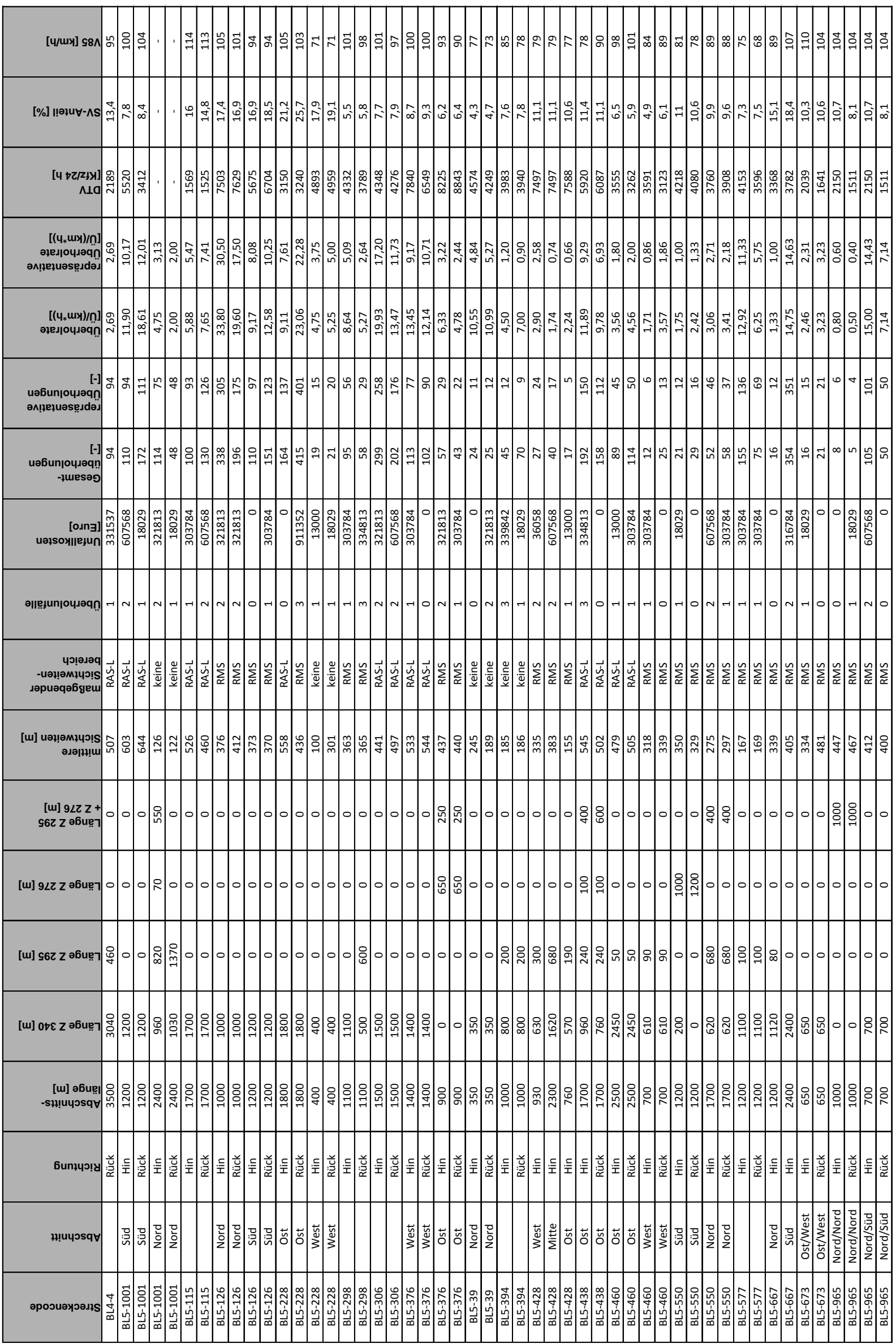




\section{GDV}

DIE DEUTSCHEN VERSICHERER

\section{Gesamtverband der Deutschen Versicherungswirtschaft e.V.}

Wilhelmstraße 43/43G, 10117 Berlin

Postfach 0802 64, 10002 Berlin

Tel.: 030/20 20 - 50 00, Fax: 030/2020-6000

www.gdv.de, www.udv.de 